Prepared for the U.S. Department of Energy

Under Contract DE-AC05-76RL01830

\title{
The Disruption of Vessel-Spanning Bubbles with Sloped Fins in Flat- Bottom and 2:1 Elliptical-Bottom Vessels
}

PA Gauglitz

B Buchmiller

JJ Jenks

September 2010
J Chun

RL Russell

AJ Schmidt
MM Mastor 


\section{DISCLAIMER}

This report was prepared as an account of work sponsored by an agency of the United States Government. Neither the United States Government nor any agency thereof, nor Battelle Memorial Institute, nor any of their employees, makes any warranty, express or implied, or assumes any legal liability or responsibility for the accuracy, completeness, or usefulness of any information, apparatus, product, or process disclosed, or represents that its use would not infringe privately owned rights. Reference herein to any specific commercial product, process, or service by trade name, trademark, manufacturer, or otherwise does not necessarily constitute or imply its endorsement, recommendation, or favoring by the United States Government or any agency thereof, or Battelle Memorial Institute. The views and opinions of authors expressed herein do not necessarily state or reflect those of the United States Government or any agency thereof.

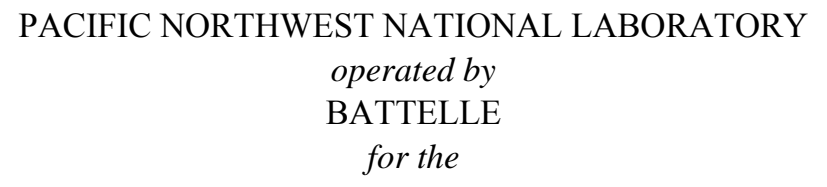

UNITED STATES DEPARTMENT OF ENERGY under Contract DE-ACO5-76RL01830

Printed in the United States of America

Available to DOE and DOE contractors from the Office of Scientific and Technical Information, P.O. Box 62, Oak Ridge, TN 37831-0062; ph: (865) 576-8401 fax: (865) 5765728

email: reports@adonis.osti.gov

Available to the public from the National Technical Information Service, U.S. Department of Commerce, 5285 Port Royal Rd., Springfield, VA 22161 ph: (800) 553-6847 fax: (703) 605-6900 email: orders@nits.fedworld.gov online ordering: http://www.ntis.gov/ordering.htm 


\section{The Disruption of Vessel-Spanning Bubbles with Sloped Fins in Flat- Bottom and 2:1 Elliptical-Bottom Vessels}

$\begin{array}{lll}\text { PA Gauglitz } & \text { J Chun } & \text { MM Mastor } \\ \text { B Buchmiller } & \text { RL Russell } & \\ \text { JJ Jenks } & \text { AJ Schmidt } & \end{array}$

September 2010

Prepared for

the U.S. Department of Energy

under Contract DE-AC05-76RL01830

Pacific Northwest National Laboratory

Richland, Washington 99352 



\section{Executive Summary}

Radioactive sludge was generated in the K-East Basin and K-West Basin fuel storage pools at the Hanford Site while irradiated uranium metal fuel elements from the N Reactor were being stored and packaged. The fuel has been removed from the K Basins, and currently, the sludge resides in the KW Basin in large underwater Engineered Containers. The first phase to the Sludge Treatment Project being led by CH2MHILL Plateau Remediation Company (CHPRC) is to retrieve and load the sludge into sludge transport and storage containers (STSCs) and transport the sludge to T Plant for interim storage. The STSCs will be stored inside T Plant cells that are equipped with secondary containment and leakdetection systems. The sludge is composed of a variety of particulate materials and water, including a fraction of reactive uranium metal particles that are a source of hydrogen gas. If a situation occurs where the reactive uranium metal particles settle out at the bottom of a container, previous studies have shown that a vessel-spanning gas layer above the uranium metal particles can develop and can push the overlying layer of sludge upward. The major concern, in addition to the general concern associated with the retention and release of a flammable gas such as hydrogen, is that if a vessel-spanning bubble (VSB) forms in an STSC, it may drive the overlying sludge material to the vents at the top of the container. Then it may be released from the container into the cell's secondary containment system at T Plant.

A previous study demonstrated that sloped walls on vessels, both cylindrical coned-shaped vessels and rectangular vessels with rounded ends, provided an effective approach for disrupting a VSB by creating a release path for gas as a VSB began to rise. Based on the success of sloped-wall vessels, a similar concept is investigated here where a sloped fin is placed inside the vessel to create a release path for gas. A key potential advantage of using a sloped fin compared to a vessel with a sloped wall is that a small fin decreases the volume of a vessel available for sludge storage by a very small fraction compared to a cone-shaped vessel.

The purpose of this study is to quantify the capability of sloped fins to disrupt VSBs and to conduct sufficient tests to estimate the performance of fins in full-scale STSCs. Experiments were conducted with a range of fin shapes to determine what slope and width were sufficient to disrupt VSBs. Additional tests were conducted to demonstrate how the fin performance scales with the sludge layer thickness and the sludge strength, density, and vessel diameter based on the gravity yield parameter, which is a dimensionless ratio of the force necessary to yield the sludge to its weight. ${ }^{(a)}$ Further experiments evaluated the difference between vessels with flat and 2:1 elliptical bottoms and a number of different simulants, including the KW container sludge simulant (complete), which was developed to match actual K-Basin sludge. Testing was conducted in 5-in., 10-in., and 23-in.-diameter vessels to quantify how fin performance is impacted by the size of the test vessel. The most significant results for these scale-up tests are the trend in how behavior changes with vessel size and the results from the 23 -in. vessel. The key objective in evaluating fin performance is to determine the conditions that minimize the volume of a VSB when disruption occurs because this reduces the potential for material inside the STSC from being released through vents.

Key findings and conclusions from this study are provided in bullets and described in more detail below.

(a) The gravity yield parameter is defined as $Y_{G}=\tau_{s} /\left(\rho_{s} g\right.$ D) where $\tau_{s}$ is the shear strength of the sludge, $\rho_{s}$ is the sludge bulk density, $\mathrm{g}$ is gravitational acceleration, and $\mathrm{D}$ is the vessel diameter. 
- Compared with tests without vessel internals, fins promoted the disruption of VSBs and decreased the volume of the VSB (before disruption) in a clearly defined region of sludge-layer thickness and simulant shear strength..

- Results from the 5-in. and 10-in.-diameter test vessels showed well-defined regions of sludge layer height and simulant properties (shear strength) where VSBs are stable and not disrupted by fins.

- In the largest test vessel (23-in. diameter), which should best represent full-scale behavior, the fins tested always disrupted VSBs for a wide range of layer thickness and simulant properties.

- The scale-up testing in the 5-in, 10-in., and 23-in. vessels demonstrated that the region of sludge height and strength where fins do not disrupt VSBs becomes smaller in progressively larger vessels (absent in the 23-in. vessel), which is favorable for designing the 58-in. full-scale STSC.

- Under the conditions tested, the geometry of the 2:1 elliptical-bottom vessel was shown to be inherently unstable with respect to VSBs (i.e., VSBs were eventually unstable without vessel internals). However, without mitigation, the sludge layer can rise to problematic levels before the bubbles self-collapse.

- Tests with the KW container sludge simulant (complete) showed effective bubble disruption with fins under conditions of layer thickness and strength where VSBs with clay simulants were not disrupted by fins. The KW container sludge simulant (complete) slumps less than kaolin, and this is the likely reason why fins perform effectively with this material. It is expected that actual K-Basin container sludge will behave closer to this simulant material.

This study also developed a simple scaling relationship describing when the sludge will slump under its own weight and seal the gas-release path along a sloped fin. By combining this new relationship with the existing scaling result for the instability of VSBs based on the dimensionless gravity yield parameter $\left(\mathrm{Y}_{\mathrm{G}}\right)$, a fin-performance result is predicted that shows three distinct regions of behavior for bubble stability and fin performance. For sufficiently weak sludge simulants, corresponding to low $\mathrm{Y}_{\mathrm{G}}$ and identified as Region 1, all VSBs are unstable. For a $\mathrm{Y}_{\mathrm{G}}$ large enough to form stable VSBs, sloped fins effectively disrupt the bubbles when the dimensionless clay (or sludge) layer height is less than a value determined by a slumping criterion. Under these conditions, sloped fins create gas-release pathways that remain open (no slumping) to release gas. This is identified as Region 2. In Region 3, VSBs are stable, but fins do not release retained gas because the sludge continuously slumps and closes the gas-release path.

Experimental results were obtained for 10-in.-diameter vessels with both a flat bottom and a 2:1 elliptical bottom for a range of different simulants and a range of fin shapes. One of the simulants was the KW container sludge simulant (complete). Only three tests were conducted with this simulant because it is difficult to use, but this simulant is likely the most representative simulant tested, so the limited results with this material are particularly important. Finally, a more focused suite of experiments was conducted in 5-in. and 23-in. vessels to quantify how fin performance and the three regions of behavior change with increasing vessel size. For these scale-up tests, the trend in how behavior changes with vessel size, specifically any shifting in the location of the three regions, and the results from the 23in. vessel are the most significant results.

Tests were conducted in the 10-in., flat-bottom vessel with kaolin clay simulants with shear strengths ranging from 160 to $1090 \mathrm{~Pa}$ (48 to $58 \mathrm{wt} \%$ ), giving a range of 0.044 to 0.28 for $\mathrm{Y}_{\mathrm{G}}$. This corresponds to 
a shear-strength range of about 900 to 6,300 $\mathrm{Pa}$ for this $\mathrm{Y}_{\mathrm{G}}$ range in the full-scale STSCs. In comparison, the reported range of shear strengths for K-Basin sludge is 1 to 8,200 $\mathrm{Pa}$, and the simulants cover the important portion of this range for VSB behavior. In these tests, the clay layer thickness was also varied from $\mathrm{H} / \mathrm{D}=0.25$ to 1 . Tests without fins were conducted to define the transition between stable and unstable bubbles and to compare the results with previous studies. In the flat-bottom vessel with kaolin simulants, the transition between unstable and stable VSBs occurred at $Y_{G}=0.05$ for $H / D=1$ and increased to about $Y_{G}=0.08$ at $H / D=0.5$, which is consistent with previous studies that found the transition to occur at $Y_{G}=0.09$ for similar kaolin clay simulants at an $H / D$ of 0.5 . Larger scale testing in a 23-in. vessel showed stable VSBs at lower values of $Y_{G}$ than in the 10-in. vessel, and these results suggest $Y_{G}=0.04$ for layer thicknesses of $H / D$ between 0.5 and 1 as the transition between stable and unstable VSBs rather than the value of 0.09 .

Fin performance tests in the 10-in., flat-bottom vessel with kaolin simulants demonstrated the expected three regions of behavior. For sufficiently strong simulants (high $\mathrm{Y}_{\mathrm{G}}$ and Region 2), the fins always disrupt potentially stable bubbles. For Region 3, stable VSBs were observed with the fin present. In this region, the $Y_{G}$ is high enough to have stable VSBs but still sufficiently low for slumping along the fin to make the fin ineffective. For sufficiently small $Y_{G}$, the VSBs are always unstable. Scaled fins with a range of slopes and widths were evaluated, and a straight-sided fin with a 5-degree slope and a full-scale width of 2 inches was selected as the primary fin for further testing.

Two additional simulants were selected, characterized, and tested in the 10-in. vessel to extend these results to more realistic simulants. The two simulants were the KW container sludge simulant (complete) and mixtures of kaolin and Min-U-Sil 30. Both of these simulants have a more granular nature, and slumping experiments demonstrated that they slump less than kaolin simulants at equivalent strengths. Fin performance tests with the KW container simulant (complete) were the most striking. The results showed rapid disruption of bubbles by the fin at $\mathrm{Y}_{\mathrm{G}}$ and $\mathrm{H} / \mathrm{D}$ values where Region 3 behavior (stable bubbles with a fin) was most likely to occur. These results suggest that fins will be effective at all $\mathrm{Y}_{\mathrm{G}}$ and $\mathrm{H} / \mathrm{D}$ values for actual K-Basin material. The fin performance results for the kaolin/Min-U-Sil 30 simulants were equivalent to the kaolin results.

With the 2:1 elliptical-bottom vessel, the bottom of the clay is not flat as a gas bubble begins lifting the clay. The stability of the VSB was strongly affected by this different geometry, and VSBs were significantly less stable in the elliptical-bottom vessel. This different behavior from the flat-bottom tests is likely due to the clay layer having a thickness that varies across the layer, an imbalance that apparently initiates gas release. Tests were conducted with both kaolin and kaolin/Min-U-Sil simulants both with and without fins. Fin performance in the 2:1 elliptical-bottom vessel showed similar, but not identical, behavior to the flat-bottom-vessel tests. For the fin tests in the strongest simulant (kaolin with a $\mathrm{Y}_{\mathrm{G}}=$ 0.28), the VSBs were clearly disrupted by the fin. For the weaker simulant (and lower $Y_{G}$ ), the bubbles became progressively less stable. Overall, testing in the elliptical bottom vessel with fins shows that bubble release always happened in the vessel, either because of the bubble being unstable at lower strengths or the fin disrupting the bubble at higher strengths.

Scale-up testing of fin performance was conducted using 5-in. and 23-in. test vessels to complement the 10 -in. vessel results. Fin performance in the 5-in. vessel showed the three regions of behavior that were observed in the 10-in. vessel, with the Region 3 behavior spanning a wider range of $Y_{G}$. In the 23-in. vessel, tests were conducted with kaolin and kaolin/Min-u-Sil 30 simulants. The most significant finding from the 23-in., large-scale tests is that there is no region of gravity yield parameter $\left(\mathrm{Y}_{\mathrm{G}}\right)$ and 
layer thickness (H/D) where the fin fails to disrupt VSBs. Of the 13 tests with potentially stable bubbles, the fin disrupted the bubble within 4 minutes in 12 of these tests, and one test took 6 minutes. For this duration of gas injection, there was only a negligible rise $(\sim 1 / 2$ inch $)$ in the clay layer.

T-shaped fins were tested in both the 10-in. and 23-in. vessels, with the specific fins tested scaled to match a 5-degree, full-scale fin with a width of 4 inches. In the six T-fin tests, the T-shaped fin performed equal to or better than the 5-degree, straight-sided fin.

The overall conclusion of scale-up testing in the 5-in., 10-in., and 23-in. vessels is that the region of $\mathrm{Y}_{\mathrm{G}}$ and $\mathrm{H} / \mathrm{D}$ values where fins do not disrupt VSBs (Region 3) becomes smaller in progressively larger vessels, which is a favorable trend for designing the full-scale STSC. These tests were all conducted with a scaled 5-degree, 2-in. wide fin. While this trend was clearly shown by the data, this effect of scale was not predicted by the simple model with $\mathrm{Y}_{\mathrm{G}}$ scaling. One experimental parameter that has not been systematically varied is the rate the clay layer is lifted, and it is possible that the lifting rate is an important parameter. With this experimental scale-up trend and the 23-in. test results where the fins always disrupt VSBs in kaolin and kaolin/Min-U-Sil simulants, the overall conclusion is that fins should perform even better at full scale. Accordingly, the data indicated that fins will disrupt bubbles for any material strength and layer depth. In addition, the results for fin performance with the KW container sludge simulant (complete) showed that the fins performed better in this material and nearly always disrupted VSBs, even in the 10-in vessel. This simulant is probably the most realistic for actual K-Basin material, and the 10-in. vessel test results for this simulant suggest that fins will always release VSBs. Although not tested, the fins should perform even better at full-scale with actual K-Basin material considering that the scale-up trend of fin performance improves in larger vessels with more realistic materials. 


\title{
Acronyms and Abbreviations
}

CHPRC CH2MHILL Plateau Remediation Company

KW-A KW container sludge simulant (complete)

STP Sludge Treatment Project

STSC sludge transport and storage container

VSB vessel-spanning bubble

\section{Symbols}

\author{
D diameter of vessel \\ g gravitational acceleration \\ $\mathrm{H} \quad$ height of sludge or simulant layer \\ $\mathrm{P} \quad$ pressure in sludge layer \\ $\mathrm{P}_{\mathrm{o}} \quad$ nominal pressure in water layer at the top of a sludge layer \\ $\mathrm{Y}_{\mathrm{G}} \quad$ gravity yield parameter
}

\section{Greek Letters}

$\begin{array}{ll}\rho & \text { density } \\ \rho_{\mathrm{s}} & \text { bulk sludge density } \\ \rho_{\mathrm{L}} & \text { liquid density } \\ \rho_{\mathrm{w}} & \text { water density } \\ \tau_{\mathrm{s}} & \text { shear strength }\end{array}$





\section{Contents}

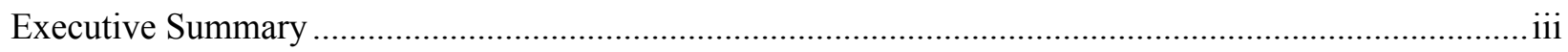

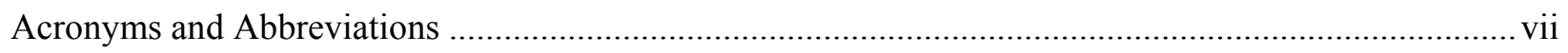

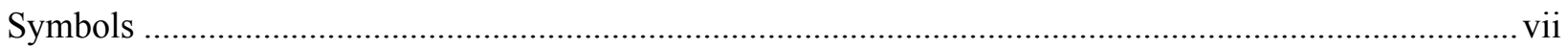

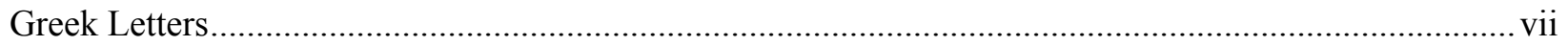

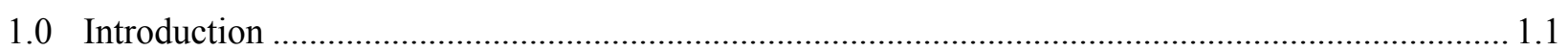

1.1 Sludge Transport and Storage Containers and Waste Properties .......................................... 1.3

2.0 Mechanism for Disruption of Vessel-Spanning Bubbles with Sloped Fins ................................. 2.1

2.1 Simulants, Vessels, and Fins for Scaled Testing ................................................................ 2.4

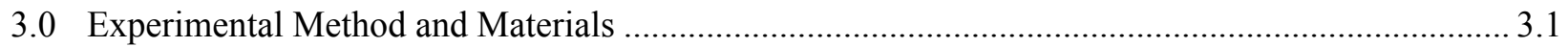

3.1 Small-Scale Tests-10-in. and 5-in.-Diameter Test Vessels ............................................... 3.1

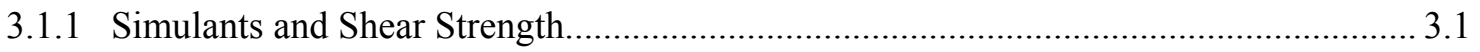

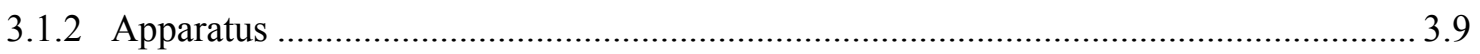

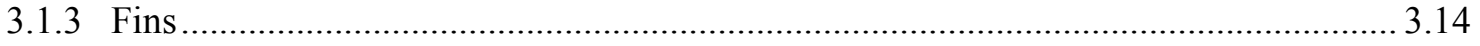

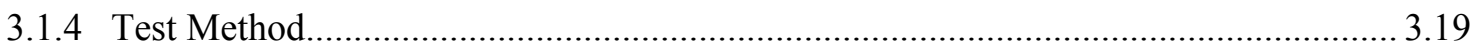

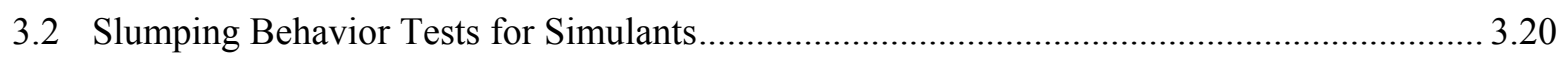

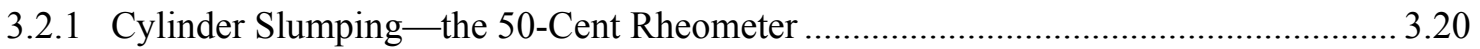

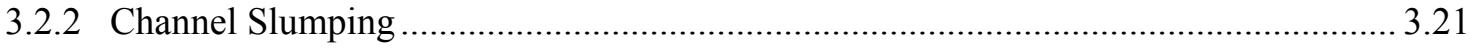

3.3 Large-Scale Tests -23-in.-Diameter Test Vessel ........................................................... 3.22

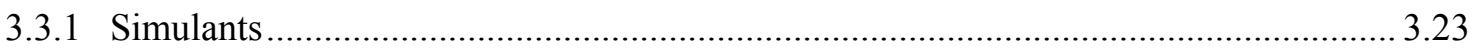

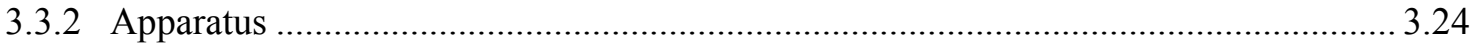

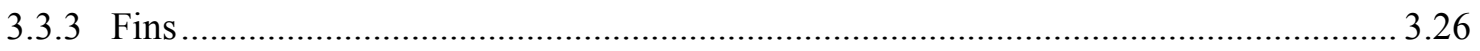

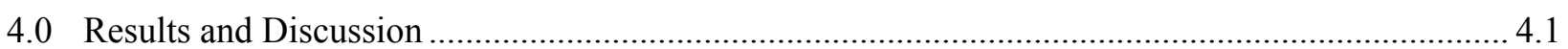

4.1 10-in., Flat-Bottom Test Vessel with Kaolin Clay ............................................................... 4.1

4.2 10-in. 2:1 Elliptical Bottom Vessel with Kaolin and Kaolin/Min-U-Sil 30 Simulants ............. 4.5

4.3 Effect of Kaolin Layer Depth on Fin Performance ......................................................... 4.10

4.4 Comparison of Slumping Behavior for Kaolin Clay, Kaolin Clay/Min-U-Sil 30, and

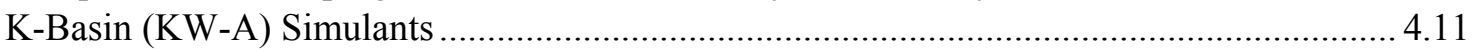

4.5 Fin Performance and Vessel-Spanning Bubble Stability with KW Container Sludge Simulant (Complete) and other More Non-Cohesive Simulants......................................... 4.15

4.6 Large-Scale Fin Performance and Scale-up Behavior........................................................ 4.17

4.7 Comparison of Results with Previous Studies .......................................................................2 4.22

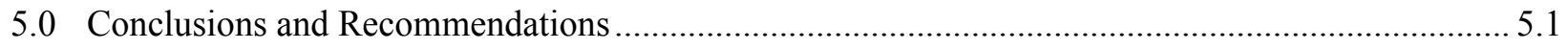

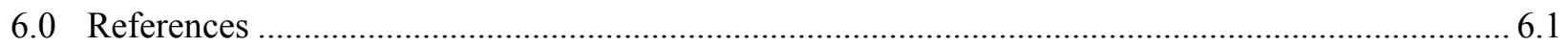

Appendix A: Shear-Strength Method and Measurements ................................................................. A.1

Appendix B: KW Container Sludge Simulant (Complete) (KW-A) Provided to the Pacific

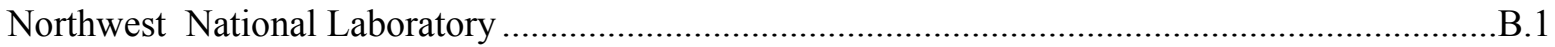

Appendix C: Vessel-Spanning Bubble Test Conditions and Results..................................................... 


\section{Figures}

1.1. Laboratory Examples of Vessel-Spanning Bubbles in a Graduated Cylinders and the General Configuration of a Vessel-Spanning Bubble .

1.2. Simplified Schematic of STSC Showing Inner Diameter and Height from the Bottom of the 2:1 Elliptical Head to the Beginning of the Elliptical Head at the Vessel Top

1.3. STSC Shown with an Inner Annulus that Will Be Used with Settler Sludge But Will Be Removed for Other Sludge Materials; diagram above reproduced from CHPRC ENGINEERING SKETCH SK-4K-M-002-1R0)

2.1. Mechanism of Gas Release Along a Sloped Fin and Slumping Causing the Release

Pathway to be Sealed.

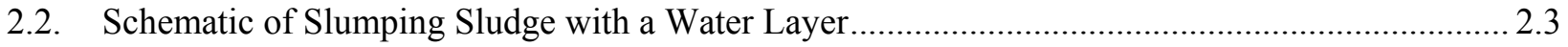

2.3. Three Regions for Vessel-Spanning Bubble Stability and Fin Performance................................. 2.3

3.1. Shear Strength of Kaolin Clays Used in Vessel-Spanning Bubble Tests ..................................... 3.2

3.2. Shear-Strength Variation of Kaolin Clays as a Function of Time............................................... 3.4

3.3. Shear Strength of Kaolin Clay/Min-U-Sil 30 Mixture with Two Different wt\% of Kaolin............ 3.5

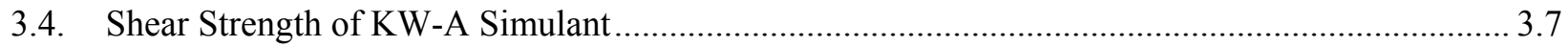

3.5. Depth Profile of Shear Strengths for Three Different KW-A Simulants ....................................... 3.9

3.6. 10-in.-Diameter, Flat-Bottom Test Apparatus ....................................................................... 3.10

3.7. 10-in.-Diameter, Flat-Bottom Test Vessel Without a Fin ....................................................... 3.10

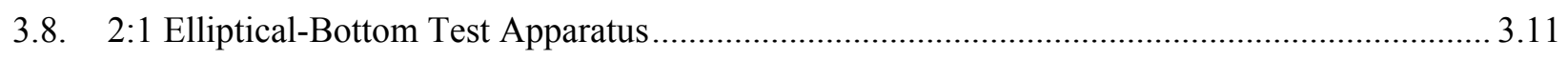

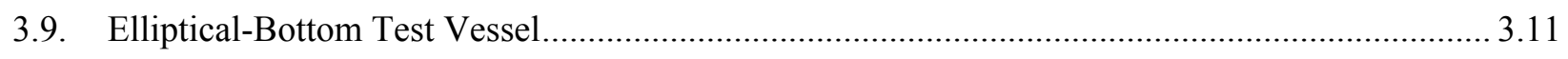

3.10. Measuring Locations to Confirm the Shape of the $2: 1$ Ellipse................................................. 3.12

3.11. 5-in.-Diameter, Flat-Bottom Test Apparatus......................................................................... 3.13

3.12. 5-in.-Diameter, Flat-Bottom Test Vessel Without a Fin ......................................................... 3.14

3.13. Fins Having 5-Degree Slopes and Widths of 0.182, 0.342, and 0.634 inches............................. 3.15

3.14. 0.34-in.-Thick Fins with Slopes of 2.5, 5, and 10 Degrees ................................................... 3.15

3.15. Diagrams of Straight-Side and T-Shape Fins with Mounting Bolts .......................................... 3.17

3.16. "T"-Shaped Fin with a Width of 0.69 inches along the Top of the "T" and a Comparison of the T-Fin with a Straight-Side Fin with a Width of 0.634 Inches .......................................... 3.18

3.17. T-Fin Installed in the 10-in.-Diameter Flat-Bottom Vessel...................................................... 3.18

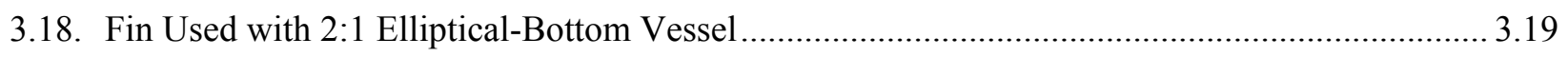

3.19. Schematic Diagram on the Procedure for the 50-cent Rheometer Test..................................... 3.21

3.20. Example Pictures for the 50-Cent Rheometer Test with 49-wt\% Kaolin Slurry ......................... 3.21

3.21. Schematic Diagram on the Procedure for the Channel Slumping Test ...................................... 3.22

3.22. Example Pictures for the Channel Slumping Test with 49-wt \% Kaolin Slurry .......................... 3.22

3.23. 23-in.-Diameter, Flat-Bottom Test Vessel ........................................................................... 3.24 
3.24. 23-in.-Diameter, Flat-Bottom Test Vessel Without a Fin

3.25. 23-in. (left), 10-in.(middle), and 5-in. (right) Diameter Flat-Bottom Test Vessels Without Fins.

3.26. Straight 5-Degree Fins for 23-in. (Fin 10-top), 10-in. (Fin 3-middle), and 5-in. (Fin 8bottom) Vessels

3.27. T-shaped, 5-Degree Fins for 10-in. (Fin 9-left) and 23-in. (Fin 11-right) Vessels (Fins Placed Face-Down)

4.1. Initial Stable Plug Beginning to Rise, After $80 \mathrm{~min}$, and After $130 \mathrm{~min}$ with a 5-in. Rise

4.2. Comparison of Stability Results with Different Clay Layer Thickness ........................................ 4.3

4.3. 2:1 Elliptical Bottom Test Vessel Loaded with 10 Inches of Kaolin Clay.................................... 4.6

4.4. Visual Indication of Clay Detachment from the Bottom of the $2: 1$ Ellipse ................................ 4.7

4.5. Location of Bubble Breakthrough

4.6. Comparison of Experimental Results in the Flat-Bottom Vessel with the Three Regions of Behavior for Vessel-Spanning Bubble Stability and Fin Performance (5, 0.34 -in. Fin) ......... 4.11

4.7. Comparison of Slumping Behavior (50-cent Rheometer) ......................................................... 4.13

4.8. Comparison of Slumping Behavior (Channel Slumping).......................................................... 4.14

4.9. Stable Vessel-Spanning Bubble with $76.5 \mathrm{wt} \% \mathrm{~K}$ West Container Simulant (KW-A) Shown at the Beginning of the Test and After $60 \mathrm{~min}$ and $125 \mathrm{~min}$

4.10. Fin Performance and Vessel-Spanning Bubble Stability for Kaolin/Min-U-Sil 30 Simulants Spanning a Range of Gravity Yield Parameter $\left(\mathrm{Y}_{\mathrm{G}}\right)$ and Layer Thickness $(\mathrm{H} / \mathrm{D})$ in the 10 -in. Vessel

4.11. Fin Performance and Vessel-Spanning Bubble Stability for Kaolin Simulants Spanning a Range of Gravity Yield Parameter $\left(\mathrm{Y}_{\mathrm{G}}\right)$ and Layer Thickness $(\mathrm{H} / \mathrm{D})$ in the 23-in. Vessel

4.12. Fin Performance and Vessel-Spanning Bubble Stability for Kaolin/Min-U-Sil 30 Simulants Spanning a Range of Gravity Yield Parameter $\left(\mathrm{Y}_{\mathrm{G}}\right)$ and Layer Thickness $(\mathrm{H} / \mathrm{D})$ in the 23-in. Vessel

4.13. Fin Performance and Vessel-Spanning Bubble Stability for a Combination of Kaolin and Kaolin/Min-U-Sil 30 Simulants Spanning a Range of Gravity Yield Parameter $\left(\mathrm{Y}_{\mathrm{G}}\right)$ and Layer Thickness (H/D) in the 23-in. Vessel

4.14. Fin Performance and Vessel-Spanning Bubble Stability for Kaolin Simulants Spanning a Range of Gravity Yield Parameter $\left(\mathrm{Y}_{\mathrm{G}}\right)$ and Layer Thickness (H/D) in the 5-in. Vessel

4.15. Fin Performance and Vessel-Spanning Bubble Stability for a Combination of Kaolin and Kaolin/Min-U-Sil 30 Simulants Spanning a Range of Gravity Yield Parameter $\left(\mathrm{Y}_{\mathrm{G}}\right)$ and Layer Thickness (H/D) in the 10-in. Vessel..... 


\section{Tables}

1.1. Evaluation of Velocity of Rising Sludge Layer in STSCs at a Reaction Temperature of $60^{\circ} \mathrm{C}$

2.1. Shear Strength in Full- and Small-Scale Vessels Based on Gravity Yield Parameter Scaling for the Maximum Shear Strength in an STSC and the Strength at the Onset of Instability ....

2.2. Summary of Test Variables Evaluated for Determining Fin Performance and Scale-up Behavior 2.6

2.4. Dimensions of Scaled Vessels and Fin Heights 2.6

2.5. Dimensions of Scaled Fins with a Range of Slopes and Widths for the 10-in., Flat-Bottom Vessel and Corresponding Full-Scale Fins..

2.6. Dimensions of Straight-Sided Scaled Fins for Scale-up Testing that Represent a 5-Degree, 2-in. Wide, Full-Scale Fin .

2.7. Dimensions of T-Shaped Scaled Fins used in 10-in. and 23-in. Vessel Testing that Represent a 5-Degree, 4-in. Wide Full-Scale T-Fin

3.1. Gravity Yield Parameter Values and Average Shear Strengths for Kaolin Simulants Used in 10-in. (0.254-m) Vessels

3.2. Gravity Yield Parameter Values and Average Shear Strengths for Kaolin Simulants Used in 5-in. (0.127-m) Vessels

3.3. Gravity Yield Parameter Values Based on 10-in. (0.254-m) Vessels and Average Shear Strengths for Kaolin/Min-U-Sil 30 Mixtures

3.4. Gravity Yield Parameter Values and Average Shear Strengths for Kaolin/Min-U-Sil 30 Simulants Used in 10-in. (0.254-m) Flat-Bottom and Elliptical-Bottom Tests

3.5. Gravity Yield Parameter Values Based on 10-in. (0.254-m) Vessels and Average Shear Strengths for KW-A Simulants.

3.6. Calculated Dimensions and As-Built Dimensions for 2:1 Ellipse.

3.7. As-Built Fin Dimensions

3.8. As-Built Dimensions of the Fin for the 2:1 Elliptical-Bottom Vessel

3.9. Gravity Yield Parameter Values and Average Shear Strengths for Kaolin Simulants Used in 23-in. (0.584-m) Vessel.

3.10. Gravity Yield Parameter Values and Average Shear Strengths for Kaolin/Min-U-Sil 30 Simulants Used in 23-in. (0.584-m) Vessel.

3.11. As-Built Fin Dimensions

4.1. Effect of Shear Strength on the Stability of VSBs in the 10-in., Flat-Bottom Vessel Without Fins

4.2. Fin Performance Results in the 10-in., Flat-Bottom Vessel with 55-wt\% Clay (720 Pa, $\left.\mathrm{Y}_{\mathrm{G}}=0.19\right)$

4.3. Effect of Clay Strength on the Performance of 5-Degree Straight-Sided and "T"-Shaped Fins in a Flat-Bottom Vessel..... 
4.4. Effect of Gravity Yield Parameter on the Stability of VSBs and Fin Performance in a 2:1 Elliptical-Bottom Vessel for Kaolin Clay Simulants.

4.5. Effect of Gravity Yield Parameter on the Stability of VSBs and Fin Performance in a 2:1 Elliptical-Bottom Vessel for Kaolin/Min-U-Sil 30 Simulants

4.6. Slumping Heights (50-cent Rheometer) as a Function of $\mathrm{H}^{*}$ for Comparison

4.7. Open Channel Depths (Channel Slumping) as a Function of $\mathrm{H}^{*}$ for Comparison.

4.8. Effect of Gravity Yield Parameter on the Stability of VSBs and Fin Performance with KW Container Sludge Simulant (Complete) (KW-A) in a 10-in., Flat-Bottom Vessel 



\subsection{Introduction}

Radioactive sludge was generated in the K-East Basin and the K-West Basin fuel storage pools at the Hanford Site while irradiated uranium metal fuel elements from the $\mathrm{N}$ Reactor were being stored and packaged. The fuel has been removed from the K Basins, and currently, the sludge resides in the KW Basin in large underwater Engineered Containers. The first phase to the Sludge Treatment Project being led by CH2MHILL Plateau Remediation Company (CHPRC) is to retrieve and load the sludge into sludge transport and storage containers (STSCs) and transport the waste to T Plant for interim storage (Honeyman and Rourk 2009). The STSCs will be stored inside T Plant cells that are equipped with secondary containment and leak-detection systems. The second phase of the project will be to retrieve the sludge from interim storage and treat and package the sludge in preparation for eventual shipment to the Waste Isolation Pilot Plant.

The Engineered Container and settler tank sludge is composed of a variety of particulate materials and water, including a fraction of reactive uranium metal particles. Johnson (2010) and Schmidt (2009) give summaries of characterization studies of these materials. Hydrogen gas is generated through corrosion reactions of uranium metal in addition to the radiolysis of water, and a number of studies have quantified the gas generation behavior (see, for example, Delegard and Schmidt 2009, Bryan et al. 2001, Delegard et al. 2000, Baker et al. 2000, Johnson 1995). The generated hydrogen gas can be retained and released by a number of different mechanisms, and the retention and release behavior has been evaluated by a number of studies.

The specific gas-retention mechanism being considered in this study is the formation of vesselspanning bubbles (VSBs). VSBs in sludge were first documented by Makenas et al. (1997) (see further description by Baker et al. 2000) in an experiment conducted with $1996 \mathrm{KE}$ canister sludge in a 2-L glass graduated cylinder. The image on the left in Figure 1.1 shows an example from this study. The second laboratory example in Figure 1.1 shows a VSB in a 100-mL graduated cylinder with a KW actual sludge sample (Baker et al. 2000). In both of these experiments, most of the uranium metal particulate was at the bottom of the sludge layer, and a VSB formed that lifted a layer of sludge. The general conditions and configuration when VSBs may occur is when most of the reactive uranium metal particles settle out at the bottom of a container and generate sufficient gas to form a container-spanning gas layer above the uranium metal particles that expands and pushes the overlying layer of sludge upward. Figure 1.1 also shows this general configuration. The major concern, in addition to the general concern associated with the retention and release of a flammable gas such as hydrogen, is that if a VSB forms in an STSC, it may drive the overlying sludge material to the vents at the top of the container where it may be released from the container into the cell secondary containment system at $\mathrm{T}$ Plant. 


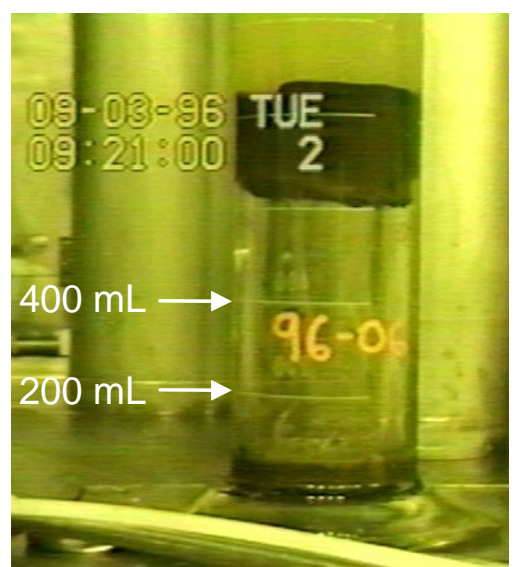

KE Canister Sludge (96-06)

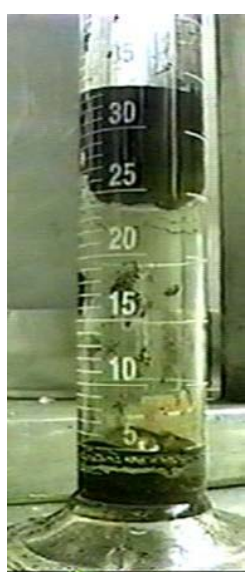

KW Canister

Sludge (96-17)

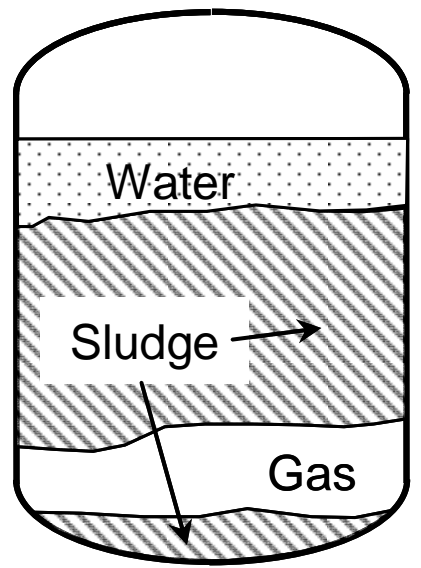

Figure 1.1. Laboratory Examples of VSBs in a Graduated Cylinders and the General Configuration of a VSB

More recently, Epstein and Gauglitz (2010) studied the stability of VSBs and quantified the conditions when the bubbles became unstable because of a Taylor instability where the more dense sludge slumps into the less dense gas and allows gas to release through the sludge. A series of different geometry and size vessels were studied, and the results showed that a dimensionless gravity yield parameter, $\mathrm{Y}_{\mathrm{G}}$, which is a dimensionless ratio of the force necessary to yield the sludge to its weight (see Section 1.1 for a discussion), provides a criterion that dictates whether a VSB will be unstable and also defines how the instability scales with vessel diameter and the strength and density of the sludge. These experiments confirmed the previous theoretical predictions of the Taylor instability in solids given by Epstein (2002) and the general conclusion that the gravity yield parameter describes the dominant behavior of other release gas-release mechanisms for VSBs (Terrones and Gauglitz 2002).

Epstein and Gauglitz (2010) also reported test results demonstrating that sloped walls on vessels, both in cylindrical coned-shaped vessels and on straight walls of rectangular vessels with rounded ends (obround vessels), provide an effective approach for disrupting a VSB by creating a release path for gas as a plug of sludge begins to rise. In all these experiments, the clays never rose more than about $1 / 4$ inch. Epstein and Gauglitz (2010) also investigated the capability of rings, or rims, placed above the clay layer to disrupt layers being lifted by VSBs. In both cylindrical and obround vessels, the rims caused the clay layers to collapse as they attempted to flow past the ring. In most experiments, collapse occurred quickly with the clay layer only moving a short distance past the shelf $(\sim 4 \mathrm{~cm})$. In one test with relatively strong clay $\left(\mathrm{Y}_{\mathrm{G}}=0.23\right)$, however, the clay layer did not collapse until about two-thirds of the layer had moved through the ring, showing that the performance of the ring can be less than ideal in some conditions. Based on the success of sloped walls for disrupting VSBs and the potential limitations of rings, a potential useful concept is to use a sloped-vessel internal device, such as an angled fin, to create a release path for gas and disrupt a VSB as it begins to rise. A key potential advantage of using a sloped fin in comparison to using a vessel with sloped walls is that a small fin decreases the volume of a vessel available for sludge storage by a very small fraction compared to a cone-shaped vessel. A similar concept was used in gas generation testing with K-Basin sludge (see Delegard et al. 2000, Figure 2.4). A key aspect of quantifying gas release along a sloped fin or wall is determining if the sludge will slump and seal off the 
release pathway when it is sufficiently weak. The previous experiments of bubble release in vessels with sloped walls by Epstein and Gauglitz (2010) did not investigate this behavior.

The purpose of this study is to quantify the capability of sloped fins to disrupt VSBs and to conduct sufficient tests to estimate the performance of fins in full-scale STSCs. Experiments have been conducted with a range of fin shapes to determine what slope and width are sufficient to make certain that VSBs are disrupted. Additional tests were conducted to demonstrate how the fin performance scales with sludge strength, density, and vessel diameter based on the gravity yield parameter. The key objective in evaluating fin performance is to determine the conditions that minimize the volume of a VSB when disruption occurs because this reduces the potential for material inside the STSC from being released through vents.

In the following subsection, the geometry of the full-scale STSC is shown, and the range of sludge shear strength, density, and depth at full loading is described. Section 2 discusses the mechanism of gas release due to a sloped fin and how this behavior scales with the gravity yield parameter and the approach to conducting scaled tests. Section 3 discusses the experimental method and materials, and the results are discussed in Section 4 followed by conclusions and recommendations in Section 5.

\subsection{Sludge Transport and Storage Containers and Waste Properties}

KW and KE Engineered Container sludge and settler tank sludge will be loaded into STSCs before being transported to the T Plant. Figure 1.2 shows a simplified schematic of an STSC, and Figure 1.3 shows details and dimensions of the STSC, which include an inner annulus that can be removed (Johnson and Dhaliwal 2009). The current plan for the project is to use the annulus with the settler sludge, but it will be removed for the other sludge materials, and different amounts of sludge will be transferred, depending on the waste. ${ }^{(a)}$ The current plan assumes that $0.5 \mathrm{~m}^{3}$ of settler sludge, which corresponds to a sludge height of 20.5 inches with the annulus in place, will be loaded into the STSC. For the KE Engineered Container sludge, the plan is to load the STSC (without the annulus) with $2.1 \mathrm{~m}^{3}$ of sludge, which corresponds to a height of 55 inches from the bottom of the elliptical head. The KW Engineered Container sludge will be loaded to a depth of 43.5 inches, which corresponds to $1.6 \mathrm{~m}^{3}$ of sludge.

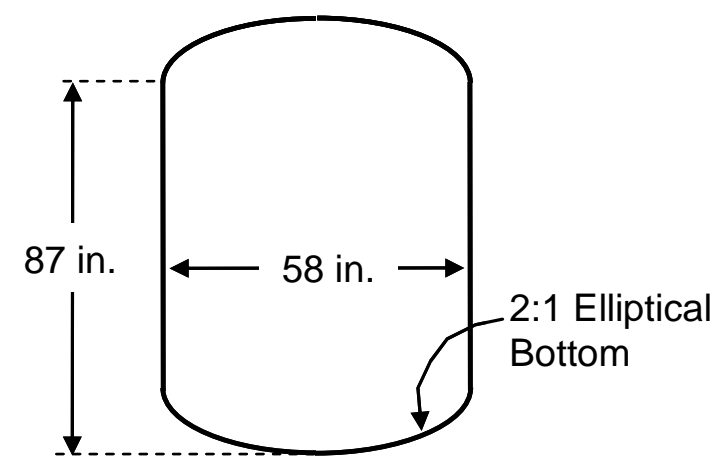

Figure 1.2. Simplified Schematic of STSC Showing Inner Diameter and Height from the Bottom of the 2:1 Elliptical Head to the Beginning of the Elliptical Head at the Vessel Top

(a) E-mail communication from ME Johnson to PA Gauglitz dated 3/3/2010 (see also Johnson and Dhaliwal 2009). 


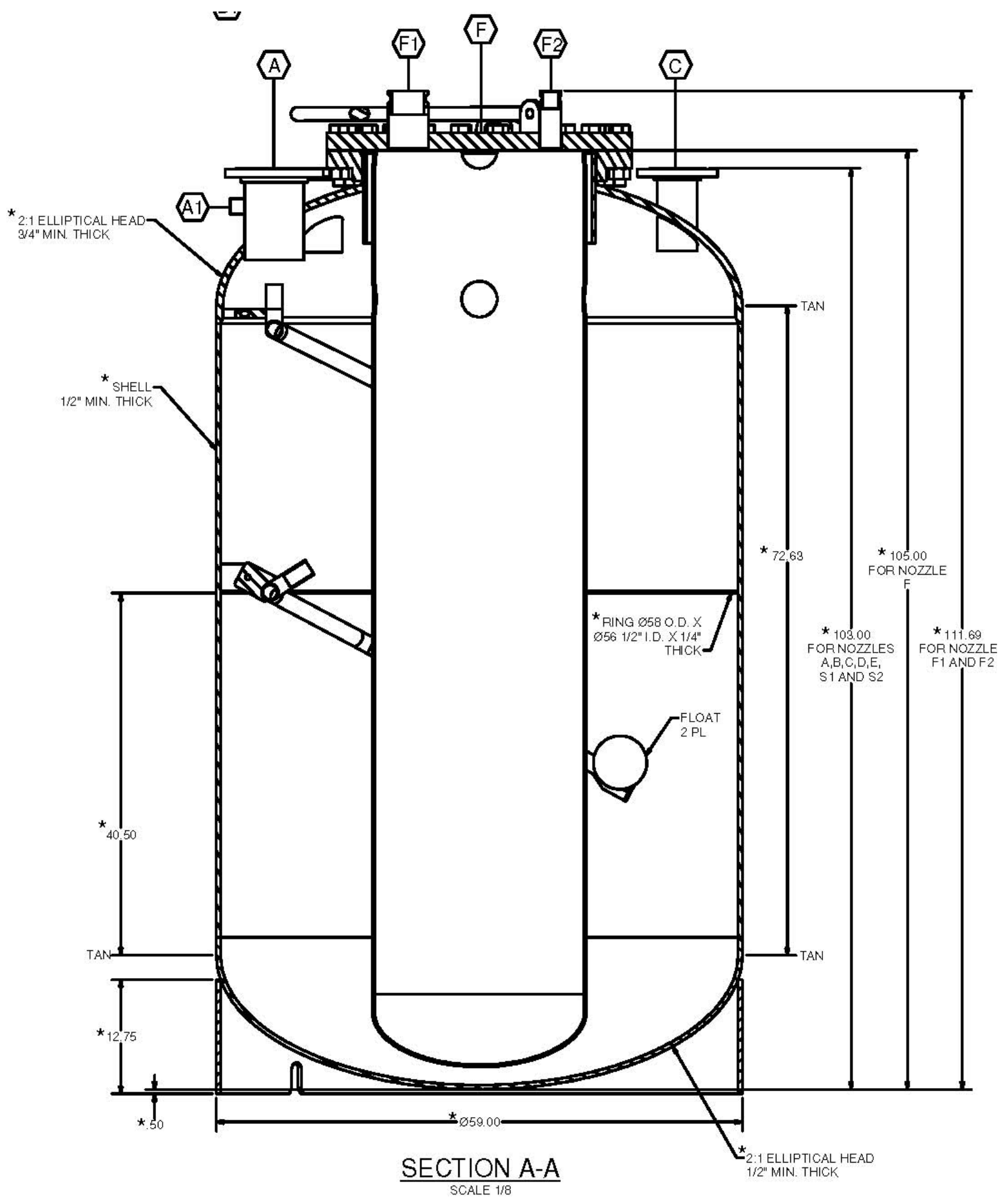

Figure 1.3. STSC Shown with an Inner Annulus that Will Be Used with Settler Sludge But Will Be Removed for Other Sludge Materials (schematic given in Figure 8 of Johnson and Dhaliwal [2009]; diagram above reproduced from CHPRC ENGINEERING SKETCH SK-4K-M-0021R0) 
For these loading plans, the maximum initial depth of sludge in an STSC is 55 inches, which corresponds to a ratio of layer depth-to-vessel diameter of about one, and this will be used as the sludge depth for calculating the appropriate maximum sludge depth in small-scale tests. The settler sludge depth will be significantly less than this, so tests will also need to evaluate behavior for smaller layer depths. For the current testing, it is assumed that the presence or absence of the annulus will not affect the performance of a sloped fin for releasing gas from a VSB. The current testing will not consider sludge depths greater than the equivalent of 55 inches, though volume expansion of the sludge due to uranium corrosion and the growth of uniformly distributed small gas bubbles can occur (Johnson and Dhaliwal 2009, Schmidt 2009, Schmidt and Delegard 2002).

The planned loading of the STSCs includes having a water layer above the sludge. Johnson and Dhaliwal (2009) (see Section 3.3) give the maximum fill level of the STSCs with water and note that the volume of the air space is $\sim 0.4 \mathrm{~m}^{3}$ for a full STSC. This volume of headspace corresponds to the sludge level rising $\sim 9$ inches. For a level rise of less than 9 inches, water and sludge will not be displaced from an STSC as a result of a VSB. For a 9-in. rise, the ratio of level rise-to-vessel diameter is 0.15 , and this is a suitable dimensionless criterion for determining if a VSB is stable and whether a fin is successful at disrupting an otherwise stable VSB. This criterion will be used for categorizing experimental results in this study.

Characterization data of Engineered Container sludge samples have been summarized and reviewed by Johnson (2010), and characterization data for a broader range of sludge samples have been summarized by Schmidt (2009). The data reported in the Sludge Data Book (Schmidt 2009), which summarizes values for design and safety basis calculations, gives a shear-strength range of 1 to 8,200 $\mathrm{Pa}$, and all of the available data for Engineered Container sludge are within this range (Johnson 2010). For the current study on the disruption of VSBs with fins, this full range of shear strength is plausible for sludge in the full-scale STSCs. In Section 2, a discussion is presented on how to conduct small-scale experiments, and it will be shown that the shear strength for small-scale tests needs to be reduced (scaled) to match the behavior expected at full scale.

Table 1.1 summarizes the Sludge Data Book (Schmidt 2009) and sludge treatment project (STP) material balance (Johnson and Dhaliwal 2009) input data and results for calculating the velocity of rising sludge in STSCs above a VSB formed by hydrogen gas produced from the reaction of uranium metal particles with water at $60^{\circ} \mathrm{C}$. ${ }^{\text {(a) }}$ The calculated rise velocities range from 0.48 to $4.9 \mathrm{~cm} / \mathrm{hr}$. Experiments will be conducted at and above the upper end of the range of this rise velocity for the current study on the disruption of VSBs with fins.

(a) Note: the temperature, $60^{\circ} \mathrm{C}$, was arbitrarily selected for this table. It is expected to be near the maximum temperature that must be evaluated for transport of the STSCs to the T Plant. 
Table 1.1. Evaluation of Velocity of Rising Sludge Layer in STSCs at a Reaction Temperature of $60^{\circ} \mathrm{C}$

\begin{tabular}{|c|c|c|c|c|c|c|c|c|}
\hline \multirow{3}{*}{ Source Streams } & \multicolumn{8}{|c|}{ Container Sludge Source Streams } \\
\hline & \multicolumn{2}{|c|}{ KE Container $^{(a)}$} & \multicolumn{2}{|c|}{ KW Container ${ }^{(a)}$} & \multicolumn{2}{|c|}{ Settler Sludge $^{(\mathrm{a})}$} & \multicolumn{2}{|c|}{ STP Settler Sludge ${ }^{(\mathrm{b})}$} \\
\hline & Design & Safety & Design & Safety & Design & Safety & Design & Safety \\
\hline Sludge $\mathrm{STSC}^{(\mathrm{b})}, \mathrm{m}^{3}$ & 2.1 & 2.1 & 1.6 & 1.6 & 0.5 & 0.5 & 0.5 & 0.5 \\
\hline Sludge Density, $\mathrm{g} / \mathrm{cm}^{3}$ & 1.4 & 1.6 & 1.6 & 1.8 & 3.0 & 4.0 & 2.45 & 3.25 \\
\hline Percent Water in Sludge, \% & 75 & 75 & 74 & 74 & 65 & 65 & 70 & 70 \\
\hline U Metal Concentration, $\mathrm{g} / \mathrm{cm}^{3}$ & 0.006 & 0.03 & 0.030 & 0.082 & 0.063 & 0.2 & 0.052 & 0.163 \\
\hline U Metal Concentration, g/L & 6 & 30 & 30 & 82 & 63 & 200 & 52 & 163 \\
\hline U Metal, kg/STSC & 13 & 63 & 48 & 131 & 32 & 100 & 26 & 81 \\
\hline Rate Enhancement Factor & 3 & 3 & 3 & 3 & 3 & 3 & 3 & 3 \\
\hline U Metal particle dia., $\mu \mathrm{m}$ & 500 & 500 & 500 & 500 & 375 & 375 & 375 & 375 \\
\hline U Metal Surface Area, $\mathrm{cm}^{2} / \mathrm{STSC}^{(\mathrm{c})}$ & $8.0 \mathrm{E}+04$ & $4.0 \mathrm{E}+05$ & $3.0 \mathrm{E}+05$ & $8.3 \mathrm{E}+05$ & $2.7 \mathrm{E}+05$ & $8.4 \mathrm{E}+05$ & $2.2 \mathrm{E}+05$ & $6.8 \mathrm{E}+05$ \\
\hline $\mathrm{H}_{2}$ gen rate in $\mathrm{STSC}, \mathrm{mol} \mathrm{H}_{2} / \mathrm{hr}$ & $3.8 \mathrm{E}-01$ & $1.9 \mathrm{E}+00$ & $1.4 \mathrm{E}+00$ & $3.9 \mathrm{E}+00$ & $1.3 \mathrm{E}+00$ & $4.0 \mathrm{E}+00$ & $1.0 \mathrm{E}+00$ & $3.2 \mathrm{E}+00$ \\
\hline Sludge Height STSC Cylinder, cm & 121 & 121 & 92 & 92 & 35 & 35 & 35 & 35 \\
\hline Gas Bubble Pressure, atm & 1.2 & 1.3 & 1.2 & 1.3 & 1.2 & 1.3 & 1.2 & 1.3 \\
\hline $\mathrm{H}_{2}$ Gen Rate in STSC, L/hr & 8.4 & 41 & 32 & 86 & 28 & 85 & 23 & 71 \\
\hline Sludge Plug rise velocity, $\mathrm{cm} / \mathrm{hr}$ & 0.48 & 2.4 & 1.8 & 4.9 & 1.6 & 4.9 & 1.3 & 4.1 \\
\hline $\begin{array}{l}\text { Total } \mathrm{H}_{2}\left(@ \mathrm{STP}^{(\mathrm{d})}\right) \text { if all U Metal } \\
\text { reacts instantaneously, } \mathrm{m}^{3}\end{array}$ & 2.4 & 11.9 & 9.0 & 24.7 & 5.9 & 18.8 & 4.8 & 15.3 \\
\hline
\end{tabular}

All density and concentration values are based are on a settled sludge basis.

(a) Input values on density, percent water, concentration, particle diameter, rate enhancement factor from HNF-SD-SNF-TI-015, Vol. 2., Rev 14.

(b) From HNF-41051, Rev. 5 (Johnson and Dhaliwal 2009). Note: for STP engineering, settler sludge can be modeled as a $50 / 50$ vol\% mix of KE/KW Canister Sludge; see also Table 2-3.

(c) Calculated, assuming uranium metal in sludge can be modeled as spherical particles.

(d) Standard temperature and pressure. 


\subsection{Mechanism for Disruption of Vessel-Spanning Bubbles with Sloped Fins}

The concept of how a sloped surface, such as an angled fin, can release gas from a VSB is depicted in Figure 2.1. If gas generation pushes the sludge layer upwards as a stable plug, and if the sludge detaches from the surface, a pathway is created for gas to release along the sloped surface. The middle drawing in Figure 2.1 shows this configuration of a sample VSB and an open gas release path. For typical K-basin sludge, the range of shear strengths is such that the sludge can collapse or slump under its own weight. The right-hand drawing in Figure 2.1 shows this configuration where the sludge layer above a stable bubble slumps and closes the gas release path. The capability of the sludge layer to form a stable VSB and the tendency of the sludge to slump under its own weight are both determined by how the gravitational force on the sludge is resisted by its strength. In the remainder of this section, simple models are used to quantify these two effects.
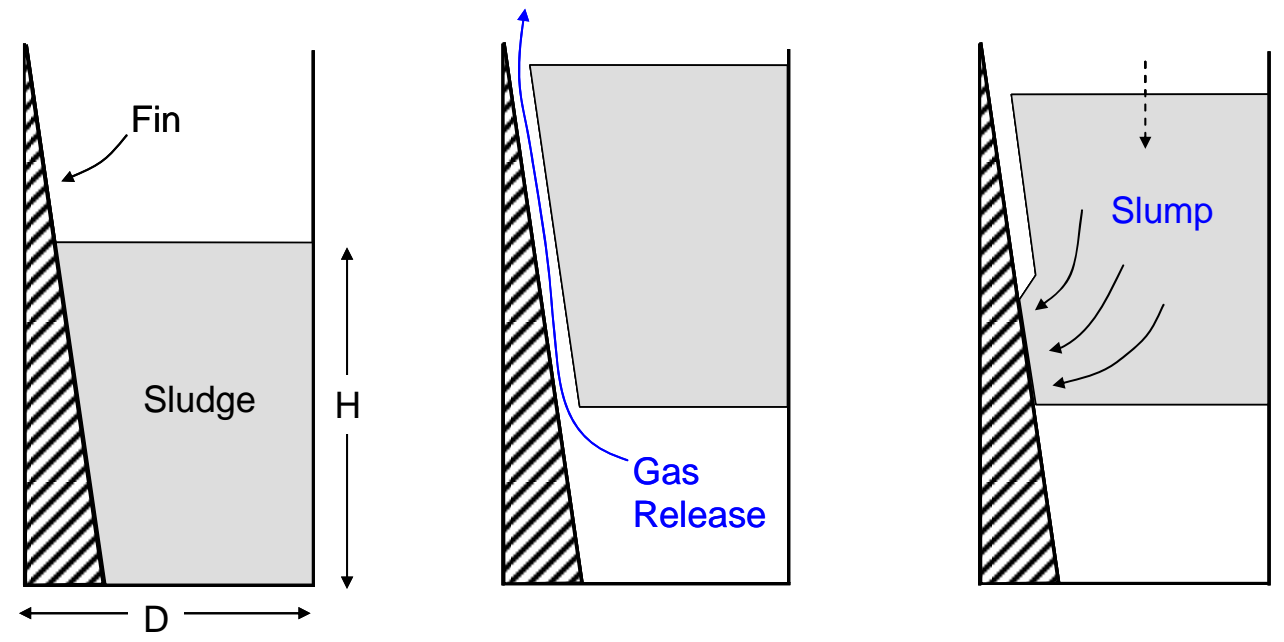

Figure 2.1. Mechanism of Gas Release Along a Sloped Fin and Slumping Causing the Release Pathway to be Sealed

Previous studies (Epstein and Gauglitz 2010, Epstein 2002, Terrones and Gauglitz 2002) have demonstrated that the dimensionless gravity yield parameter $\mathrm{Y}_{\mathrm{G}}$ is the appropriate criterion for predicting the instability of VSBs. The gravity yield parameter, $\mathrm{Y}_{\mathrm{G}}$, which is a dimensionless ratio of the force necessary to yield the sludge to its weight, is defined as

$$
\mathrm{Y}_{\mathrm{G}}=\frac{\tau_{\mathrm{s}}}{\rho_{\mathrm{s}} \mathrm{gD}}
$$

where $\tau_{\mathrm{s}}$ is the shear strength of the sludge, $\rho_{\mathrm{s}}$ is the sludge density, $\mathrm{g}$ is gravitational acceleration, and D is the vessel diameter as shown in Figure 2.1. ${ }^{(a)}$ Assuming constant density, Epstein (2002) used a theoretical analysis of a Taylor instability in a soft solid to estimate a value of $\mathrm{Y}_{\mathrm{G}}$ for the criterion

(a) Equation 2.1 shows the useful result that to conduct small- and large-scale tests at the same $Y_{G}$, the small-scale tests can be conducted with a shear strength that is reduced by the ratio of the vessel diameters, assuming the density is constant. 
between stable and unstable VSBs. Epstein and Gauglitz (2010) conducted experiments that gave an experimental stability criterion of $Y_{G}=0.09$ for cylindrical vessels with clay layers that had depths of $\mathrm{H} / \mathrm{D}=0.5$ where $\mathrm{H}$ is the depth of the sludge layer, and $\mathrm{D}$ is the vessel diameter as shown in Figure 2.1. Epstein and Gauglitz (2010) also reported results for two tests with layer depths of H/D $\sim 0.25$.

The previous studies of VSBs did not quantify the effect of the layer thickness on the stability criterion, but they did observe stable layers in two experiments with $\mathrm{H} / \mathrm{D} \sim 0.25$ at relatively high $\mathrm{Y}_{\mathrm{G}}$ values (Epstein and Gauglitz 2010; these data are shown in Figure 4.2). Epstein and Gauglitz (2010) note that theory indicates that the instability should be independent of layer thickness, and for sufficiently thick layers, this seems reasonable. However, it also seems reasonable that the sludge layer will become less stable when it becomes sufficiently thin. ${ }^{\text {(a) }}$ Equivalently, the stability criterion $\mathrm{Y}_{\mathrm{G}}$ will increase as the sludge layer becomes thinner (thinner layers must be stronger to be stable). Figure 2.3 shows a handdrawn curve for the bubble stability criterion that is an estimate for the effect of the sludge layer thickness on the value of $Y_{G}$ for bubble stability. This curve was placed to agree with the experimental result of $Y_{G}$ $=0.09$ at $\mathrm{H} / \mathrm{D}=0.5$. To the left of this curve, which is identified as Region 1, all VSBs are unstable. To the right of the curve representing this bubble stability criterion, VSBs are stable unless they are disrupted by some other mechanism, such as gas release along a fin.

To determine the onset of slumping along a fin, we will follow the approach presented by Pashias et al. (1996) for analyzing slumping of a cylinder under its own weight. Figure 2.2 shows the geometry of a material slumping against a wall. The pressure, $\mathrm{P}$, above a nominal pressure, $\mathrm{P}_{\mathrm{o}}$, at a depth $\mathrm{H}$ is

$$
\mathrm{P}-\mathrm{P}_{\mathrm{o}}=\left(\rho_{\mathrm{s}}-\rho_{\mathrm{w}}\right) \mathrm{g} \mathrm{H}
$$

where $\rho_{\mathrm{w}}$ is the density of the water. As used by Pashias et al. (1996), for simple compression of an elastic solid, the maximum shear stress is half the pressure, giving

$$
\tau_{\mathrm{s}}=\frac{1}{2}\left(\rho_{\mathrm{s}}-\rho_{\mathrm{w}}\right) \mathrm{gH}
$$

This relationship defines the height of a channel that will not slump closed in a material with a shear strength. This simple model neglects the more complex stress and failure behavior of many particulate materials, but this simple model for the onset of slumping does provide a criterion for when a gas release path along a sloped fin will be sealed by slumping. Equation 2.3 shows that the open channel height increases with shear strength and decreases as the density difference between the water and sludge becomes larger. The slumping criterion given by Equation 2.3 can be rewritten in terms of $\mathrm{H} / \mathrm{D}$ and $\mathrm{Y}_{\mathrm{G}}$ to allow it to be combined with the bubble stability criterion. Rewriting Equation 2.3 gives the following:

$$
\frac{H}{D}=2 \frac{\rho_{s}}{\left(\rho_{s}-\rho_{w}\right)}\left(\frac{\tau_{s}}{\rho_{s} g D}\right)=2 \frac{\rho_{s}}{\left(\rho_{s}-\rho_{w}\right)} Y_{G}
$$

(a) In a personal communication with PA Gauglitz, M Epstein noted that existing studies of Taylor instabilities have considered the effect of layer thickness, and these studies may provide insight on this effect. 


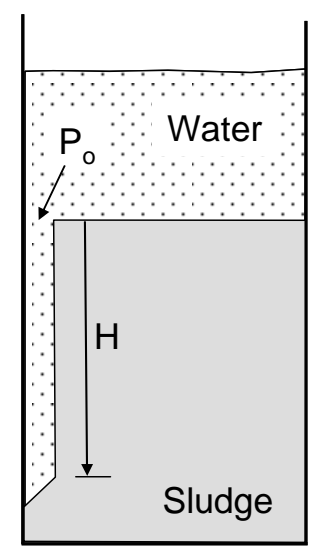

Figure 2.2. Schematic of Slumping Sludge with a Water Layer

Figure 2.3 shows the linear relationship for the channel-slumping criterion. For plotting this curve, it was assumed that the sludge density was a constant at $1,500 \mathrm{k} / \mathrm{m}^{3}$, and the liquid about the sludge is water with a density of $1,000 \mathrm{~kg} / \mathrm{m}^{3}$. At any $\mathrm{Y}_{\mathrm{G}}$ value, for sludge depths less (below) the slumping criterion, the channel will be held open by the strength of the sludge while for sludge depths greater than the criterion, the channels will slump closed. The combination of the bubble stability criterion and the slumping criterion results in three regions for the overall bubble behavior and fin performance. In Region 1, all VSBs are unstable by the Taylor instability. In Region 2, stable VSBs can form, but a sloped fin can create a gas-release pathway that will remain open to release gas. Here, fins effectively disrupt VSBs. Region 3 is the most difficult region where VSBs are stable, and fins do not release retained gas because the sludge continuously slumps and closes the gas-release path.

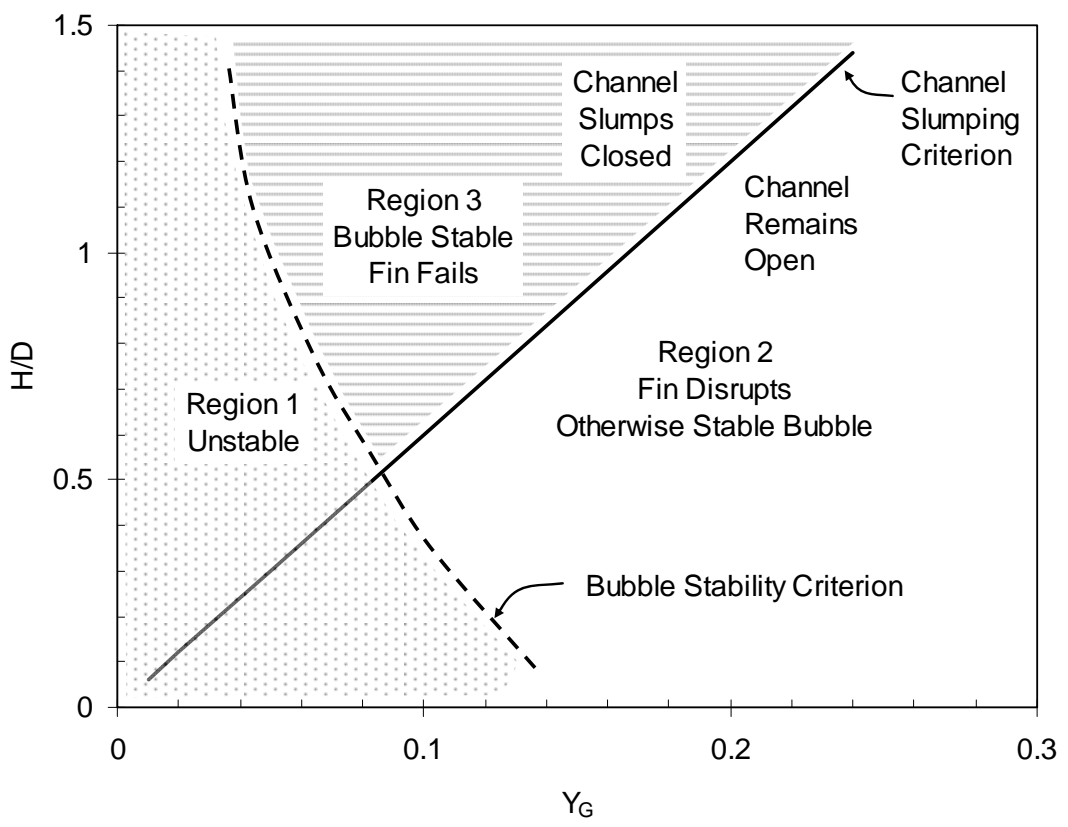

Figure 2.3. Three Regions for VSB Stability and Fin Performance 


\subsection{Simulants, Vessels, and Fins for Scaled Testing}

Previous testing by Epstein and Gauglitz (2010) has shown that the gravity yield parameter $\mathrm{Y}_{\mathrm{G}}$ given by Equation 2.1 correctly accounts for the effect of vessel diameter and simulant strength for the case when VSBs are unstable. Equation 2.4 for the slumping of sludge into a vertical channel shows how slumping also scales with $\mathrm{Y}_{\mathrm{G}}$. The approach to conducting small-scale fin performance tests is to adjust the simulant shear strength (and also density) to give the appropriate range of $\mathrm{Y}_{\mathrm{G}}$ and to use geometrically scaled vessels and fins where the small-scale vessel and fins have the same relative shape as the full-scale vessel. A small-scale vessel with a diameter of 10 inches was selected for testing because this size was sufficiently small to be manageable in the laboratory, and, based on the $Y_{G}$ scaling, the shear strengths appropriate for small-scale testing could be readily handled and made with existing simulant recipes. Previous studies (Epstein and Gauglitz 2010) used a small-scale test vessel with flat bottom, and tests with fins will also use a 10-in., flat-bottom vessel to compare with the previous work. The STSC (see Figure 1.3) has a 2:1 elliptical bottom, so a 10-in. vessel with this geometry will also be used for scaled testing. Details on the dimensions of these vessels are given in Section 3.

Table 2.1 shows the range of shear strength and gravity yield parameter values that are important in the full-scale STSCs and the corresponding values needed in the scaled tests in a 10-in. vessel. The maximum shear strength expected at full scale is $8200 \mathrm{~Pa}$ (see Section 1.1), and this corresponds to a shear strength of about $1400 \mathrm{~Pa}$ in a 10-in. vessel to give the same value of $\mathrm{Y}_{\mathrm{G}}$. The criterion for the onset of instability from previous work (Epstein and Gauglitz 2010) is $\mathrm{Y}_{\mathrm{G}}=0.09$, and this corresponds to $\sim 2000 \mathrm{~Pa}$ in the full-scale STSC. In a 10-in. vessel, the onset of instability will occur when the shear strength is $\sim 340 \mathrm{~Pa}$ based on $\mathrm{Y}_{\mathrm{G}}=0.09$. Accordingly, scaled tests in 10-in. vessels will need to span shear strengths from below $340 \mathrm{~Pa}$ to confirm the onset of unstable bubbles to as high as $\sim 1,400 \mathrm{~Pa}$.

Table 2.1. Shear Strength in Full- and Small-Scale Vessels Based on Gravity Yield Parameter Scaling for the Maximum Shear Strength in an STSC and the Strength at the Onset of Instability

\begin{tabular}{c|c|c|c|c|}
\hline & \multicolumn{2}{|c|}{ Maximum Shear Strength } & \multicolumn{2}{c|}{ At Onset of Instability } \\
\cline { 2 - 5 } & Full Scale & 10 -in. Vessel & Full Scale & 10 -in. Vessel \\
\hline Shear Strength & $8200 \mathrm{~Pa}$ & $1400 \mathrm{~Pa}$ & $1900 \mathrm{~Pa}$ & $340 \mathrm{~Pa}$ \\
\hline Vessel & $1.47 \mathrm{~m}$ & $0.254 \mathrm{~m}$ & $1.47 \mathrm{~m}$ & $0.254 \mathrm{~m}$ \\
Diameter & $(58 \mathrm{in})$. & $(10 \mathrm{in})$. & $(58$ in. $)$ & $(10$ in.) \\
\hline $\mathrm{Y}_{\mathrm{G}}$ & \multicolumn{2}{|c}{0.38} \\
\hline Density is assumed to be $1,500 \mathrm{~kg} / \mathrm{m}^{3}$ for all conditions. \\
\hline
\end{tabular}

Testing to determine the scaling of fin performance needs to be conducted over a range of gravity yield parameter, fin shapes, and vessel shapes. The gravity yield parameter depends on both the shear strength and vessel diameter, so both of these parameters need to be varied independently. The effect of slumping also shows that the layer depth needs to be varied. Finally, different simulants that may behave differently at the same shear strength also need to be considered. 
Table 2.2 shows a summary of the testing for evaluating the key parameters. Most of the testing was conducted in a 10-in., flat bottom vessel with a kaolin simulant and with a 5-degree fin with straight sides. Selected experiments were conducted to evaluate the role of fin slope and width, the effect of having an elliptical bottom, and the behavior of a different simulant from kaolin (KW container sludge simulant [complete] [also referred to as KW-A in this report and in Burns et al. 2009] and kaolin/Min-U-Sil 30). Selected tests were also conducted in 5-in. and 23-in.-diameter vessels to determine how the vessel size affects the scaling given by the gravity yield parameter. Finally, a few tests were done with a T-shaped fin to compare its performance with straight-sided fins.

Previous studies have used kaolin clay mixtures to quantify the behavior of VSBs (Epstein and Gauglitz 2010), and these previous tests support using kaolin as a reasonable simulant for testing. Actual $\mathrm{K}$-Basin waste is certainly different from clay materials, and the $\mathrm{KW}$ container sludge simulant (complete) mentioned above was selected for testing because it is expected that actual K-Basin container sludge will behave closer to this simulant material. While there are no studies that compare slumping or VSB behavior of actual K-Basin sludges and various simulants, the KW container sludge simulant (complete) is expect to represent that actual waste better for two general reasons. First, the particles and relative quantities used in the KW container sludge simulant (complete) were selected to match the distribution of sizes and densities of the actual waste particles based on characterization data of a number of actual waste samples (Burbank 2009). This matching of particle size and density distributions should provide more representative simulant behavior than a simple clay simulant. The second reason for asserting that the KW container sludge simulant (complete) represents the actual waste better is based on a comparison of the shear vane test data between the simulants and actual waste. As discussed in Appendix A, for a shear vane test, the shear stress is recorded as a function of time as the vane is rotated in the sample. The transient relationship between stress and deformation, rather than just the peak stress that is reported as the shear strength, provides additional information regarding the deformation behavior of a material. In Appendix A, plots showing shear stress as a function of time are provided for KW container sludge simulants (complete) (Figures A.147 through A.188) and kaolin simulants (Figures A.3 through A.110). These plots can be compared with actual waste results reported in Appendix B of Poloski et al. (2002). In comparison to the smooth, rapid increase in stress with kaolin simulants, the KW container sludge simulant (complete) plots show a slower rise to a peak stress and then significant fluctuation in the stress as the vane rotates. The actual waste stress and deformation behavior reported in Poloski et al. (2002) is matched better by the KW container sludge simulant (complete) than the kaolin clay. As mentioned previously, while there are no studies that compare slumping or VSB behavior of actual K-Basin sludges and various simulants, the KW container sludge simulant (complete) should represent the actual waste better. 
Table 2.2. Summary of Test Variables Evaluated for Determining Fin Performance and Scale-up Behavior

\begin{tabular}{|c|c|c|c|c|}
\hline $\begin{array}{c}\text { Vessel } \\
\text { Diameter } \\
\text { (in.) }\end{array}$ & Simulant & $\operatorname{Fin}^{(a)}$ & $\begin{array}{c}\text { Vessel } \\
\text { Bottom } \\
\text { Shape }\end{array}$ & $\begin{array}{c}\text { Layer } \\
\text { H/D }\end{array}$ \\
\hline \multirow{5}{*}{10} & Kaolin & $\begin{array}{l}\text { Straight } \\
\text { - vary slope } \\
\text { - vary width }\end{array}$ & Flat & range \\
\hline & Kaolin/Min-U-Sil 30 & $5^{\circ}-$ Straight & Flat & range \\
\hline & KW Container (KW-A) & $5^{\circ}$ - Straight & Flat & 1 \\
\hline & $\begin{array}{l}\text { Kaolin } \\
\text { Kaolin/Min-U-Sil } 30\end{array}$ & $5^{\circ}$ - Straight & Elliptical & 1 \\
\hline & Kaolin & $5^{\circ}-\mathrm{T}-$ Fin & Flat & 1 \\
\hline 23 & $\begin{array}{l}\text { Kaolin } \\
\text { Kaolin/Min-U-Sil } 30\end{array}$ & $\begin{array}{l}5^{\circ}-\text { Straight } \\
5^{\circ}-T-F i n\end{array}$ & Flat & range \\
\hline 5 & Kaolin & $5^{\circ}$ - Straight & Flat & range \\
\hline $\begin{array}{l}\text { (a) The fins } \\
\text { of } 2 \mathrm{inc}\end{array}$ & ntified as " $5^{\circ}$ - Straight" ar & scaled to matc & scale fin $w$ & width \\
\hline
\end{tabular}

Table 2.3 shows the dimensions of the 5 -in, 10-in., and 23-in. scaled test vessels and fin heights in comparison to the corresponding full-scale values. As an example, for a small-scale vessel with a diameter of 10 inches, the small-scale fin height is ${ }^{10} / 58$ times the full-scale height of 87 inches, or 15 inches. For the fins, a scaled height of 15 inches corresponds to a full-scale fin that rises 87 inches (see Figure 1.2). Table 2.4, Table 2.5, and Table 2.6 give specific dimensions of the scaled fins used in the testing in comparison to the corresponding full-scale dimensions. For the 10-in., flat-bottom vessel, the fins tested had slopes ranging from 2.5 to 10 degrees and had widths corresponding to full-scale fins varying from $1 / 2$ inch to 4 inches. This selection of scaled fins was chosen to span a reasonable range of fin slope and width. The straight-sided fins for scale-up testing in the 23-in. and 5-in. vessels match a full-scale 5-degree fin with a 2-in. width. T-shaped fins were used as an alternate fin shape, and the fins tested match a full-scale fin with a face width (top of the " $T$ ") that is 4 inches.

Table 2.3. Dimensions of Scaled Vessels and Fin Heights

\begin{tabular}{lccccc}
\hline \multirow{2}{*}{ Dimension } & \multicolumn{5}{c}{ Vessel } \\
\cline { 2 - 6 } & Full Scale & $\begin{array}{c}\text { 10-in. } \\
\text { Flat Bottom }\end{array}$ & $\begin{array}{c}\text { 10-in. 2:1 } \\
\text { Elliptical }\end{array}$ & $\begin{array}{c}\text { 23-in. } \\
\text { Flat Bottom }\end{array}$ & $\begin{array}{c}\text { 5-in. } \\
\text { Flat Bottom }\end{array}$ \\
\hline Diameter (in.) & 58 & 10 & 10 & 23 & 5 \\
Fin Height (in.) & $87^{\text {(a) }}$ & 15 & $15^{(\text {b) }}$ & 34.5 & 7.5 \\
\hline (a) See Figure 1.2. \\
(b) From center bottom of elliptical head.
\end{tabular}


Table 2.4. Dimensions of Scaled Fins with a Range of Slopes and Widths for the 10-in., Flat-Bottom Vessel and Corresponding Full-Scale Fins

\begin{tabular}{c|c|c|c|c|}
\hline \multirow{2}{*}{$\begin{array}{c}\text { Slope } \\
\text { (degrees) }\end{array}$} & \multicolumn{2}{|c|}{$\begin{array}{c}\text { Fin for } \\
\text { Full-Scale Vessel } \\
\text { (87-in. tall fin) }\end{array}$} & $\begin{array}{c}\text { Fin for } \\
\text { 10-in., Flat-Bottom Vessel } \\
\text { (15-in. tall fin) }\end{array}$ \\
\cline { 2 - 5 } & $\begin{array}{c}\text { Width } \\
\text { (in.) }\end{array}$ & $\begin{array}{c}\text { Base } \\
\text { (in.) }\end{array}$ & $\begin{array}{c}\text { Width } \\
\text { (in.) }\end{array}$ & $\begin{array}{c}\text { Base } \\
\text { (in.) }\end{array}$ \\
\hline & 0.5 & 3.8 & $\begin{array}{l}0.086 \\
0.34\end{array}$ & 0.65 \\
\hline & 2 & & 0.086 & \\
& 0.5 & & 0.17 & 1.31 \\
\hline 10 & 2 & 7.6 & 0.34 & \\
\hline & 2 & & 0.69 & 2.64 \\
\hline
\end{tabular}

Table 2.5. Dimensions of Straight-Sided Scaled Fins for Scale-up Testing that Represent a 5-Degree, 2-in. Wide, Full-Scale Fin

\begin{tabular}{ccccc}
\hline $\begin{array}{c}\text { Vessel Diameter } \\
\text { (in.) }\end{array}$ & $\begin{array}{c}\text { Slope } \\
\text { (degrees) }\end{array}$ & $\begin{array}{c}\text { Height } \\
\text { (in.) }\end{array}$ & $\begin{array}{c}\text { Base } \\
\text { (in.) }\end{array}$ & $\begin{array}{c}\text { Width } \\
\text { (in.) }\end{array}$ \\
\hline 5 & 5 & 7.5 & 0.66 & 0.17 \\
10 & 5 & 15 & 1.31 & 0.34 \\
23 & 5 & 34.5 & 3.02 & 0.79 \\
58 & 5 & 87 & 7.6 & 2 \\
\hline
\end{tabular}

Table 2.6. Dimensions of T-Shaped Scaled Fins used in 10-in. and 23-in. Vessel Testing that Represent a 5-Degree, 4-in. Wide Full-Scale T-Fin

\begin{tabular}{ccccc}
\hline $\begin{array}{c}\text { Vessel Diameter } \\
\text { (in.) }\end{array}$ & $\begin{array}{c}\text { Slope } \\
\text { (degrees) }\end{array}$ & $\begin{array}{c}\text { Height } \\
\text { (in.) }\end{array}$ & $\begin{array}{c}\text { Base } \\
\text { (in.) }\end{array}$ & $\begin{array}{c}\text { Face Width } \\
\text { (in.) }\end{array}$ \\
\hline 10 & 5 & 15 & 1.31 & 0.69 \\
23 & 5 & 34.5 & 3.02 & 1.59 \\
58 & 5 & 87 & 7.6 & 4 \\
\hline
\end{tabular}





\subsection{Experimental Method and Materials}

Experiments were conducted in a number of different scaled-down test vessels. All vessels were designed and fabricated in acrylic to allow observation of VSBs and the performance of the sloped fins at disrupting these bubbles. Two of these vessels had 10-in. diameters, with one having a flat bottom and one having a 2:1 elliptical bottom. Additionally, two other flat-bottom test vessels larger and smaller than the 10-in. vessel were used to allow scaling confirmation given by the gravity yield parameter. These flat-bottom vessels had 23-in. and 5-in. diameters. All vessels were designed to allow fins of different shapes to be inserted and removed. This section describes details of the test vessels, simulants, fins, and the method for conducting the experiments.

\subsection{Small-Scale Tests-10-in. and 5-in.-Diameter Test Vessels}

Small-scale tests were performed using 10-in. and 5-in.-diameter, flat-bottom vessels and a 10-in.diameter vessel with a 2:1 elliptical bottom. A range of kaolin clay, Min-U-Sil 30, and KW container sludge (complete) (KW-A) simulants were used together with a number of scaled fins. The simulants were selected to give the appropriate range of gravity yield parameter, $\mathrm{Y}_{\mathrm{G}}$, and the fins were fabricated from stainless steel to match the dimensions given in Table 2.4, Table 2.5, and Table 2.6. The specific simulants and as-built dimensions of the fins and vessels are summarized in the subsections below. Note that only kaolin clays were tested in the 5-in.-diameter vessel.

\subsubsection{Simulants and Shear Strength}

\subsubsection{Kaolin Clay}

Kaolin clay was previously used by Epstein and Gauglitz (2010) and is thought to be a reasonable simulant for studying VSBs. Individual batches of about 2.5 to 4 gallons of EPK Kaolin clay (Edgar Minerals Inc., Edgar, FL) in deionized water were prepared at 45, 47, 48, 49, 50, 52, 55, and 58-wt\% clay. The $58-w t \%$ and $55-w t \%$ clays were made in multiple $3-\mathrm{kg}$ batches with a KitchenAid® mixer. The remaining clays were produced in single batches with either an overhead drum mixer or double auger mixer and poly drum. All of the clays were allowed to hydrate for 24 hours before evaluating the shear strength or conducting VSB tests. After the 24-hr period, a subsample of each clay was mixed in a KitchenAid ${ }^{\circledR}$ mixer for 2 minutes, placed in a sample container, and then allowed to rest for 1 hour before taking shear-strength measurements. The shear strength was measured in triplicate with a Haake RV20-M5 rheometer using the vane technique (Nguyen and Boger 1985) following an established procedure (Daniel 2007). Appendix A gives details on the method and calibration procedure and also gives the individual results and uncertainty estimates. Figure 3.1 shows the results for the shear strength for each batch of Kaolin clay used in the 10-in.-diameter, VSB tests, and Table 3.1 gives the average values that are plotted in Figure 3.1 The average uncertainty for the triplicate measurements is about $4 \%$. The shear strengths for the current kaolin mixtures are noticeably higher than results obtained in previous studies by Rassat et al. (2003), even though the same grade and supplier of kaolin were used. Variation in shear strength between different supplies (such as different lots from different years) of kaolin clay is often seen (Burns et al. 2010). 


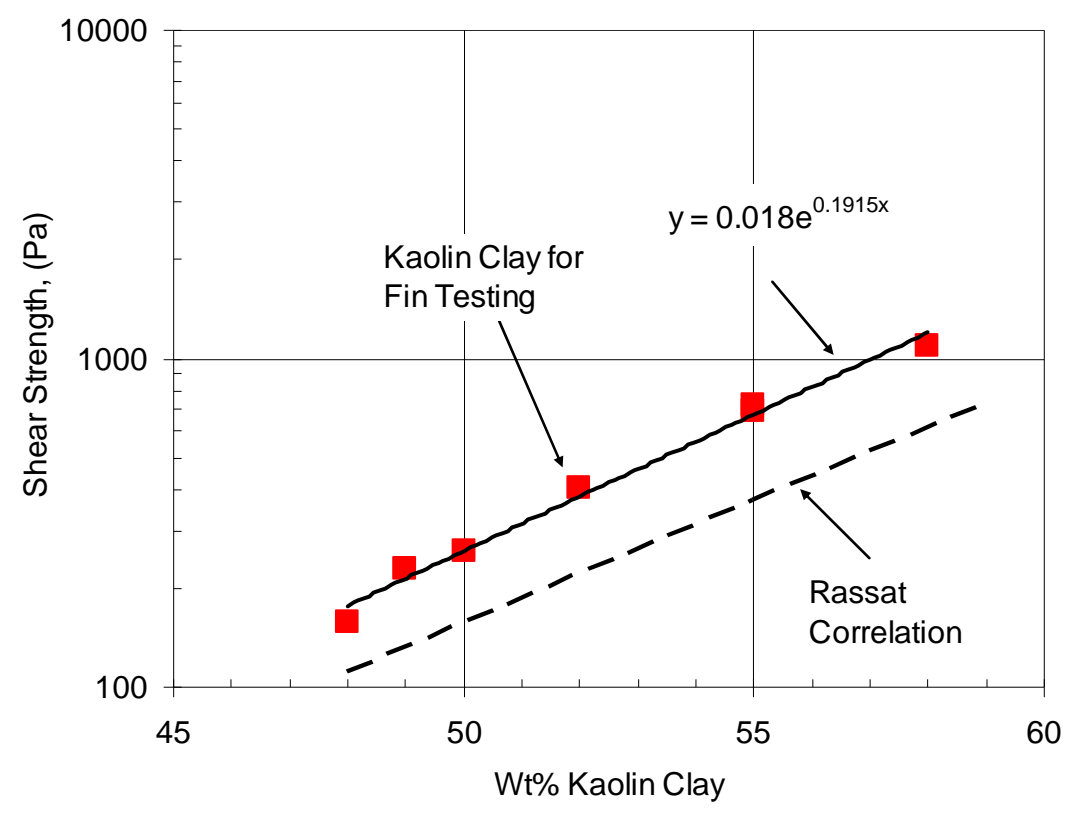

Figure 3.1. Shear Strength of Kaolin Clays Used in VSB Tests

Table 3.1 summarizes the shear strength, density, and $\mathrm{Y}_{\mathrm{G}}$ values for the kaolin simulants used in the small-scale, 10-in.-diameter, VSB and fin performance tests. The density of the mixture was calculated assuming that both the kaolin and the water do not contain a significant amount of entrained air or other gas. The density, $\rho_{\mathrm{s}}$, of the kaolin simulant is then

$$
\rho_{\mathrm{s}}=\frac{1}{\left(1-\mathrm{x}_{\mathrm{k}}\right) / \rho_{\mathrm{w}}+\mathrm{x}_{\mathrm{k}} / \rho_{\mathrm{k}}}
$$

where $\mathrm{x}_{\mathrm{k}}$ is the mass fraction of kaolin, and $\rho_{\mathrm{w}}\left(998 \mathrm{~kg} / \mathrm{m}^{3}\right)$ and $\rho_{\mathrm{k}}\left(2650 \mathrm{~kg} / \mathrm{m}^{3}\right)$ are, respectively, the intrinsic densities of the water and kaolin components of the mixture (Rassat et al. 2003). The $Y_{G}$ values for the small-scale tests sufficiently cover the range given in Table 2.1 for full-scale STSCs of below 0.09 to nearly 0.38 . While the strongest kaolin simulant does not give a $\mathrm{Y}_{\mathrm{G}}$ as high as the maximum value expected in the STSCs of 0.38 , the testing results discussed below will show that once $\mathrm{Y}_{\mathrm{G}}$ is sufficiently high, there is no further change in behavior. Hence, a kaolin $\mathrm{Y}_{\mathrm{G}}$ of 0.28 is sufficiently high for the simulant testing. Table 3.1 also shows the volume percent water $\left[100 \rho_{\mathrm{s}}\left(1-\mathrm{x}_{\mathrm{k}}\right) / \rho_{\mathrm{w}}\right]$ in the kaolin slurry, which is similar to the water content given in Table 1.1 for the different actual sludge materials. 
Table 3.1. Gravity Yield Parameter Values and Average Shear Strengths for Kaolin Simulants Used in 10-in. (0.254-m) Vessels

\begin{tabular}{cccccc}
\hline Kaolin & Density & $\begin{array}{c}\text { Volume } \\
\text { Percent } \\
\text { Water } \\
(\mathrm{wt.} \%)\end{array}$ & $\begin{array}{c}\text { Shear } \\
\text { Strength } \\
\text { Average } \\
\left(\mathrm{kg} / \mathrm{m}^{3}\right)\end{array}$ & $\begin{array}{c}\text { Vessel } \\
\text { Diameter } \\
(\mathrm{Pa})\end{array}$ & $\mathrm{Y}_{\mathrm{G}}$ \\
\hline 48 & 1424 & 74.2 & 157 & 0.254 & 0.044 \\
49 & 1437 & 73.4 & 229 & 0.254 & 0.064 \\
50 & 1450 & 72.6 & 259 & 0.254 & 0.072 \\
52 & 1477 & 71.0 & 405 & 0.254 & 0.110 \\
55 & 1519 & 68.5 & 723 & 0.254 & 0.191 \\
58 & 1563 & 65.8 & 1090 & 0.254 & 0.281 \\
\hline \multicolumn{7}{l}{ Note: shear strength is a measured value; and density, volume percent water, and } \\
$\mathrm{Y}_{\mathrm{G}}$ are calculated
\end{tabular}

Similar to Table 3.1, Table 3.2 details the kaolin clays used for the 5-in.-diameter vessel. Completely new clays were produced for this vessel with the exception of the $50-\mathrm{wt} \%$ clay, which was previously used during the 10-in.-diameter vessel testing. The shear strength was measured again for this $50-\mathrm{wt} \%$ clay and was $5 \%$ stronger.

Table 3.2. Gravity Yield Parameter Values and Average Shear Strengths for Kaolin Simulants Used in 5-in. (0.127-m) Vessels

\begin{tabular}{cccccc}
\hline $\begin{array}{c}\text { Kaolin } \\
(\mathrm{wt} \%)\end{array}$ & $\begin{array}{c}\text { Density } \\
\left(\mathrm{kg} / \mathrm{m}^{3}\right)\end{array}$ & $\begin{array}{c}\text { Volume } \\
\text { Percent Water } \\
(\%)\end{array}$ & $\begin{array}{c}\text { Shear Strength } \\
\text { Average } \\
(\mathrm{Pa})\end{array}$ & $\begin{array}{c}\text { Vessel } \\
\text { Diameter } \\
(\mathrm{m})\end{array}$ & $\mathrm{Y}_{\mathrm{G}}$ \\
\hline 45 & 1387 & 76.4 & 62 & 0.127 & 0.036 \\
47 & 1412 & 75.0 & 112 & 0.127 & 0.064 \\
49 & 1437 & 73.4 & 176 & 0.127 & 0.098 \\
$50^{(\mathrm{a})}$ & 1450 & 72.6 & 259 & 0.127 & 0.144 \\
$52^{(\mathrm{b})}$ & 1477 & 71 & 346 & 0.127 & 0.188 \\
$55^{(\mathrm{b})}$ & 1519 & 68.5 & 524 & 0.127 & 0.277 \\
\hline
\end{tabular}

(a) The clay is the same as used in the 10 -in.-vessel tests.

(b) The clay is the same as used in the 23 -in.-vessel tests.

Because we use the kaolin simulants over a reasonably long time period, a time variation of shear strength of the simulants needs to be checked. Previous work has suggested that the shear strength of kaolin clays depends on shear history (duration and magnitude) and will change over time, although there are little data for kaolin slurries. Figure 3.2 shows that the shear strength changes with the duration of the rest period (up to 336 hours) for three representative wt $\%$ of kaolin slurries, 49, 52, and $58 \mathrm{wt} \%$. All of the shear-strength data are scaled by the strength at 1 hour. It is shown that the shear strength is within the typical uncertainty of 5\% for repeat measurements between 15 minutes and 48 hours. These results suggest that 1 hour is sufficient to obtain reasonable shear-strength data. This will be also useful when conducting large-scale tests where it might not be easy to pre-shear and wait 1 hour for a test. 


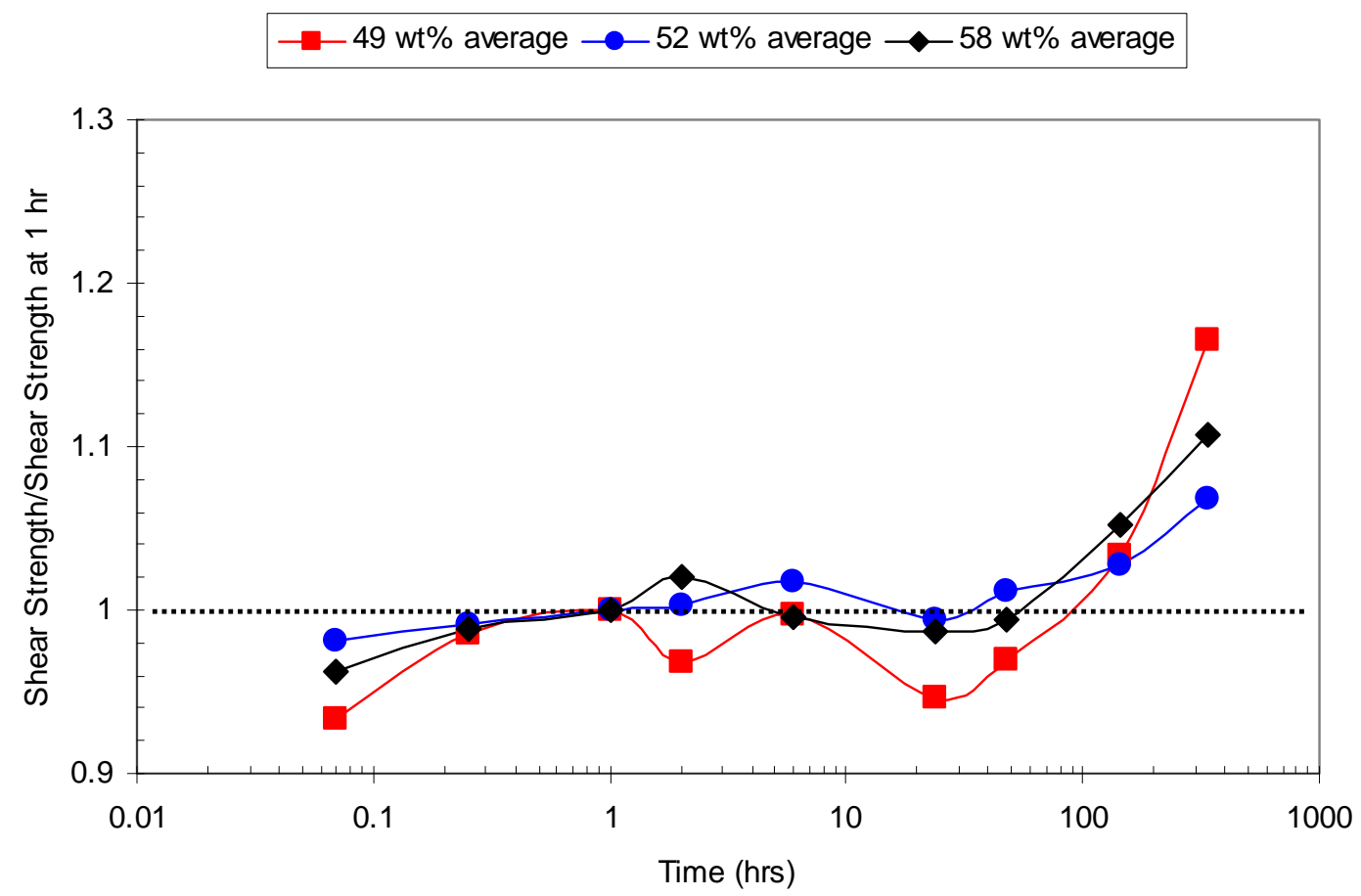

Figure 3.2. Shear-Strength Variation of Kaolin Clays as a Function of Time

\subsubsection{Kaolin Clay/Min-U-Sil 30 Mixture}

Our initial test results showed that single fins (straight-sided fin or T-shaped) do not quickly release VSBs in all situations because of slumping, which strongly suggests that slumping behavior needs to be considered as a critical characteristic to select a representative simulant of actual K-Basin material. More non-cohesive simulants will likely slump less than the kaolin clay, and the fins may work better for all strengths of materials. To observe the effect of particulates on the slumping behavior, a kaolin clay/MinU-Sil 30 mixture was chosen as one candidate for the less cohesive (more frictional component in the shear strength) simulants. Min-U-Sil 30 (U.S. Silica Co., Berkeley Springs, WV) is mainly composed of $\mathrm{SiO}_{2}\left(99.6 \mathrm{wt} \%\right.$ ), and its minor components are $\mathrm{Fe}_{2} \mathrm{O}_{3}(0.017 \mathrm{wt} \%)$ and $\mathrm{Al}_{2} \mathrm{O}_{3}(0.35 \mathrm{wt} \%)$, among others. Its $98^{\text {th }}$ percentile diameter is known to be less than 30 microns. Preliminary scoping tests that compared the slumping behavior of kaolin and kaolin/Min-U-Sil 30 simulants showed that the kaolin/Min-U-Sil 30 mixtures slumped noticeably less than kaolin at the same shear strength, so kaolin/Min-U-Sil 30 mixtures were selected for further testing (see Sections 3.2 and 4.4 for discussions of slumping). The Min-U-Sil 30 particles may be too small to clearly provide a frictional component to the simulant strength and slumping, and larger particles may demonstrate the role of particle friction more clearly, but the kaolin/Min-U-Sil 30 simulant was enough different from kaolin to merit conducting fin performance tests.

Scoping tests were performed with a varying wt\% of kaolin and Min-U-Sil 30 in the mixture. The correlations from the scoping tests were used to estimate the amount of Min-U-Sil 30 to achieve 150, 250, 400 , and $800 \mathrm{~Pa}$ shear strength in mixtures that also had either $30 \mathrm{wt} \%$ or $40 \mathrm{wt} \%$ kaolin in the combined mixture. Like the kaolin clay simulants, all of the kaolin clay/Min-U-Sil 30 mixtures were allowed to 
hydrate for 24 hours before evaluating the shear strength or conducting VSB tests. Shear strengths were measured in triplicate at 1 and 24 hours after being pre-sheared. The procedures for pre-shear at 1 hour and the shear-strength measurement are identical to those for kaolin clays. Figure 3.3 shows the results for the shear strength ( 1 hour) for all batches of the kaolin/Min-U-Sil 30 mixture, and Table 3.3 gives the average values that are plotted in Figure 3.3. The average uncertainty for the triplicate measurements is about $2 \%$.

Table 3.3 summarizes the shear strength, density, and $\mathrm{Y}_{\mathrm{G}}$ values for the kaolin/Min-U-Sil 30 simulants. Similar to (3.1), the density of the mixture, $\rho_{\mathrm{s}}$, can be described by

$$
\rho_{\mathrm{s}}=\frac{1}{\left(1-\mathrm{x}_{\mathrm{k}}-\mathrm{x}_{\mathrm{M}}\right) / \rho_{\mathrm{w}}+\mathrm{x}_{\mathrm{k}} / \rho_{\mathrm{k}}+\mathrm{x}_{\mathrm{M}} / \rho_{\mathrm{M}}}
$$

where $\mathrm{x}_{\mathrm{k}}$ and $\mathrm{x}_{\mathrm{M}}$ are the mass fractions of kaolin and Min-U-Sil 30, respectively. The intrinsic densities of the water, kaolin, and Min-U-Sil 30 components of the mixture are $\rho_{\mathrm{w}}\left(998 \mathrm{~kg} / \mathrm{m}^{3}\right), \rho_{\mathrm{k}}\left(2650 \mathrm{~kg} / \mathrm{m}^{3}\right)$, and $\rho_{M}\left(2645 \mathrm{~kg} / \mathrm{m}^{3}\right)$. The $\mathrm{Y}_{\mathrm{G}}$ values for the small-scale tests range from 0.039 to 0.216 , which sufficiently covers the range given in Table 2.1. Table 3.3 also shows the volume percent water $\left[100 \rho_{\mathrm{s}}\right.$ $\left.\left(1-\mathrm{x}_{\mathrm{k}}-\mathrm{x}_{\mathrm{M}}\right) / \rho_{\mathrm{w}}\right]$ in the kaolin/Min-U-Sil 30 slurry, which is similar to or a little less than the water content given in Table 1.1 for the different actual sludge materials. Figure 3.3 and Table 3.3 show that both $40-\mathrm{wt} \%$ and $30-\mathrm{wt} \%$ kaolin can cover the target range in terms of shear strength and $\mathrm{Y}_{\mathrm{G}}$ value. However, VSB tests with and without fins will be conducted with the mixtures containing $40-\mathrm{wt} \%$ kaolin because it is easier to handle in the experiments.

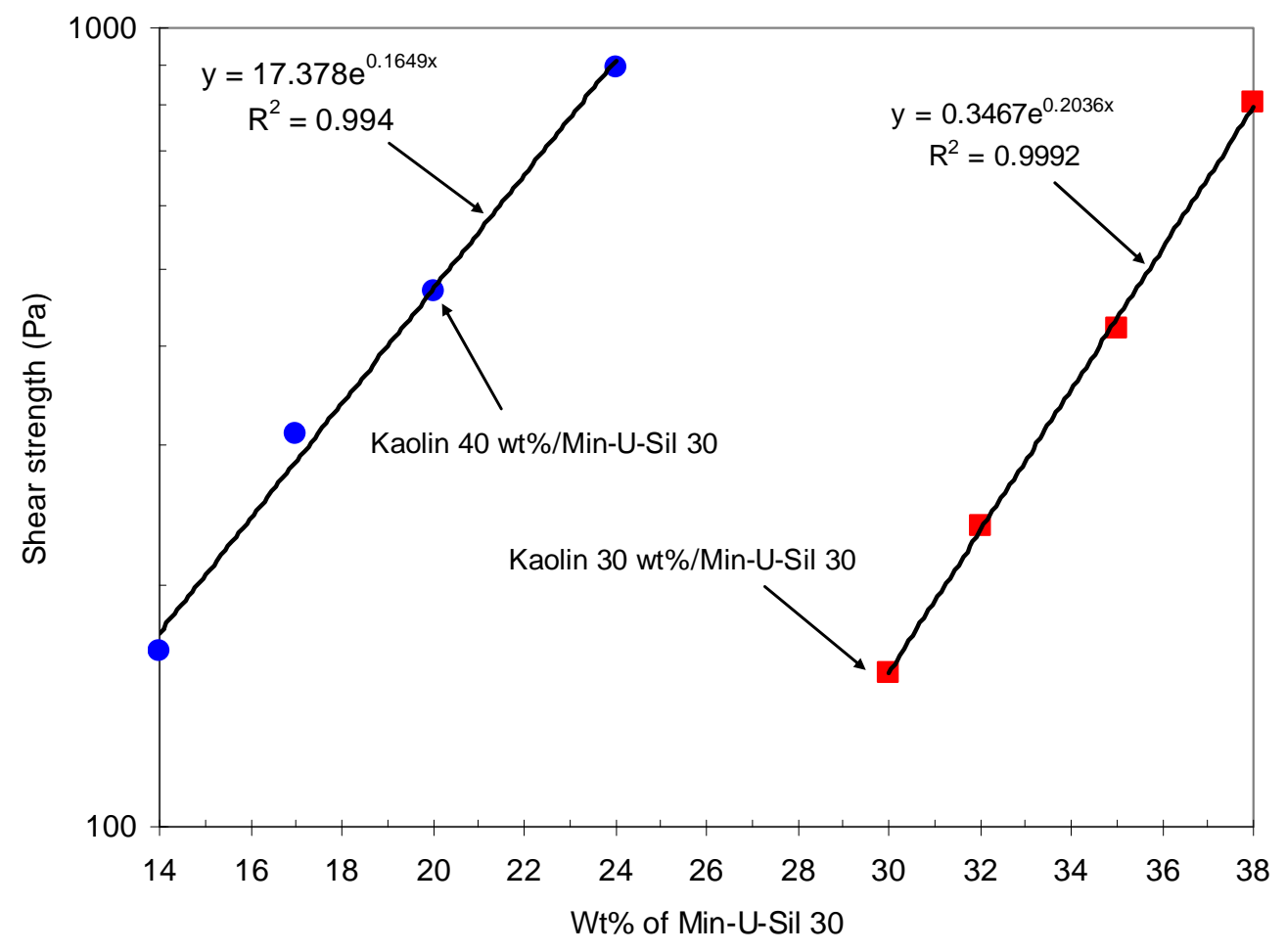

Figure 3.3. Shear Strength of Kaolin Clay/Min-U-Sil 30 Mixture with Two Different wt\% of Kaolin 
Table 3.3. Gravity Yield Parameter Values Based on 10-in. (0.254-m) Vessels and Average Shear Strengths for Kaolin/Min-U-Sil 30 Mixtures

\begin{tabular}{|c|c|c|c|c|c|c|}
\hline $\begin{array}{l}\text { Kaolin } \\
(\text { wt. \%) }\end{array}$ & $\begin{array}{c}\text { Min-U-Sil } 30 \\
\text { (wt.\%) }\end{array}$ & $\begin{array}{l}\text { Density } \\
\left(\mathrm{kg} / \mathrm{m}^{3}\right)\end{array}$ & $\begin{array}{c}\text { Volume } \\
\text { Percent } \\
\text { Water } \\
(\%)\end{array}$ & $\begin{array}{l}\text { Shear } \\
\text { Strength } \\
\text { Average } \\
(1 \mathrm{hr}, \mathrm{Pa})\end{array}$ & $\begin{array}{c}\text { Vessel } \\
\text { Diameter } \\
(\mathrm{m})\end{array}$ & $Y_{G}$ \\
\hline 30 & 30 & 1594 & 63.9 & 156 & 0.254 & 0.039 \\
\hline 30 & 32 & 1626 & 61.9 & 238 & 0.254 & 0.059 \\
\hline 30 & 35 & 1677 & 58.8 & 420 & 0.254 & 0.101 \\
\hline 30 & 38 & 1732 & 55.5 & 806 & 0.254 & 0.187 \\
\hline 40 & 14 & 1504 & 69.3 & 166 & 0.254 & 0.044 \\
\hline 40 & 17 & 1548 & 66.7 & 310 & 0.254 & 0.080 \\
\hline 40 & 20 & 1594 & 63.9 & 469 & 0.254 & 0.118 \\
\hline 40 & 24 & 1660 & 59.9 & 891 & 0.254 & 0.216 \\
\hline
\end{tabular}

Based on the results shown in Figure 3.3, a range of Min-U-Sil 30 concentrations, with $40 \mathrm{wt} \%$ kaolin, were selected for making batches of simulant spanning the desired range of $\mathrm{Y}_{\mathrm{G}}$ for testing. Table 3.4 gives the Kaolin/Min-U-Sil 30 simulants used in conducting tests in the 10-in., flat-bottom and 10-in. elliptical-bottom vessels. The shear strength measurements for these samples are presented in Appendix A.

Table 3.4. Gravity Yield Parameter Values and Average Shear Strengths for Kaolin/Min-U-Sil 30 Simulants Used in 10-in. (0.254-m) Flat-Bottom and Elliptical-Bottom Tests

\begin{tabular}{|c|c|c|c|c|c|c|}
\hline $\begin{array}{l}\text { Kaolin } \\
\text { (wt.\%) }\end{array}$ & $\begin{array}{c}\text { Min-U-Sil } 30 \\
\text { (wt.\%) }\end{array}$ & $\begin{array}{l}\text { Density } \\
\left(\mathrm{kg} / \mathrm{m}^{3}\right)\end{array}$ & $\begin{array}{c}\text { Volume } \\
\text { Percent } \\
\text { Water } \\
(\%)\end{array}$ & $\begin{array}{l}\text { Shear } \\
\text { Strength } \\
\text { Average } \\
(1 \mathrm{hr}, \mathrm{Pa})\end{array}$ & $\begin{array}{c}\text { Vessel } \\
\text { Diameter } \\
(\mathrm{m})\end{array}$ & $\mathrm{Y}_{\mathrm{G}}$ \\
\hline 40 & 16 & 1533 & 67.5 & 170 & 0.254 & 0.045 \\
\hline 40 & 19 & 1579 & 64.7 & 290 & 0.254 & 0.074 \\
\hline 40 & 20.5 & 1602 & 63.3 & 360 & 0.254 & 0.091 \\
\hline 40 & 23 & 1643 & 60.8 & 680 & 0.254 & 0.17 \\
\hline
\end{tabular}

\subsubsection{KW Container Sludge Simulant (Complete) (KW-A)}

$\mathrm{KW}$ container sludge simulant (complete) (KW-A) is considered the most realistic simulant. According to a previous report by Burbank (2009), the KW-A solid is composed of cerium oxide (30.9 wt\%, particle density: $\left.7.13 \mathrm{~g} / \mathrm{cm}^{3}\right)$, steel grit-G120 $\left(4.2 \mathrm{wt} \%\right.$, particle density: $\left.7.86 \mathrm{~g} / \mathrm{cm}^{3}\right)$, $\mathrm{Al}(\mathrm{OH})_{3}\left(7.8 \mathrm{wt} \%\right.$, particle density: $\left.2.42 \mathrm{~g} / \mathrm{cm}^{3}\right), \mathrm{Fe}(\mathrm{OOH})\left(21.9 \mathrm{wt} \%\right.$, particle density: $\left.2.85 \mathrm{~g} / \mathrm{cm}^{3}\right)$, Lane Mt. sand-LM30 (14.7 wt\%, particle density: $\left.2.6 \mathrm{~g} / \mathrm{cm}^{3}\right)$, aggregate $(16.9 \mathrm{wt} \%$, particle density: $\left.2.6 \mathrm{~g} / \mathrm{cm}^{3}\right)$, and tungsten $\left(3.6 \mathrm{wt} \%\right.$, particle density: $\left.16.9 \mathrm{~g} / \mathrm{cm}^{3}\right)$. The average density of the solid calculated from individual particle density is $3553 \mathrm{~kg} / \mathrm{m}^{3}$ (see Appendix B). Because of a wide range of density and the particle size of components, the KW-A simulant is inherently (spatial) inhomogeneous. 
We performed scoping tests varying $\mathrm{wt} \%$ of $\mathrm{KW}-\mathrm{A}$ solid in the slurry. The correlation from the scoping tests (i.e., shear strength at $1 \mathrm{hr}$ ) was obtained to determine the amount of KW-A solid to achieve target shear strengths of $150,250,400$, and $800 \mathrm{~Pa}$. The scoping tests indicated that shear strength varied from 150 to $800 \mathrm{~Pa}$ by changing only $\sim 5 \mathrm{wt} \%$ of KW-A solid. Shear strengths were measured in triplicate at 1 and 24 hours after being pre-sheared. The procedures for pre-shear at $1 \mathrm{hr}$ and shearstrength measurement are identical to previous simulants. Figure 3.4 shows the results for the shear strength for all KW-A simulants, and Table 3.5 gives the average values that are plotted in Figure 3.4. The average uncertainty for the triplicate measurements is about $22 \%$.

Table 3.5. Gravity Yield Parameter Values Based on 10-in. (0.254-m) Vessels and Average Shear Strengths for KW-A Simulants

\begin{tabular}{cccccc}
\hline $\begin{array}{c}\text { KW-A Solids } \\
(\text { wt. } \%)\end{array}$ & $\begin{array}{c}\text { Density } \\
\left(\mathrm{kg} / \mathrm{m}^{3}\right)\end{array}$ & $\begin{array}{c}\text { Volume Percent Water } \\
(\%)\end{array}$ & $\begin{array}{c}\text { Shear-Strength Average } \\
(1 \mathrm{hr}, \mathrm{Pa})\end{array}$ & $\begin{array}{c}\text { Vessel Diameter } \\
(\mathrm{m})\end{array}$ & $\mathrm{Y}_{\mathrm{G}}$ \\
\hline 73.5 & 2119 & 56.2 & 178 & 0.254 & 0.034 \\
75.0 & 2169 & 54.3 & 257 & 0.254 & 0.048 \\
76.0 & 2203 & 52.9 & 557 & 0.254 & 0.102 \\
78.0 & 2275 & 50.1 & 824 & 0.254 & 0.146 \\
\hline
\end{tabular}

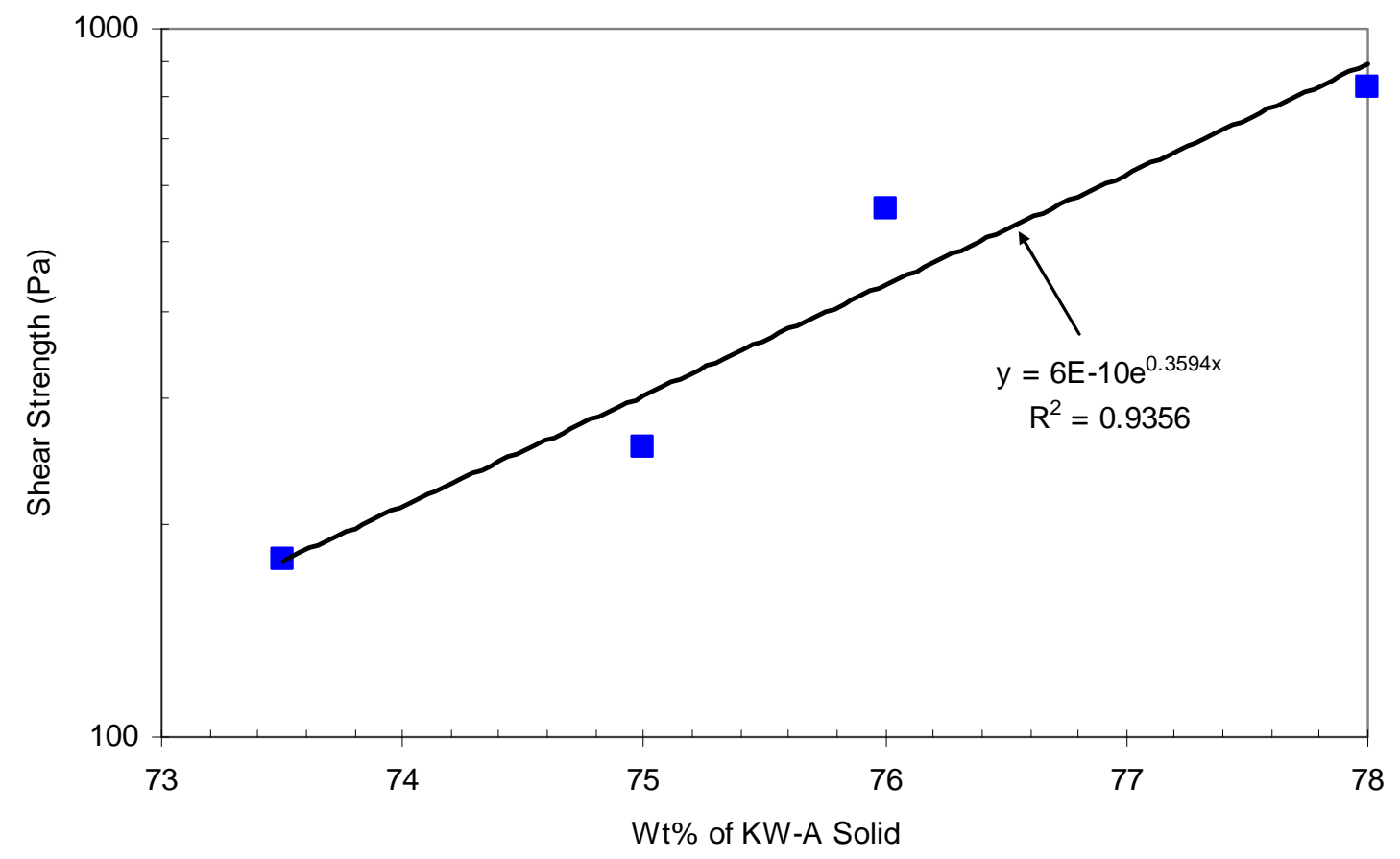

Figure 3.4. Shear Strength of KW-A Simulant

Table 3.4 summarizes the shear strength, density, and $\mathrm{Y}_{\mathrm{G}}$ values for the $\mathrm{KW}-\mathrm{A}$ simulants. Similar to (3.1), the density of the mixture, $\rho_{\mathrm{s}}$, can be described by

$$
\rho_{\mathrm{s}}=\frac{1}{\left(1-\mathrm{x}_{\mathrm{KW}-\mathrm{A}}\right) / \rho_{\mathrm{w}}+\mathrm{x}_{\mathrm{KW}-\mathrm{A}} / \rho_{\mathrm{KW}-\mathrm{A}}}
$$


where $\mathrm{x}_{\mathrm{KW}-\mathrm{A}}$ is the mass fractions of KW-A. The intrinsic densities of the water and the average for KWA particles are $\rho_{\mathrm{w}}\left(998 \mathrm{~kg} / \mathrm{m}^{3}\right)$ and $\rho_{\mathrm{KW}-\mathrm{A}}\left(3553 \mathrm{~kg} / \mathrm{m}^{3}\right)$. See Appendix B for a summary of the $\mathrm{KW}-\mathrm{A}$ simulant and average particle density. The $\mathrm{Y}_{\mathrm{G}}$ values for the small-scale tests range from 0.034 to 0.146 , which covers a sufficient portion of the range given in Table 2.1. Table 3.5 also shows the volume percent water $\left[100 \rho_{\mathrm{s}}\left(1-\mathrm{x}_{\mathrm{KW}-\mathrm{A}}\right) / \rho_{\mathrm{w}}\right]$ in the KW-A simulant, which is a little less than the water content given in Table 1.1 for the different actual sludge materials. Figure 3.4 and Table 3.5 show that the KW-A simulant, within 4.5 -wt $\%$ change of the solid, can cover the target range in terms of shear strength and $\mathrm{Y}_{\mathrm{G}}$ value. It is important to note that the spatially inhomogeneous nature of this simulant leads to the higher uncertainty for the shear strength measurements and also makes the simulant difficult to control in terms of achieving a target shear strength. In addition, the particulate material in the KW-A simulant scratches the plastic test vessel. Thus, although the KW-A simulant is the most realistic simulant, it is only used in a few selected tests.

The inhomogeneous nature of this simulant implies that the shear strength is likely to increase with depth. Thus, a depth profile test is needed to examine whether the primary shear-strength measurement (at a depth where the top of the vane is $1.6 \mathrm{~cm}$ below the surface of the sample) can provide a reasonable value to represent the shear strength of the sample. We performed the depth profile test by using three different wt $\%$ of KW-A simulants $(75,76.5$, and $78 \mathrm{wt} \%)$. Please note that the samples used in these depth profile tests were prepared to conduct VSB tests in the 10-in. vessel, so that shear-strength values are different from those shown in Table 3.5 for the simulant characterization tests. The difference in shear strength for the same wt $\%$ is mainly attributed to the inhomogeneous nature of the simulant. Each simulant was loaded into a 5-in.-diameter column to a depth of $\sim 9$ inches $(9.5$ inches for $75 \mathrm{wt} \%$ of KWA, 8.875 inches for $76.5 \mathrm{wt} \%$ of $\mathrm{KW}-\mathrm{A}$, and 9 inches for $78 \mathrm{wt} \%$ of $\mathrm{KW}-\mathrm{A}$ ) to match corresponding VSB tests in the 10-in. vessel, allowed to rest for the same period of time as in the VSB test of $1 \mathrm{hr}$, and then the shear strength was measured as a function of depth. The 5-in.-diameter column consisted of top and bottom parts, which allows the excavation of the sample (before the $6^{\text {th }}$ measurement) in the column to use a finite length (about $11 \mathrm{~cm}$ ) of the vane shaft. It took about $45 \mathrm{~min}$ between the $1^{\text {st }}$ measurement at the top of the vessel and the $10^{\text {th }}$ and last measurement at the bottom, including the time for the excavation.

Figure 3.5 shows the shear strengths as a function of height from the bottom of the column for the three simulants. For the three different wt\% KW-A simulants, the shear strength was shown to be nearly uniform at the top of the column, although the shear strength was significantly larger towards the bottom. For the purpose of comparison and calculating the gravity yield parameter for VSB tests, the representative shear strength was determined for each simulant, and these values are shown as vertical lines in Figure 3.5. Note that the second measurement from the top with $78 \mathrm{wt} \%$ of $\mathrm{KW}-\mathrm{A}$ shows a larger deviation, but it is assumed to be an outlier because of the existence of rigid particulates at the point of the measurement. 
$\rightarrow 75$ wt\% KW-A $\square 76.5$ wt\% KW-A 78 wt\% KW-A

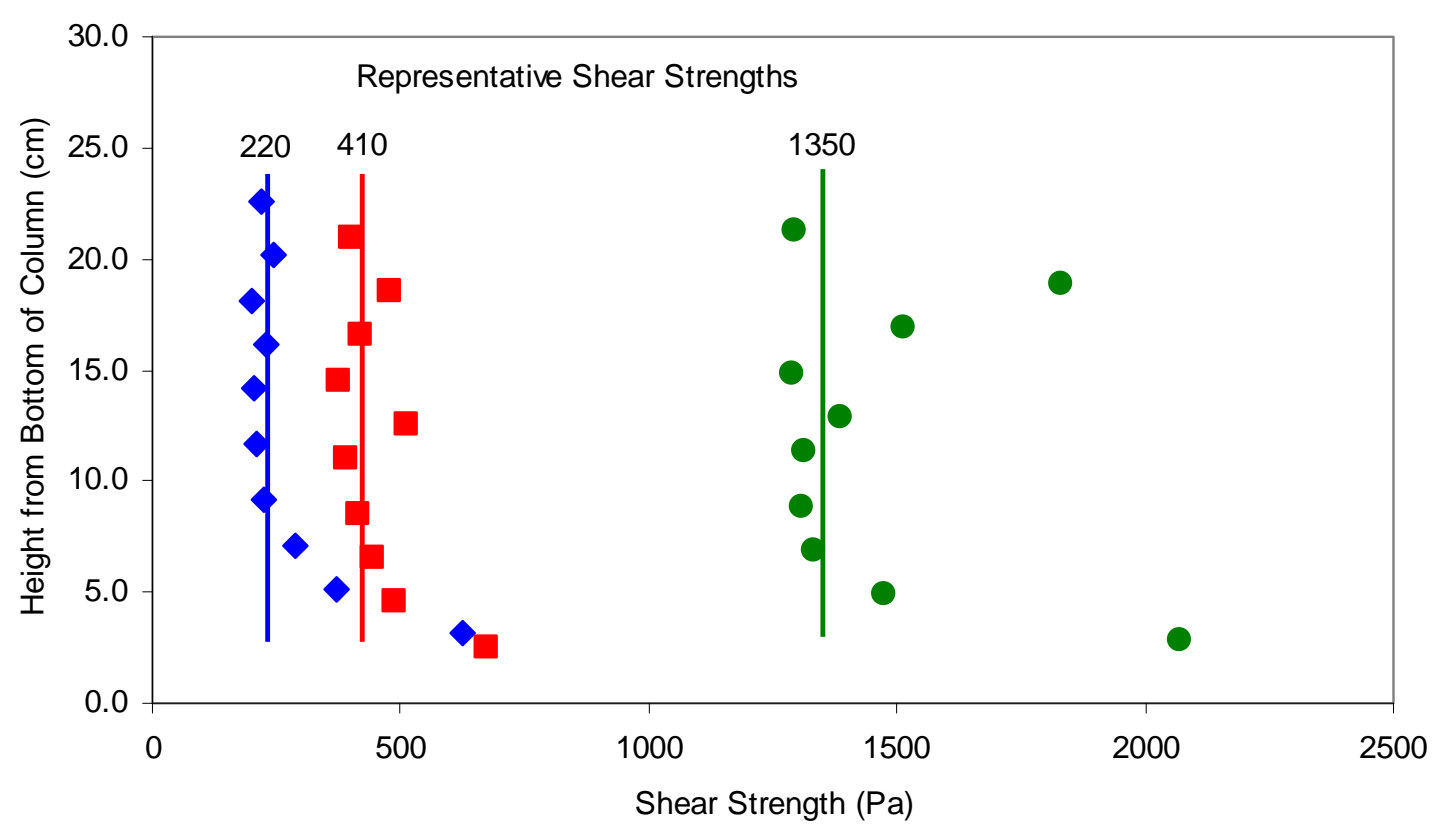

Figure 3.5. Depth Profile of Shear Strengths for Three Different KW-A Simulants

\subsubsection{Apparatus}

Figure 3.6 shows a schematic of the 10-in.-diameter, flat-bottom test apparatus with an installed internal fin. The apparatus consists of an 18-in. cylindrical column threaded onto a base structure. The base structure has an inlet gas plenum and a support structure for a stainless steel perforated plate. The perforated plate allows the injected gas uniform access to the bottom of the clay simulant.

Figure 3.7 shows images of the assembled flat-bottom test vessel without an internal fin. The stainless steel perforated plate is visible on the bottom of the test section along with the gas inlet located at the bottom-center of the base structure. 


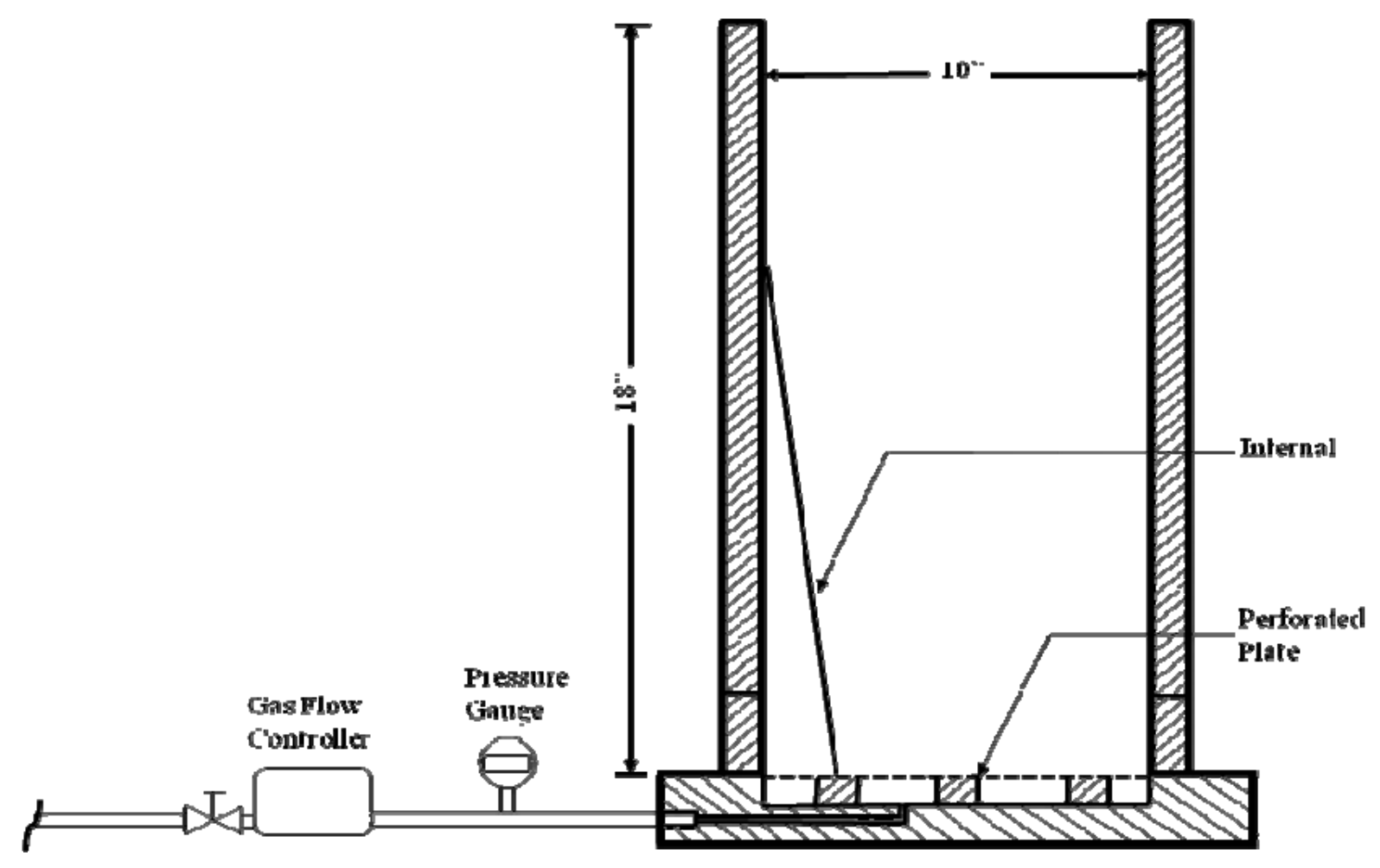

Figure 3.6. 10-in.-Diameter, Flat-Bottom Test Apparatus
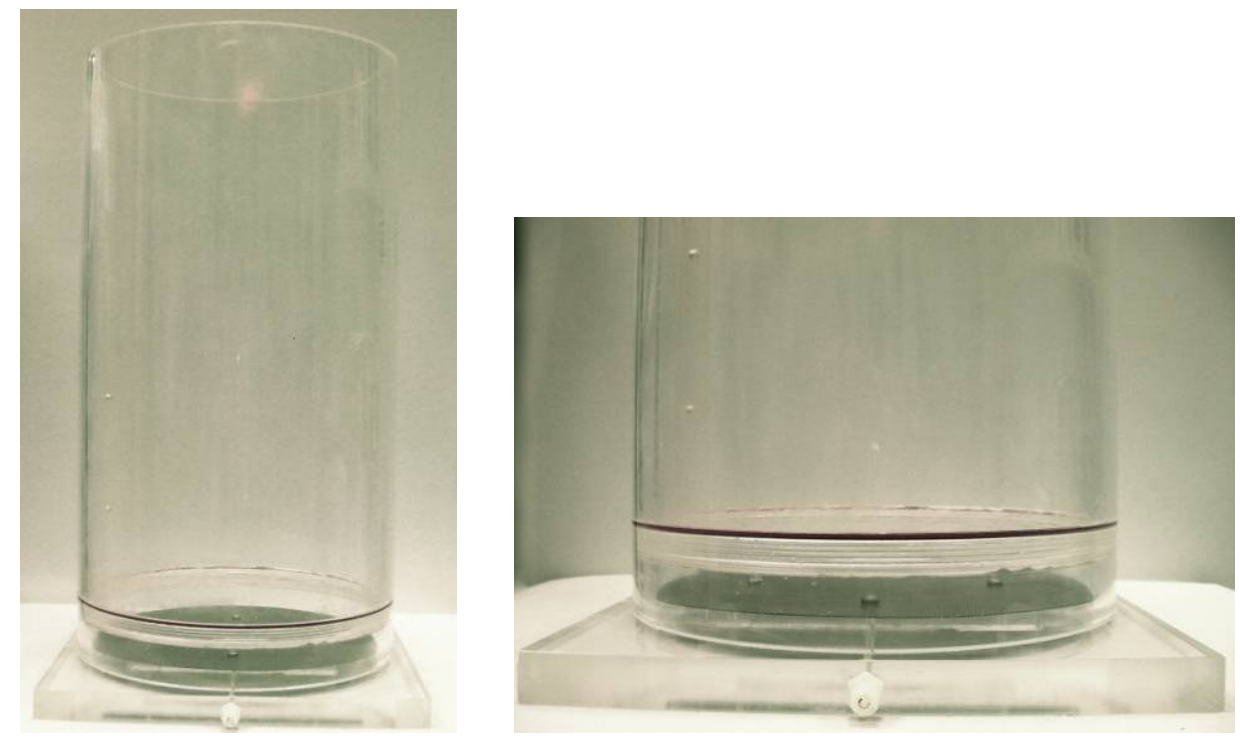

Figure 3.7. 10-in.-Diameter, Flat-Bottom Test Vessel Without a Fin

Figure 3.8 shows a schematic of the 2:1 elliptical bottom test apparatus. The test vessel is the same as the flat-bottom version with the exception of the base structure that has an elliptical shape. The perforated plate region separating the gas and the simulant has a diameter of 3 inches, and the internal fin is shaped to match the geometry of the elliptical bottom. 


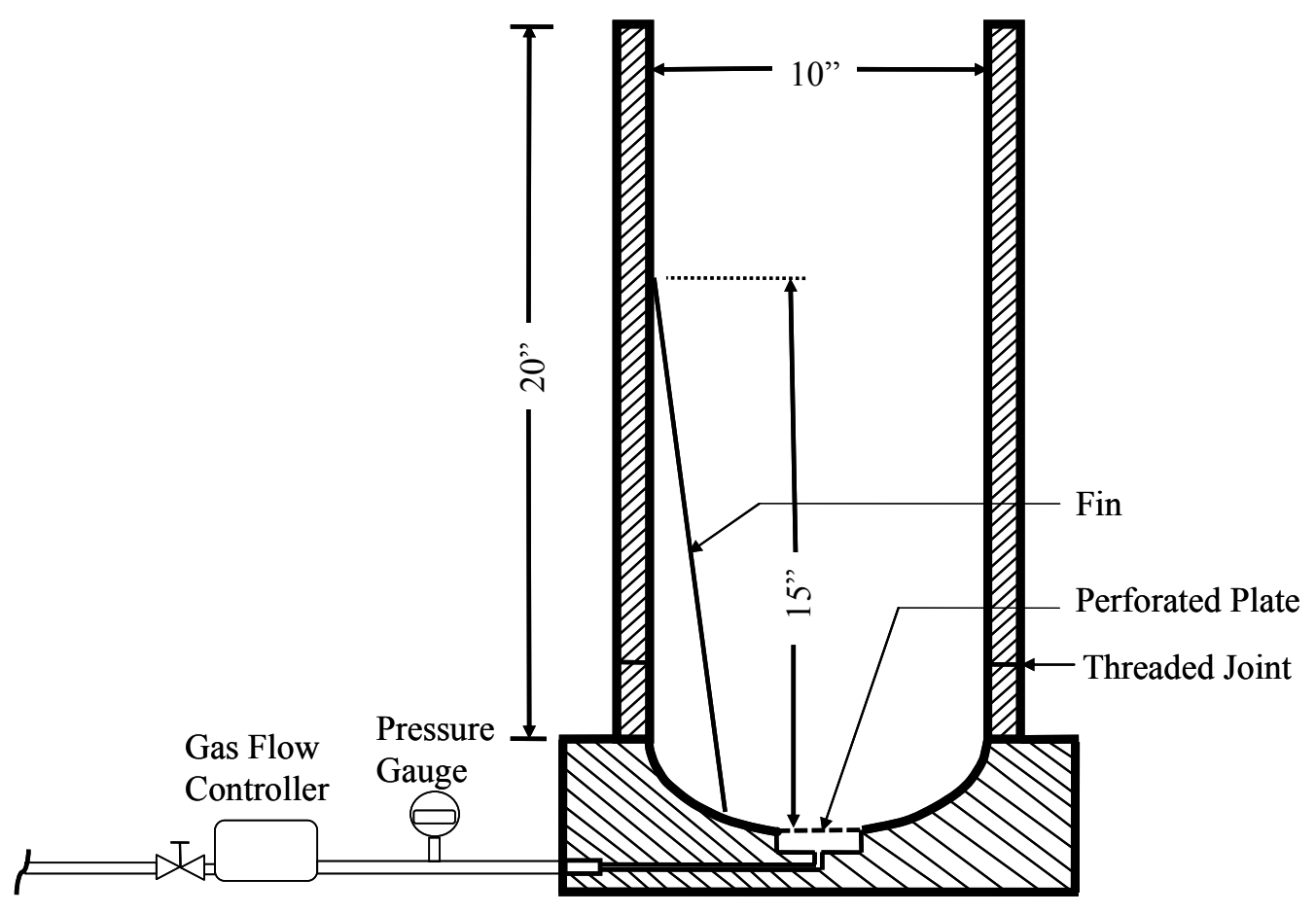

Figure 3.8. 2:1 Elliptical-Bottom Test Apparatus

Figure 3.9 shows images of the assembled elliptical bottom test section with an internal fin installed. The inlet gas plenum at the base of the elliptical bottom is visible in both of these images.
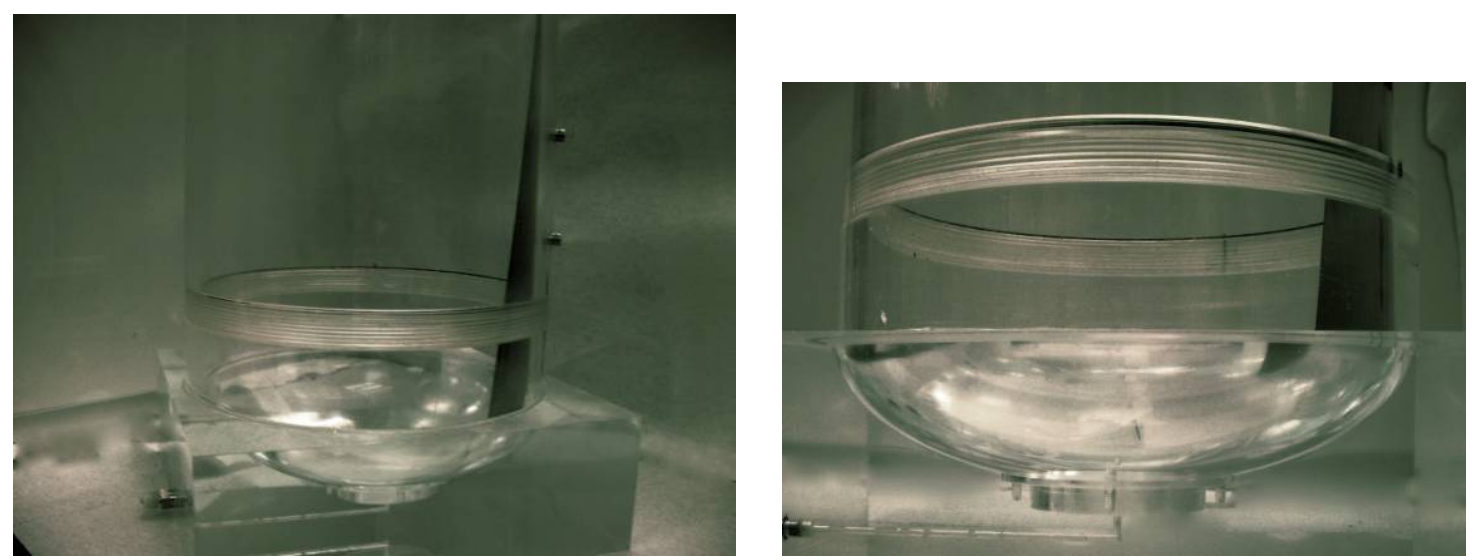

Figure 3.9. Elliptical-Bottom Test Vessel

The 2:1 elliptical tank bottom used in testing was machined from a 4-in.-thick by 12-in.-square acrylic block and then attached to a short section of 10-in.-diameter cylinder to make the bottom section. For an ellipse, the shape is given by 


$$
\frac{\left(\mathrm{x}-\mathrm{x}_{0}\right)^{2}}{\mathrm{a}^{2}}+\frac{\left(\mathrm{y}-\mathrm{y}_{0}\right)^{2}}{\mathrm{~b}^{2}}=1
$$

where the center is at $\mathrm{x}_{0}, \mathrm{y}_{0}$ and the major radius is "a," and the minor radius is "b." For a 2:1 ellipse, the major radius is twice the minor radius, so for the 10 -in. vessel, $a=5$-in. and $b=2.5$ in. This shape was used to machine the elliptical bottom, and measurements were made to confirm the as-built shape.

Figure 3.10 shows an elevation view of the elliptical bottom with specific $\left(\mathrm{x}-\mathrm{x}_{0}\right)$ positions at measurement locations of 2, 3, and 4 inches from the center of the ellipse.

\section{ELEVATION VIEW}

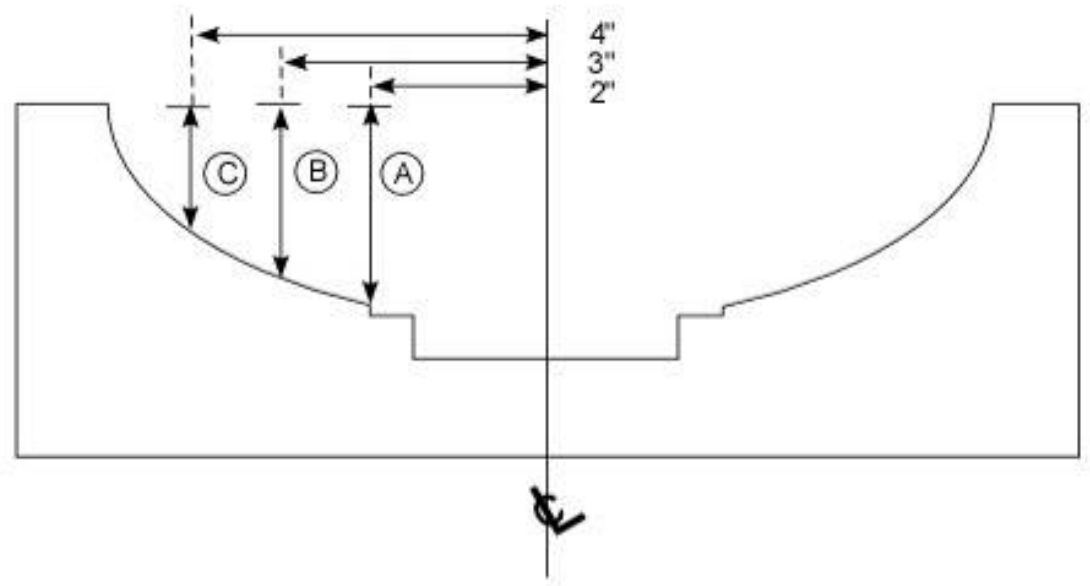

Figure 3.10. Measuring Locations to Confirm the Shape of the 2:1 Ellipse

Using Equation 3.1, ideal calculated values of $\mathrm{y}-\mathrm{y}_{0}$ were determined for positions $\mathrm{A}, \mathrm{B}$, and $\mathrm{C}$ and then compared to measured values. The depths at $\mathrm{A}, \mathrm{B}$, and $\mathrm{C}$ were measured with a dial caliper, and both the calculated and measured values are listed in Table 3.6. Due to an uneven thickness of the acrylic block, approximately $1 / 16$ inch was milled off the top surface after the ellipse was machined. The column with the heading "adjusted $y-y_{0}$ " is the calculated value less the $1 / 16$-in. adjustment. The nearly identical values for the measured and adjusted $y-y_{0}$ values (Table 3.6) show that the shape for the elliptical bottom is correct for a 2:1 ellipse. The $1 / 16$ inch of material that was milled off the top made the diameter of the elliptical bottom slightly too small at the top, so a $60^{\circ}$ chamfer (bevel) approximately $1 / 16$ inch wide was machined to increase the diameter. This chamfer helped facilitate a smooth transition from the elliptical bottom to the 10-in. acrylic tube when they were joined to form the base.

Table 3.6. Calculated Dimensions and As-Built Dimensions for 2:1 Ellipse

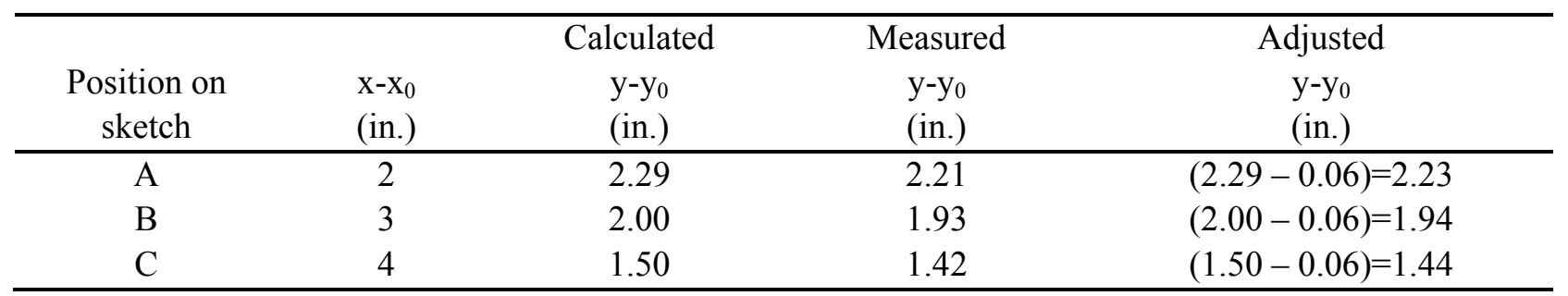


Figure 3.11 shows a schematic of the 5-in.-diameter, flat-bottom test apparatus with an installed internal fin. The apparatus consists of a 5-in. cylindrical column threaded onto a cylinder fixed to a square base structure giving an assembled column length of 12.5-inches. The base structure has an inlet gas plenum and a support structure for a stainless steel perforated plate. The perforated plate is seated $1 / 2$-in. above the gas inlet and allows the injected gas uniform access to the bottom of the clay simulant.

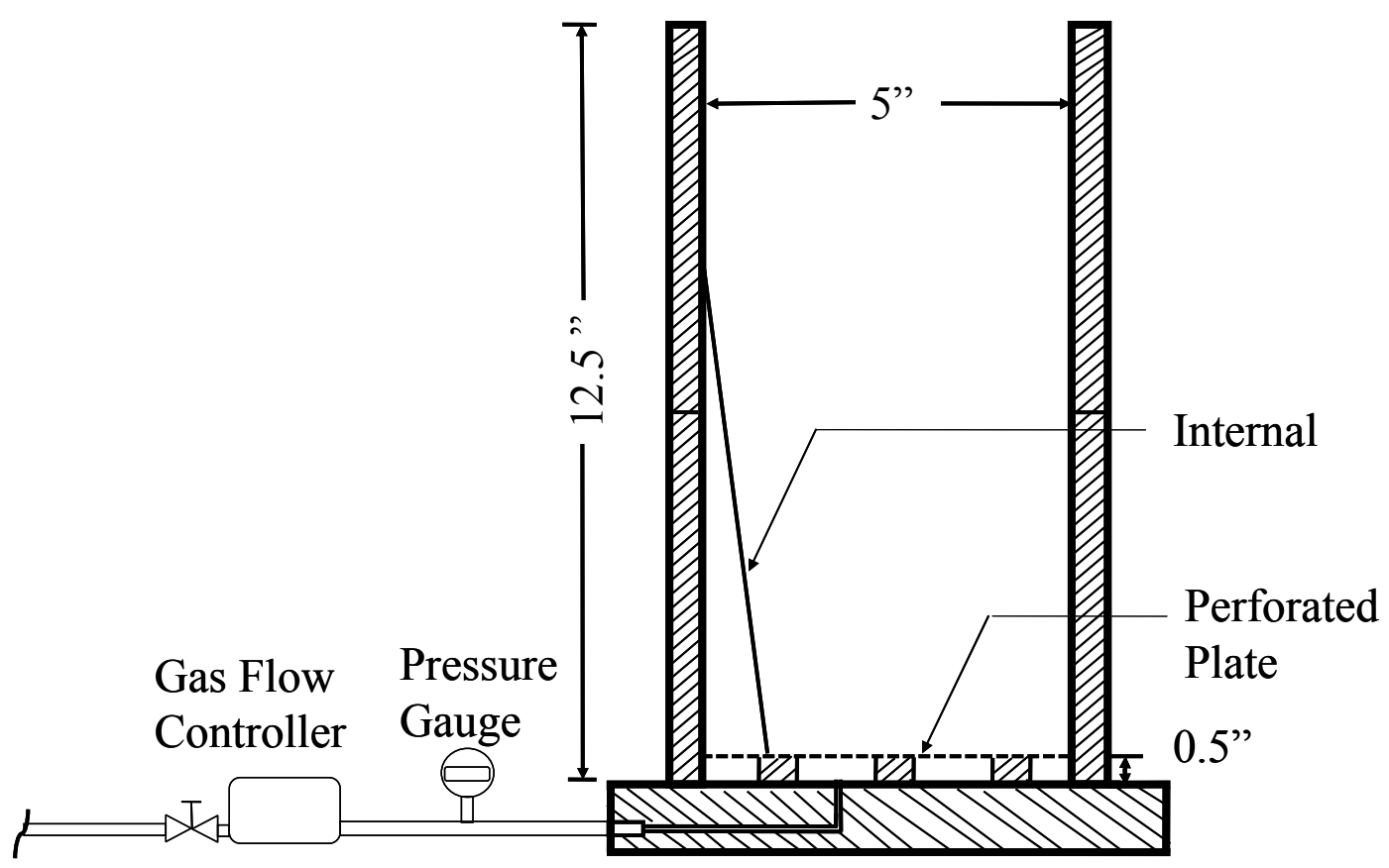

Figure 3.11. 5-in.-Diameter, Flat-Bottom Test Apparatus

Figure 3.12 shows an image of the assembled flat-bottom, 5-in.-diameter test vessel without an internal fin. The stainless steel perforated plate is visible on the bottom of the test section along with the gas inlet located at the bottom-center of the base structure. 


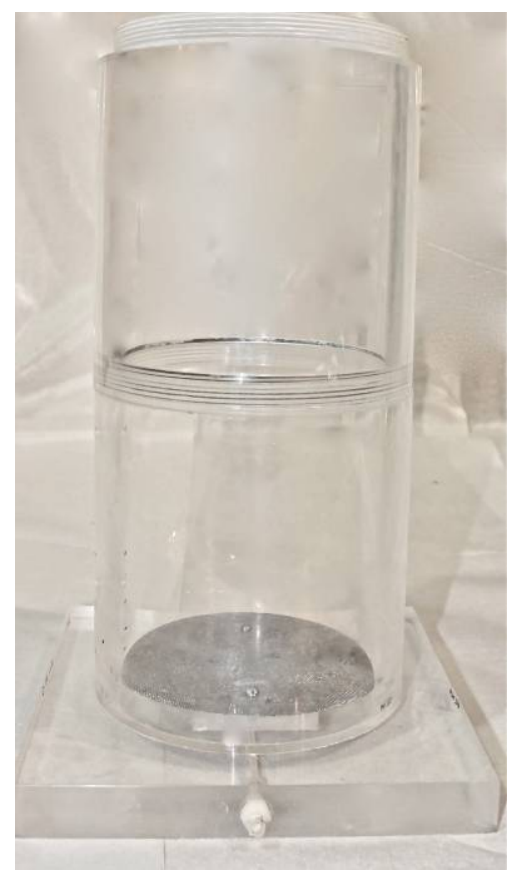

Figure 3.12. 5-in.-Diameter, Flat-Bottom Test Vessel Without a Fin

\subsubsection{Fins}

Four different types of fins were fabricated and tested in the 10-in. and 5-in. vessels. Straight-sided fins with various widths and slopes, a single T-shaped fin, a single straight-sided fin for testing in the 2:1 elliptical vessel, and a single straight-sided fin for the 5-in. vessel were used in the small-scale tests. Figure 3.13 shows examples of 5-degree fins with a range of widths, and Figure 3.14 shows fins with slopes ranging from 2.5 to 10 degrees. The fins were all fabricated from 300 series stainless steel plate. Fins 1, 4, 5, and 9 were fabricated from standard stock metal plate. Fin 2 was milled to a target width of 0.170 inches, and fins 3,6 , and 7 were milled to a target thickness of 0.34 inches.

After the fins were fabricated, the dimensions were measured, and differences between the measured base and the calculated base given in Table 2.4 were determined. Table 3.7 shows the actual dimensions and slopes of the fins, and these dimensions are quite close to the target scaled dimensions given in Table 2.4. Fins 3, 4, 6, and 7 were sufficiently wide that they could be drilled and tapped for $1 / 4-20$ mounting bolts as shown in Figure 3.15. Fin 8, the 5-in. vessel fin, was wide enough to be tapped for 6-32 mounting bolts. The remaining fins had $1 / 4 \times 20$ nuts welded on the perpendicular edge so that mounting bolts could be inserted into the attached nuts. 

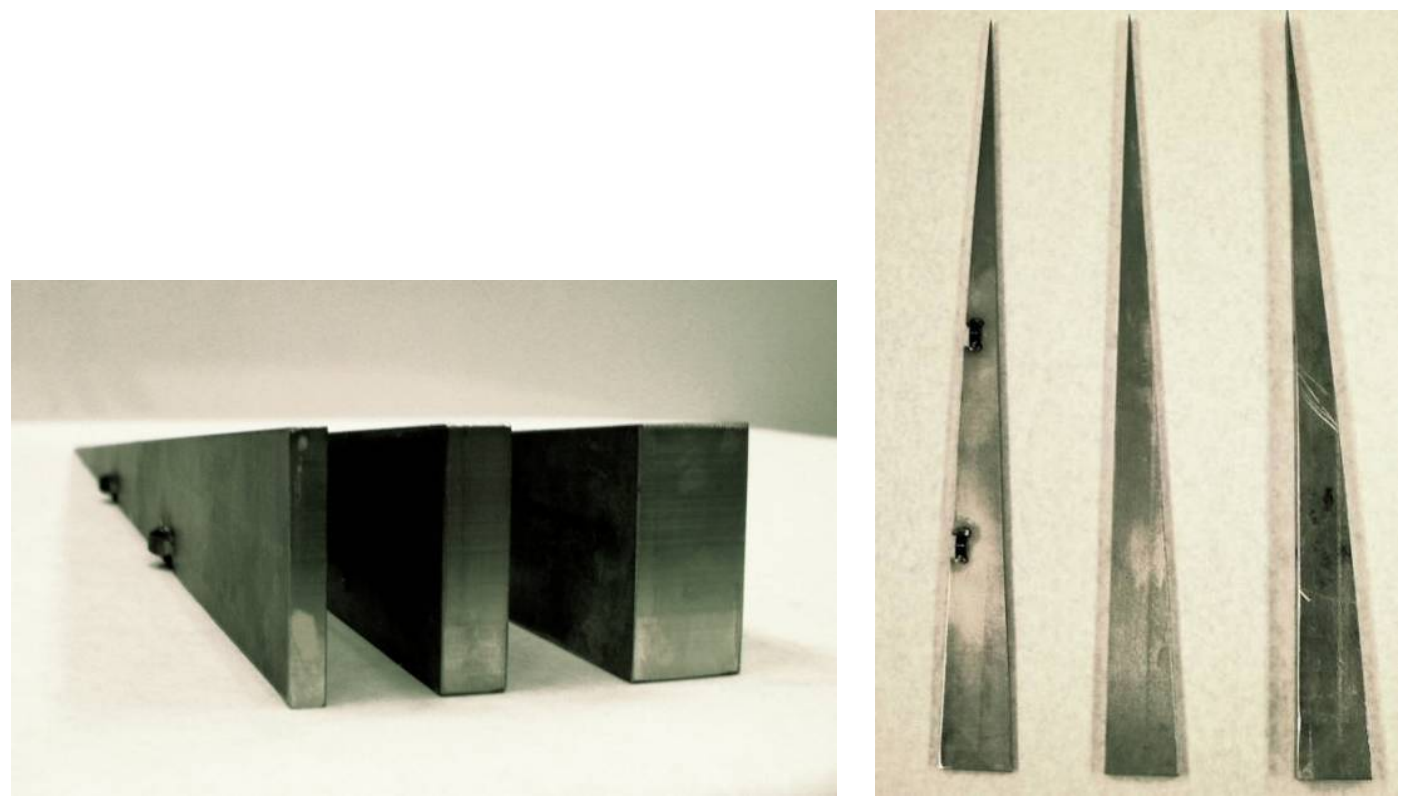

Figure 3.13. Fins Having 5-Degree Slopes and Widths of 0.182, 0.342, and 0.634 inches (0.074-in.-wide fin not shown)

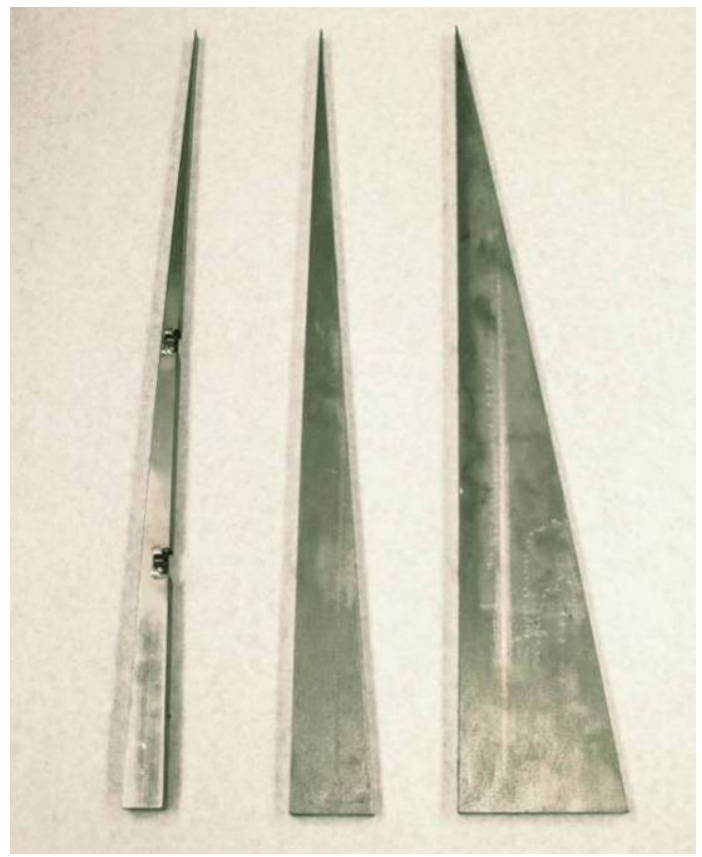

Figure 3.14. 0.34-in.-Thick Fins with Slopes of 2.5, 5, and 10 Degrees 
Table 3.7. As-Built Fin Dimensions

\begin{tabular}{|c|c|c|c|c|c|c|c|}
\hline Fin & $\begin{array}{l}\text { Design Fin } \\
\text { Slope } \\
\text { (degrees) }\end{array}$ & $\begin{array}{l}\text { Width } \\
\text { (in.) }\end{array}$ & $\begin{array}{l}\text { Base } \\
\text { (in.) }\end{array}$ & $\begin{array}{c}\text { Percent } \\
\text { Difference in } \\
\text { Width from } \\
\text { Design }^{(\mathrm{a})}\end{array}$ & $\begin{array}{l}\text { Height } \\
\text { (in.) }\end{array}$ & $\begin{array}{c}\text { Face } \\
\text { Width } \\
\text { (in.) }\end{array}$ & $\begin{array}{c}\text { As Received } \\
\text { Fin Slope } \\
\text { (degrees) }\end{array}$ \\
\hline \multicolumn{8}{|c|}{ Straight-Side Fin } \\
\hline 1 & 5 & 0.074 & 1.301 & $-14 \%{ }^{(b)}$ & 15 & NA & 4.96 \\
\hline 2 & 5 & 0.182 & 1.311 & $7 \%$ & $15^{1 / 32}$ & NA & 4.98 \\
\hline 3 & 5 & 0.342 & 1.311 & $1 \%$ & $14^{31} / 32$ & NA & 5.01 \\
\hline 4 & 5 & 0.634 & 1.301 & $-8 \%{ }^{(b)}$ & $14^{31} / 32$ & NA & 4.97 \\
\hline 5 & 2.5 & 0.073 & 0.651 & $-15 \%{ }^{(b)}$ & $14^{31} / 32$ & NA & 2.49 \\
\hline 6 & 2.5 & 0.344 & 0.648 & $1 \%$ & $15^{1 / 32}$ & NA & 2.47 \\
\hline 7 & 10 & 0.344 & 2.647 & $1 \%$ & 15 & NA & 10.01 \\
\hline 8 & 5 & 0.204 & 0.652 & $20 \%$ & $7^{1 / 2}$ & NA & 4.97 \\
\hline \multicolumn{8}{|c|}{ T-Shape Fin } \\
\hline 9 & 5 & 0.074 & 1.301 & $0 \%{ }^{(\mathrm{c})}$ & 15 & 0.690 & 4.96 \\
\hline
\end{tabular}

The fin slope is calculated from dimensions and not directly measured. Slope $=\arctan ($ base/height). A metal ruler was used for fin height and calipers for measuring fin base and width. The caliper was zeroed before use.

(a) See Table 2.4 for design width of scaled fins.

(b) Stock material that was slightly smaller than the design width was used for fins rather than machining to exactly match design width.

(c) Face width used in calculation where the design width is 0.69 inch to match a 4-in., full-scale face. 


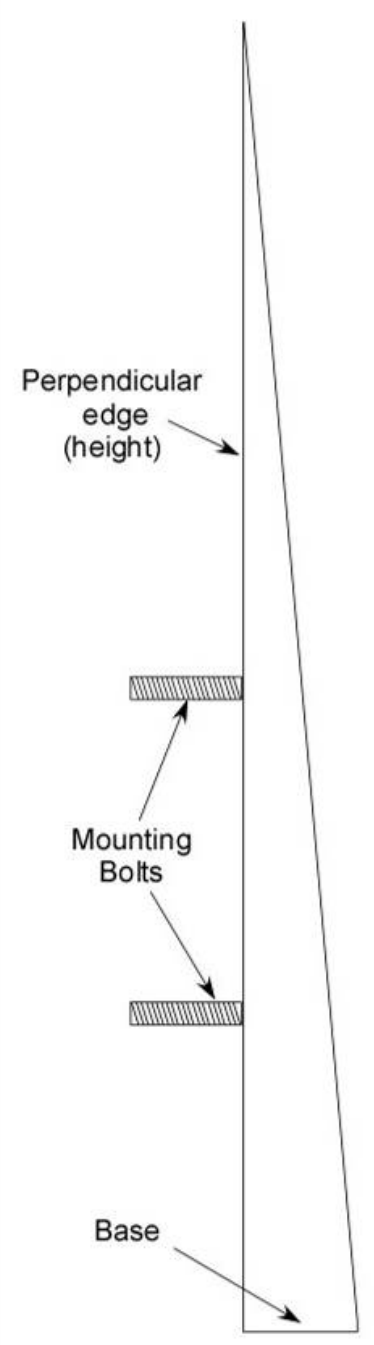

Side View

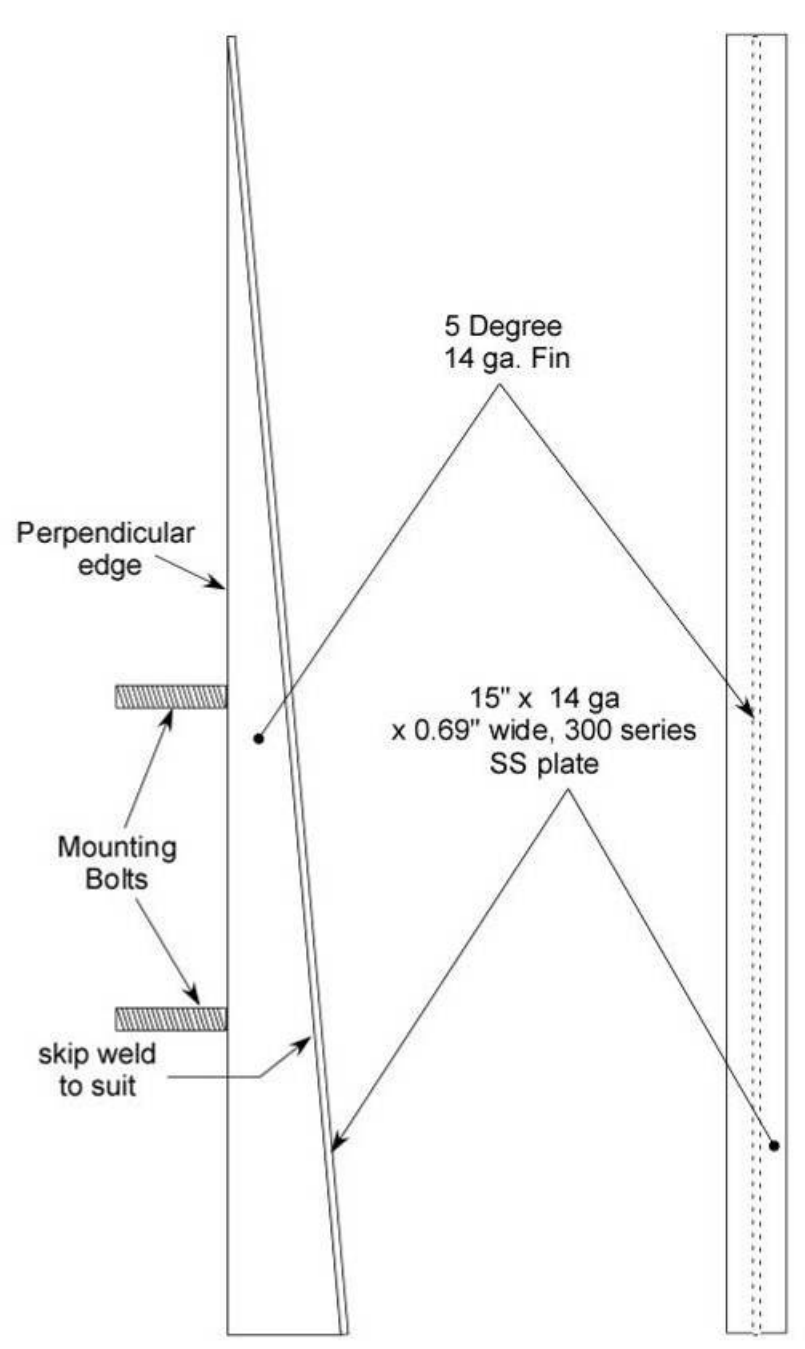

Side View

Front View

Figure 3.15. Diagrams of Straight-Side and T-Shape Fins with Mounting Bolts

A single T-shaped fin was fabricated for the 10-in., flat-bottom vessel, and Figure 3.15 gives a diagram of the 5-degree T-fin. This fin was constructed from the 0.074 -in. fin (fin 1 ) by welding a rectangular plate with a width of 0.69 inches to the face of the 5-degree fin. The as-built dimensions of the T-fin are given in Table 3.7, and Figure 3.16 and Figure 3.17 show images of the T-fin. 

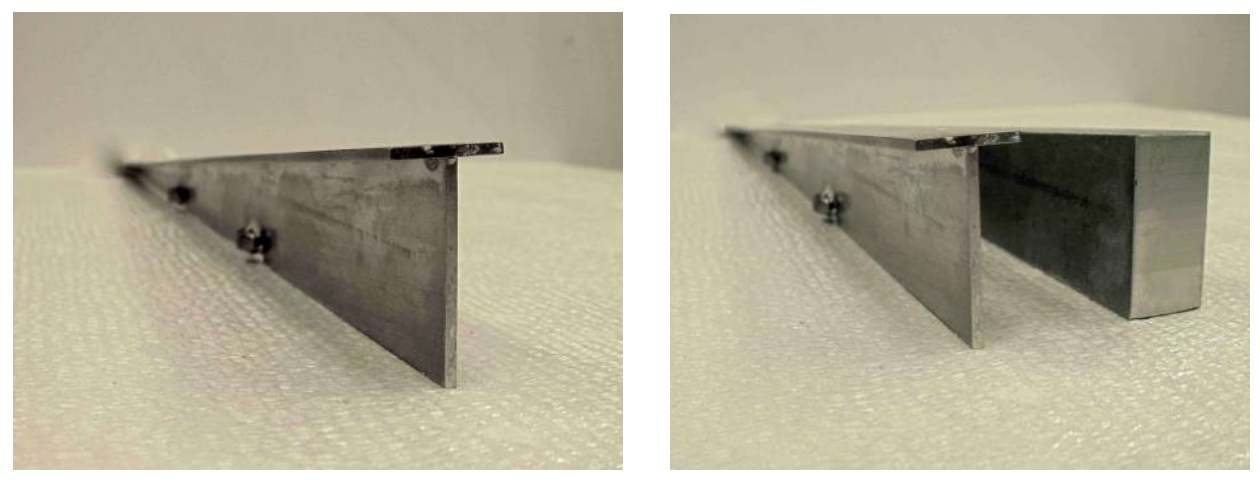

Figure 3.16. "T"-Shaped Fin with a Width of 0.69 inches along the Top of the "T" and a Comparison of the T-Fin with a Straight-Side Fin with a Width of 0.634 Inches

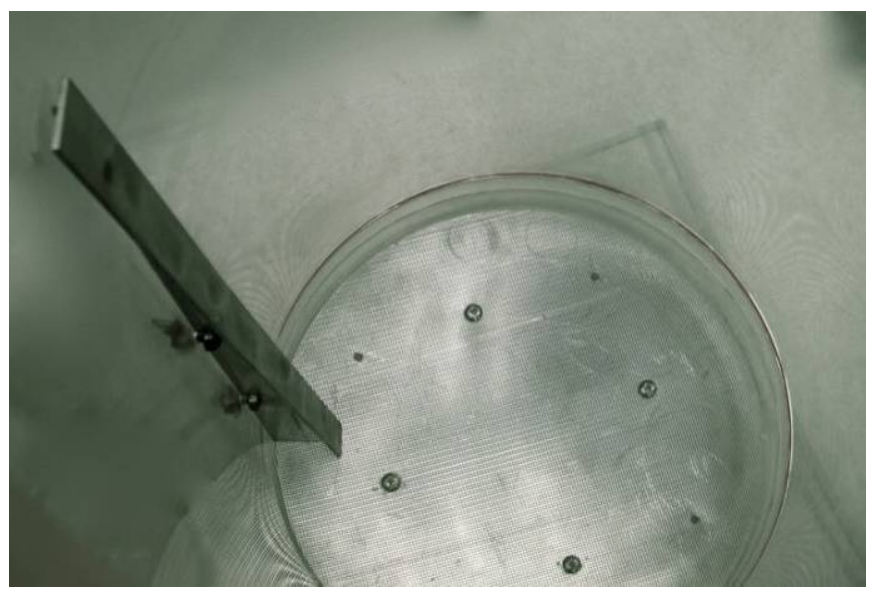

Figure 3.17. T-Fin Installed in the 10-in.-Diameter Flat-Bottom Vessel

A single fin was fabricated for testing in the 2:1 elliptical-bottom vessel. The fin selected for testing was designed to have a 5-degree slope and a width of 0.34 in. Figure 3.18 shows the design dimensions of the fin together with an image of the fin, and Table 3.8 gives a comparison of the as-built dimensions and the design.

Table 3.8. As-Built Dimensions of the Fin for the 2:1 Elliptical-Bottom Vessel

\begin{tabular}{|c|c|c|c|c|c|c|c|}
\hline $\begin{array}{c}\text { Design } \\
\text { Fin Slope } \\
\text { (degrees) }\end{array}$ & $\begin{array}{l}\text { Design } \\
\text { Width } \\
\text { (in.) } \\
\end{array}$ & $\begin{array}{l}\text { Measured } \\
\text { Width } \\
\text { (in.) } \\
\end{array}$ & $\begin{array}{c}\text { Design } \\
\text { Height Above } \\
\text { Elliptical Cut } \\
\text { (in.) }\end{array}$ & $\begin{array}{c}\text { Measured } \\
\text { Height Above } \\
\text { Elliptical Cut } \\
\text { (in.) }\end{array}$ & $\begin{array}{c}\text { Calculated } \\
\text { Base } \\
\text { (in.) }\end{array}$ & $\begin{array}{c}\text { Measured } \\
\text { Base } \\
\text { (in.) }\end{array}$ & $\begin{array}{c}\text { Actual } \\
\text { Fin Slope } \\
\text { (degrees) }\end{array}$ \\
\hline 5 & 0.340 & 0.341 & 12.5 & 12.44 & 1.088 & 1.10 & 5.05 \\
\hline
\end{tabular}



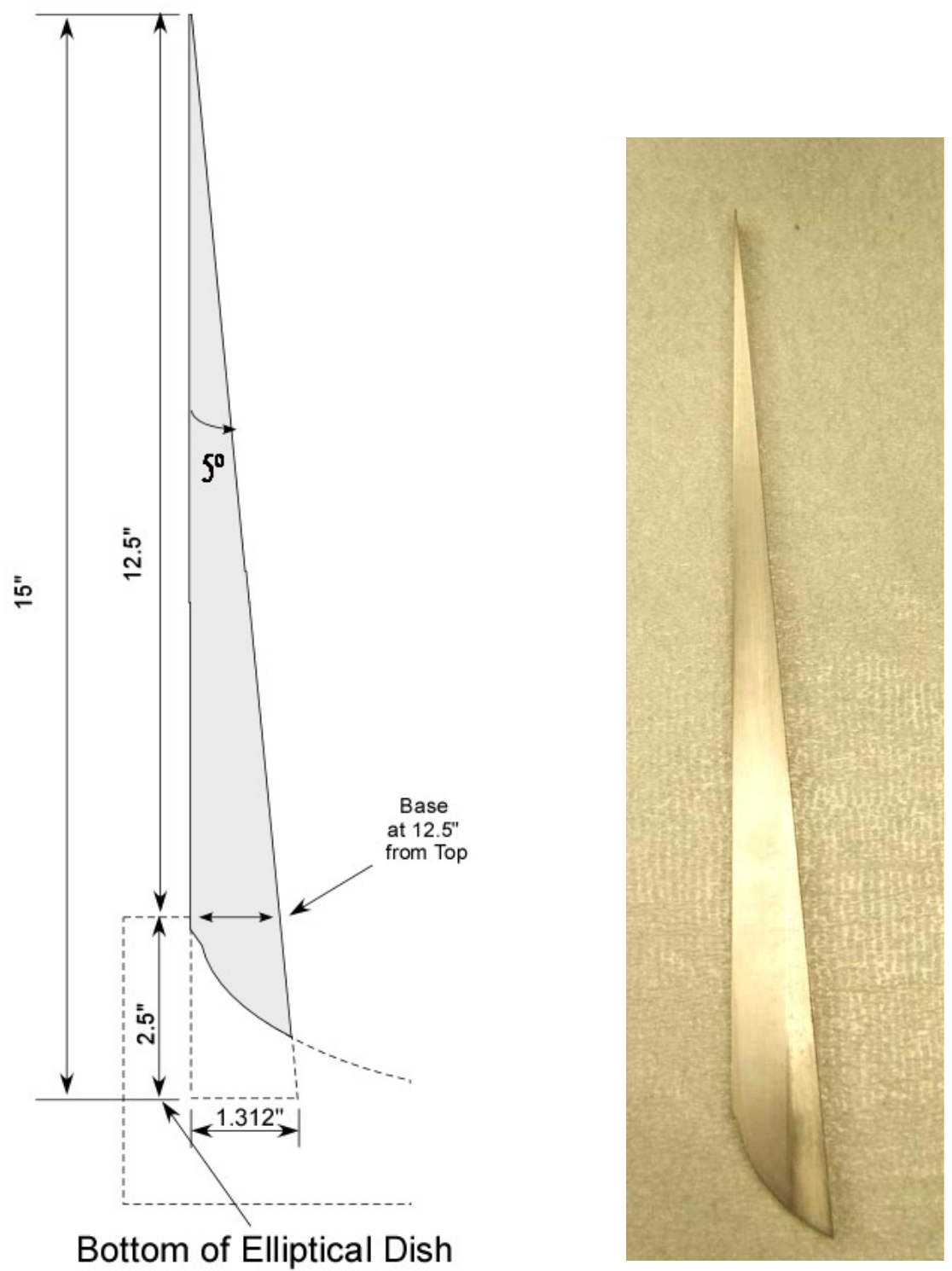

Figure 3.18. Fin Used with 2:1 Elliptical-Bottom Vessel

\subsubsection{Test Method}

For stability experiments, testing was conducted by filling the test vessel with a clay simulant to a specified height. The height was increased from an H/D of 0.25 to 0.5 followed by 1.0 , or until a stable VSB was observed. Upon reaching an H/D that yielded a stable VSB, the vessel was tipped with the clay in it, the wall where the fin attached was cleaned, and a fin with a layer of silicone grease was inserted and fastened along the vessel wall. The vessel was then tipped upright, and the simulant was pre-sheared for several minutes to allow any entrained gas to escape and verify uniform shear strength. For each test, the clay was then allowed to "rest" for 30 minutes to 1 hour before testing. Earlier 10-in. testing required a 1-hour waiting period. However, it was determined that 30 minutes was sufficient because of a negligible change in shear strength between the two waiting periods. 
The formation of a VSB was initiated by injecting nitrogen gas beneath the clay. Nitrogen was introduced through a Brooks ${ }^{\circledR} 100$-sccm mass flow controller (model 5850i). The mass flow controller allowed a steady introduction of nitrogen into the plenum below the clay. The 10-in. and 5-in. tests were conducted at an injection rate of $50 \mathrm{sccm}$ and $6.7 \mathrm{sccm}$, respectively. Typically, gas plenum pressures adequate to lift the clay layer and create a VSB varied from 0.5 to $0.75 \mathrm{psig}$ for the 10 -in. vessel. At the selected injection rates, a stable clay layer lifted to an H/D of 0.5 in about 120 minutes (note: these conditions translate into a sludge layer rise velocity of approximately $6.4 \mathrm{~cm} / \mathrm{hr}$ and $3.2 \mathrm{~cm} / \mathrm{hr}$ for 10 -in. and 5-in. vessels, respectively. This can be compared to full-scale estimates in Table 1.1. Each experiment was conducted up to the point of complete gas release or about an $\mathrm{H} / \mathrm{D}$ of 0.5 bubble rise. If the VSB was unstable, gas was typically released through the clay rather than along the wall. Observations including, but not limited to, lift height, time to reach instability, and/or time until gas release were documented for each test.

Tests without fins were conducted until the bubble rose to an $\mathrm{H} / \mathrm{D}$ of 0.5 or there was a major gas release and no further rise of the bubble. As discussed in Section 1.1, if the VSB lifted the clay layer to an $\mathrm{H} / \mathrm{D}$ of 0.15 or higher, the bubble is considered stable. For evaluating the performance of the fins, the criterion given in Section 1.1 of raising the sludge layer by $\mathrm{H} / \mathrm{D}=0.15$ is appropriate. At the gas injection rate selected for the tests, this corresponds to injecting gas for about 37 minutes. In the results section, tests where gas was released at the fin in less than $37 \mathrm{~min}$ will be identified as disruption by the fin. In some cases, partial gas releases can occur periodically, allowing some level of rise, which makes the simple criterion of 37 min difficult to use.

Installing fins along the wall of each test vessel took careful attention to avoid creating an inadvertent gas release path where the fin attaches to the wall. In these scaled experiments, vacuum-sealing silicone grease was placed between the fin and the wall before the fin was bolted securely into place. This was an effective sealing method. When conducting tests with fins, about a 1-in.-deep layer of water was placed above the clay to help visualize the location of gas release. A water layer will be present in the STSCs, and it affects the slumping as described in Section 2, so this is an important step in conducting the experiments. To compare tests with and without a water layer, Epstein and Gauglitz (2010) reported one test with a water layer above a clay layer, and the water layer did not affect the stability of a VSB in the one test.

\subsection{Slumping Behavior Tests for Simulants}

As mentioned, the performance of the fins (straight-sided fin or T-shaped) to release VSBs is dependent on the slumping of slurry. It is expected that more non-cohesive simulants will likely slump less than the kaolin clay, and the fins may work better for all strengths of materials. To determine both the relative and quantitative slumping behavior, two different tests were used, the 50-cent rheometer and the channel slumping, for three different simulants (kaolin, kaolin/Min-U-Sil 30, and KW-A) covering cohesive and non-cohesive simulants.

\subsubsection{Cylinder Slumping-the 50-Cent Rheometer}

The first test uses an open cylindrical sleeve, called the 50-cent rheometer, specified in Pashias et al. (1996). It measures a slumping height once a custom-designed transparent cylindrical sleeve $(8.9 \mathrm{~cm} \mathrm{H} \times 8.9 \mathrm{~cm} \mathrm{D})$ is filled with slurry simulant and then slipped off as shown in Figure 3.19. A 
slumping height, a parameter to measure the slumping behavior in this test, is defined by a total height change. A higher slumping tendency is indicated by a greater slumping height, and a slumping height would be governed by a balance between the strength of the slurry (i.e., shear strength) and gravity exerted on the slurry. As an example, Figure 3.20 provides illustrations for a $49 \mathrm{wt} \%$ kaolin slurry.

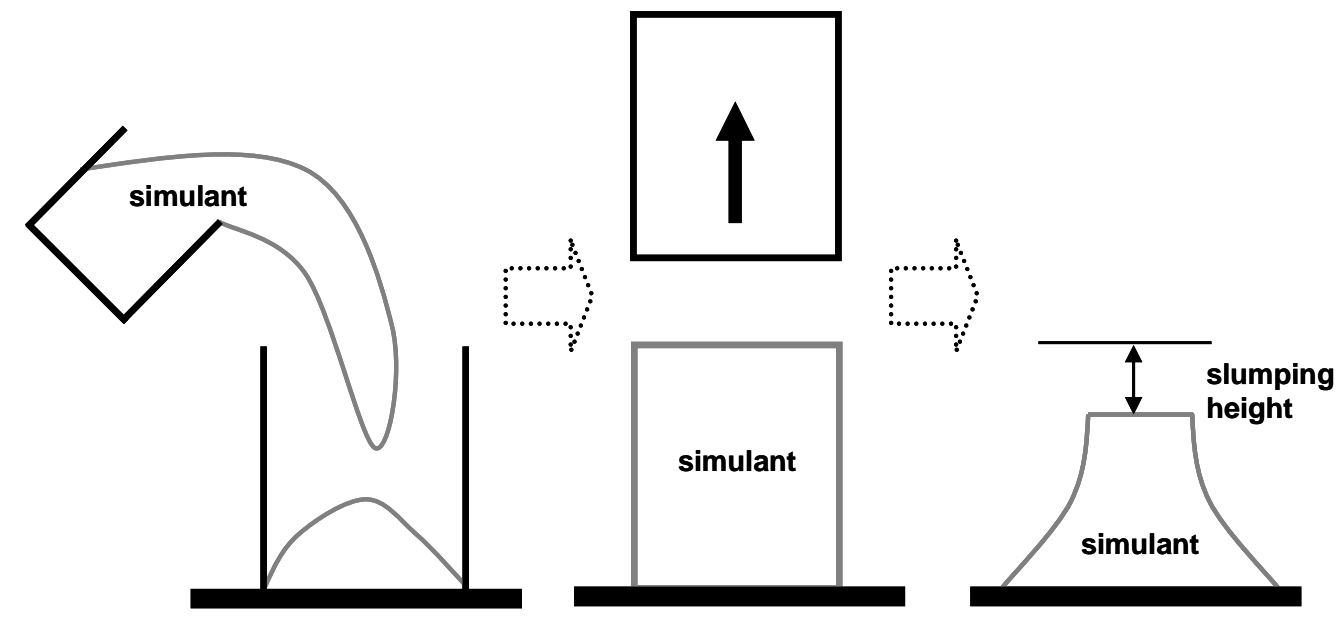

Figure 3.19. Schematic Diagram on the Procedure for the 50-cent Rheometer Test
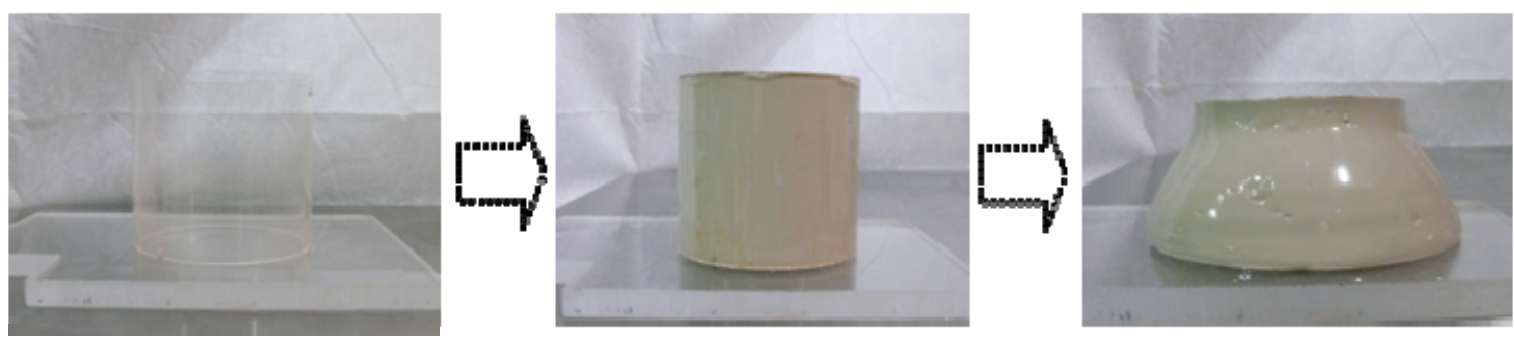

Figure 3.20. Example Pictures for the 50-Cent Rheometer Test with $49-w t \%$ Kaolin Slurry

\subsubsection{Channel Slumping}

The second slumping test uses a triangular-shaped fin and a transparent 3-in.-diameter column. An open channel depth is measured as a parameter to differentiate the slumping behavior once a sloped fin ( 2.5 degree with 0.344 in. width and 0.648 in. base) is pushed into the slurry simulant along the column wall and then pulled back with a tilted angle to create an open channel as shown in Figure 3.21. The underlying principle (i.e., a balance between strength of slurry and gravity exerted on the slurry) is similar to that of 50-cent rheometer, but, by contrast, a higher slumping tendency is indicated by a less open channel depth. Figure 3.22 provides an example for $49-\mathrm{wt} \%$ kaolin slurry. 


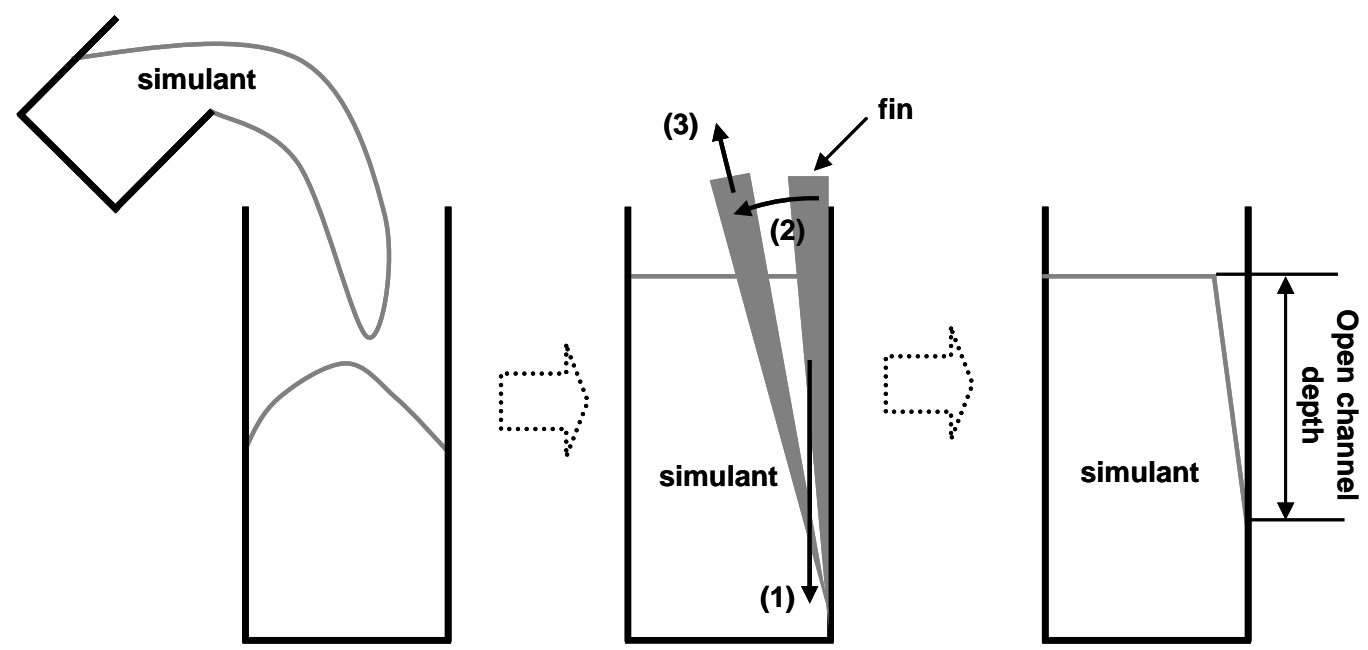

Figure 3.21. Schematic Diagram on the Procedure for the Channel Slumping Test
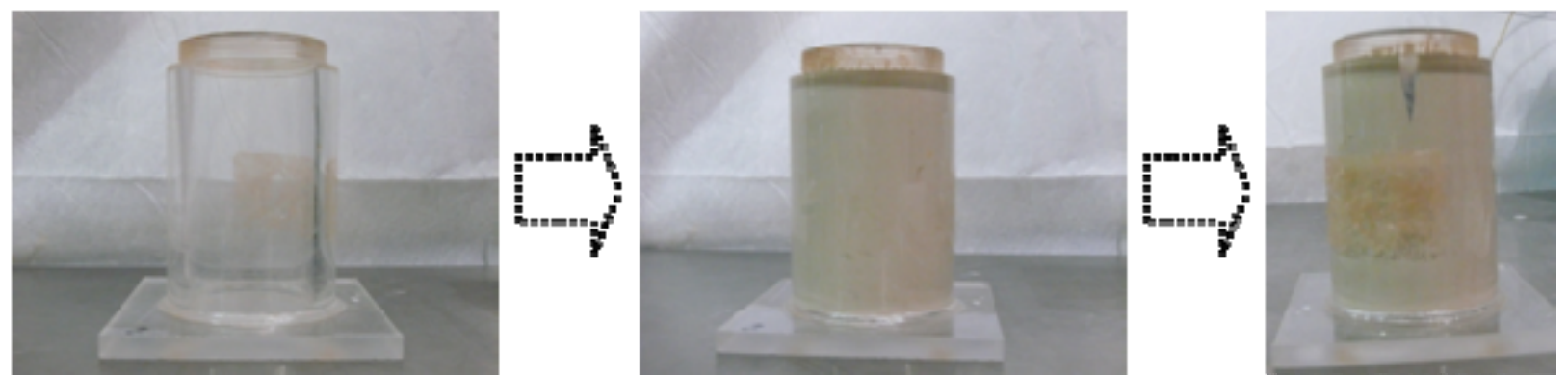

Figure 3.22. Example Pictures for the Channel Slumping Test with $49-w t \%$ Kaolin Slurry

\subsection{Large-Scale Tests-23-in.-Diameter Test Vessel}

Large-scale tests were performed using the same methodology as the small-scale tests. The only difference was that the injected nitrogen flow rate was higher to achieve the same VSB rise to an H/D of 0.5 in 120 minutes. This corresponds to a lift of 11.5 inches in the large vessel. A Brooks ${ }^{\circledR} 1000$-sccm mass flow controller (model 5850i) was used to control the flow to $650 \mathrm{sccm}$. Gas pressures required to lift the simulant plug ranged from 1 to $2 \mathrm{psig}$. At the aforementioned injection rate, a stable clay layer lifted to an H/D of 0.5 in 120 minutes (note: these conditions translate into a sludge layer rise velocity of approximately $14.6 \mathrm{~cm} / \mathrm{hr}$ and can be compared to full-scale estimates in Table 1.1). Testing in the 10-in., 2:1 elliptical-bottom vessel with kaolin was completed before designing and fabricating the 23 -in. vessel. This testing (see Section 4.2) showed that the elliptical bottom makes VSBs less stable, so a flat-bottom vessel gives more conservative results from the perspective of avoiding VSBs. Because the flat-bottom shape is more conservative, and using a flat-bottom addresses the possibility that a VSB might form above the elliptical bottom in an STSC as depicted in Figure 1.1, the 23-in. vessel was designed with a flat bottom. 


\subsubsection{Simulants}

The 23-in.-diameter vessel required much more simulant than the small-scale tests. As such, large batches of over 40 gallons of a given simulant were made and transferred to nine individual 5-gal buckets for storage. These batches were mixed vigorously using an auger mixer before transferring to the storage buckets. As with all simulants, testing was not conducted until the batches were allowed to fully hydrate for 24 hours. Each bucket was then individually premixed again and added to the vessel, whereupon an additional pre-shearing occurred with a drill mixer to release trapped bubbles and make the clay as uniform as possible. The simulant was then allowed to rest for 30 minutes before a test was conducted.

Table 3.9 and Table 3.10 detail the wt.\% solids, density, shear strength, and gravity yield parameter for all of the simulants used during the large-scale testing. The shear strength was measured using the same method as with the small-scale tests. The same shear vane was used to test presheared, fully hydrated clay that was allowed to rest for at least 1 hour. Each bucket for a particular simulant was presheared after it had hydrated for at least 24 hours with an auger mixer, and a subsample was taken from each bucket. These subsamples were all mixed together in the KitchenAid® mixer. The 52- and $55-w t \%$ simulant buckets were originally pre-mixed with a drill mixer before subsamples were transferred to the KitchenAid ${ }^{\circledR}$ for additional mixing. Later, these simulants were presheared with an auger mixer before transfer to the KitchenAid ${ }^{\circledR}$, and it was found that the shear-strength change between the two methods was negligible (less than $4 \%$ ).

Table 3.9. Gravity Yield Parameter Values and Average Shear Strengths for Kaolin Simulants Used in 23-in. (0.584-m) Vessel

\begin{tabular}{cccccc}
\hline $\begin{array}{c}\text { Kaolin } \\
(\text { wt.\% })\end{array}$ & $\begin{array}{c}\text { Density } \\
\left(\mathrm{kg} / \mathrm{m}^{3}\right)\end{array}$ & $\begin{array}{c}\text { Volume Percent } \\
\text { Water } \\
(\%)\end{array}$ & $\begin{array}{c}\text { Shear Strength } \\
\text { Average } \\
(\mathrm{Pa})\end{array}$ & $\begin{array}{c}\text { Vessel } \\
\text { Diameter } \\
(\mathrm{m})\end{array}$ & $\mathrm{Y}_{\mathrm{G}}$ \\
\hline 49 & 1437 & 73.4 & 183 & 0.584 & 0.022 \\
52 & 1477 & 71.0 & $346^{(\mathrm{a})}$ & 0.584 & 0.041 \\
55 & 1519 & 68.5 & $524^{(\mathrm{a})}$ & 0.584 & 0.060 \\
58 & 1563 & 65.8 & 1234 & 0.584 & 0.138 \\
\hline
\end{tabular}

(a) Duplicate measurements were made using double auger versus a drill mixer to pre-shear clay, and values varied less than $4 \%$. These two values represent those obtained using the drill-mixer.

Table 3.10. Gravity Yield Parameter Values and Average Shear Strengths for Kaolin/Min-U-Sil 30 Simulants Used in 23-in. (0.584-m) Vessel

\begin{tabular}{cccccc}
\hline $\begin{array}{c}\text { Kaolin/ } \\
\text { Min-U-Sil } \\
(\text { wt.\%) }\end{array}$ & $\begin{array}{c}\text { Density } \\
\left(\mathrm{kg} / \mathrm{m}^{3}\right)\end{array}$ & $\begin{array}{c}\text { Volume Percent } \\
\text { Water } \\
(\%)\end{array}$ & $\begin{array}{c}\text { Shear Strength } \\
\text { Average } \\
(\mathrm{Pa})\end{array}$ & $\begin{array}{c}\text { Vessel } \\
\text { Diameter } \\
(\mathrm{m})\end{array}$ & $\mathrm{Y}_{\mathrm{G}}$ \\
\hline $40 / 20.5$ & 1602 & 63.4 & 512 & 0.584 & 0.056 \\
$40 / 25$ & 1678 & 58.8 & 1010 & 0.584 & 0.105 \\
\hline
\end{tabular}




\subsubsection{Apparatus}

Figure 3.23 shows a schematic of the 23-in.-diameter, flat-bottom test apparatus with an installed internal fin. The apparatus consists of a 32.5-in.-tall $\times 24$-in.-outer diameter base cylindrical column. A 17.4-in. column is attached on top of the base via a 28-bolt, gasket-sealed flange. The base has an inlet gas plenum and a support structure for a stainless steel perforated plate. The perforated plate is seated 2 inches above the gas inlet and allows the injected gas uniform access to the bottom of the clay simulant.

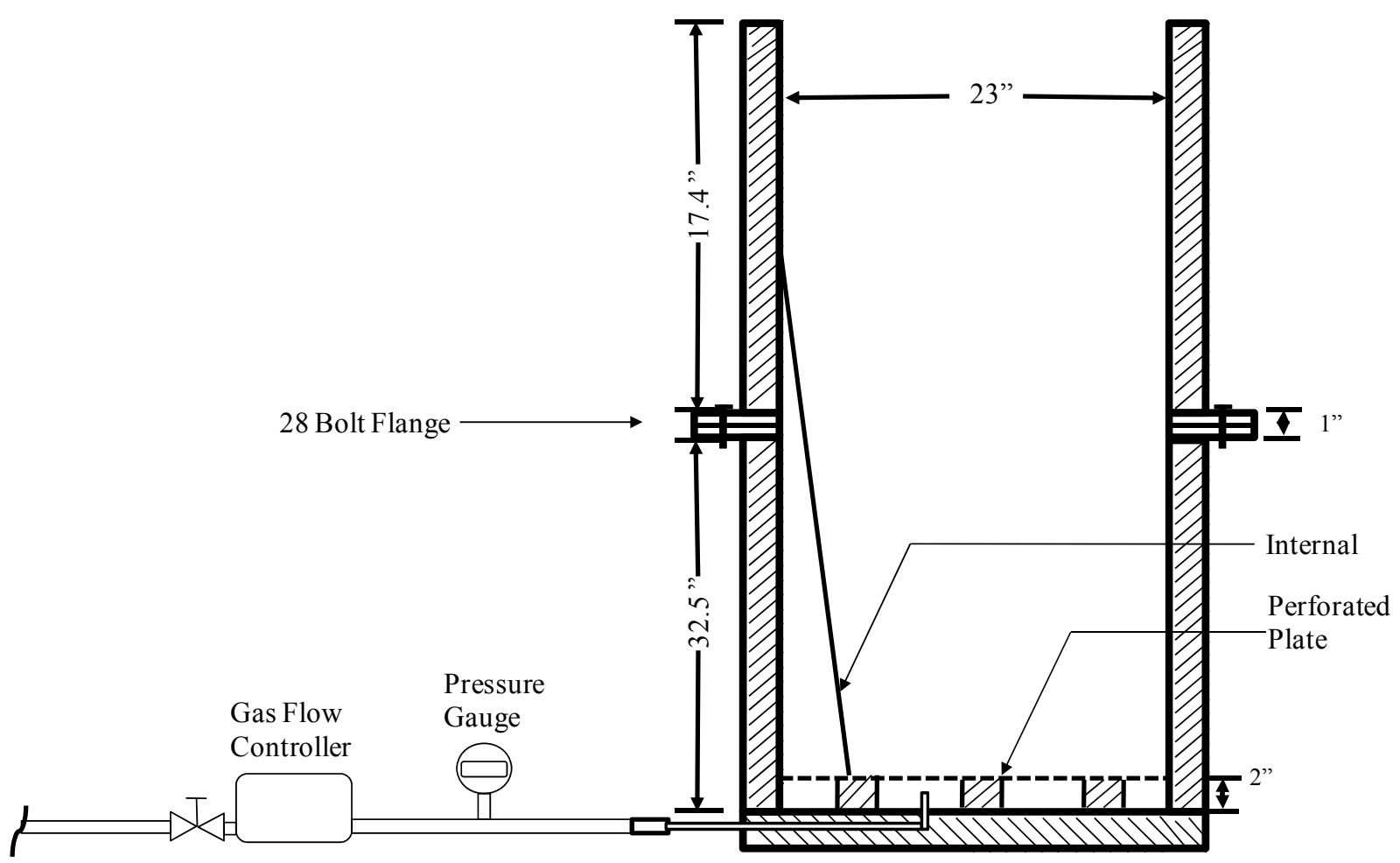

Figure 3.23. 23-in.-Diameter, Flat-Bottom Test Vessel

Figure 3.24 shows an image of the assembled, flat-bottom, 23-in.-diameter test vessel without an internal fin. The stainless steel perforated plate is visible on the bottom of the test section along with the gas inlet located at the bottom-center of the base structure. 


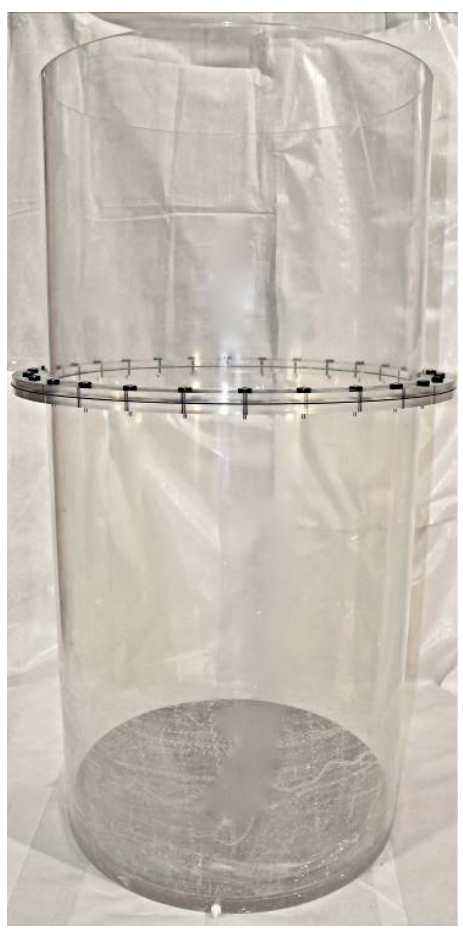

Figure 3.24. 23-in.-Diameter, Flat-Bottom Test Vessel Without a Fin

Figure 3.25 shows all of the flat-bottom vessels used for this study. This image shows the scale-up from the 5-in. vessel to the 23 -in. vessel.

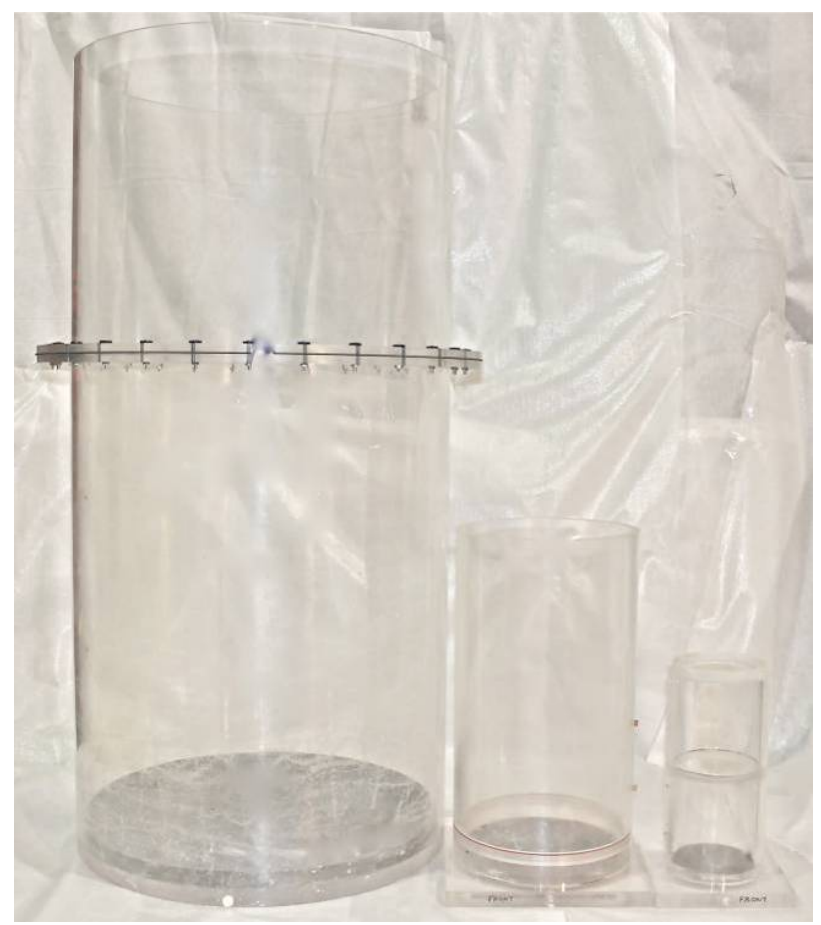

Figure 3.25. 23-in. (left), 10-in. (middle), and 5-in. (right) Diameter Flat-Bottom Test Vessels Without Fins 


\subsubsection{Fins}

The two fins used for the large-scale tests were a 5-degree straight-sided and a T-shaped fin. The image in Figure 3.26 shows the scale-up from the 5-degree, straight edge fin used in the 5-in. vessel to the same sloped fin used in the 23-in. vessel. Obvious from this image are the different fin heights and thicknesses. Fin 10, the straight-edge, 23-in.-diameter vessel fin, was machined to a target width of 0.79 inches and tapped in two places for $1 / 4-20$ bolts used in attaching to the vessel wall.

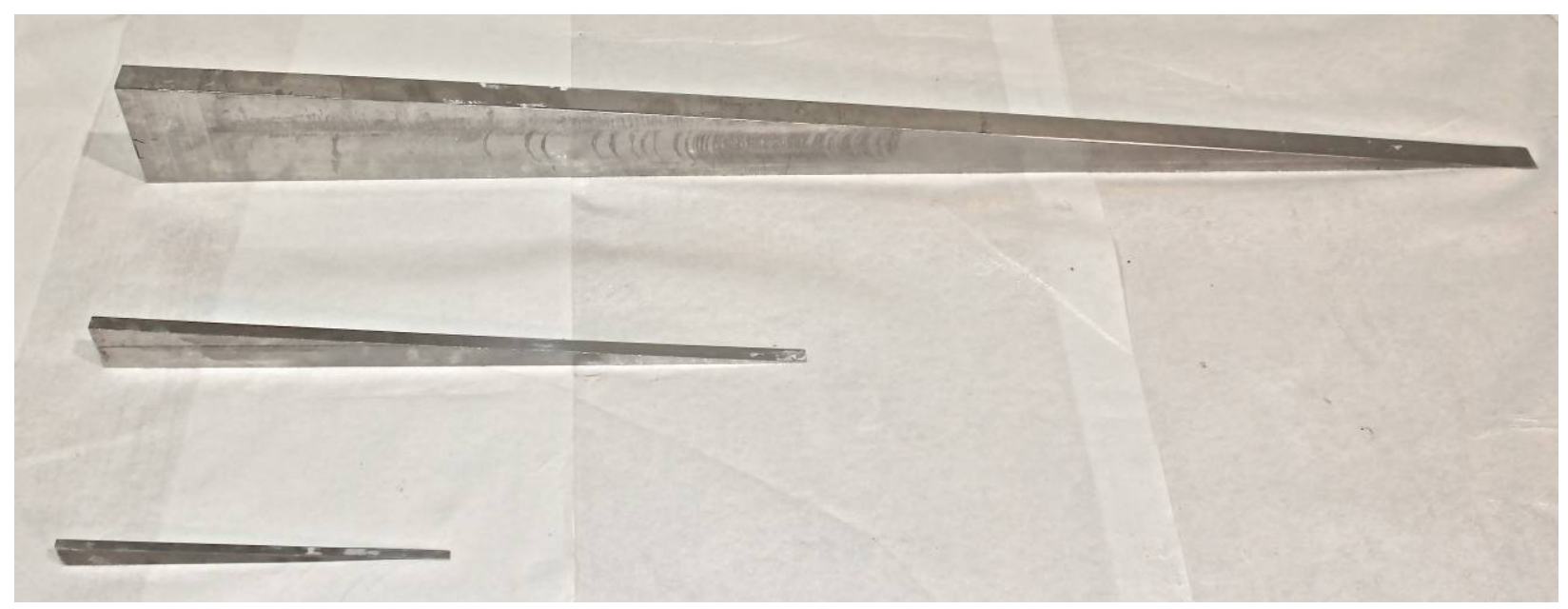

Figure 3.26. Straight 5-Degree Fins for 23-in. (Fin 10-top), 10-in. (Fin 3-middle), and 5-in. (Fin 8-bottom) Vessels

Figure 3.27 shows the two T-shaped fins used in this study. The fin shown on the left (fin 9) was used in the 10-in. vessel, and the larger fin (fin 11) on the right was used in the 23-in. vessel. The front face of fin 11 was machined to a target width of 1.59 inches and was welded in several places along the length of a 5-degree base fin. The back of the base fin was tapped in two places for $1 / 4-20$ bolts used in attaching to the vessel wall. 


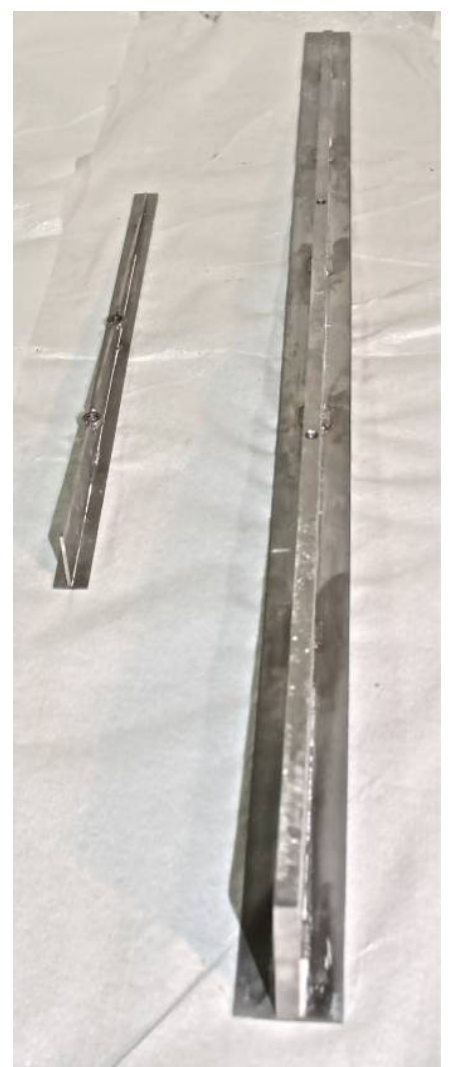

Figure 3.27. T-shaped, 5-Degree Fins for 10-in. (Fin 9-left) and 23-in. (Fin 11-right) Vessels (Fins Placed Face-Down)

Table 3.11 details the fins shown in Figure 3.26 and Figure 3.27. The small-scale fins were previously detailed but are given here to show the differing scales.

Table 3.11. As-Built Fin Dimensions

\begin{tabular}{|c|c|c|c|c|c|c|c|}
\hline Fin & $\begin{array}{l}\text { Design Fin } \\
\text { Slope } \\
\text { (degrees) } \\
\end{array}$ & $\begin{array}{c}\text { Width } \\
\text { (in.) }\end{array}$ & $\begin{array}{l}\text { Base } \\
\text { (in.) }\end{array}$ & $\begin{array}{c}\text { Percent Difference } \\
\text { in Width from } \\
\text { Design }^{(\mathrm{a})}\end{array}$ & $\begin{array}{l}\text { Height } \\
\text { (in.) }\end{array}$ & $\begin{array}{c}\text { Face } \\
\text { Width } \\
\text { (in.) }\end{array}$ & $\begin{array}{l}\text { As Received } \\
\text { Fin Slope } \\
\text { (degrees) }\end{array}$ \\
\hline \multicolumn{8}{|c|}{ Straight-Side Fin } \\
\hline 3 & 5 & 0.342 & 1.311 & $1 \%$ & $14^{31 / 32}$ & NA & 5.01 \\
\hline 8 & 5 & 0.204 & 0.652 & $20 \%{ }^{(b)}$ & $7^{1 / 2}$ & NA & 4.97 \\
\hline 10 & 5 & 0.788 & 3.018 & $-0.25 \%$ & $34^{1 / 2}$ & NA & 5.0 \\
\hline \multicolumn{8}{|c|}{ T-Shape Fin } \\
\hline 9 & 5 & 0.074 & 1.301 & $0 \%{ }^{(\mathrm{c})}$ & 15 & 0.690 & 4.96 \\
\hline 11 & 5 & 0.34 & 3.125 & $0.6 \%{ }^{(\mathrm{c})}$ & $34 \frac{1}{2}$ & 1.60 & 5.176 \\
\hline \multicolumn{8}{|c|}{$\begin{array}{l}\text { The fin slope is calculated from dimensions and not directly measured. Slope }=\text { arctan (base/height). A metal rul } \\
\text { was used for fin height, and calipers were used to measure fin base and width. The caliper was zeroed before use. } \\
\text { (a) See Table } 2.5 \text { for design width of scaled fins. } \\
\text { (b) Stock material that was slightly larger than the design width was used for the fin rather than machining to } \\
\text { (c) Factly match the design width. } \\
\text { (c) width used in calculation with the design face width given in Table } 2.6\end{array}$} \\
\hline
\end{tabular}





\subsection{Results and Discussion}

Bubble-stability and fin-performance tests were conducted with a number of different simulants with strengths ranging from less than what is needed to form stable VSBs to about 5-fold larger than the minimum shear strength needed to form stable bubbles. Tests were completed with and without fins in a 10-in.-diameter, flat-bottom vessel, a 10-in.-diameter vessel with a 2:1 elliptical bottom with a range of simulants. Tests were also completed in 5-in. and 23-in. flat-bottom vessels to provide results on the role of vessel size. Kaolin clay and water slurries were the primary simulant materials used in the testing, and selected tests were conducted with slurries of kaolin clay and Min-U-Sil 30 and a KW container sludge simulant. The testing results are presented below together with comparisons to previous studies and the bubble-stability diagram presented in Section 2. Appendix C provides tables summarizing all of the tests, including specific test parameters and results. The results of the slumping tests for all the simulants are also discussed below.

\subsection{0-in., Flat-Bottom Test Vessel with Kaolin Clay}

A series of tests were conducted without fins to demonstrate the conditions when a stable VSB would form and to clearly demonstrate that in the absence of a fin, the bubbles were stable. Figure 4.1 shows an example of a stable bubble lifting a layer of $50-\mathrm{wt} \%$ kaolin clay. In all of the experiments, if the bubble lifted the clay layer 5 inches, which is half the vessel diameter, the bubble was considered stable. The clay layer being lifted half the vessel diameter is roughly comparable to 55 inches of sludge being lifted to the vents at the top of an STSC. If the clay layer collapsed with gas before rising 5 inches, then the bubble was considered unstable. All the experiments were conducted at a gas injection rate of $50 \mathrm{cc} / \mathrm{min}$, and a bubble rise of 5 inches corresponds to injecting gas for about 130 minutes.
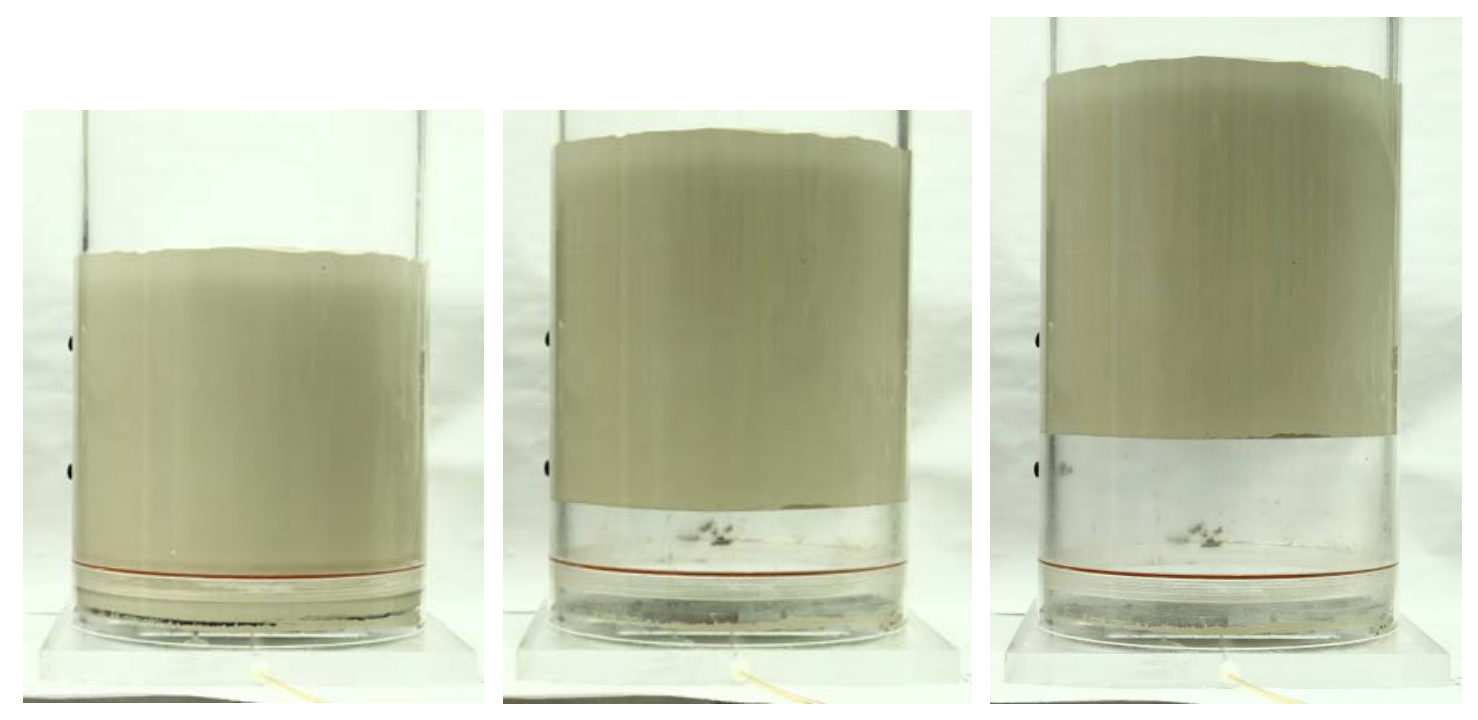

Figure 4.1. Initial Stable Plug Beginning to Rise, After $80 \mathrm{~min}$, and After $130 \mathrm{~min}$ with a 5-in. Rise 
For sufficiently weak clays, VSBs will eventually fail because of the Taylor instability mechanism as described previously. Table 4.1 shows the results for each of the no-fin experiments. For these tests, the transition between stable and unstable bubbles occurred between 160 and $230 \mathrm{~Pa}$ for kaolin clay when the depth of the clay layer was 10 inches $(\mathrm{H} / \mathrm{D}=1)$. Figure 4.2 shows these data on a plot of gravity yield parameter, $\mathrm{Y}_{\mathrm{G}}$, and dimensionless clay depth. Figure 4.2 also compares these results with the previous work of Epstein and Gauglitz (2010) where the clay layer depth was $\mathrm{H} / \mathrm{D}=0.5$. In comparison to the results from Epstein and Gauglitz (2010) where $\mathrm{Y}_{\mathrm{G}}=0.09$ for $\mathrm{H} / \mathrm{D}=0.5$, the new results with an $\mathrm{H} / \mathrm{D}=1$ had a transition to unstable bubbles at a lower value of $\mathrm{Y}_{\mathrm{G}}$, or about $\mathrm{Y}_{\mathrm{G}} \sim 0.05$. The curve for the bubble stability criterion is drawn by eye to fit through these two sets of data and extrapolated based on the expected behavior, as discussed in Section 2. Epstein and Gauglitz (2010) note that theory indicates that the instability should be independent of layer thickness. This seems reasonable, particularly for sufficiently thick layers, so the bubble stability curve should become a vertical line for a larger H/D. However, as mentioned in Section 2, it also seems reasonable that the sludge layer will become less stable when it becomes sufficiently thin, which implies that the stability criterion will have $\mathrm{Y}_{\mathrm{G}}$ increasing as H/D becomes smaller. The extrapolation shown in Figure 4.2 follows this general expected behavior, but additional data are needed to confirm the suggested shape.

Table 4.1. Effect of Shear Strength on the Stability of VSBs in the 10-in., Flat-Bottom Vessel Without Fins

\begin{tabular}{l|ccccc}
\hline Parameter & \multicolumn{4}{|c}{ Test Conditions and Results } \\
\cline { 1 - 3 } \cline { 5 - 6 } Wt\% Clay & $58 \mathrm{wt} \%$ & $55 \mathrm{wt} \%$ & $50 \mathrm{wt} \%$ & $49 \mathrm{wt} \%$ & $48 \mathrm{wt} \%$ \\
\hline Shear Strength of Clay & $1090 \mathrm{~Pa}$ & $720 \mathrm{~Pa}$ & $260 \mathrm{~Pa}$ & $230 \mathrm{~Pa}$ & $160 \mathrm{~Pa}$ \\
\hline $\mathrm{Y}_{\mathrm{G}}$ & 0.28 & 0.19 & 0.072 & 0.064 & 0.044 \\
\hline Stability of VSB & Stable & Stable & Stable & $\begin{array}{c}\text { Stable Once } \\
\text { Unstable } \\
\text { Once }\end{array}$ & $\begin{array}{c}\text { Unstable } \\
\text { Twice }\end{array}$ \\
\hline
\end{tabular}




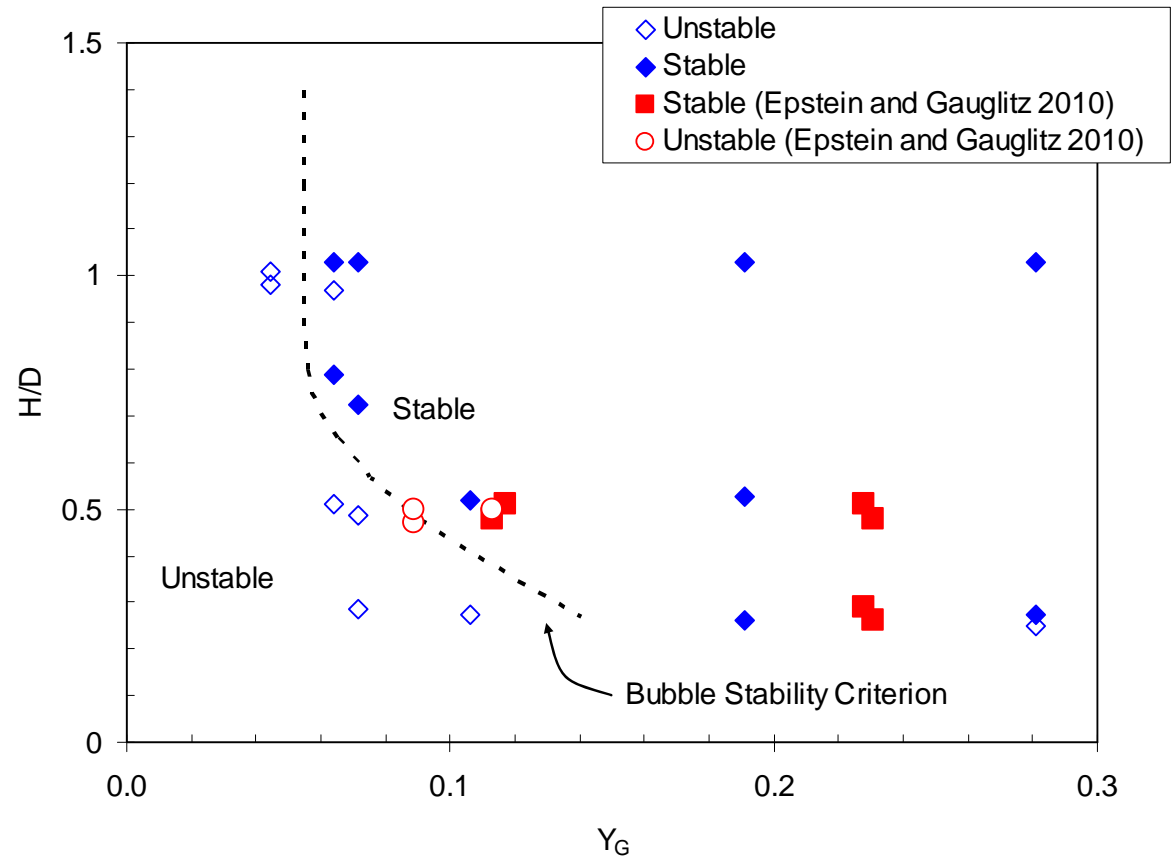

Figure 4.2. Comparison of Stability Results with Different Clay Layer Thickness

The first series of fin performance tests was conducted using the $55-\mathrm{wt} \%$ clay where the gravity yield parameter was $\mathrm{Y}_{\mathrm{G}}=0.19$ and in a range where VSBs are clearly stable as seen in Figure 4.2. Table 4.2 shows the test results for the various fins used in the testing. For all of the tests conducted with the 55$\mathrm{wt} \%$ clay, the gas release occurred at the fin in every test. In each of these tests, the clay lifted no more than about $1 / 8$ inch when the gas release occurred. The table shows both the full-scale equivalent width and the scaled fin used in the testing. The majority of the experiments were conducted with 5-degree fins of different widths. A 0.34-in.-wide fin (equivalent to a 2-in.-wide full-scale fin) with different slopes was also tested. While these tests showed that all the fins disrupted the VSBs, the 5-degree fin that had a width 0.34 in., which represents a full-scale width of 2 inches, was selected as the primary fin for further testing.

Table 4.2. Fin Performance Results in the 10 -in., Flat-Bottom Vessel with 55 -wt $\%$ Clay ( $720 \mathrm{~Pa}$, $\left.\mathrm{Y}_{\mathrm{G}}=0.19\right)$

\begin{tabular}{c|ccccc}
\hline $\begin{array}{c}\text { Scaled Fin Width for } \\
\text { 10-in. Vessel (in.) }\end{array}$ & 0.086 & 0.17 & 0.34 & 0.69 \\
\hline $\begin{array}{c}\text { Equivalent Full-Scale } \\
\text { Fin Width in STSC (in.) }\end{array}$ & 0.5 & 1 & 2 & 4 \\
\hline $\begin{array}{l}\text { Fin Slope } \\
\text { (degrees) }\end{array}$ & 2.5 & $\begin{array}{c}\text { bubble } \\
\text { disrupted } \\
\text { bubble } \\
\text { disrupted }\end{array}$ & $\begin{array}{c}\text { bubble } \\
\text { disrupted }\end{array}$ & $\begin{array}{c}\text { bubble } \\
\text { disrupted } \\
\text { bubble } \\
\text { disrupted } \\
\text { bubble } \\
\text { disrupted }\end{array}$ & $\begin{array}{c}\text { bubble } \\
\text { disrupted }\end{array}$ \\
\hline -- not tested & 10 & -- & -- & \\
\hline
\end{tabular}


Table 4.3 summarizes the effect of kaolin shear strength on the performance of the two fins tested in kaolin clay simulants in the 10-in.-diameter, flat-bottom vessel. The top row gives the no-fin stability results from Table 4.1 for comparison. For the fin testing results, the comments in the table describe both the observed gas-release mechanisms and the duration of gas injection when gas retained in a VSB was essentially fully released. For all of these tests, gas was injected at $50 \mathrm{cc} / \mathrm{min}$, so the duration of gas injection is a good measure of the total gas retained at the point when the gas was released. For these fin tests, the fin had a 5-degree slope, straight sides, and a width of 0.34 inches. The fin performed very well in the stronger 58 and $55-\mathrm{wt} \%$ clays. Using the gravity yield parameter to scale the strengths for these clays from the 10-in.-scale vessel to the full-scale STSC, these strengths are equivalent to 6,300 and 4,200 $\mathrm{Pa}$ in a 58-in.-diameter vessel.

For the weaker clays of 52, 50, and 49-wt $\%$ clay, Table 4.3 shows that stable VSBs were observed, and they rose a significant distance. In some cases, the fin would disrupt the bubble, but for the 52-wt $\%$ clay, the bubble was stable for a full 5 inches of rise. In a number of these tests, gas would release for a short duration at the fin, but then quickly stop as the clay sealed the release pathway. Assuming the gravity yield parameter for the scaling, the 49 to $52-\mathrm{wt} \%$ clay corresponds to shear strengths of 1,300 to 2,300 $\mathrm{Pa}$ in a 58-in.-diameter vessel. These data are evaluated in terms of the scaled slumping and bubble stability model in Section 4.3.

Table 4.3 also shows the results for the T-shaped fin. The fin had a 5-degree slope, and the width along the "T" was 0.69 inches, which is equivalent to a 4-in.-wide " $T$ " at full scale. The base of the " $T$ " was along the wall of the test vessel, and the top of the "T" protruded into the clay. The first advantage of the " $T$ " shape is that relatively thin and light material could be used to fabricate a full-scale "T," such as $1 / 4$-in. steel plate. The second advantage is that the top of the " $T$ " provides a sloped pathway for gas release, while the " $\mathrm{T}$ " also behaves as a hook that will hold down the waste and potentially initiate gas release by distorting a clay layer as it rises. The results for the T-fin are shown in the bottom row of the table. The T-fin was more successful at releasing gas with less bubble rise (or equivalently shorter durations of gas injection). However, for the 49 and 50-wt\% clay, stable VSBs still lifted the clay layer a significant distance before they were ultimately disrupted with gas release at the fin. While the T-fin is promising, it was not fully successful.

Three tests were completed with the combination of a 5-degree T-fin and a 5-degree straight-sided fin, and the results are summarized in Table 3.4. The tests were conducted with 49-, 50-, and 52-wt $\%$ kaolin, which are the simulant strengths where the fins perform poorly. The combination clearly caused the clay layer to twist as it rose, but stable VSBs still formed. For the 49-wt\% clay, the VSB rose for 90 min, or about 3 inches, before it failed. Overall, the results with the combination of two fins were essentially equivalent to the results with single fins. Specifically, with the combined fins, there were one or more kaolin simulants where VSBs were stable for more than 37 minutes of gas injection, which corresponds to the criterion for bubble stability of a bubble rise of $\mathrm{H} / \mathrm{D}=0.15$ (see Section 3.1.4) . 
Table 4.3. Effect of Clay Strength on the Performance of 5-Degree Straight-Sided and "T"-Shaped Fins in a Flat-Bottom Vessel

\begin{tabular}{|c|c|c|c|c|c|c|}
\hline \multirow[b]{2}{*}{ wt $\%$ Clay } & \multicolumn{6}{|c|}{ Clay Simulants } \\
\hline & $58 \mathrm{wt} \%$ & $55 \mathrm{wt} \%$ & $52 \mathrm{wt} \%$ & $50 \mathrm{wt} \%$ & $49 \mathrm{wt} \%$ & $48 \mathrm{wt} \%$ \\
\hline $\begin{array}{c}\text { Shear } \\
\text { Strength }\end{array}$ & $1090 \mathrm{~Pa}$ & $720 \mathrm{~Pa}$ & $400 \mathrm{~Pa}$ & $260 \mathrm{~Pa}$ & $230 \mathrm{~Pa}$ & $160 \mathrm{~Pa}$ \\
\hline $\mathrm{Y}_{\mathrm{G}}$ & 0.28 & 0.19 & 0.11 & 0.072 & 0.064 & 0.044 \\
\hline $\begin{array}{l}\text { Vessel } \\
\text { (Fin) }\end{array}$ & \multicolumn{6}{|c|}{ Stability Results and Gas Injection Duration ${ }^{(a)}$} \\
\hline $\begin{array}{c}\text { Flat Bottom } \\
\text { (none) }\end{array}$ & Stable & Stable & -- & Stable & $\begin{array}{c}\text { Stable Once } \\
\text { Unstable Once }\end{array}$ & $\begin{array}{c}\text { Unstable } \\
\text { Twice }\end{array}$ \\
\hline $\begin{array}{l}\text { Flat Bottom } \\
\text { (Straight- } \\
\text { Sided Fin } \\
5 \text { degree } \\
0.34 \text { inch) }\end{array}$ & $\begin{array}{l}\text { Unstable } \\
\text { Disrupted at } \\
\sim^{1 / 4-i n . ~ r i s e ~}\end{array}$ & $\begin{array}{l}\text { Unstable } \\
\text { Disrupted at } \\
\sim 1 / 8 \text {-in. rise } \\
\text { (twice) } \\
\text { (2\&4 min) }\end{array}$ & $\begin{array}{c}\text { Stable } \\
\text { to } \\
\sim 5 \text {-in. rise at } \\
150 \mathrm{~min}\end{array}$ & $\begin{array}{l}\text { Stable to } \\
\sim 4 \text {-in. rise } \\
\text { then } \\
\text { disrupted } \\
\text { (101 min) }\end{array}$ & $\begin{array}{l}\text { Unstable Once } \\
\qquad(4 \mathrm{~min}) \\
\text { Stable to } \\
\sim 4 \text {-in. rise and } \\
\text { then disrupted } \\
\text { (121 min) }\end{array}$ & -- \\
\hline $\begin{array}{l}\text { Flat Bottom } \\
\qquad \begin{array}{c}\text { (T-Fin } \\
5 \text { degree } \\
0.69 \text { inch } \\
\text { wide) }\end{array}\end{array}$ & -- & $\begin{array}{c}\text { Unstable } \\
\text { Disrupted at } \\
\sim 1 / 8 \text {-in. rise }\end{array}$ & $\begin{array}{l}\text { Unstable } \\
\text { Disrupted at } \\
\sim 1 / 2 \text {-in. rise }\end{array}$ & $\begin{array}{l}\text { Stable to } \\
2.5 \text {-in. rise } \\
\text { then } \\
\text { disrupted } \\
\text { (76 min) }\end{array}$ & $\begin{array}{c}\text { Stable to } \\
\sim 2 \text { inches and } \\
\text { then disrupted } \\
\text { (47 min) } \\
\text { Stable to } \\
\sim 4 \text { inches and } \\
\text { then disrupted } \\
\text { ( } 89 \text { min) }\end{array}$ & -- \\
\hline $\begin{array}{l}\text { Flat Bottom } \\
\text { (Combined } \\
\text { T-Fin and } \\
\text { Straight- } \\
\text { Sided Fin) }\end{array}$ & -- & -- & $\begin{array}{l}\text { Stable to } \\
\sim 2 \text { inches } \\
\text { and then } \\
\text { disrupted } \\
\text { (45 min) }\end{array}$ & $\begin{array}{c}\text { Unstable } \\
\text { Disrupted at } \\
\sim 1 / 2 \text {-in. rise } \\
(15 \mathrm{~min})\end{array}$ & $\begin{array}{l}\text { Stable to } \sim 3 \text {-in. } \\
\text { rise and then } \\
\text { disrupted } \\
\quad(\sim 90 \mathrm{~min})\end{array}$ & -- \\
\hline
\end{tabular}

\subsection{0-in. 2:1 Elliptical Bottom Vessel with Kaolin and Kaolin/Min-U- Sil 30 Simulants}

Tests were conducted in a 10-in. vessel with a 2:1 elliptical bottom to determine both fin performance and the stability of VSBs in the absence of a fin for both kaolin and kaolin/Min-U-Sil 30 simulants. Figure 4.3 shows the elliptical test vessel loaded with $50 \mathrm{wt} \%(260 \mathrm{~Pa})$ kaolin clay to a depth of 10 inches. In comparison to the flat-bottom vessel, the clay layer does not have a uniform depth across the vessel with the depth being less at the side walls. When the clay layer is pushed upwards by the injected 
gas, the clay layer will have a greater load in the center than at the wall, and this may affect the stability of the layer.

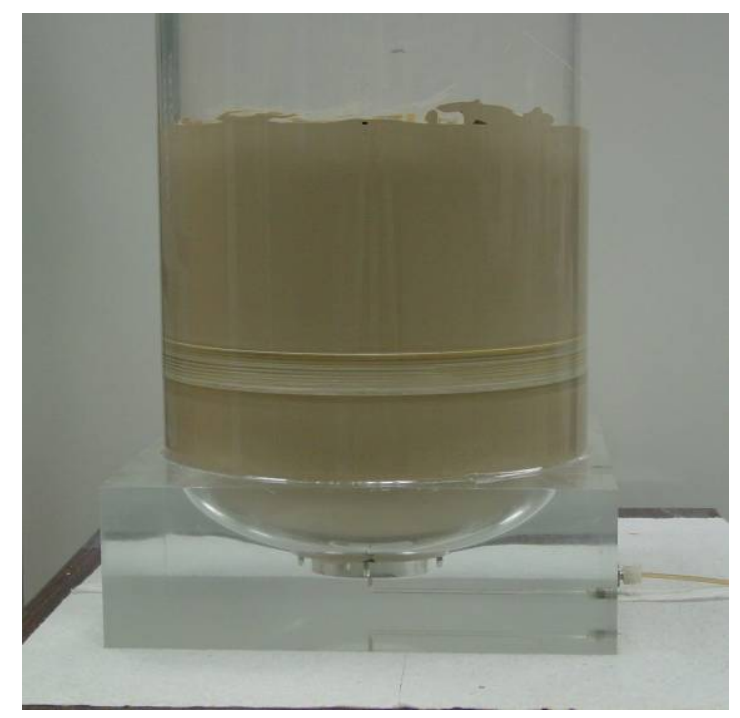

Figure 4.3. 2:1 Elliptical Bottom Test Vessel Loaded with 10 Inches of Kaolin Clay

In a typical experiment, as gas was injected, the clay would detach from the bottom of the ellipse and begin to rise. Figure 4.4 shows a thin gas bubble (less than $\sim 1 / 16$ inch) that was often easily observed as the clay detached from the bottom of the ellipse. As gas was injected in this relatively weak clay, a bubble began to grow on one side. At a certain size, the unstable bubble would rise through the clay. Figure 4.5 shows the surface of the clay after a gas bubble rose and burst through it. The clay was sufficiently strong to hold the shape that is seen in the image. This behavior was typical of the weaker clays tested and with progressively stronger clays, detachment from the bottom would occur, but the bubble would rise unevenly in comparison to bubble rise in the flat-bottom vessel. 

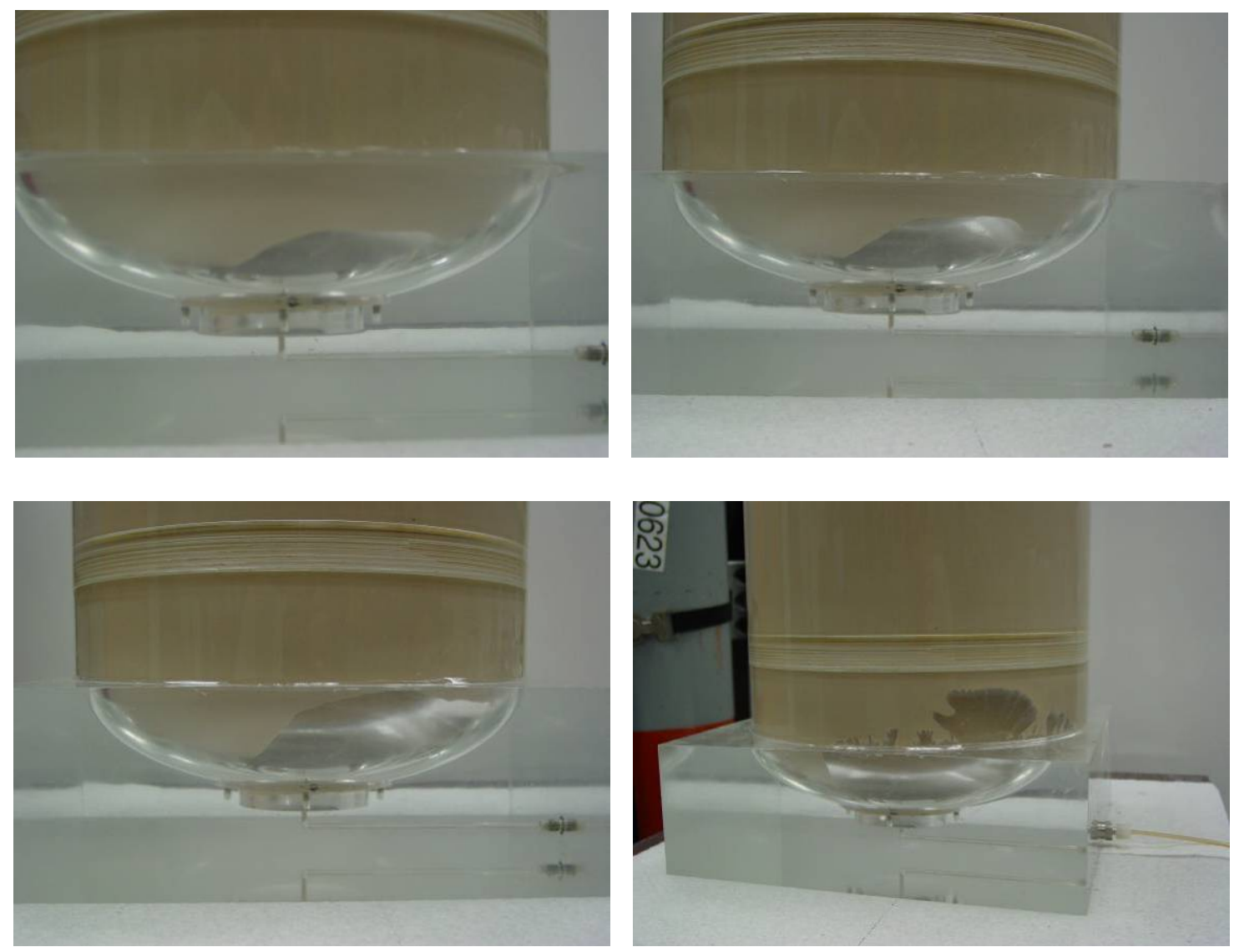

Figure 4.4. Visual Indication of Clay Detachment from the Bottom of the 2:1 Ellipse

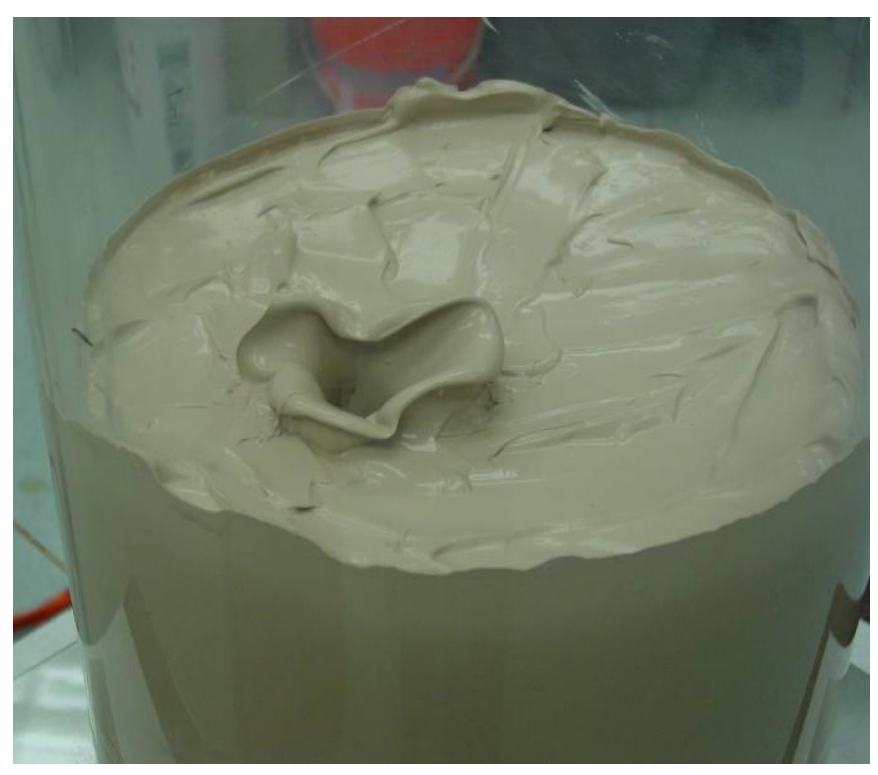

Figure 4.5. Location of Bubble Breakthrough 
Table 4.4 summarizes the behavior of VSBs with kaolin simulants in a 10-in.-diameter vessel with a 2:1 elliptical bottom that matches the shape of STSC vessel. Tests were conducted both without a fin and then with a straight-sided 5-degree fin with a 0.34 -in. width. This fin is equivalent to a 2 -in.-wide fin in a full-scale vessel. For comparison, the top row of the results shows the results reported in Table 4.1 for the stability of VSBs without a fin in the flat-bottom vessel. With the 2:1 elliptical vessel, the bottom of the clay is not flat as a gas bubble begins lifting the clay. The stability of the VSB was strongly affected by this different geometry. For the tests without a fin, gas eventually released for all the clays tested, i.e., all of the tests eventually showed unstable VSBs. The specific criterion being used in this study for a bubbles being stable (see Section 1.1) is whether the bubble can lift the simulant by more than $H / D=0.15$ (which is equivalent to $37 \mathrm{~min}$ of gas injection without a release), so some of these bubbles are categorized as stable. The comments in Table 4.4 describe the behavior of the clay layer and the duration of gas injection at the point when gas retained in a VSB was essentially fully released. For all of these tests, gas was injected at $50 \mathrm{cc} / \mathrm{min}$, so again the duration of gas injection is a good measure of the total gas retained at the point when the gas was released.

For the fin tests with kaolin, the VSB was clearly disrupted by the fin, with gas release at the fin for the strongest kaolin simulant $(58 \mathrm{wt} \%)$. For the $55-\mathrm{wt} \%$ clay, one test showed bubble disruption at the fin, and one test had a bubble that is categorized as stable though gas released at 39 min which is just barely beyond the criterion for stability. For the weaker 52 to $49-\mathrm{wt} \%$ kaolin clays, the bubbles became progressively less stable.

A series of equivalent tests were completed in the 10-in. elliptical bottom vessel with four kaolin/Min-U-Sil 30 simulants. Table 4.5 shows these results, including results for kaolin/Min-U-Sil 30 in the flat-bottom vessel that will be discussed in Section 4.5. While there are some differences between kaolin and kaolin/Min-U-Sil 30 results, the results for bubble stability fin performance are generally similar. Without a fin in the elliptical-bottom vessel, bubbles in the kaolin/Min-U-Sil 30 simulants progressed from unstable to stable with increasing simulant strength and $\mathrm{Y}_{\mathrm{G}}$. In comparison to the flatbottom vessel results, bubbles in the elliptical-bottom vessel were less stable. With the fin installed, the bubbles were unstable with quick gas release though the gas release never occurred at the fin. This is also similar to the kaolin results. The strongest kaolin had a $\mathrm{Y}_{\mathrm{G}}$ of 0.28 and bubble disruption at the fin. The strongest kaolin/Min-U-Sil 30 simulant had a $\mathrm{Y}_{\mathrm{G}}$ of 0.17 , which is equivalent to the $55 \mathrm{wt} \%$ kaolin.

Overall, testing in the elliptical bottom vessel shows that bubble release always happened in the vessel, either due to the bubble being unstable at lower strengths or the fin disrupting the bubble at higher strengths. With the fin installed, the longest period of bubble rise for both kaolin and kaolin/Min-U-Sil simulants was $39 \mathrm{~min}$ for the $55-\mathrm{wt} \%$ kaolin. This duration is just slightly above the stability criterion of 37 min which corresponds to a level rise of $\mathrm{H} / \mathrm{D}=0.15$. 
Table 4.4. Effect of Gravity Yield Parameter on the Stability of VSBs and Fin Performance in a 2:1 Elliptical-Bottom Vessel for Kaolin Clay Simulants

\begin{tabular}{|c|c|c|c|c|c|c|}
\hline \multirow[b]{2}{*}{$\mathrm{wt} \%$ Clay } & \multicolumn{6}{|c|}{ Kaolin Simulants } \\
\hline & $58 \mathrm{wt} \%$ & $55 \mathrm{wt} \%$ & $52 \mathrm{wt} \%$ & $50 \mathrm{wt} \%$ & $49 \mathrm{wt} \%$ & $48 \mathrm{wt} \%$ \\
\hline $\begin{array}{c}\text { Shear } \\
\text { Strength }\end{array}$ & $1090 \mathrm{~Pa}$ & $720 \mathrm{~Pa}$ & $400 \mathrm{~Pa}$ & $260 \mathrm{~Pa}$ & $230 \mathrm{~Pa}$ & $160 \mathrm{~Pa}$ \\
\hline $\mathrm{Y}_{\mathrm{G}}$ & 0.28 & 0.19 & 0.11 & 0.072 & 0.064 & 0.044 \\
\hline $\begin{array}{l}\text { Vessel } \\
\text { (Fin) }\end{array}$ & \multicolumn{6}{|c|}{ Stability Results and Gas Injection Duration ${ }^{(a)}$} \\
\hline $\begin{array}{c}\text { Flat Bottom } \\
\text { (none) }\end{array}$ & Stable & Stable & -- & Stable & $\begin{array}{c}\text { Stable Once } \\
\text { Unstable Once }\end{array}$ & $\begin{array}{c}\text { Unstable } \\
\text { Twice }\end{array}$ \\
\hline 2:1 Elliptical & Stable & $\begin{array}{l}\text { Stable } \\
\text { release at } \\
72 \mathrm{~min}\end{array}$ & Stable & $\begin{array}{l}\text { Unstable } \\
\text { twice }\end{array}$ & Unstable & \\
\hline (none) & $\begin{array}{l}\text { release at } \\
77 \mathrm{~min}\end{array}$ & $\begin{array}{l}\text { Unstable } \\
\text { release at } \\
35 \mathrm{~min}\end{array}$ & $\begin{array}{l}\text { release at } \\
52 \mathrm{~min}\end{array}$ & $\begin{array}{c}\text { release at } \\
23 \& 14 \mathrm{~min}\end{array}$ & $\begin{array}{l}\text { release at } \\
4 \mathrm{~min}\end{array}$ & -- \\
\hline $\begin{array}{l}\text { 2:1 Elliptical } \\
\text { (Straight- } \\
\text { Sided Fin } \\
5 \text { degree } \\
0.34 \text { inch) }\end{array}$ & $\begin{array}{l}\text { Disrupted at } \\
\text { fin } \\
19 \mathrm{~min}\end{array}$ & $\begin{array}{l}\text { Disrupted at fin } \\
28 \mathrm{~min} \\
\text { Unstable } \\
\text { release at } \\
39 \mathrm{~min}\end{array}$ & $\begin{array}{l}\text { Unstable } \\
\text { release at } \\
15 \mathrm{~min}\end{array}$ & $\begin{array}{l}\text { Unstable } \\
\text { release at } \\
9 \mathrm{~min}\end{array}$ & $\begin{array}{l}\text { Unstable } \\
\text { release at } \\
3 \mathrm{~min}\end{array}$ & -- \\
\hline
\end{tabular}

"-- " indicates not tested

(a) Duration of gas injection at the point when gas retained in a VSB was fully released. 
Table 4.5. Effect of Gravity Yield Parameter on the Stability of VSBs and Fin Performance in a 2:1 Elliptical-Bottom Vessel for Kaolin/Min-U-Sil 30 Simulants

\begin{tabular}{|c|c|c|c|c|}
\hline & \multicolumn{4}{|c|}{ Kaolin/Min-U-Sil Simulants } \\
\hline $\begin{array}{l}\text { Min-U-Sil } 30 \\
\text { (with } 40 \text { wt } \% \\
\text { Kaolin) }\end{array}$ & $23 \mathrm{wt} \%$ & $20.5 \mathrm{wt} \%$ & $19 \mathrm{wt} \%$ & $16 \mathrm{wt} \%$ \\
\hline $\begin{array}{l}\text { Shear } \\
\text { Strength }\end{array}$ & $680 \mathrm{~Pa}$ & $360 \mathrm{~Pa}$ & $290 \mathrm{~Pa}$ & $170 \mathrm{~Pa}$ \\
\hline $\mathrm{Y}_{\mathrm{G}}$ & 0.17 & 0.091 & 0.074 & 0.045 \\
\hline $\begin{array}{l}\text { Vessel } \\
\text { (Fin) }\end{array}$ & \multicolumn{4}{|c|}{ Stability Results and Gas Injection Duration ${ }^{(a)}$} \\
\hline $\begin{array}{l}\text { Flat Bottom } \\
\text { (none) }\end{array}$ & Assumed stable & $\begin{array}{l}\text { Stable to } \\
120 \mathrm{~min}\end{array}$ & $\begin{array}{l}\text { Stable to } \\
120 \mathrm{~min}\end{array}$ & $\begin{array}{l}\text { Unstable } \\
\text { release at } \\
9 \mathrm{~min}\end{array}$ \\
\hline $\begin{array}{l}\text { 2:1 Elliptical } \\
\quad \text { (none) }\end{array}$ & $\begin{array}{l}\text { Stable } \\
\text { release at } \\
83 \mathrm{~min}\end{array}$ & $\begin{array}{l}\text { Unstable } \\
\text { release at } \\
6 \mathrm{~min}\end{array}$ & $\begin{array}{l}\text { Unstable } \\
\text { release at } \\
8 \mathrm{~min}\end{array}$ & $\begin{array}{l}\text { Unstable } \\
\text { release at } \\
4 \mathrm{~min}\end{array}$ \\
\hline $\begin{array}{c}\text { 2:1 Elliptical } \\
\text { (Straight- } \\
\text { Sided Fin } \\
5 \text { degree } \\
0.34 \text { inch) }\end{array}$ & $\begin{array}{l}\text { Unstable } \\
\text { release at } \\
8 \mathrm{~min} \\
\text { (not at fin) }\end{array}$ & $\begin{array}{l}\text { Unstable } \\
\text { release at } \\
22 \mathrm{~min} \\
\text { (not at fin) }\end{array}$ & $\begin{array}{l}\text { Unstable } \\
\text { release at } \\
8 \mathrm{~min} \\
\text { (not at fin) }\end{array}$ & $\begin{array}{l}\text { Unstable } \\
\text { release at } \\
2 \text { min } \\
\text { (not at fin) }\end{array}$ \\
\hline
\end{tabular}

\subsection{Effect of Kaolin Layer Depth on Fin Performance}

Section 2 presented a model (see Figure 2.3) of the expected overall behavior and scaling for the stability of VSBs and sludge slumping that affects fin performance. Experiments were conducted in the flat-bottom vessel to evaluate this model in combination with results discussed previously in this section. Experiments were conducted spanning a range of simulant strength (and thus $\mathrm{Y}_{\mathrm{G}}$ ) and a range of thickness for the clay layers (H/D). The 5-degree, 0.34-in. fin was used in these tests. Figure 4.6 shows the experimental results with the bubble stability curve determined from the no-fin tests shown in Figure 4.2 and the slumping criterion that fit the observed data. In Figure 4.6, unstable bubbles are shown with open symbols, stable VSBs are depicted by closed symbols, and conditions where the fin caused bubble disruption within $37 \mathrm{~min}$ (corresponding to a level rise of $\mathrm{H} / \mathrm{D}=0.15$ ) are indicated by the crosses. The individual test results are also tabulated in Appendix C.

This map of bubble stability and fin performance clearly shows the three regions of behavior. For sufficiently strong simulants (high $\mathrm{Y}_{\mathrm{G}}$ and Region 2), the fins always disrupt potentially stable bubbles. For Region 3, stable VSBs were observed with the fin present. In this region, the $\mathrm{Y}_{\mathrm{G}}$ is high enough to 
have stable VSBs but still sufficiency low for slumping along the fin to make the fin ineffective. Although these results are for a single simulant material and vessel size, they do support the general behavior in the three regions.

It is expected that the actual sludges and simulants that are different from kaolin clay, which may have different particle size distributions and different particle-particle interactions (such as less cohesive particles that stick less to each other) will have different slumping behavior. Specifically, it is likely that the channel slumping line given in Figure 4.6 will shift to the left for materials that are more non-cohesive than the kaolin clay being tested. Accordingly, the size of Region 3 where fins are not effective may be smaller, and fins may be a more robust method of disrupting VSBs. In the following sections, the slumping behavior of different simulants is shown followed by testing of fin performance to compare with the kaolin results.

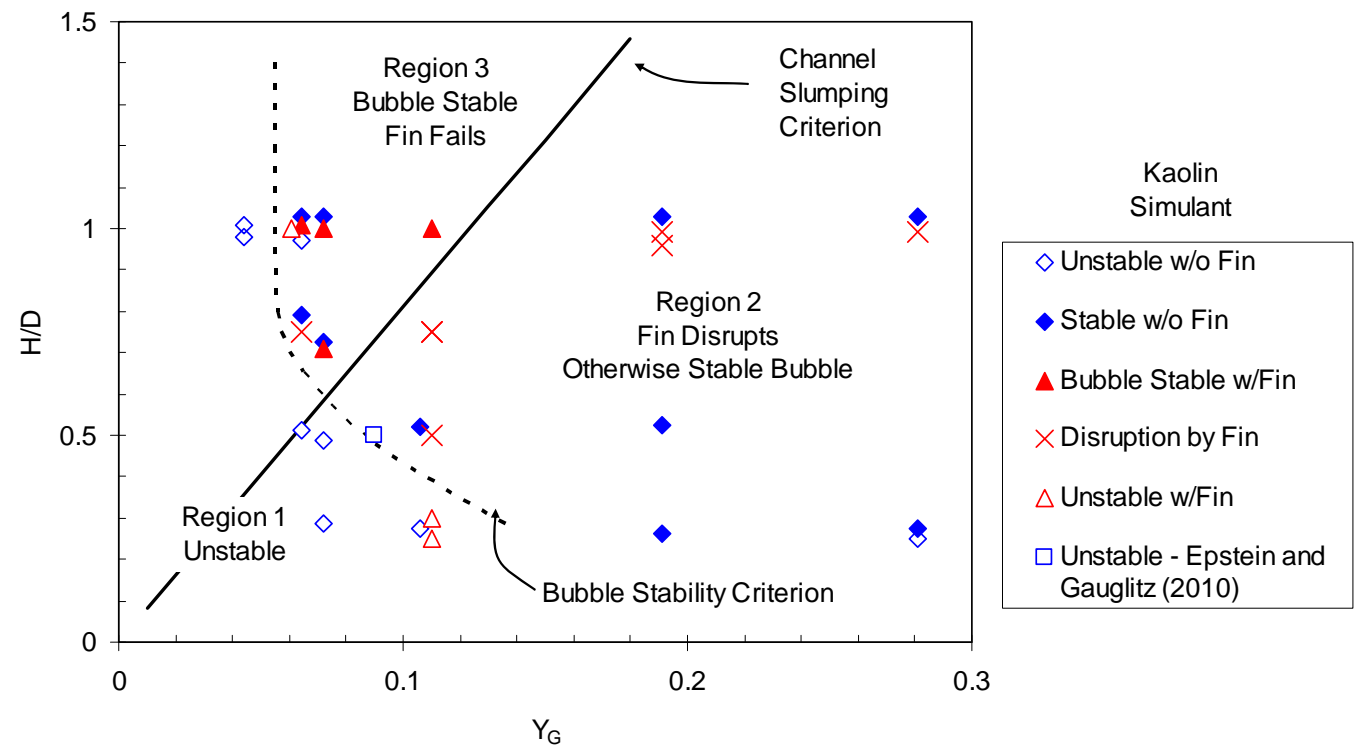

Figure 4.6. Comparison of Experimental Results in the Flat-Bottom Vessel with the Three Regions of Behavior for VSB Stability and Fin Performance $\left(5^{\circ}, 0.34\right.$-in. Fin)

\subsection{Comparison of Slumping Behavior for Kaolin Clay, Kaolin Clay/Min-U-Sil 30, and K-Basin (KW-A) Simulants}

Two slumping tests (50-cent rheometer and channel slumping) were conducted for the kaolin clay, kaolin clay/Min-U-Sil 30, and KW-A simulants. The purpose of these tests was to show that 1) a significantly different slumping behavior that originated from the degree of cohesiveness of simulant exists for different simulants, even with very similar shear strength and 2) kaolin/Min-U-Sil 30 mixtures mimic the behavior of KW-A simulant, which provides a technical basis to use kaolin/Min-U-Sil 30 mixtures in the large-scale tests.

The targeted range of shear strength was 150 to 800 Pa for all tested simulants. Six kaolin clays, eight kaolin clay/Min-U-Sil 30 mixtures, and four KW-A simulants were used to span the targeted range of shear strength. Characteristics of simulants used in the tests are shown in Table 3.1, Table 3.3, and 
Table 3.5, respectively. To present the slumping behavior accurately, we use a new combined parameter $\mathrm{H}^{*}$ defined by $\tau_{\mathrm{s}} /\left(\rho_{\mathrm{s}} \mathrm{g}\right)$ where $\tau_{\mathrm{s}}$ is the measured shear strength of the simulant, $\rho_{\mathrm{s}}$ is the bulk density of the simulant, and $\mathrm{g}$ is gravitational acceleration. A main rationale to use $\mathrm{H}^{*}$ rather than shear strength is to incorporate the bulk density of the simulant to understand the slumping behavior correctly because a different bulk density will drive a different slumping behavior at the same shear strength. Thus, the comparison of slumping behavior as a function of $\mathrm{H}^{*}$ will show a clear difference only from degree of cohesiveness of simulant. Furthermore, $\mathrm{H}^{*}$ provides a useful length scale where strength and gravitational force of material are in balance so that it may be possible to present a different slumping nature of simulant via a dimensionless number, which is the slumping length (either slumping height or open channel depth) normalized by $\mathrm{H}^{*}$. It is worth noting that the sleeve height/diameter can be used to normalize both the slumping height and $\mathrm{H}^{*}$ for the 50-cent rheometer test (e.g., Pashias et al. 1996), but there is no appropriate length scale to normalize the open channel depth and $\mathrm{H}^{*}$ for the channel slumping test. We, therefore, compared both slumping behaviors as a function of $\mathrm{H}^{*}$ (i.e., as dimensional forms) for a uniform presentation of both slumping behaviors.

Table 4.6 summarizes the values of shear strength, $\mathrm{H}^{*}$, and the slumping height (from 50-cent rheometer) for three different simulants tested. Values in Table 3.1, Table 3.3, and Table 3.5 are used to calculate $\mathrm{H}^{*}$ from the shear strength and bulk density of the simulants, and the slumping heights were measured following the procedure described in Section 3.2.1.

Table 4.6. Slumping Heights (50-cent Rheometer) as a Function of $\mathrm{H}^{*}$ for Comparison

\begin{tabular}{|c|c|c|c|c|c|c|c|c|}
\hline \multicolumn{3}{|c|}{ Kaolin } & \multicolumn{3}{|c|}{ Kaolin/Min-U-Sil 30} & \multicolumn{3}{|c|}{ KW-A } \\
\hline $\begin{array}{c}\text { Shear } \\
\text { Strength } \\
\text { Average } \\
(1 \mathrm{hr}, \mathrm{Pa})\end{array}$ & $\begin{array}{l}\mathrm{H}^{*} \\
(\mathrm{~cm})\end{array}$ & $\begin{array}{c}\text { Slumping } \\
\text { Height } \\
(\mathrm{cm})\end{array}$ & $\begin{array}{c}\text { Shear } \\
\text { Strength } \\
\text { Average } \\
(1 \mathrm{hr}, \mathrm{Pa})\end{array}$ & $\begin{array}{c}\mathrm{H}^{*} \\
(\mathrm{~cm})\end{array}$ & $\begin{array}{c}\text { Slumping } \\
\text { Height } \\
(\mathrm{cm})\end{array}$ & $\begin{array}{c}\text { Shear } \\
\text { Strength } \\
\text { Average } \\
(1 \mathrm{hr}, \mathrm{Pa})\end{array}$ & $\begin{array}{c}\mathrm{H}^{*} \\
(\mathrm{~cm})\end{array}$ & $\begin{array}{c}\text { Slumping } \\
\text { Height } \\
(\mathrm{cm})\end{array}$ \\
\hline 157 & 1.13 & 6.0 & 156 & 1.00 & 4.3 & 178 & 0.86 & 3.4 \\
\hline 229 & 1.63 & 4.3 & 238 & 1.49 & 3.2 & 257 & 1.21 & 2.4 \\
\hline 259 & 1.82 & 3.1 & 420 & 2.56 & 1.5 & 557 & 2.58 & 1.4 \\
\hline 405 & 2.80 & 2.4 & 806 & 4.75 & 0.6 & 824 & 3.70 & 0.6 \\
\hline 723 & 4.86 & 0.9 & 166 & 1.13 & 4.0 & & & \\
\hline 1090 & 7.14 & 0.0 & 310 & 2.04 & 2.2 & & & \\
\hline & & & 469 & 3.00 & 1.1 & & & \\
\hline & & & 891 & 5.48 & 0.3 & & & \\
\hline
\end{tabular}


Kaolin/Min-U-Sil $30 \bullet$ Kaolin $\diamond \mathrm{KW}$-A

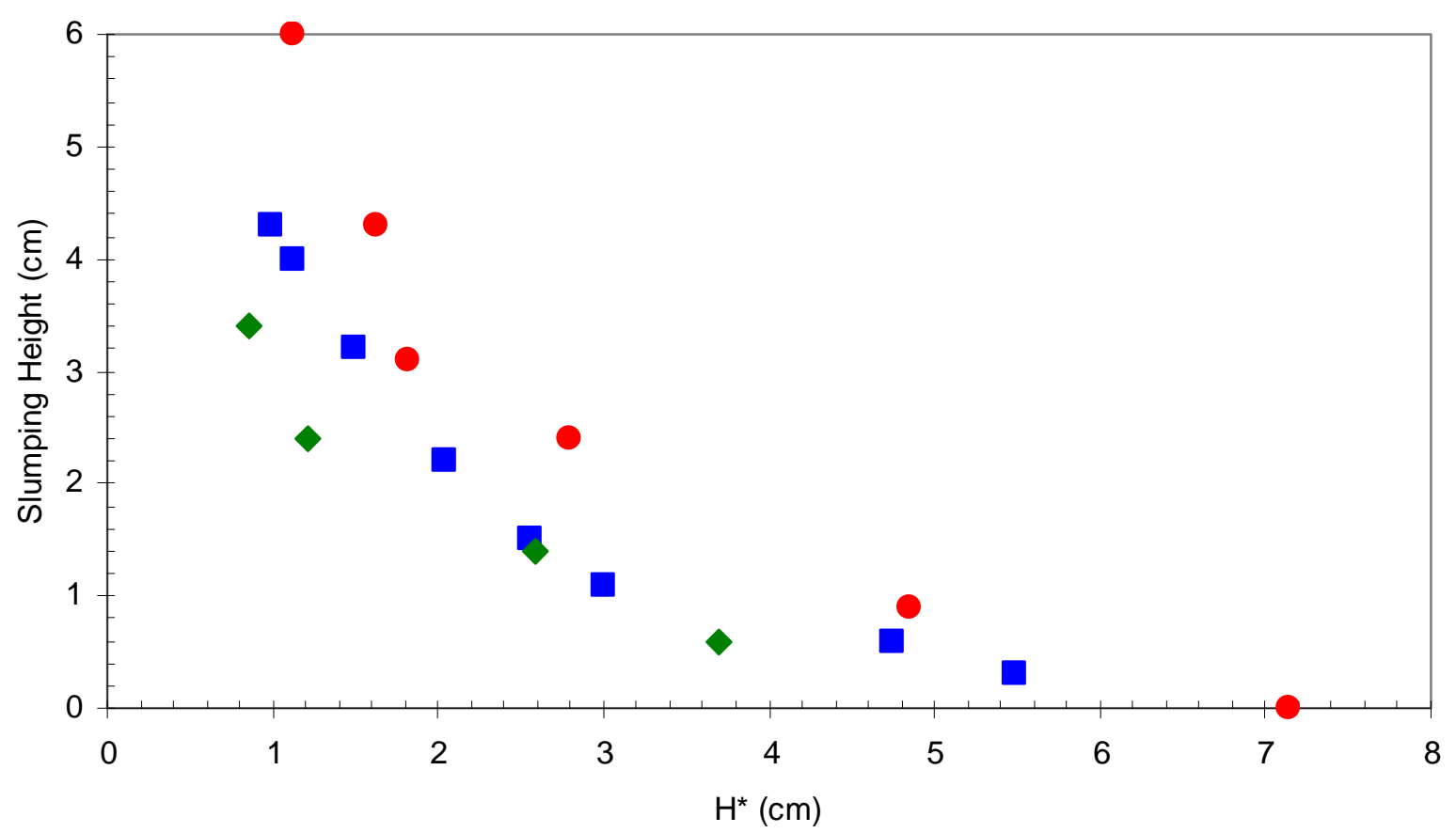

Figure 4.7. Comparison of Slumping Behavior (50-cent Rheometer)

Figure 4.7 shows the 50-cent rheometer results for three different simulants. Here, the slumping height is the distance that the top of an open cylinder falls under its own weight, and larger values thus correspond to greater slumping. Generally, the slumping height increases as the $\mathrm{H}^{*}$ decreases (shear strength decreases and/or bulk density increases), and the addition of Min-U-Sil 30 reduces the slumping in comparison to kaolin only at the same $\mathrm{H}^{*}$ (i.e., becoming non-cohesive). Figure 4.7 clearly indicates that slumping behavior at the same $\mathrm{H}^{*}$ value is significantly different, especially at a smaller $\mathrm{H}^{*}$, depending on the simulant used. More importantly, at the same $\mathrm{H}^{*}, \mathrm{KW}-\mathrm{A}$ simulant and kaolin clay show the least and the most slumping behaviors, respectively. In comparison to the kaolin clay, the KW-A results are more similar to the kaolin/Min-U-Sil 30 simulants, which strongly suggests that kaolin/Min-USil 30 is a more reasonable match for the KW-A slumping behavior.

Additional insight on slumping behavior can be obtained from channel slumping tests. In contrast to the 50-cent rheometer test, the larger open channel depth corresponds to less slumping because the slumping will fill the open channel in this case. Table 4.7 summarizes the values of shear strength, $\mathrm{H}^{*}$ and the open channel depth for two simulants: kaolin clay, and kaolin/Min-U-Sil 30. Note that no data can be obtained for KW-A. The coarse granules, such as aggregates and sands of KW-A simulant, prohibit creating a complete and clear open channel at the beginning so that the open channel depth was illegible. Similar to the 50-cent rheometer slumping test, values shown in Table 3.1, Table 3.3, and Table 3.5 are used to calculate $\mathrm{H}^{*}$ from shear strength and bulk density of the simulants, and the open channel depths were measured following the procedure described in Section 3.2.2. 
Table 4.7. Open Channel Depths (Channel Slumping) as a Function of $\mathrm{H}^{*}$ for Comparison

\begin{tabular}{|c|c|c|c|c|c|}
\hline \multicolumn{3}{|c|}{ Kaolin } & \multicolumn{3}{|c|}{ Kaolin/Min-U-Sil 30} \\
\hline Shear & & Open & Shear & & Open \\
\hline Strength & & Channel & Strength & & Channel \\
\hline $\begin{array}{l}\text { Average } \\
(1 \mathrm{hr}, \mathrm{Pa})\end{array}$ & $\begin{array}{l}\mathrm{H}^{*} \\
(\mathrm{~cm})\end{array}$ & $\begin{array}{l}\text { Depth } \\
(\mathrm{cm})\end{array}$ & $\begin{array}{l}\text { Average } \\
(1 \mathrm{hr}, \mathrm{Pa})\end{array}$ & $\begin{array}{l}\mathrm{H}^{*} \\
(\mathrm{~cm})\end{array}$ & $\begin{array}{l}\text { Depth } \\
(\mathrm{cm})\end{array}$ \\
\hline 157 & 1.13 & 2.2 & 156 & 1.00 & 3.5 \\
\hline 229 & 1.63 & 3.5 & 238 & 1.49 & 4.6 \\
\hline 259 & 1.82 & 4.7 & 420 & 2.56 & 9.5 \\
\hline 405 & 2.80 & 6.0 & 806 & 4.75 & 21.2 \\
\hline 723 & 4.86 & 12.0 & 166 & 1.13 & 4.1 \\
\hline 1093 & 7.14 & 19.0 & 310 & 2.04 & 6.2 \\
\hline & & & 469 & 3.00 & 11.7 \\
\hline & & & 891 & 5.48 & 24.4 \\
\hline
\end{tabular}

Figure 4.8 shows the channel slumping test results for kaolin clay and the kaolin/Min-U-Sil 30 mixture. It is shown that the open channel depth increases as $\mathrm{H}^{*}$ increases (shear strength increases and/or bulk density decreases). Figure 4.8 clearly indicates that the slumping behavior of two simulants at the same $\mathrm{H}^{*}$ value is significantly different, especially at a larger $\mathrm{H}^{*}$. Like the 50 -cent rheometer tests, adding Min-U-Sil 30 is shown to reduce the slumping (i.e., increases the open channel depth) in comparison to kaolin only at the same $\mathrm{H}^{*}$.

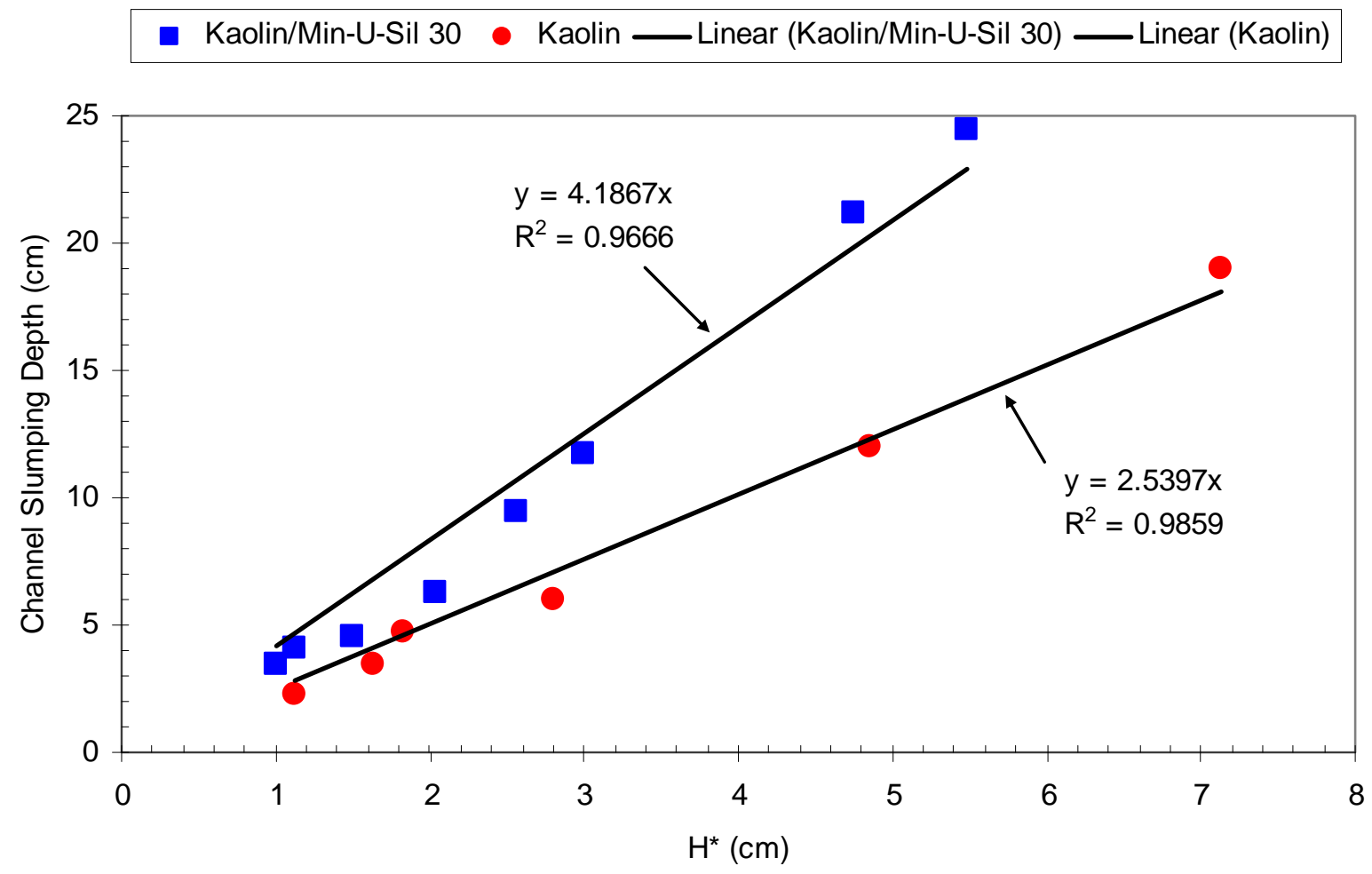

Figure 4.8. Comparison of Slumping Behavior (Channel Slumping) 
A possible advantage of the channel slumping test is that one may use a dimensionless number $\left(\mathrm{N}_{\mathrm{S}}\right)$, an open channel depth normalized by $\mathrm{H}^{*}$, to characterize the slumping behavior of a simulant. The slumping height in the 50-cent rheometer test can be approximately represented by a quadratic function of $\mathrm{H}^{*}, \mathrm{a}+\mathrm{bH}^{*}+\mathrm{c}\left(\mathrm{H}^{*}\right)^{2}$, according to Pashias et al. (1996), where $\mathrm{a}, \mathrm{b}$, and $\mathrm{c}$ are undetermined constants. Thus, it is difficult to characterize the slumping behavior of a simulant via a relation between the slumping height and $\mathrm{H}^{*}$. However, the open channel depth appears to be linearly proportional to $\mathrm{H}^{*}$ over a wide range of $\mathrm{H}^{*}$ values shown in Figure 4.8. The two linear fitting equations shown in Figure 4.8 provide simple relations between an open channel depth and $\mathrm{H}^{*}$, based on the assumption that no open channel depth exists at $\mathrm{H}^{*}=0$. The fitting equations imply that $\mathrm{N}_{\mathrm{S}} \sim 4.2$ for kaolin/Min-U-Sil 30 and $\mathrm{N}_{\mathrm{S}} \sim 2.5$ for kaolin clay from their slopes. Thus, $\mathrm{N}_{\mathrm{S}}$ can be used as a reasonable measure to evaluate the slumping behavior; the larger $\mathrm{N}_{\mathrm{S}}$ indicates less slumping for the same shear strength as measured by a shear vane (and is less cohesive). Although no channel slumping test data are available for the KW-A, $\mathrm{N}_{\mathrm{S}}$ for the $\mathrm{KW}-\mathrm{A}$ is expected to be larger than 4.2 based on the results from the 50 -cent rheometer tests.

\subsection{Fin Performance and Vessel-Spanning Bubble Stability with KW Container Sludge Simulant (Complete) and other More Non- Cohesive Simulants}

Tests were conducted with KW container sludge simulant (complete), which is also referred to as KW-A, and kaolin/Min-U-Sil 30 simulants. These simulants represent materials that behave differently from kaolin in slumping tests (they slump less as shown in Figure 4.7 and Figure 4.8) and are being investigated to determine if the fin performance is also affected by the different slumping behavior. The KW container sludge simulant (complete) is thought to be the most representative simulant for the actual K-Basin material that will be contained in the STSCs. Both of these simulants are more non-cohesive in comparison to kaolin clay where some of the shear strength is due to frictional interactions between the particles.

VSB and fin performance tests were conducted with the KW container sludge simulant (complete) mixed at three solids fractions of $75,76.5$, and $78 \mathrm{wt} \%$ to span the needed range of $\mathrm{Y}_{\mathrm{G}}$. These are the first VSB tests conducted with this simulant. The overall behavior of the KW container sludge simulant (complete) was similar to the kaolin test results, with the exception that the fin performance was better. Figure 4.9 shows an example of stable VSB lifting the $76.5 \mathrm{wt} \% \mathrm{KW}$ container sludge simulant (complete) until the test was stopped at $120 \mathrm{~min}$. This behavior is equivalent to the kaolin behavior shown in Figure 4.1. Table 4.8 shows results for all the KW container sludge simulant (complete) (KWA) tests with and without fins together with the simulant properties and $Y_{G}$ values for each test. For these tests, the fin was a 5-degree, straight-sided fin with a width of 0.34 inches (scaled version of a 2 -in. wide full-scale fine). For the tests without fins, the VSB was unstable at the lowest $\mathrm{Y}_{\mathrm{G}}$ and became stable at a $\mathrm{Y}_{\mathrm{G}}$ of 0.074 where the bubble rose until the test was stopped at 120 minutes. At the higher $\mathrm{Y}_{\mathrm{G}}$ of 0.24 , gas release occurred after 61 minutes when a thin bubble formed a gap between the simulant and the vessel wall and expanded upward to allow gas to release. For the fin tests with the two higher values of $\mathrm{Y}_{\mathrm{G}}$ where stable VSBs are likely, gas release occurred at the fin after about $10 \mathrm{~min}$ of gas injection so these bubbles were disrupted.

Overall, the testing results with KW container sludge simulant (complete) shows very effective fin performance for all conditions when stable VSBs are possible. In comparison, kaolin tests showed a significant range of $\mathrm{Y}_{\mathrm{G}}$ and $\mathrm{H} / \mathrm{D}$ values where fins did not disrupt the bubbles. The slumping tests shown 
in Figure 4.7 and Figure 4.8 show that KW container sludge simulant (complete) slumps less than the kaolin simulants, so this is a likely explanation why the fins disrupt bubbles in this simulant more effectively. The KW container sludge simulant is probably the most representative simulant for the actual K-basin material that will be contained in the STSCs, so these tests results suggest that a fin will disrupt a VSB in the a actual STSC if it forms.
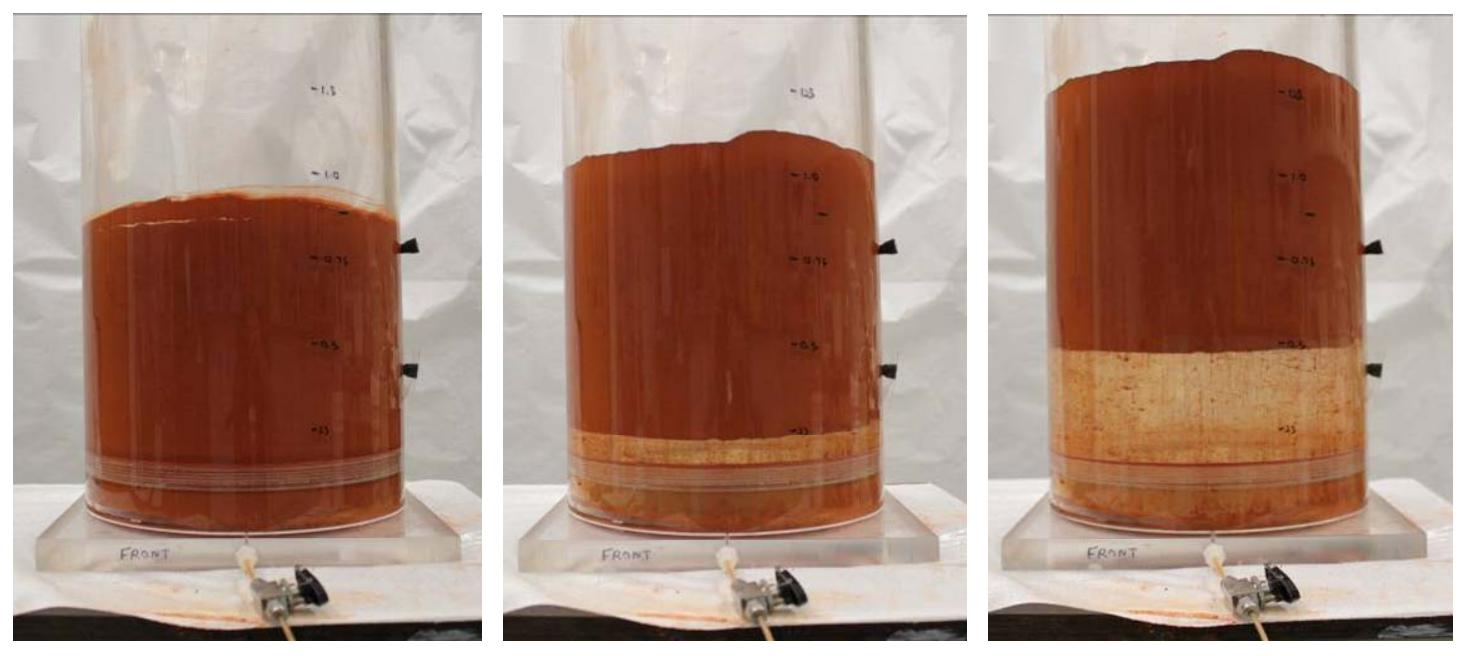

Figure 4.9. Stable VSB with $76.5 \mathrm{wt} \% \mathrm{~K}$ West Container Simulant (KW-A) Shown at the Beginning of the Test and After $60 \mathrm{~min}$ and $125 \mathrm{~min}$. The simulant has a representative shear strength of about $410 \mathrm{~Pa}\left(\mathrm{Y}_{\mathrm{G}}=0.074\right)$.

Table 4.8. Effect of Gravity Yield Parameter on the Stability of VSBs and Fin Performance with KW Container Sludge Simulant (Complete) (KW-A) in a 10-in., Flat-Bottom Vessel

\begin{tabular}{|c|c|c|c|}
\hline \multirow[b]{2}{*}{$\begin{array}{c}\mathrm{wt} \% \\
\mathrm{KW}-\mathrm{A}\end{array}$} & \multicolumn{3}{|c|}{ Simulants } \\
\hline & $78 \mathrm{wt} \%$ & $76.5 \mathrm{wt} \%$ & $75 \mathrm{wt} \%$ \\
\hline Shear Strength $^{(b)}$ & $1350 \mathrm{~Pa}$ & $410 \mathrm{~Pa}$ & $220 \mathrm{~Pa}$ \\
\hline $\mathrm{Y}_{\mathrm{G}}$ & 0.24 & 0.074 & 0.041 \\
\hline Vessel (Fin) & \multicolumn{3}{|c|}{ Stability Results and Gas Injection Duration ${ }^{(a)}$} \\
\hline $\begin{array}{l}\text { Flat Bottom } \\
\text { (none) }\end{array}$ & $\begin{array}{l}\text { Stable release at } \\
61 \mathrm{~min}\end{array}$ & $\begin{array}{l}\text { stable through } \\
120 \mathrm{~min}\end{array}$ & $\begin{array}{l}\text { Unstable release at } \\
1 \mathrm{~min}\end{array}$ \\
\hline $\begin{array}{l}\text { Flat Bottom (Straight-Sided Fin } \\
5 \text { degree, } 0.34 \text { inch) }\end{array}$ & $\begin{array}{l}\text { disrupted by fin } \\
7 \mathrm{~min}\end{array}$ & $\begin{array}{l}\text { disrupted by fin } \\
9 \text { min \& } 10 \text { min }\end{array}$ & $\begin{array}{c}\text { Unstable release at } \\
1 \mathrm{~min} \\
\text { (not at fin) }\end{array}$ \\
\hline
\end{tabular}

(a) Duration of gas injection at the point when gas retained in a VSB was fully released.

(b) Shear strength from representative values given in Figure 3.5

The second simulant tested for fin performance with different slumping behavior was kaolin/Min-USil 30 mixtures. This simulant slumped less than kaolin but more than the KW container sludge simulant (complete) as shown in Figure 4.7 and Figure 4.8. Figure 4.10 summarizes the results for the stability of VSBs and fin performance, and a summary of each experiment is provided in Appendix C. The bubble stability and channel slumping criteria are the same as used for the kaolin result in Figure 4.6. Overall, 
the kaolin/Min-U-Sil simulant shows equivalent behavior to kaolin, with a region where VSBs are stable with a fin. The data point at $Y_{G}=0.07$ and $H / D=1$, that is shown as disruption by the fin, appears to be inconsistent with the kaolin results, but this specific test had release at the fin at just under $20 \mathrm{~min}$. All of the fin performance data are plotted using the criterion of anything with fin release faster than 20 min of gas injection is disruption.

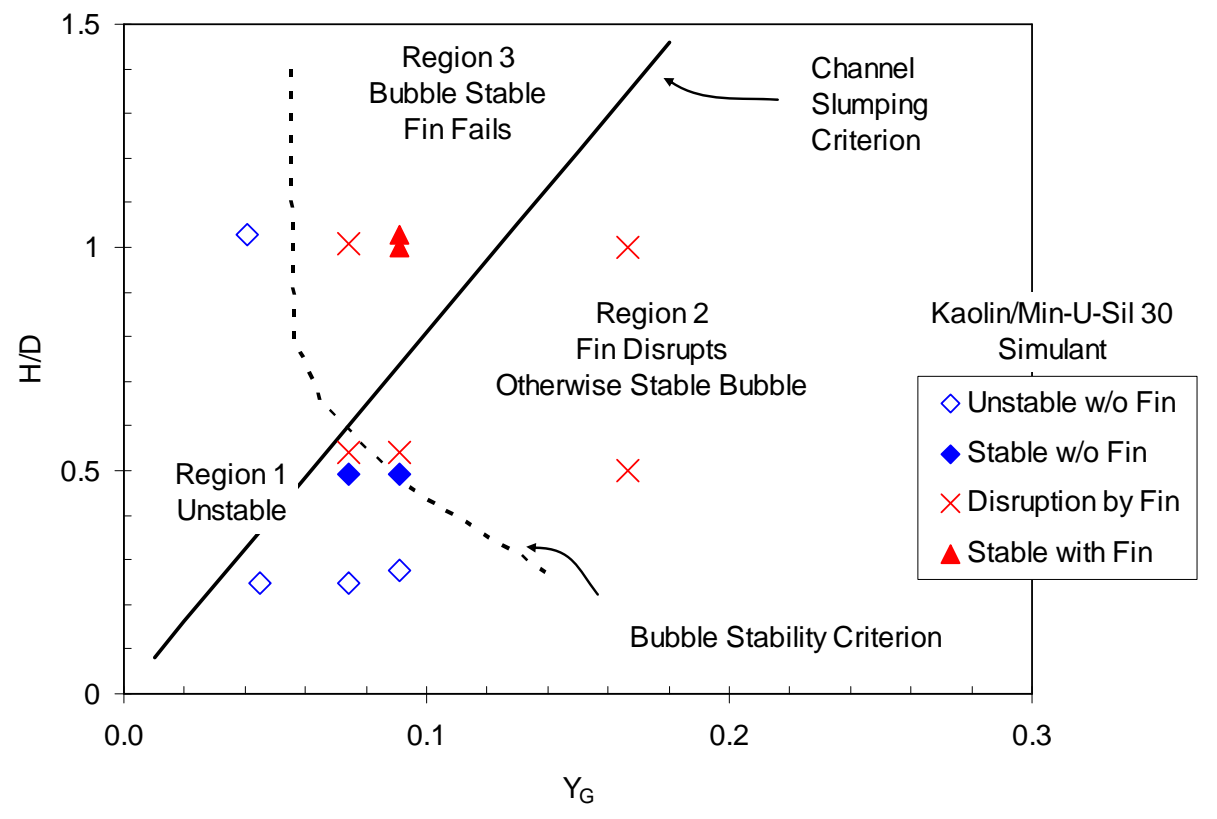

Figure 4.10. Fin Performance and VSB Stability for Kaolin/Min-U-Sil 30 Simulants Spanning a Range of Gravity Yield Parameter $\left(\mathrm{Y}_{\mathrm{G}}\right)$ and Layer Thickness (H/D) in the 10-in. Vessel. A scaled version of a 5-degree, 2-in. wide fin was used. The bubble stability and channel slumping criteria are the same as used for the kaolin result in Figure 4.6.

\subsection{Large-Scale Fin Performance and Scale-up Behavior}

Experiments were conducted in 23-in. and 5-in. diameter vessels to determine the scale-up behavior of fin performance and the stability of VSBs. In general, tests conducted in the larger vessels should be more accurate for estimating actual full-scale behavior, so the best data for judging full-scale behavior will be from the 23 -in. vessel. The scale-up behavior, or equivalently any trend due to vessel size that shows shifting in the location of the three regions, can be gleaned from equivalent tests done in a series of different size vessels. Combining any scale-up trend with vessel size (such as larger or smaller Region 3) with the behavior in the 23 -in. vessel provides an even better estimate of full-scale behavior. In conducting scale-up testing, one or more dimensionless groups will show how the behavior scales with the experimental parameters. For VSBs and slumping, as discussed in Section 2, the behavior should be scaled by the gravity yield parameter $\left(\mathrm{Y}_{\mathrm{G}}\right)$ and the dimensionless layer thickness $(\mathrm{H} / \mathrm{D})$. In this study, tests were conducted in 5-, 10-, and 23-in. vessels over the same range of $\mathrm{Y}_{\mathrm{G}}$ and $\mathrm{H} / \mathrm{D}$ and the test results for the 23-in. and 5-in. vessels are presented in this section.

Figure 4.11 shows the bubble stability and fin performance results for kaolin clay simulants in the 23-in. vessel, and Appendix C provides a summary of each test. The bubble stability and channel 
slumping criteria are different from what has been used previously. For tests without a fin, the transition between stable and unstable bubbles occurs at a $Y_{G}$ of about 0.04 for an $H / D=1$, which is lower than the 10 -in.-vessel results given in Figure 4.6. This assumes that the bubble that was stable at an $\mathrm{H} / \mathrm{D}=0.5$ and $\mathrm{Y}_{\mathrm{G}}=0.04$ would also be stable at an $\mathrm{H} / \mathrm{D}=1$. The most significant differences are the fin performance results and then the location of the slumping criteria. The results for fin performance show bubble disruption by the fin for all of the tests conducted with the exception of the one fin test identified as "unstable w/fin" where gas was released after 3 minutes but at a location away from the fin. To fit with these fin performance results, the bubble stability criterion needs to shift to lower $Y_{G}$ values as shown in Figure 4.11. With the data collected, the bubble stability curve could possibly be shifted to even lower $\mathrm{Y}_{\mathrm{G}}$ values than drawn, but the current placement is the most conservative based on the data. Figure 4.12 shows a similar suite of bubble stability and fin performance test results for kaolin/Min-U-Sil 30 simulants. The specific test conditions and results are tabulated in Appendix C. Fewer test conditions were studied with the kaolin/Min-U-Sil 30 simulants, but the same general behavior was observed, including the result that the fins disrupted the bubbles for all of the tests conducted.

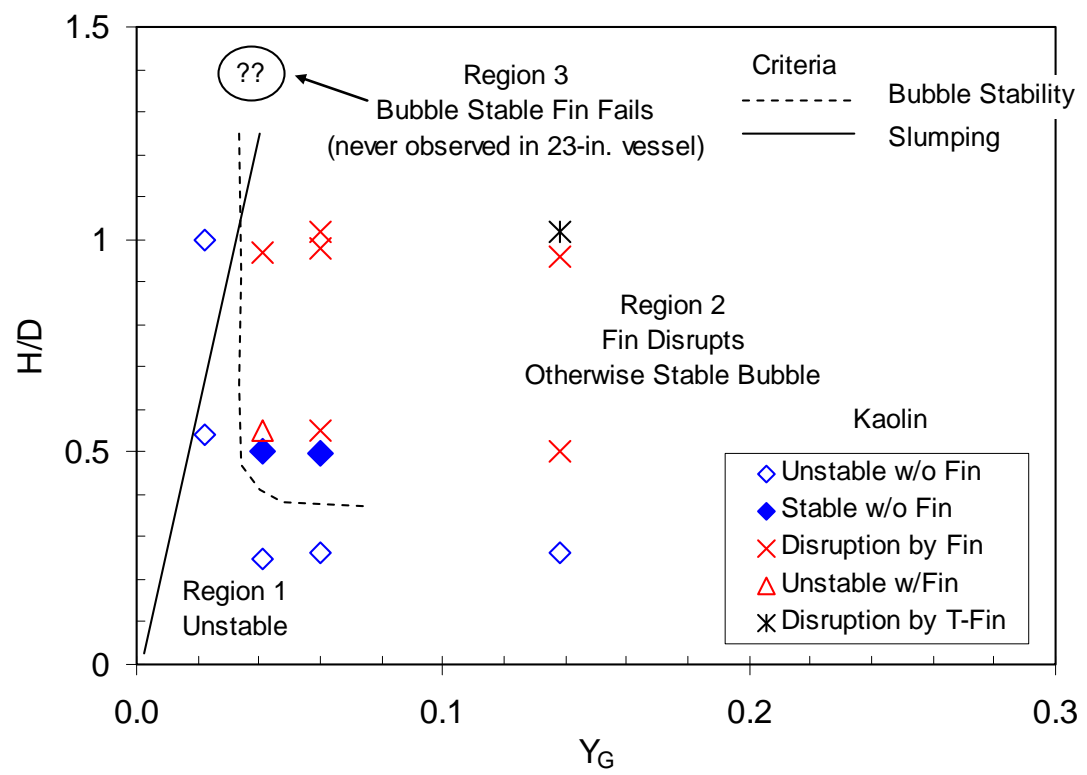

Figure 4.11. Fin Performance and VSB Stability for Kaolin Simulants Spanning a Range of Gravity Yield Parameter $\left(\mathrm{Y}_{\mathrm{G}}\right)$ and Layer Thickness $(\mathrm{H} / \mathrm{D})$ in the 23-in. Vessel. A scaled version of a 5-degree, 2-in. wide fin was used in all experiments except the single test with a 5-degree T-fin. 


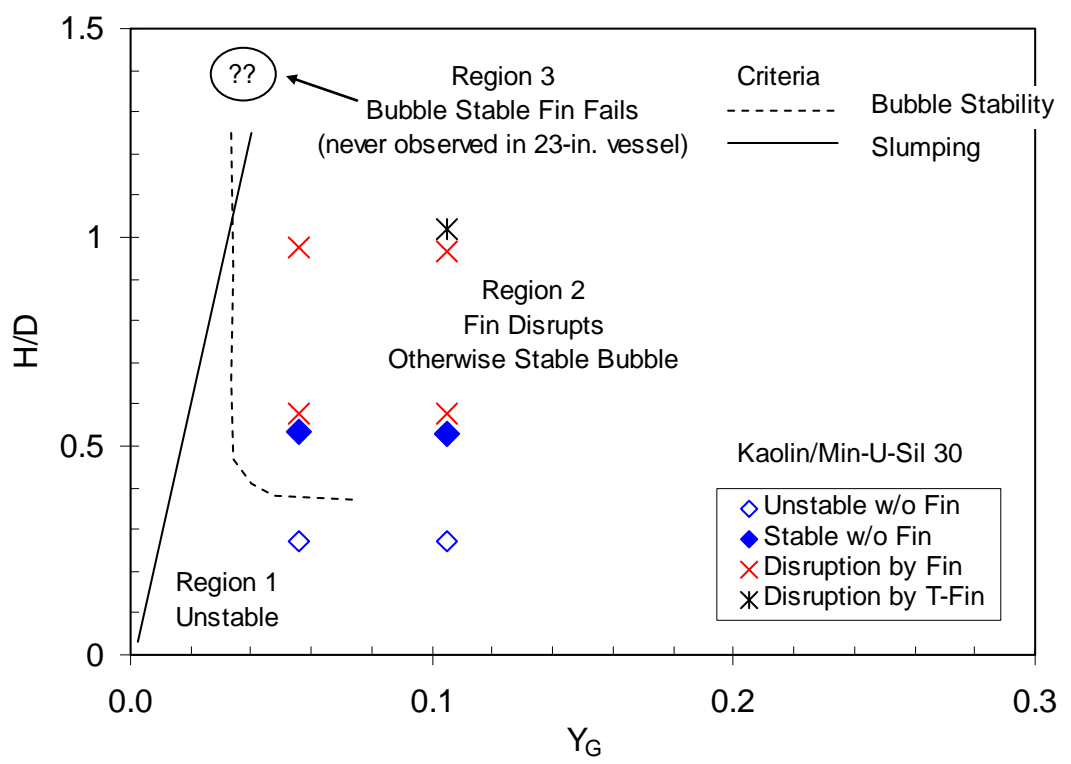

Figure 4.12. Fin Performance and VSB Stability for Kaolin/Min-U-Sil 30 Simulants Spanning a Range of Gravity Yield Parameter $\left(\mathrm{Y}_{\mathrm{G}}\right)$ and Layer Thickness $(\mathrm{H} / \mathrm{D})$ in the 23-in. Vessel. A scaled version of a 5-degree, 2-in. wide fin was used in all experiments except the single test with a 5-degree T-fin.

The results for the kaolin and kaolin/Min-U-Sil 30 simulants are similar, so determining the three regions of behavior can also be done with all of the data. Figure 4.13 shows all of the data collected for bubble stability and fin performance and also shows three regions of behavior based on these data. As discussed for each of the simulants individually, the most significant finding from these large-scale tests is that there is no region of gravity yield parameter $\left(\mathrm{Y}_{\mathrm{G}}\right)$ and layer thickness $(\mathrm{H} / \mathrm{D})$ where the fin fails to disrupt vessel-spanning bubbles. Of the 13 tests with potentially stable bubbles, the fin disrupted the bubble in every test with exception of one test where gas was released away from the fin. For these 13 tests, gas was released within 4 minutes in 12 of these tests, and one test took 6 minutes. For this duration of gas injection, there was only a negligible rise $(\sim 1 / 2$ inch) in the clay layer.

Figure 4.13 also shows the two test results, one with kaolin and one with kaolin/Min-U-Sil 30, using the 5-degree T-Fin. For this test, the fin disrupted the bubble after 2 minutes of gas injection for both tests. In these two T-Fin tests and the five T-Fin tests conducted in the 10-in vessel, the T-Fin disrupted the same or faster than the straight-sided fin. While comparatively fewer tests were conducted with a TFin in comparison to the straight-sided fin, the T-Fin appears to disrupt VSBs just as effectively. The Tfin has the advantage of being lighter. 


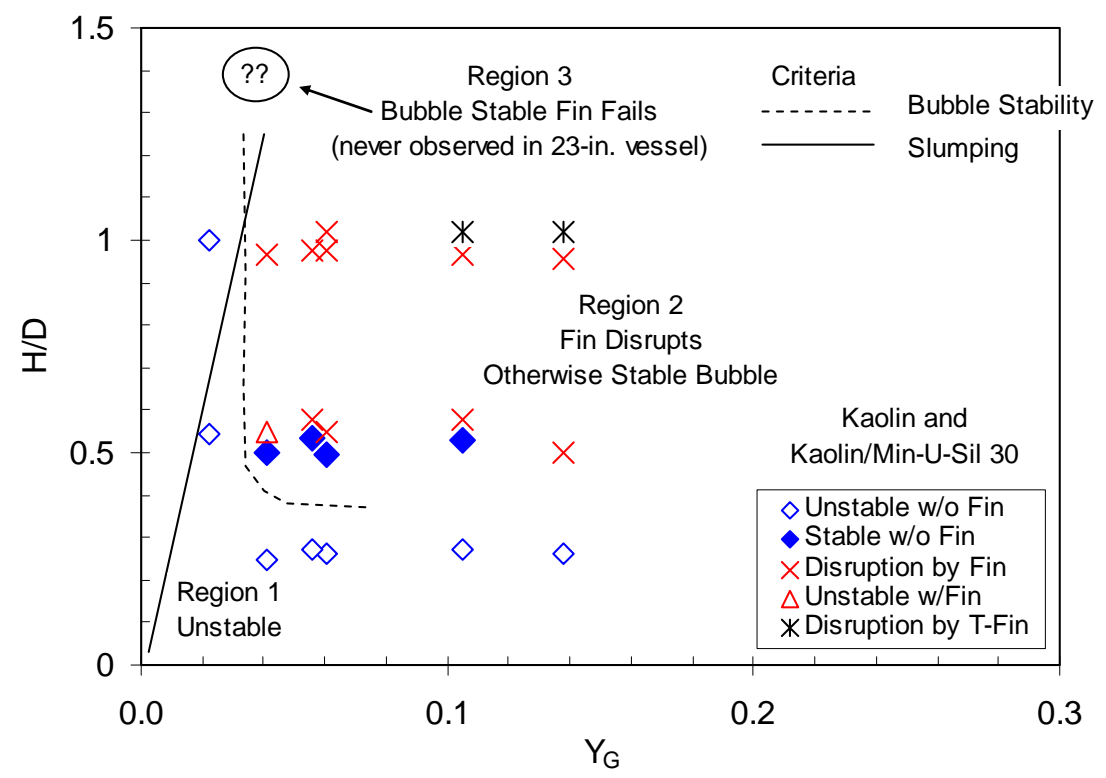

Figure 4.13. Fin Performance and VSB Stability for a Combination of Kaolin and Kaolin/Min-U-Sil 30 Simulants Spanning a Range of Gravity Yield Parameter $\left(\mathrm{Y}_{\mathrm{G}}\right)$ and Layer Thickness $(\mathrm{H} / \mathrm{D})$ in the 23-in. Vessel. A scaled version of a 5-degree, 2-in wide fin was used in all experiments except the single test with a 5-Degree T-fin.

To better define the effect of vessel size on the stability of VSBs and fin performance, tests were also conducted in a 5-in. test vessel with and without a 5-degree fin that was equivalent to the 5-degree fin tested in the 10-in. and 23-in. vessels. Figure 4.14 shows the results of these tests and the three regions of behavior are clearly apparent in the test results. The most significant finding from these tests is that the range of $Y_{G}$ values with Region 3 behavior is larger than in the 10-in. and 23-in vessels. For comparison with the 5-in. and 23-in. vessel results, Figure 4.15 shows a combination of all of the data collected with kaolin and kaolin/Min-U-Sil simulants in the 10-in. vessel for bubble stability and fin performance. 


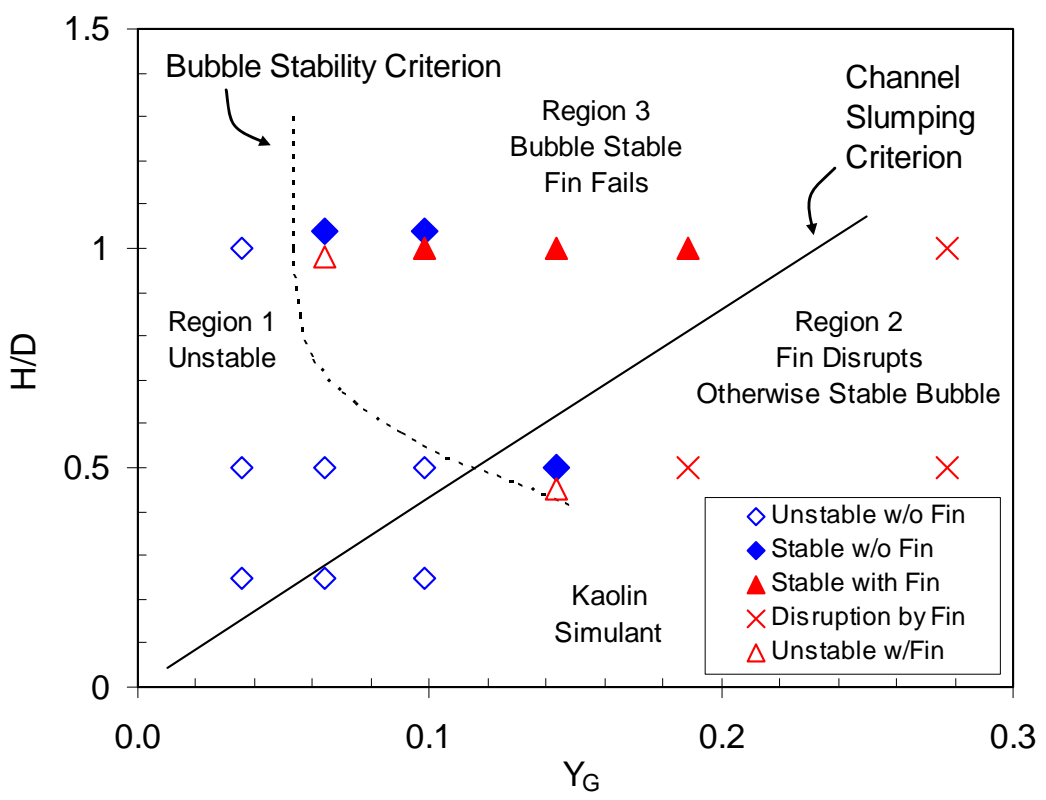

Figure 4.14. Fin Performance and VSB Stability for Kaolin Simulants Spanning a Range of Gravity Yield Parameter $\left(\mathrm{Y}_{\mathrm{G}}\right)$ and Layer Thickness $(\mathrm{H} / \mathrm{D})$ in the 5-in. Vessel. A scaled version of a 5-degree, 2-in. wide fin was used.

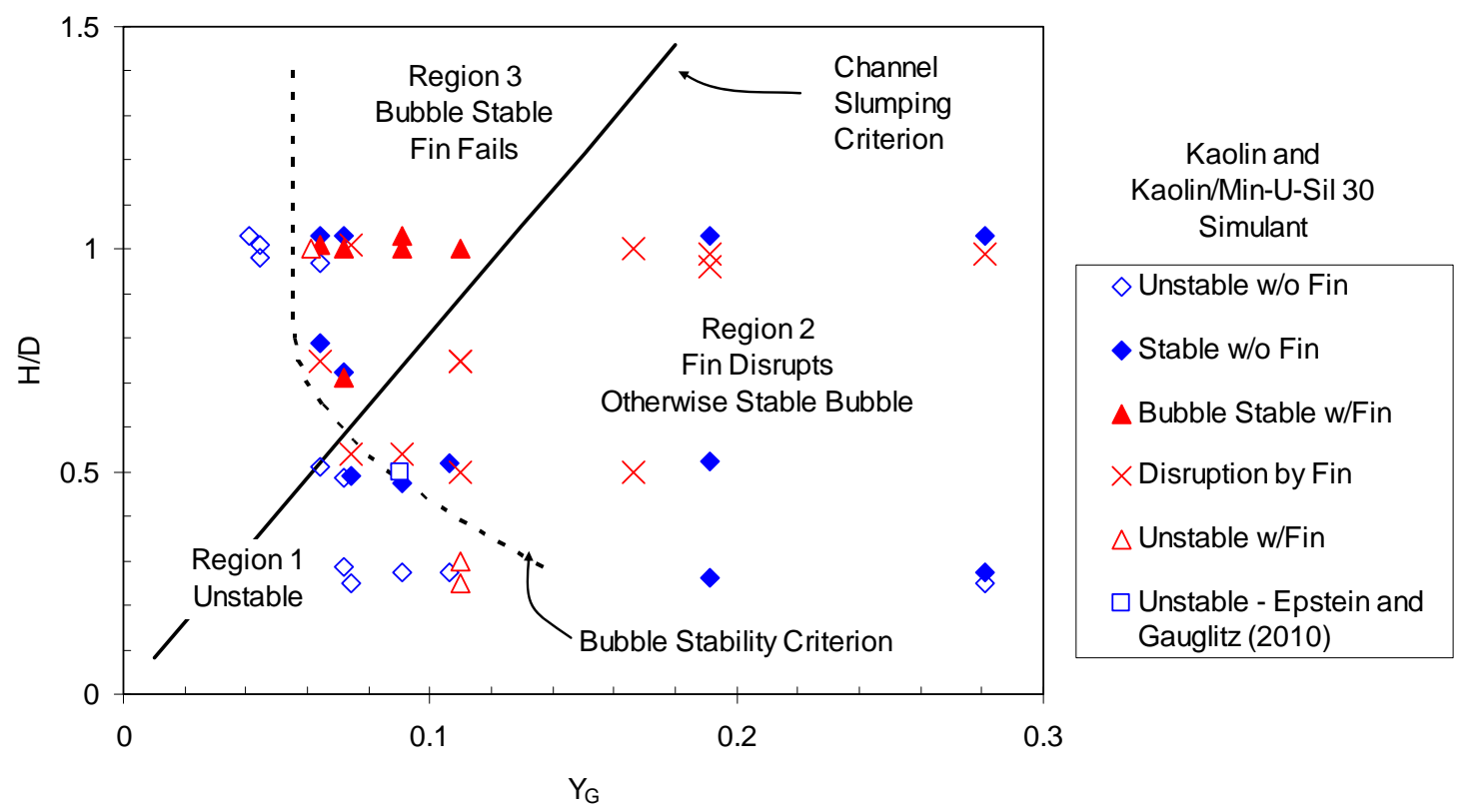

Figure 4.15. Fin Performance and VSB Stability for a Combination of Kaolin and Kaolin/Min-U-Sil 30 Simulants Spanning a Range of Gravity Yield Parameter $\left(\mathrm{Y}_{\mathrm{G}}\right)$ and Layer Thickness $(\mathrm{H} / \mathrm{D})$ in the 10-in. Vessel. A scaled version of a 5-degree, 2-in. wide fin was used in all experiments. 
The overall conclusion of scale-up testing in the 5-in., 10-in. and 23-in. vessels is that the region of $\mathrm{Y}_{\mathrm{G}}$ and $\mathrm{H} / \mathrm{D}$ values where fins do not disrupt VSBs (Region 3) becomes smaller in progressively larger vessels, which is favorable for designing the full-scale STSCs. These tests were all conducted using a scaled 5-degree, 2-in.-wide fin. While this trend was clearly shown by the data, this effect of scale was not predicted by the simple model with $\mathrm{Y}_{\mathrm{G}}$ scaling. One experimental parameter that has not been systematically varied is the rate the clay layer is lifted, and it is possible that the lifting rate is an important parameter. With this experimental scale-up trend and the 23 -in. test results showing that the fins always disrupt VSBs, the overall conclusion is that fins should perform even better at full scale. Accordingly, the data indicated that fins will disrupt bubbles for any material strength and layer depth. In addition, the results for fin performance with the KW container sludge simulant (complete) in the 10-in. vessel showed that the fins always disrupted VSBs. This simulant is probably the most realistic for actual K-Basin material, and these test results for this simulant suggest that fins would always disrupt VSBs. Although not tested, if the scale-up trend of fin performance getting better in larger vessels holds true for the more realistic KW container sludge simulant (complete), fins should work even better at full-scale.

\subsection{Comparison of Results with Previous Studies}

The current test results can be compared with the previous results of Epstein and Gauglitz (2010). Epstein and Gauglitz (2010) conducted a number of VSB tests with an equivalent method of gas injection using a 17.5-in.-diameter vessel and kaolin layers with $\mathrm{H} / \mathrm{D}=0.5$. In this previous work, the criterion for the instability of VSBs was determined to be $Y_{G}=0.09$. Epstein and Gauglitz (2010) also reported results for a series of smaller test vessels to determine the effect of vessel size on the onset of instability, but these smaller tests were conducted by inverting containers holding the clay, which is different from the experimental method of injecting gas from below. The results in Epstein and Gauglitz (2010) for the effect of vessel size generally supported the conclusion that the gravity yield parameter $\left(\mathrm{Y}_{\mathrm{G}}\right)$ correctly accounts for vessel size. For the current study, the results in Figure 4.13, Figure 4.14, and Figure 4.15 for three vessel diameters shows the onset of instability occurring at progressively lower $Y_{G}$ in progressively larger test vessels. For example, at $\mathrm{H} / \mathrm{D}=0.5$, the bubble stability criteria are about $0.12,0.08$, and 0.04 in the 5-in., 10-in. and 23-in. test vessels, respectively. The current results for the 10-in. and 5-in. vessels also show that VSBs are more stable, and the $\mathrm{Y}_{\mathrm{G}}$ for the transition between stable and unstable bubbles is lower, at $\mathrm{H} / \mathrm{D}=1$, in comparison to when $\mathrm{H} / \mathrm{D}=0.5$. In the 23 -in. vessel, there are fewer data, but lower values of $\mathrm{H} / \mathrm{D}$ are certainly less stable. Overall, the current results suggest a lower value of $\mathrm{Y}_{\mathrm{G}}$, such as 0.04 for a layer thickness of H/D between 0.5 and 1, for the transition between stable and unstable VSBs rather than the value of 0.09 reported by Epstein and Gauglitz (2010). Previously, in Table 2.1 we showed that at a $\mathrm{Y}_{\mathrm{G}}$ of 0.09 , stable VSBs are expected in a 58-in., full-scale STSC for shear strengths above $1900 \mathrm{~Pa}$, assuming a density of $1500 \mathrm{~kg} / \mathrm{m}^{3}$. In comparison, based on a stability criterion of $\mathrm{Y}_{\mathrm{G}}=0.04$ that was observed in the 23 -in. vessel, stable VSBs are predicted at shear strength above about $870 \mathrm{~Pa}$.

As described in Section 2 and discussed in Epstein and Gauglitz (2010), it was expected that the gravity yield parameter would correctly account for the role of vessel diameter, but the experimental results suggest that there is an effect of vessel scale that is not completely represented with the gravity yield parameter. One alternative explanation for the role of vessel size not being completely represented by the gravity yield parameter is that the gas injection rates, and hence the rate of rise for the clay layers, were different at different scales. In the current tests, the experiments in different size vessels were conducted so that the clay layer would rise to $\mathrm{H} / \mathrm{D}=0.5$ in about 120 minutes in each vessel. Accordingly, 
the actual velocity of the rising clay layers increased with increasing vessel size. In the previous study (Epstein and Gauglitz 2010), a few tests were conducted at different gas injection rates in a cone-shaped vessel. These tests were conducted to evaluate whether the rate of bubble rise would affect slumping and disruption of a bubble with a sloped wall. In the faster experiments, gas release occurred after about 30 minutes and in the slower tests the release occurred after about 2 to 3 hours. For these experiments, there was little difference on the mechanism of release. Based on this previous work not showing a significant role for gas injection rate, the current study did not explore this parameter.

Epstein and Gauglitz (2010) conducted six tests in a cone-shaped vessel (14.2 degree slope) with kaolin simulants to determine if the sloped wall would provide a release pathway for VSBs, which is equivalent to the gas release mechanism shown in Figure 2.1 for release along a sloped fin. These tests were conducted in an 8.66-in. vessel with $\mathrm{Y}_{\mathrm{G}}$ values ranging from 0.054 to 0.29 and clay depths of $\mathrm{H} / \mathrm{D}=1.4$ and 2.3. In all of these tests, gas was released through a thin gas film along the sloped wall, and there was no example of slumping eliminating gas release. In comparison to the bubble stability and fin performance results for the 10-in. vessel shown in Figure 4.15, the tests at $\mathrm{Y}_{\mathrm{G}}=0.29$ reported by Epstein and Gauglitz are in Region 2 where gas release along a sloped wall is expected. Three tests were conducted at $\mathrm{Y}_{\mathrm{G}}=0.14$ with $\mathrm{H} / \mathrm{D}=1.4$, and these tests are in Region 3 of Figure 4.15. Based on the results shown in Figure 4.15 for the fin, slumping and no gas release would be expected for these tests in a cone-shaped vessel. There are no data to explain the difference between the results with the 5-degree, 0.34-in.-wide fin and the 14.2-degree cone, but it seems reasonable that a cone-shaped vessel would release gas more effectively than the comparatively small sloped fin.

Finally, in the current study, a thin water layer was placed on the top of the simulants when testing fin performance to allow easy identification of the location of gas release by observing released bubbles, but the effect of this water layer thickness was not evaluated. The previous study by Epstein and Gauglitz (2010) reported a pair of VSB tests where no difference in stability was observed when a $0.25-\mathrm{m}$ overlying water layer was added to one of the tests. This single test suggests that the value of the gravity yield parameter for unstable VSBs (bubble stability criterion) should not depend on the depth of a water layer. The slumping criterion given by Equation 2.4 also does not depend on the depth of the overlying water layer, which also indicates that the depth of the water layer is not an important parameter. 



\subsection{Conclusions and Recommendations}

Experimental results were obtained with simulants to quantify the stability of VSBs and the capability of sloped fins to disrupt these bubbles and inhibit the lifting of sludge layers. Both the instability of the bubbles and the slumping of the simulants that degrade fin performance were evaluated in terms of the gravity-yield parameter, $\mathrm{Y}_{\mathrm{G}}$, and the scaled height of the simulated sludge layer $(\mathrm{H} / \mathrm{D})$. The evaluation predicts three regions of behavior, bubble stability, and fin performance (see Figure 2.3). For sufficiently weak sludge simulants, corresponding to low $\mathrm{Y}_{\mathrm{G}}$ and identified as Region 1, all VSBs are unstable. For $\mathrm{Y}_{\mathrm{G}}$ large enough to form stable VSBs, sloped fins effectively disrupt the bubbles when the dimensionless clay layer height is less than a value determined by a slumping criterion. Under these conditions, sloped fins create gas-release pathways that remain open (no slumping) to release gas. This is identified as Region 2. In Region 3, VSBs are stable even with fins. In this region, fins do not release retained gas because the sludge continuously slumps and closes the gas-release path.

Experimental results were obtained for 10-in.-diameter vessels with both a flat bottom and a 2:1 elliptical bottom for a range of different simulants and a range of fin shapes. One of the simulants was the KW container sludge (complete) simulant. Only three tests were conducted with this simulant because it is difficult to use, but this simulant is likely the most representative simulant tested, so the limited results with this material are particularly important. Finally, a more focused suite of experiments was conducted in 5-in. and 23-in. vessels to quantify how fin performance and the three regions of behavior change with increasing vessel size. For these scale-up tests, the trend in how behavior changes with vessel size, specifically any shifting in the location of the three regions, and the results from the 23-in. vessel are the most significant results.

Tests were conducted in the 10-in., flat-bottom vessel with kaolin clay simulants with shear strengths ranging from 160 to $1090 \mathrm{~Pa}$ (48 to $58 \mathrm{wt} \%$ ), giving a range of 0.044 to 0.28 for $\mathrm{Y}_{\mathrm{G}}$. This corresponds to a shear-strength range of about 900 to $6,300 \mathrm{~Pa}$ for this $\mathrm{Y}_{\mathrm{G}}$ range in the full-scale STSCs. In these tests, the clay layer thickness was also varied from $H / D=0.25$ to 1 . Tests without fins were conducted to define the transition between stable and unstable bubbles and to compare with previous studies. In the 10-in., flat-bottom vessel with kaolin simulants, the transition between unstable and stable VSBs occurred at $Y_{G}=0.05$ for $H / D=1$ and increased to about $Y_{G}=0.08$ at $H / D=0.5$. This is consistent a previous study that found the transition to occur at $Y_{G}=0.09$ for similar kaolin clay simulants at an $\mathrm{H} / \mathrm{D}$ of 0.5 . Larger-scale testing in a 23-in. vessel showed stable VSBs at lower values of $Y_{G}$ than in the 10-in. vessel, and these results suggest $Y_{G}=0.04$ for layer thicknesses of $H / D$ between 0.5 and 1 as the transition between stable and unstable VSBs rather than the value of 0.09 .

Fin performance tests in the 10-in., flat-bottom vessel with kaolin simulants demonstrated the expected three regions of behavior. For sufficiently strong simulants (high $\mathrm{Y}_{\mathrm{G}}$ and Region 2), the fins always disrupt potentially stable bubbles. For Region 3, stable VSBs were observed with the fin present. In this region, the $Y_{G}$ is high enough to have stable VSBs but still sufficiency low for slumping along the fin to make the fin ineffective. For sufficiently small $Y_{G}$, the VSBs are always unstable. Scaled fins with a range of slopes and widths were evaluated, and a straight-sided fin with a 5-degree slope and a full-scale width of 2 inches was selected as the primary fin for further testing.

To extend these results to more realistic simulants, two additional simulants were selected, characterized, and tested in the 10-in. vessel. The two simulants were the KW container sludge 
(complete) simulant and mixtures of kaolin and Min-U-Sil 30. Both of these simulants have a more granular nature, and slumping experiments demonstrated that they slump less than kaolin simulants at equivalent strengths. Fin performance tests with the KW container (complete) simulant were the most striking. The results showed rapid disruption of bubbles by the fin at $\mathrm{Y}_{\mathrm{G}}$ and $\mathrm{H} / \mathrm{D}$ values where Region 3 behavior (stable bubbles with a fin) was most likely to occur. These results suggest that fins will be effective at all $\mathrm{Y}_{\mathrm{G}}$ and $\mathrm{H} / \mathrm{D}$ values for actual $\mathrm{K}$-Basin material. The fin performance results for the kaolin/Min-U-Sil 30 simulants were equivalent to the kaolin results.

With the 2:1 elliptical-bottom vessel, the bottom of the clay is not flat as a gas bubble begins lifting the clay. The stability of the VSB was strongly affected by this different geometry, and VSBs were significantly less stable in the elliptical-bottom vessel. This different behavior from the flat-bottom tests is likely because the clay layer has a thickness that varies across the layer, an imbalance that apparently initiates gas release. Tests were conducted with both kaolin and kaolin/Min-U-Sil simulants both with and without fins. Fin performance in the 2:1 elliptical-bottom vessel showed similar, but not identical, behavior to the flat-bottom-vessel tests. For the fin tests in the strongest simulant (kaolin with a $\mathrm{Y}_{\mathrm{G}}=$ 0.28 ), the VSBs were clearly disrupted by the fin. For the weaker simulant (and lower $Y_{G}$ ), the bubbles became progressively less stable. Overall, testing in the elliptical-bottom vessel with fins shows that bubble release always happened in the vessel, either because the bubble was unstable at lower strengths, or the fin disrupted the bubble at higher strengths.

Scale-up testing of fin performance was conducted using 5-in. and 23-in. test vessels to complement the 10-in. vessel results. Fin performance in the 5-in. vessel showed the three regions of behavior that were observed in the 10-in. vessel, with the Region 3 behavior spanning a wider range of $Y_{\mathrm{G}}$. In the 23-in. vessel, tests were conducted with kaolin and kaolin/Min-U-Sil 30 simulants. The most significant finding from the 23-in., large-scale tests is that there is no region of gravity yield parameter $\left(\mathrm{Y}_{\mathrm{G}}\right)$ and layer thickness (H/D) where the fin fails to disrupt VSBs. Of the 13 tests with potentially stable bubbles, the fin disrupted the bubble within 4 minutes in 12 of these tests, and one test took 6 minutes. For this duration of gas injection, there was only a negligible rise $(\sim 1 / 2$ inch $)$ in the clay layer.

T-shaped fins were tested in both the 10-in. and 23-in. vessels, with the specific fins tested scaled to match a 5-degree, full-scale fin with a width of 4 inches. In the six T-fin tests, the T-shaped fin performed equal to or better than the 5-degree, straight-sided fin.

The overall conclusion of scale-up testing in the 5-in, 10-in., and 23-in. vessels is that the region of $\mathrm{Y}_{\mathrm{G}}$ and $\mathrm{H} / \mathrm{D}$ values where fins do not disrupt VSBs (Region 3) becomes smaller in progressively larger vessels, which is favorable for designing the full-scale STS. These tests were all conducted using a scaled 5-degree, 2-in.-wide fin. While this trend was clearly shown by the data, this effect of scale was not predicted by the simple model with $\mathrm{Y}_{\mathrm{G}}$ scaling. One experimental parameter that has not been systematically varied is the rate the clay layer is lifted, and it is possible that the lifting rate is an important parameter. With this experimental scale-up trend and the 23 -in. test results showing the fins always disrupting bubbles, the overall conclusion is that fins should perform even better at full scale. Accordingly, the data indicated that fins will disrupt bubbles for any material strength and layer depth. In addition, the results for fin performance with the KW container simulant (complete) showed that the fins nearly always disrupted VSBs. This simulant is probably the most realistic for actual K-Basin material, and the test results for this simulant suggest that fins would always release VSBs. Although not tested, the fins should work even better at full-scale with actual K-Basin material considering that the scale-up trend of fin performance improves in larger vessels. 



\subsection{References}

Baker RB, BJ Makenas, and JA Pottmeyer. 2000. Observations of K Basins Sludge Behavior in Relation to Sludge Container Design and Storage at T Plant. HNF-6705 Rev. 0, Fluor Hanford, Inc., Richland, Washington.

Bryan SA, CH Delegard, AJ Schmidt, RL Sell, KL Silvers, SR Gano, and BM Thornton. 2001. Gas Generation from K East Basin Sludges-Series II Testing. PNNL-13446, Pacific Northwest National Laboratory, Richland, Washington.

Burbank DA. 2009. Sludge Simulant Strategy and Design Basis. PRC-STP-00034 Rev. 0, CH2M Hill Plateau Remediation Company, Richland, Washington.

Burns CA, PA Gauglitz, and RL Russell. 2010. Shear Strength Correlations for Kaolin/Water Slurries: A Comparison of Recent Measurements with Historical Data. PNNL-19094, Pacific Northwest National Laboratory, Richland, Washington.

Daniel RC. 2007. PNNL Technical Procedure, "Measurement of Physical and Rheological Properties of Solutions, Slurries and Sludges.” RPL-Colloid-02 Rev. 1, Pacific Northwest National Laboratory, Richland, Washington.

Delegard CH and AJ Schmidt. 2009. Uranium Metal Reaction Behavior in Water, Sludge, and Grout Matrices. PNNL-17815, Rev 1. Pacific Northwest National Laboratory, Richland, Washington.

Delegard CH, SA Bryan, AJ Schmidt, PR Bredt, CM King, RL Sell, LL Burger, and KL Silvers. 2000. Gas Generation from K East Basin Sludges - Series I Testing. PNNL-13320, Pacific Northwest National Laboratory, Richland, Washington.

Epstein M. 2002. Taylor Instability of a High-Strength Sludge Plug in a Storage Container. Appendix in Vessel-Spanning Bubble Formation in K Basin Sludge Stored in Large-Diameter Containers by G Terrones and PA Gauglitz, PNNL-13805, Pacific Northwest National Laboratory, Richland, Washington.

Epstein M and PA Gauglitz. 2010. An Experimental Study of the Stability of Vessel-Spanning Bubbles in Cylindrical, Annular, Obround and Conical Containers. Fauske \& Associates Report FAI/09-272, Rev. 2, (April), Burr Ridge, Illinois.

Honeyman JO and RJ Rourk. 2009. Sludge Treatment Project - Project Execution Plan. KBC-30811, Rev 3 (PRC-EDC-09-43288, Rev 3), CH2MHILL Plateau Remediation Company, Richland, Washington.

Johnson AB. 1995. K-Basin Corrosion Program Report. WHC-EP-0877, Westinghouse Hanford Company, Richland, Washington.

Johnson ME. 2010. Screening Evaluation of Characterization Data for Engineered Container SCSCON-220, -240, -250, and -260. PRC-STP-00212, Rev 0, CH2MHILL Plateau Remediation Company, Richland, Washington. 
Johnson ME and TK Dhaliwal. 2009. Preliminary STP Container and Settler Sludge Process System Description and Material Balance. HNF-41051, Rev 5, CH2M HILL Plateau Remediation Company, Richland, Washington.

Makenas BJ, TL Welsh, RB Baker, EW Hoppe, AJ Schmidt, J Abrefah, JM Tingey, PR Bredt, and GR Golcar. 1997. Analysis of Sludge from Hanford K East Basin Canisters. HNF-SP-1201, Rev. 0, prepared by DE\&S Hanford, Inc., for Fluor Daniel Hanford, Inc., Richland, Washington.

Nguyen QD and DV Boger. 1985. "Direct Yield Stress Measurement with the Vane Method.” Journal of Rheology 29(3):335-347.

Pashias N, DV Boger, J Summers, and DJ Glenister. 1996. "A Fifty Cent Rheometer for Yield Stress Measurement." J. Rheol. 40(6):1179-1189.

Poloski AP, PR Bredt, AJ Schmidt, RG Swoboda, JW Chenault, and SR Gano. 2002. Thermal Conductivity and Shear Strength of K Basin Sludge. PNNL-13911, Pacific Northwest National Laboratory, Richland, Washington.

Rassat SD, LM Bagaasen, LA Mahoney, RL Russell, DD Caldwell, and DP Mendoza. 2003. Physical and Liquid Chemical Simulant Formulations for Transuranic Wastes in Hanford Single-Shell Tanks. PNNL-14333, Pacific Northwest National Laboratory, Richland, Washington.

Schmidt AJ. 2009. Spent Nuclear Fuel Project Technical Databook, Vol. 2, Sludge. HNF-SD-SNF-TI015, Rev 14A, Volume 2, Fluor Hanford, Richland, Washington.

Schmidt AJ, and CH Delegard. 2002. Assessment of K Basin Sludge Volume Expansion Resulting from Uranium Corrosion During Storage. PNNL-13786, Pacific Northwest National Laboratory, Richland, Washington.

Terrones G and PA Gauglitz. 2002. Vessel-Spanning Bubble Formation in K-Basin Sludge Stored in Large Diameter Containers. PNNL-13805, Pacific Northwest National Laboratory, Richland, Washington. 


\section{Appendix A}

Shear-Strength Method and Measurements 



\title{
Appendix A: Shear-Strength Method and Measurements
}

\section{Acronyms and Abbreviations}

\author{
APEL Applied Process and Engineering Laboratory \\ LHS left-hand side \\ DI de-ionized (water) \\ FY fiscal year \\ NIST National Institute of Standards and Technology \\ PNNL Pacific Northwest National Laboratory \\ QA quality assurance \\ RHS right-hand side \\ RPM revolutions per minute
}

\section{Symbols}

$\mathrm{h} \quad$ immersion depth to top of vane

$\mathrm{h}_{\text {floor }} \quad$ separation between bottom of vane and container floor

$\mathrm{H} \quad$ vane height

$\mathrm{M}_{\max } \quad$ maximum torque

$\mathrm{R} \quad$ vane radius

$\mathrm{R}_{\text {cont }} \quad$ container radius, or radial distance from vane to an outer boundary (see Figure A.1)

\section{Greek Letters}

shear stress applied to sample

$\tau_{\mathrm{s}} \quad$ shear strength

$\Omega \quad$ vane rotation rate in rpm 



\section{A.1 Introduction}

The purpose of this appendix is to describe the methods followed to measure the shear strength of the kaolin clay simulants used in testing as described in PNNL Test Instruction 53451-TI23, Vessel Spanning Bubbles with Vessel Inserts: Testing in 10" ID Flat Bottom and 2:1 Elliptical Bottom Vessels, and two subsequent test instructions (53451-TI26 and 53451-T131). Most of the information presented in the Background, Test Method, and Test Approach sections was taken from Shear Strength Correlations for Kaolin/Water Slurries: A Comparison of Recent Measurements with Historical Data (Burns 2010). Data plots and a summary table for the shear-strength measurements are included.

\section{A.2 Background}

Rheology is the science of material flow and deformation. For fluid systems, including pure liquids, mixtures of liquids, and suspensions of solids in liquids, the rheological properties of that system describe how it responds to an applied force or stress. When applied to solids, stress induces a strain or finite deformation in the material. When applied to pure liquids, stress causes a continuous deformation of the substance or, in simpler terms, fluid flow. Suspensions of solids in liquids or liquid mixtures with internal structure can show a combination of both solid-like and liquid-like behavior. In addition, the response of materials to force and deformation may not be constant. Changes in the internal structure of materials that occur as a result of mechanical and chemical processes, such as breakage, precipitation of solids, and gelation, may alter the macroscopic flow and deformation properties. For the current study, the rheology of kaolin/water slurries is considered. A single region of slurry flow behavior is considered: incipient motion in a paste composed of kaolin solids in water.

For a kaolin slurry, a finite stress must be applied before the settled solids will begin to flow. The stress required to transition the settled solids from elastic deformation to plastic deformation or viscous flow is referred to as the shear strength, and its origin can be attributed to a combination of cohesion arising from interparticle adhesive forces such as van der Waals forces and static and kinetic friction between individual particles and/or aggregates. The resistance of settled solids to motion can be quantified through shear-strength testing.

The vane method (Nguyen and Boger 1985) was used to measure the shear strength of kaolin slurry. For the vane method, the stress required to begin motion is determined by slowly rotating a vane immersed in the test sample while continuously monitoring the resisting torque as a function of time. A material's static shear strength is then associated with the maximum torque measured during the transition from initial to steady-state vane rotation. A typical experimental setup for measuring shear strength with a vane is shown in Figure A.1.

For the current tests, the kaolin slurry did not settle, so a supernatant layer (water) in Figure A.1 was not present.

A sludge/slurry sample is placed in a container of radius $R_{\text {cont }}$, and a vane tool attached to a viscometer (i.e., a torque sensor) is immersed into the settled solids portion of a sludge or slurry to a depth $h$ (relative to the top of the vane blades). The vane blades have a radius, $R$, and a height, $H$. The vane is then slowly rotated at a constant rotational speed, $\Omega$. The torque versus time profile is recorded, 
and the maximum torque required to initiate rotation is determined. The shear strength is then calculated from this maximum torque based on the assumption of a uniform stress distribution on the known vane tool geometry.

An example torque-versus-time curve is shown in Figure A.2. The maximum torque corresponds to the onset of plastic deformation. Here, the stress applied by vane rotation is finally sufficient to overcome frictional, cohesive, and other structural forces stabilizing the settled solids. The maximum torque required for incipient plastic deformation is dependent on vane geometry. To account for vane geometry effects, the shear strength is expressed in terms of uniform and isotropic stress acting over the surface area of the cylinder of rotation swept out by the vane. This uniform stress (i.e., the shear strength of the material) is related to the maximal torque during incipient motion by the equation:

$$
\tau_{S}=\frac{M_{\max }}{4 \pi R^{3}\left(\frac{H}{2 R}+\frac{1}{3}\right)}
$$

Here, $\tau_{s}$ is the shear strength $\left[\mathrm{N} / \mathrm{m}^{2}\right], M_{\max }$ is the maximum torque $[\mathrm{N} \cdot \mathrm{m}]$, and $R$ and $H$ are the radius and height of the cylinder of rotation swept out by the vane $[\mathrm{m}]$. Because the shear band observed upon slow rotation of the vane does not extend appreciably beyond the vane paddles, $R$ and $H$ are taken to be the dimensions of the vane itself.
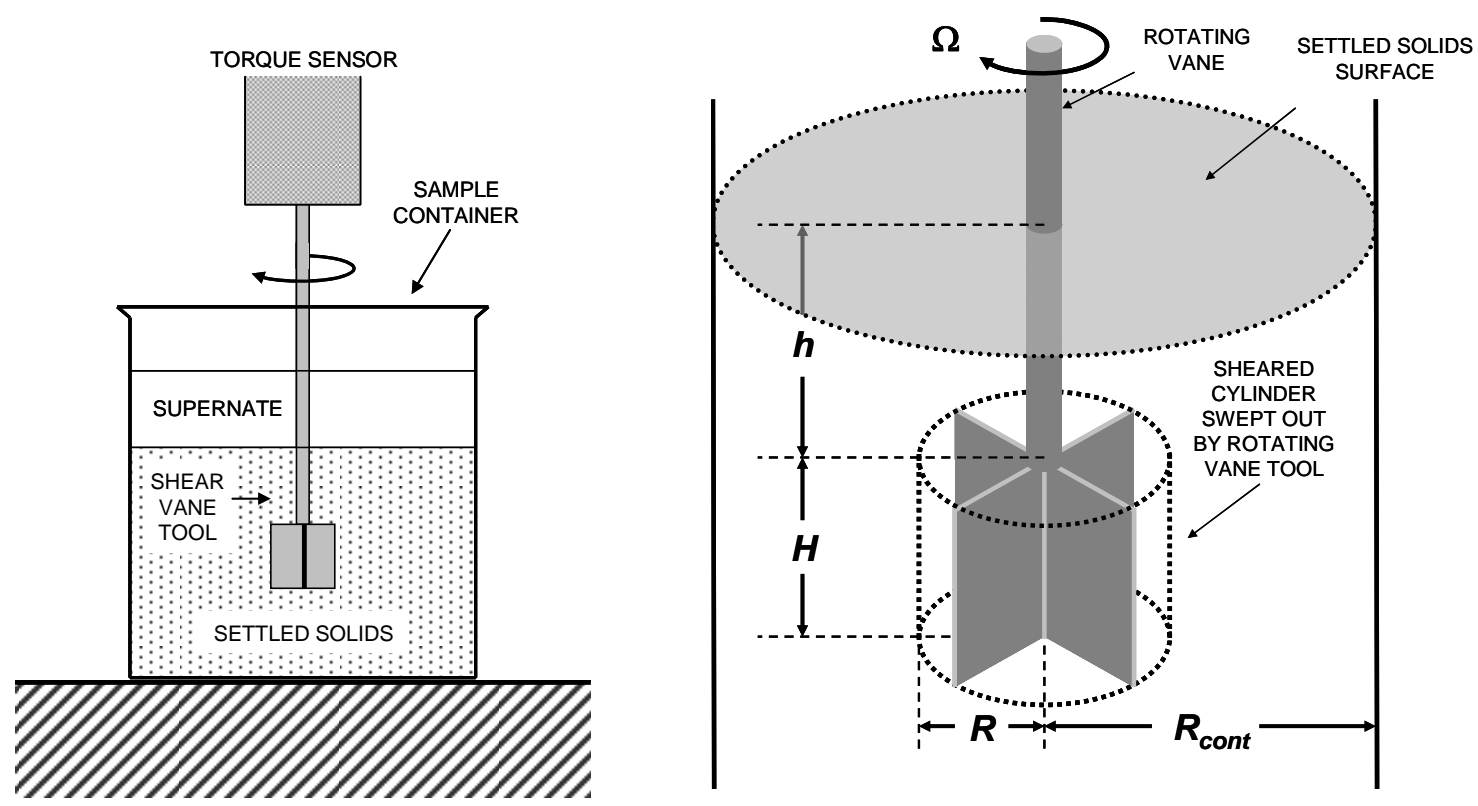

Figure A.1. Typical Shear-Strength Experimental Setup 


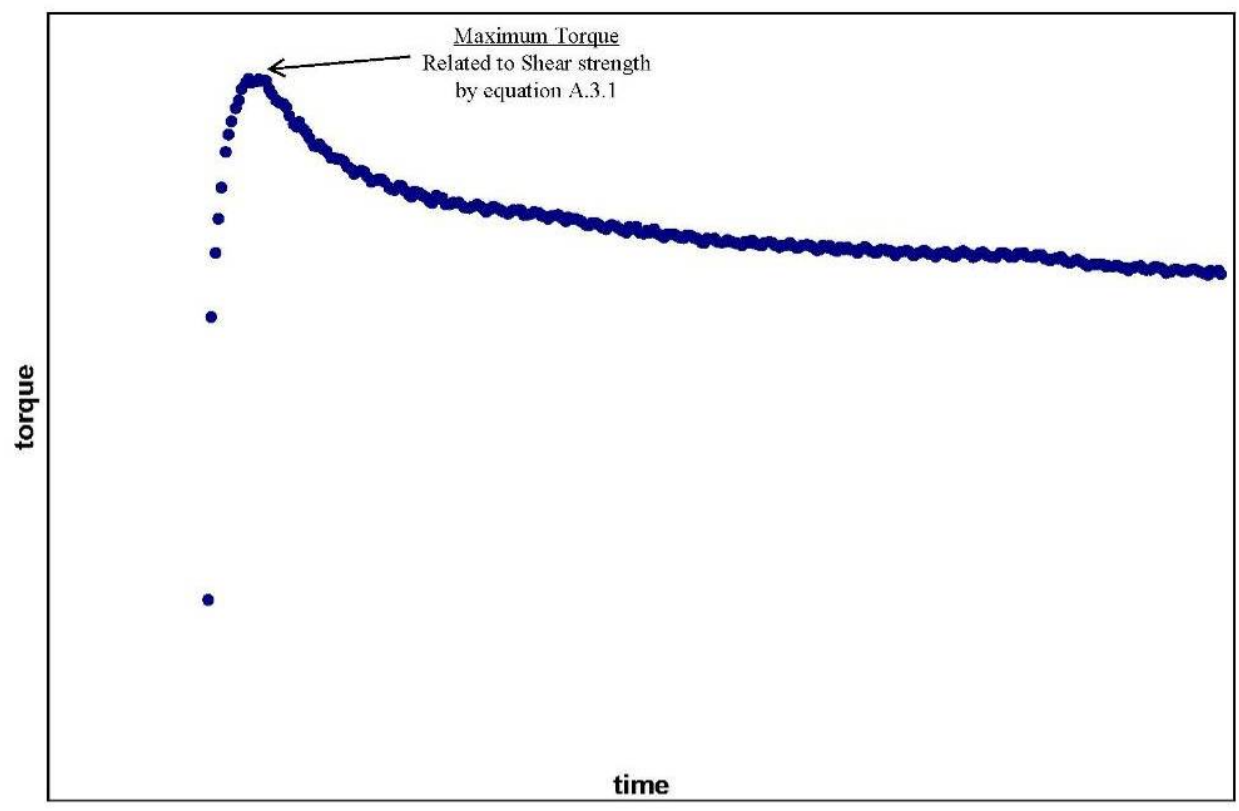

Figure A.2. Example of a Shear-Strength Torque-Versus-Time Curve

The proximity of the vane to the sample container inner surfaces as well as to the free surface of the settled solids can impact shear-strength results. As such, certain geometric constraints must be satisfied for the test to be considered independent of container geometry. These constraints are outlined in Table A.1 (along with example constraint dimensions for a $16 \times 16-\mathrm{mm}(2 \mathrm{R} \times \mathrm{H})$ vane tool, which is the vane-tool geometry employed in the current study).

Table A.1. Vane Immersion Depth and Container Geometry Constraints for Shear-Strength Tests Using the Vane Technique

\begin{tabular}{|c|c|c|}
\hline Constraint & Criterion & For $8 \times 16 \mathrm{~mm}(\mathrm{R} \times \mathrm{H})$ Vane \\
\hline Vane height $(\mathrm{H})$ to radius $(\mathrm{R})$ & $\mathrm{H}<7 \mathrm{R}$ & $\mathrm{H}<56 \mathrm{~mm}$ \\
\hline Container radius $\left(\mathrm{R}_{\text {cont }}\right)$ to vane radius $(\mathrm{R})$ & $\mathrm{R}_{\text {cont }}>2 \mathrm{R}$ & $\mathrm{R}_{\text {cont }}>16 \mathrm{~mm}$ \\
\hline Immersion depth (h) to vane height $(\mathrm{H})$ & $\mathrm{h}>\mathrm{H}$ & $\mathrm{h}>16 \mathrm{~mm}$ \\
\hline $\begin{array}{l}\text { Separation between bottom of vane and } \\
\text { container floor }\left(\mathrm{h}_{\text {floor }}\right)\end{array}$ & $\mathrm{h}_{\text {floor }}>0.5 \mathrm{H}$ & $\mathrm{h}_{\mathrm{floor}}>8 \mathrm{~mm}$ \\
\hline
\end{tabular}

\section{A.3 Test Method}

The shear strength was measured with a Rotovisco ${ }^{\circledR}$ RV20 Measuring System equipped with an M5 measuring head and RC20 controller. These components were purchased from Haake Mess-Technik $\mathrm{GmbH}$ u. Co. (now the Thermo Electron Corporation, Madison, WI 53711). This system is located in the Applied Process and Engineering Laboratory (APEL), Room 112. The M5 measuring head (SN\# 920020) is a "Searle" type viscometer capable of producing rotational speeds up to 500 RPM and 
measuring torques up to $0.049 \mathrm{~N} \cdot \mathrm{m}$. The minimum rotational speed and torque resolution achievable by this measuring head are $0.05 \mathrm{RPM}$ and $0.49 \mathrm{mN} \cdot \mathrm{m}$, respectively. Table A.2 summarizes the M5 measuring system information.

Table A.2. Summary of Haake RV20 System with M5 Measuring Head

\begin{tabular}{lc}
\hline \multicolumn{1}{c}{ Analyzer: } & $\begin{array}{r}\text { Rotorvisco® RV20 Measuring System M } \\
\text { with M5 Measuring Head. }\end{array}$ \\
\hline Measurement principle: & Controlled Rate \\
Serial Number: & 930020 \\
Torque Sensor Range & 0.49 to $49 \mathrm{mN} \cdot \mathrm{m}$ \\
Rotational Rate Range & 0.05 to $500 \mathrm{RPM}$ \\
\hline
\end{tabular}

Specific measurement tools, such as cup and rotor assemblies and shear vanes, are attached to measure selected rheological properties. Shear-strength measurements employed a 16-mm $\times 16-\mathrm{mm}$ $(2 \mathrm{R} \times \mathrm{H})$ shear vane tool. The dimensions of the vane measuring system are listed in Table A.3.

Table A.3. Vane and Cup and Rotor Measuring System Dimensions

\begin{tabular}{lcccc}
\hline \multirow{2}{*}{ Measuring System } & $\begin{array}{c}\text { Vane/Rotor } \\
\text { Diameter }\end{array}$ & $\begin{array}{c}\text { Vane/Rotor } \\
\text { Height }\end{array}$ & Cup Radius & Gap Width \\
\hline Vane Tool & $16 \mathrm{~mm}$ & $16 \mathrm{~mm}$ & $>16 \mathrm{~mm}^{(\mathrm{a})}$ & $>8 \mathrm{~mm}^{(\mathrm{a})}$ \\
\hline
\end{tabular}

(a) Vane tests must satisfy the requirements outlined in Table A.1.

A remote computer connection using the RheoWin Pro Job Manager Software, Version 2.96 (1996), was used to control the rheometer and acquire data. The RheoWin software serves as a central program for obtaining, processing, and recording to disk data from the RV20-M5 measuring system. During measurement, the software automatically converted rotor torque readings into shear stresses based on the appropriate A-factor conversion, such that

$$
\tau=A M
$$

For vane tools, the A-factor is defined as:

$$
A=\frac{1}{4 \pi R^{3}\left(\frac{H}{2 R}+\frac{1}{3}\right)}
$$

The A-factor for the $16-\mathrm{mm} \times 16$-mm vane tool sensor system is $\sim 117,000 \mathrm{~m}^{-3}$. The RheoWin software also allows post-measurement processing and interpretation of data. Specifically, it can be used to determine maxima points in shear-strength testing. 


\section{A.4 Test Approach}

\section{A.4.1 Instrument Performance Check}

As required by procedure RPL-COLLOID-02, Rev. 1, Measurement of Physical and Rheological Properties of Solutions, Slurries, and Sludges (Daniel 2007), the performance of the Haake RV20-M5 rheometer in APEL/112 must be verified at the beginning of each series of analyses (with the period between performance checks not to exceed 30 days during use). A performance verification at the end of each series of analyses was also required. Checks are performed using Newtonian viscosity standards certified by methods traceable to the U.S. National Institute of Standards and Technology (NIST). Checks verify that the Haake RV20-M5 rheometer can measure the standard's viscosity to within 10\% for fluids of $10 \mathrm{cP}$ or greater and to within $15 \%$ for fluids less than $10 \mathrm{cP}$ at the temperature listed on the certificate of analysis (hereafter referred to as the list viscosity). Verification of the Haake RV20-M5 in APEL/112 involves :

1) measuring Newtonian viscosities at $25^{\circ} \mathrm{C}$ and ambient temperatures with a second reference bench-top rheometer (the Haake RS600 located in the APEL)

2) verifying that the RS600 measures the viscosity standard to within the limits defined by RPL-COLLOID-02, Rev. 1 , at $25^{\circ} \mathrm{C}$

3) measuring the viscosity of the standard at ambient temperature on the RV20-M5 rheometer system

4) comparing RS600 and RV20-M5 viscosities at ambient temperature to verify that they agree within acceptable limits of tolerance.

This three-point check allows verification of the RV20-M5 rheometer performance at ambient temperature. To verify the capability of the RV20-M5 rheometer to properly determine torque and stress, two conditions must be satisfied. First, measurements of viscosity at ambient temperature on the RV20-M5 must agree with measurements on the cold bench-top rheometer within $10 \%$. Second, the RS600 measurement of the viscosity standard at $25^{\circ} \mathrm{C}$ must be within the limits defined by RPL-COLLOID-02 (Daniel 2007). The rheometer software (RheoWin 2.96, 1996) is also verified during this check, as it is used to calculate the Newtonian viscosity of the standard viscosity fluid tested.

For the measurements described in this report, the performance check employed a General Purpose Silicone Fluid purchased from Brookfield Engineering Laboratories, Inc. (Middleboro, Massachusetts, USA, 02346). Silicone oil viscosity standards are single-phase liquids and have no suspended solids. Testing employed Brookfield Fluid 50 and Brookfield Fluid 100. Table A.4 provides a summary of these viscosity standards' properties. 
Table A.4. Properties of Brookfield Fluids $50 \& 100$

\begin{tabular}{lcc}
\hline Fluid & 50 & 100 \\
\hline List Viscosity & $48.0 \mathrm{cP}$ & $101 \mathrm{cP}$ \\
\hline Acceptable Range $^{(a)}$ & 43.2 to $52.8 \mathrm{cP}$ & 90.9 to $111.1 \mathrm{cP}$ \\
\hline Temperature & $25^{\circ} \mathrm{C}$ & $25^{\circ} \mathrm{C}$ \\
Lot Number & 062408 & 122109 \\
Expires $^{(\text {b) }}$ & May 4, 2010 & March 15, 2011 \\
\hline (a) As defined by RPL-COLLOID-02, Rev .1. \\
(b) Expires 1-year after opening (standard opened May 4, 2009). \\
\hline
\end{tabular}

Performance checks consisted of temperature-controlled, flow-curve measurements that employed the MV1 measuring cup and rotor. The measurements reported herein were covered by a single performance. Performance verifications were executed as follows:

1) The MV1 rotor (concentric cylinder geometry) was installed on the M5 measuring head.

2) Approximately $40 \mathrm{~mL}$ of viscosity fluid was added to the MV1 cup.

3) The measuring cup was installed into the measuring system by slowly raising it on a laboratory jack stand. During installation, the rotor volume displaces the viscosity standard fluid, forcing it to fill the gap between cup and rotor. While the cup was being raised, the liquid level relative to the top of the rotor was monitored through an opening in the top of the measuring system. The cup was raised until the test material was observed to spill over the top of the rotor. Before continuing, an attempt was made to remove the excess viscosity standard from the top of the rotor using a plastic transfer pipette. However, typically 1 to $3 \mathrm{~mL}$ of excess test liquid remains in the upper rotor recess during flow-curve measurement. ${ }^{(a)}$

4) The flow curve (shear stress versus shear rate) data were measured. A rheological analysis was performed over an 11-min period, split into three intervals. Over the first 5 minutes, the shear rate was gradually increased from zero to $1000 \mathrm{~s}^{-1}$. For the next minute, the shear rate was held constant at $1000 \mathrm{~s}^{-1}$. For the final 5 minutes, the shear rate was gradually reduced back to zero. During this time, the resisting torque and rotational rate were continuously monitored and recorded.

After the measurement, flow-curve data were analyzed with the RheoWin 2.96 Pro software to determine the standard viscosity measured on both the RV20-M5 and RS600 systems. The performance check is considered acceptable when the relative percent difference between measured and list viscosity was less than $10 \%$ for fluids with listed viscosities greater than or equal to $10 \mathrm{cP}$ or less than $15 \%$ for fluids with list viscosities less than $10 \mathrm{cP}$. For Brookfield Fluid 50 (see Table A.5), the acceptable range of viscosity is $43.2 \mathrm{cP}$ to $52.8 \mathrm{cP}$ at $25^{\circ} \mathrm{C}$. For Brookfield Fluid 100 (see Table A.4), the acceptable range of viscosity is $90.9 \mathrm{cP}$ to $111.1 \mathrm{cP}$ at $25^{\circ} \mathrm{C}$. Viscosities at temperatures other than $25^{\circ} \mathrm{C}$ were not provided by the manufacturer.

(a) When the rotational rate of the rotor is sufficiently high, any excess material in the upper recess of the rotor can migrate from the top of the rotor to the gap (through inertia). This can lead to a change in the measured slope of the flow curve and flow and flow-curve hysteresis. The migration of excess material is often characterized by a slope discontinuity in the flow curve. Such discontinuities were excluded from analysis of flow-curve data. 
Table A.5 lists the results of the performance verification/check before analysis. The performance of the RV20-M5 measuring system was verified to be acceptable.

Table A.5. Performance Check of RV20-M5 and Temperature Control Instruments Using Brookfield Fluid 50 Viscosity Standard

\begin{tabular}{|c|c|c|c|c|c|}
\hline \multirow[b]{2}{*}{ Period of Performance } & \multirow[b]{2}{*}{ Instrument } & \multirow{2}{*}{$\begin{array}{c}\text { Temperature } \\
{\left[{ }^{\circ} \mathrm{C}\right]}\end{array}$} & \multicolumn{2}{|c|}{ Viscosity [cP] } & \multirow[b]{2}{*}{ Acceptable $^{\text {(a) }}$} \\
\hline & & & List $^{(b)}$ & Measured & \\
\hline \multirow{3}{*}{$\begin{array}{c}\text { Opening } \\
2 / 09 / 2010-3 / 11 / 2010\end{array}$} & RS600 & 25 & 48.0 & 51.43 & Yes \\
\hline & M5 & Ambient (18.5) & $\mathrm{n} / \mathrm{a}$ & 56.95 & Agrees with RS600 $0^{(\text {b }}$ \\
\hline & RS600 & Ambient (18.5) & $\mathrm{n} / \mathrm{a}$ & 57.89 & Agrees with M5 $^{(\mathrm{b})}$ \\
\hline
\end{tabular}

(a) As per RPL-COLLOID-02 Rev. 1, the acceptable range for Brookfield Fluid 50 (calculated as $\pm 10 \%$ of the list viscosity of $48.0 \mathrm{cP}$ ) is 43.2 to $52.8 \mathrm{cP}$ at $25^{\circ} \mathrm{C}$.

(b) List viscosities at temperatures other than $25^{\circ} \mathrm{C}$ are not provided by the manufacturer. Viscosity measurements at ambient temperature were conducted on two measurement systems (RV20-M5 and RS600); results were to agree within $10 \%$ to show acceptable performance.

Table A.6 lists the results of the performance verification/check after analysis. The performance of the RV20-M5 measuring and temperature control systems was again verified to be acceptable.

Table A.6. Performance Check of RV20-M5 and Temperature Control Instruments Using Brookfield Fluid 100 Viscosity Standard

\begin{tabular}{|c|c|c|c|c|c|}
\hline \multirow[b]{2}{*}{ Period of Performance } & \multirow[b]{2}{*}{ Instrument } & \multirow{2}{*}{$\begin{array}{c}\text { Temperature } \\
{\left[{ }^{\circ} \mathrm{C}\right]}\end{array}$} & \multicolumn{2}{|c|}{ Viscosity [cP] } & \multirow[b]{2}{*}{ Acceptable $^{(a)}$} \\
\hline & & & List $^{(b)}$ & Measured & \\
\hline \multirow{3}{*}{$\begin{array}{c}\text { Closing } \\
3 / 14 / 2010-4 / 13 / 2010\end{array}$} & RS600 & 25 & 101 & 101.1 & Yes \\
\hline & M5 & Ambient (23.1) & $\mathrm{n} / \mathrm{a}$ & 110.2 & $\begin{array}{l}\text { Agrees with } \\
\text { RS600 }\end{array}$ \\
\hline & RS600 & Ambient (23.1) & $\mathrm{n} / \mathrm{a}$ & 105.0 & Agrees with $\mathrm{M}^{(\mathrm{b})}$ \\
\hline \multirow{3}{*}{$\begin{array}{c}\text { Closing } \\
4 / 16 / 2010-5 / 17 / 2010\end{array}$} & RS600 & 25 & 101 & 101.7 & Yes \\
\hline & M5 & Ambient (24.1) & $\mathrm{n} / \mathrm{a}$ & 106.7 & $\begin{array}{l}\text { Agrees with } \\
\text { RS600 }\end{array}$ \\
\hline & RS600 & Ambient (24.3) & $\mathrm{n} / \mathrm{a}$ & 102.2 & Agrees with M5 $5^{(\mathrm{b})}$ \\
\hline
\end{tabular}

(a) As per RPL-COLLOID-02 Rev. 1, the acceptable range for Brookfield Fluid 100 (calculated as $\pm 10 \%$ of the list viscosity of $101 \mathrm{cP}$ ) is 90.9 to $111.1 \mathrm{cP}$ at $25^{\circ} \mathrm{C}$.

(b) List viscosities at temperatures other than $25^{\circ} \mathrm{C}$ are not provided by the manufacturer. Viscosity measurements at ambient temperature were conducted on two measurement systems (RV20-M5 and RS600); results were to agree within $10 \%$ to show acceptable performance.

\section{A.4.2 Shear-Strength Testing}

Shear-strength testing was conducted as follows:

1) A 16- $\times 16-\mathrm{mm}$ (diameter by height) shear vane tool was installed on the measuring head.

2) The sample jar being tested was opened and positioned on a laboratory jack stand directly beneath the measuring head/vane.

3) The laboratory jack was slowly raised until the tops of the vane blades were (typically) 1-vane height $(16 \mathrm{~mm})$ below the surface of the settled solids. 
4) The vane was slowly rotated at 0.3 RPM for 120 seconds. For the entire duration of rotation, the time, rotational rate, and vane torque were continuously monitored and recorded.

5) At the completion of testing, the vane was removed from the settled solids, rinsed clean of residual solids with de-ionized (DI) water, and dried before the next test. The sample jar was closed and set aside.

At the end of the measurement, the software parsed the shear stress versus time data and determined and reported the maximum measured shear stress (i.e., the material's shear strength). The curve of shear stress versus time was visually inspected using the RheoWin software to verify that the appropriate stress maximum was selected. All information relevant to the measurement, including raw and calculated measurement results and sample information, were saved to disk using the RheoWin file format and a unique filename identifier. It should be noted that shear-strength measurements were conducted at ambient room temperature, which was recorded using a thermocouple and temperature display. The torque-versus-time curves are given in shear strength plots.

\section{A.5 Clay Shear-Strength Test Results}

\section{A.5.1 Clay Shear-Strength Test Results}

Table A.7 gives the shear-strength results for the six clay samples used in the vessel-spanning bubble testing. The three repeat measurements for each sample are identified from their location in the sample container: center, left-hand-side (LHS), and right-hand-side (RHS). The uncertainties in the average values given in Table A.7 vary from $2 \%$ to $6 \%$ of the mean value, and the average of these uncertainties is about $4 \%$.

Table A.7. Kaolin Clay Shear Strength Measurements for Clays Used in 10-in. Vessels

\begin{tabular}{cccccccc}
\hline \multicolumn{7}{c}{ Shear Strength [Pa] } \\
\hline Wt\% & & \multicolumn{3}{c}{ Sampling Location } \\
\cline { 3 - 6 } Kaolin & Aging & & & & & \\
in & Time & Immersion & & & & \\
DIW & $(\mathrm{h})$ & Depth (mm) & LHS & Center & RHS & Mean & Uncertainty $^{(\text {a) }}$ \\
\hline 48 & 1 & 16 & 154.9 & 159.2 & 155.5 & 157 & \pm 6 \\
49 & 1 & 16 & 233.9 & 224.3 & 227.8 & 229 & \pm 12 \\
50 & 1 & 16 & 255.1 & 257.3 & 264.2 & 259 & \pm 12 \\
52 & 1 & 16 & 408.4 & 404.2 & 401.7 & 405 & \pm 8 \\
55 & 1 & 16 & 703.6 & 737.8 & 726.4 & 723 & \pm 43 \\
55 & 1 & 16 & 692.2 & 694.1 & 700.8 & 696 & \pm 11 \\
58 & 1 & 16 & 1105 & 1071 & 1103 & 1093 & \pm 47 \\
\hline
\end{tabular}

(a) Reported uncertainty is the $95 \%$ confidence limit as determined from t-distribution, where the standard error of the mean [standard deviation/(sample size) ${ }^{1 / 2}$ ] is multiplied by 4.3 (Kreyszig 1979). 
Table A.8. Kaolin Clay Shear Strength Measurements for Clays Used in 5-in. Vessels

\begin{tabular}{cccccccc}
\hline \multicolumn{7}{c}{ Shear Strength [Pa] } \\
\hline Wt\% & & \multicolumn{3}{c}{ Sampling Location } \\
\cline { 3 - 6 } Kaolin & Aging & & & & & \\
in & Time & Immersion & & & & \\
DIW & (h) & Depth $(\mathrm{mm})$ & LHS & Center & RHS & Mean & Uncertainty $^{(\text {a) }}$ \\
\hline 45 & 2 & 16 & 63.15 & 60.39 & 63.24 & 62.3 & \pm 4 \\
47 & 1 & 16 & 107.4 & 112.6 & 114.9 & 111.6 & \pm 9.5 \\
48 & 1.5 & 16 & 147.5 & 156.1 & 152.5 & 152 & \pm 11 \\
49 & 1.5 & 16 & 172.9 & 177.1 & 177.2 & 175.7 & \pm 6 \\
\hline
\end{tabular}

(a) Reported uncertainty is the $95 \%$ confidence limit as determined from t-distribution, where the standard error of the mean [standard deviation/(sample size) $)^{1 / 2}$ ] is multiplied by 4.3 (Kreyszig 1979).

Table A.9. Kaolin Clay Shear Strength Measurements for Clays Used in 23-in. Vessels

\begin{tabular}{cccccccc}
\hline \multicolumn{7}{c}{ Shear Strength [Pa] } \\
\hline Wt\% & & \multicolumn{3}{c}{ Sampling Location } \\
\cline { 3 - 6 } $\begin{array}{c}\text { Kaolin } \\
\text { in }\end{array}$ & $\begin{array}{c}\text { Aging } \\
\text { Time }\end{array}$ & Immersion & & & & \\
DIW & (h) & Depth $(\mathrm{mm})$ & LHS & Center & RHS & Mean & Uncertainty $^{(\text {(a) }}$ \\
\hline 49 & 3 & 16 & 184.6 & 173.4 & 189.4 & 182.5 & \pm 20 \\
52 & 2 & 16 & 347.7 & 339.2 & 350.1 & 345.6 & \pm 14 \\
55 & 1.5 & 16 & 519.7 & 534.7 & 518.5 & 524.3 & \pm 22 \\
58 & 4 & 16 & 1215 & 1246 & 1242 & 1234 & \pm 42 \\
\hline
\end{tabular}

(a) Reported uncertainty is the $95 \%$ confidence limit as determined from t-distribution, where the standard error of the mean [standard deviation/(sample size) $)^{1 / 2}$ ] is multiplied by 4.3 (Kreyszig 1979).

\section{A.5.2 Time Variation of Shear-Strengths for Clay}

Table A.10 gives the shear-strength results with the duration of the rest period (up to 336 hours) for three representative $\mathrm{wt} \%$ of kaolin slurries, 49,52 , and $58 \mathrm{wt} \%$. Up to 2 hours, a single measurement was performed to reduce the time for the measurement, and then three repeat measurements for each sample were made (note that a standard rectangular container was not used in this test, so the description based on center, left-hand-side (LHS), and right-hand-side (RHS) shown in A.6.1 is not appropriate in this test). The uncertainties in the average values given in Table A.10 vary from $1 \%$ to $10 \%$ of the mean value, and the average of these uncertainties is about $4 \%$. 
Table A.10. Time Variation of Shear Strength for Kaolin Clay

\begin{tabular}{|c|c|c|c|c|c|c|c|}
\hline \multicolumn{8}{|c|}{ Shear Strength [Pa] } \\
\hline \multirow{2}{*}{$\begin{array}{c}\mathrm{Wt} \% \\
\text { Kaolin } \\
\text { in } \\
\text { DIW }\end{array}$} & \multirow{2}{*}{$\begin{array}{c}\text { Aging } \\
\text { Time } \\
\text { (h) }\end{array}$} & \multirow[b]{2}{*}{$\begin{array}{l}\text { Immersion } \\
\text { Depth (mm) }\end{array}$} & \multicolumn{3}{|c|}{ Sampling Location } & \multirow[b]{2}{*}{ Mean } & \multirow[b]{2}{*}{ Uncertainty $^{(a)}$} \\
\hline & & & $\# 1$ & $\# 2$ & $\# 3$ & & \\
\hline 49 & 0 & 16 & & 182.0 & & 182.0 & $\mathrm{~N} / \mathrm{A}$ \\
\hline 49 & 0.25 & 16 & & 192.4 & & 192.4 & $\mathrm{~N} / \mathrm{A}$ \\
\hline 49 & 1 & 16 & & 195.1 & & 195.1 & $\mathrm{~N} / \mathrm{A}$ \\
\hline 49 & 2 & 16 & & 188.9 & & 188.9 & N/A \\
\hline 49 & 6 & 16 & 194.7 & 194.9 & 193.7 & 194.4 & \pm 2 \\
\hline 49 & 24 & 16 & 187.3 & 190.6 & 176.1 & 184.7 & \pm 19 \\
\hline 49 & 48 & 16 & 184.0 & 189.2 & 193.9 & 189.0 & \pm 12 \\
\hline 49 & 144 & 16 & 202.6 & 197.1 & 205.2 & 201.6 & \pm 10 \\
\hline 49 & 336 & 16 & 230.0 & 221.3 & 230.4 & 227.2 & \pm 13 \\
\hline 52 & 0 & 16 & & 341.0 & & 341.0 & $\mathrm{~N} / \mathrm{A}$ \\
\hline 52 & 0.25 & 16 & & 344.8 & & 344.8 & N/A \\
\hline 52 & 1 & 16 & & 347.8 & & 347.8 & N/A \\
\hline 52 & 2 & 16 & & 348.8 & & 348.8 & N/A \\
\hline 52 & 6 & 16 & 353.6 & 347.0 & 361.3 & 354.0 & \pm 18 \\
\hline 52 & 24 & 16 & 340.2 & 351.7 & 346.2 & 346.0 & \pm 14 \\
\hline 52 & 48 & 16 & 350.6 & 351.5 & 353.0 & 351.7 & \pm 3 \\
\hline 52 & 144 & 16 & 354.4 & 354.5 & 363.1 & 357.3 & \pm 12 \\
\hline 52 & 336 & 16 & 358.3 & 374.2 & 381.3 & 371.3 & \pm 29 \\
\hline 58 & 0 & 16 & & 1046 & & 1046 & $\mathrm{~N} / \mathrm{A}$ \\
\hline 58 & 0.25 & 16 & & 1075 & & 1075 & N/A \\
\hline 58 & 1 & 16 & & 1087 & & 1087 & N/A \\
\hline 58 & 2 & 16 & & 1109 & & 1109 & N/A \\
\hline 58 & 6 & 16 & 1071 & 1120 & 1054 & 1082 & \pm 85 \\
\hline 58 & 24 & 16 & 1074 & 1070 & 1073 & 1072 & \pm 5 \\
\hline 58 & 48 & 16 & 1092 & 1066 & 1083 & 1080 & \pm 33 \\
\hline 58 & 144 & 16 & 1145 & 1145 & 1141 & 1144 & \pm 6 \\
\hline 58 & 336 & 16 & 1207 & 1192 & 1212 & 1204 & \pm 26 \\
\hline
\end{tabular}

(a) Reported uncertainty is the $95 \%$ confidence limit as determined from t-distribution, where the standard error of the mean [standard deviation/(sample size) $)^{1 / 2}$ ] is multiplied by 4.3 (Kreyszig 1979).

\section{A.5.3 Kaolin Clay/Min-U-Sil 30 Mixture Shear-Strength Test Results}

Table A.11 gives the shear-strength results for the eight kaolin clay/Min-U-Sil 30 samples used in the tests to show how the shear strength varies with the weight fraction of Min-U-Sil 30 with different amounts of kaolin. The three repeat measurements for each sample are identified from their location in the sample container: right-hand-side (RHS), center, and left-hand-side (LHS). The uncertainties in the average values given in Table A.11 vary from $1 \%$ to $4 \%$ of the mean value, and the average of these uncertainties is about $2 \%$. Note that an immersion depth is set to $16 \mathrm{~mm}$ for all measurements. 
Table A.12 gives shear-strength results for the two kaolin clay/Min-U-Sil 30 simulants used in the 23-in. vessel testing.

Table A.11. Kaolin Clay/Min-U-Sil 30 Shear-Strength Measurements

\begin{tabular}{|c|c|c|c|c|c|c|c|}
\hline \multicolumn{8}{|c|}{ Shear Strength [Pa] } \\
\hline $\mathrm{Wt} \%$ & $\mathrm{Wt} \%$ & & & ling Loc & & & \\
\hline $\begin{array}{l}\text { in } \\
\text { DIW }\end{array}$ & $\begin{array}{c}\text { Sil } 30 \\
\text { in DIW }\end{array}$ & $\begin{array}{l}\text { Aging Time } \\
\text { (h) }\end{array}$ & LHS & Center & RHS & Mean & Uncertainty $^{(a)}$ \\
\hline 40 & 14 & 1 & 167.0 & 166.9 & 164.1 & 166.0 & \pm 4 \\
\hline 40 & 17 & 1 & 307.8 & 309.9 & 311.5 & 309.7 & \pm 5 \\
\hline 40 & 20 & 1 & 464.1 & 470.7 & 471.9 & 468.9 & \pm 10 \\
\hline 40 & 24 & 1 & 894.5 & 885.9 & 893.5 & 891.3 & \pm 12 \\
\hline 30 & 30 & 1 & 156.7 & 156.1 & 154.4 & 155.7 & \pm 3 \\
\hline 30 & 32 & 1 & 240.2 & 236.0 & 238.2 & 238.1 & \pm 5 \\
\hline 30 & 35 & 1 & 420.5 & 414.1 & 425.9 & 420.2 & \pm 15 \\
\hline 30 & 38 & 1 & 814.7 & 796.7 & 806.2 & 805.9 & \pm 22 \\
\hline
\end{tabular}

(a) Reported uncertainty is the $95 \%$ confidence limit as determined from t-distribution, where the standard error of the mean [standard deviation/(sample size) ${ }^{1 / 2}$ ] is multiplied by 4.3 (Kreyszig 1979).

Table A.12. Kaolin/Min-U-Sil Clay Shear Strength Measurements for Clays Used in 23-in. Vessel

\begin{tabular}{|c|c|c|c|c|c|c|c|}
\hline \multicolumn{8}{|c|}{ Shear Strength $[\mathrm{Pa}]$} \\
\hline \multirow{2}{*}{$\begin{array}{c}\mathrm{Wt} \% \\
\text { Kaolin/Min- } \\
\text { U-Sil in DIW }\end{array}$} & \multirow{2}{*}{$\begin{array}{l}\text { Aging } \\
\text { Time } \\
\text { (h) }\end{array}$} & \multirow{2}{*}{$\begin{array}{l}\text { Immersion } \\
\text { Depth } \\
(\mathrm{mm})\end{array}$} & \multicolumn{3}{|c|}{ Sampling Location } & \multirow[b]{2}{*}{ Mean } & \multirow[b]{2}{*}{ Uncertainty $^{(\mathrm{a})}$} \\
\hline & & & LHS & Center & RHS & & \\
\hline $40 / 20.5$ & 1 & 16 & 517.9 & 488.2 & 530.4 & 512.6 & \pm 54 \\
\hline $40 / 25$ & 3 & 16 & 1033 & 999.9 & 997 & 1010 & \pm 50 \\
\hline
\end{tabular}

(a) Reported uncertainty is the $95 \%$ confidence limit as determined from t-distribution, where the standard error of the mean [standard deviation/(sample size) ${ }^{1 / 2}$ ] is multiplied by 4.3 (Kreyszig 1979).

Table A.13. Kaolin/Min-U-Sil Clay Shear-Strength Measurements for Clays Used in 10-in. Vessel

\begin{tabular}{cccccccc}
\hline \multicolumn{7}{c}{ Shear Strength [Pa] } \\
\hline Wt\% & Aging & Immersion & \multicolumn{3}{c}{ Sampling Location } \\
\cline { 4 - 7 } Kaolin/Min- & Time & Depth & & & & \\
U-Sil in DIW & $(\mathrm{h})$ & $(\mathrm{mm})$ & LHS & Center & RHS & Mean & Uncertainty $^{(\text {a) }}$ \\
\hline $40 / 16$ & 1 & 16 & 173.1 & 172.6 & 169.6 & 171.8 & \pm 5 \\
$40 / 19$ & 1 & 16 & 292.1 & 288.3 & 291.4 & 290.6 & \pm 5 \\
$40 / 20.5$ & 1 & 16 & 365.1 & 356.1 & 370.1 & 363.8 & \pm 18 \\
$40 / 23$ & 1 & 16 & 677.0 & 697.9 & 669.4 & 681.4 & \pm 37 \\
\hline
\end{tabular}

(a) Reported uncertainty is the $95 \%$ confidence limit as determined from t-distribution, where the standard error of the mean [standard deviation/(sample size) $)^{1 / 2}$ ] is multiplied by 4.3 (Kreyszig 1979). 


\section{A.5.4 KW Container Sludge Simulant (Complete) (KW-A) Shear- Strength Test Results}

Table A.14 gives the shear-strength results for the four KW-A samples used in the test. The three repeat measurements for each sample are identified from their location in the sample container: righthand-side (RHS), center, and left-hand-side (LHS). The uncertainties in the average values given in Table A.14 vary from $6 \%$ to $29 \%$ of the mean value, and the average of these uncertainties is about $22 \%$.

Table A.14. KW-A Shear-Strength Measurements

\begin{tabular}{|c|c|c|c|c|c|c|c|}
\hline \multicolumn{8}{|c|}{ Shear Strength $[\mathrm{Pa}]$} \\
\hline \multirow{2}{*}{$\begin{array}{c}\mathrm{Wt} \% \\
\mathrm{KW}-\mathrm{A} \\
\text { solids in } \\
\text { DIW }\end{array}$} & \multirow[b]{2}{*}{$\begin{array}{c}\text { Aging } \\
\text { Time (h) }\end{array}$} & \multirow{2}{*}{$\begin{array}{l}\text { Immersion } \\
\text { Depth } \\
(\mathrm{mm})\end{array}$} & \multicolumn{3}{|c|}{ Sampling Location } & \multirow[b]{2}{*}{ Mean } & \multirow[b]{2}{*}{ Uncertainty $^{(a)}$} \\
\hline & & & LHS & Center & RHS & & \\
\hline 73.5 & 1 & 16 & 191.9 & 187.3 & 153.7 & 177.6 & \pm 52 \\
\hline 75 & 1 & 16 & 232.7 & 284.1 & 254.1 & 257.0 & \pm 64 \\
\hline 76 & 1 & 16 & 570.5 & 543.9 & 555.2 & 556.5 & \pm 33 \\
\hline 78 & 1 & 16 & 755.9 & 924.9 & 791.0 & 823.9 & \pm 221 \\
\hline
\end{tabular}

(a) Reported uncertainty is the $95 \%$ confidence limit as determined from t-distribution, where the standard error of the mean [standard deviation/(sample size) $)^{1 / 2}$ ] is multiplied by 4.3 (Kreyszig 1979).

\section{A.5.5 Depth Profile of Shear Strengths for KW Container Sludge Simulant (Complete) (KW-A)}

Table A.15 gives the shear-strength results for the depth profile test with three representative KW-A samples, 75, 76.5, and $78 \mathrm{wt} \%$ of $\mathrm{KW}$-A solids. A single measurement was made at each depth to minimize the time to measure all shear strengths over an entire depth $(9.5$ inches for $75 \mathrm{wt} \%$ of $\mathrm{KW}-\mathrm{A}$, 8.875 inches for $76.5 \mathrm{wt} \%$ of KW-A, and 9 inches for $78 \mathrm{wt} \%$ of KW-A). 
Table A.14. Depth Profile Measurements for KW-A Simulants

\begin{tabular}{|c|c|c|c|c|}
\hline $\begin{array}{l}\text { Wt\% KW-A } \\
\text { Solids in DIW }\end{array}$ & $\begin{array}{l}\text { Difference in } \\
\text { Time } \\
\text { Between This } \\
\text { Measurement } \\
\text { and the First } \\
\text { Measurement } \\
\text { (min) }\end{array}$ & $\begin{array}{l}\text { Total Solid Height } \\
\text { in Column }(\mathrm{cm})\end{array}$ & $\begin{array}{l}\text { Height from } \\
\text { Bottom of } \\
\text { Column }(\mathrm{cm})\end{array}$ & Shear Strength $(\mathrm{Pa})$ \\
\hline 75 & 0 & 24.13 & 22.5 & 217.3 \\
\hline 75 & 4 & 24.13 & 20.1 & 246.3 \\
\hline 75 & 8 & 24.13 & 18.1 & 198.1 \\
\hline 75 & 12 & 24.13 & 16.1 & 229.2 \\
\hline 75 & 16 & 24.13 & 14.1 & 204.7 \\
\hline 75 & 33 & 24.13 & 11.6 & 212.3 \\
\hline 75 & 37 & 24.13 & 9.1 & 225.6 \\
\hline 75 & 41 & 24.13 & 7.1 & 287.3 \\
\hline 75 & 45 & 24.13 & 5.1 & 372.7 \\
\hline 75 & 49 & 24.13 & 3.1 & 626.7 \\
\hline 76.5 & 0 & 22.54 & 20.9 & 400.5 \\
\hline 76.5 & 5 & 22.54 & 18.5 & 476.1 \\
\hline 76.5 & 8 & 22.54 & 16.5 & 418.9 \\
\hline 76.5 & 13 & 22.54 & 14.5 & 373.6 \\
\hline 76.5 & 17 & 22.54 & 12.5 & 514.6 \\
\hline 76.5 & 31 & 22.54 & 11.0 & 389.3 \\
\hline 76.5 & 35 & 22.54 & 8.5 & 417.4 \\
\hline 76.5 & 38 & 22.54 & 6.5 & 442.0 \\
\hline 76.5 & 41 & 22.54 & 4.5 & 489.6 \\
\hline 76.5 & 44 & 22.54 & 2.5 & 675.1 \\
\hline 78 & 0 & 22.86 & 21.3 & 1295 \\
\hline 78 & 5 & 22.86 & 18.9 & 1832 \\
\hline 78 & 10 & 22.86 & 16.9 & 1514 \\
\hline 78 & 15 & 22.86 & 14.9 & 1290 \\
\hline 78 & 21 & 22.86 & 12.9 & 1387 \\
\hline 78 & 31 & 22.86 & 11.4 & 1313 \\
\hline 78 & 35 & 22.86 & 8.9 & 1311 \\
\hline 78 & 39 & 22.86 & 6.9 & 1335 \\
\hline 78 & 43 & 22.86 & 4.9 & 1473 \\
\hline 78 & 47 & 22.86 & 2.9 & 2068 \\
\hline
\end{tabular}




\section{A.6 Shear Strength Plots}

\section{A.6.1 Kaolin Clay}

This section presents the shear-strength-versus-time plots that show the maximum shear strength of a given clay. The first series of plots represent clays used in the 10 -in. vessel. The next series of plots represent clays used in the 5-in. vessel. Finally, the last series of plots in this section show clays used in the 23-in. vessel.

The following figures represent clays used in the 10-in.-diameter vessels:

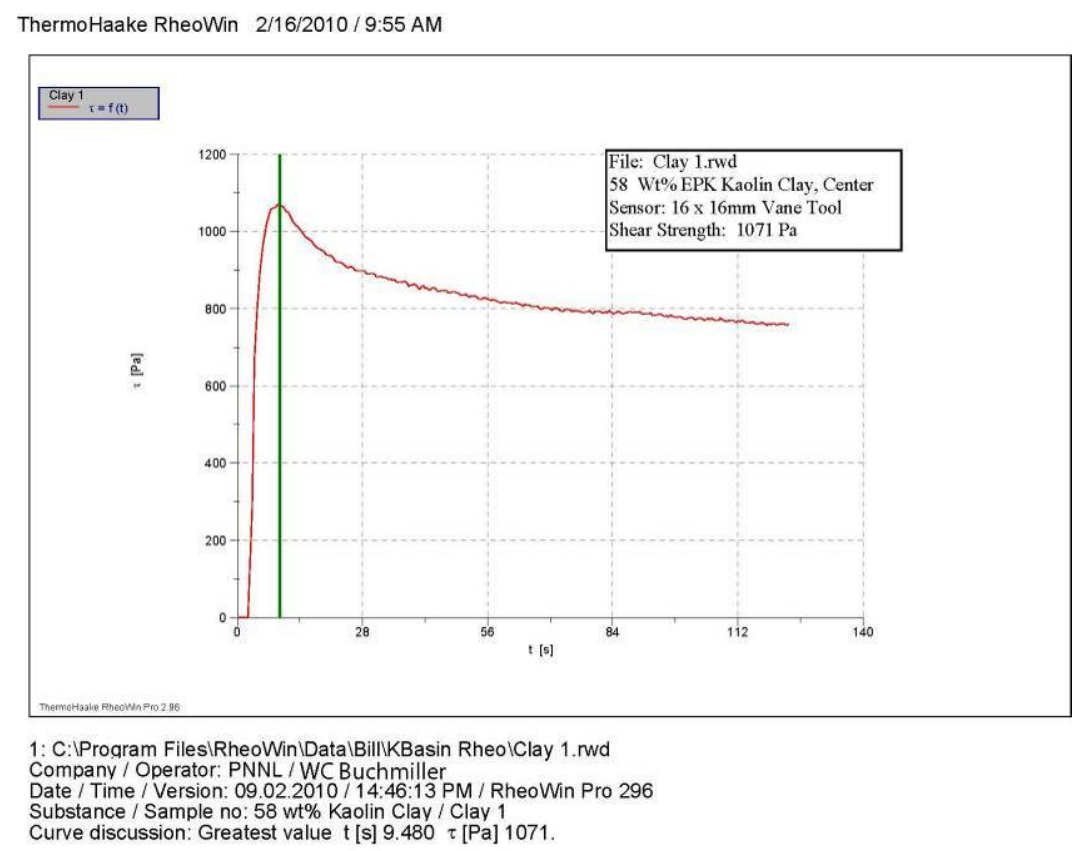

Figure A.3. 58-wt\% Kaolin Clay, Center Sampling Location 
ThermoHaake RheoWin 2/16/2010/9:56 AM

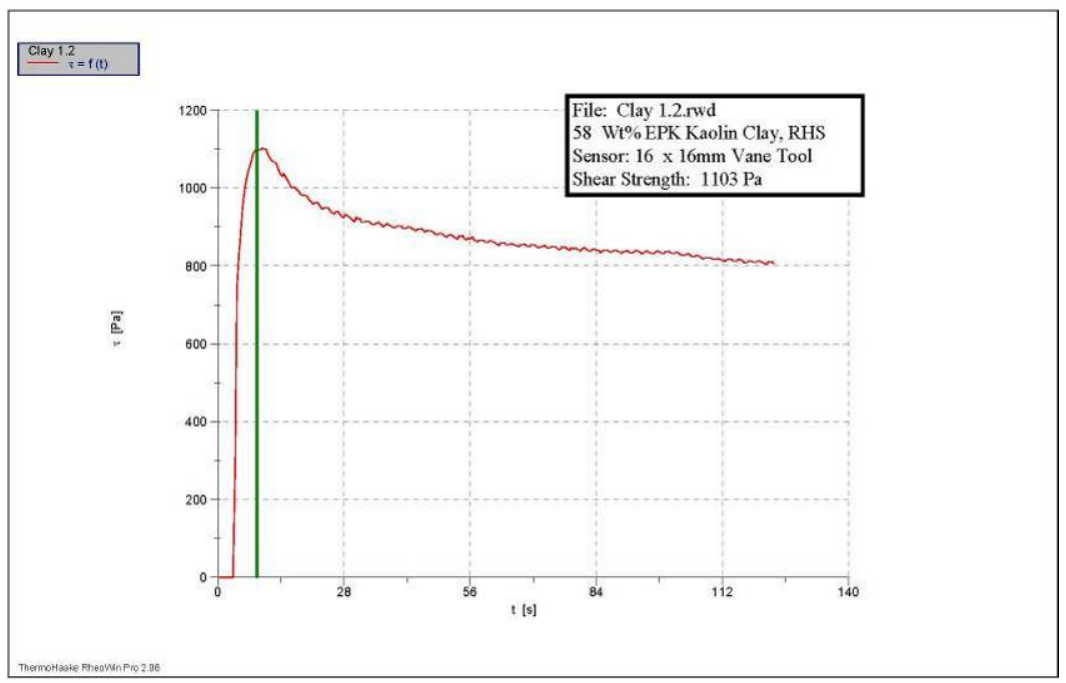

1: C:IProgram Files IRheoWin \DatalBill KKasin RheolClay 1.2.rwd

Date / Time / Version: 09.02.2010/14:54:49 PM / RheoWin Pro 296

Lubs / 58 wh Kaolin Clay / Clay 1.2

Curvence/ dample 09 : 58 wh Kaolin Clay / Clay 1.2

Figure A.4. 58-wt\% Kaolin Clay, RHS Sampling Location

ThermoHaake RheoWin 2/16/2010/9:57 AM

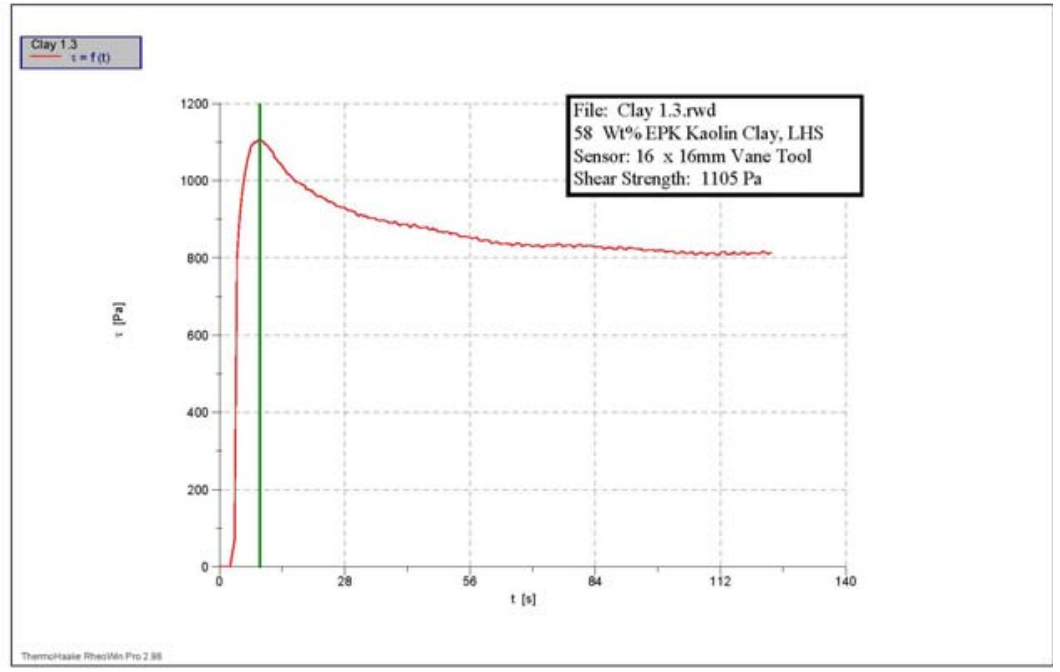

1: C:IProgram Files $|R h e o W i n \backslash D a t a| B i l l K B a s i n$ RheolClay 1.3.rwd

Company / Operator. PNNL / WC Buchmiller

Sula 296

Substance/Sample: no:

Figure A.5. $58-w t \%$ Kaolin Clay, LHS Sampling Location 
ThermoHaake RheoWin 2/24/2010/10:27 PM

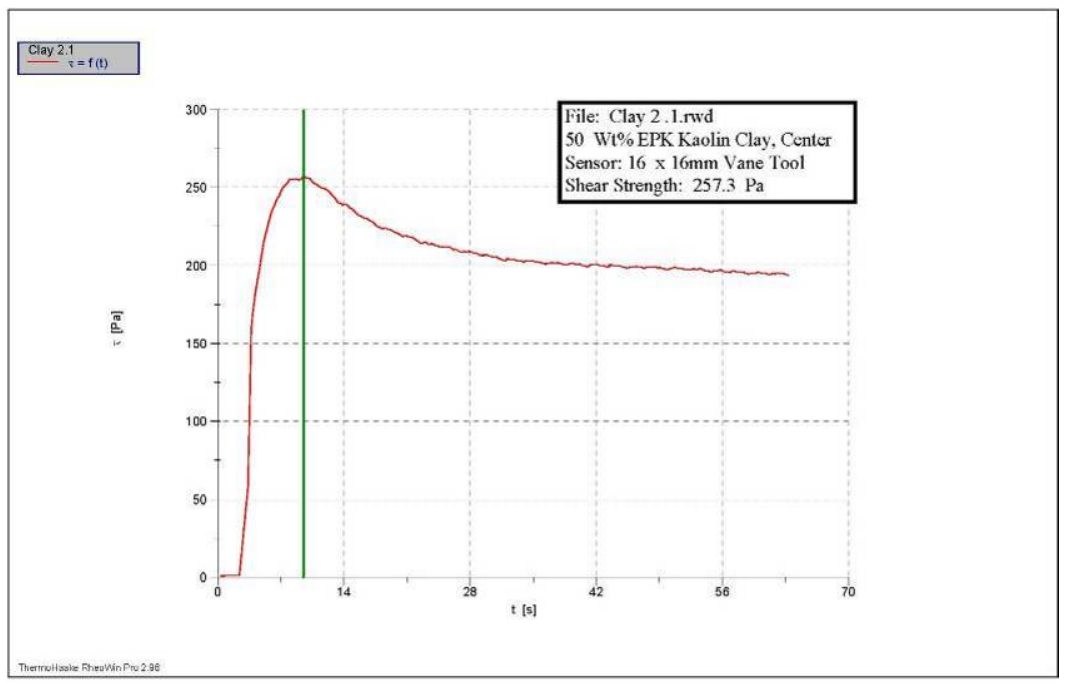

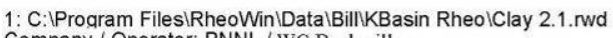

Date / Time / Version: 24.02.2010/ 21:59:36 PM / RheoWin Pro 296

Substance/Sample no: Clay 2/Clay 21

Curve discussion: Greatest value t [s] $9.501 \tau[\mathrm{Pa}] 257.3$

Figure A.6. $50-w t \%$ Kaolin Clay, Center Sampling Location

ThermoHaake RheoWin 2/24/2010/10:18 PM

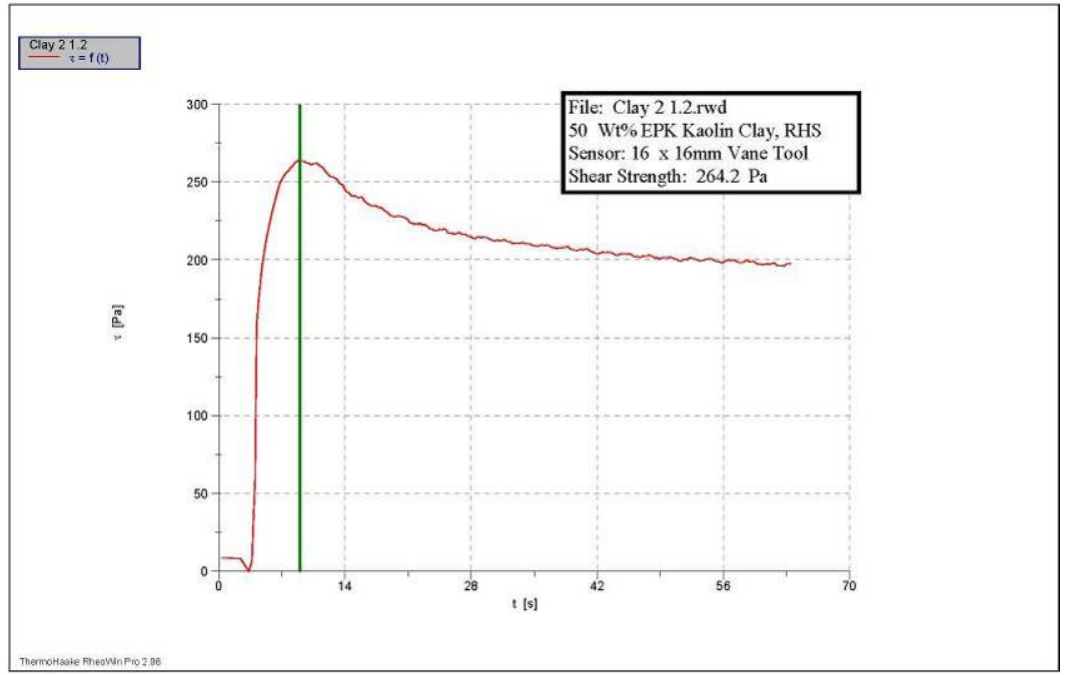

1: C:IProgram Files\RheoWin IDatalBillKKBasin RheolClay 2 1.2.rwd

Date / Time / Version: 24.02.2010 / 22:07:10 PM / RheoWin Pro 296

Substance / Sample no: Clay 2/ Clay 21.2

Curve discussion: Greatest value $\mathrm{t}[\mathrm{s}] 9.000 \tau[\mathrm{Pa}] 264.2$

Figure A.7. $50-\mathrm{wt} \%$ Kaolin Clay, RHS Sampling Location 
ThermoHaake RheoWin 2/24/2010/10:25 PM

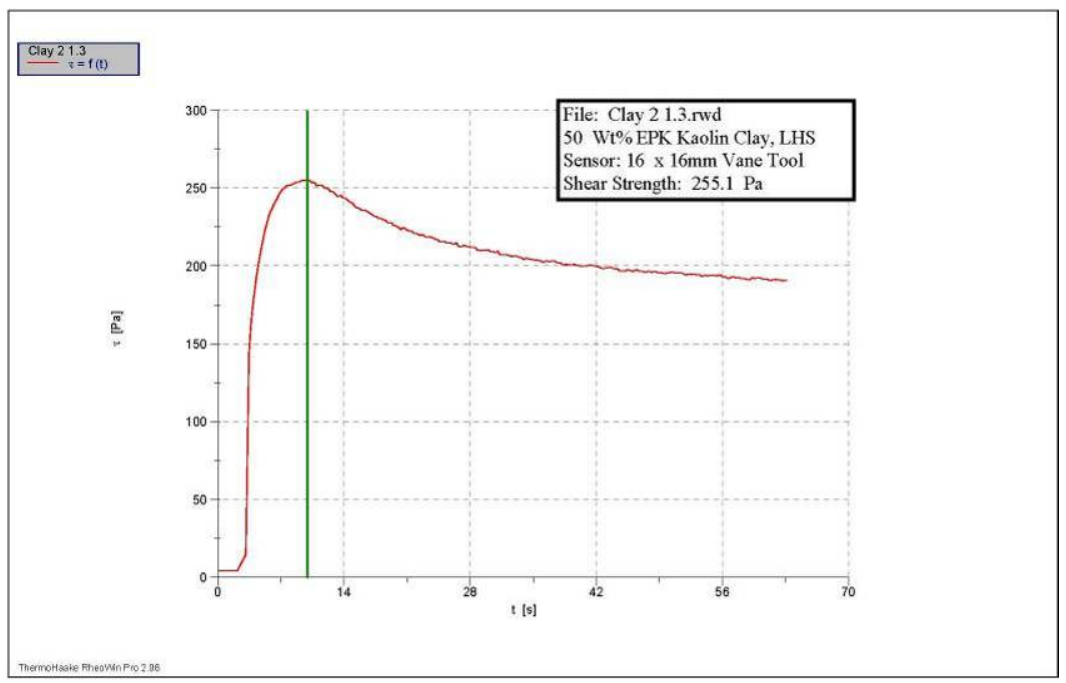

1: C:IProgram Files|RheoWin|Data|Bill|KBasin RheolClay 21.3.nwd Company / Operator: PNNL / WC Buchmiller

源

Curve discussion: Greatest value $\mathrm{t}[\mathrm{s}] 9.931 \tau[\mathrm{Pa}] 255.1$

Figure A.8. $50-\mathrm{wt} \%$ Kaolin Clay, LHS Sampling Location

ThermoHaake RheoWin 3/1/2010/2:12 PM

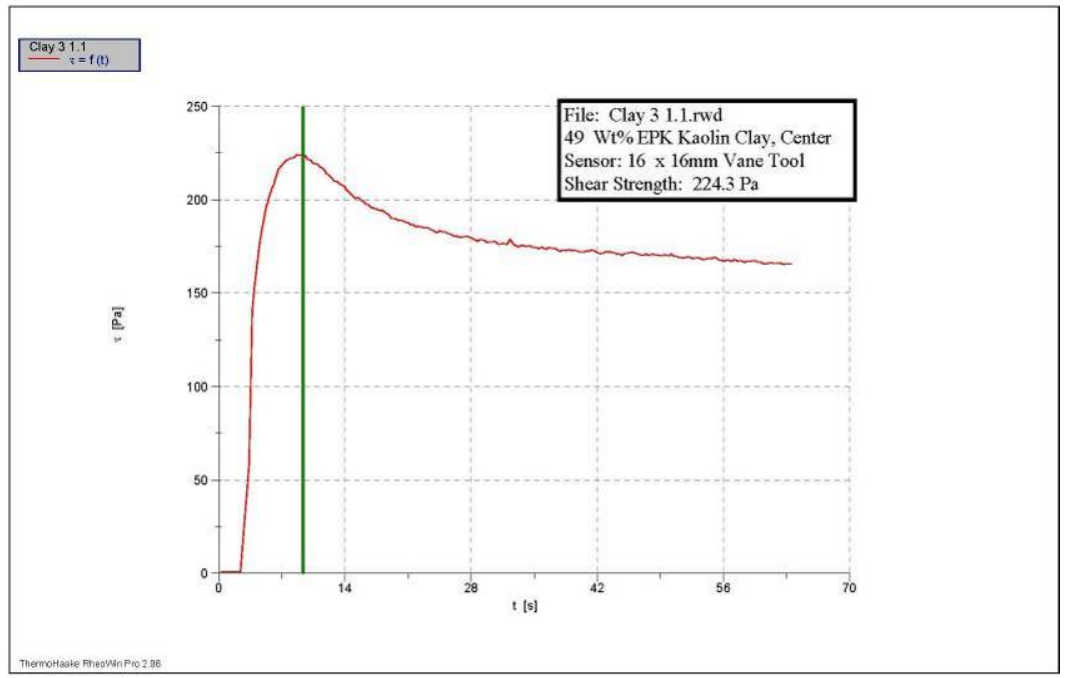

1: C:IProgram Files\RheoWin $\backslash$ DatalBill $\backslash$ Clay 3 1.1.rwd

Company / Operator: PNNL / WC Buchmille

Date / Time / Version: 01.03.2010 / 14:08:34 PM / RheoWin Pro 296

Substance / Sample no: Clay $3 /$ Clay 31.

Curve discussion: Greatest value $\mathrm{t}[\mathrm{s}] 9.340 \tau[\mathrm{Pa}] 224.3$

Figure A.9. 49-wt\% Kaolin Clay, Center Sampling Location 
ThermoHaake RheoWin 3/1/2010/2:18 PM

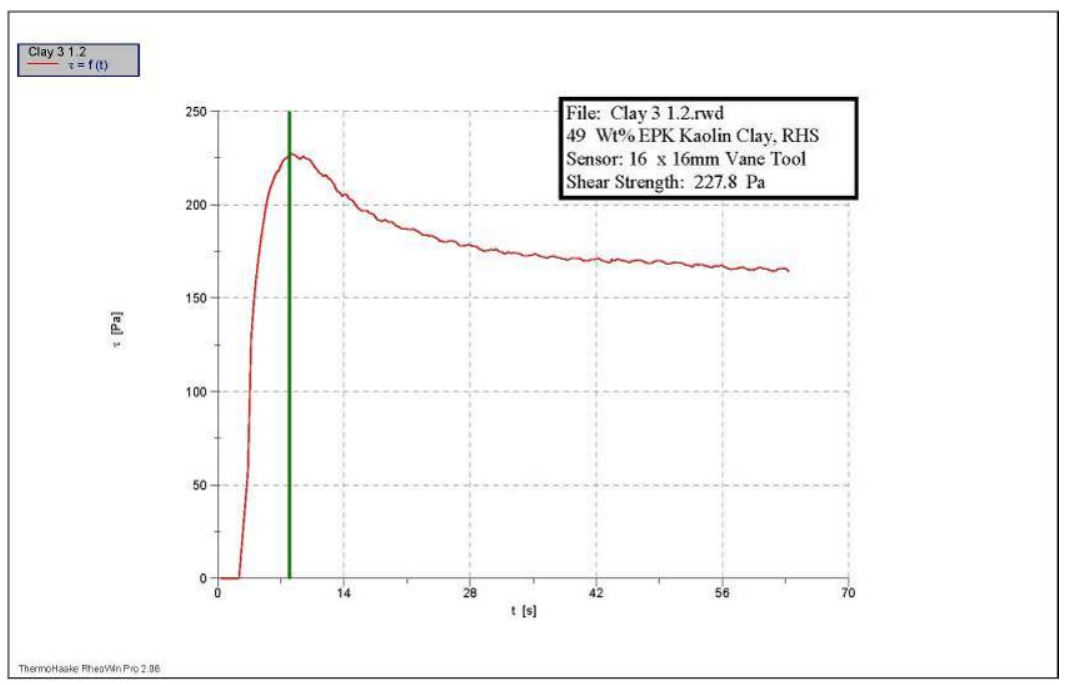

1: C:IProgram Files $\mid R$ heoWin $\backslash$ DatalBill $\backslash$ Clay 3 1.2.rwd

Compari

2 PM / RheoWin Pro 296

Curve discussion: Greatest value $\mathrm{t}[\mathrm{s}] 7.958 \tau[\mathrm{Pa}] 227.8$

Figure A.10. 49-wt\% Kaolin Clay, RHS Sampling Location

ThermoHaake RheoWin 3/1/2010/2:23 PM

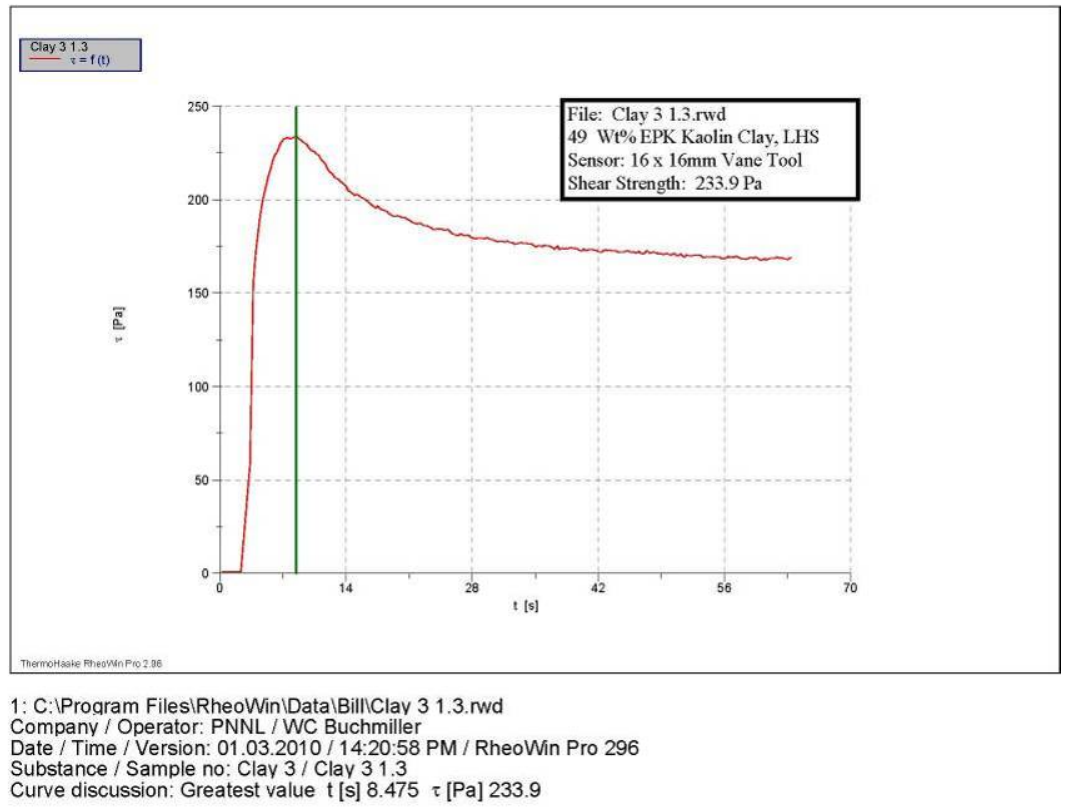

Figure A.11. 49-wt\% Kaolin Clay, LHS Sampling Location 
ThermoHaake RheoWin 3/2/2010 / 6:53 PM

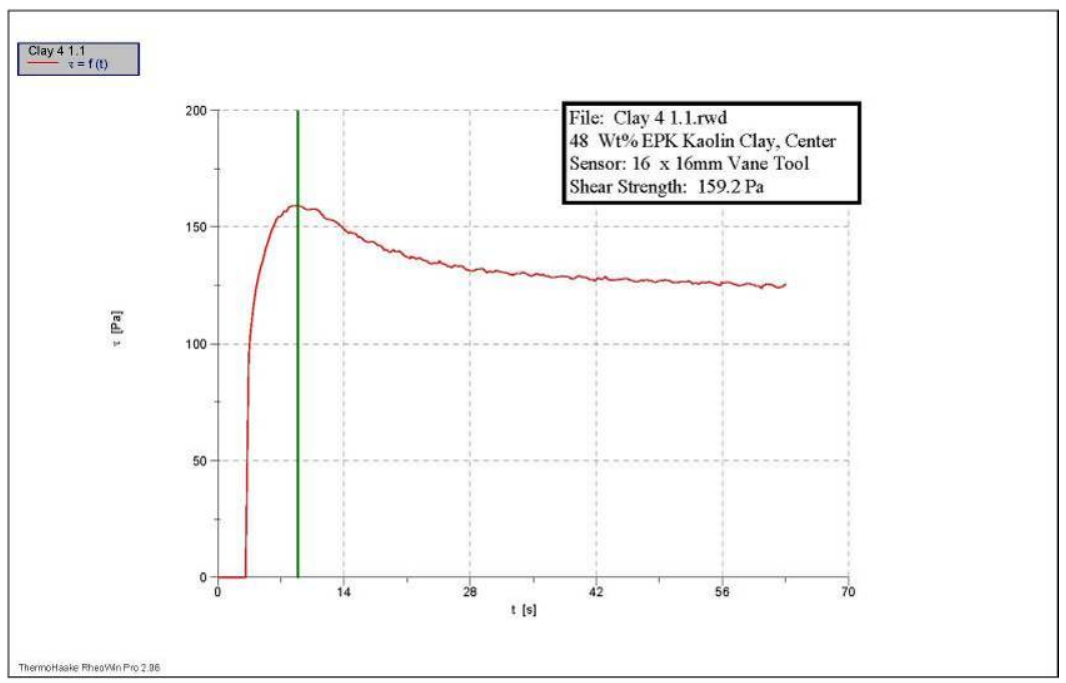

1: C:IProgram Files\RheoWin $\backslash$ Data|Bill IClay 4 1.1, rwd

Company / Operator. PNNL/WC Buchmiller

5 PM / RheoWin Pro 296

Curve discussion: Greatest value $\mathrm{t}[\mathrm{s}] \mathbf{8 . 9 0 0} \tau[\mathrm{Pa}] 159.2$

Figure A.12. $48-w t \%$ Kaolin Clay, Center Sampling Location

ThermoHaake RheoWin 3/2/2010/6:58 PM

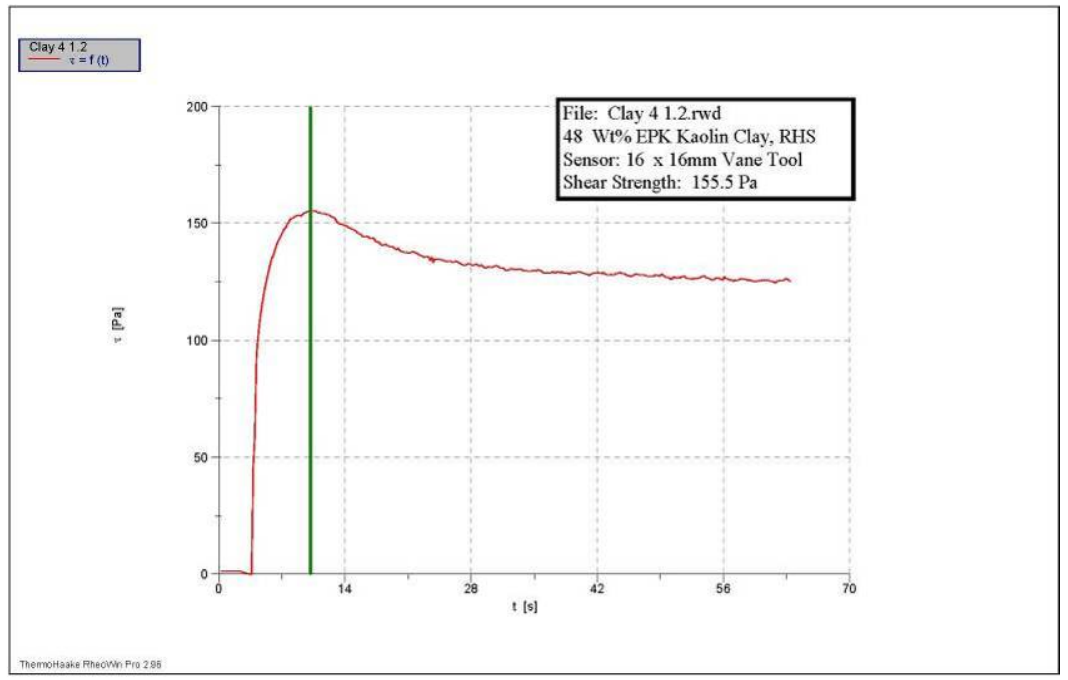

1: C:IProgram FilesiRheoWin IDatalBilliClay 4 1.2.nwd

Company / Operator: PNNL / WC Buchmiller

Date / Time / Version: 02.03.2010/18:56:37 PM / RheoWin Pro 296

Substance/Sample no: Clay $4 /$ Clay 41.2

Curve discussion: Greatest value $\mathrm{t}[\mathrm{s}] 10.15 \tau[\mathrm{Pa}] 155.5$

Figure A.13. $48-w t \%$ Kaolin Clay, RHS Sampling Location 
ThermoHaake RheoWin 3/2/2010/7:03 PM

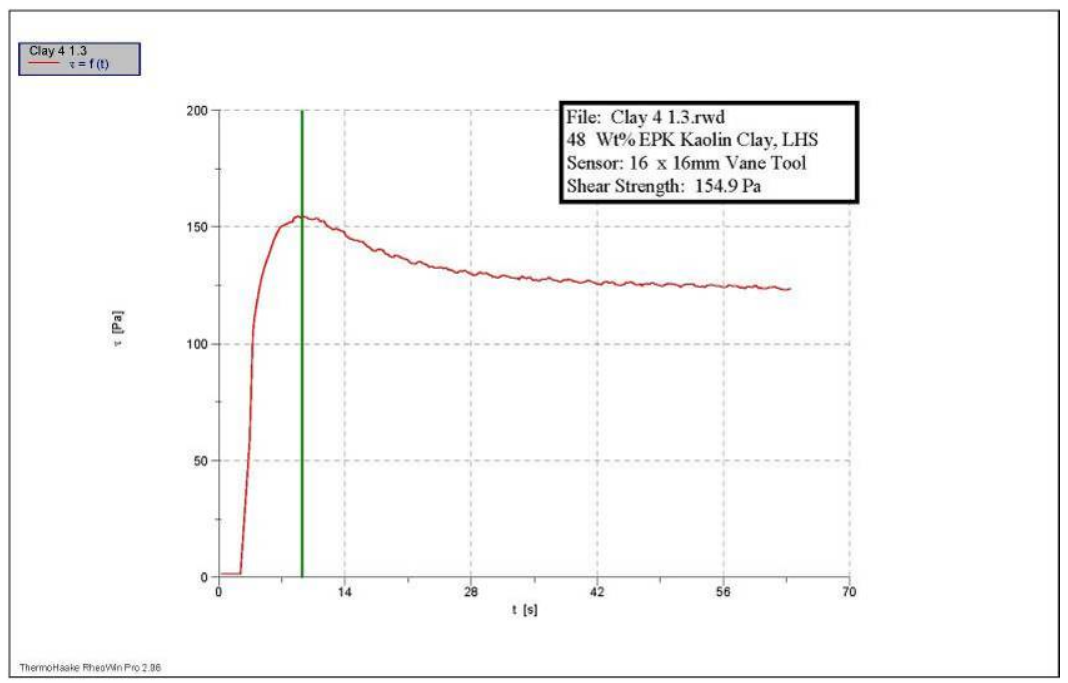

1: C:IProaram Files $\backslash R$ ReoWin $\backslash$ Data|Bill IClay 4 1.3.rwd

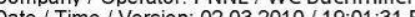

PM / RheoWin Pro 296

Curve discussion: Greatest value $\mathrm{t}[\mathrm{S}] 9.230 \tau[\mathrm{Pa}] 154.9$

Figure A.14. 48-wt\% Kaolin Clay, LHS Sampling Location

ThermoHaake RheoWin 2/17/2010/9:51 PM

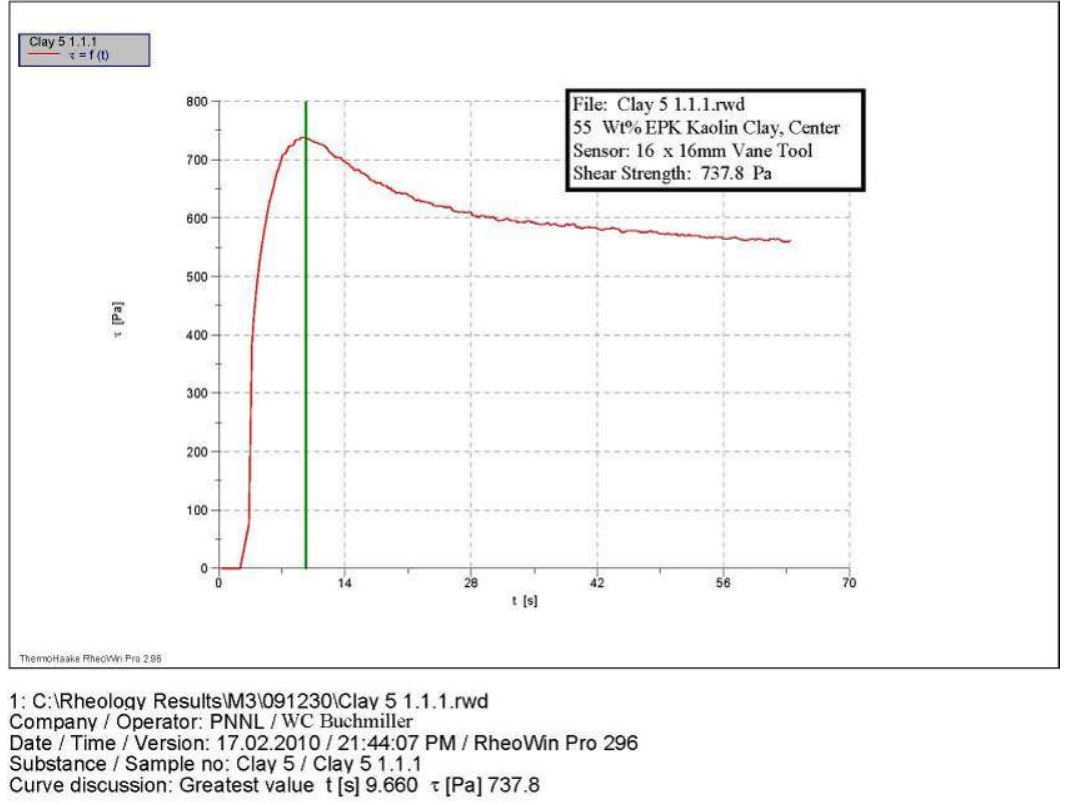

Figure A.15. 55-wt \% Kaolin Clay, Center Sampling Location 
ThermoHaake RheoWin 2/17/2010/9:57 PM

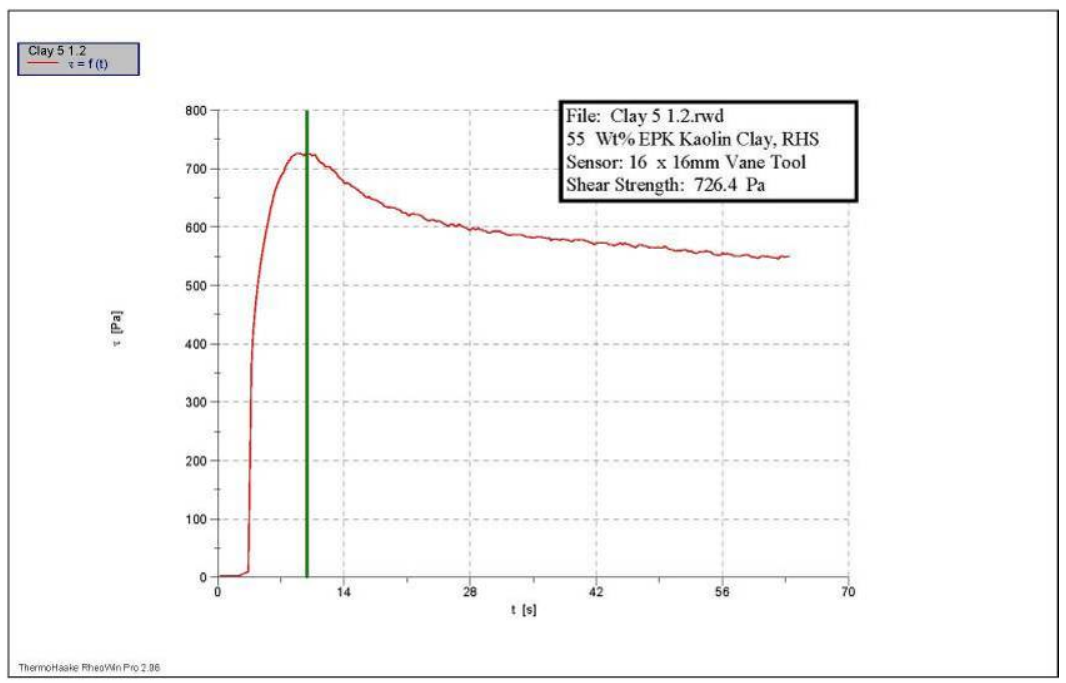

1: C:IRheology Results M3l091230lClay 5 1.2.rwd

Company / perator. PNNL/ Wuchmiller

PM / RheoWin Pro 296

Curve discussion: Greatest value $\mathrm{t}[\mathrm{s}] 9.901 \tau[\mathrm{Pa}] 726.4$

Figure A.16. $55-w t \%$ Kaolin Clay, RHS Sampling Location

ThermoHaake RheoWin 2/17/2010/10:20 PM

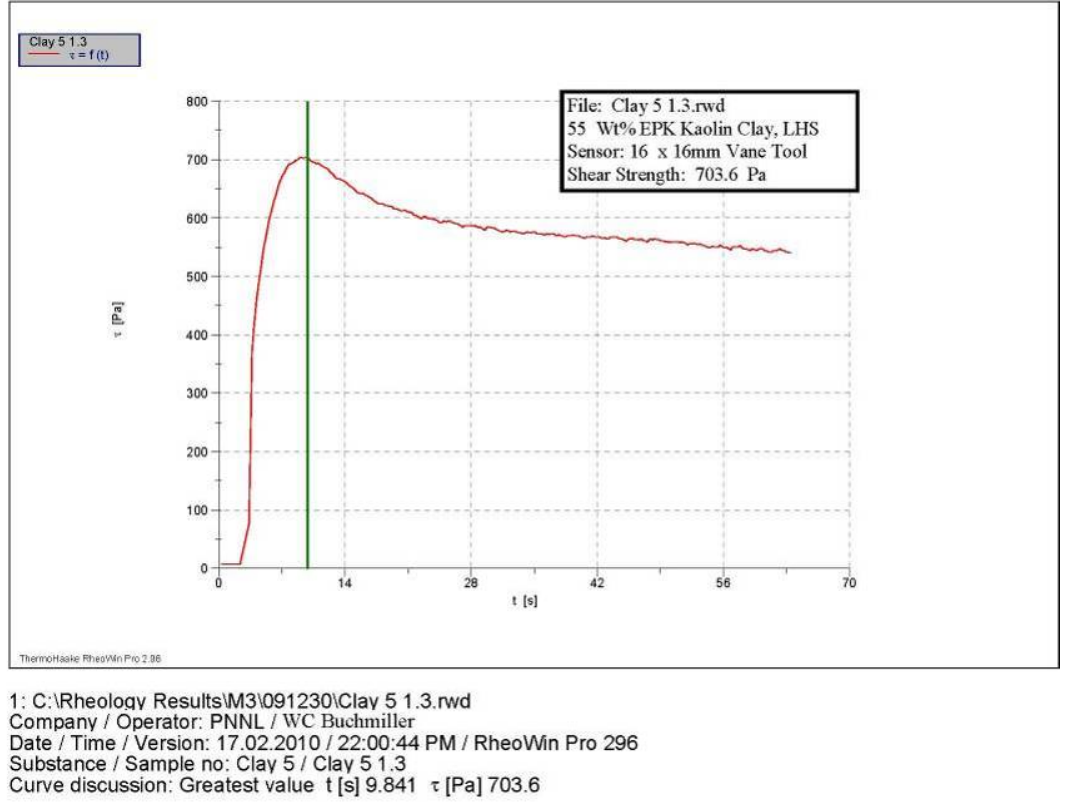

Figure A.17. 55-wt\% Kaolin Clay, LHS Sampling Location 
ThermoHaake RheoWin 3/23/2010/12:56 PM

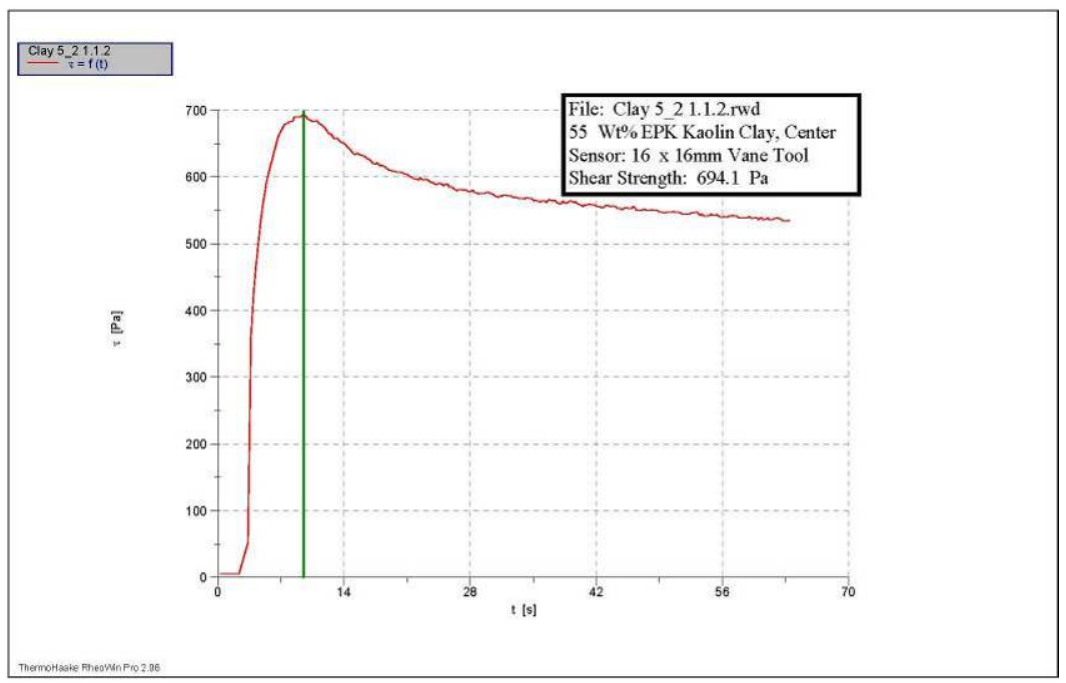

1: C: Program Files $\backslash$ RheoWin $\backslash$ DatalBill $K K$ Basin RheolClay 5_2 1.1.2.rwd

Date / Time / Version: 23.03.2010 / 12:52:31 PM / RheoWin Pro 296

Substance / Sample no: Clay 52 / Clay 521.12

Curve discussion: Greatest value $\mathrm{t}$ [s] $9.490 \tau[\mathrm{Pa}] 694.1$

Figure A.18. $55-w t \%$ Kaolin Clay, Center Sampling Location

ThermoHaake RheoWin 3/23/2010/1:00 PM

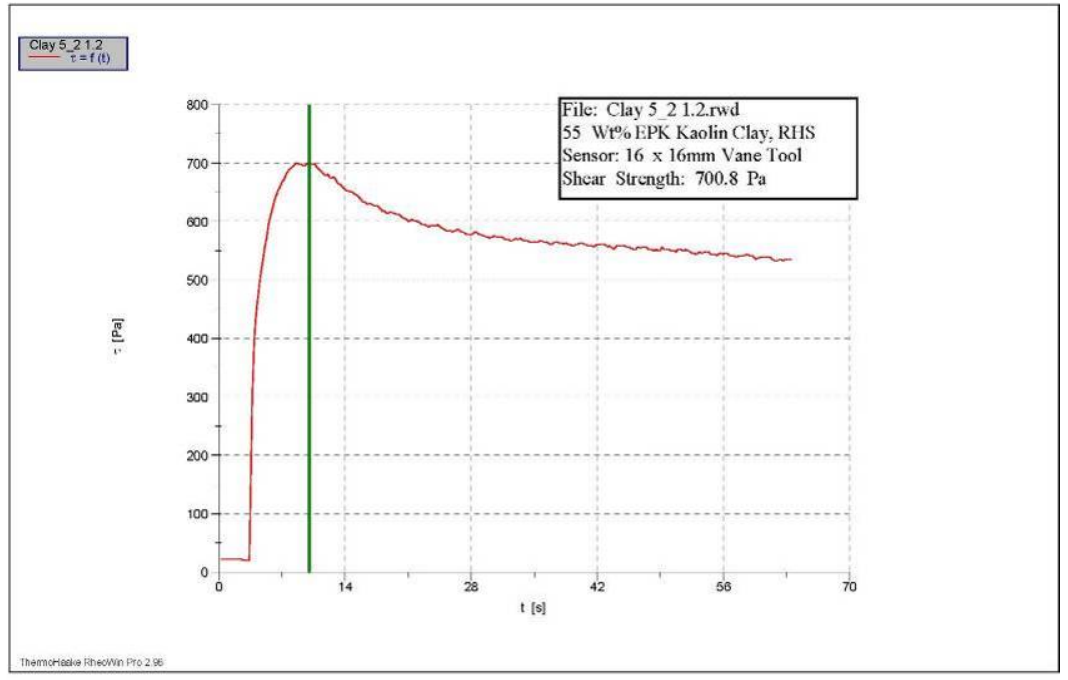

1: C:IProgram FilesIRheoWin|DatalBillKKBasin RheolClay 5_2 1.2.rwd

Company / Operator: PNNL / WC Buchmille

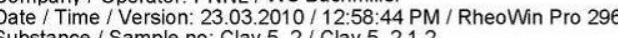

. Clay 521.2

Curve discussion: Greatest value $\mathrm{t}[\mathrm{s}] 10.04 \tau[\mathrm{Pa}] 700.8$

Figure A.19. 55-wt\% Kaolin Clay, RHS Sampling Location 
ThermoHaake RheoWin 3/23/2010/1:05 PM

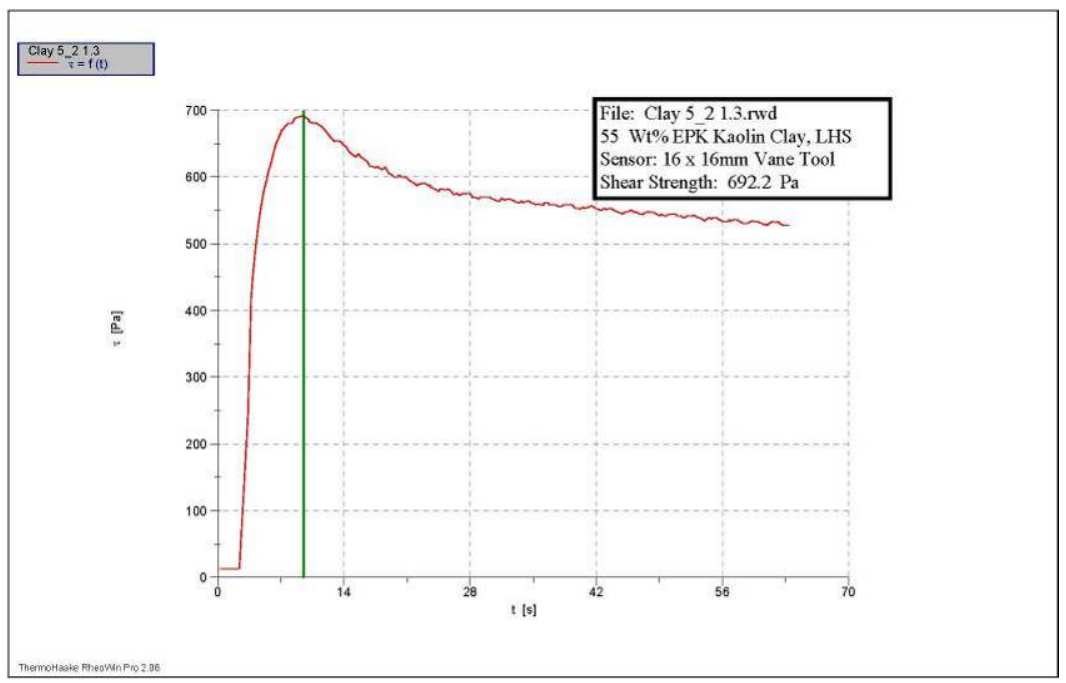

1: C:IProgram Files IRheoWin \DatalBill|KBasin RheolClay 5_2 1.3.rwd

Company / Operator: PNNL / WC Buchmiller

Date / Time/ / 296

Curve discussion: Greatest value $\mathrm{t}[\mathrm{s}] 9.501 \tau[\mathrm{Pa}] 692.2$

Figure A.20. $55-w t \%$ Kaolin Clay, LHS Sampling Location

ThermoHaake RheoWin 3/10/2010/8:54 PM

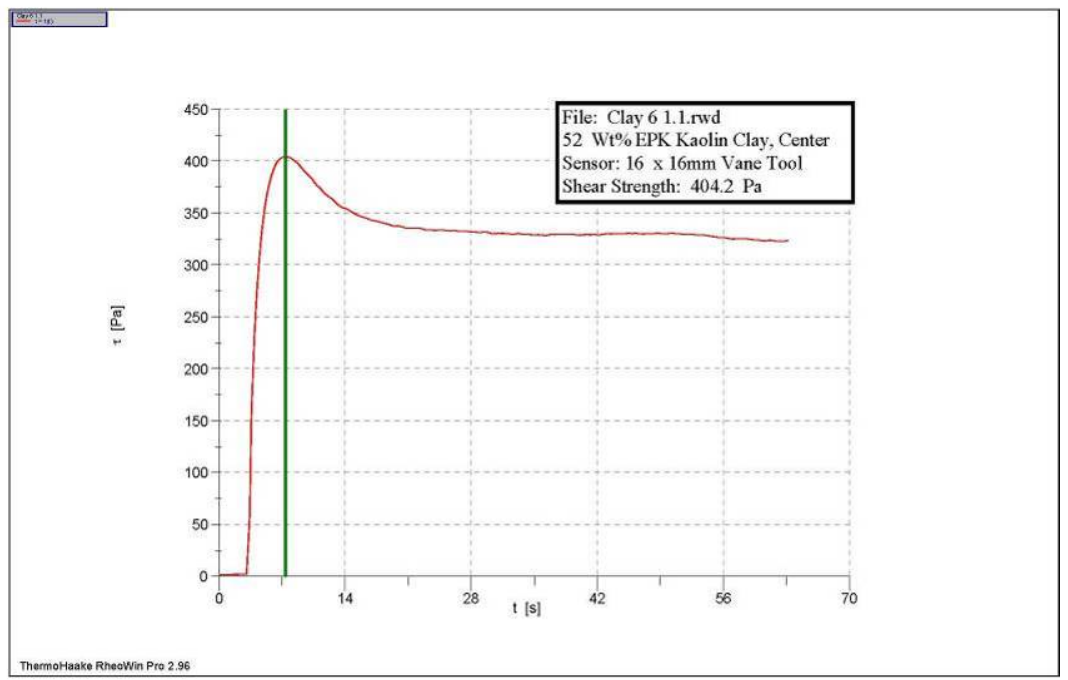

1: C:IProgram Files $|R h e o W i n \backslash D a t a| B i l l K K B a s i n$ RheolClay 6 1.1.nd

Company / Operator: PNNL / WC Buchmiller

Date / Time / Version: 10.03.2010 / 20:50:14 PM / RheoWin Pro 296

Substance / Sample no: Clay 6 / Clay 61.1

Curve discussion: Greatest value $\mathrm{t}[\mathrm{s}] 7.374 \tau[\mathrm{Pa}] 404.2$

Figure A.21. 52-wt $\%$ Kaolin Clay, Center Sampling Location 
ThermoHaake RheoWin 3/10/2010/9:09 PM

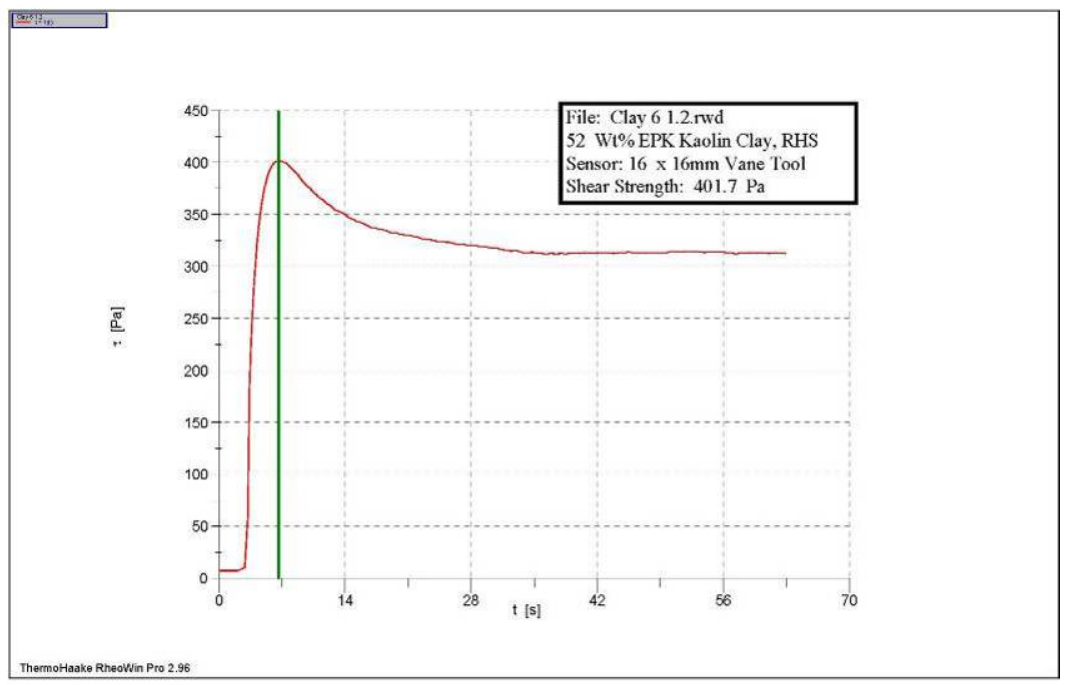

1: C:IProgram Files $\backslash R$ ReoWin $\backslash$ DatalBill KBasin RheolClay 6 1.2.rwd

Company / Operator: PNNL / WC Buchmiller

年

Curve discussion: Greatest value $\mathrm{t}[\mathrm{s}] 6.616 \tau[\mathrm{Pa}] 401.7$

Figure A.22. 52-wt \% Kaolin Clay, RHS Sampling Location

ThermoHaake RheoWin 3/10/2010/9:17 PM

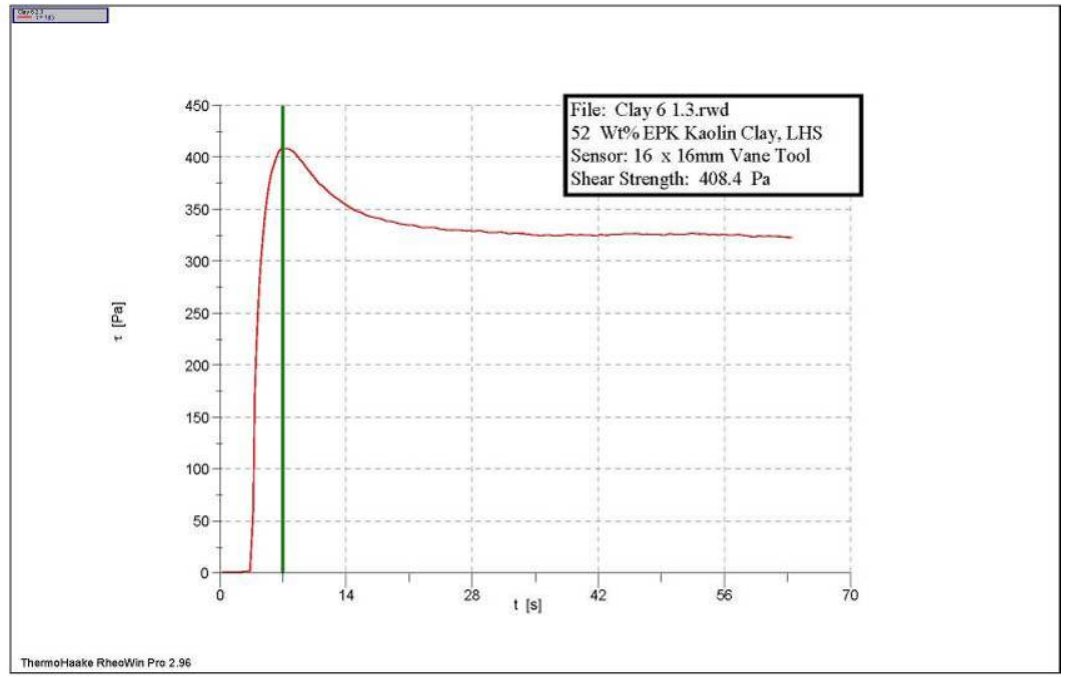

1: C: IProgram Files\RheoWin \Data \Bill|KBasin RheolClay 6 1.3.rwd Company / Operator: PNNL / WC Buchmiller

Date / Time / Version: 10.03.2010 / 21:14:24 PM / RheoWin Pro 296

Substance / Sample no: Clay 6 / Clay 61.3

Curve discussion: Greatest value $\mathrm{t}[\mathrm{s}] 6.957 \tau[\mathrm{Pa}] 408.4$

Figure A.23. $52-w t \%$ Kaolin Clay, LHS Sampling Location 


\section{A.6.2 Kaolin Clays Used in the 5-in.-Diameter Vessel}

ThermoHaake RheoWin 8/5/2010/7:18 PM

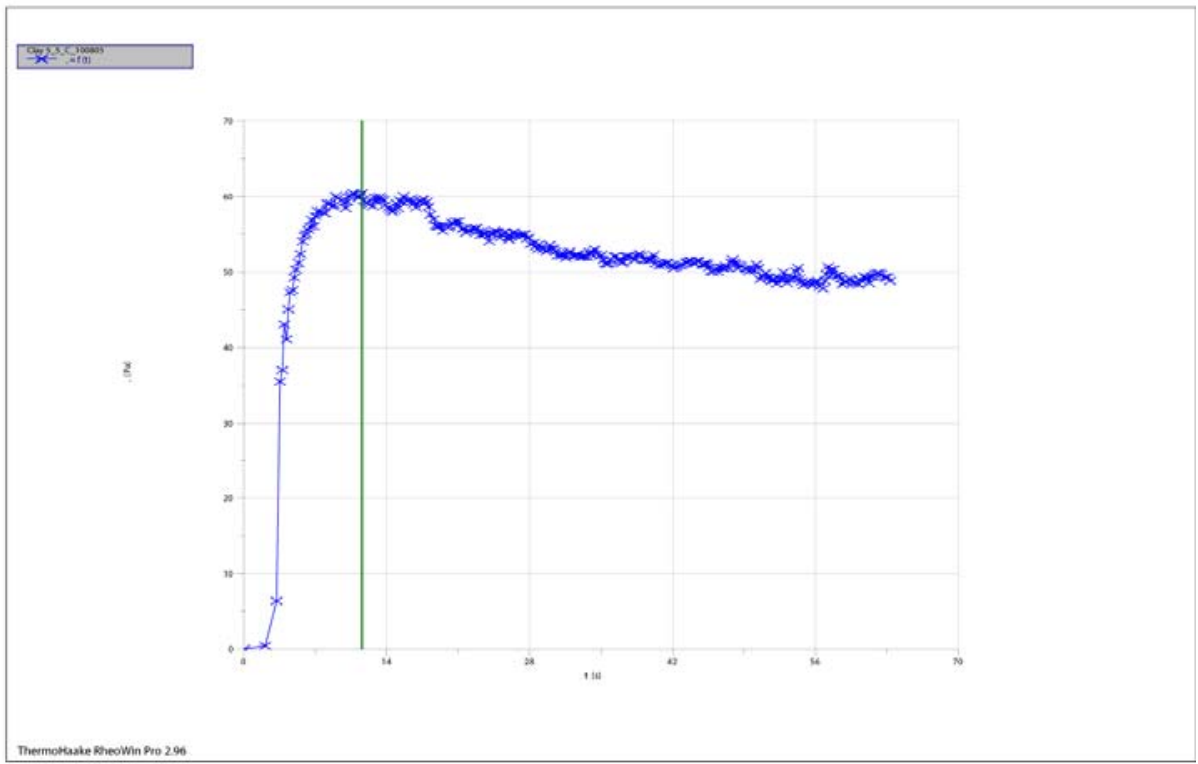

1: C: Rheoloqy Results VJKK Basin VSB\Clay 5 5\Clay 5_5_C_100805.rwd

Company / Operator: PNNL / Jeromy Jenks

Date / Time / Version: 05.08.2010 / 19:06:45 PM / RheoWin Pro 296

Substance / Sample no: Clay 5 5/Clay 5 _ C 100805

Curve discussion: Greatest value $\mathrm{t}[\mathrm{s}] 11.58,[\mathrm{~Pa}] 60.39$

Figure A.24. $45-w t \%$ Kaolin Clay, Center Sampling Location

ThermoHaake RheoWin 8/5/2010/7:19 PM

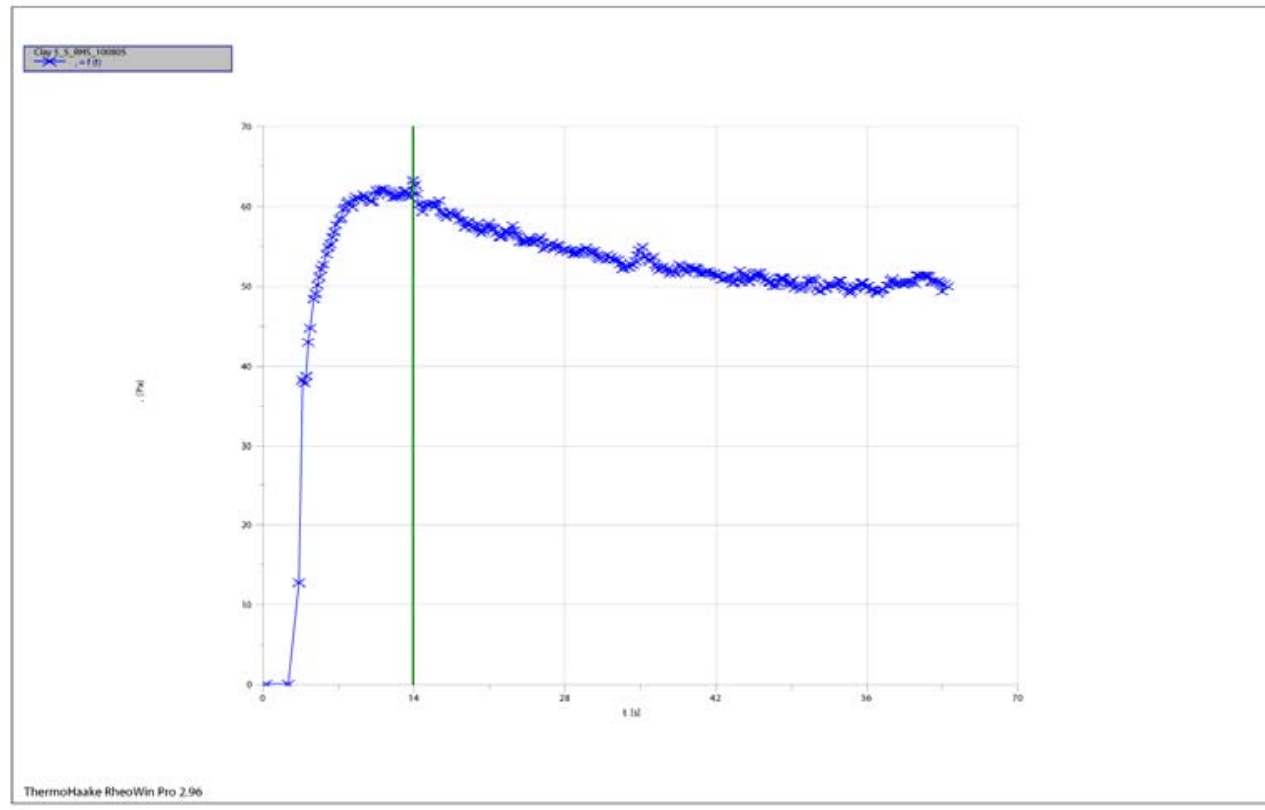

1: C:IRheoloqy Results \J\K Basin VSB\Clay 5 5\Clay 5_5_RHS_100805.rwd

Company / Operator: PNNL / Jeromy Jenks

Date / Time / Version: 05.08.2010 / 19:10:45 PM / RheoWin Pro 296

Substance / Sample no: Clay 5_5 / Clay 5_5_RHS_100805

Curve discussion: Greatest value $\mathrm{t}[\mathrm{s}] 13.93,[\mathrm{~Pa}] 63.24$

Figure A.25. 45-wt\% Kaolin Clay, RHS Sampling Location 


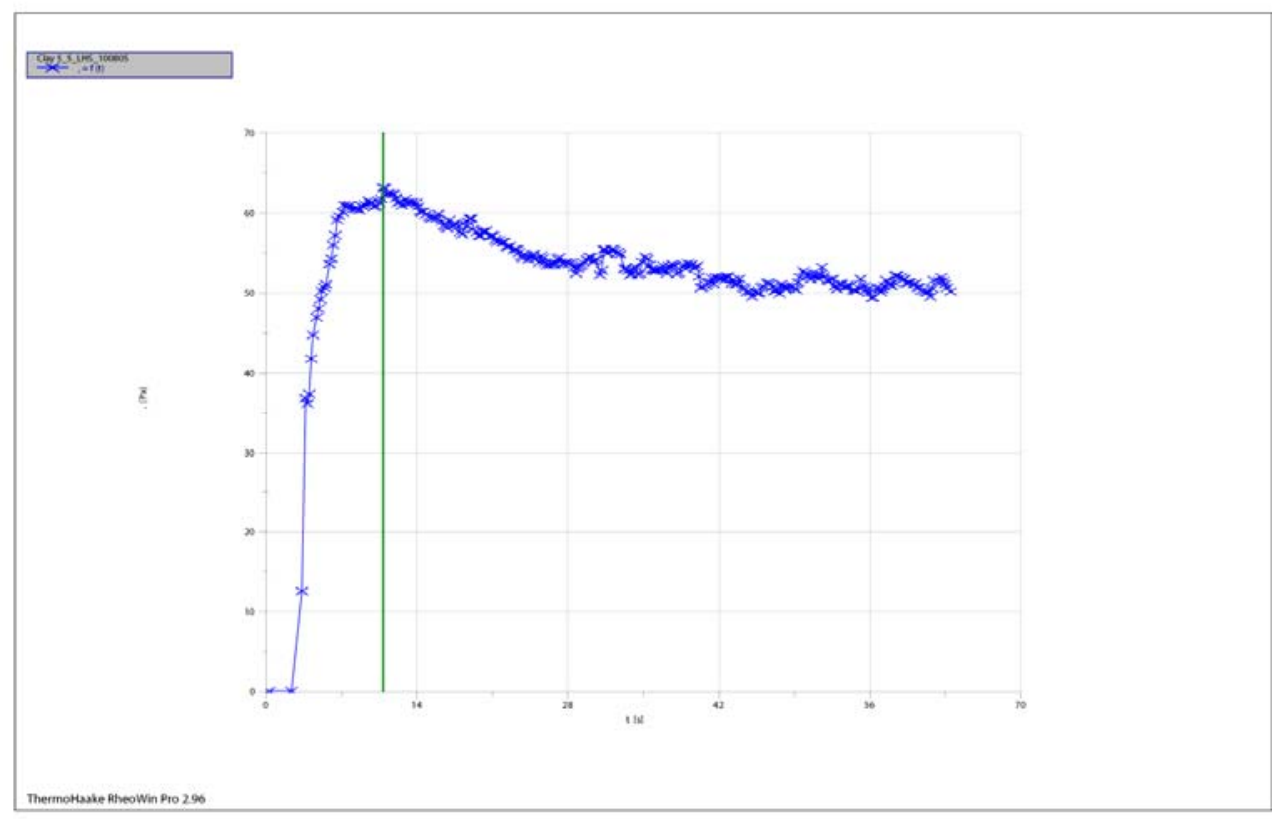

1: C:IRheoloqy Results VJK Basin VSB\Clay 5 5\Clay 5 5 LHS 100805.rwd

Company / Operator: PNNL / Jeromy Jenks

Date / Time / Version: 05.08.2010 / 19:13:53 PM / RheoWin Pro 296

Substance / Sample no: Clay 5_5 / Clay 5_5_LHS_100805

Curve discussion: Greatest value $\mathrm{t}[\mathrm{s}] 10.87,[\mathrm{~Pa}] 63.15$

Figure A.26. $45-w t \%$ Kaolin Clay, LHS Sampling Location

ThermoHaake RheoWin 8/5/2010/2:29 PM

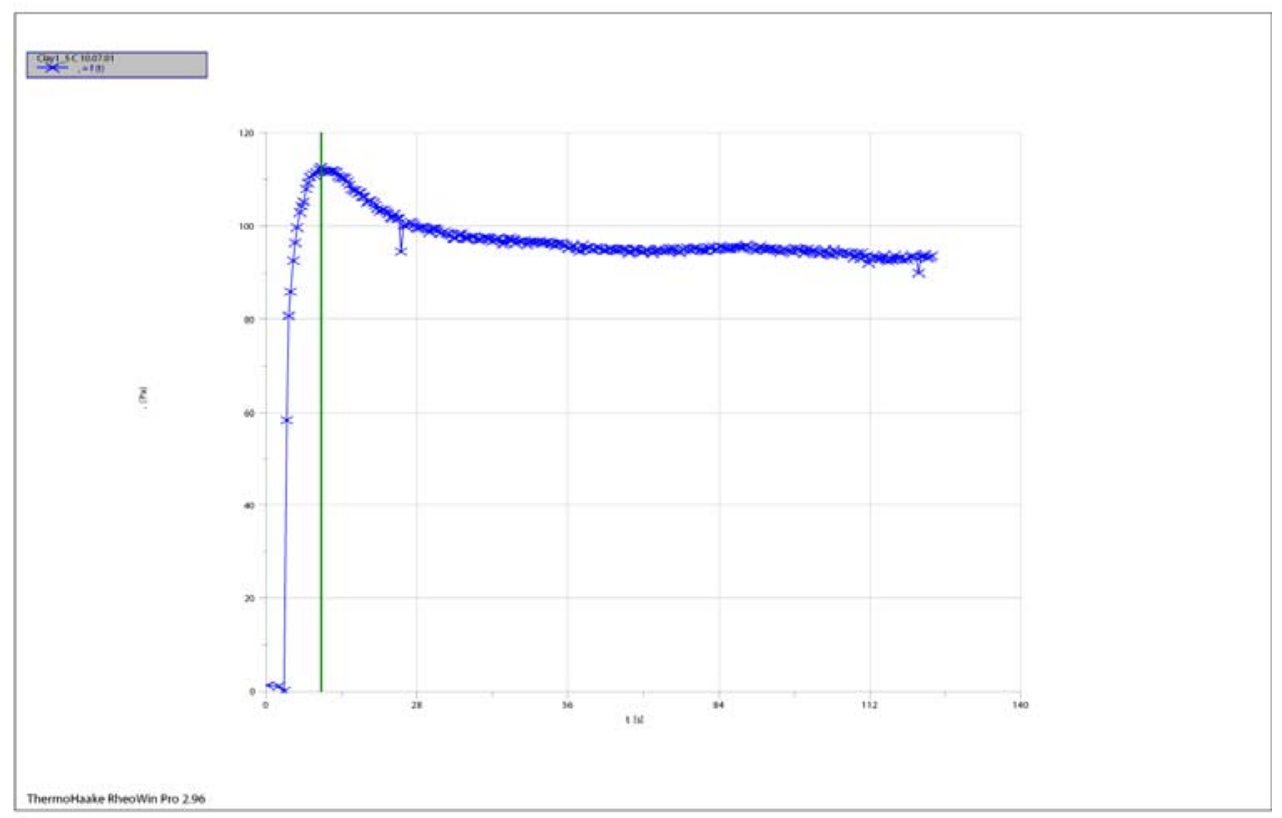

1: C:IRheoloqy Results\J\K Basin VSB\Clay 1 5\Clay1_5 C 10.07.01.rwd

Company / Operator: PNNL / Jeromy Jenks

Date / Time / Version: 01.07.2010 / 15:42:17 PM / RheoWin Pro 296

Substance / Sample no: Clay2_5 / Clay2_5 C 10.07.01

Curve discussion: Greatest value $t[s] 10.23$, $[\mathrm{Pa}] 112.6$

Figure A.27. 47-wt\% Kaolin Clay, Center Sampling Location 


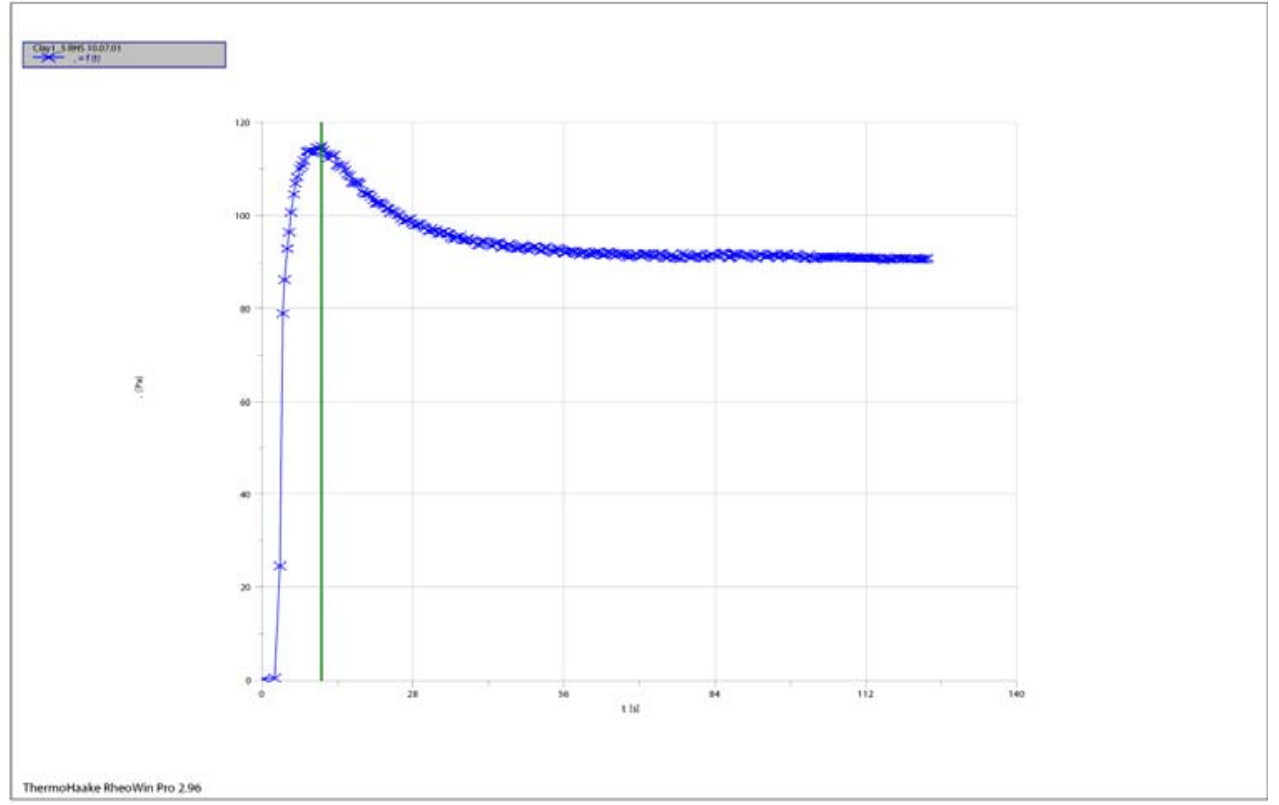

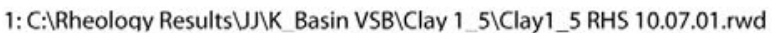
Company / Operator: PNNL / Jeromy Jenks

Date / Time / Version: 01.07.2010 / 15:49:51 PM / RheoWin Pro 296

Substance / Sample no: Clay2_5 / Clay2_5 RHS 10.07.01

Curve discussion: Greatest value $\mathrm{t}[\mathrm{s}] 11.04$, [Pa] 114.9

Figure A.28. 47-wt\% Kaolin Clay, RHS Sampling Location

ThermoHaake RheoWin 8/5/2010/ 2:31 PM

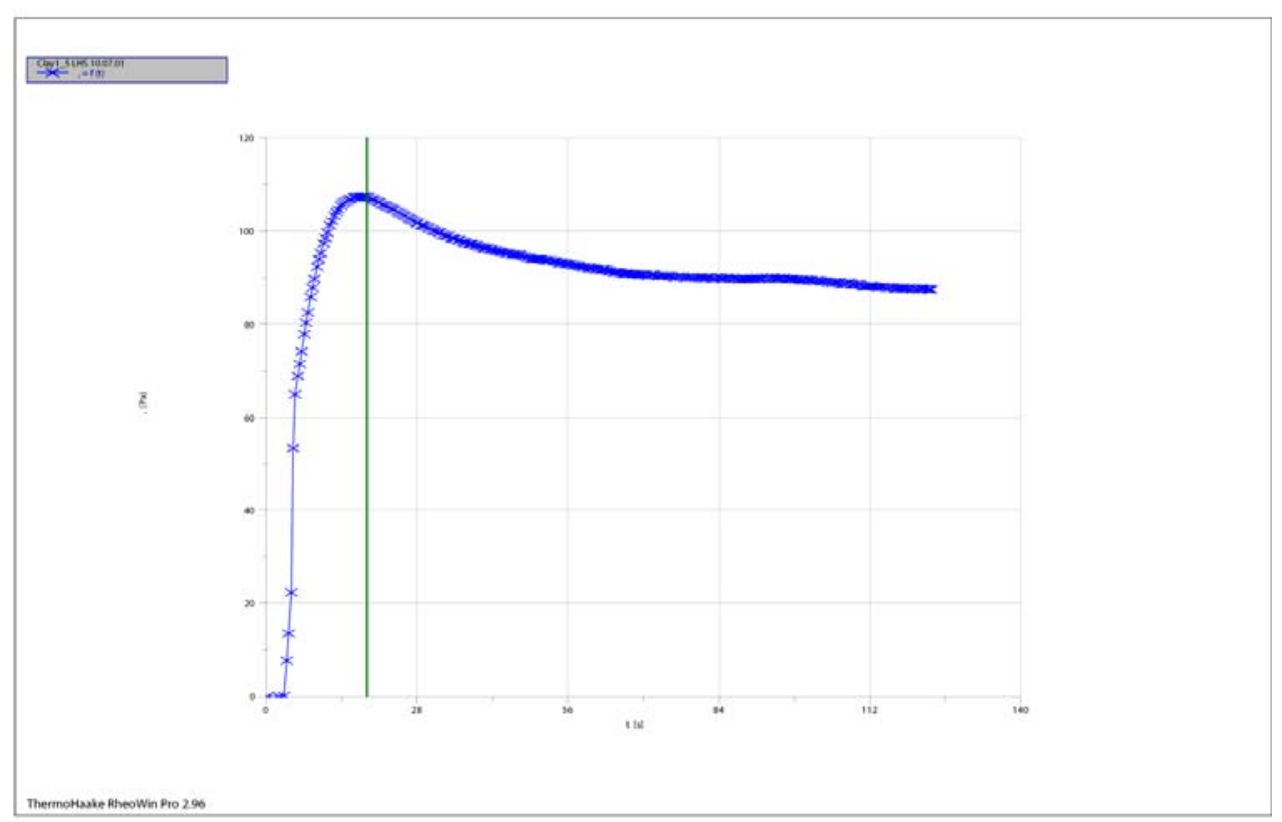

1: C:IRheoloqy Results \J\K Basin VSB\Clay 1 5\Clay1_5 LHS 10.07.01.rwd

Company / Operator: PNNL / Jeromy Jenks

Date / Time / Version: 01.07.2010 / 15:54:21 PM / RheoWin Pro 296

Substance / Sample no: Clay2_5 / Clay2_5 LHS 10.07.01

Curve discussion: Greatest value $\mathrm{t}[\mathrm{s}] 18.71$, [Pa] 107.4

Figure A.29. 47-wt\% Kaolin Clay, LHS Sampling Location 
ThermoHaake RheoWin 8/5/2010/ 2:33 PM

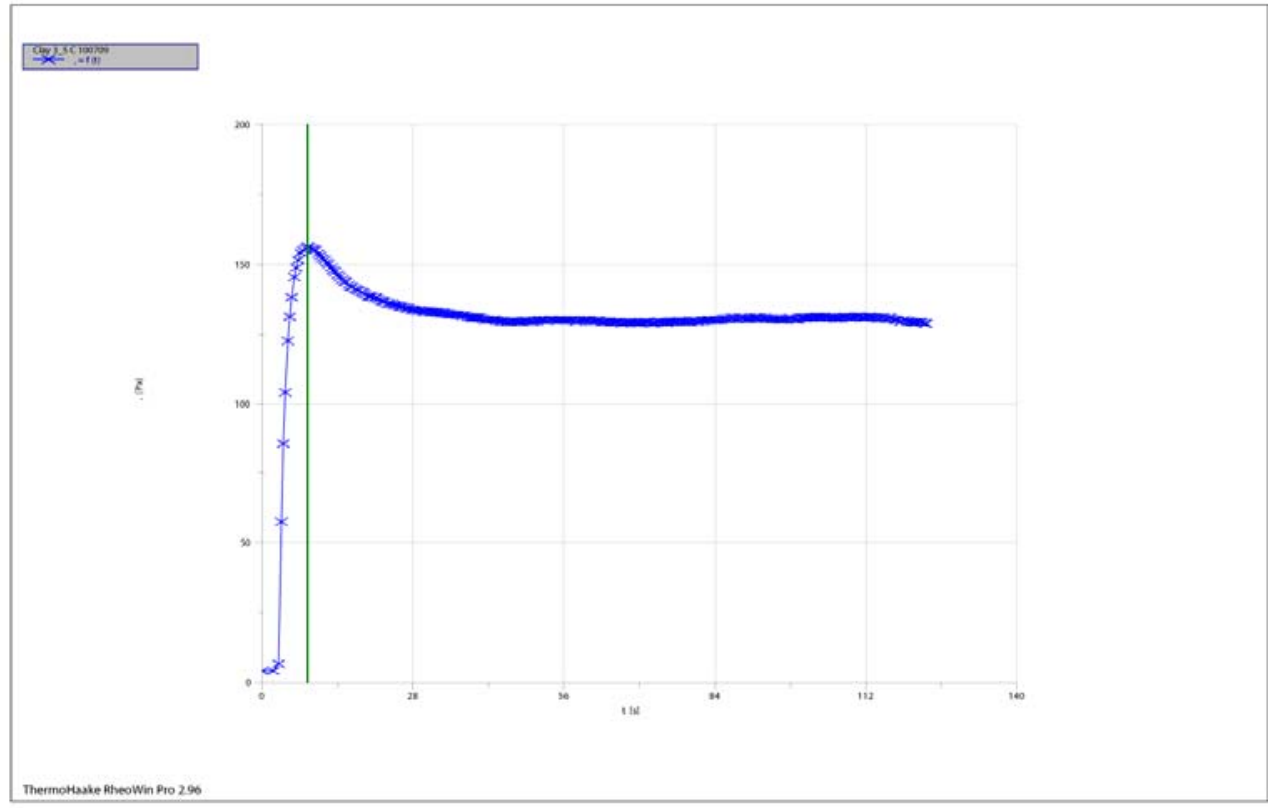

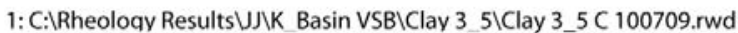

Company / Operator: PNNL / Jeromy Jenks

Date / Time / Version: 09.07.2010 / 13:31:13 PM / RheoWin Pro 296

Substance / Sample no: Kaolin_48 / Clay 3_5 C 100709

Curve discussion: Greatest value $t[\mathrm{~s}] 8.419$, [Pa] 156.1

Figure A.30. $48-w t \%$ Kaolin Clay, Center Sampling Location ThermoHaake RheoWin 8/5/2010 / 2:35 PM

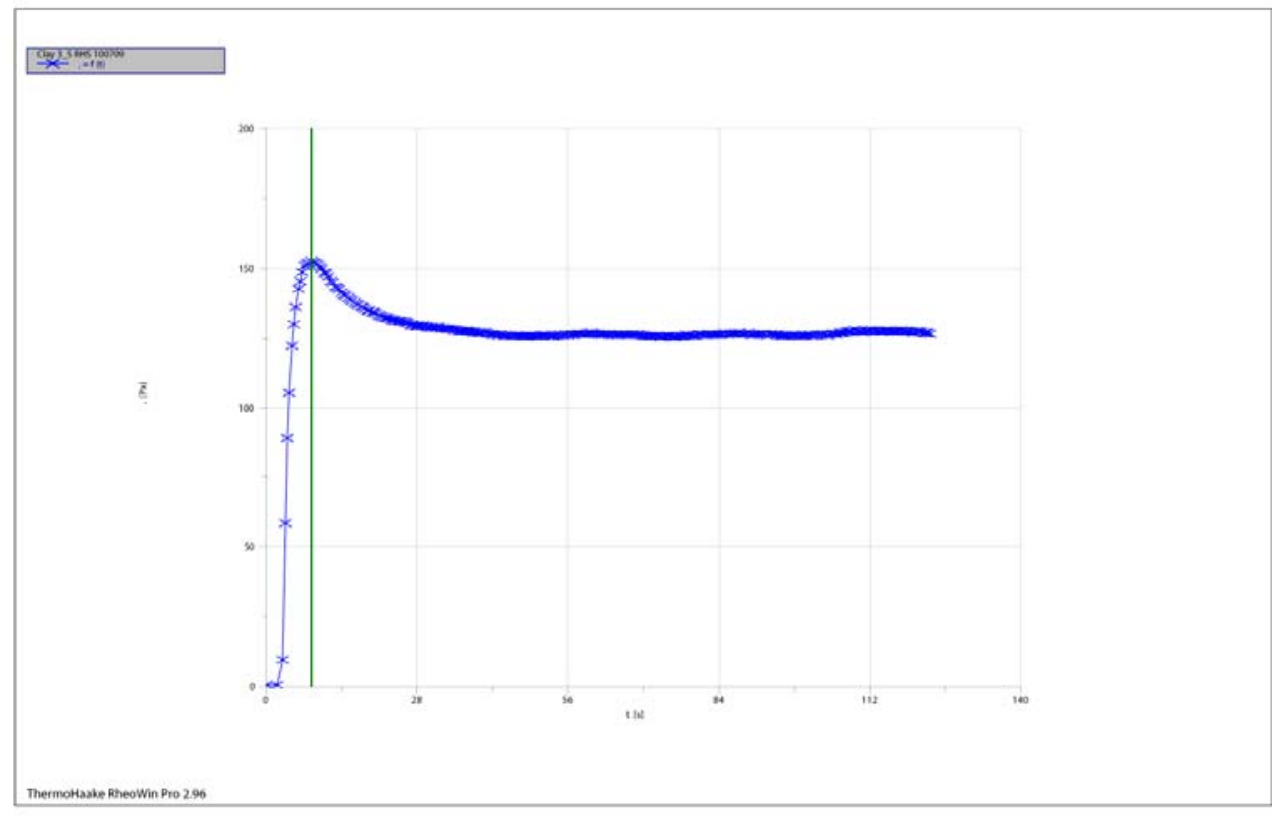

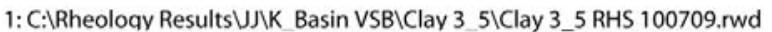

Company / Operator: PNNL / Jeromy Jenks

Date / Time / Version: 09.07.2010 / 13:35:46 PM / RheoWin Pro 296

Substance / Sample no: Kaolin_48 / Clay 3_5 RHS 100709

Curve discussion: Greatest value $\mathrm{t}[\mathrm{s}] \mathbf{8 . 4 3 9}$, [Pa] 152.5

Figure A.31. $48-w t \%$ Kaolin Clay, RHS Sampling Location 


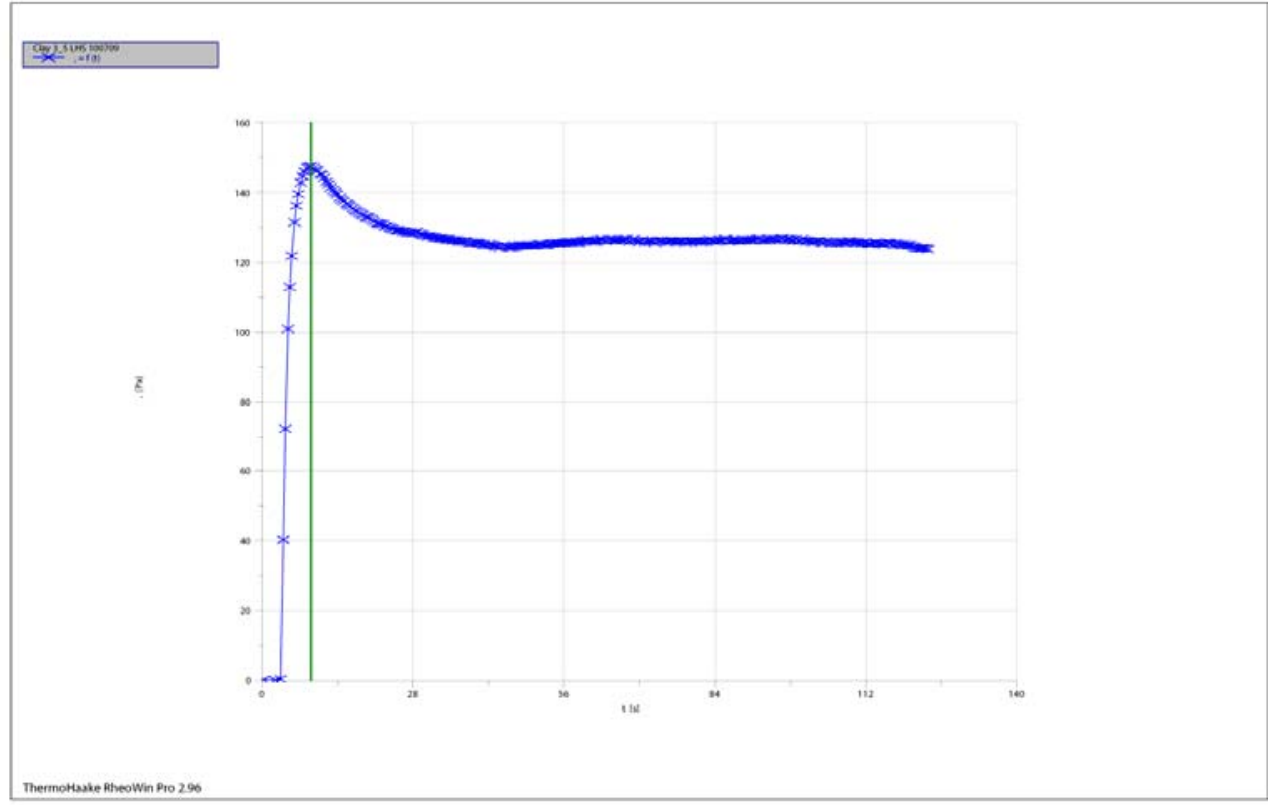

1: C:IRheoloqy Results VJKK Basin VSB\Clay 3 5\Clay 3_5 LHS 100709.rwd Company / Operator: PNNL / Jeromy Jenks

Date / Time / Version: 09.07.2010 / 13:39:35 PM / RheoWin Pro 296

Substance / Sample no: Kaolin_48 / Clay 3_5 LHS 100709

Curve discussion: Greatest value $\mathrm{t}[\mathrm{s}] 9.110$, [Pa] 147.5

Figure A.32. 48-wt\% Kaolin Clay, LHS Sampling Location ThermoHaake RheoWin 8/5/2010/ 2:40 PM

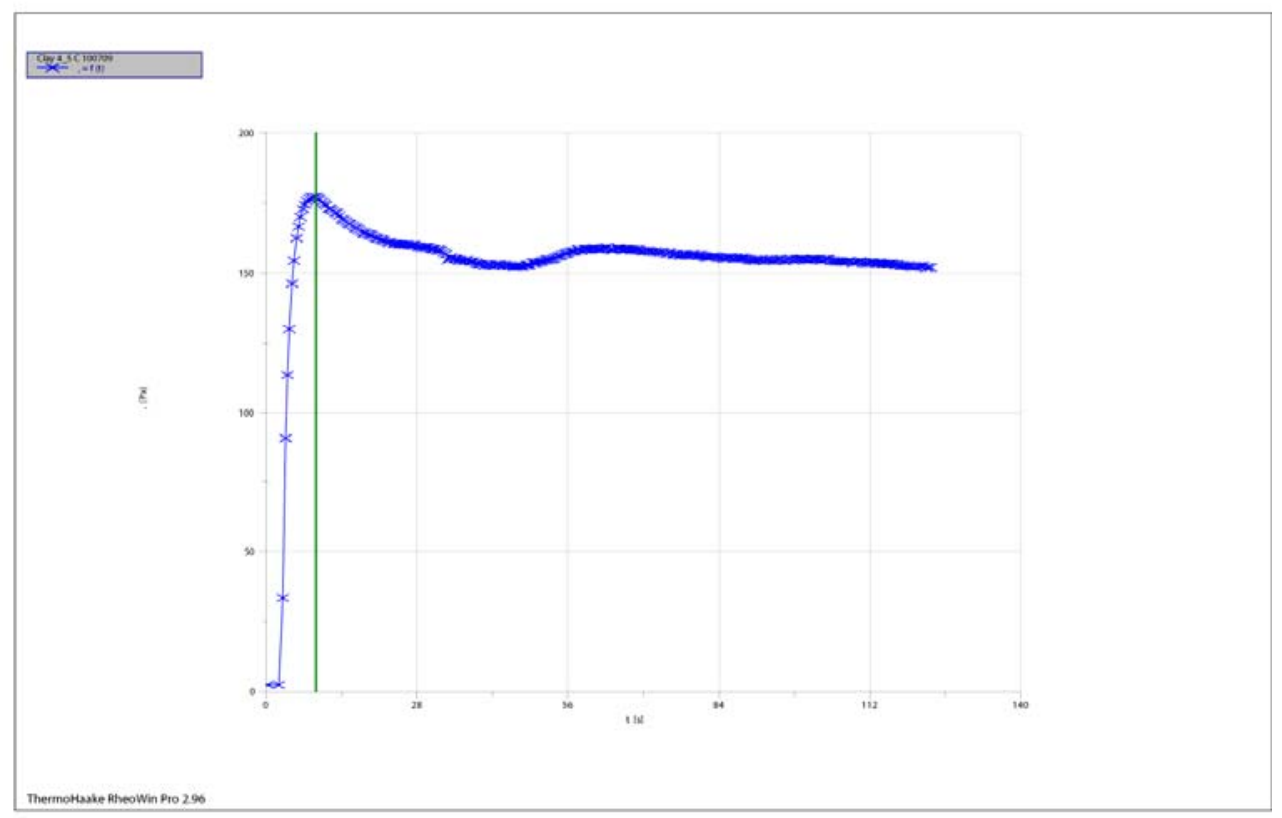

1: C:IRheoloqy Results VJ\K Basin VSB\Clay 4 5\Clay 4 5 C 100709.rwd Company / Operator: PNNL / Jeromy Jenks

Date / Time / Version: 09.07.2010 / 13:44:34 PM / RheoWin Pro 296

Substance / Sample no: Kaolin_49 / Clay 4_5 C 100709

Curve discussion: Greatest value $\mathrm{t}[\mathrm{s}] 9.29 \overline{7}$, [Pa] 177.

Figure A.33. 49-wt\% Kaolin Clay, Center Sampling Location 
ThermoHaake RheoWin 8/5/2010/ 2:41 PM

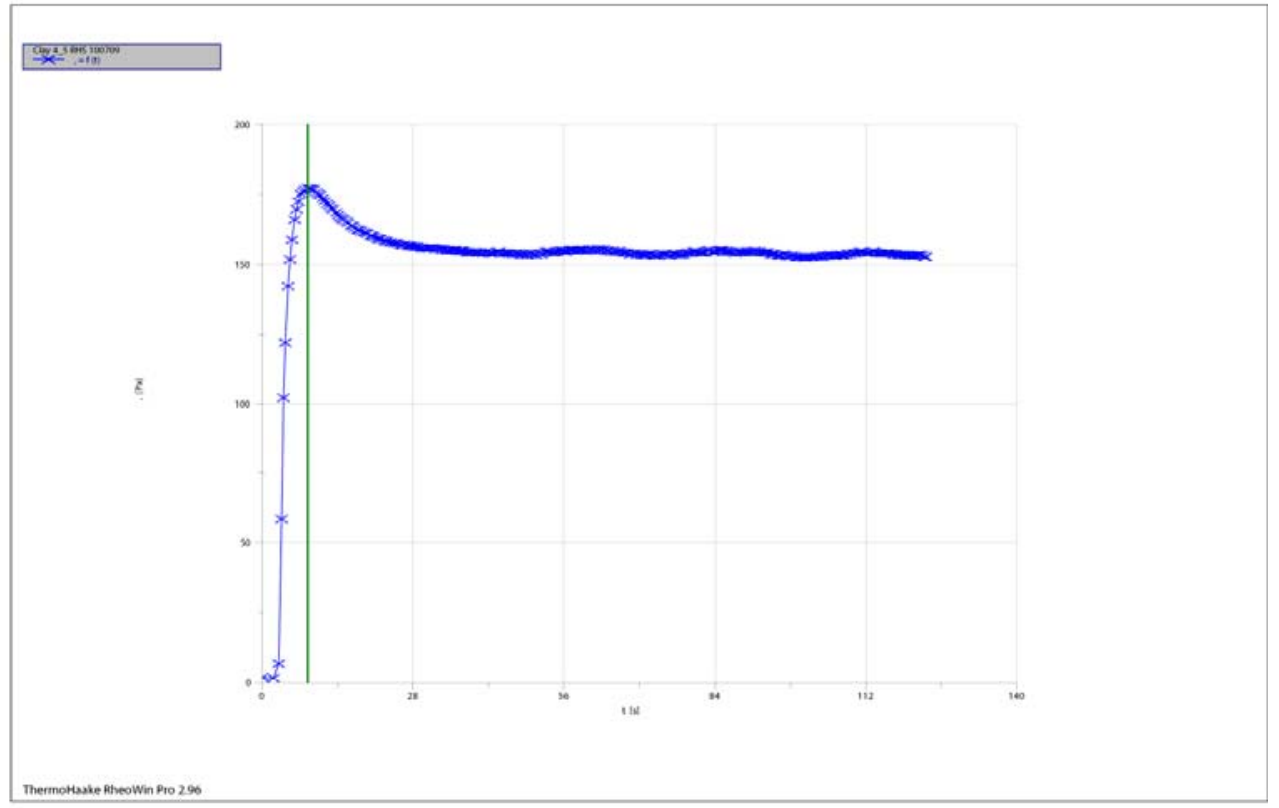

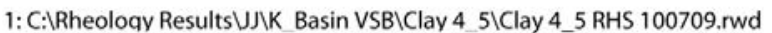

Company / Operator: PNNL / Jeromy Jenks

Date / Time / Version: 09.07.2010 / 13:48:37 PM / RheoWin Pro 296

Substance / Sample no: Kaolin_49 / Clay 4_5 RHS 100709

Curve discussion: Greatest value $\mathrm{t}[\mathrm{s}] \mathrm{8.489}$, [Pa] 177.2

Figure A.34. 49-wt\% Kaolin Clay, RHS Sampling Location ThermoHaake RheoWin 8/5/2010/ 2:42 PM

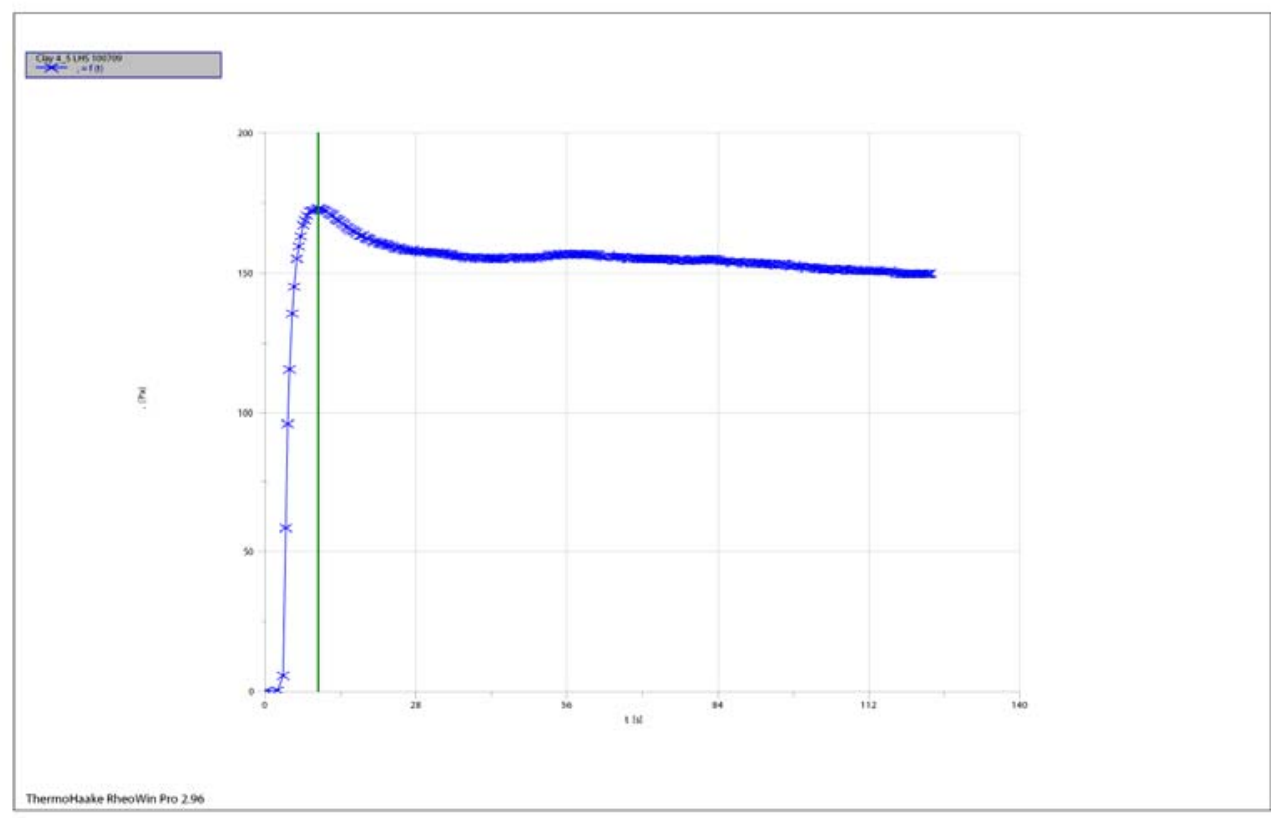

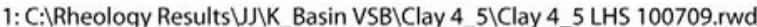

Company / Operator: PNNL / Jeromy Jenks

Date / Time / Version: 09.07.2010 / 13:52:22 PM / RheoWin Pro 296

Substance / Sample no: Kaolin_49 / Clay 4_5 LHS 100709

Curve discussion: Greatest value $\mathrm{t}[\mathrm{s}] 9.87 \overline{2}$, [Pa] 172.9

Figure A.35. 49-wt\% Kaolin Clay, LHS Sampling Location 


\section{A.6.3 Kaolin Clays Used in the 23-in.-Diameter Vessel}

ThermoHaake RheoWin 8/5/2010/2:23 PM

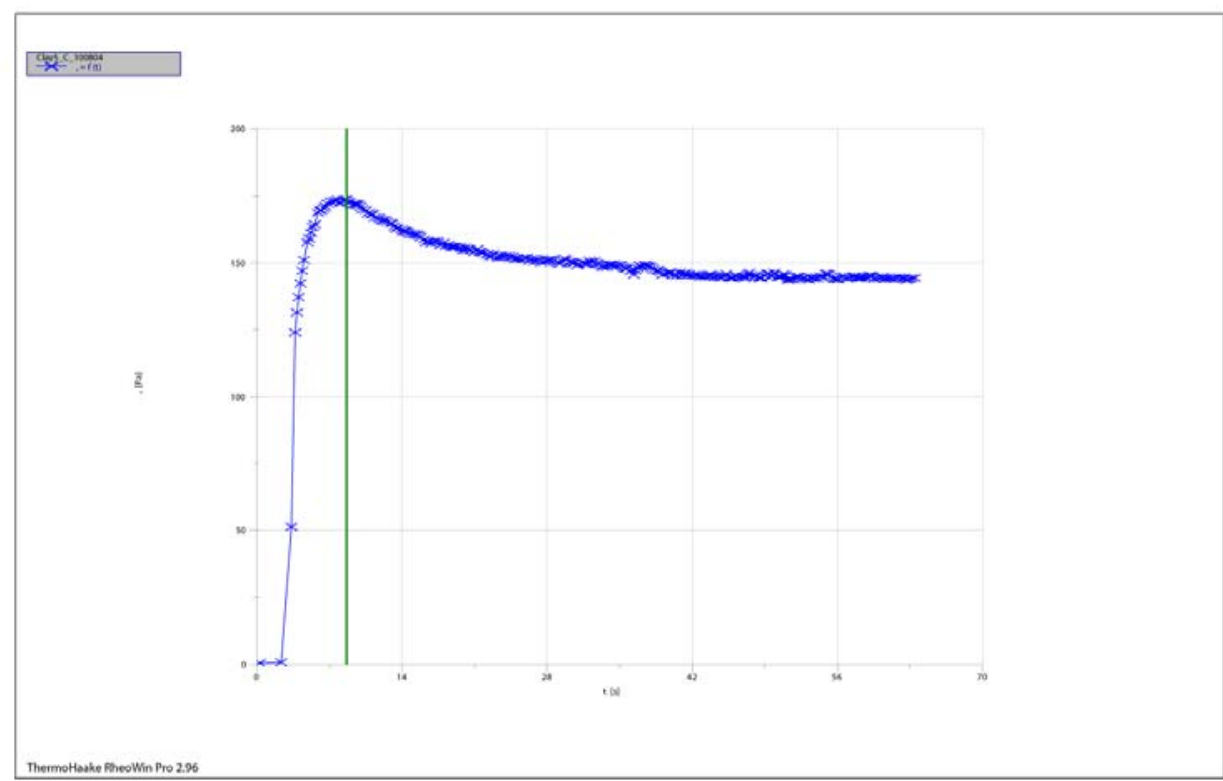

1: C:IRheoloay Results \J\K Basin VSB\Clay 5\Clay5_C_100804.rwd

Company / Operator: PNNL / Jeromy Jenks

Date / Time / Version: 04.08.2010 / 13:49:00 PM / RheoWin Pro 296

Substance / Sample no: Clay 5 / Clay5 C 100804

Curve discussion: Greatest value $t[\mathrm{~s}] 8.663,[\mathrm{~Pa}] 173.4$

Figure A.36. $49-w t \%$ Kaolin Clay, Center Sampling Location

ThermoHaake RheoWin 8/5/2010/2:24 PM

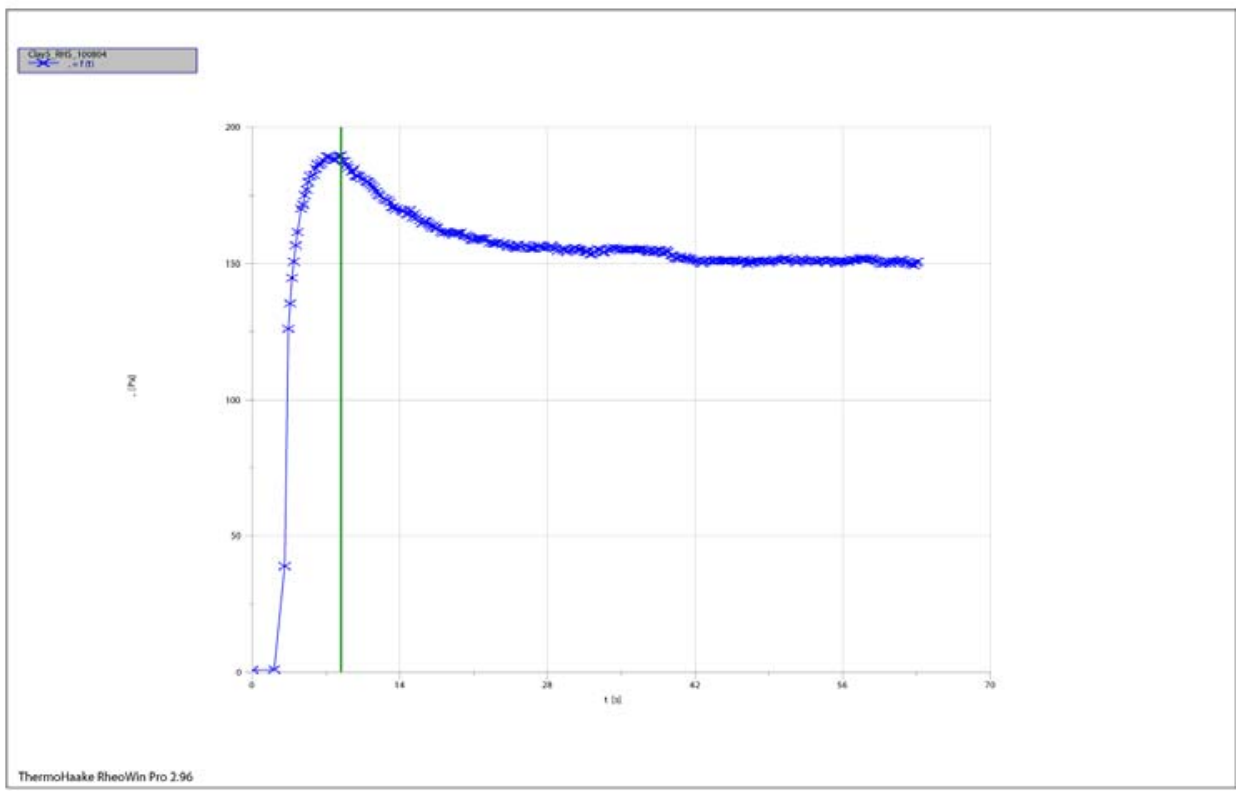

1: C:\Rheoloqy Results \J\K Basin VSB\Clay 5\Clay5_RHS_100804.rwd

Company / Operator: PNNL / Jeromy Jenks

Date / Time / Version: 04.08.2010/ 13:51:52 PM / RheoWin Pro 296

Substance / Sample no: Clay 5 / Clay5_RHS_100804

Curve discussion: Greatest value $\mathrm{t}[\mathrm{s}] \mathrm{8.429}$, [Pa] 189.4

Figure A.37. 49-wt\% Kaolin Clay, RHS Sampling Location 
ThermoHaake RheoWin 8/5/2010/2:24 PM

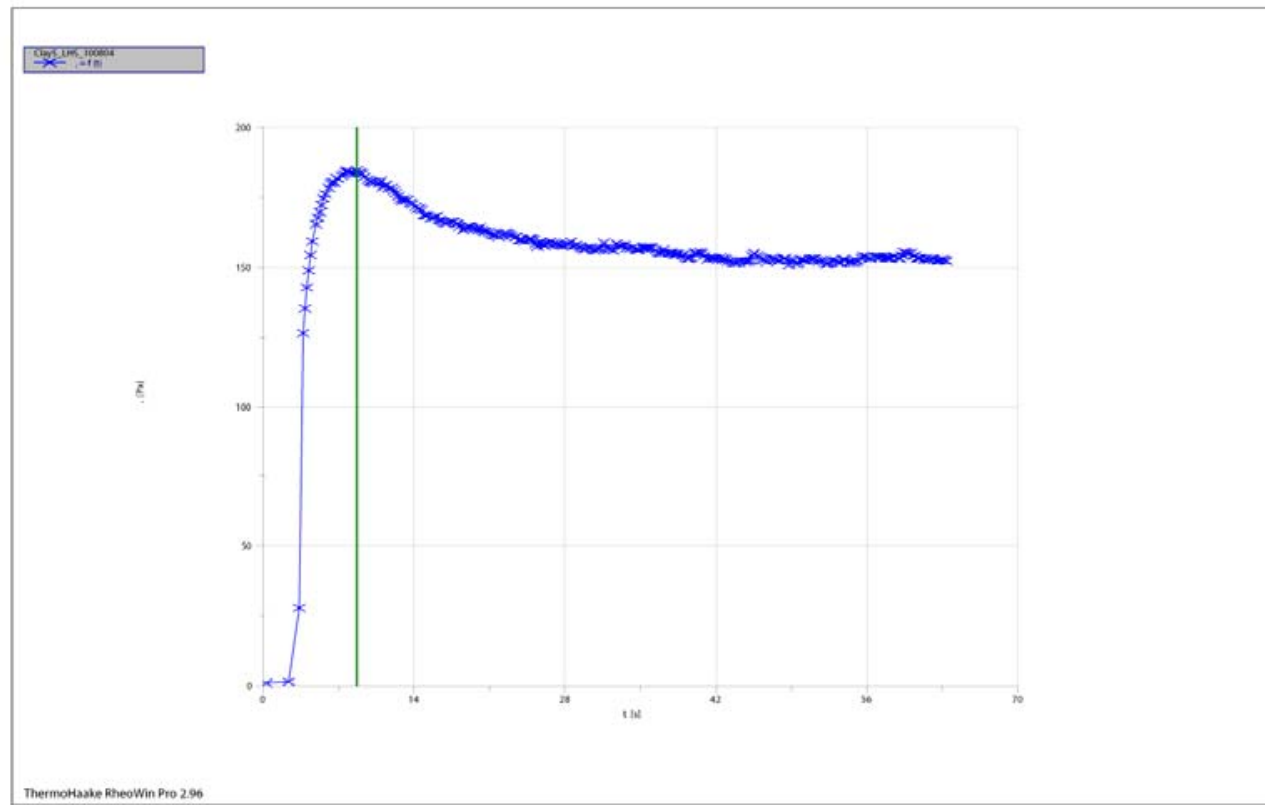

1: C:IRheoloqy Results\J\K Basin VSB\Clay 5\Clay5_LHS_100804.rwd Company / Operator: PNNL / Jeromy Jenks

Date / Time / Version: 04.08.2010 / 13:55:02 PM / RheoWin Pro 296

Substance / Sample no: Clay 5 / Clay5_LHS 100804

Curve discussion: Greatest value $\mathrm{t}[\mathrm{s}] \mathrm{8.709}$, $[\mathrm{Pa}] 184.6$

Figure A.38. $49-\mathrm{wt} \%$ Kaolin Clay, LHS Sampling Location ThermoHaake RheoWin 8/5/2010/ 2:09 PM

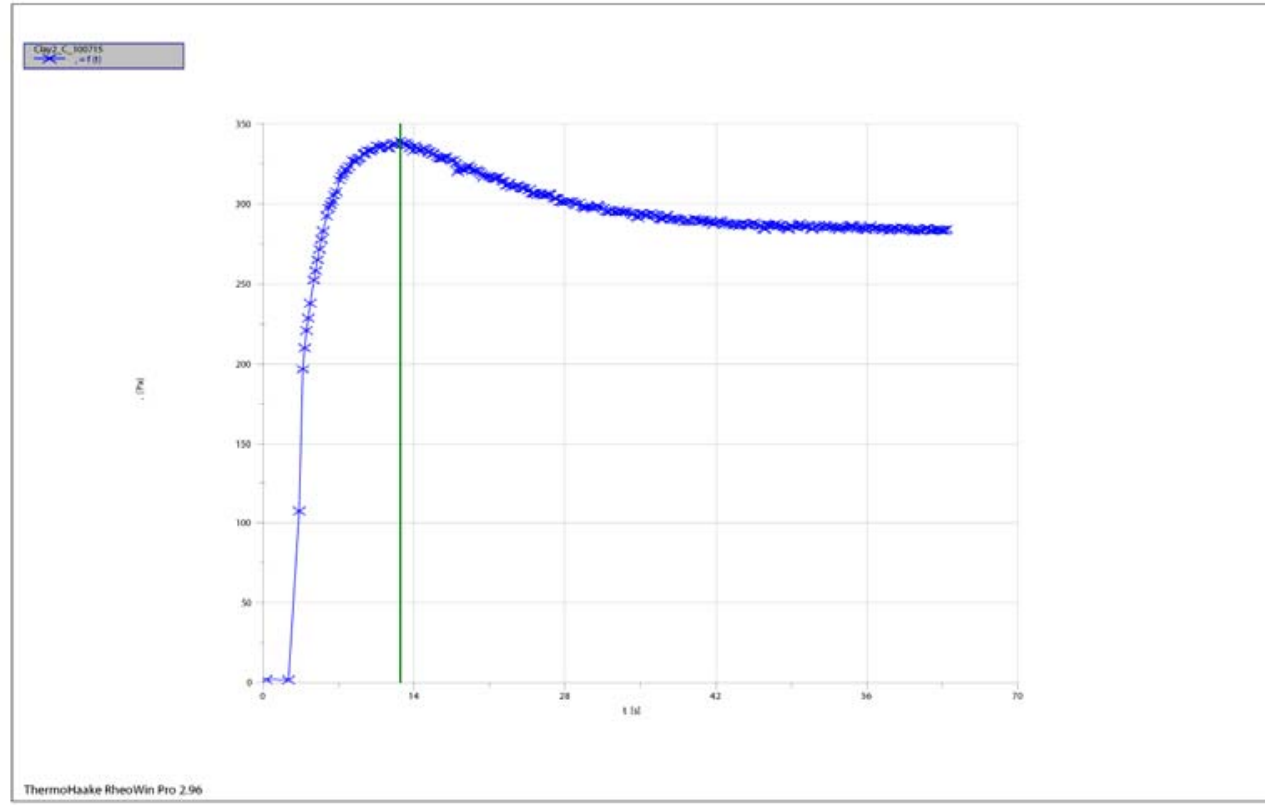

1: C:IRheoloqy Results VJ\K Basin VSB\Clay 2\Clay2_C_100715.rwd Company / Operator: PNNL / Jeromy Jenks

Date / Time / Version: 15.07.2010 / 18:37:04 PM / RheoWin Pro 296

Substance / Sample no: Clay 2 / Clay2_C_100715

Curve discussion: Greatest value $\mathrm{t}[\mathrm{s}] 12.75$, [Pa] 339.2

Figure A.39. 52-wt\% Kaolin Clay, Center Sampling Location 


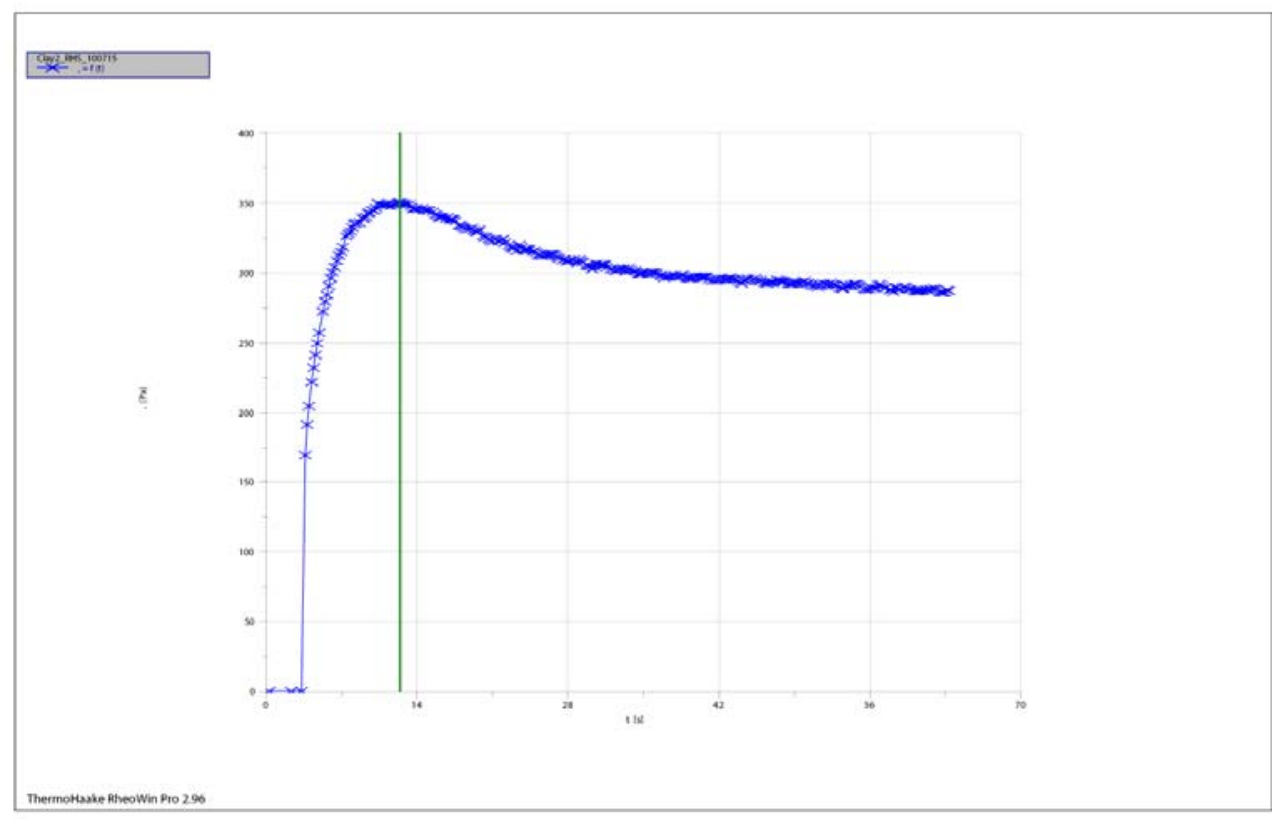

1: C:IRheoloqy Results UJ\K Basin VSB\Clay 2\Clay2 RHS 100715.rwd

Company / Operator: PNNL / Jeromy Jenks

Date / Time / Version: 15.07.2010 / 18:40:52 PM / RheoWin Pro 296

Substance / Sample no: Clay 2 / Clay2_RHS_100715

Curve discussion: Greatest value $\mathrm{t}[\mathrm{s}] \mathrm{12.43},[\mathrm{Pa}] 350.1$

Figure A.40. 52-wt\% Kaolin Clay, RHS Sampling Location

ThermoHaake RheoWin 8/5/2010/ 2:12 PM

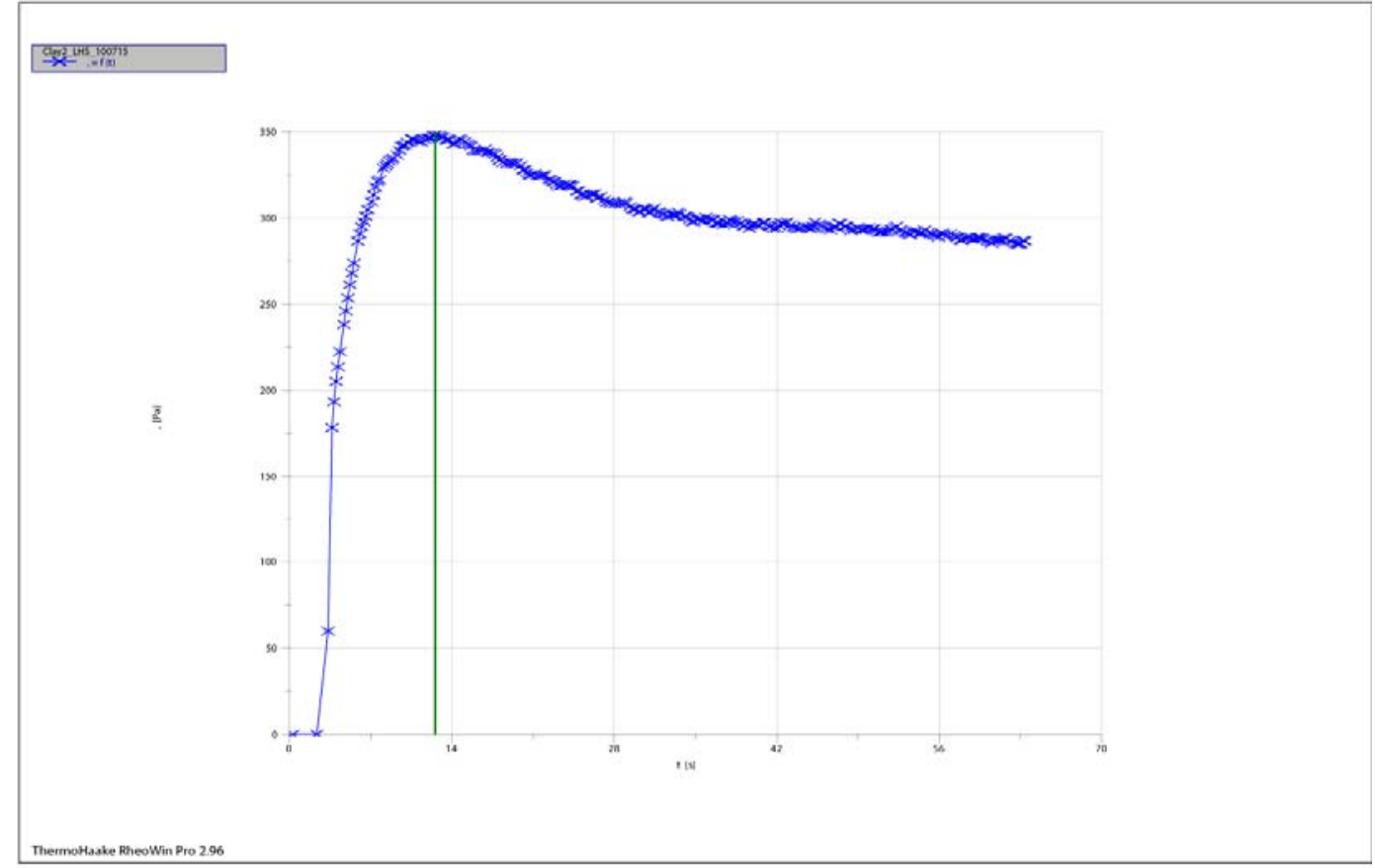

1: C:IRheoloay Results \J\K Basin VSB\Clay 2\Clay2_LHS_100715.rwd

Company / Operator: PNNL / Jeromy Jenks

Date / Time / Version: 15.07.2010 / 18:44:21 PM / RheoWin Pro 296

Substance / Sample no: Clay 2/Clay2_LHS_100715

Curve discussion: Greatest value $\mathrm{t}[\mathrm{s}] 12.58$, [Pa] 347.7

Figure A.41. 52-wt\% Kaolin Clay, LHS Sampling Location 
ThermoHaake RheoWin 8/5/2010/1:54 PM

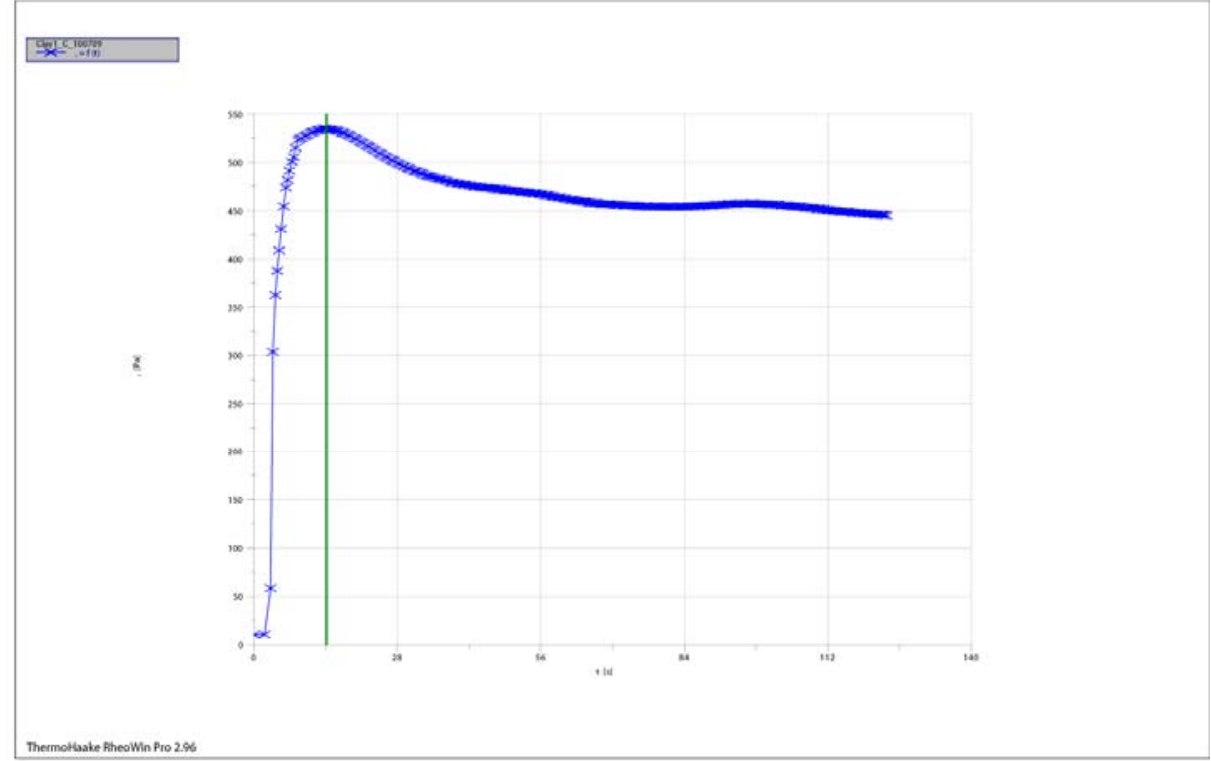

1: C:IRheology Results UJ\K Basin VSB\Clay 1\Clay1_C_100709.rwd Company / Operator: PNNL / Jeromy Jenks

Date / Time / Version: 09.07.2010 / 15:27:54 PM / RheoWin Pro 296

Substance / Sample no: Kaolin_55/Clay1 C 100709

Curve discussion: Greatest value A [1/s] 0.03088 , [Pa] 534.7

Curve discussion: Greatest value Á [1/s] 0.03088 , [Pa] 534.7

Curve discussion: Greatest value $\mathrm{t}[\mathrm{s}] 14.17$, $[\mathrm{Pa}] 534.7$

Figure A.42. 55-wt\% Kaolin Clay, Center Sampling Location

ThermoHaake RheoWin 8/5/2010/2:13 PM

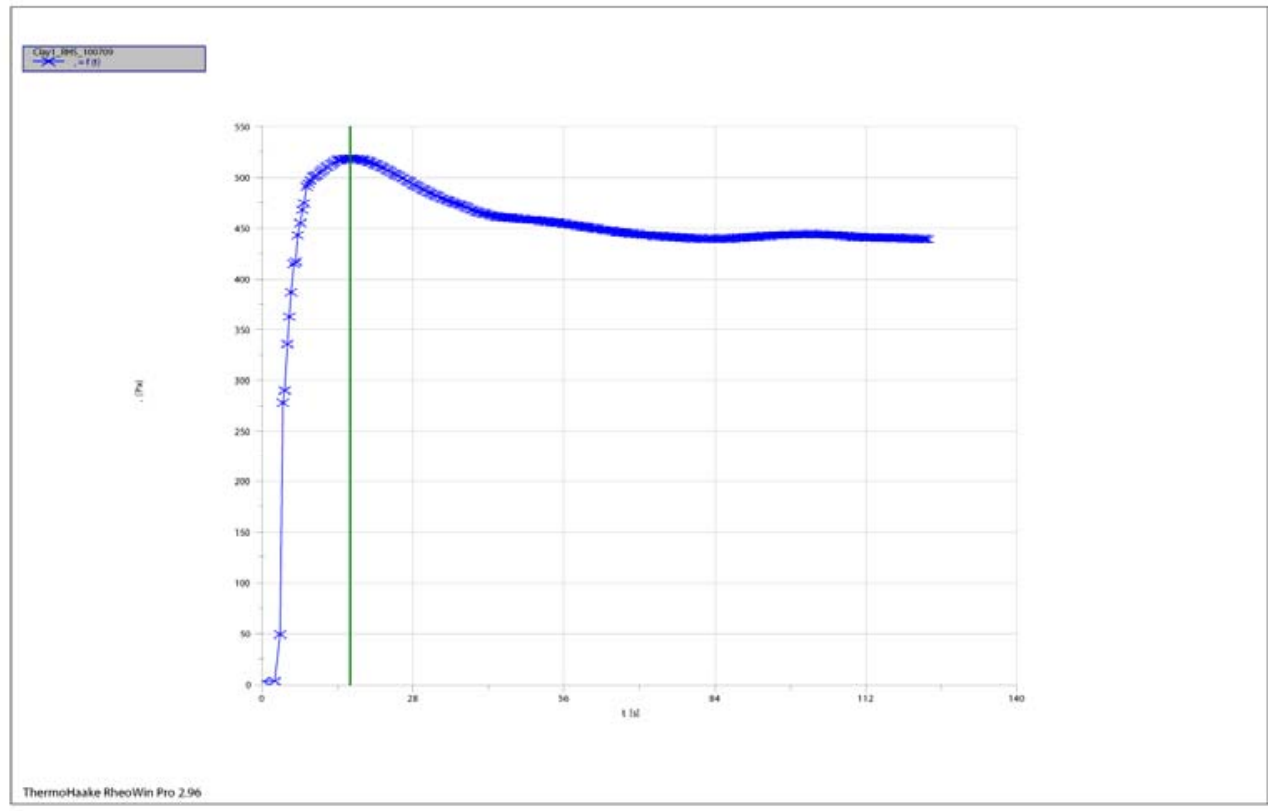

1: C:\Rheoloqy Results\J\K Basin VSB\Clay 1\Clay1_RHS_100709.rwd

Company / Operator: PNNL / Jeromy Jenks

Date / Time / Version: 09.07.2010 / 15:32:30 PM / RheoWin Pro 296

Substance / Sample no: Kaolin_55 / Clay1_RHS_100709

Curve discussion: Greatest value $\mathrm{t}[\mathrm{s}] 16.34$, [Pa] 518.5

Figure A.43. 55-wt\% Kaolin Clay, RHS Sampling Location 


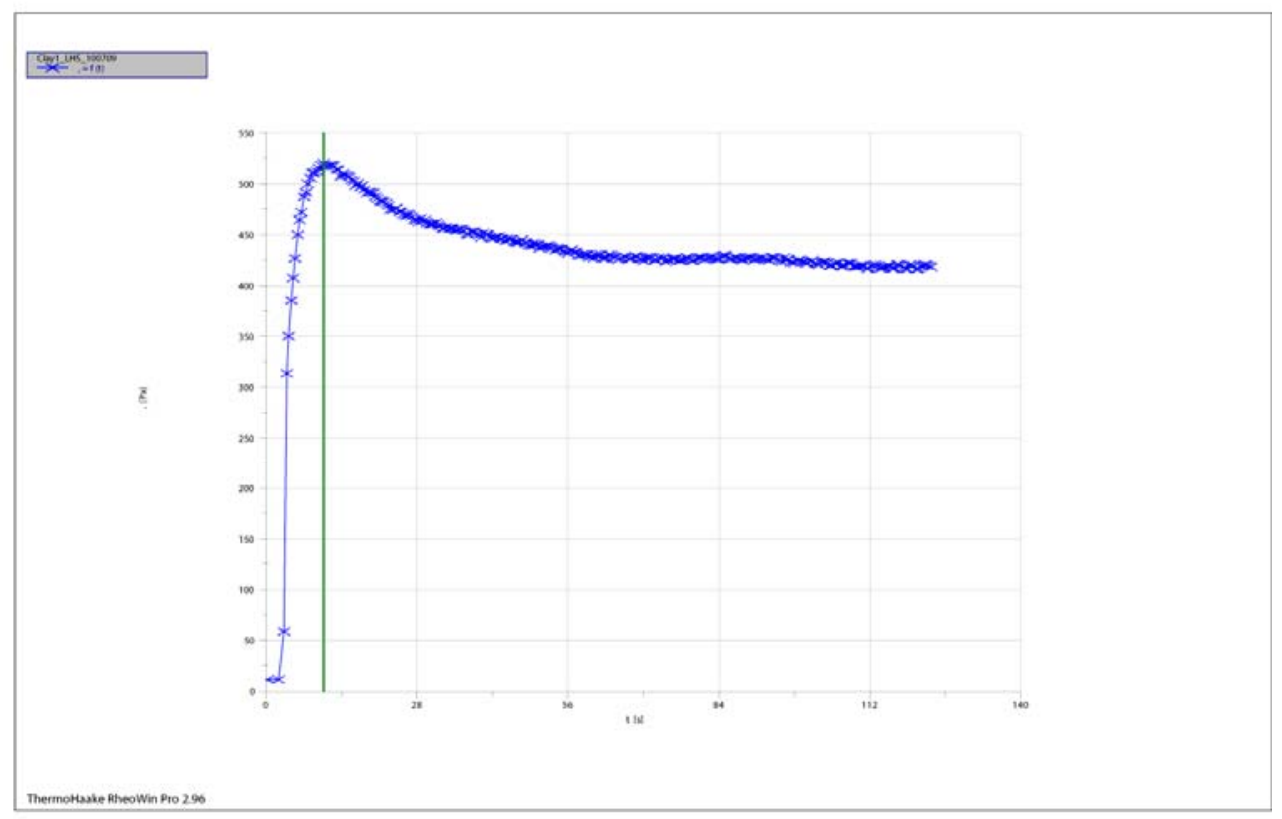

1: C:IRheoloqy Results\JKK Basin VSB\Clay 1\Clay1_LHS_100709.rwd

Company / Operator: PNNL / Jeromy Jenks

Date / Time / Version: 09.07.2010 / 15:37:10 PM / RheoWin Pro 296

Substance / Sample no: Kaolin_55 / Clay1_LHS_100709

Curve discussion: Greatest value $\mathrm{t}[\mathrm{s}] 10.70$, [Pa] 519.7

Figure A.44. 55-wt\% Kaolin Clay, LHS Sampling Location

ThermoHaake RheoWin 8/5/2010/ 2:26 PM

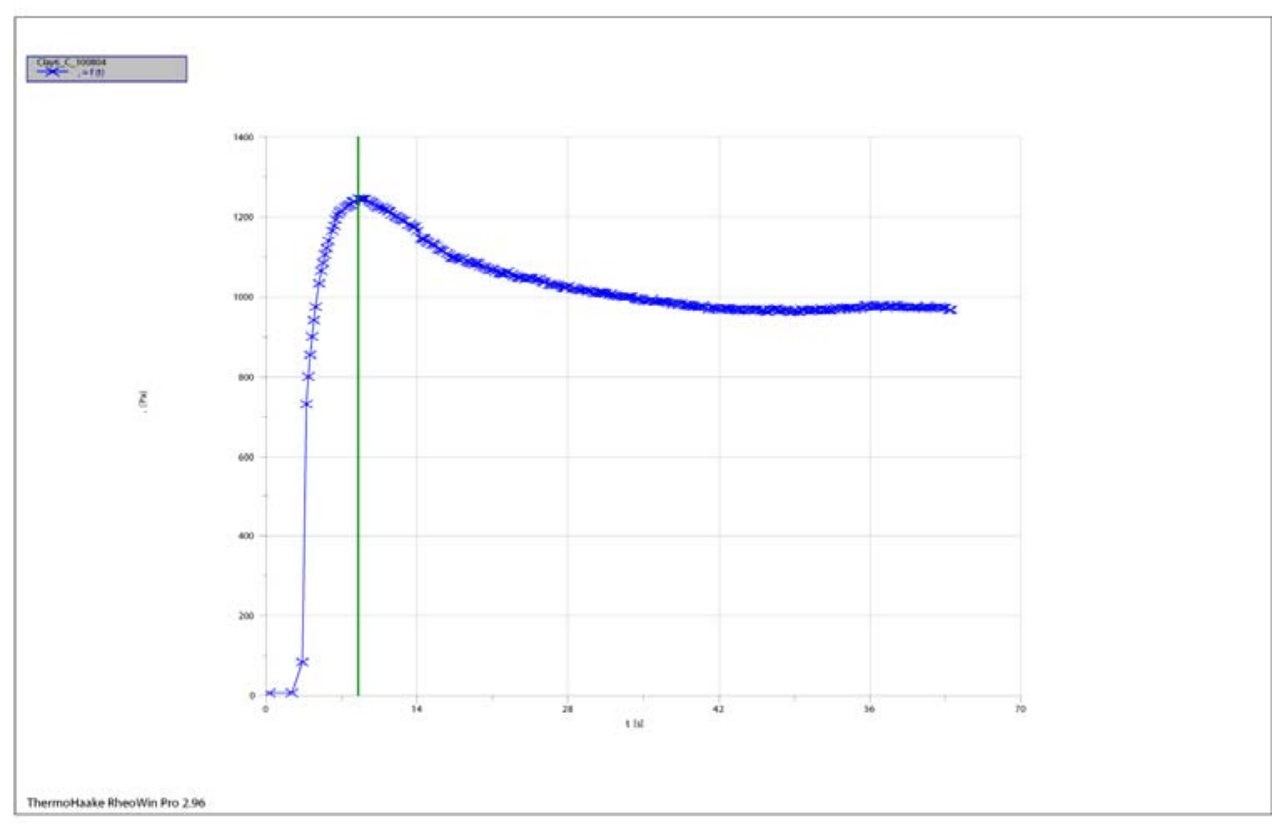

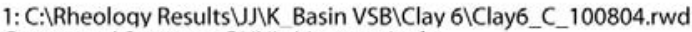

Company / Operator: PNNL / Jeromy Jenks

Date / Time / Version: 04.08.2010 / 13:45:10 PM / RheoWin Pro 296

Substance / Sample no: Clay 6 / Clay6_C_100804

Curve discussion: Greatest value $\mathrm{t}[\mathrm{s}] \mathbf{8 . 5 4 9}$, [ [Pa] 1246.

Figure A.45. 58-wt\% Kaolin Clay, Center Sampling Location 


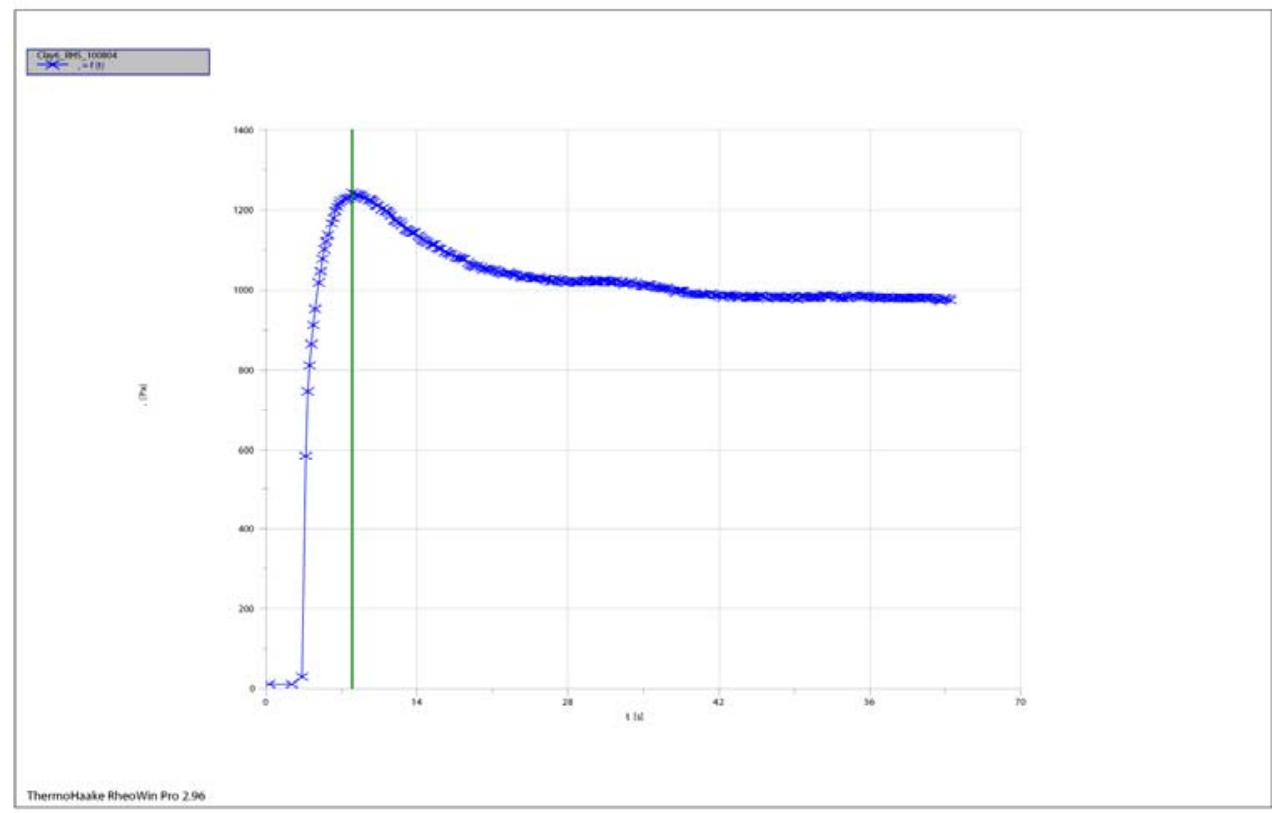

1: C:IRheoloqy Results UJ\K Basin VSB\Clay 6\Clay6 RHS 100804.rwd

Company / Operator: PNNL / Jeromy Jenks

Date / Time / Version: 04.08.2010 / 13:39:21 PM / RheoWin Pro 296

Substance / Sample no: Clay 6 / Clay6_RHS_100804

Curve discussion: Greatest value $\mathrm{t}[\mathrm{s}] \mathrm{7} .991$, [Pa] 1242.

Figure A.46. 58 -wt\% Kaolin Clay, RHS Sampling Location

ThermoHaake RheoWin 8/5/2010/2:27 PM

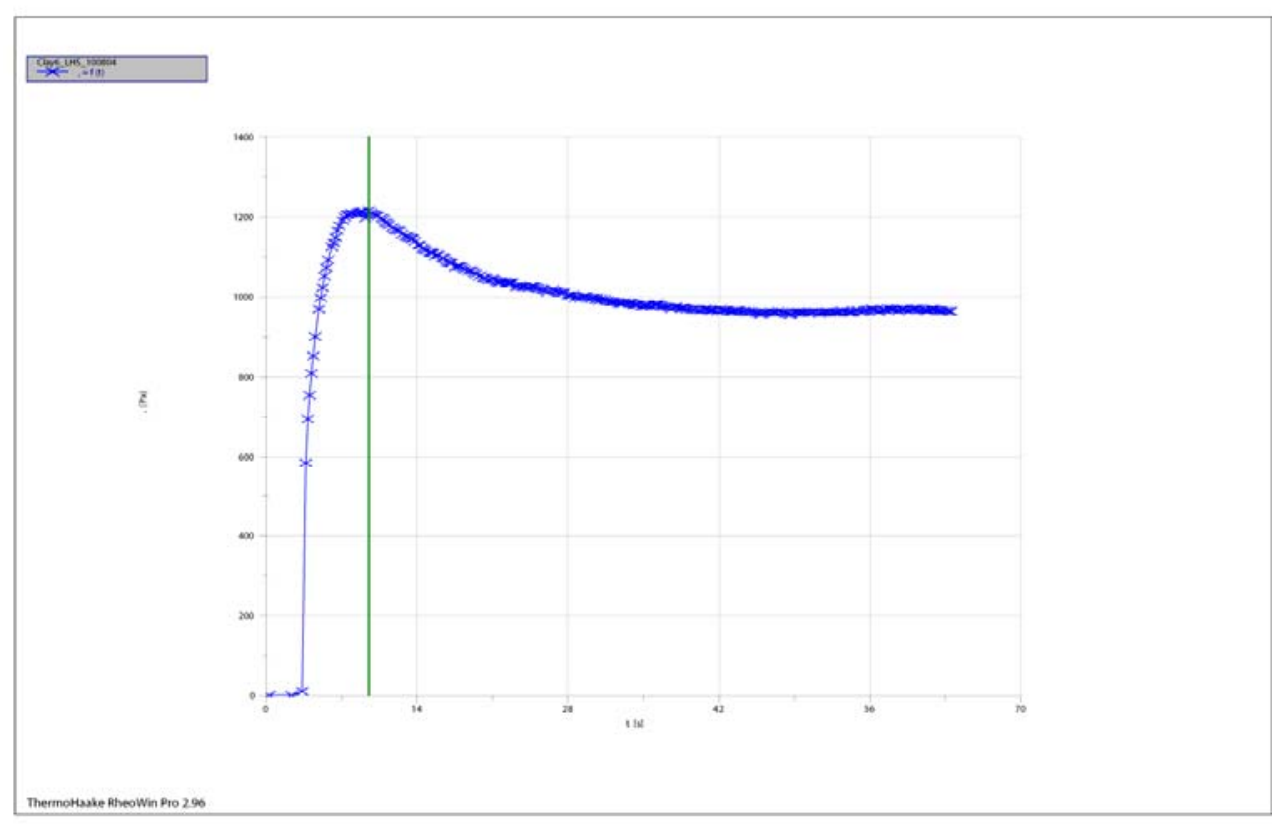

1: C:\Rheoloqy Results \J\K Basin VSB\Clay 6\Clay6_LHS_100804.rwd

Company / Operator: PNNL / Jeromy Jenks

Date / Time / Version: 04.08.2010 / 13:42:12 PM / RheoWin Pro 296

Substance / Sample no: Clay 6 / Clay6 LHS 100804

Curve discussion: Greatest value $\mathrm{t}[\mathrm{s}] \mathrm{9.541},[\mathrm{Pa}] 1215$

Figure A.47. 58-wt\% Kaolin Clay, LHS Sampling Location 


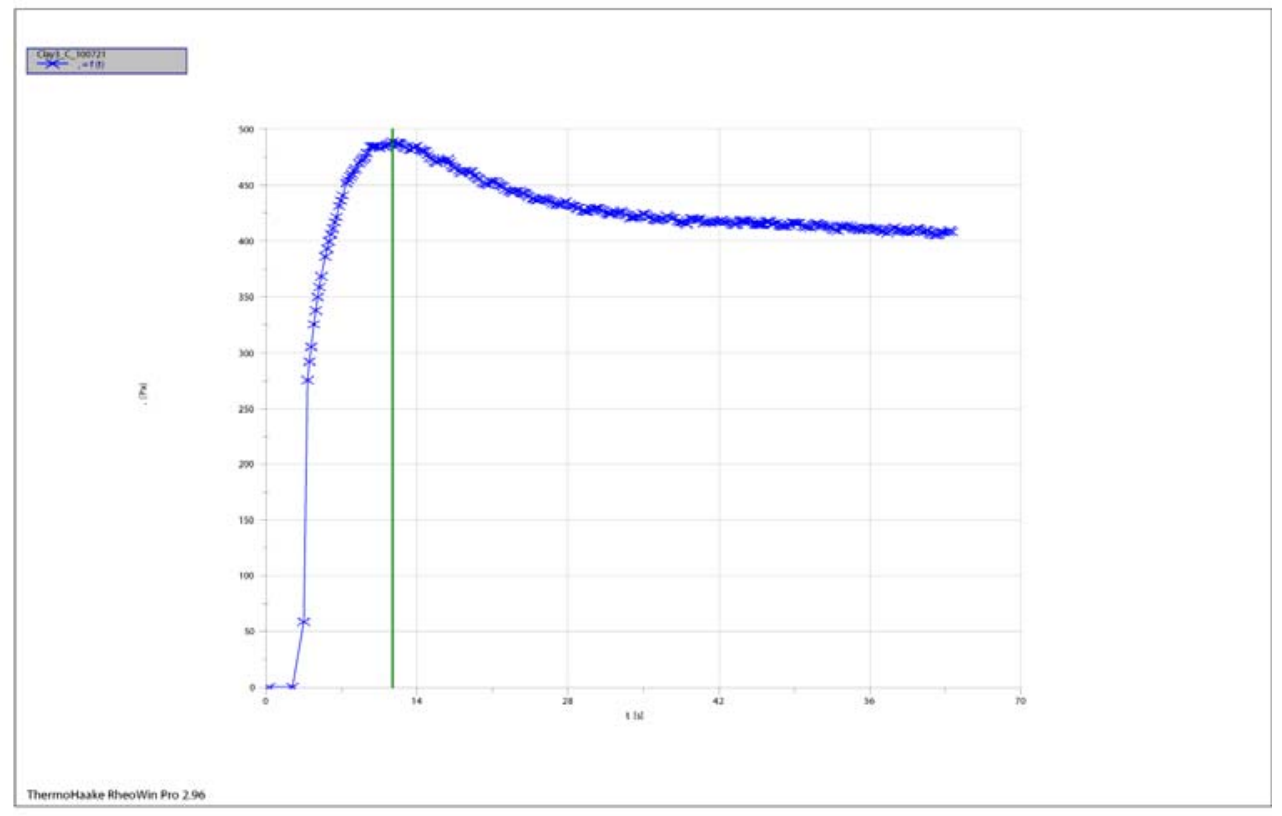

1: C: Rheology Results \JKK Basin VSB\Clay 3\Clay3 C 100721.rwd Company / Operator: PNNL / Jeromy Jenks

Substance / Sample no: Clay 3 / Clay3_C_100721

Curve discussion: Greatest value $\mathrm{t}[\mathrm{s}] \overline{1} 1.75$, [Pa] 488.2

Figure A.48. $40-w t \%$ Kaolin/20.5-wt $\%$ Min-U-Sil Clay, Center Sampling Location

ThermoHaake RheoWin 8/5/2010/2:17 PM

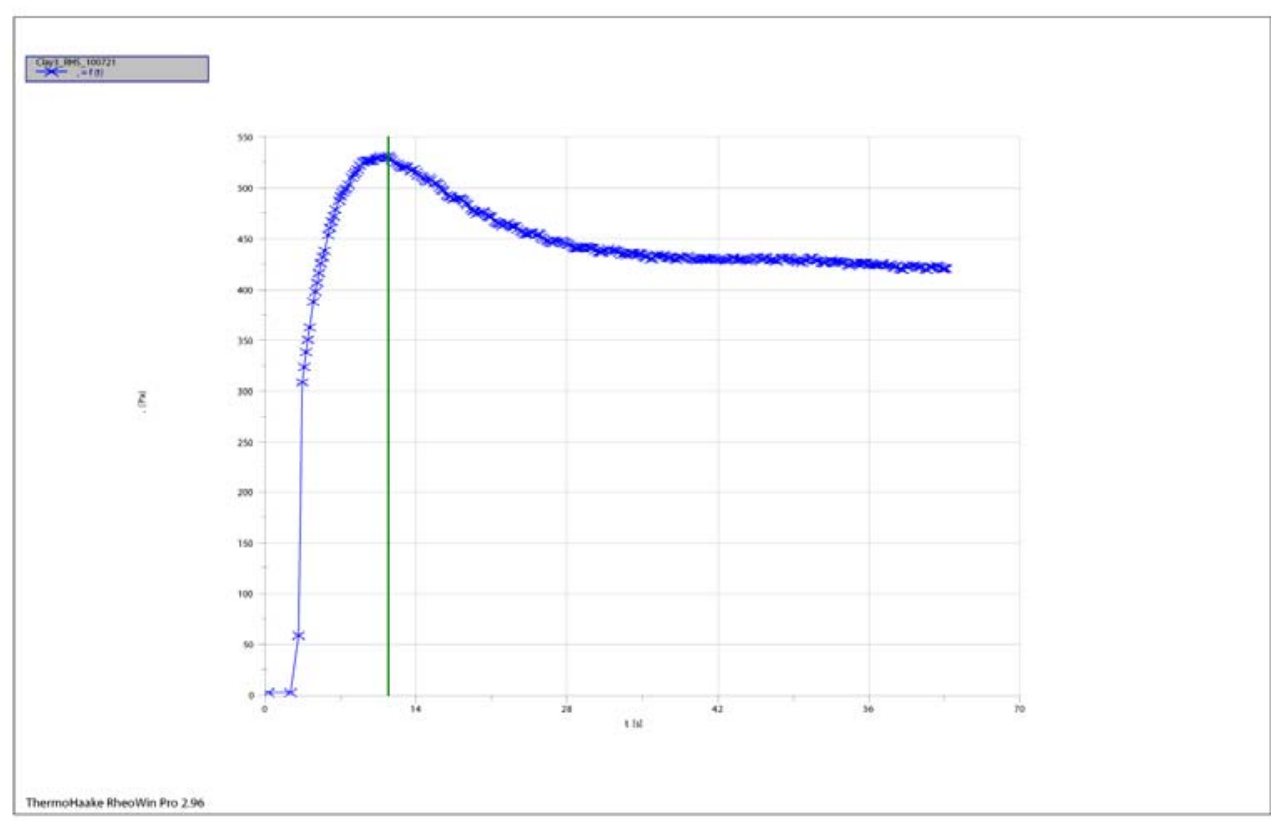

1: C:\Rheoloay Results\J\K Basin VSB\Clay 3\Clay3_RHS_100721.rwd

Company / Operator: PNNL / Jeromy Jenks

Date / Time / Version: 21.07.2010 / 11:15:24 AM / RheoWin Pro 296

Substance / Sample no: Clay 3 / Clay3_RHS_100721

Curve discussion: Greatest value $\mathrm{t}[\mathrm{s}] \mathrm{1} 1.44$, [Pa] 530.4

Figure A.49. 40-wt\% Kaolin/20.5-wt\% Min-U-Sil Clay, RHS Sampling Location 


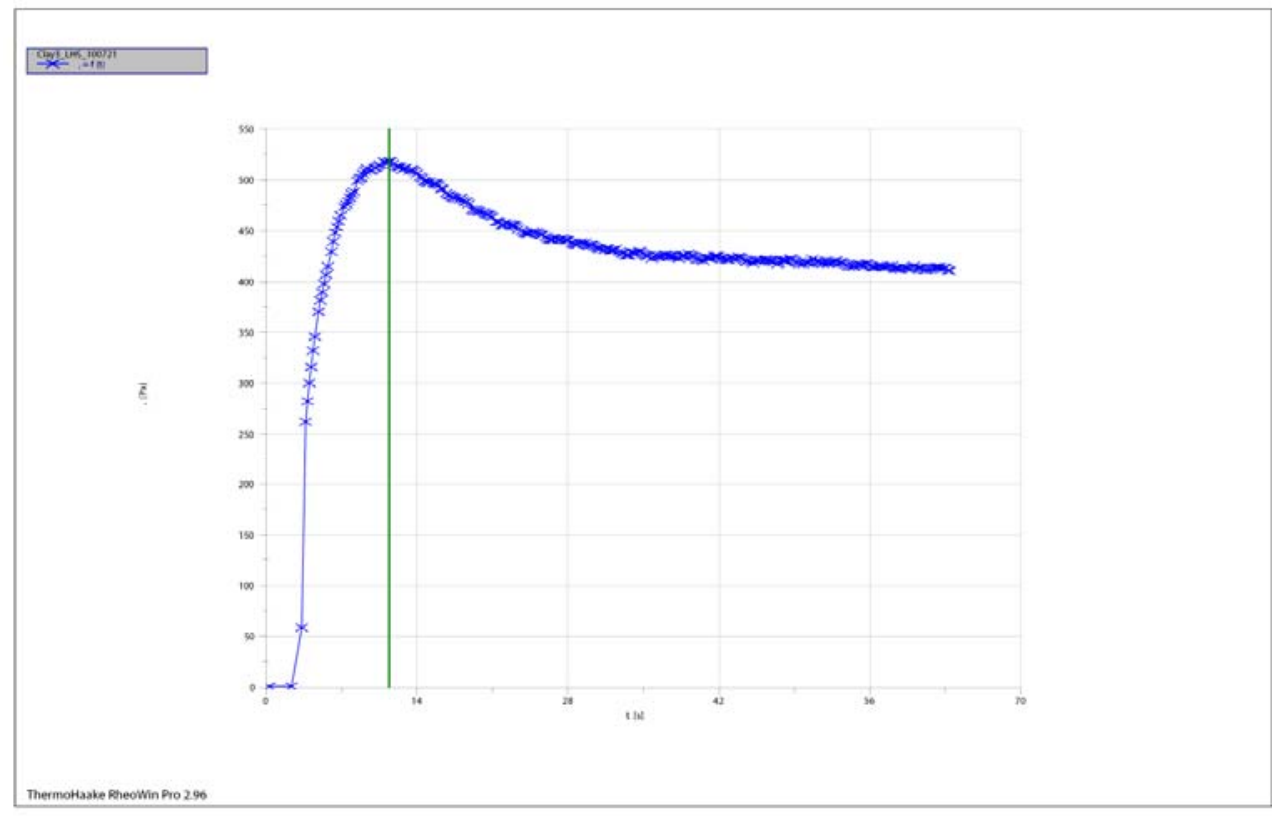

1: C:IRheoloay Results \J\K Basin VSB\Clay 3\Clay3_LHS_100721.rwd

Company / Operator: PNNL / Jeromy Jenks

Date / Time / Version: 21.07.2010 / 11:18:58 AM / RheoWin Pro 296

Substance / Sample no: Clay 3 / Clay3_LHS_100721

Curve discussion: Greatest value $\mathrm{t}[\mathrm{s}] 11.42$, [Pa] 517.9

Figure A.50. $40-w t \%$ Kaolin/20.5-wt\% Min-U-Sil Clay, LHS Sampling Location

ThermoHaake RheoWin 8/5/2010/2:20 PM

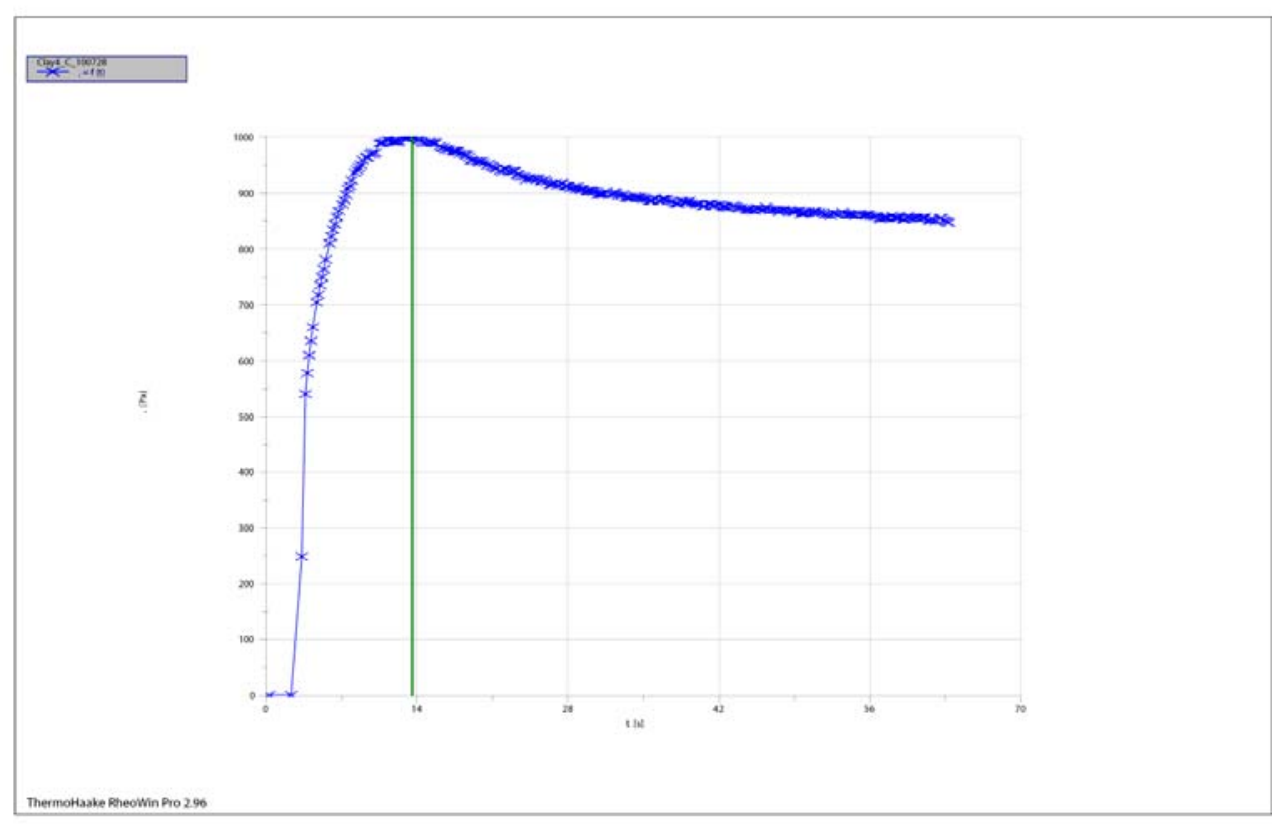

1: C:IRheoloqy Results VJ\K Basin VSB\Clay 4\Clay4_C_100728.rwd

Company / Operator: PNNL / Jeromy Jenks

Date / Time / Version: 28.07.2010 / 12:41:10 PM / RheoWin Pro 296

Substance / Sample no: Clay4 / Clay4_C_100728

Curve discussion: Greatest value $\mathrm{t}[\mathrm{s}] 13.57,[\mathrm{~Pa}] 999.9$

Figure A.51. $40-\mathrm{wt} \%$ Kaolin $/ 25-\mathrm{wt} \%$ Min-U-Sil Clay, Center Sampling Location 


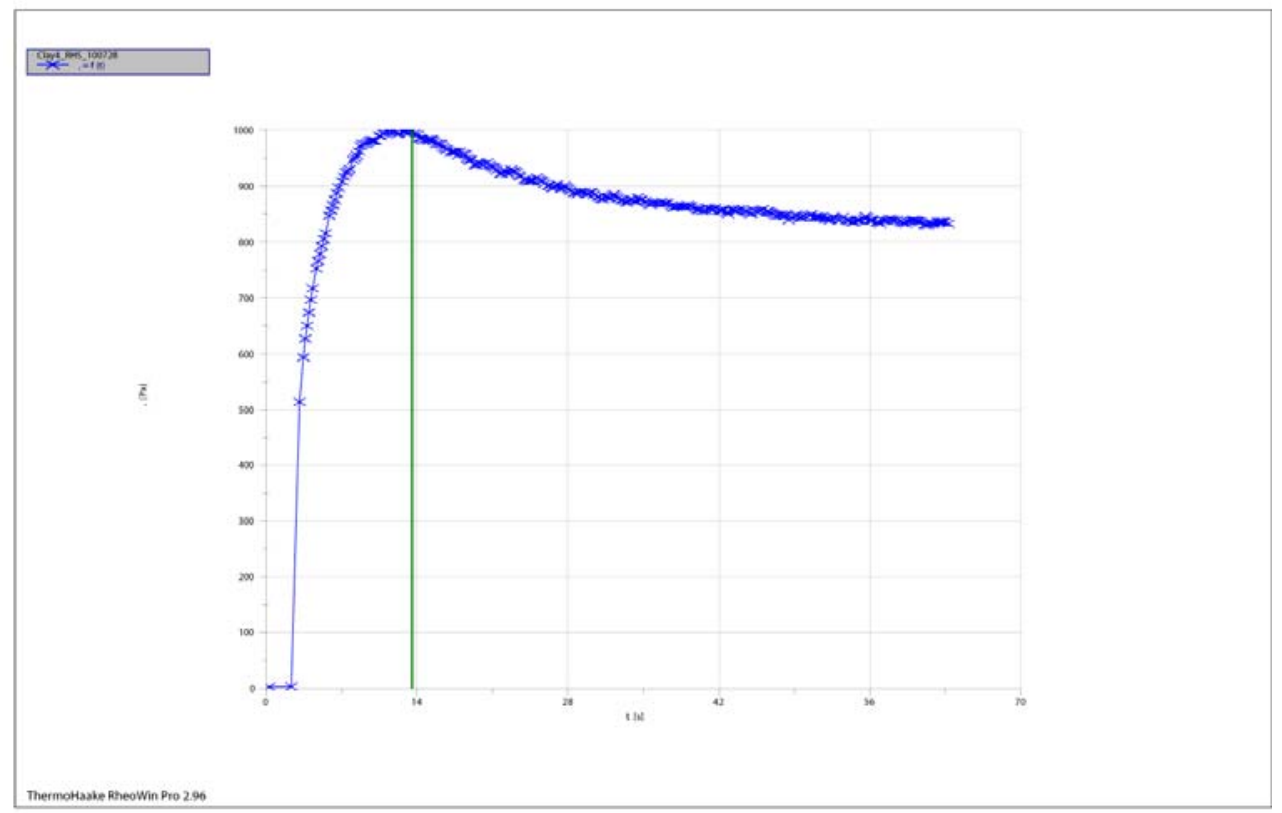

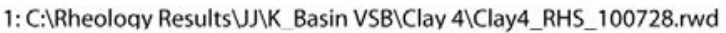

Company / Operator: PNNL / Jeromy Jenks

Date / Time / Version: 28.07.2010 / 12:44:32 PM / RheoWin Pro 296

Substance / Sample no: Clay4 / Clay4_RHS_100728

Curve discussion: Greatest value $\mathrm{t}[\mathrm{s}] 13.56$, [Pa] 997.0

Figure A.52. $40-w t \%$ Kaolin/25-wt $\%$ Min-U-Sil Clay, RHS Sampling Location

ThermoHaake RheoWin 8/5/2010/2:21 PM

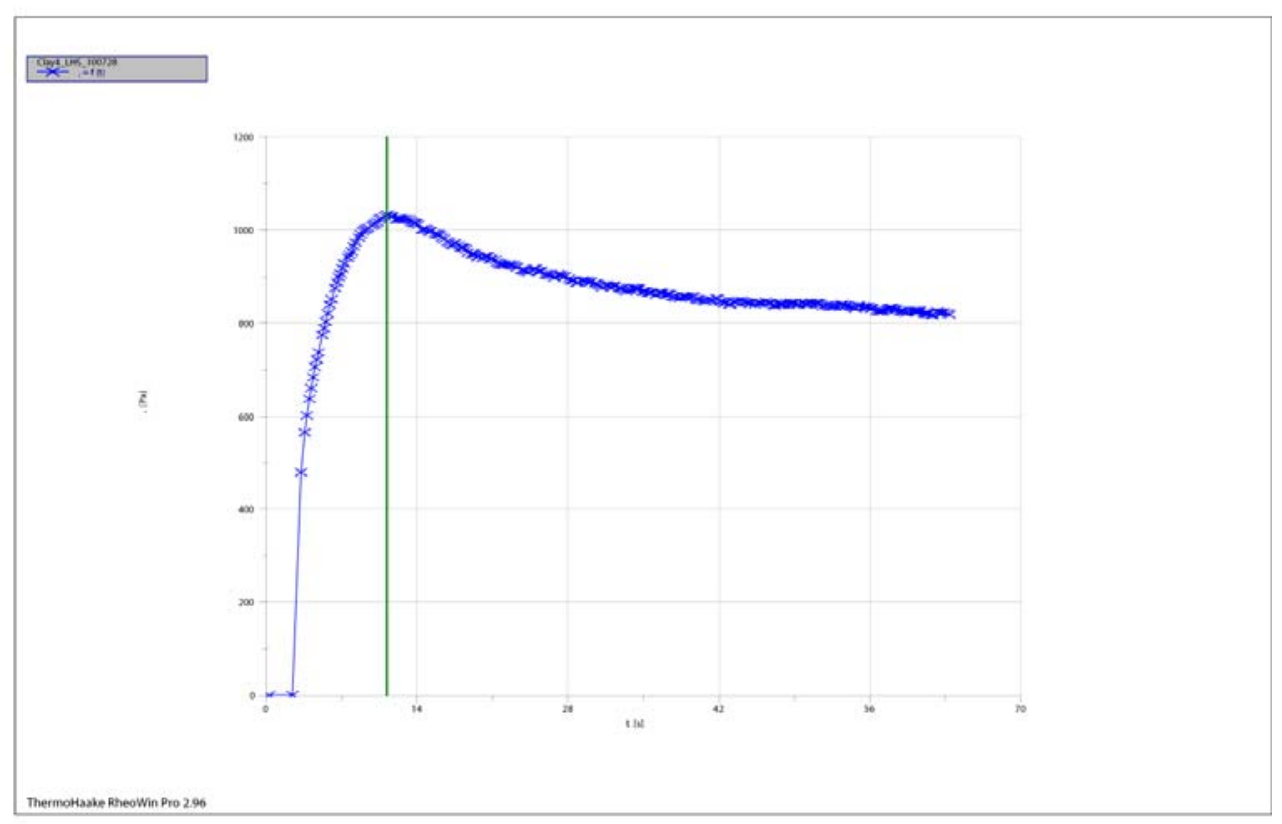

1: C:IRheoloqy Results \J\K Basin VSB\Clay 4\Clay4_LHS_100728.rwd

Company / Operator: PNNL / Jeromy Jenks

Date / Time / Version: 28.07.2010 / 12:47:35 PM / RheoWin Pro 296

Substance / Sample no: Clay4 / Clay4_LHS_100728

Curve discussion: Greatest value $\mathrm{t}[\mathrm{s}] 11.20$, [Pa] 1033.

Figure A.53. $40-\mathrm{wt} \%$ Kaolin/25-wt \% Min-U-Sil Clay, LHS Sampling Location 


\section{A.6.4 Time Variation of Shear-Strengths for Kaolin Clay}

ThermoHaake RheoWin 4/21/2010 / 3:03 PM

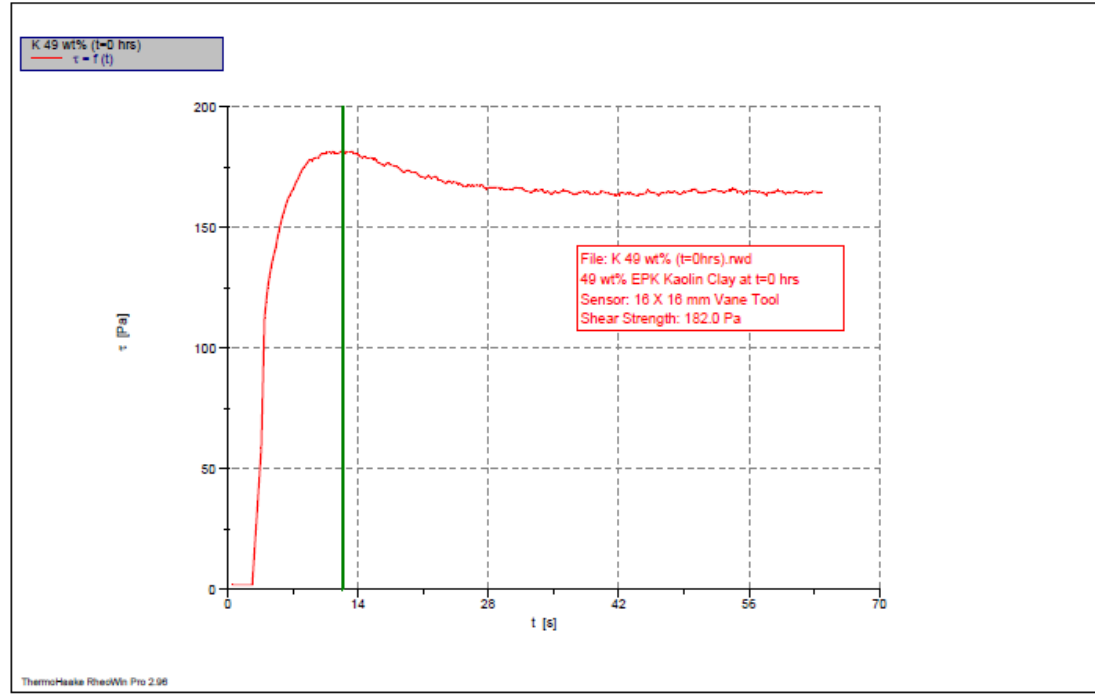

1: C:IRheologv Resultsitime -varving Kaolin strength $\backslash \mathrm{K} 49 \mathrm{wt} \%$ ( $\mathrm{t}=0 \mathrm{hrs})$.rwd

Companv / Operator: PNNL / Jaehun Chun

Date/Time/Version. 06.04.2010/ 10.46.23 AM / RheoWin Pro 296

Substance / Sample no: K 49 wt\% ( $\mathrm{t}=0 \mathrm{hrs}$ ) / K $49 \mathrm{wt} \%$ ( $\mathrm{t}=0 \mathrm{hrs}$ )

Curve discussion: Greatest value t [s] $12.35 \tau[\mathrm{Pa}] 182.0$

Figure A.54. $49-w t \%$ Kaolin Clay at $0 \mathrm{hr}$ Aging

ThermoHaake RheoWin 4/21/2010 / 3:05 PM

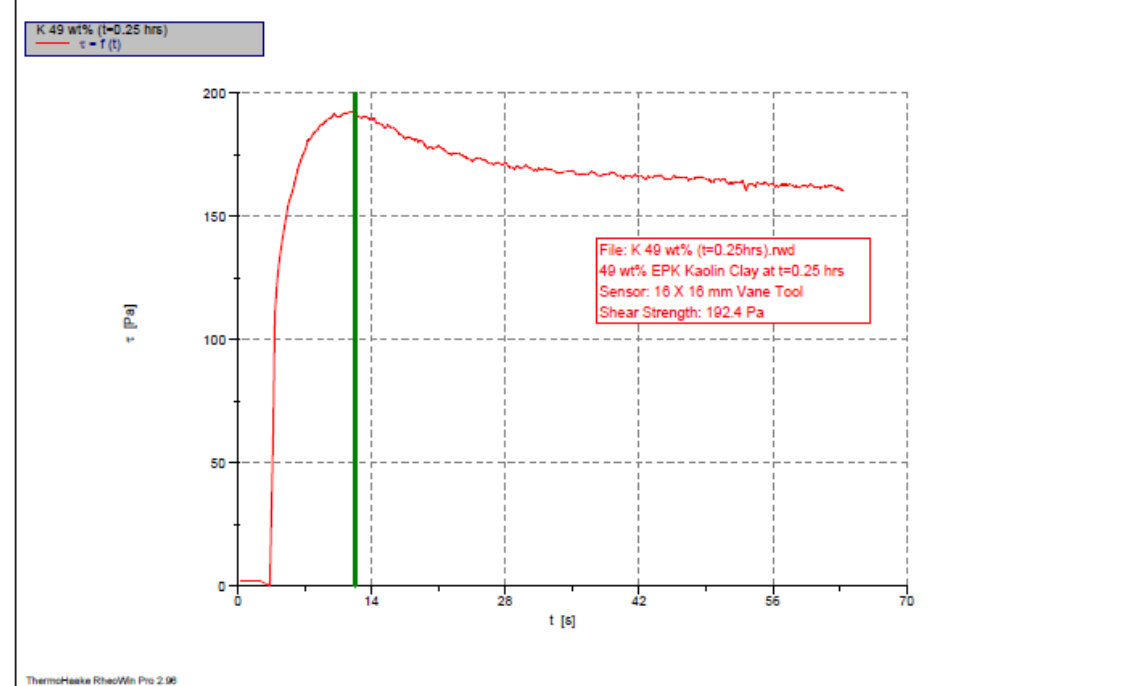

1: C:IRheoloqv Resultsitime -varving Kaolin strength $\backslash \mathrm{K} 49 \mathrm{wt} \%(\mathrm{t}=0.25 \mathrm{hrs}) . \mathrm{rwd}$ Companv / Operator: PNNL / Jaehun Chun

1:06:16 AM / RheoWin Pro 296

Substance/Sample no. K $49 \mathrm{wt} \%$ ( $\mathrm{t}=15 \mathrm{~min} .0 .25 \mathrm{hrs}$ ) / $\mathrm{K} 49 \mathrm{wt} \%$ ( $\mathrm{t}=15 \mathrm{~min}, 0.25 \mathrm{hrs}$ )

Curve discussion: Greatest value $\mathrm{t}[\mathrm{s}] 12.26 \tau[\mathrm{Pa}] 192.4$

Figure A.55. 49-wt\% Kaolin Clay at $0.25 \mathrm{hr}$ Aging 


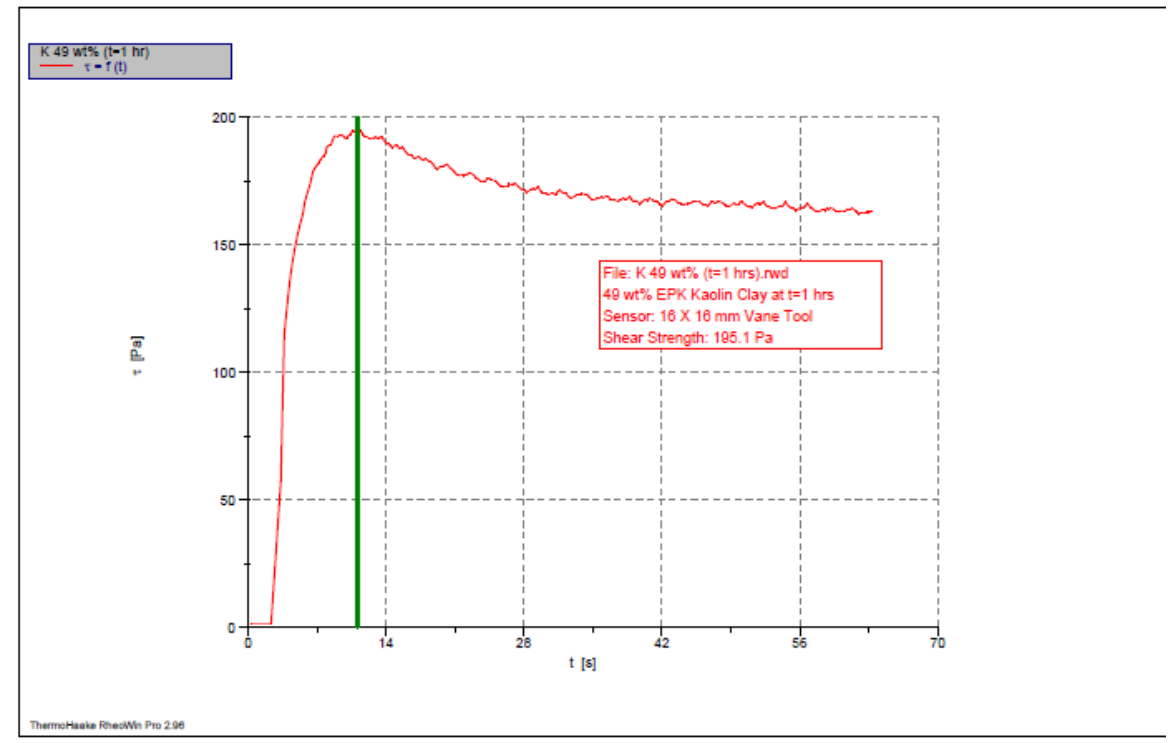

1: C:IRheoloav Resultsitime -varvina Kaolin strengthlK 49 wt\% ( $t=1 \mathrm{hr})$.rwd Companv / Operator: PNNL / Jaehun Chun

Date / Time / Version: 06.04.2010/11:55:54 AM / RheoWin Pro 296

Substance / Sample no: K 49 wt\% (t=1 hr) / K 49 wt\% ( $t=1 \mathrm{hr})$

Curve discussion: Greatest value $\mathrm{t}[\mathrm{s}] 11.11 \tau[\mathrm{Pa}]$ 195.1

Figure A.56. $49-w t \%$ Kaolin Clay at $1 \mathrm{hr}$ Aging

ThermoHaake RheoWin 4/21/2010/3:12 PM

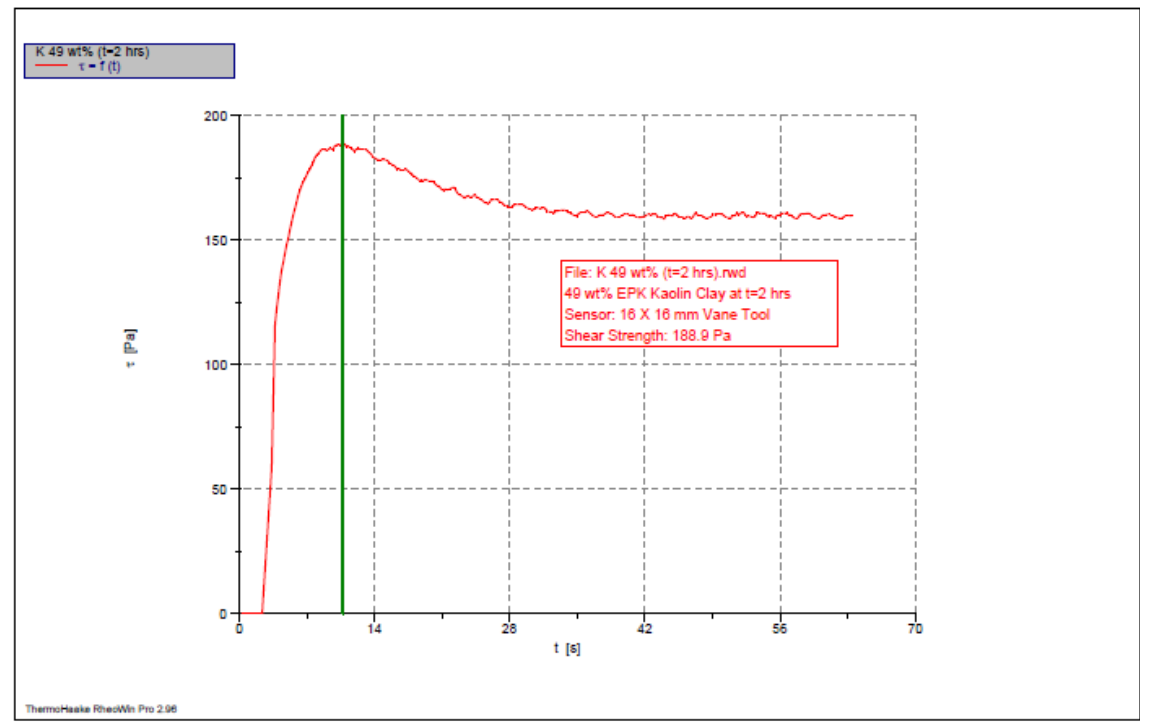

1: C:IRheoloqv Resultsitime -varyina Kaolin strength $\mathrm{K} 49 \mathrm{wt} \%$ ( $\mathrm{t}=2 \mathrm{hrs}$ ).rwd Companv / Operator: PNNL / Jaehun Chun

Date / Time / Version: 06.04.2010 / 12:46:05 PM / RheoWin Pro 296

stance / Sample no: K 49 wt\% (t=2 hrs) / K 49 wt\% (t=2 hrs)

Curve discussion: Greatest value $\mathrm{t}[\mathrm{s}] 10.74 \tau[\mathrm{Pa}] 188.9$

Figure A.57. $49-w t \%$ Kaolin Clay at $2 \mathrm{hrs}$ Aging 


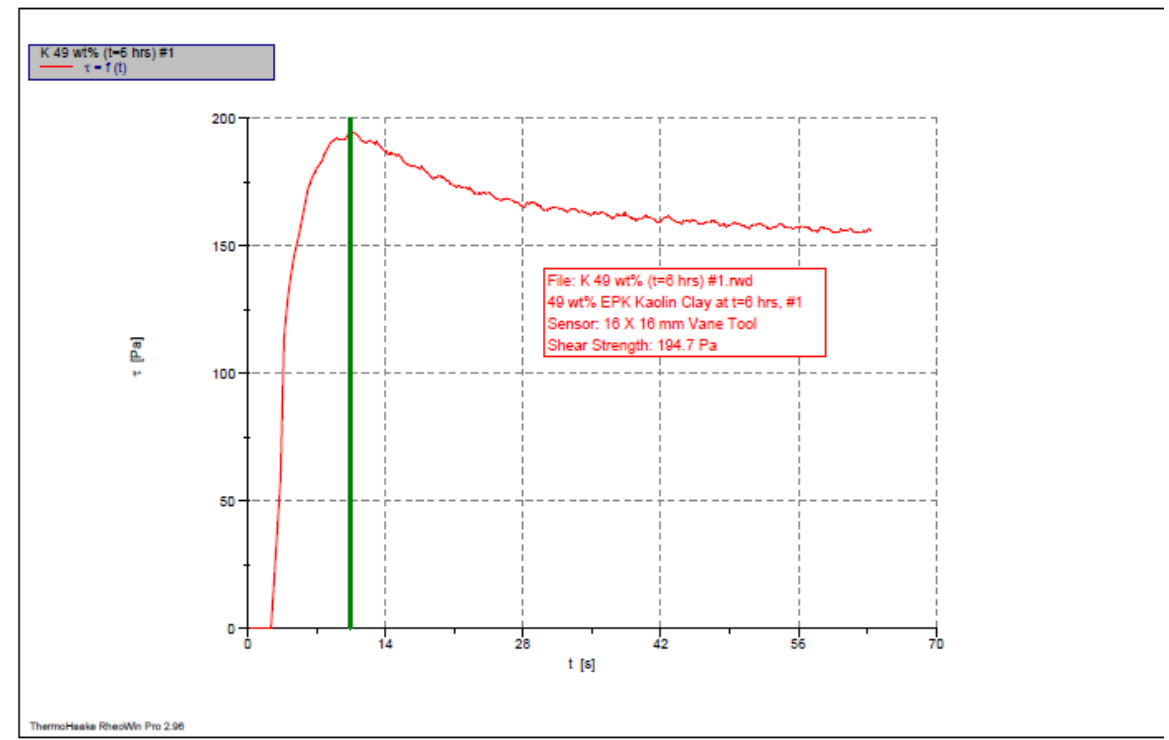

1: C:IRheoloqv Resultsitime -varvina Kaolin strength $\backslash \mathrm{K} 49 \mathrm{wt} \%$ ( $\mathrm{t}=6 \mathrm{hrs})$ \#1.rwd Companv / Operator: PNNL / Jaehun Chun

Date / Time / Version: 06.04.2010 / 17:02:07 PM / RheoWin Pro 296

Substance / Sample no: K 49 wt\% (t=6 hrs) \#1 / K 49 wt\% (t=6 hrs) \#1

Curve discussion: Greatest value $\mathrm{t}[\mathrm{s}] 10.45 \tau[\mathrm{Pa}] 194.7$

Figure A.58. $49-w t \%$ Kaolin Clay at 6 hrs Aging (\#1)

ThermoHaake RheoWin 4/21/2010 / 3:53 PM

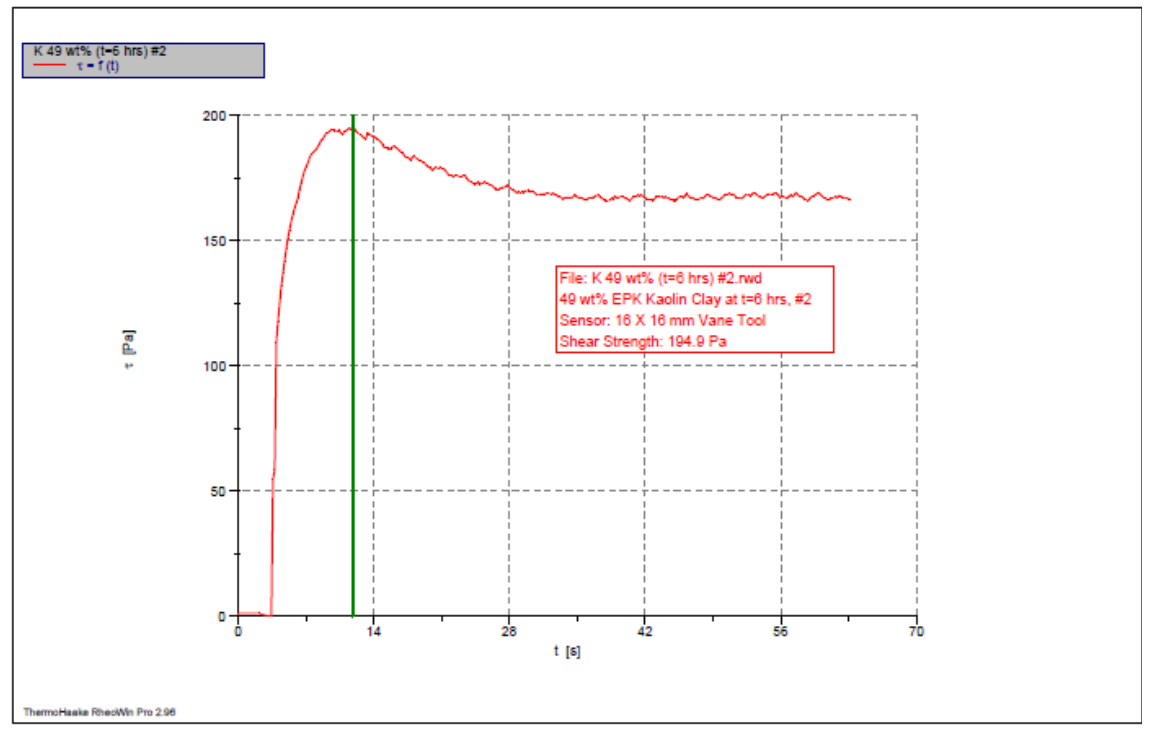

1: C:IRheologv Resultsitime -varying Kaolin strength $\backslash \mathrm{K} 49 \mathrm{wt} \%$ (t=6 hrs) \#2.rwd

Companv / Operator: PNNL / Jaehun Chun

17:05:44 PM / RheoWin Pro 296

Substance / Sample no: K 49 wt\% (t=6 hrs) \#2 / K 49 wt\% ( $\mathrm{t}=6 \mathrm{hrs}$ ) \#2

Curve discussion: Greatest value $t[s] 11.83 \tau[\mathrm{Pa}] 194.9$

Figure A.59. $49-w t \%$ Kaolin Clay at 6 hrs Aging (\#2) 


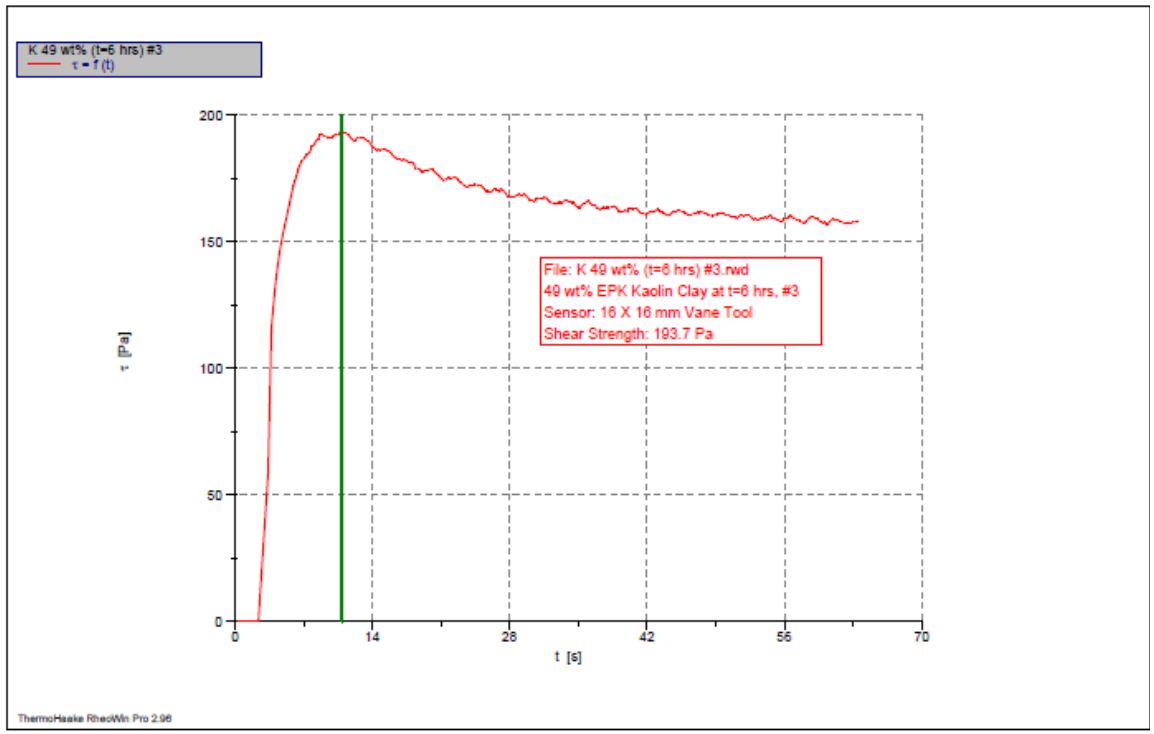

1: C:IRheoloqv Resultsitime -varving Kaolin strength $\backslash \mathrm{K} 49$ wt\% ( $\mathrm{t}=6 \mathrm{hrs})$ \#3.rwd

Companv / Operator: PNNL / Jaehun Chun
Date / Time / Version: 06.04 2010/17:08:27 PM / RheoWin Pro 296

Substance / Sample no: K 49 wt\% ( $\mathrm{t}=6 \mathrm{hrs}$ ) \#3 / K 49 wt\% ( $\mathrm{t}=6 \mathrm{hrs}) \# 3$

Curve discussion: Greatest value $\mathrm{t}[\mathrm{s}] 10.88 \tau[\mathrm{Pa}] 193.7$

Figure A.60. $49-w t \%$ Kaolin Clay at 6 hrs Aging (\#3)

ThermoHaake RheoWin 4/21/2010 / 3.55 PM

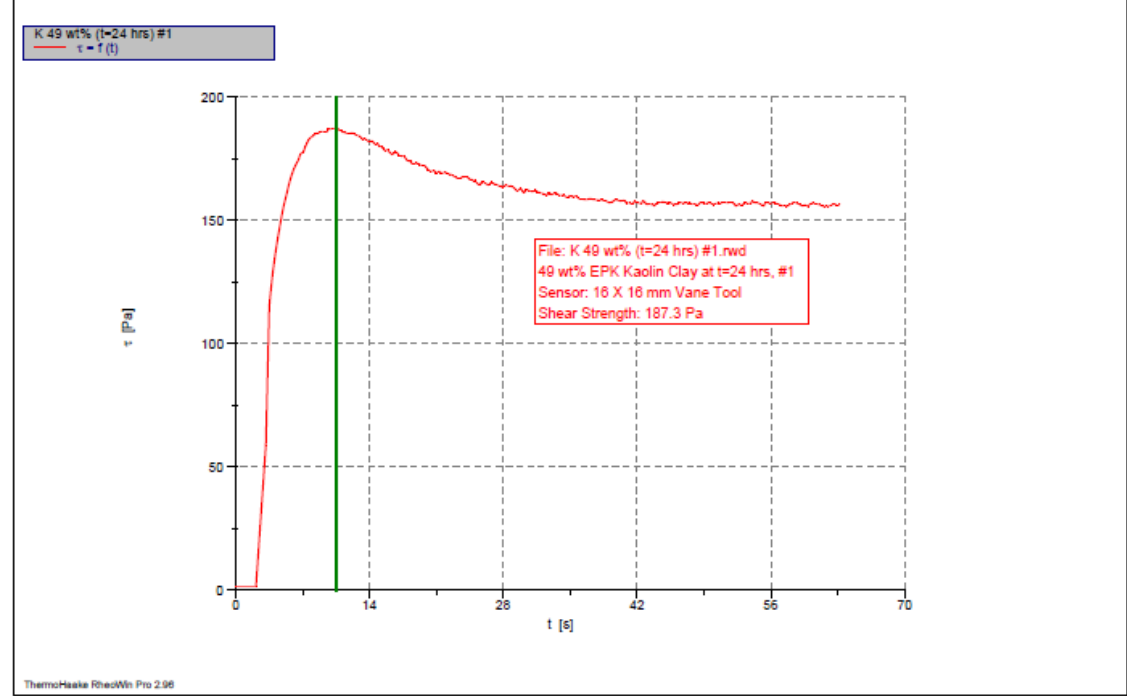

1: C:IRheologv Resultsitime -varvina Kaolin strength $\backslash \mathrm{K} 49 \mathrm{wt} \%(\mathrm{t}=24 \mathrm{hrs})$ \#1.rwd

Companv / Operator: PNNL / Jaehun Chun

AM/RheoWin Pro 296

Substance / Sample no: K 49 wt\% ( $\mathrm{t}=24 \mathrm{hrs}) \# 1 / \mathrm{K} 49 \mathrm{wt} \%$ ( $\mathrm{t}=24 \mathrm{hrs}) \#$

Curve discussion: Greatest value $\mathrm{t}[\mathrm{s}] 10.52 \tau[\mathrm{Pa}] 187.3$

Figure A.61. $49-\mathrm{wt} \%$ Kaolin Clay at $24 \mathrm{hrs}$ Aging (\#1) 


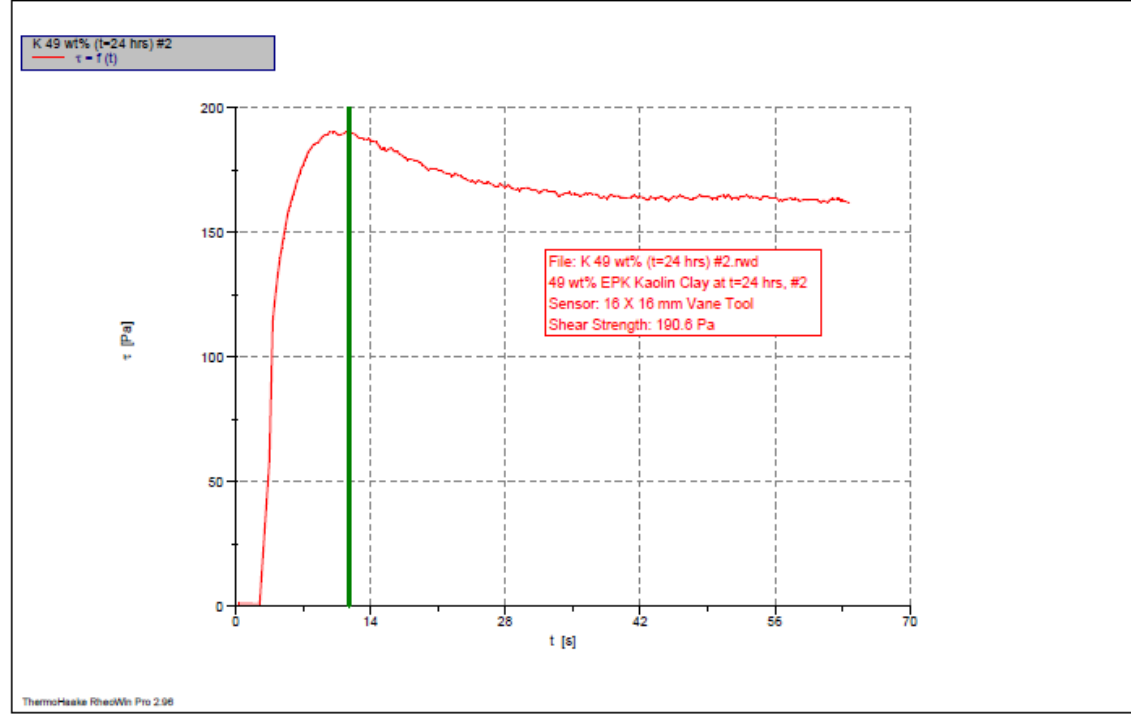

1: C:IRheoloav Resultsltime -varving Kaolin strength $\backslash \mathrm{K} 49 \mathrm{wt} \%$ (t=24 hrs) \#2.rwd Companv / Operator: PNNL / Jaehun Chun

AMrooWin Pro 296

Substance / Sample no: K 49 wt\% ( $\mathrm{t}=24 \mathrm{hrs}$ ) \#2 / K $49 \mathrm{wt} \%$ ( $\mathrm{t}=24 \mathrm{hrs}) \# 2$ Curve discussion: Greatest value $\mathrm{t}[\mathrm{s}] 11.81 \tau[\mathrm{Pa}] 190.6$

Figure A.62. $49-w t \%$ Kaolin Clay at $24 \mathrm{hrs}$ Aging (\#2)

ThermoHaake RheoWin 4/21/2010/4:18 PM

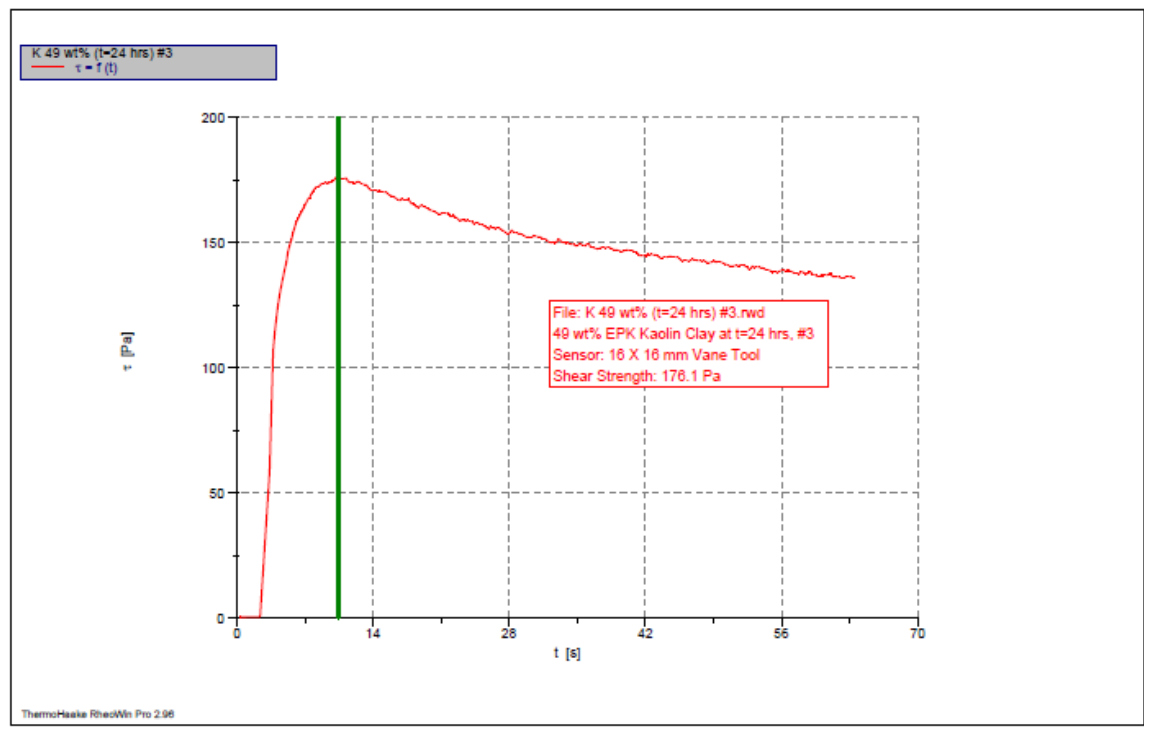

1: C:IRheoloav Resultsitime -varving Kaolin strengthlK 49 wt\% (t=24 hrs) \#3.rwd Companv / Operator: PNNL / Jaehun Chun

Date/ Time/ Version. 07.04.2010/ 10:56:35 AM / RheoWin Pro 296

Substance / Sample no: K 49 wt\% (t=24 hrs) \#3 / K 49 wt\% ( $\mathrm{t}=24 \mathrm{hrs}) \# 3$

Curve discussion: Greatest value $\mathrm{t}[\mathrm{s}] 10.44 \tau[\mathrm{Pa}] 176.1$

Figure A.63. $49-\mathrm{wt} \%$ Kaolin Clay at 24 hrs Aging (\#3) 


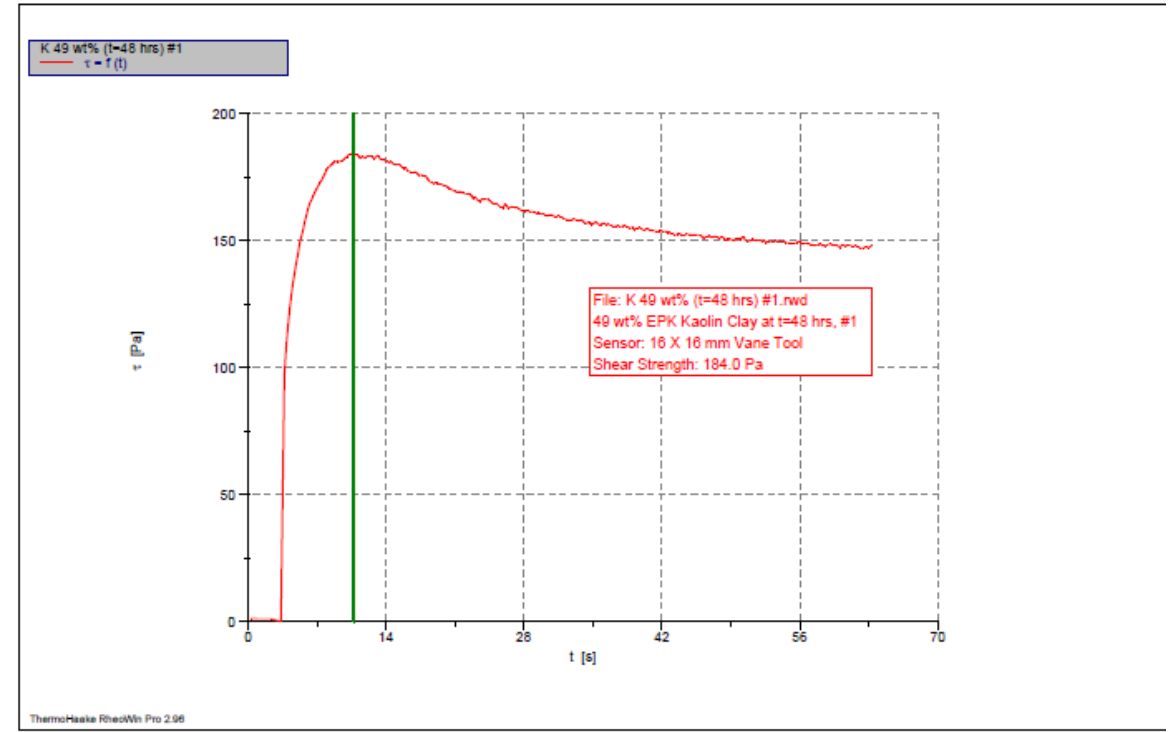

1: C:IRheoloav Resultsitime -varving Kaolin strength $\ \mathbf{K} 49 \mathrm{wt} \%$ ( $\mathrm{t}=48 \mathrm{hrs})$ \#1.rwd Companv / Operator: PNNL / Jaehun Chun

10:51:49 AM / RheoWin Pro 296

Substance / Sample no: $\mathrm{K} 48 \mathrm{wt} \%$ (t=48 hrs) \#1 / K $48 \mathrm{wt} \%$ (t=48 hrs) \#1 Curve discussion: Greatest value $\mathrm{t}[\mathrm{s}] 10.71 \tau[\mathrm{Pa}] 184.0$

Figure A.64. $49-w t \%$ Kaolin Clay at 48 hrs Aging (\#1)

ThermoHaake RheoWin 4/21/2010/3:58 PM

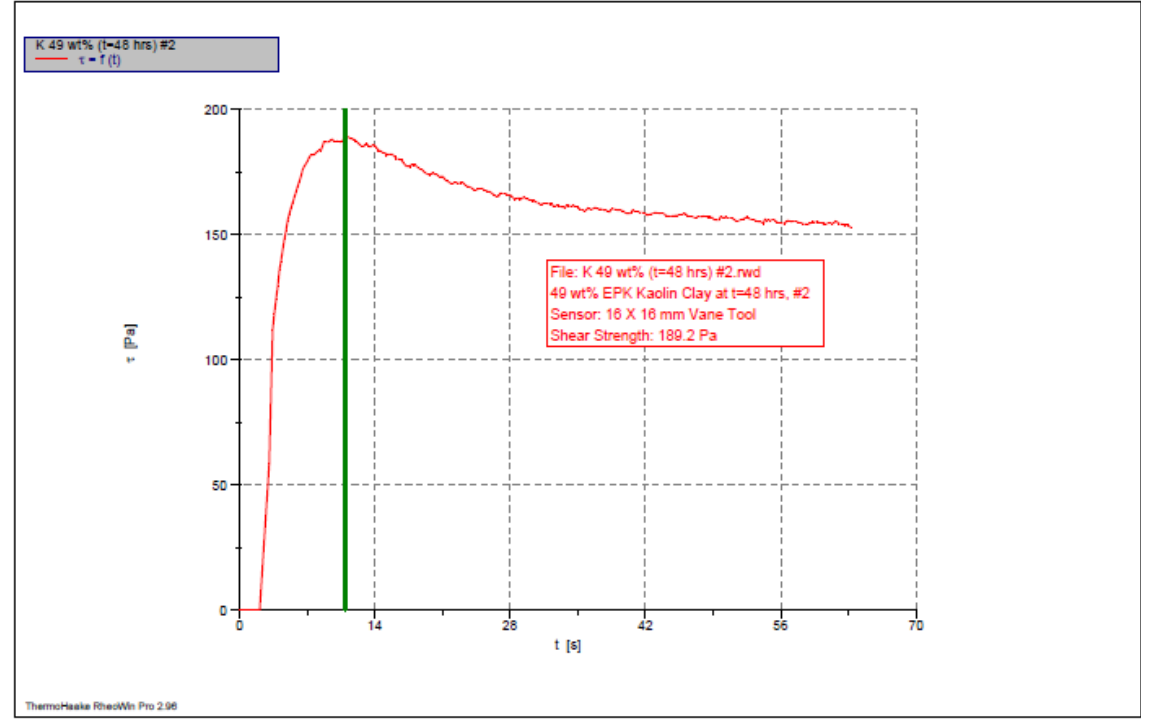

1: C:IRheologv Resultsitime -varying Kaolin strength $\backslash \mathrm{K} 49 \mathrm{wt} \%$ ( $\mathrm{t}=48 \mathrm{hrs})$ \#2.rwd

Companv / Operator: PNNL / Jaehun Chun
Date / Time / Version: 08.04 2010 / 10:55:08 AM / RheoWin Pro 296

Substance / Sample no: K 48 wt $\%$ ( $\mathrm{t}=48 \mathrm{hrs}$ ) \#2 / $\mathrm{K} 48 \mathrm{wt} \%$ (t=48 hrs) \#2

Curve discussion: Greatest value $\mathrm{t}[\mathrm{s}] 10.96 \tau[\mathrm{Pa}] 189.2$

Figure A.65. $49-w t \%$ Kaolin Clay at 48 hrs Aging (\#2) 
ThermoHaake RheoWin 4/21/2010/4:00 PM

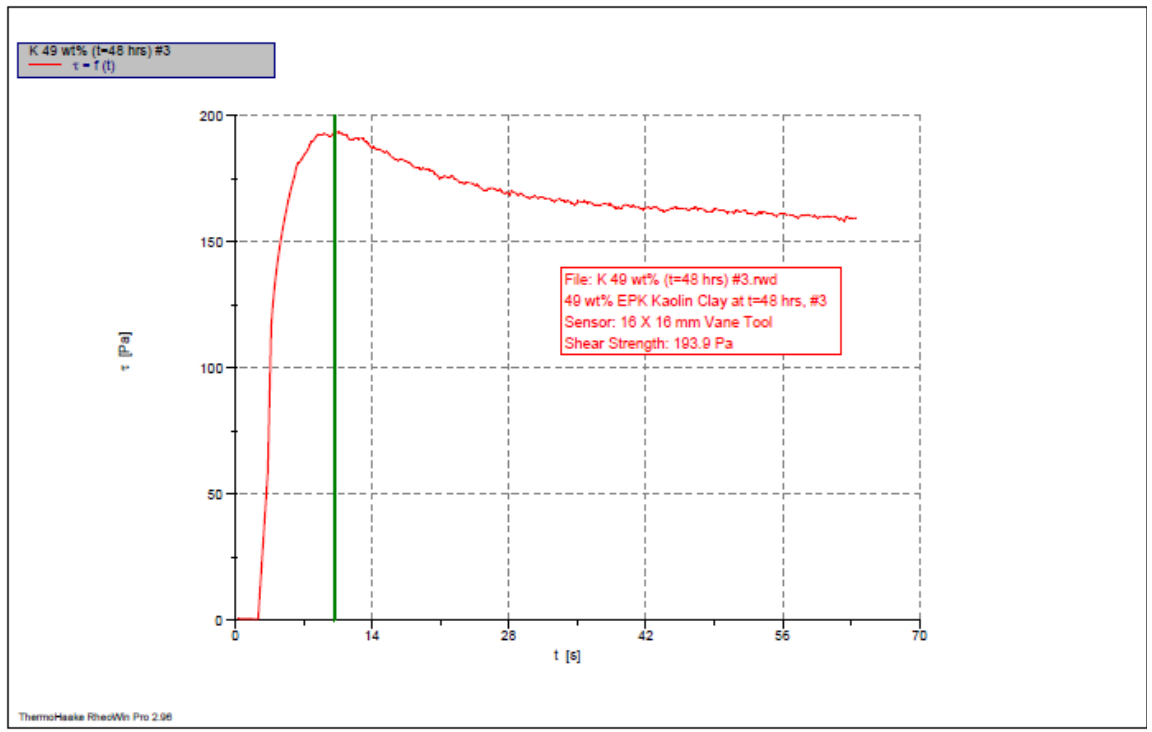

1: C:IRheoloav Resultsitime -varving Kaolin strengthlK 49 wt\% ( $\mathrm{t}=48 \mathrm{hrs})$ \#3.rwd Companv / Operator: PNNL / Jaehun Chun

Date / Time / Version: 08.04.2010 / 10:58.26 AM / RheoWin Pro 296

Substance / Sample no: K 48 wt\% ( $\mathrm{t}=48 \mathrm{hrs}$ ) \#3 / K 48 wt\% (t=48 hrs) \#3

Curve discussion: Greatest value $\mathrm{t}[\mathrm{s}] 10.18 \tau[\mathrm{Pa}] 193.9$

Figure A.66. $49-w t \%$ Kaolin Clay at 48 hrs Aging (\#3)

ThermoHaake RheoWin 4/21/2010/2:31 PM

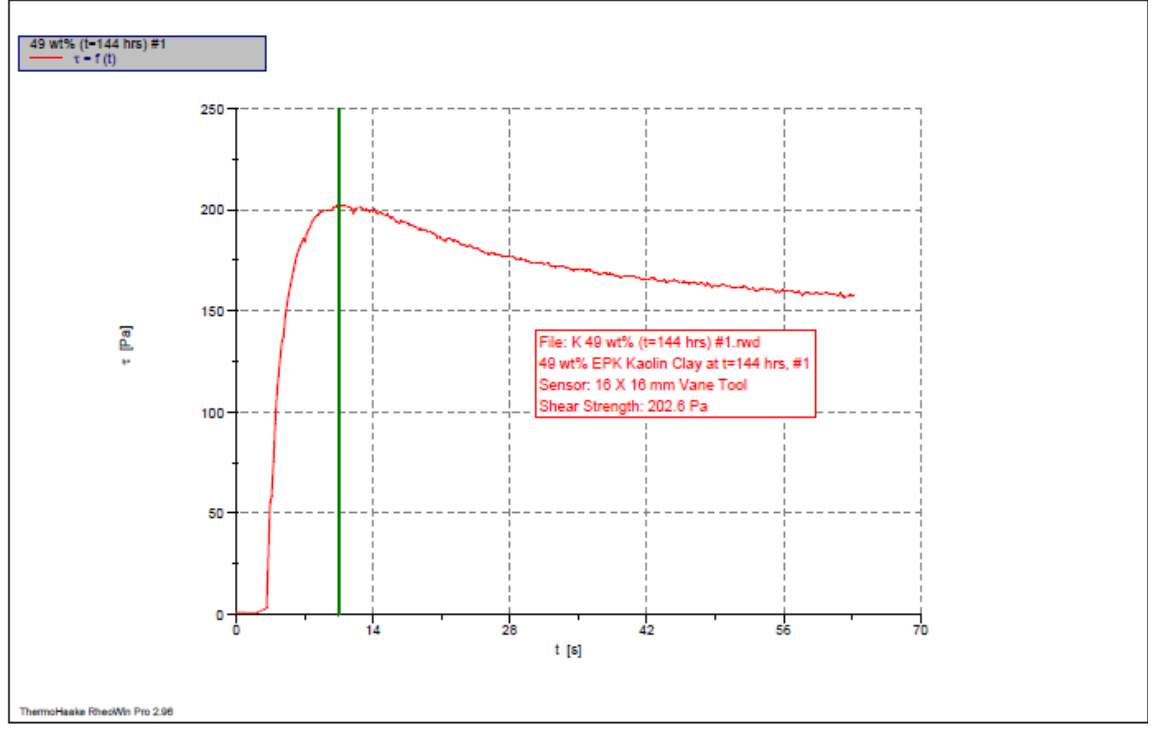

1: C:IRheologv Resultsitime -varvina Kaolin strength $\backslash 49 \mathrm{wt} \%$ (t=144 hrs) \#1.rwd

Companv / Operator: PNNL / Jaehun Chun

Date / Time/ Version. 12.04.2010/10.49:05 AM / RheoWin Pro 296

Substance / Sample no: $49 \mathrm{wt} \%$ ( $\mathrm{t}=144 \mathrm{hrs}) \# 1 / 49 \mathrm{wt} \%$ (t=144 hrs) \#1

Curve discussion: Greatest value $t[s] 10.48 \tau[\mathrm{Pa}] 202.6$

Figure A.67. 49-wt\% Kaolin Clay at 144 hrs Aging (\#1) 
ThermoHaake RheoWin 4/21/2010/2:33 PM

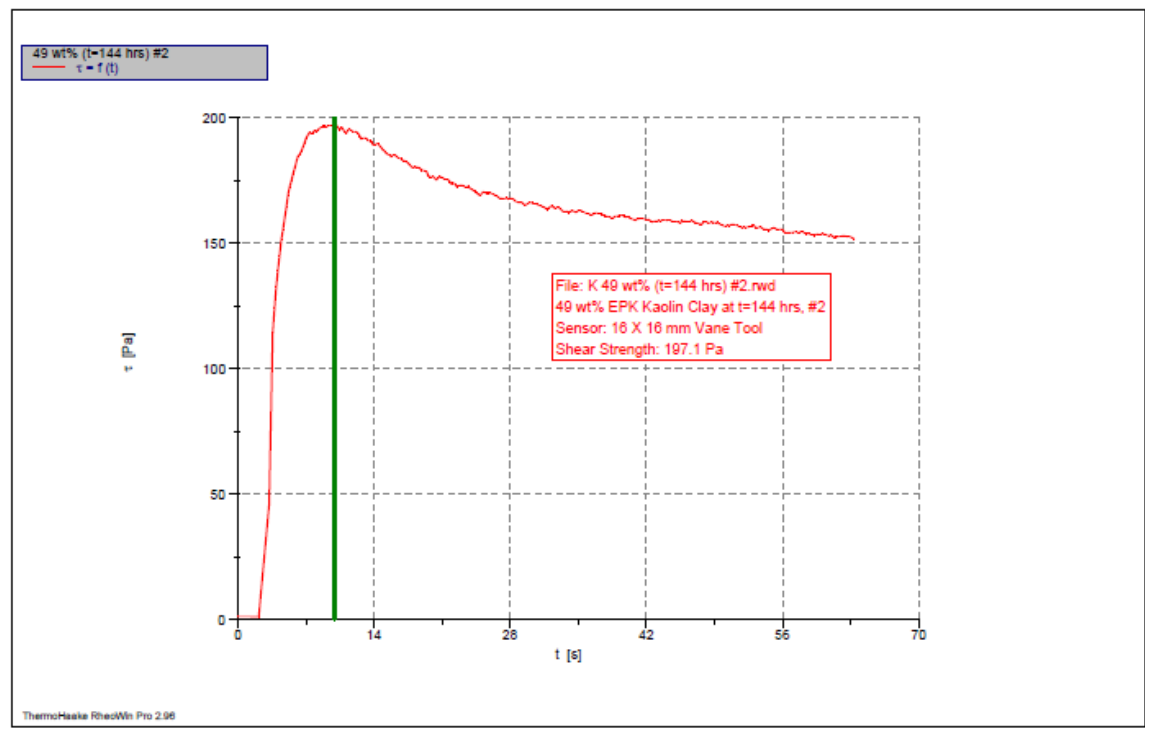

1: C:IRheologv Resultsitime -varving Kaolin strength 449 wt\% ( $\mathrm{t}=144 \mathrm{hrs})$ \#2.rwd

Company / Operator. PNNL / Jaehun Chun

Date / Time / Version: 12.04 2010 / 10:58:46 AM / RheoWin Pro 296

Substance / Sample no: 49 wt\% (t=144 hrs) \#2 / 49 wt\% (t=144 hrs) \#2

Curve discussion: Greatest value $\mathrm{t}[\mathrm{s}] 9.948 \tau[\mathrm{Pa}]$ 197.1

Figure A.68. $49-w t \%$ Kaolin Clay at 144 hrs Aging (\#2)

ThermoHaake RheoWin 4/21/2010/2:35 PM

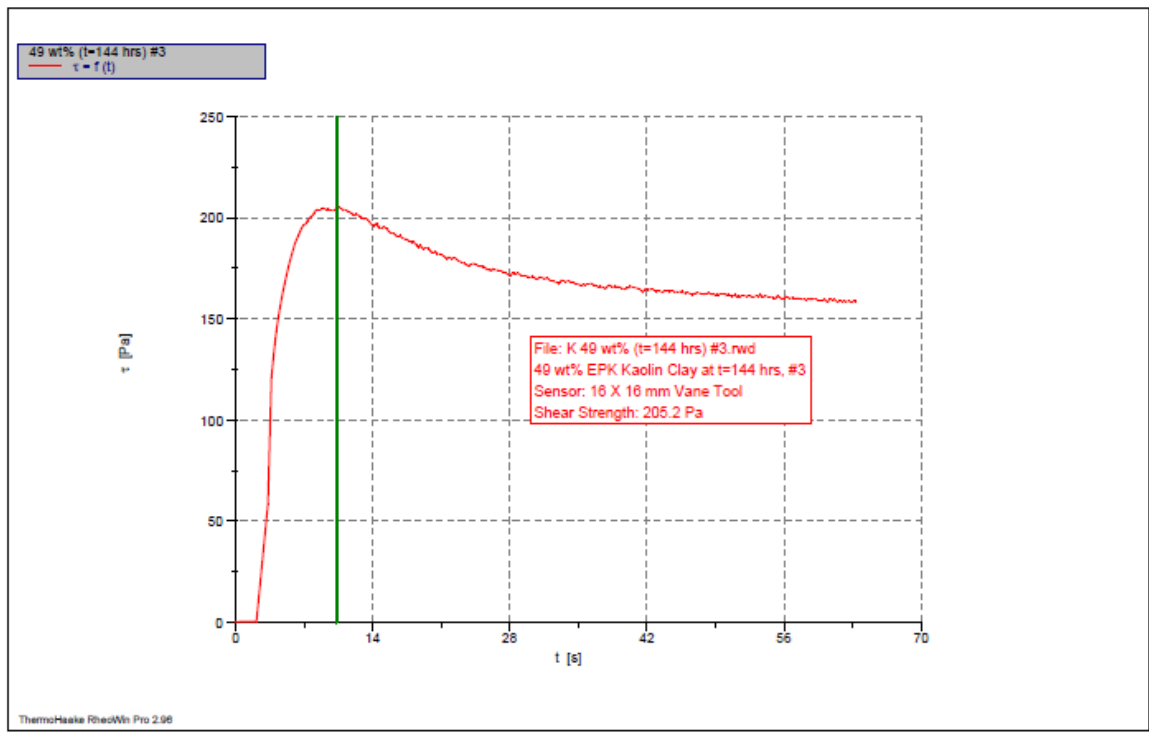

1: C:IRheologv Resultsltime -varvina Kaolin strengthl49 wt\% (t=144 hrs) \#3.rwd Companv / Operator: PNNL / Jaehun Chun

Date / Time / Version: 12.04.2010/11:03:01 AM / RheoWin Pro 296

Substance / Sample no: $49 \mathrm{wt} \%$ (t=144 hrs) \#3 / $49 \mathrm{wt} \%$ (t=144 hrs) \#3

Curve discussion: Greatest value $\mathrm{t}[\mathrm{s}] 10.35 \tau[\mathrm{Pa}] 205.2$

Figure A.69. $49-w t \%$ Kaolin Clay at 144 hrs Aging (\#3) 


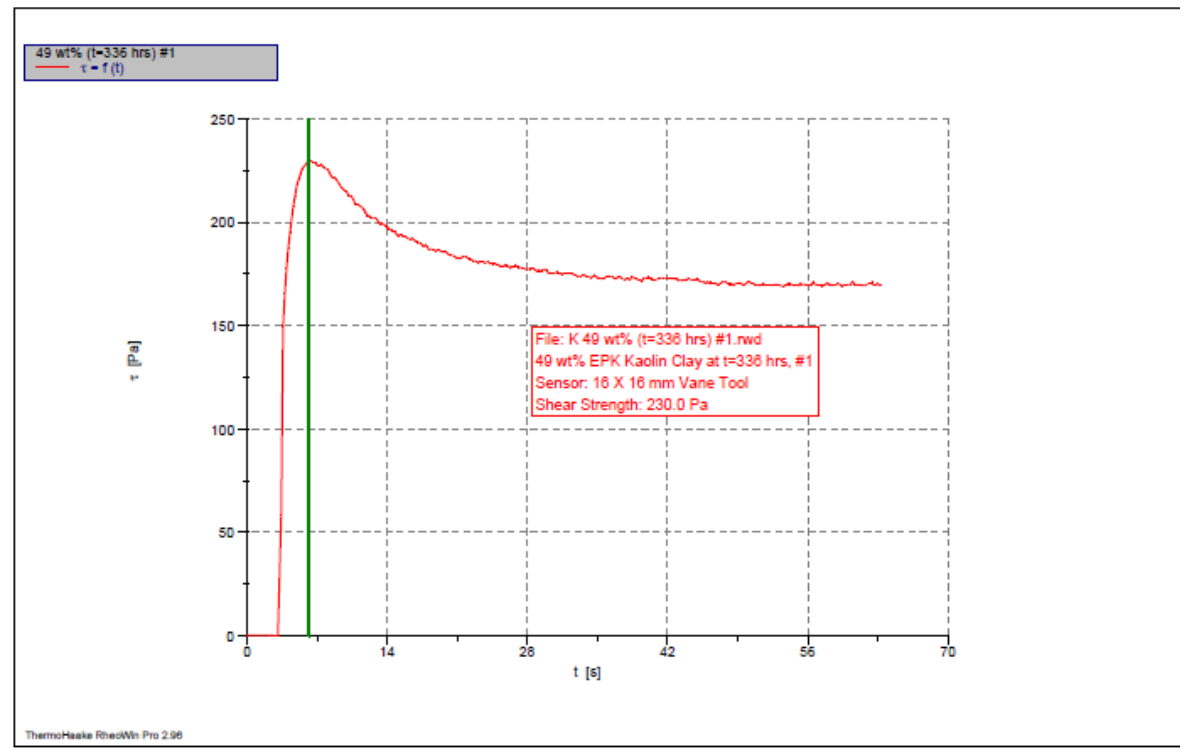

1: C:IRheoloqv Resultsitime -varyinq Kaolin strength $\backslash 49$ wt\% (t=336 hrs) \#1.rwd Companv / Operator: PNNL / Jaehun Chun

Date / Time / Version: 20.04.2010 / 11:19:11 AM / RheoWin Pro 296

Substance / Sample no: 49 wt\% ( $\mathrm{t}=336 \mathrm{hrs}$ ) \#1 / $49 \mathrm{wt} \%$ ( $\mathrm{t}=336 \mathrm{hrs}) \# 1$

Curve discussion: Greatest value $\mathrm{t}[\mathrm{s}] 6.176 \tau[\mathrm{Pa}] 230.0$

Figure A.70. 49 -wt\% Kaolin Clay at 336 hrs Aging (\#1)

ThermoHaake RheoWin 4/21/2010/2:37 PM

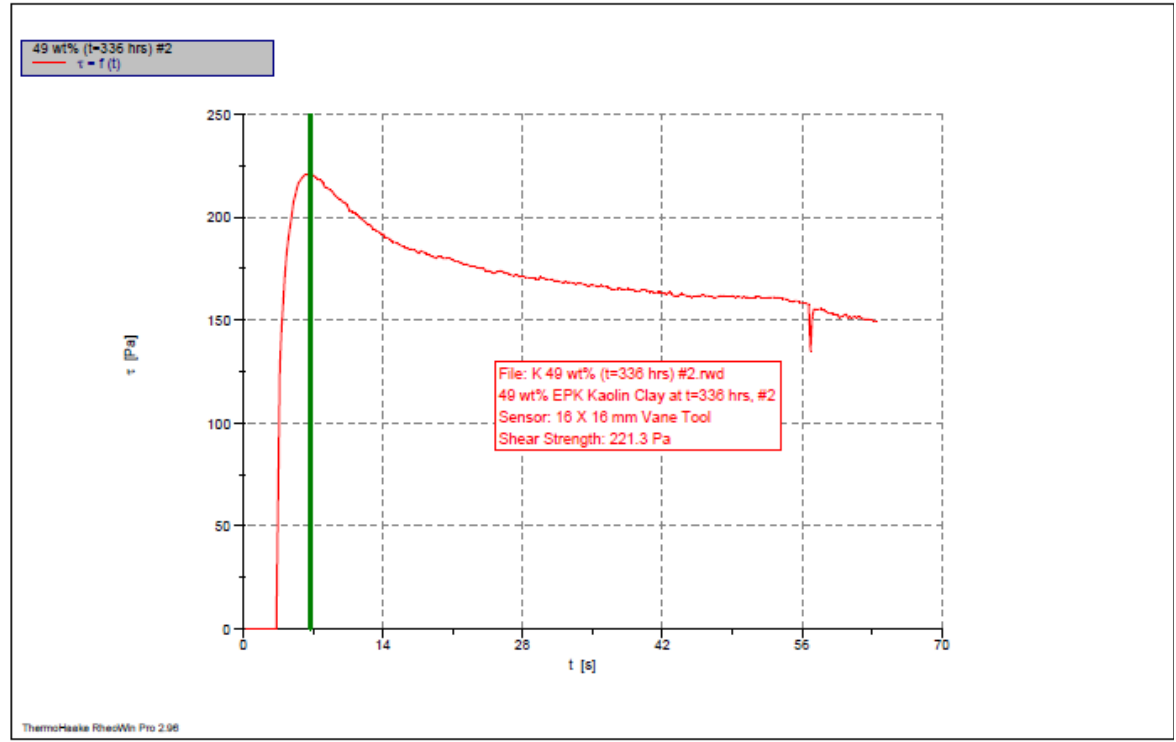

1: C:IRheoloav Resultsltime -varving Kaolin strength 49 wt\% ( $\mathrm{t}=336 \mathrm{hrs}$ ) \#2.rwd Companv/ Operator: PNNL / Jaehun Chun

Date / Time / Version: 20.04.2010 / 11:23:25 AM / RheoWin Pro 296

Substance / Sample no: $49 \mathrm{wt} \%$ ( $\mathrm{t}=336 \mathrm{hrs}$ ) \#2 / $49 \mathrm{wt} \%$ (t=336 hrs) \#2

Curve discussion: Greatest value $\mathrm{t}[\mathrm{s}] 6.747 \tau[\mathrm{Pa}] 221.3$

Figure A.71. $49-w t \%$ Kaolin Clay at 336 hrs Aging (\#2) 


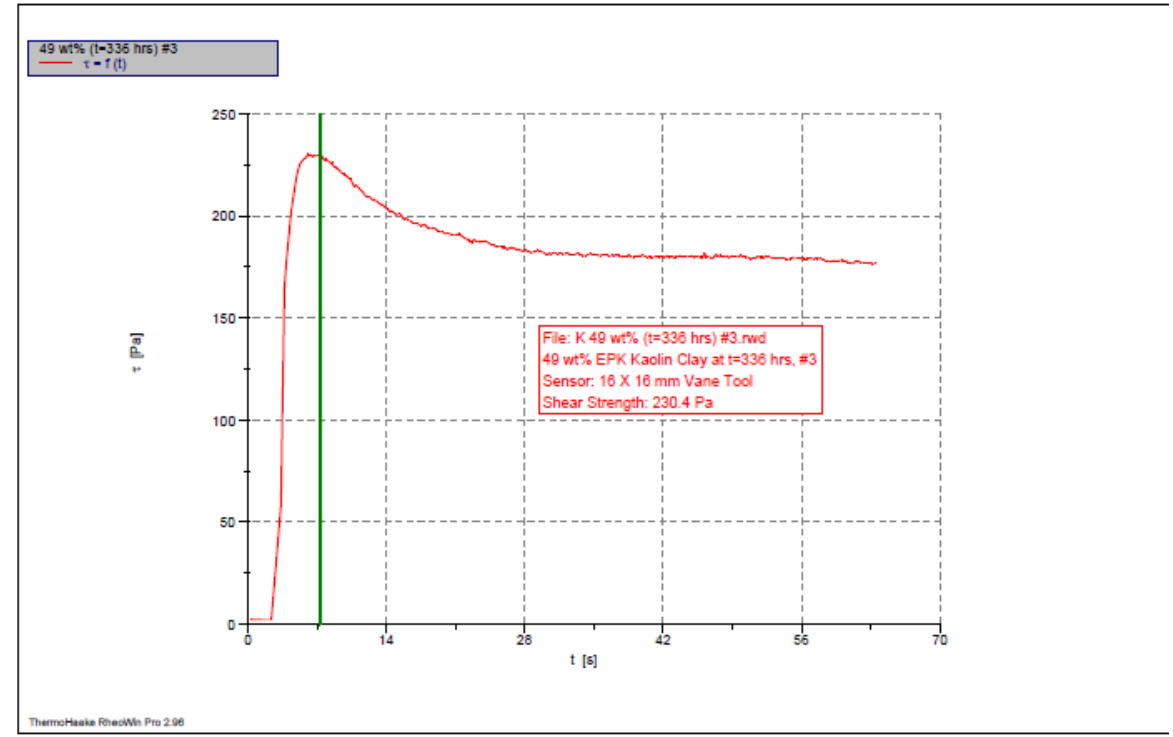

1: C:IRheoloqv Resultsitime -varvina Kaolin strength 449 wt\% ( $\mathrm{t}=336 \mathrm{hrs})$ \#3.rwd

Companv / Operator: PNNL / Jaehun Chun

Substance / Sample no: 49 wt\% ( $\mathrm{t}=336 \mathrm{hrs}$ ) \#3/49 wt\% ( $\mathrm{t}=336 \mathrm{hrs})$ \#3

Curve discussion: Greatest value $t[s] 7.301 \tau[\mathrm{Pa}] 230.4$

Figure A.72. $49-w t \%$ Kaolin Clay at 336 hrs Aging (\#3)

ThermoHaake RheoWin 4/29/2010 / 2:19 PM

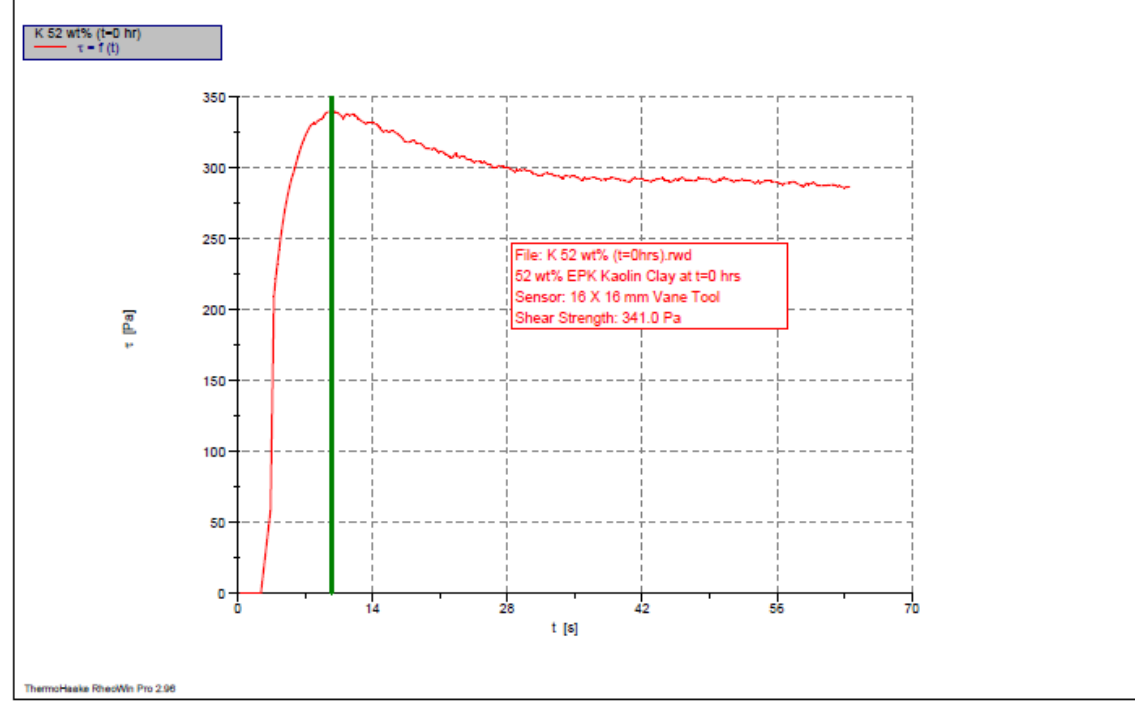

1: C:IRheologv Resultsitime -varvina Kaolin strength $\mathrm{K} 52 \mathrm{wt} \%(\mathrm{t}=0 \mathrm{hr}) . \mathrm{rwd}$

Date / Time / Version: 07.04.2010 / 11:03:22 AM / RheoWin Pro 296

Substance / Sample no: $\mathrm{K} 52 \mathrm{wt} \%(\mathrm{t}=0 \mathrm{hr}) / \mathrm{K} 52 \mathrm{wt} \%(\mathrm{t}=0 \mathrm{hr})$

Curve discussion: Greatest value $\mathrm{t}[\mathrm{s}] 9.771 \tau[\mathrm{Pa}] 341.0$

Figure A.73. $52 \mathrm{wt} \%$ Kaolin Clay at $0 \mathrm{hrs}$ Aging 


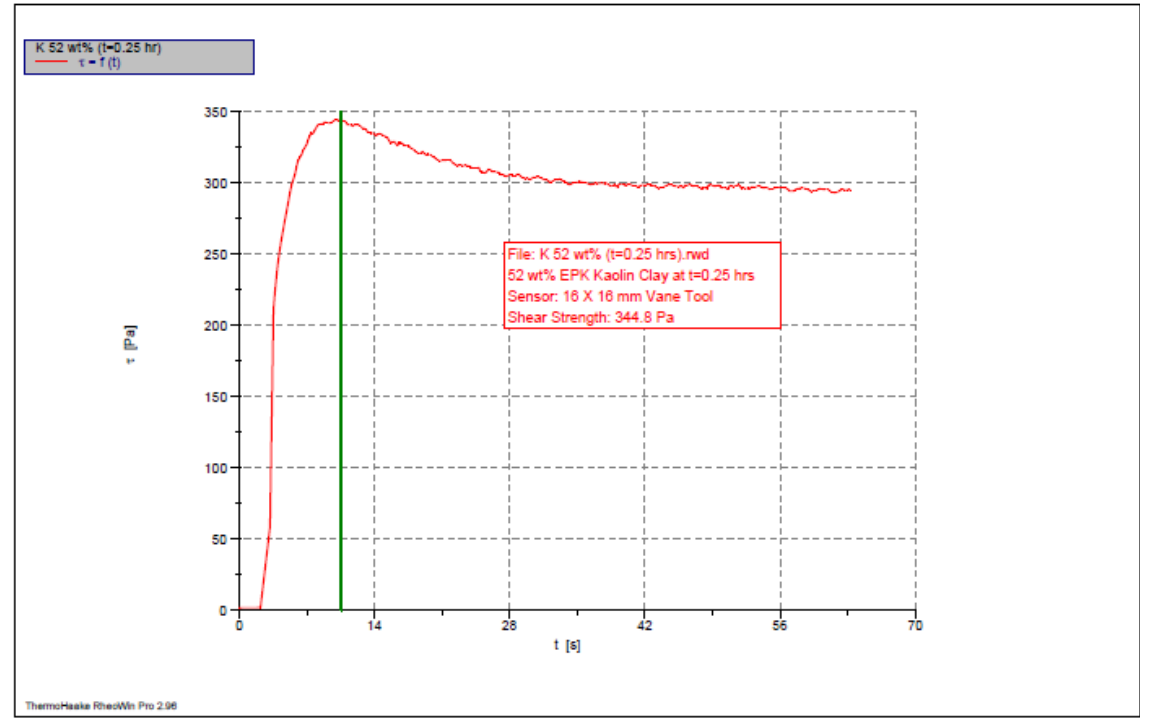

1: C:IRheoloav Resultsltime -varvina Kaolin strengthlK $52 \mathrm{wt} \%(\mathrm{t}=0.25 \mathrm{hr})$.rwd Companv / Operator: PNNL / Jaehun Chun

Date / Time / Version. 07.04.2010/11:12:19 AM / RheoWin Pro 296

Substance / Sample no: K $52 \mathrm{wt} \%$ ( $\mathrm{t}=0.25 \mathrm{hr}$ ) / K $52 \mathrm{wt} \%$ ( $\mathrm{t}=0.25 \mathrm{hr})$

Curve discussion: Greatest value $\mathrm{t}[\mathrm{s}] 10.55 \tau[\mathrm{Pa}] 344.8$

Figure A.74. $52 \mathrm{wt} \%$ Kaolin Clay at $0.25 \mathrm{hrs}$ Aging

ThermoHaake RheoWin 4/29/2010/2:21 PM

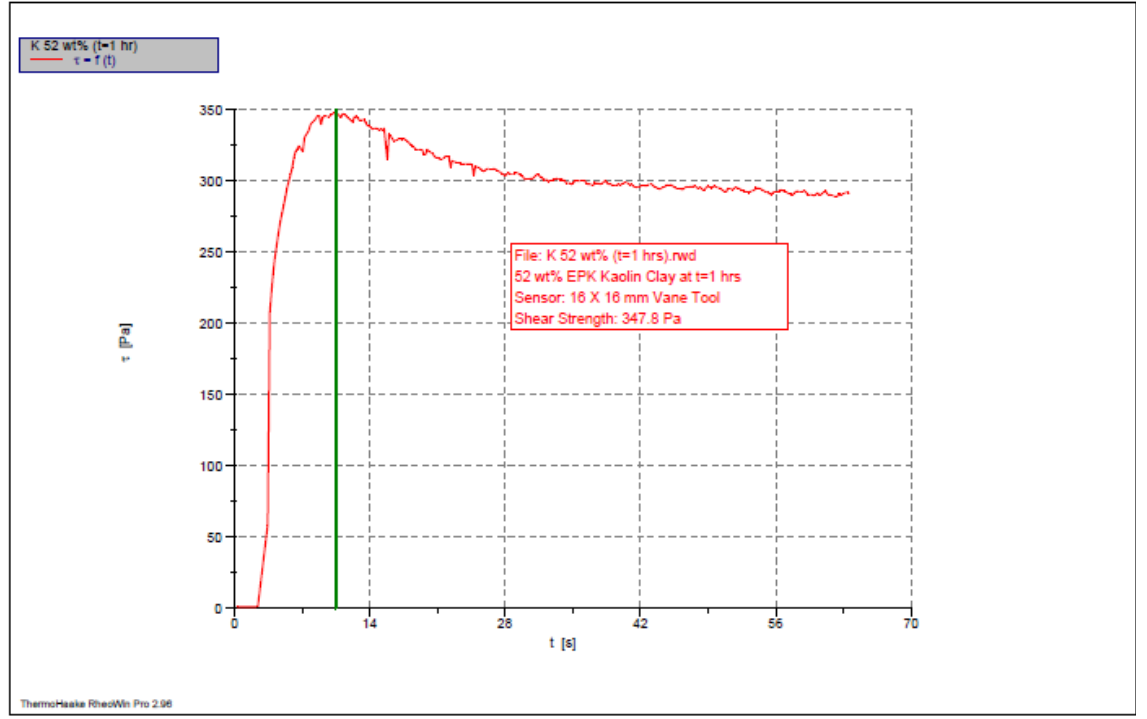

1: C:IRheoloqv Resultsitime -varvina Kaolin strength $\backslash K 52$ wt\% (t=1 hr).rwd

Companv / Operator: PNNL / Jaehun Chun

Date/Time/Version. 07.04.2010/11:48:43 AM / RheoWin Pro 296

Substance / Sample no: K $52 \mathrm{wt} \%$ (t=1 hr) / K $52 \mathrm{wt} \%$ (t=1 hr)

Curve discussion: Greatest value $\mathrm{t}[\mathrm{s}] 10.50 \tau[\mathrm{Pa}] 347.8$

Figure A.75. $52 \mathrm{wt} \%$ Kaolin Clay at $1 \mathrm{hrs}$ Aging 


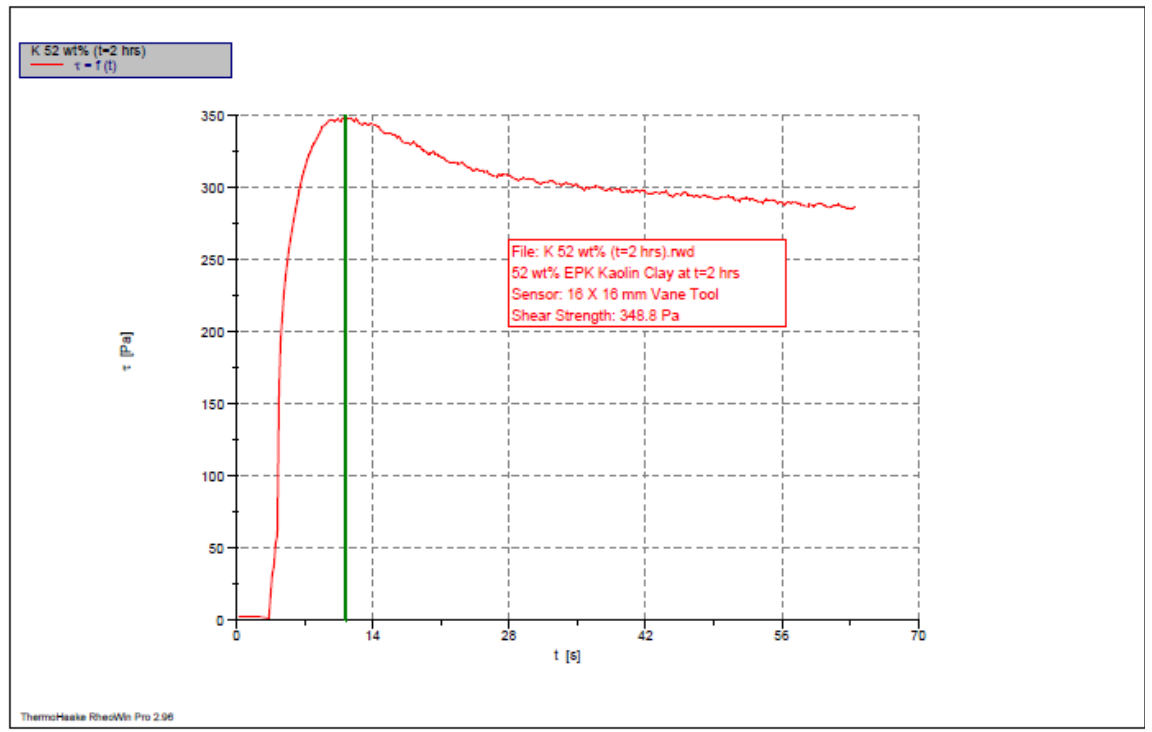

1: C:IRheologv Resultsitime -varving Kaolin strength $\backslash \mathrm{K} 52 \mathrm{wt} \%$ ( $\mathrm{t}=2 \mathrm{hrs})$.rwd

Companv / Operator: PNNL / Jaehun Chun

Date / Time / Version: 07.04.2010/ 12:59:05 PM / RheoWin Pro 296

Substance / Sample no: K $52 \mathrm{wt} \%$ ( $\mathrm{t}=2 \mathrm{hrs}) / \mathrm{K} 52 \mathrm{wt} \%$ (t=2 hrs)

Curve discussion: Greatest value $\mathrm{t}[\mathrm{s}]$ 11.22 $\tau[\mathrm{Pa}] 348.8$

Figure A.76. $52 \mathrm{wt} \%$ Kaolin Clay at $2 \mathrm{hrs}$ Aging

ThermoHaake RheoWin 4/29/2010/2:22 PM

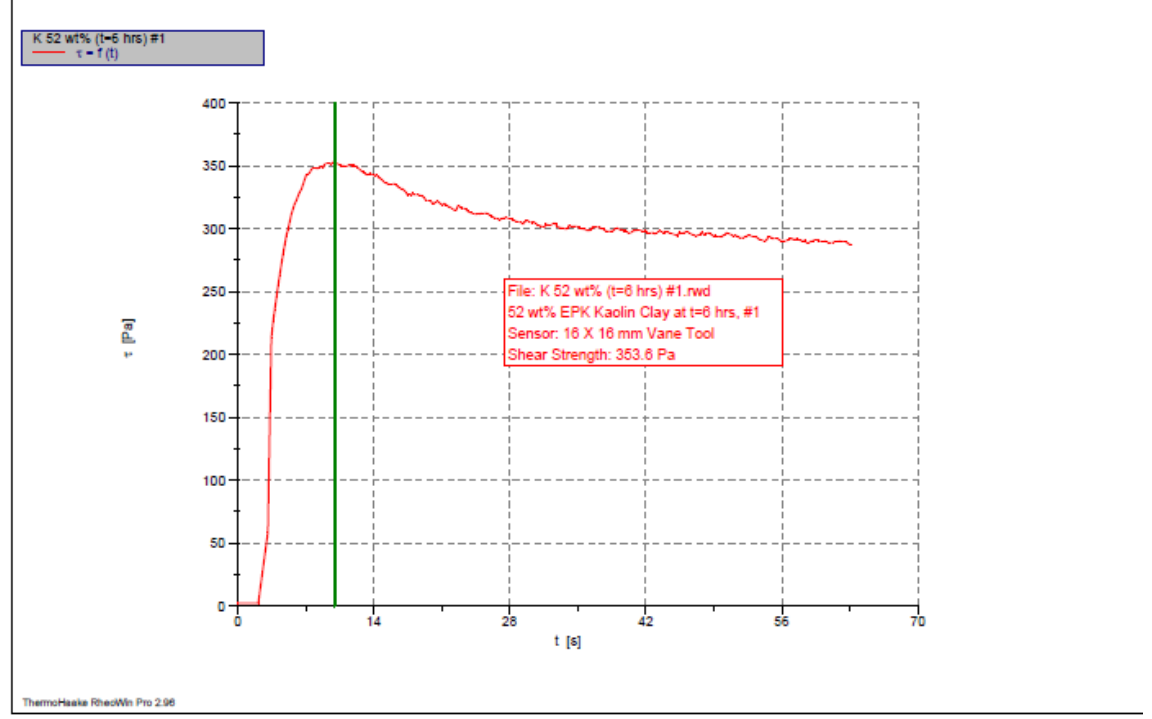

1: C:IRheoloqv Resultsitime -varying Kaolin strength $\backslash K 52$ wt\% (t=6 hrs) \#1.rwd Companv / Operator: PNNL / Jaehun Chun

年

Substance / Sample no: K $52 \mathrm{wt} \%$ (t=6 hrs) \#1 / K $52 \mathrm{wt} \%$ (t=6 hrs) \#1

Curve discussion: Greatest value $\mathrm{t}[\mathrm{s}] 9.971 \tau[\mathrm{Pa}] 353.6$

Figure A.77. $52 \mathrm{wt} \%$ Kaolin Clay at $6 \mathrm{hrs}$ Aging (\#1) 
ThermoHaake RheoWin 4/29/2010/2:23 PM

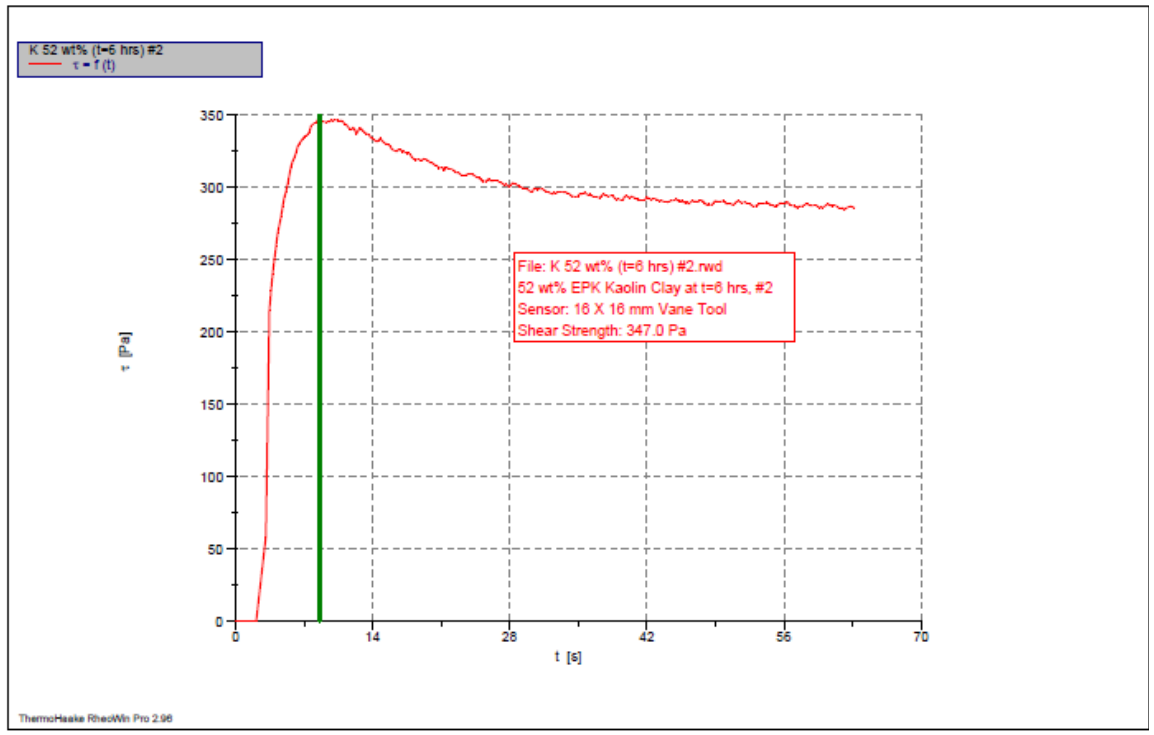

1: C:IRheologv Resultsltime -varying Kaolin strength $\backslash \mathrm{K} 52 \mathrm{wt} \%$ (t=6 hrs) \#2.rwd Companv / Operator: PNNL / Jaehun Chun

Date / Time / Version: 07.04.2010 / 16:56:21 PM / RheoWin Pro 296

Substance / Sample no: K $52 \mathrm{wt} \%$ (t=6 hrs) \#2 / K 52 wt\% (t=6 hrs) \#2 Curve discussion: Greatest value $\mathrm{t}[\mathrm{s}] 8.579 \tau[\mathrm{Pa}] 347.0$

Figure A.78. $52 \mathrm{wt} \%$ Kaolin Clay at $6 \mathrm{hrs}$ Aging (\#2)

ThermoHaake RheoWin 4/29/2010/2:24 PM

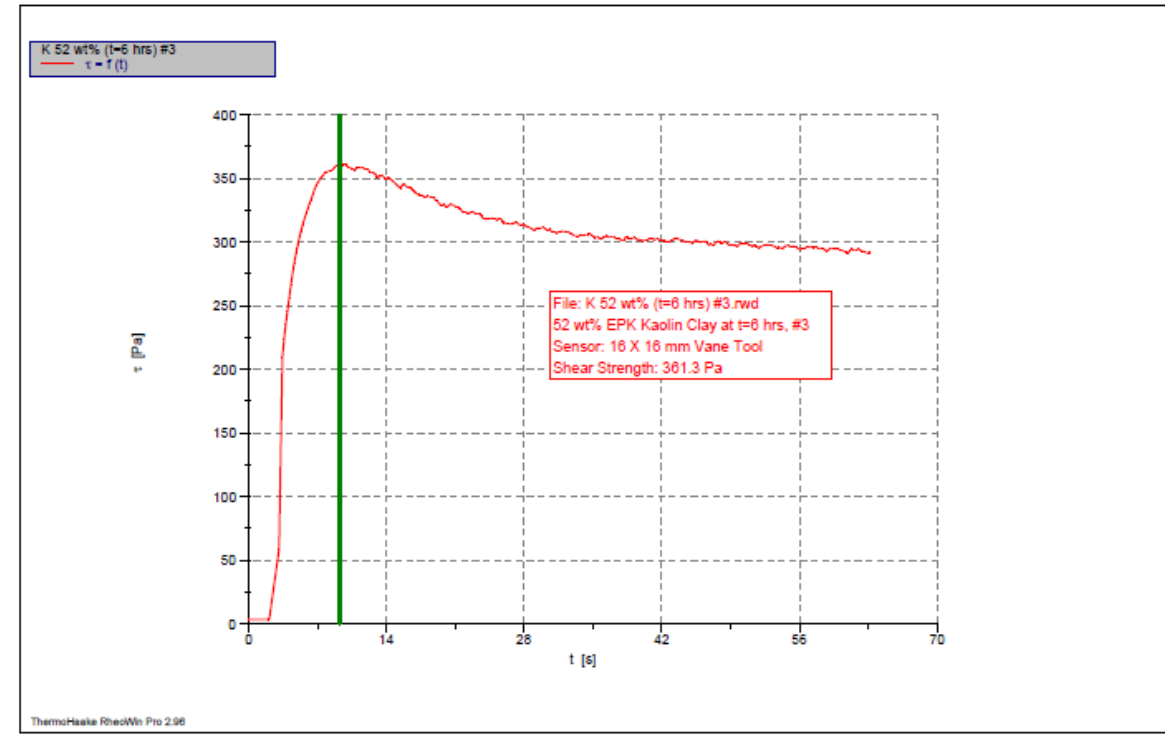

1: C:IRheoloqv Resultsitime -varving Kaolin strength $\backslash \mathrm{K} 52 \mathrm{wt} \%$ (t=6 hrs) \#3.rwd Companv / Operator: PNNL / Jaehun Chun

Date / Time / Version: 07.04 2010 / 17:00:05 PM / RheoWin Pro 296

Substance / Sample no: K 52 wt\% ( $\mathrm{t}=6 \mathrm{hrs}$ ) \#3 / K $52 \mathrm{wt} \%$ ( $\mathrm{t}=6 \mathrm{hrs}) \# 3$

Curve discussion: Greatest value $\mathrm{t}[\mathrm{s}] 9.270 \tau[\mathrm{Pa}] 361.3$

Figure A.79. $52 \mathrm{wt} \%$ Kaolin Clay at 6 hrs Aging (\#3) 


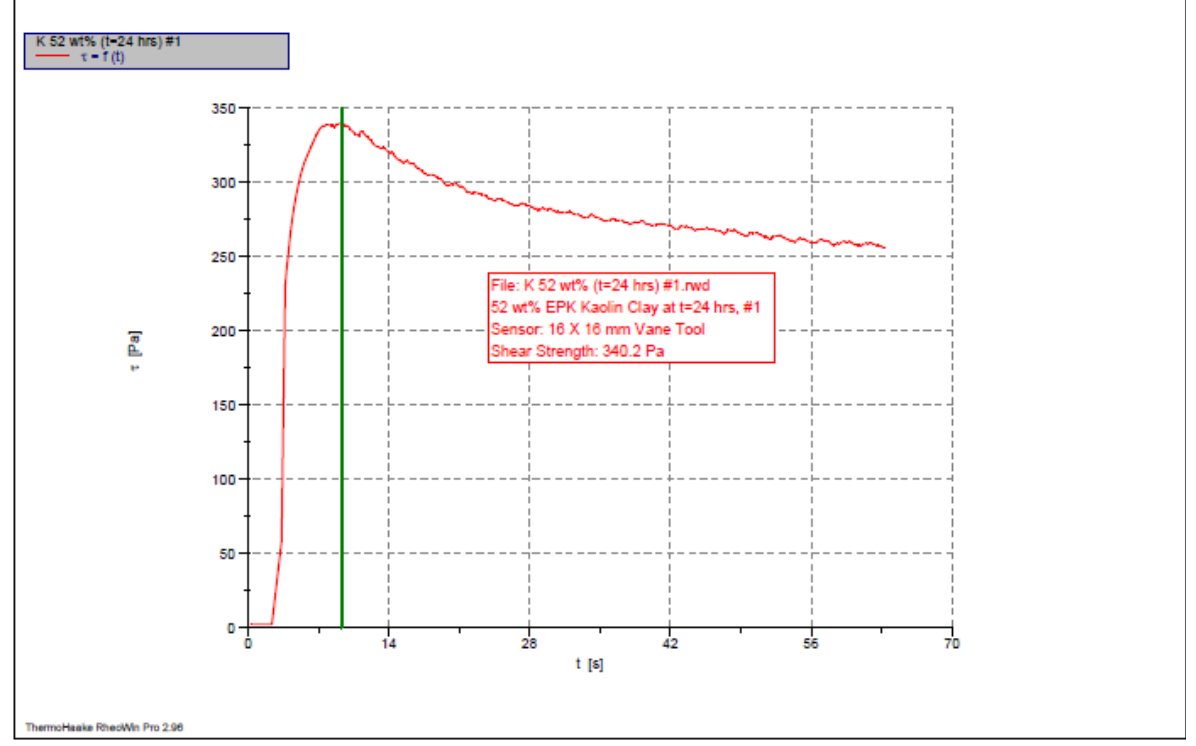

1: C:IRheologv Resultsitime -varyina Kaolin strength $\backslash \mathrm{K} 52 \mathrm{wt} \%$ (t=24 hrs) \#1.rwd

Companv / Operator: PNNL / Jaehun Chun
Date / Time / Version: 08.04 2010/ 11:01:48 AM / RheoWin Pro 296

Substance / Sample no: K 52 wt\% (t=24 hrs) \#1 / K 52 wt\% (t=24 hrs) \#1

Curve discussion: Greatest value $\mathrm{t}[\mathrm{s}] 9.320 \tau[\mathrm{Pa}] 340.2$

Figure A.80. $52 \mathrm{wt} \%$ Kaolin Clay at $24 \mathrm{hrs}$ Aging (\#1)

ThermoHaake RheoWin 4/29/2010 / 2:26 PM

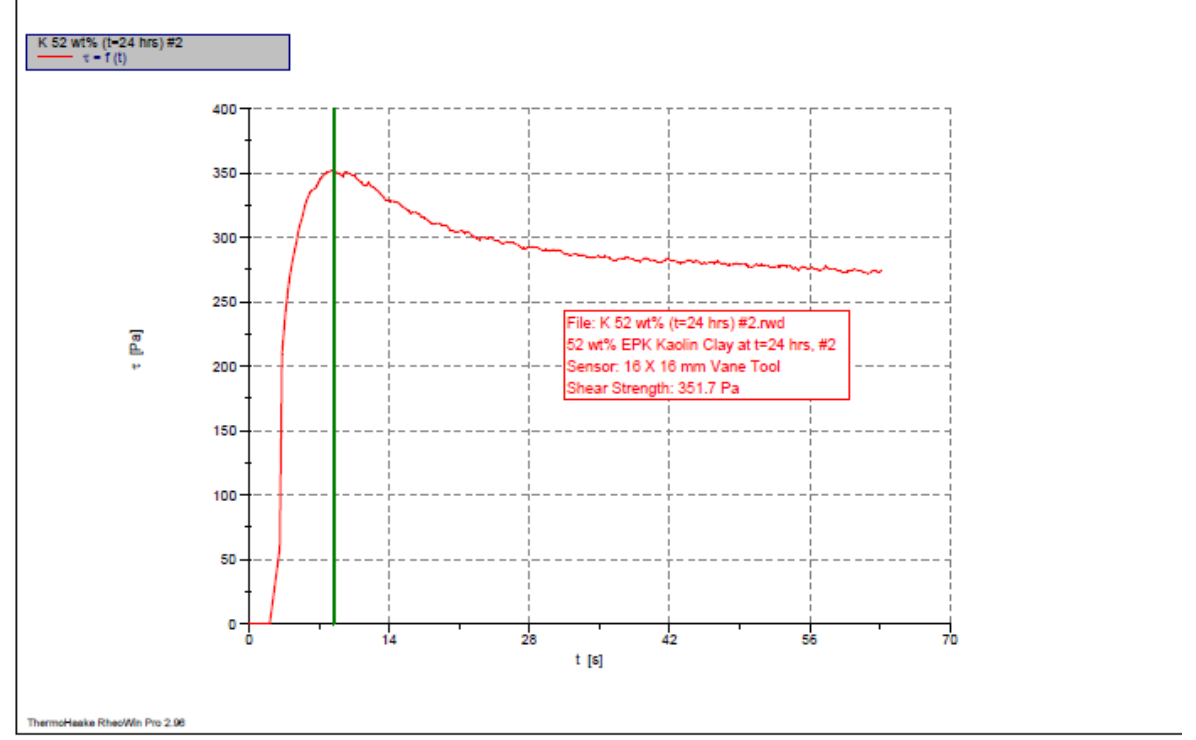

1: C:IRheoloqv Resultsitime-varving Kaolin strength $\backslash \mathrm{K} 52 \mathrm{wt} \%$ (t=24 hrs) \#2.rwd

Companv / Operator: PNNL / Jaehun Chun

Substance / Sample no: K 52 wt\% (t=24 hrs) \#2 / K 52 wt\% (t=24 hrs) \#2

Curve discussion: Greatest value $\mathrm{t}[\mathrm{s}] 8.499 \tau[\mathrm{Pa}] 351.7$

Figure A.81. $52 \mathrm{wt} \%$ Kaolin Clay at $24 \mathrm{hrs}$ Aging (\#2) 


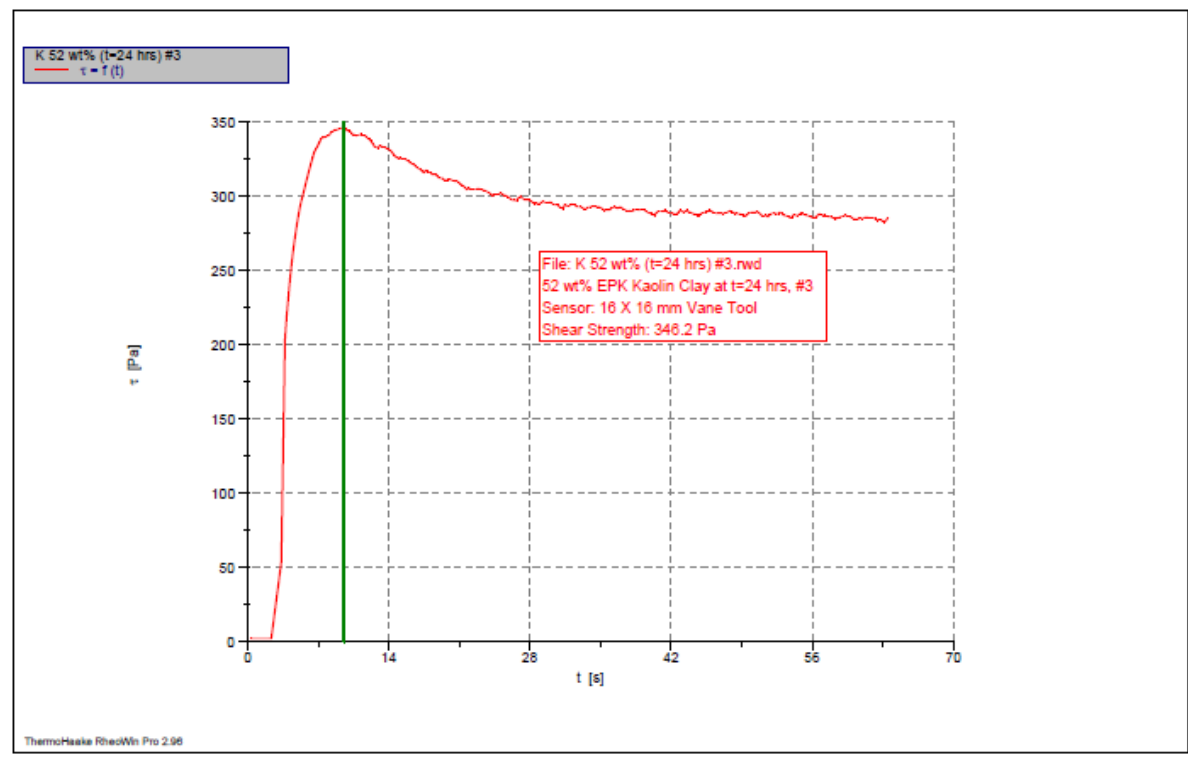

1: C:IRheologv Resultsitime -varvina Kaolin strength $\backslash \mathrm{K} 52 \mathrm{wt} \%$ ( $\mathrm{t}=24 \mathrm{hrs}$ ) \#3.rwd Company / Operator: PNNL / Jaehun Chun

Date / Time / Version: 08.04 2010/ 11.08.59 AM / RheoWin Pro 296

Substance / Sample no: K 52 wt\% (t=24 hrs) \#3 / K 52 wt $\%$ (t=24 hrs) \#3

Curve discussion: Greatest value $\mathrm{t}[\mathrm{s}] 9.520 \tau[\mathrm{Pa}] 346.2$

Figure A.82. $52 \mathrm{wt} \%$ Kaolin Clay at $24 \mathrm{hrs}$ Aging (\#3)

ThermoHaake RheoWin $4 / 29 / 2010 / 2: 29$ PM

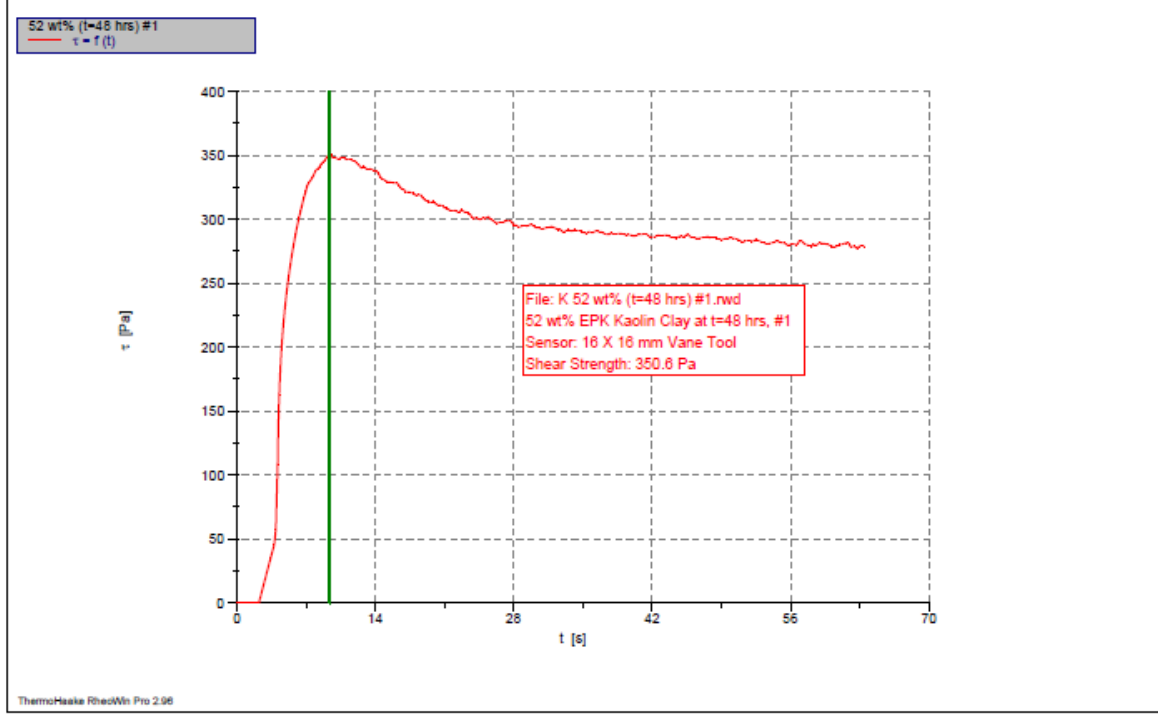

1: C:IRheologv Resultsitime -varving Kaolin strength $152 \mathrm{wt} \%$ (t=48 hrs) \#1.rwd Companv / Operator: PNNL / Jaehun Chun

Date / Time / Version: 09.04.2010 / 11:21:50 AM / RheoWin Pro 296

Substance / Sample no: 52 wt\% (t=48 hrs) \#1 / 52 wt\% ( $\mathrm{t}=48 \mathrm{hrs}$ ) \#1

Curve discussion: Greatest value $\mathrm{t}[\mathrm{s}] 9.361 \tau[\mathrm{Pa}] 350.6$

Figure A.83. $52 \mathrm{wt} \%$ Kaolin Clay at $48 \mathrm{hrs}$ Aging (\#1) 


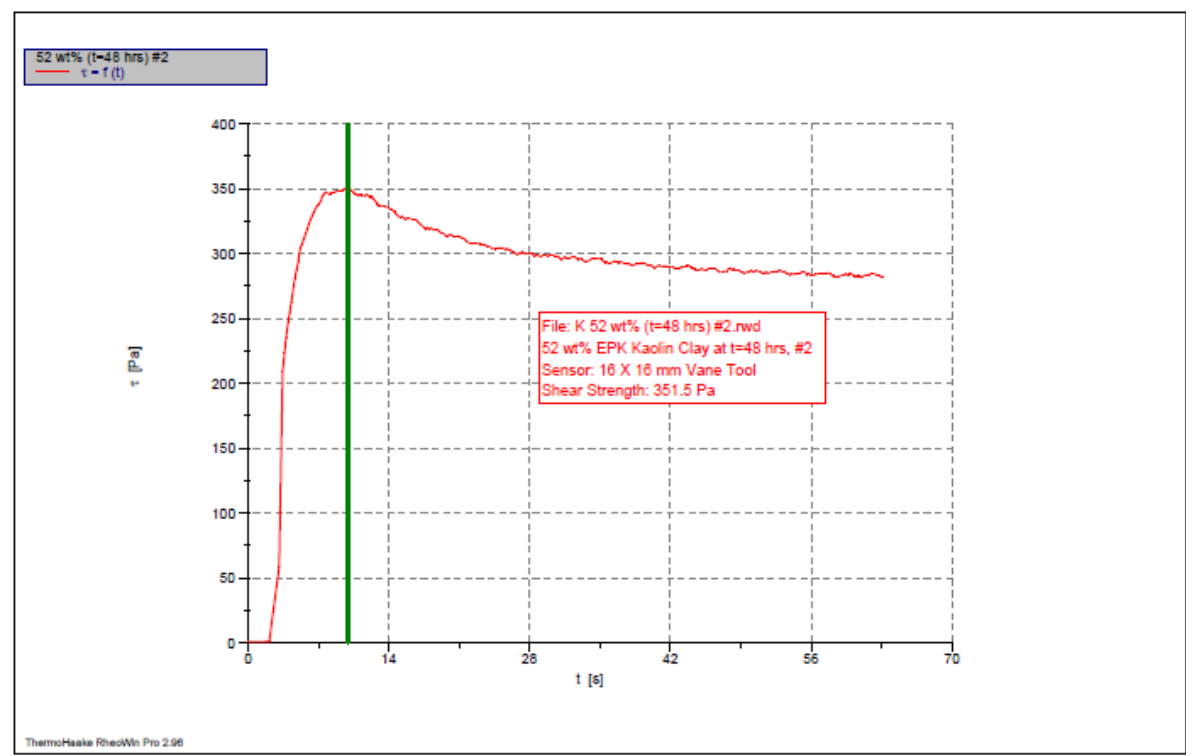

1: C:IRheoloqv Resultsitime -varvina Kaolin strength $\backslash 52 \mathrm{wt} \%$ ( $\mathrm{t}=48 \mathrm{hrs})$ \#2.rwd

Companv / Operator: PNNL / Jaehun Chun
Date / Time / Version: 09.04 2010 / 11:25:30 AM / RheoWin Pro 296

Substance / Sample no: $52 \mathrm{wt} \%$ ( $\mathrm{t}=48 \mathrm{hrs}$ ) \#2 / $52 \mathrm{wt} \%$ (t=48 hrs) \#2

Curve discussion: Greatest value $\mathrm{t}[\mathrm{s}] 9.941 \tau[\mathrm{Pa}] 351.5$

Figure A.84. $52 \mathrm{wt} \%$ Kaolin Clay at $48 \mathrm{hrs}$ Aging (\#2)

ThermoHaake RheoWin 4/29/2010/2:31 PM

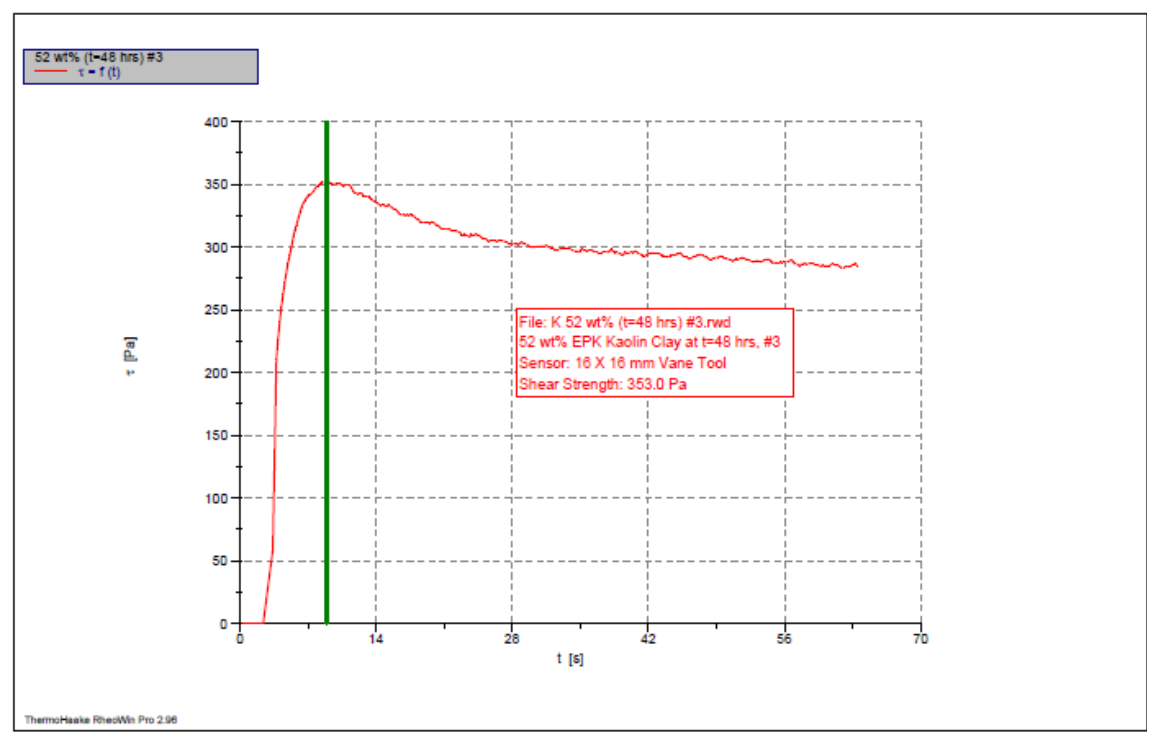

1: C:IRheoloqv Resultsltime-varving Kaolin strength $152 \mathrm{wt} \%$ ( $\mathrm{t}=48 \mathrm{hrs})$ \#3.rwd

Companv / Operator: PNNL / Jaehun Chun

Date / Time / Version: 09.04.2010 / 11:29:36 AM / RheoWin Pro 296

Substance / Sample no: 52 wt\% (t=48 hrs) \#3 / 52 wt\% ( $=48$ hrs) \#3

Curve discussion: Greatest value $\mathrm{t}[\mathrm{s}] 8.926 \tau[\mathrm{Pa}] 353.0$

Figure A.85. 52 wt\% Kaolin Clay at 48 hrs Aging (\#3) 


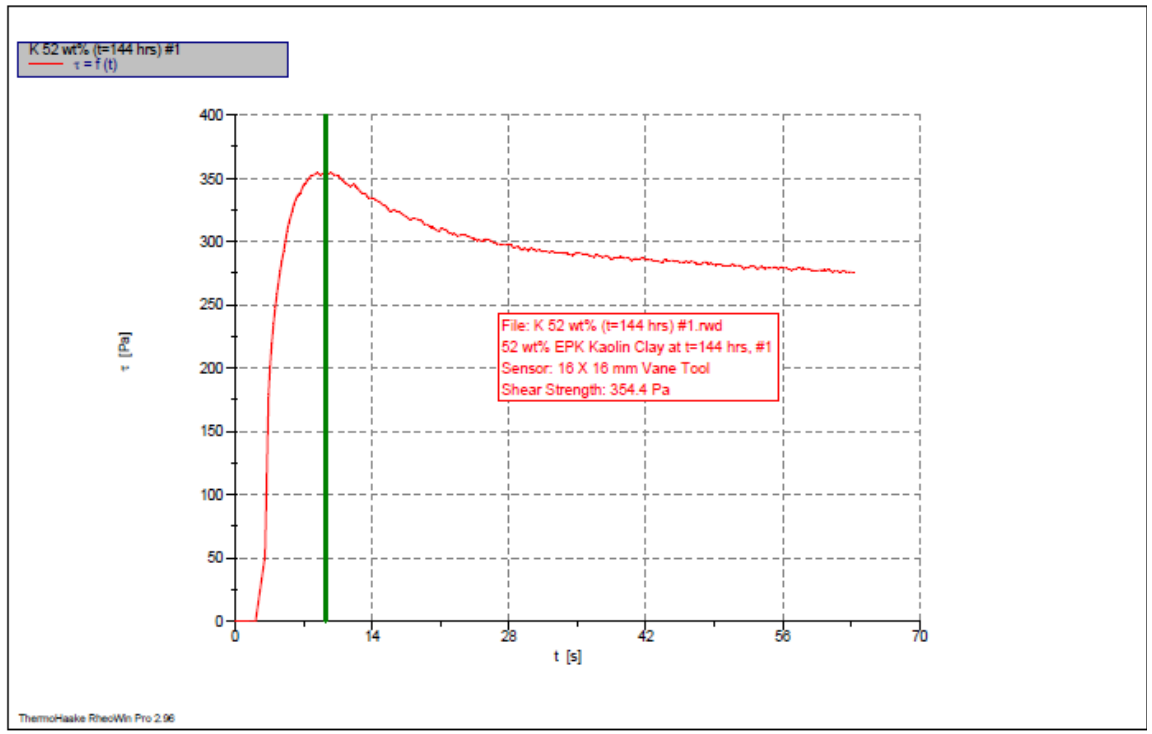

1: C:IRheologv Resultsitime -varying Kaolin strength $\backslash \mathrm{K} 52 \mathrm{wt} \%$ (t=144 hrs) \#1.rwd Company / Operator: PNNL / Jaehun Chun

Date / Time / Version: 13.04.2010/11:51:28 AM / RheoWin Pro 296

Substance / Sample no: $52 \mathrm{wt} \%$ (t=144 hrs) \#1 / $52 \mathrm{wt} \%$ (t=144 hrs) \#1

Curve discussion: Greatest value $t[s] 9.250 \tau[\mathrm{Pa}] 354.4$

Figure A.86. $52 \mathrm{wt} \%$ Kaolin Clay at $144 \mathrm{hrs}$ Aging (\#1)

ThermoHaake RheoWin 4/29/2010 / 2:34 PM

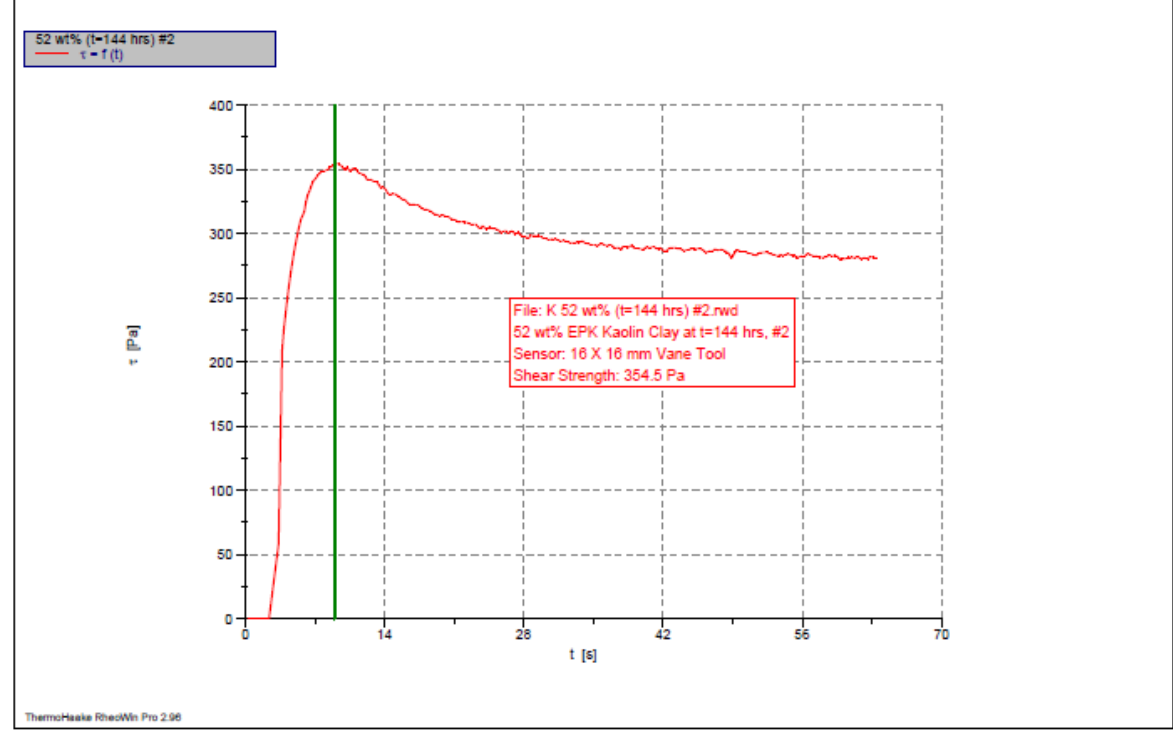

1: C:IRheologv Resultsltime -varving Kaolin strength $\backslash 52$ wt\% (t=144 hrs) \#2.rwd Companv / Operator: PNNL / Jaehun Chun

Date / Time / Version: 13.04.2010 / 11:56:23 AM / RheoWin Pro 296

Substance / Sample no: $52 \mathrm{wt} \%$ (t=144 hrs) \#2/52 wt\% (t=144 hrs) \#2

Curve discussion: Greatest value $\mathrm{t}[\mathrm{s}] 9.000 \tau[\mathrm{Pa}] 354.5$

Figure A.87. $52 \mathrm{wt} \%$ Kaolin Clay at $144 \mathrm{hrs}$ Aging (\#2) 


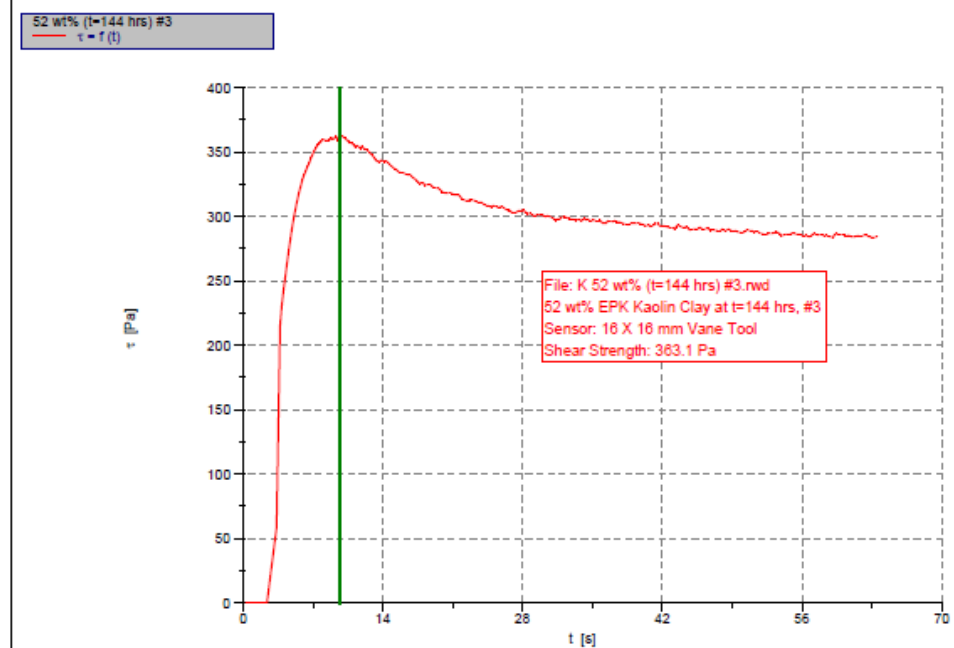

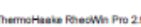

1: C:IRheoloqv Resultsltime -varvina Kaolin strength $\backslash 52 \mathrm{wt} \%$ (t=144 hrs) \#3.rwd Company / Operator: PNNL / Jaehun Chun

Date / Time / Version: 13.04.2010 / 12:00:26 PM / RheoWin Pro 296

Substance / Sample no: 52 wt\% (t=144 hrs) \#3 / 52 wt\% (t=144 hrs) \#3

Curve discussion: Greatest value t [s] $9.681 \tau[\mathrm{Pa}] 363.1$

Figure A.88. $52 \mathrm{wt} \%$ Kaolin Clay at $144 \mathrm{hrs}$ Aging (\#3)

ThermoHaake RheoWin 4/29/2010 / 2:36 PM

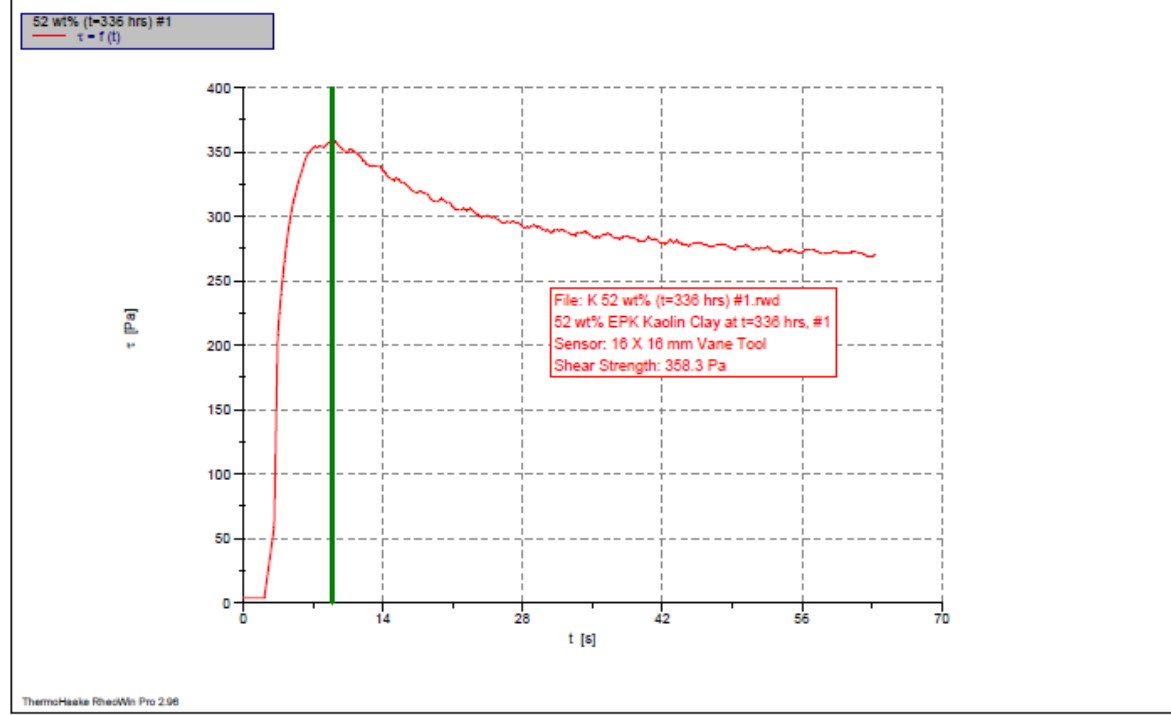

1: C:IRheoloqv Resultsltime -varyina Kaolin strength $\backslash 52 \mathrm{wt} \%$ (t=336 hrs) \#1.rwd Companv / Operator: PNNL / Jaehun Chun

Date / Time / Version: 21.04.2010 / 11:06:37 AM / RheoWin Pro 296

Substance / Sample no: $52 \mathrm{wt} \%$ (t=336 hrs) \#1 / $52 \mathrm{wt} \%$ (t=336 hrs) \#1

Curve discussion: Greatest value $\mathrm{t}[\mathrm{s}] 8.939 \tau[\mathrm{Pa}] 358.3$

Figure A.89. $52 \mathrm{wt} \%$ Kaolin Clay at $336 \mathrm{hrs}$ Aging (\#1) 


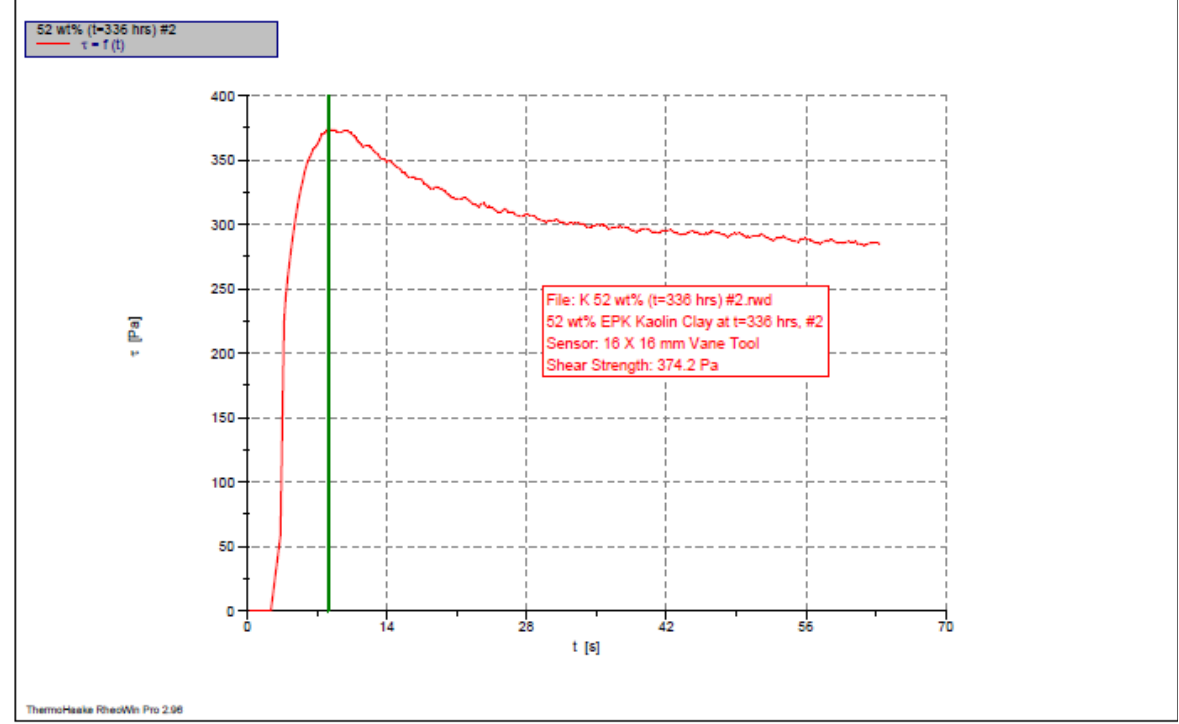

1: C:IRheoloav Resultsitime -varvina Kaolin strength 152 wt\% (t=336 hrs) \#2.rwd

Companv / Operator: PNNL / Jaehun Chun
Date / Time / Version: 21.04.2010 / 11:11:05 AM / RheoWin Pro 296

Substance / Sample no: 52 wt $\%$ ( $\mathrm{t}=336 \mathrm{hrs}$ ) \#2 / $52 \mathrm{wt} \%$ ( $\mathrm{t}=336 \mathrm{hrs}$ ) \#2

Curve discussion: Greatest value $\mathrm{t}[\mathrm{s}] \mathrm{8.152} \tau[\mathrm{Pa}] 374.2$

Figure A.90. $52 \mathrm{wt} \%$ Kaolin Clay at $336 \mathrm{hrs}$ Aging (\#2)

ThermoHaake RheoWin 4/29/2010/2:37 PM

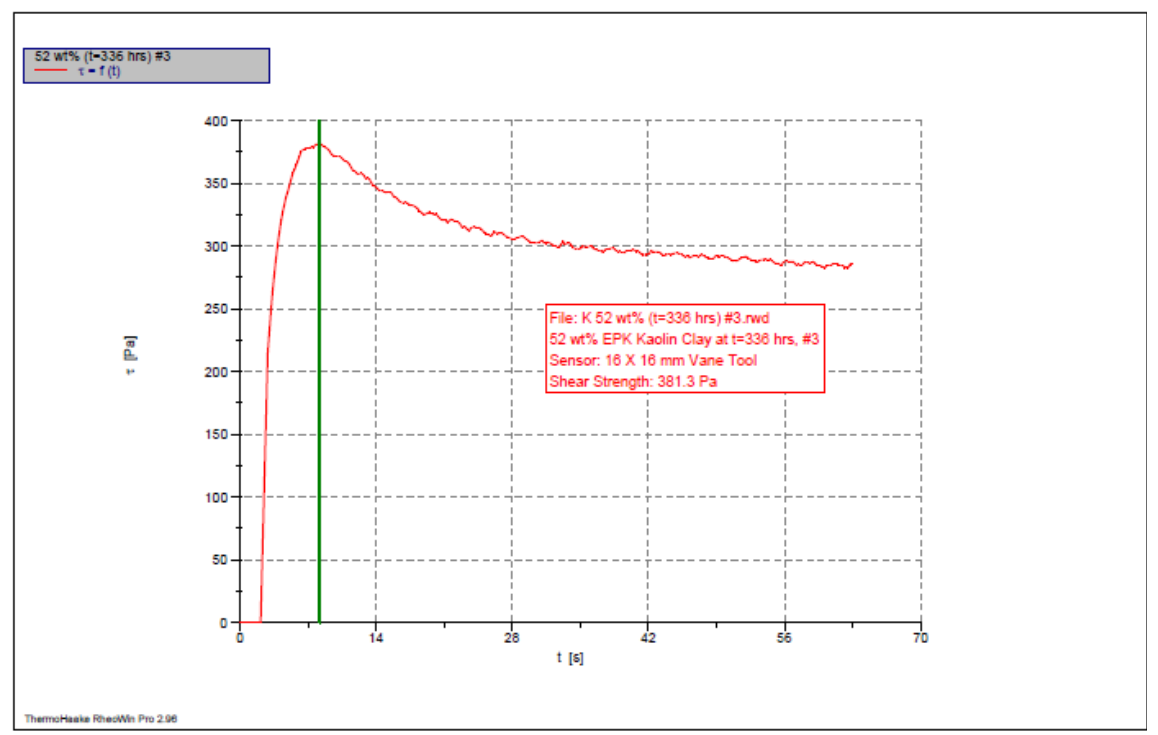

1: C:IRheologv Resultsitime -varyinq Kaolin strength 152 wt\% (t=336 hrs) \#3.rwd

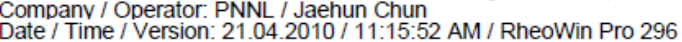

Substance / Sample no: $52 \mathrm{wt} \%$ ( $\mathrm{t}=336 \mathrm{hrs}$ ) \#3 / $52 \mathrm{wt} \%$ ( $\mathrm{t}=336 \mathrm{hrs}$ ) \#3

Curve discussion: Greatest value $\mathrm{t}[\mathrm{s}] \mathrm{8.189} \tau[\mathrm{Pa}] 381.3$

Figure A.91. $52 \mathrm{wt} \%$ Kaolin Clay at 336 hrs Aging (\#3) 
ThermoHaake RheoWin 4/29/2010/3:00 PM

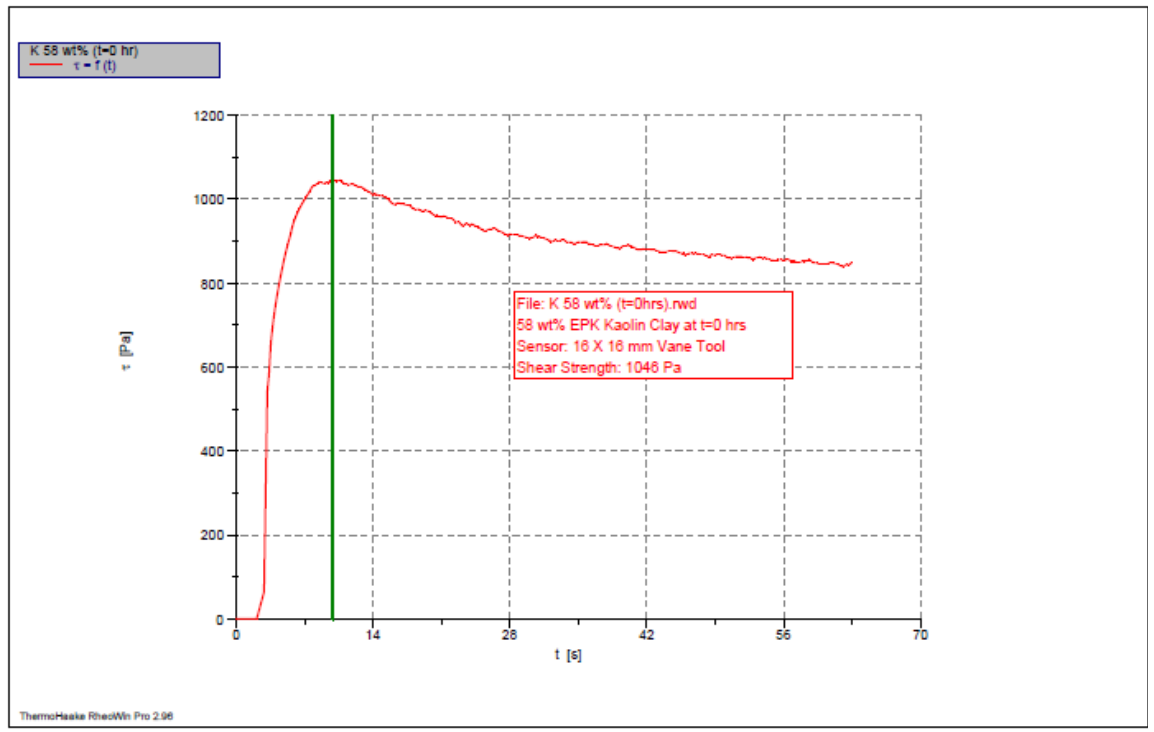

1: C:IRheologv Resultsitime -varvina Kaolin strength $\mathrm{K} 58 \mathrm{wt} \%(\mathrm{t}=0 \mathrm{hr})$.rwd Companv / Operator: PNNL / Jaehun Chun

Date / Time / Version: 06.04.2010/11:14:44 AM / RheoWin Pro 296

Substance / Sample no: K $58 \mathrm{wt} \%$ ( $\mathrm{t}=0 \mathrm{~min}$ ) / K $58 \mathrm{wt} \%$ ( $\mathrm{t}=0 \mathrm{~min})$

Curve discussion: Greatest value $t[s] 9.885 \tau[\mathrm{Pa}] 1046$.

Figure A.92. $58 \mathrm{wt} \%$ Kaolin Clay at $0 \mathrm{hrs}$ Aging

ThermoHaake RheoWin 4/29/2010 / 3:02 PM

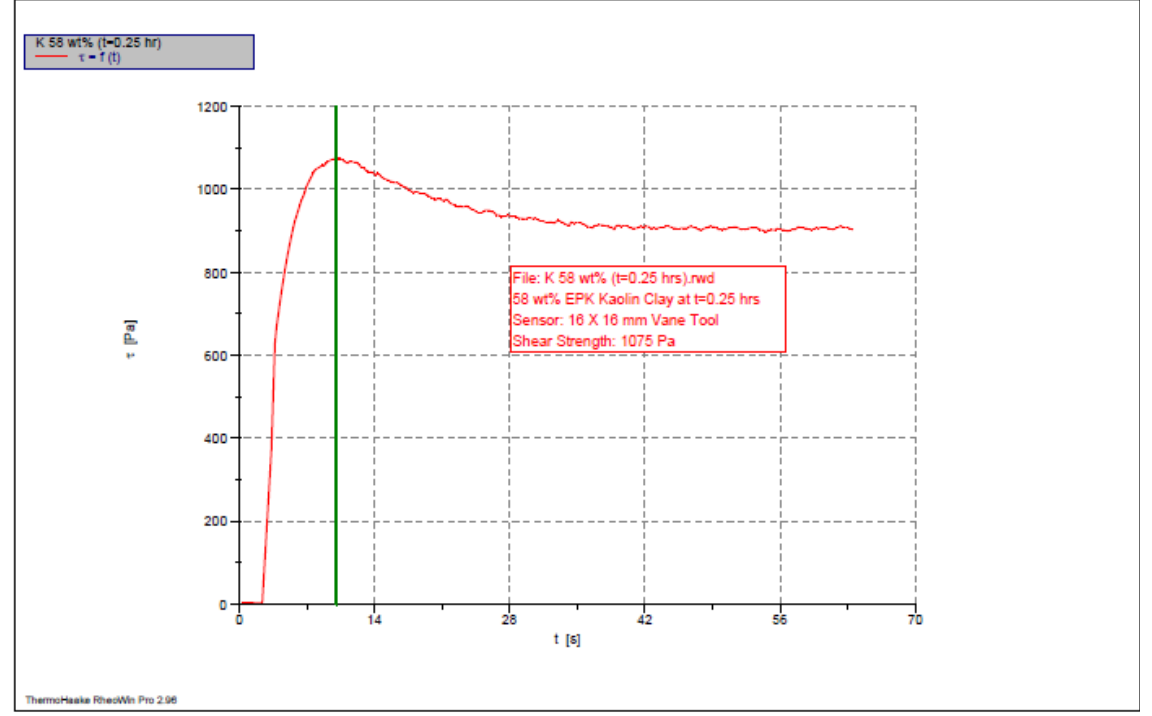

1: C:IRheologv Resultsitime -varving Kaolin strength $\backslash \mathrm{K} 58 \mathrm{wt} \%(\mathrm{t}=0.25 \mathrm{hr}) . \mathrm{wwd}$

Companv / Operator: PNNL / Jaehun Chun

Date / Time / Version: 06.04.2010 / 11:31:44 AM / RheoWin Pro 296

Substance / Sample no: K $58 \mathrm{wt} \%(\mathrm{t}=15 \mathrm{~min}) / \mathrm{K} 58 \mathrm{wt} \%(\mathrm{t}=15 \mathrm{~min})$

Curve discussion: Greatest value $\mathrm{t}[\mathrm{s}] 10.03 \tau[\mathrm{Pa}] 1075$.

Figure A.93. $58 \mathrm{wt} \%$ Kaolin Clay at $0.25 \mathrm{hrs}$ Aging 


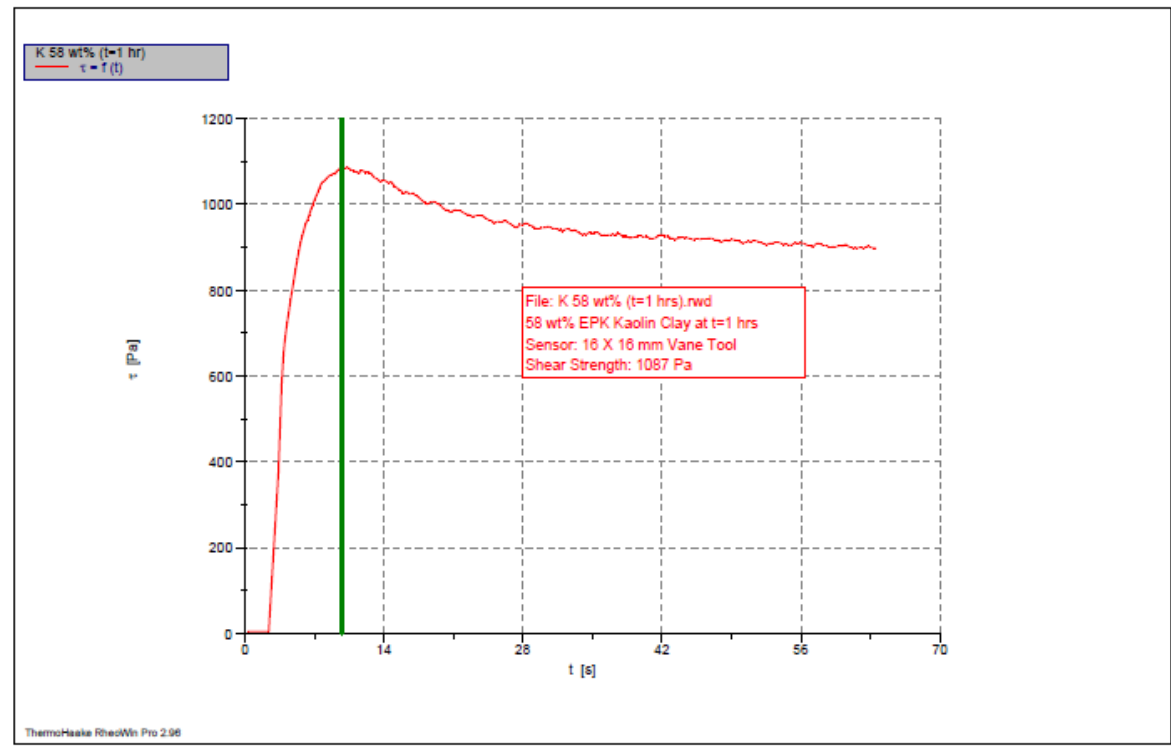

1: C:IRheologv Resultsitime -varving Kaolin strength $\backslash \mathrm{K} 58 \mathrm{wt} \%$ (t=1 hr).rwd Companv / Operator: PNNL / Jaehun Chun

Date / Time / Version: 06.04.2010 / 12:17:04 PM / RheoWin Pro 296

Substance / Sample no: K 58 wt\% (t=1 hr) / K 58 wt\% (t=1 hr)

Curve discussion: Greatest value t [s] $9.761 \tau[\mathrm{Pa}] 1087$.

Figure A.94. $58 \mathrm{wt} \%$ Kaolin Clay at $1 \mathrm{hrs}$ Aging

ThermoHaake RheoWin 4/29/2010/3:03 PM

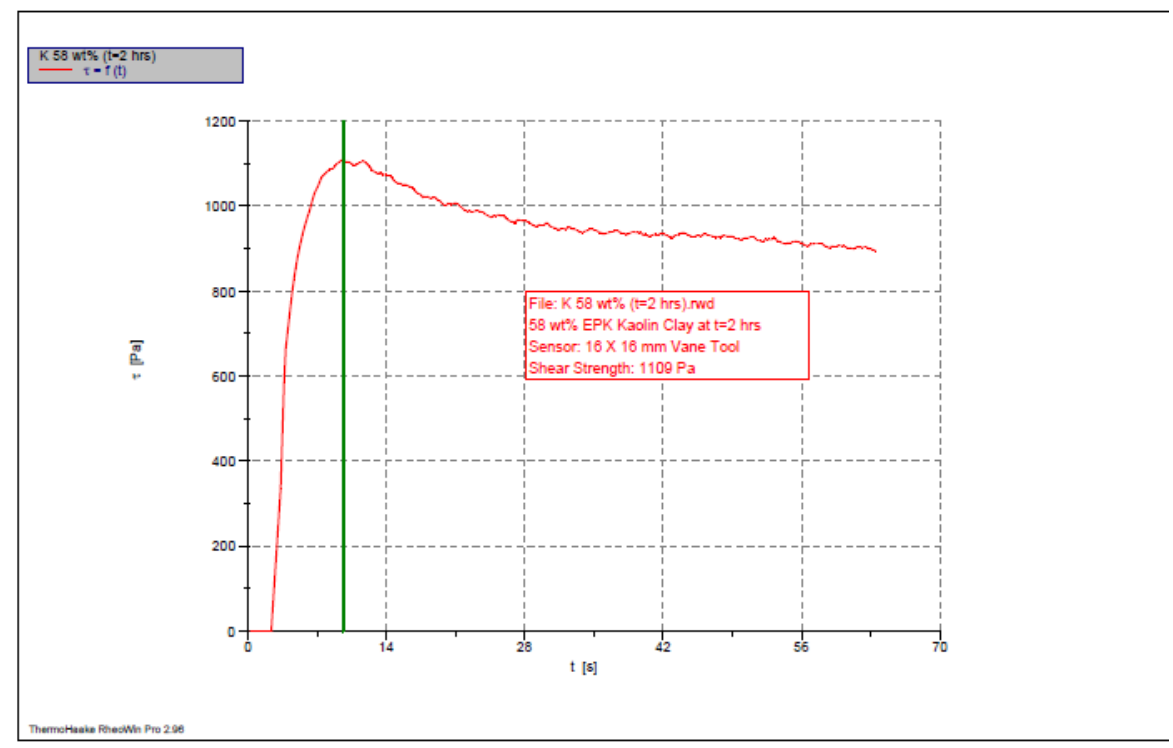

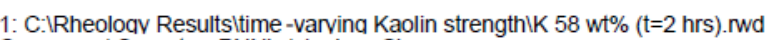

Companv / Operator: PNNL / Jaehun Chun

Date / Time/Version: 06.04.2010/13.13:46 PM / RheoWin Pro 296

Substance / Sample no: K 58 wt\% (t=2 hrs) / K 58 wt\% (t=2 hrs)

Curve discussion: Greatest value $\mathrm{t}[\mathrm{s}] 9.641 \tau[\mathrm{Pa}] 1109$.

Figure A.95. $58 \mathrm{wt} \%$ Kaolin Clay at $2 \mathrm{hrs} \mathrm{Aging}$ 


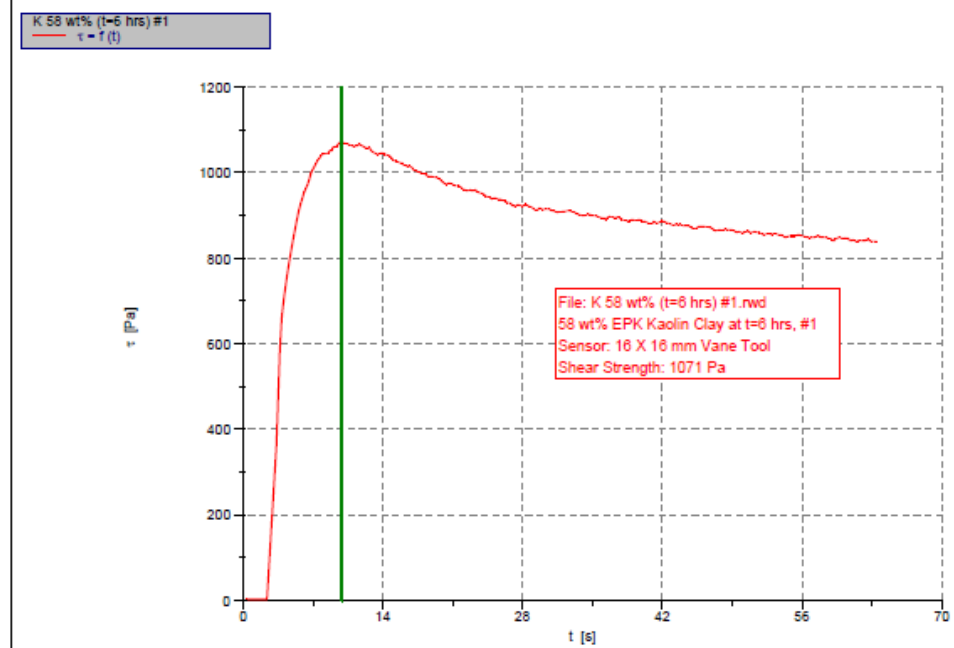

1: C:IRheoloqv Resultsltime -varving Kaolin strength $\backslash \mathrm{K} 58 \mathrm{wt} \%$ (t=6 hrs) \#1.rwd

Date / Time / Version: 06.04.2010 / 17:12:34 PM / RheoWin Pro 296

Substance / Sample no: K 58 wt\% (t=6 hrs) \#1 / K 58 wt\% (t=6 hrs) \#1

Curve discussion: Greatest value t [s] $9.881 \tau[\mathrm{Pa}] 1071$.

Figure A.96. $58 \mathrm{wt} \%$ Kaolin Clay at 6 hrs Aging (\#1)

ThermoHaake RheoWin 4/29/2010/3:05 PM

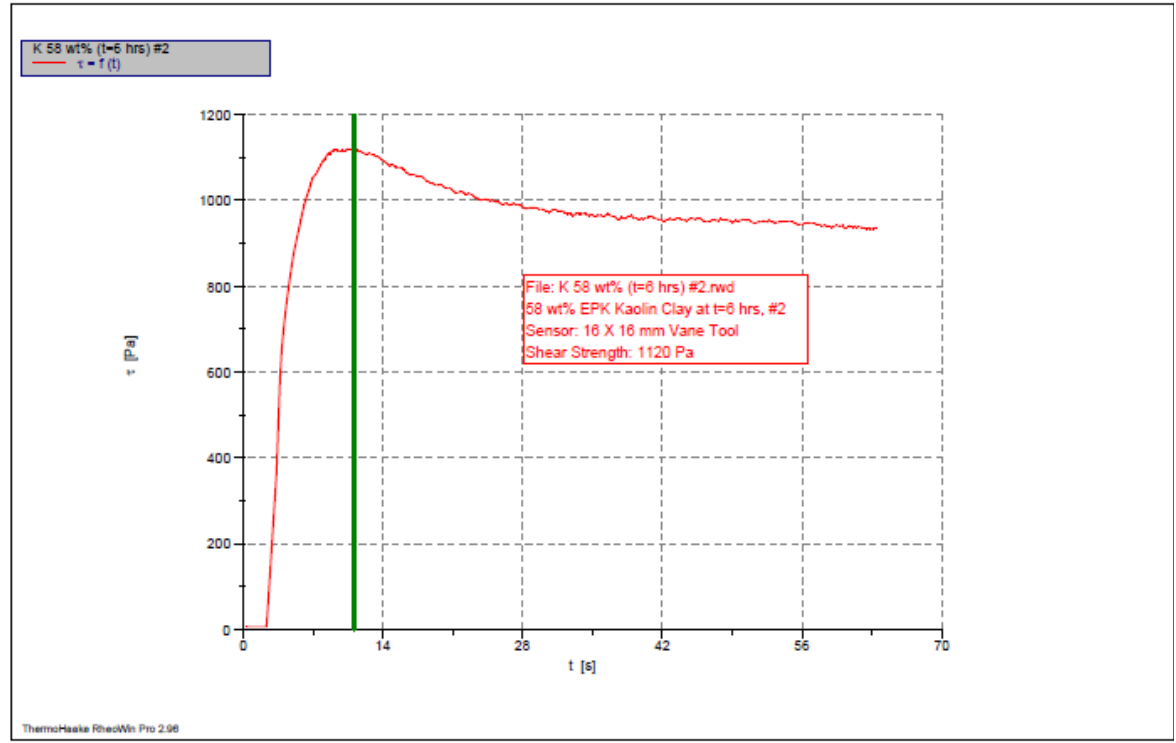

1: C:IRheoloav Resultsitime -varvina Kaolin strength $\backslash \mathrm{K} 58 \mathrm{wt} \%$ ( $\mathrm{t}=6 \mathrm{hrs}$ ) \#2.rwd Companv / Operator: PNNL / Jaehun Chun

Date / Time / Version: 06.04.2010 / 17:16:21 PM / RheoWin Pro 296

Substance / Sample no: K 58 wt\% ( $\mathrm{t}=6 \mathrm{hrs}$ ) \#2 / K 58 wt\% ( $\mathrm{t}=6 \mathrm{hrs}$ ) \#2

Curve discussion: Greatest value t [s] $11.13 \tau[\mathrm{Pa}] 1120$.

Figure A.97. $58 \mathrm{wt} \%$ Kaolin Clay at 6 hrs Aging (\#2) 
ThermoHaake RheoWin 4/29/2010/3:05 PM

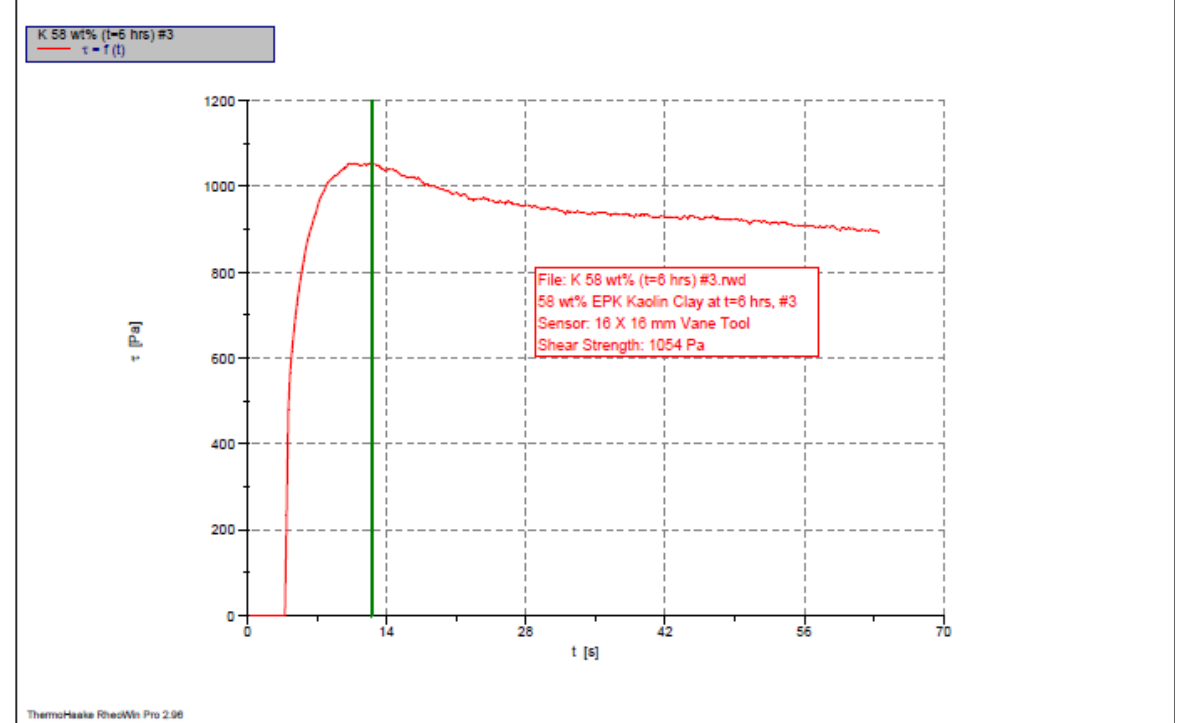

1: C:IRheologv Resultsitime -varving Kaolin strength $\backslash \mathrm{K} 58 \mathrm{wt} \%$ (t=6 hrs) \#3.rwd

Companv / Operator: PNNL / Jaehun Chun

Date / Time / Version: 06.04.2010 / 17:21:01 PM / RheoWin Pro 296

Substance / Sample no: K 58 wt \% ( $\mathrm{t}=6 \mathrm{hrs}$ ) \#3 / K 58 wt\% ( $\mathrm{t}=6 \mathrm{hrs}) \# 3$

Curve discussion: Greatest value $\mathrm{t}$ [s] $12.51 \tau[\mathrm{Pa}] 1054$.

Figure A.98. 58 wt\% Kaolin Clay at 6 hrs Aging (\#3)

ThermoHaake RheoWin 4/29/2010/3:06 PM

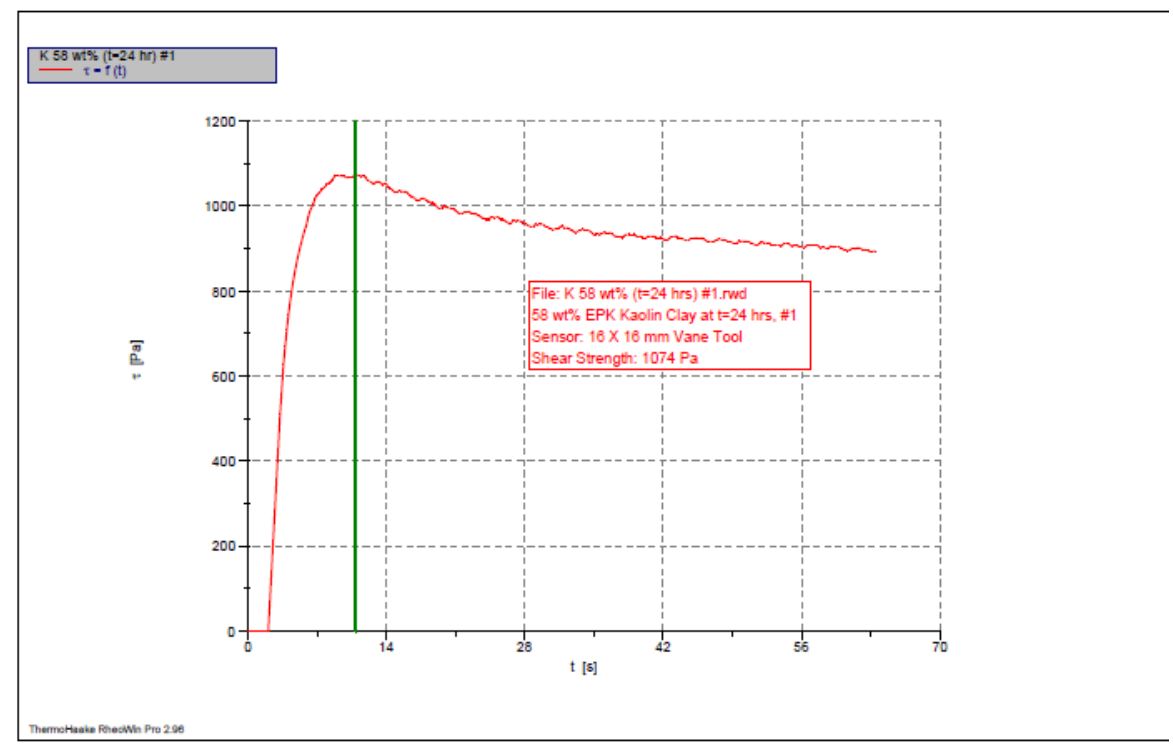

1: C:IRheoloav Resultsitime -varvina Kaolin strength $\backslash \mathrm{K} 58 \mathrm{wt} \%(\mathrm{t}=24 \mathrm{hr})$ \#1.rwd

Companv / Operator: PNNL / Jaehun Chun

Date/Time/Version: 07.04.2010/11:17:40 AM / RheoWin Pro 296

Substance / Sample no: K $58 \mathrm{wt} \%$ ( $\mathrm{t}=24 \mathrm{hr}) \# 1 / \mathrm{K} 58 \mathrm{wt} \%(\mathrm{t}=24 \mathrm{hr}) \# 1$

Curve discussion: Greatest value t [s] $10.89 \tau[\mathrm{Pa}] 1074$.

Figure A.99. $58 \mathrm{wt} \%$ Kaolin Clay at $24 \mathrm{hrs}$ Aging (\#1) 


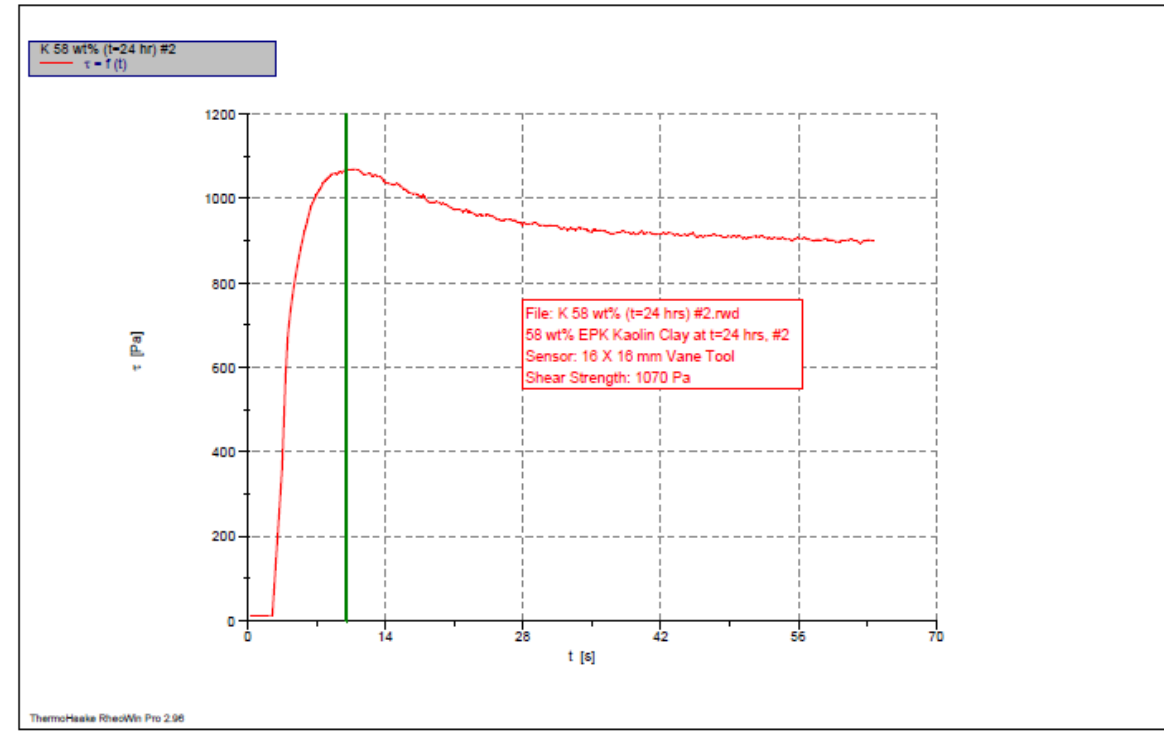

1: C:IRheoloqv Resultsitime -varyina Kaolin strength $\backslash \mathrm{K} 58 \mathrm{wt} \%(\mathrm{t}=24 \mathrm{hr})$ \#2.rwd Companv / Operator: PNNL / Jaehun Chun

Date / Time / Version: 07.04.2010 / 11:22:09 AM / RheoWin Pro 296

Substance / Sample no: K 58 wt\% (t=24 hr) \#2 / K 58 wt\% (t=24 hr) \#2

Curve discussion: Greatest value $t[\mathrm{~s}] 10.05 \tau[\mathrm{Pa}] 1070$.

Figure A.100. $58 \mathrm{wt} \%$ Kaolin Clay at $24 \mathrm{hrs}$ Aging (\#2)

ThermoHaake RheoWin 4/29/2010/3:09 PM

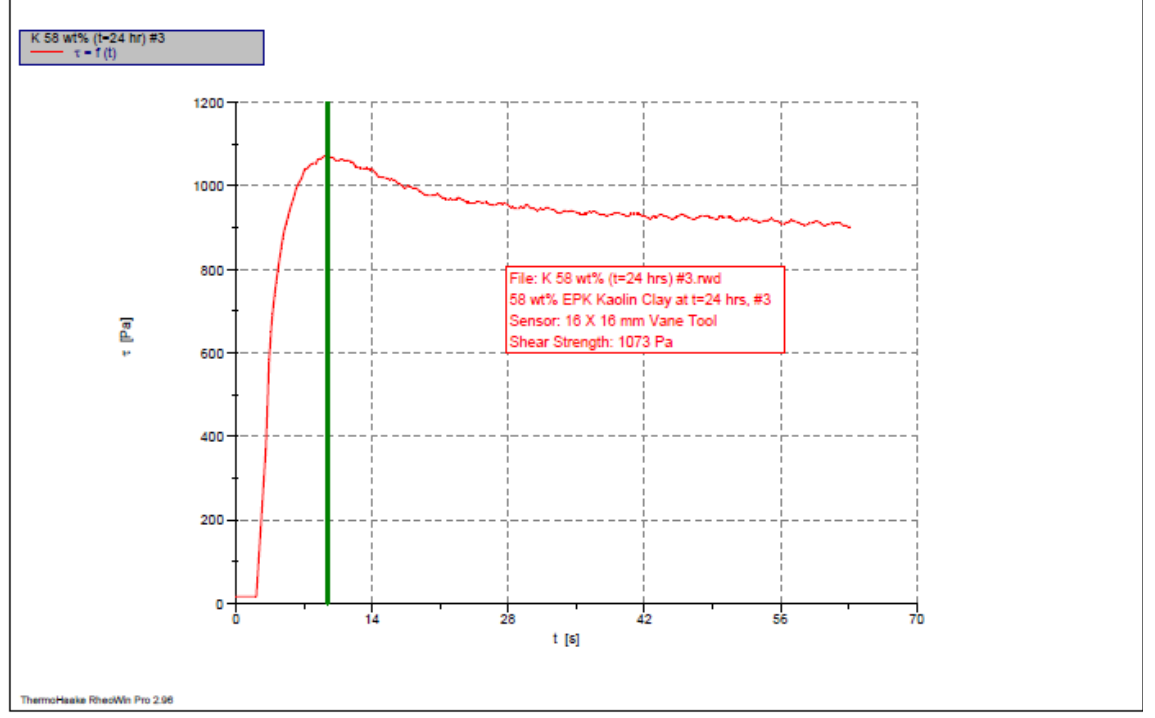

1: C:IRheologv Resultsitime -varying Kaolin strength $1 \mathrm{~K} 58 \mathrm{wt} \%$ (t=24 hr) \#3.rwd

Companv / Operator: PNNL / Jaehun Chun
Date / Time / Version: 07.04 2010 / 11:26:13 AM / RheoWin Pro 296

Substance / Sample no: K $58 \mathrm{wt} \%$ ( $\mathrm{t}=24 \mathrm{hr})$ \#3 / K $58 \mathrm{wt} \%$ (t=24 hr) \#3

Curve discussion: Greatest value $\mathrm{t}[\mathrm{s}] 9.457 \tau[\mathrm{Pa}] 1073$.

Figure A.101. $58 \mathrm{wt} \%$ Kaolin Clay at $24 \mathrm{hrs}$ Aging (\#3) 


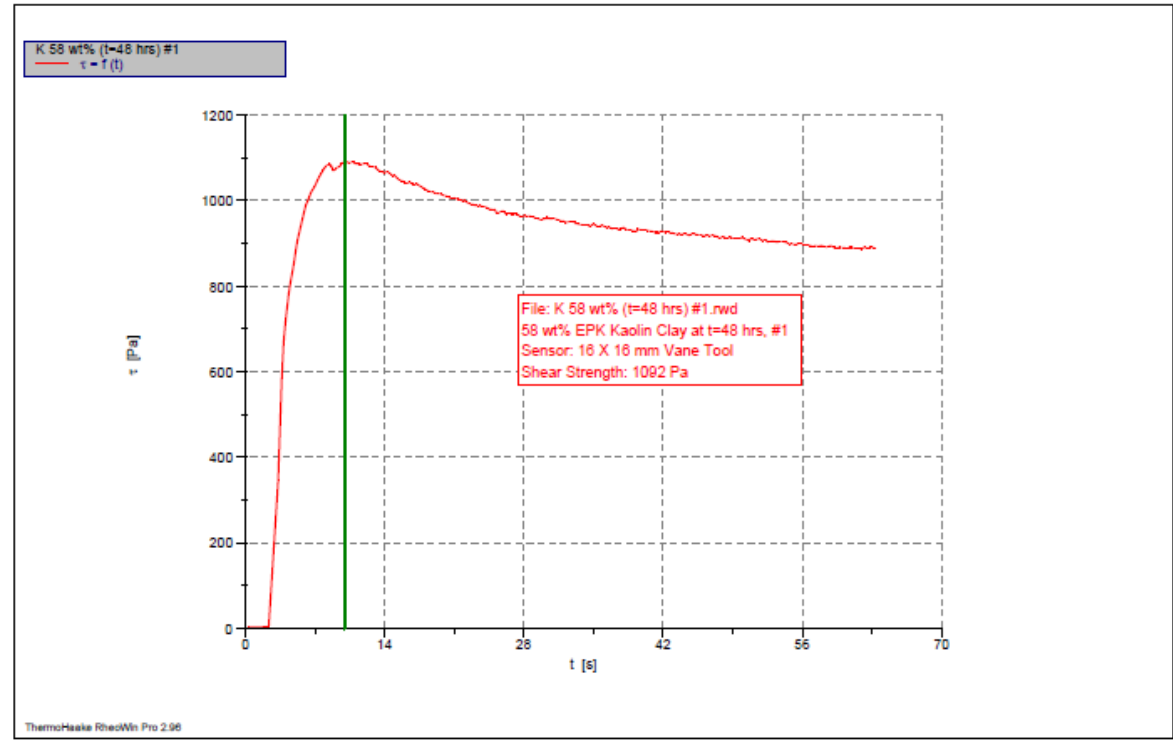

1: C:IRheoloav Resultsitime -varvina Kaolin strength $\backslash \mathrm{K} 58 \mathrm{wt} \%$ (t=48 hrs) \#1.rwd Company / Operator: PNNL / Jaehun Chun

Date / Time / Version: 08.04.2010 / 11:25:25 AM / RheoWin Pro 296

Substance / Sample no: K 58 wt\% (t=48 hrs) \#1 / K 58 wt\% (t=48 hrs) \#1

Curve discussion: Greatest value t [s] $10.01 \tau[\mathrm{Pa}] 1092$.

Figure A.102. 58 wt\% Kaolin Clay at 48 hrs Aging (\#1)

ThermoHaake RheoWin 4/29/2010/3:10 PM

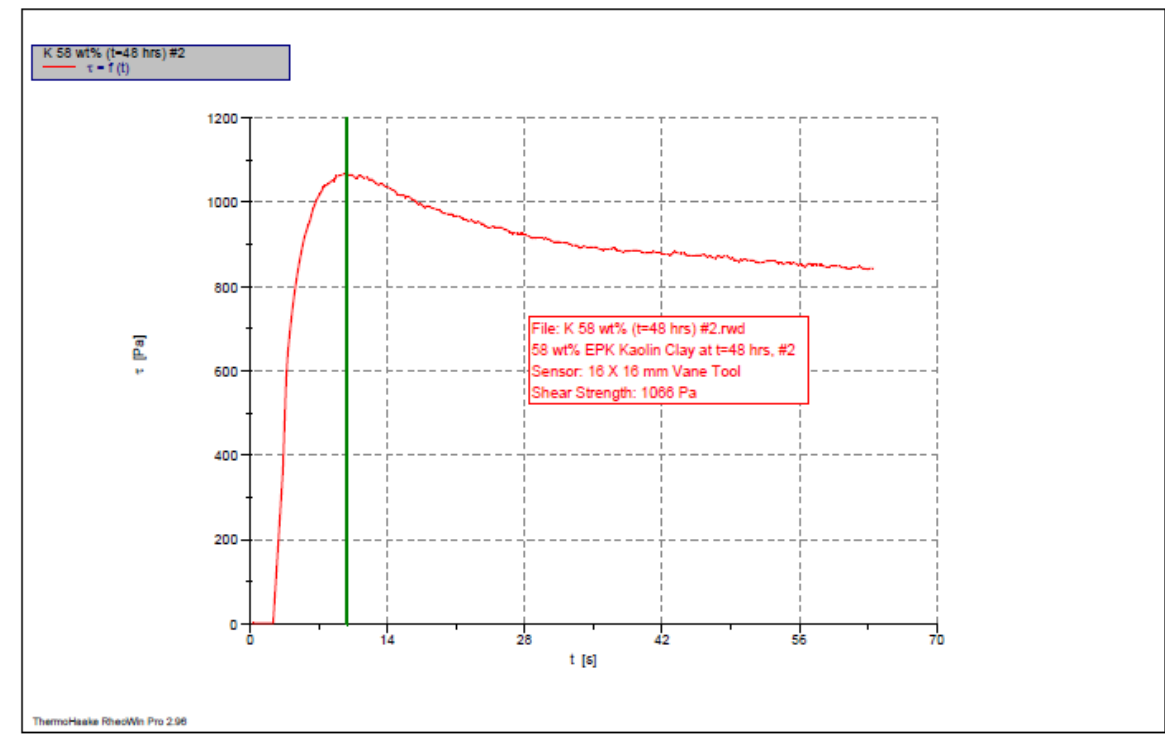

1: C:IRheologv Resultsitime-varyinq Kaolin strength $\backslash \mathrm{K} 58 \mathrm{wt} \%$ (t=48 hrs) \#2. rwd Companv / Operator: PNNL / Jaehun Chun

Date / Time / Version: 08.04.2010 / 11:29:11 AM / RheoWin Pro 296

Substance / Sample no: K 58 wt $\%$ (t=48 hrs) \#2 / K 58 wt $\%$ ( $\mathrm{t}=48 \mathrm{hrs}$ ) \#2

Curve discussion: Greatest value $\mathrm{t}[\mathrm{s}] 9.884 \tau[\mathrm{Pa}] 1066$.

Figure A.103. $58 \mathrm{wt} \%$ Kaolin Clay at $48 \mathrm{hrs}$ Aging (\#2) 
ThermoHaake RheoWin 4/29/2010/3:11 PM

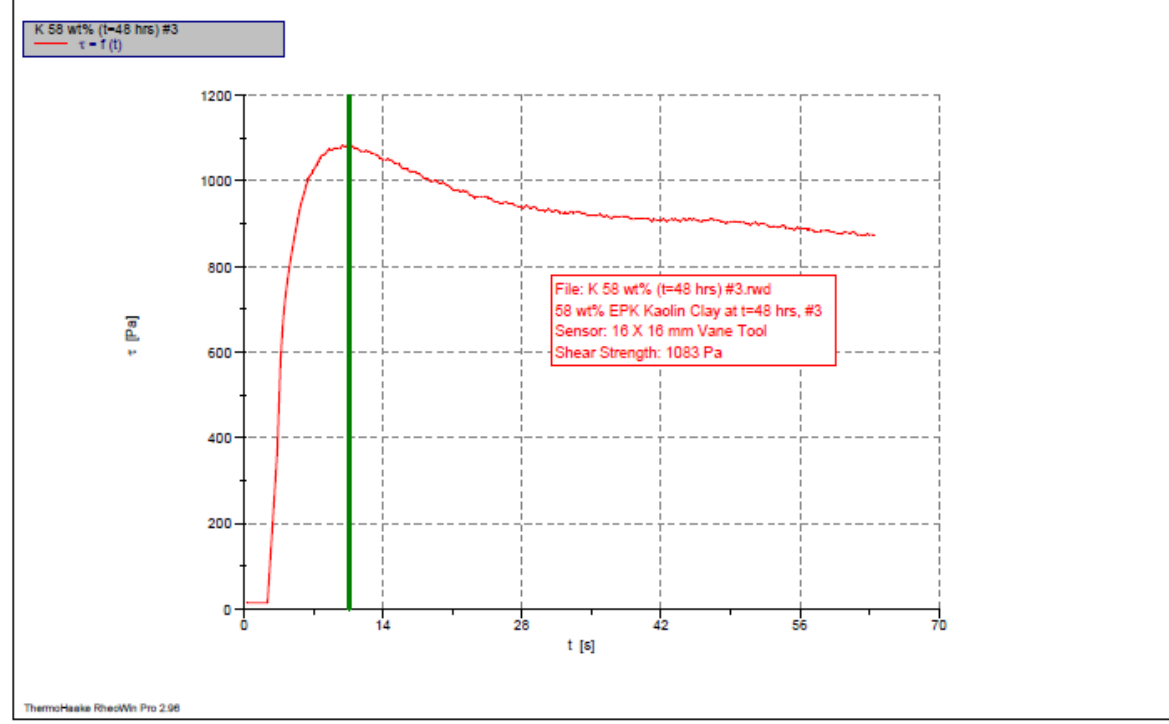

1: C:IRheologv Resultsltime -varving Kaolin strength $\backslash \mathrm{K} 58 \mathrm{wt} \%$ (t=48 hrs) \#3.rwd

Companv / Operator: PNNL / Jaehun Chun

Date / Time / Version: 08.04.2010/11:32:45 AM / RheoWin Pro 296

Substance / Sample no: K 58 wt\% ( $\mathrm{t}=48 \mathrm{hrs})$ \#3 / K 58 wt $\%$ ( $\mathrm{t}=48 \mathrm{hrs}) \# 3$

Curve discussion: Greatest value $\mathrm{t}[\mathrm{s}] 10.59 \tau[\mathrm{Pa}] 1083$.

Figure A.104. $58 \mathrm{wt} \%$ Kaolin Clay at $48 \mathrm{hrs}$ Aging (\#3)

ThermoHaake RheoWin 4/29/2010/3:12 PM

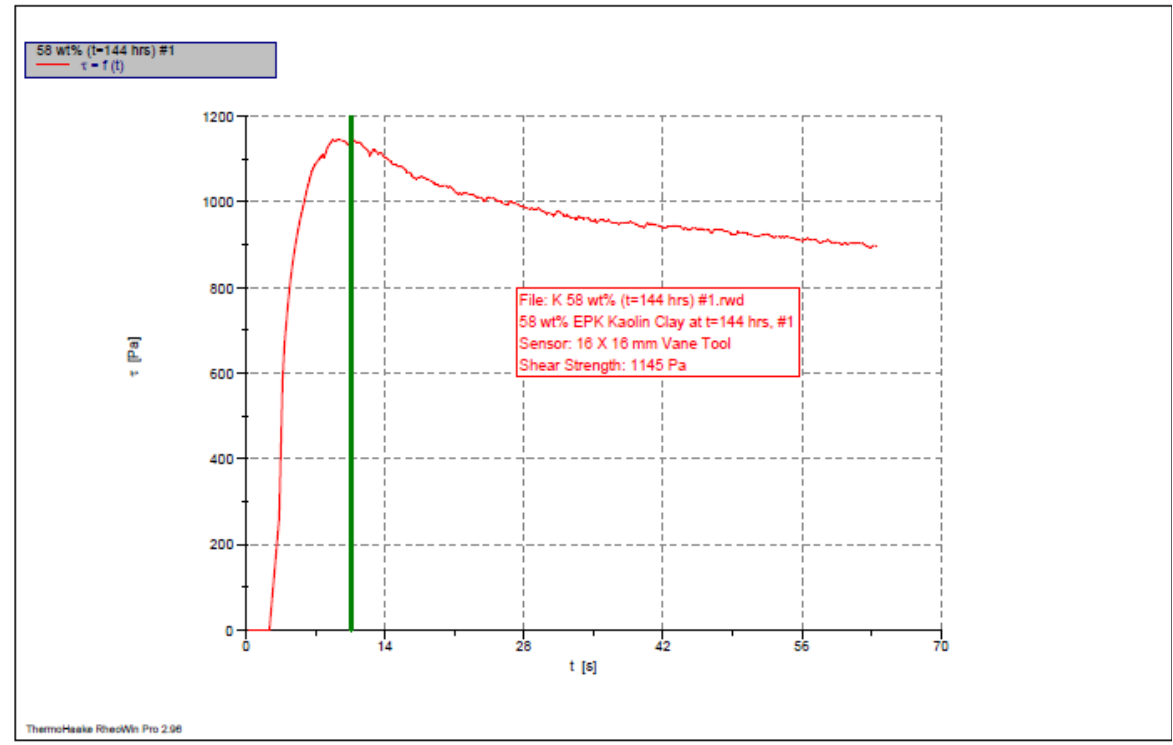

1: C:IRheologv Resultsitime -varvina Kaolin strength 158 wt\% (t=144 hrs) \#1.rwd Companv / Operator: PNNL / Jaehun Chun

Date / Time / Version: 12.04.2010 / 11:19:22 AM / RheoWin Pro 296

Substance / Sample no: 58 wt\% (t=144 hrs) \#1 / 58 wt\% (t=144 hrs) \#1

Curve discussion: Greatest value $\mathrm{t}[\mathrm{s}] 10.59 \tau[\mathrm{Pa}] 1145$.

Figure A.105. $58 \mathrm{wt} \%$ Kaolin Clay at $144 \mathrm{hrs} \mathrm{Aging} \mathrm{( \# 1)}$ 


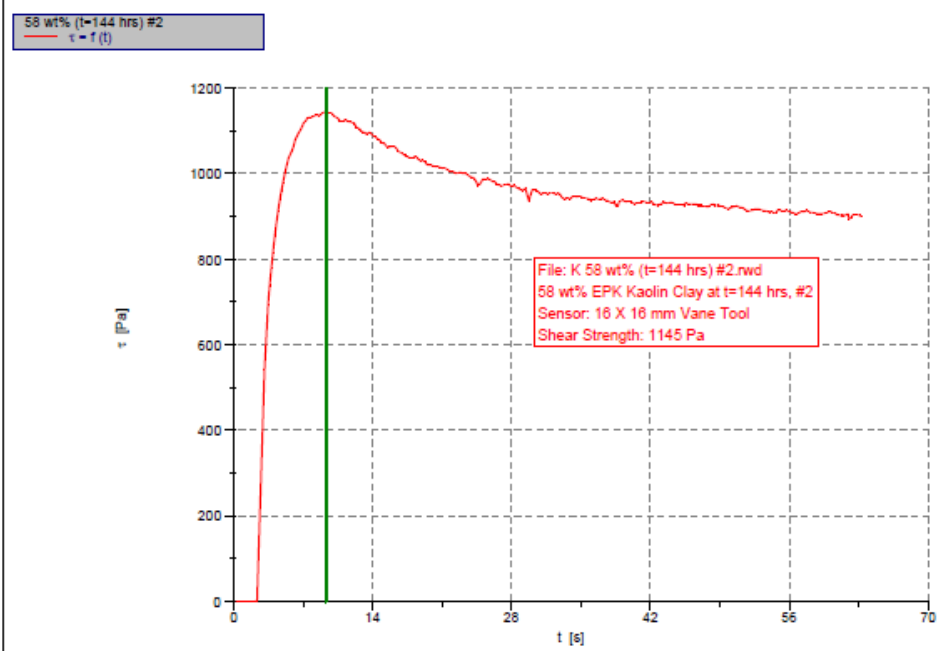

1: C:IRheoloav Resultsitime -varvina Kaolin strength 158 wt\% (t=144 hrs) \#2.rwd Companv / Operator: PNNL / Jaehun Chun

Date / Time / Version: 12.04.2010 / 11:27:16 AM / RheoWin Pro 296

Substance / Sample no: 58 wt\% (t=144 hrs) \#2 / 58 wt\% (t=144 hrs) \#2

Curve discussion: Greatest value t [s] $9.290 \tau[\mathrm{Pa}] 1145$.

Figure A.106. $58 \mathrm{wt} \%$ Kaolin Clay at $144 \mathrm{hrs}$ Aging (\#2)

ThermoHaake RheoWin 4/29/2010/3:13 PM

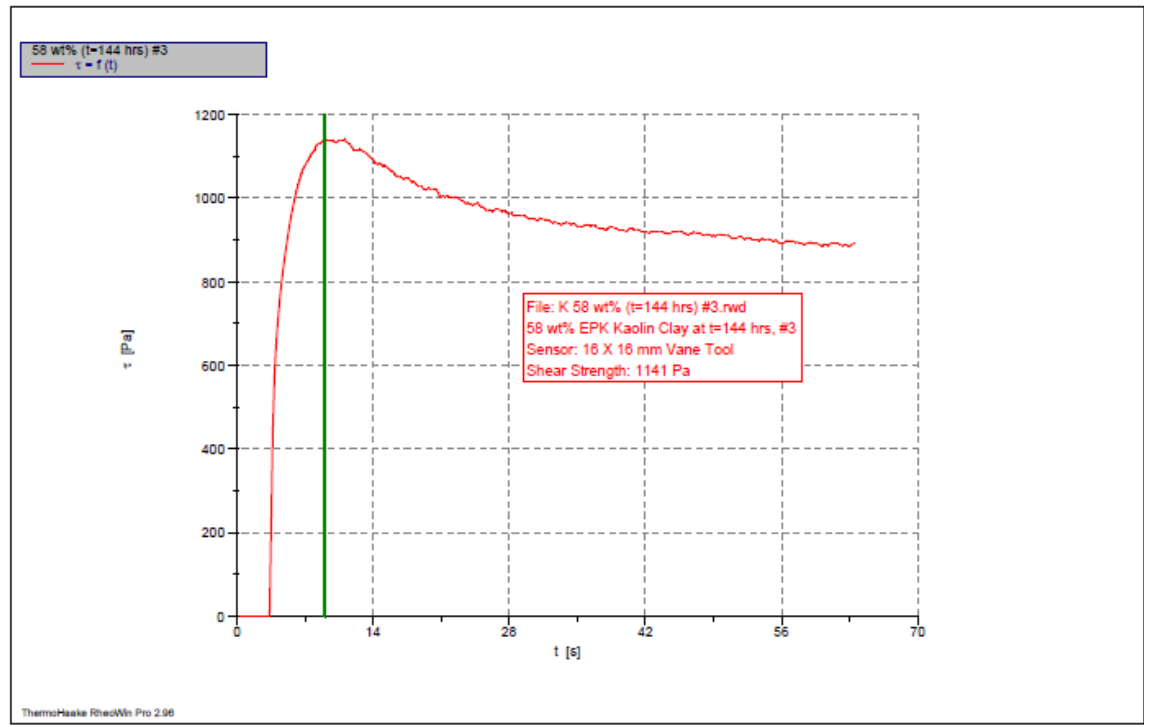

1: C:IRheologv Resultsltime -varving Kaolin strength 158 wt\% (t=144 hrs) \#3.rwd

Companv / Operator: PNNL / Jaehun Chun

Substance / Sample no: 58 wt\% (t=144 hrs) \#3 / 58 wt\% (t=144 hrs) \#3

Curve discussion: Greatest value $\mathrm{t}[\mathrm{s}] 9.040 \tau[\mathrm{Pa}] 1141$.

Figure A.107. $58 \mathrm{wt} \%$ Kaolin Clay at $144 \mathrm{hrs} \mathrm{Aging} \mathrm{( \# 3)}$ 
ThermoHaake RheoWin 4/29/2010/3:14 PM

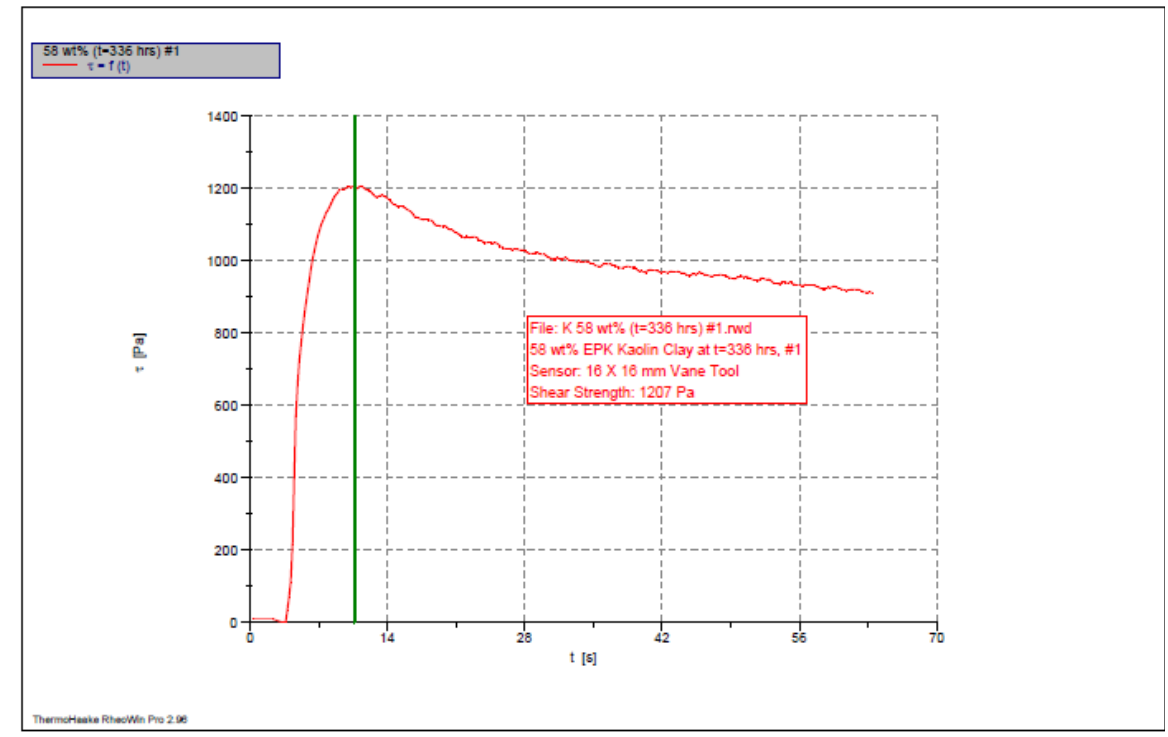

1: C:IRheologv Resultsitime -varvina Kaolin strength $158 \mathrm{wt} \%(\mathrm{t}=336 \mathrm{hrs})$ \#1.rwd Companv / Operator: PNNL / Jaehun Chun

Date/ Time/ Version: 20.04.2010/11.34:36 AM / RheoWin Pro 296

Substance / Sample no: $58 \mathrm{wt} \%$ ( $\mathrm{t}=336 \mathrm{hrs}$ ) \#1 / $58 \mathrm{wt} \%$ ( $\mathrm{t}=336 \mathrm{hrs}) \# 1$ Curve discussion: Greatest value $\mathrm{t}[\mathrm{s}] 10.68 \tau[\mathrm{Pa}] 1207$.

Figure A.108. $58 \mathrm{wt} \%$ Kaolin Clay at $336 \mathrm{hrs}$ Aging (\#1)

ThermoHaake RheoWin 4/29/2010/3:15 PM

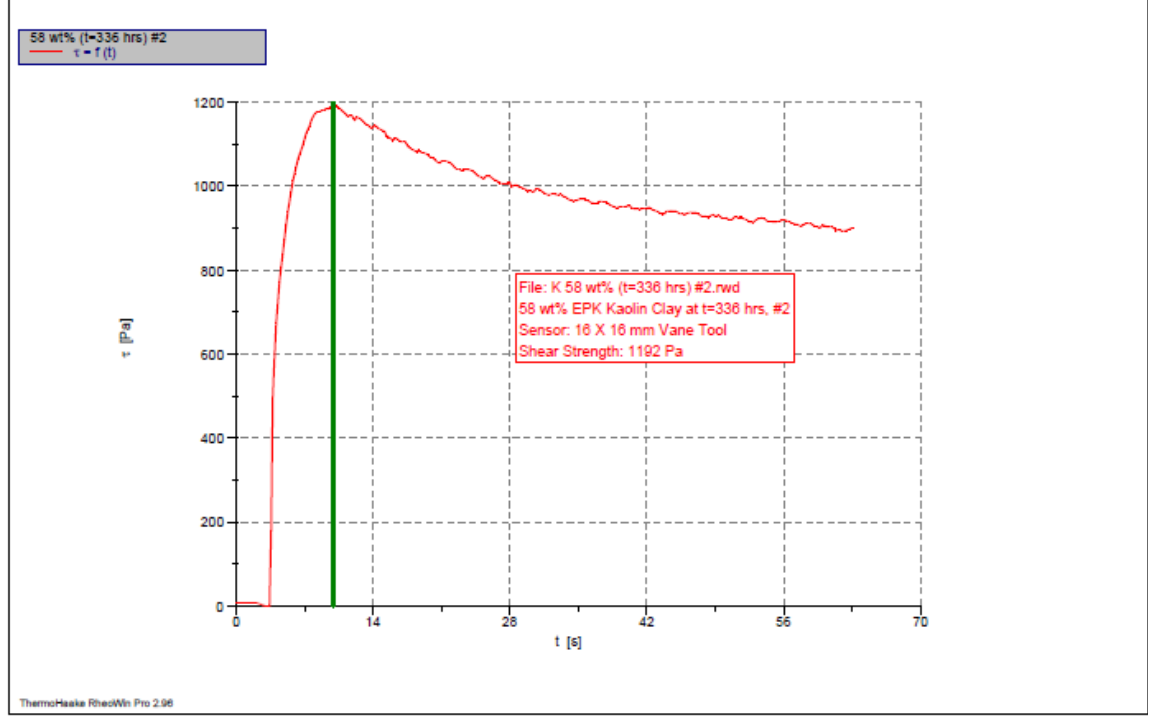

1: C:IRheoloqv Resultsitime -varving Kaolin strength $158 \mathrm{wt} \%$ (t=336 hrs) \#2.rwd

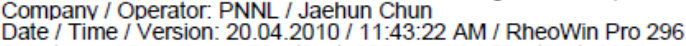

Substance / Sample no: $58 \mathrm{wt} \%$ (t=336 hrs) \#2 / $58 \mathrm{wt} \%$ (t=336 hrs) \#2

Curve discussion: Greatest value t [s] $9.912 \tau[\mathrm{Pa}] 1192$.

Figure A.109. 58 wt\% Kaolin Clay at 336 hrs Aging (\#2) 
ThermoHaake RheoWin 4/29/2010/3:15 PM

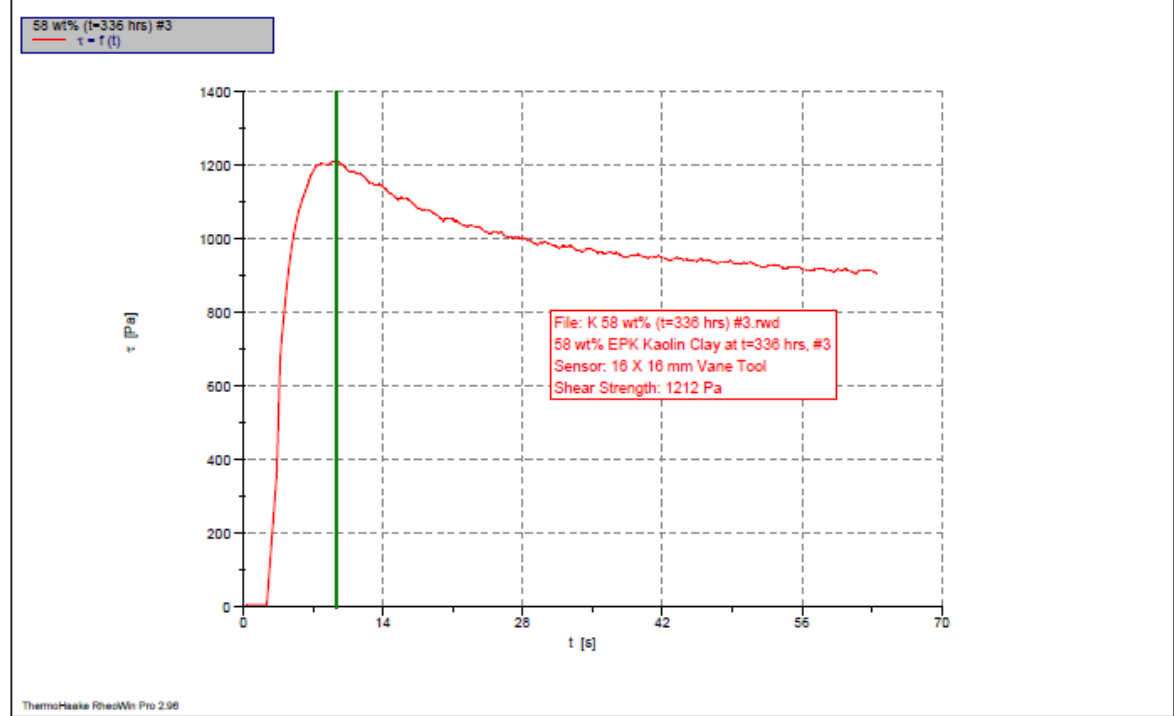

1: C:IRheologv Resultsitime -varyinq Kaolin strength 158 wt\% ( $\mathrm{t}=336 \mathrm{hrs}$ ) \#3.rwd

Companv / Operator: PNNL / Jaehun Chun

Date / Time / Version: 20.04.2010 / 11:49:10 AM / RheoWin Pro 296

Substance / Sample no: 58 wt \% (t=336 hrs) \#3 / 58 wt $\%$ ( $\mathrm{t}=336 \mathrm{hrs}$ ) \#3

Curve discussion: Greatest value $\mathrm{t}[\mathrm{s}] \mathrm{9}$.351 $\tau[\mathrm{Pa}] 1212$.

Figure A.110. 58 wt\% Kaolin Clay at 336 hrs Aging (\#3) 


\section{A.6.5 Kaolin Clay/Min-U-Sil 30 Simulants}

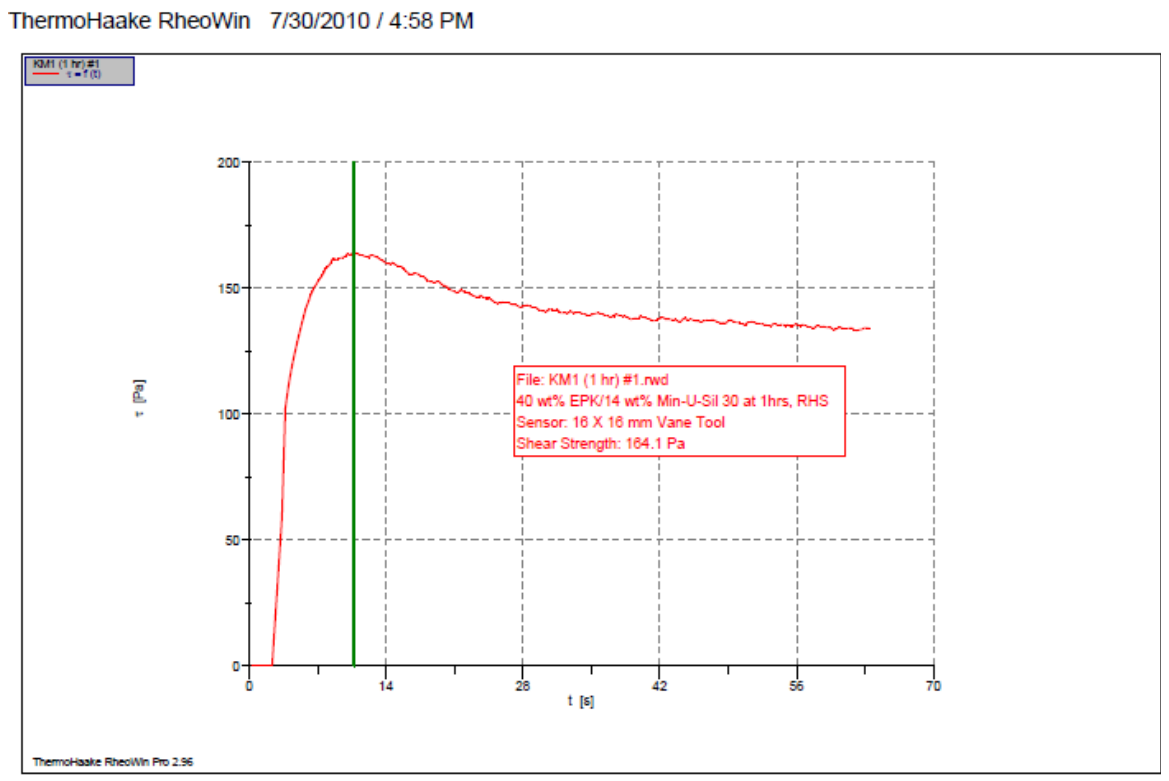

1: C:IK -Basin Rheol05272010VKM1 (1 hr) \#1.rwd

Companv / Operator: PNNL / Jaehun Chun

Date / Time/Version. 27.05.2010/12:03:52 PM / RheoWin Pro 296

Substance / Sample no: KM1 (1 hr) \#1 / KM1 (1 hr) \#1

Curve discussion: Greatest value $\mathrm{t}[\mathrm{s}] 10.72 \tau[\mathrm{Pa}] 164.1$

Figure A.111. $40 \mathrm{wt} \%$ Kaolin Clay/14 wt\% Min-U-Sil 30, RHS Sampling Location (1 hr)

ThermoHaake RheoWin 7/30/2010/5:01 PM

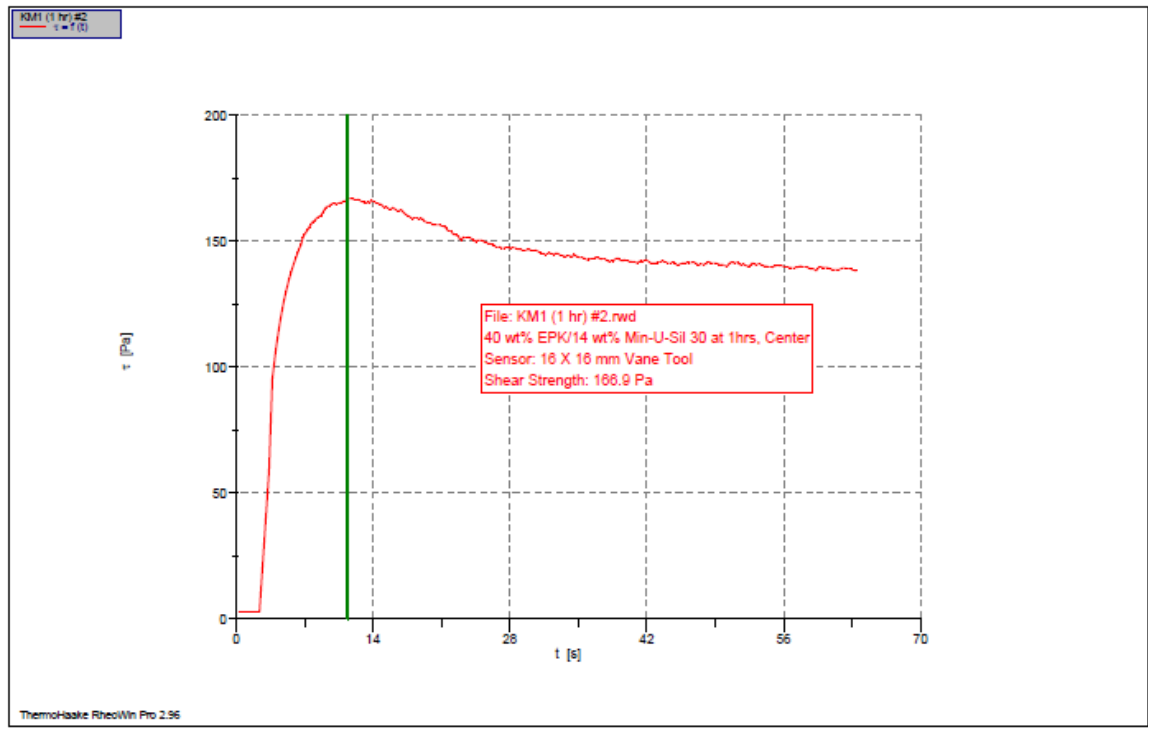

1: C:IK -Basin Rheol05272010IKM1 (1 hr) \#2.rwd

Company / Operator: PNNL / Jaehun Chun

Date / Time / Version: 27.05.2010 / 12:07:20 PM / RheoWin Pro 296

Substance / Sample no: KM1 (1 hr) \#2 / KM1 (1 hr) \#2

Curve discussion: Greatest value $\mathrm{t}[\mathrm{s}] 11.41 \tau[\mathrm{Pa}] 166.9$

Figure A.112. $40 \mathrm{wt} \%$ Kaolin Clay/14 wt $\%$ Min-U-Sil 30, Center Sampling Location (1 hr) 


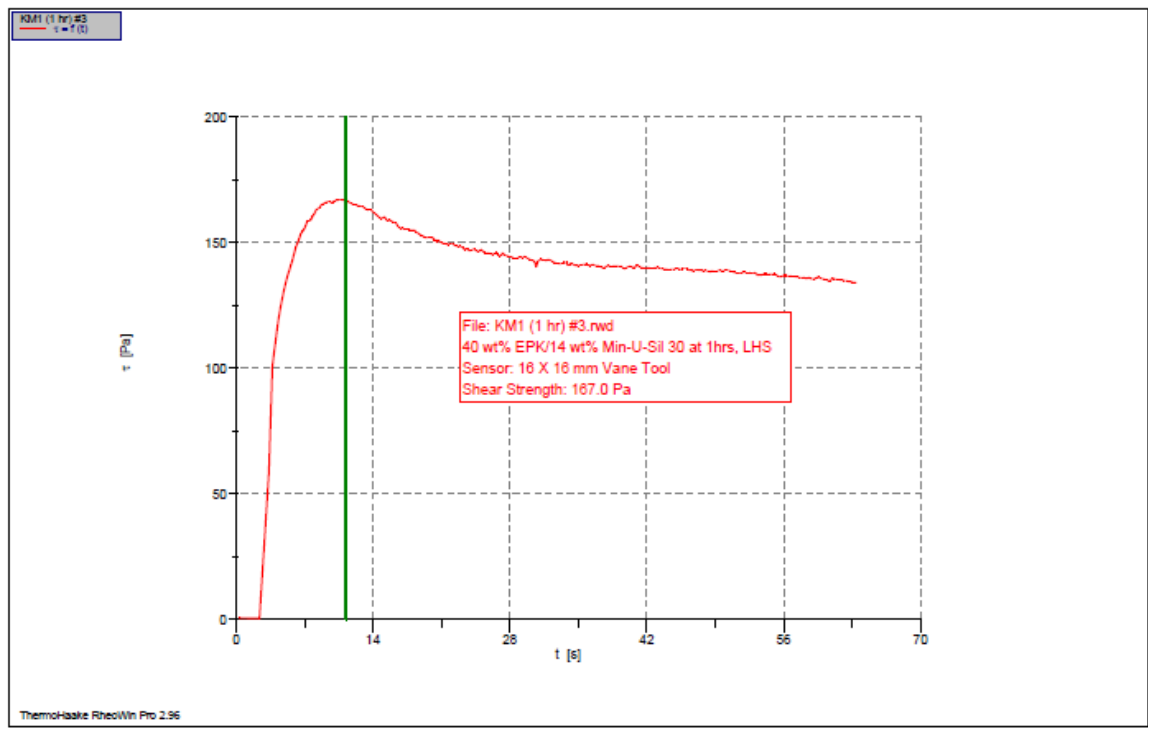

1: C:IK-Basin Rheol05272010VKM1 (1 hr) \#3.rwd

Company / Operator: PNNL / Jaehun Chun

Date / Time / Version: 27.05.2010 / 12:10:23 PM / RheoWin Pro 296

Substance / Sample no: KM1 (1 hr) \#3 / KM1 (1 hr) \#3

Curve discussion: Greatest value $\mathrm{t}[\mathrm{s}] 11.23 \tau[\mathrm{Pa}] 167.0$

Figure A.113. $40 \mathrm{wt} \%$ Kaolin Clay/14 wt\% Min-U-Sil 30, LHS Sampling Location (1 hr)

ThermoHaake RheoWin 7/30/2010 / 5:05 PM

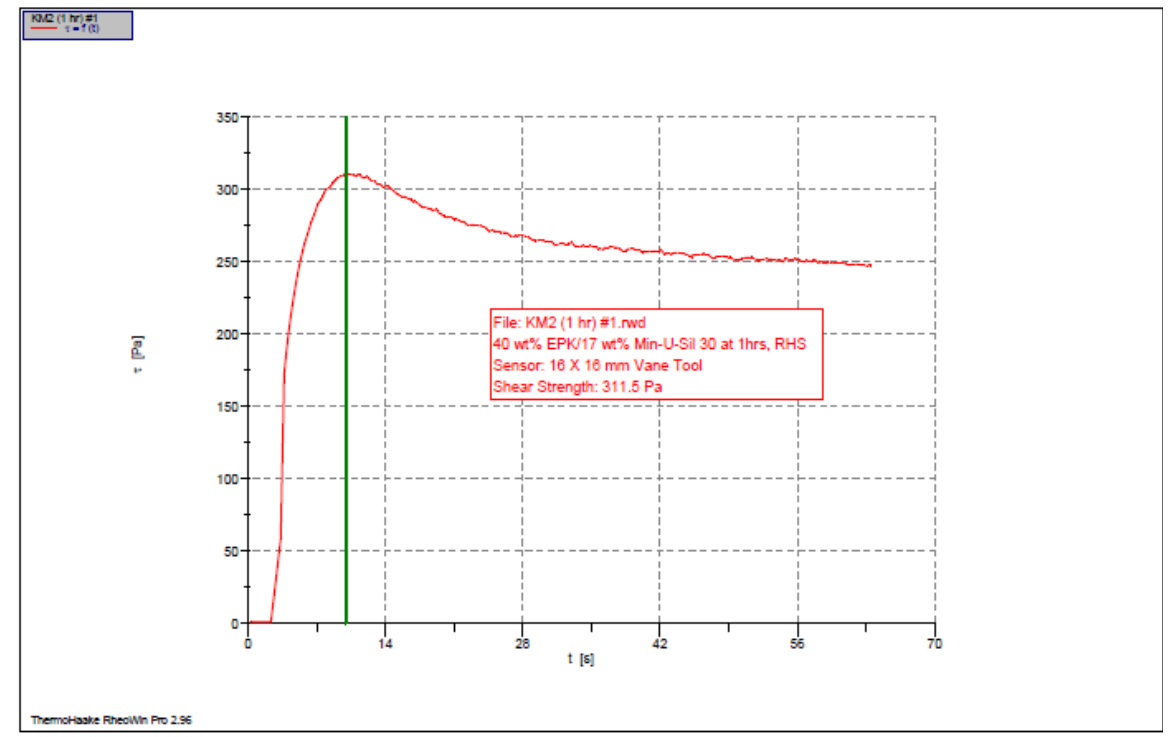

1: C:IK -Basin Rheol05272010UKM2 (1 hr) \#1.rwd

Date / Time / Version: 27.05.2010 / 13:01:33 PM / RheoWin Pro 296

Substance / Sample no: KM2 (1 hr) \#1 / KM2 (1 hr) \#1

Curve discussion: Greatest value $\mathrm{t}[\mathrm{s}] 10.02 \tau[\mathrm{Pa}] 311.5$

Figure A.114. 40 wt\% Kaolin Clay/17 wt \% Min-U-Sil 30, RHS Sampling Location (1 hr) 


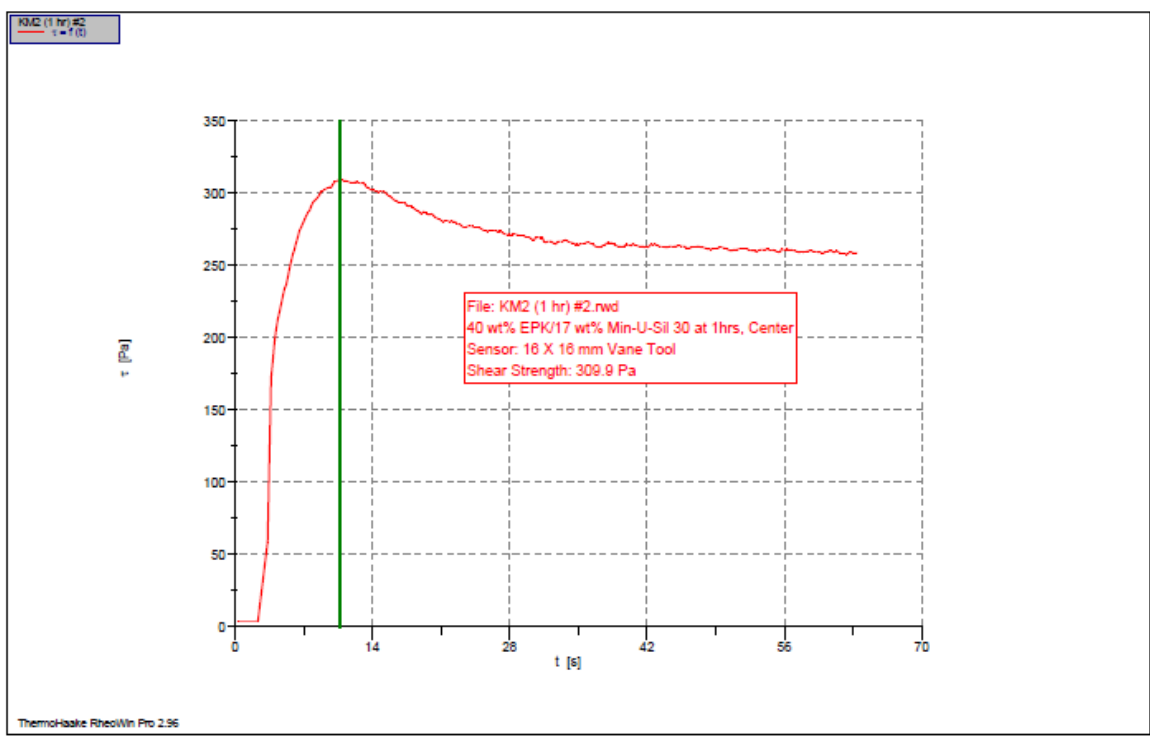

1: C:IK -Basin Rheol05272010KKM2 (1 hr) \#2.rwd

Companv / Operator: PNNL / Jaehun Chun

Date / Time / Version: 27.05.2010 / 13:04:21 PM / RheoWin Pro 296

Substance / Sample no: KM2 (1 hr) \#2 / KM2 (1 hr) \#2

Curve discussion: Greatest value $\mathrm{t}[\mathrm{s}] 10.69 \tau[\mathrm{Pa}] 309.9$

Figure A.115. 40 wt\% Kaolin Clay/17 wt\% Min-U-Sil 30, Center Sampling Location (1 hr)

ThermoHaake RheoWin 7/30/2010/5:08 PM

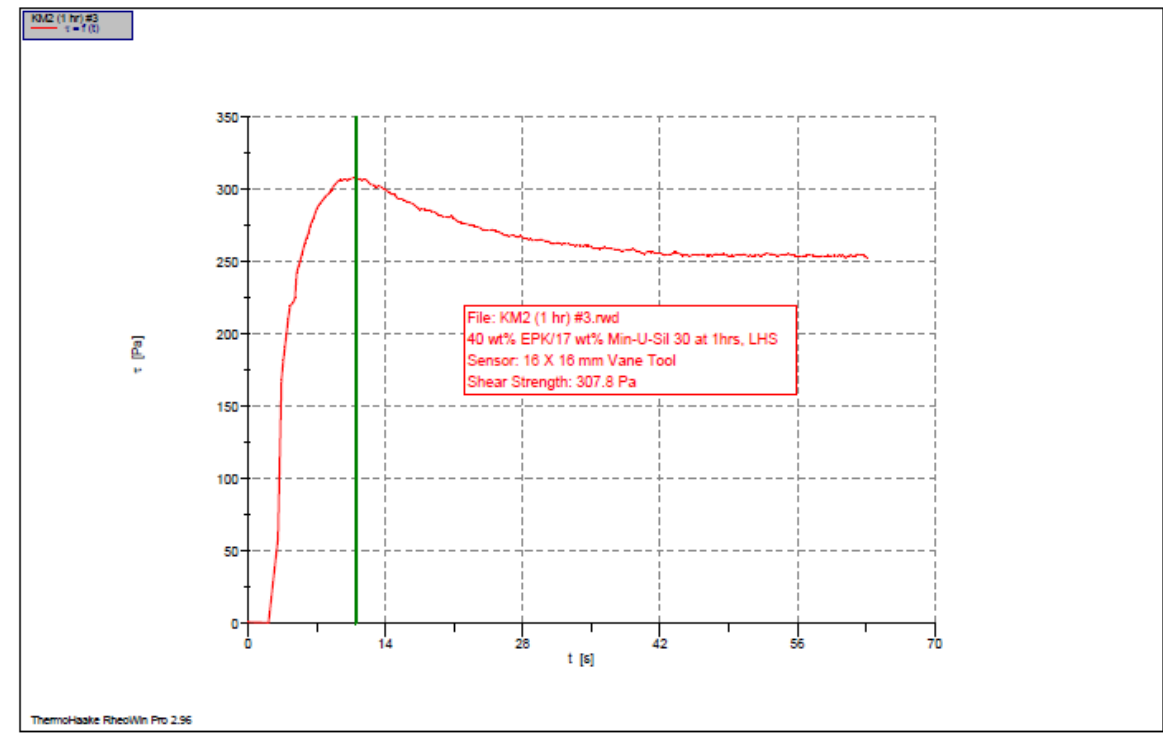

1: C:IK -Basin Rheol05272010 KKM2 (1 hr) \#3.rwd

Companv / Operator: PNNL / Jaehun Chun

Date/Time/Version. 27.05.2010/13:07:28 PM / RheoWin Pro 296

Substance / Sample no: KM2 (1 hr) \#3 / KM2 (1 hr) \#3

Curve discussion: Greatest value $\mathrm{t}[\mathrm{s}] 11.02 \tau[\mathrm{Pa}] 307.8$

Figure A.116. 40 wt $\%$ Kaolin Clay $/ 17$ wt\% Min-U-Sil 30, LHS Sampling Location (1 hr) 


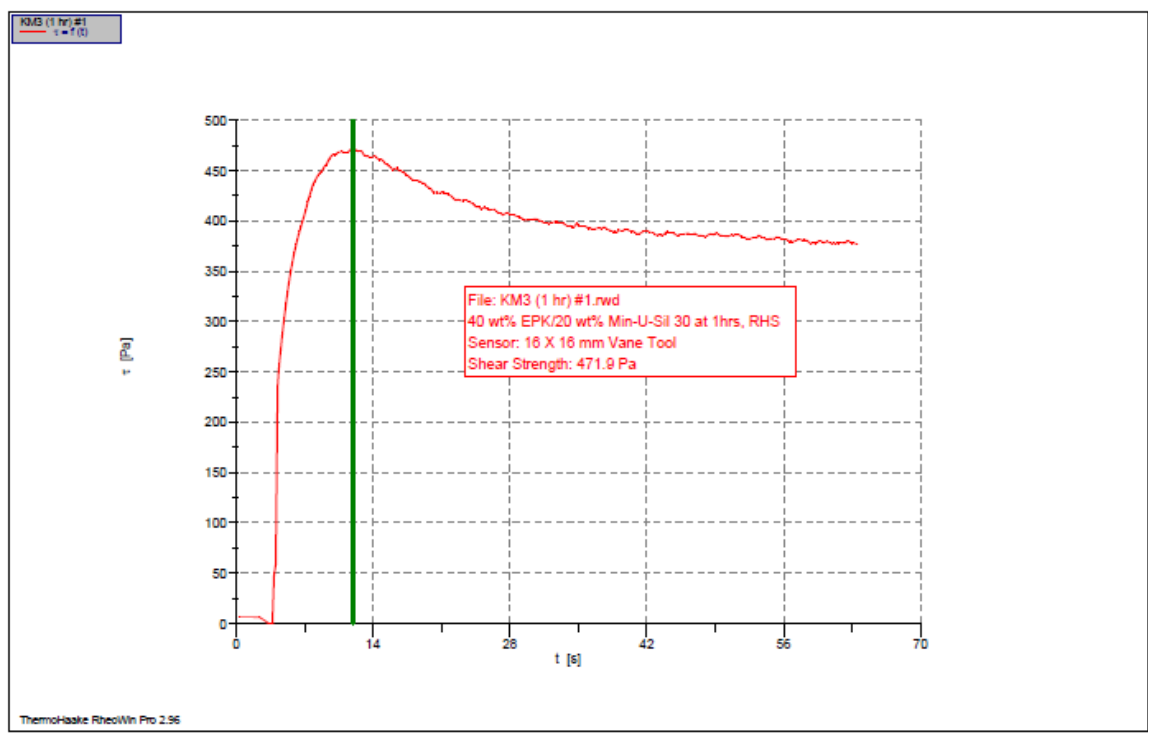

1: C:IK-Basin Rheol05272010【KM3 (1 hr) \#1.rwd

Companv / Operator: PNNL / Jaehun Chun

Date / Time / Version: 27.05.2010 / 14:16:23 PM / RheoWin Pro 296

Substance / Sample no: KM3 (1 hr) \#1 / KM3 (1 hr) \#1

Curve discussion: Greatest value $\mathrm{t}[\mathrm{s}] 11.94 \tau[\mathrm{Pa}] 471.9$

Figure A.117. 40 wt \% Kaolin Clay $/ 20$ wt $\%$ Min-U-Sil 30, RHS Sampling Location (1 hr)

ThermoHaake RheoWin 7/30/2010/5:10 PM

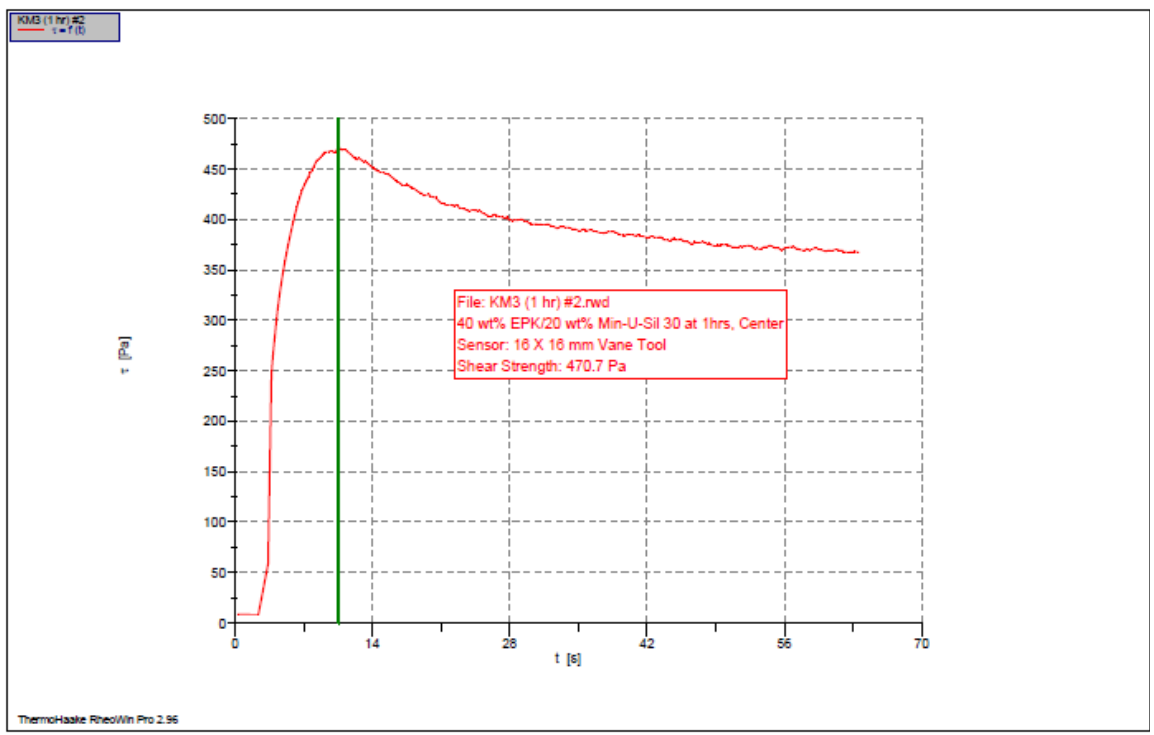

1: C:IK-Basin Rheol05272010\KM3 (1 hr) \#2.rwd

Date / Time / Version: 27.05.2010 / 14:19:02 PM / RheoWin Pro 296

Substance / Sample no: KM3 (1 hr) \#2 / KM3 (1 hr) \#2

Curve discussion: Greatest value $\mathrm{t}[\mathrm{s}] 10.56 \tau[\mathrm{Pa}] 470.7$

Figure A.118. $40 \mathrm{wt} \%$ Kaolin Clay/20 wt\% Min-U-Sil 30, Center Sampling Location (1 hr) 


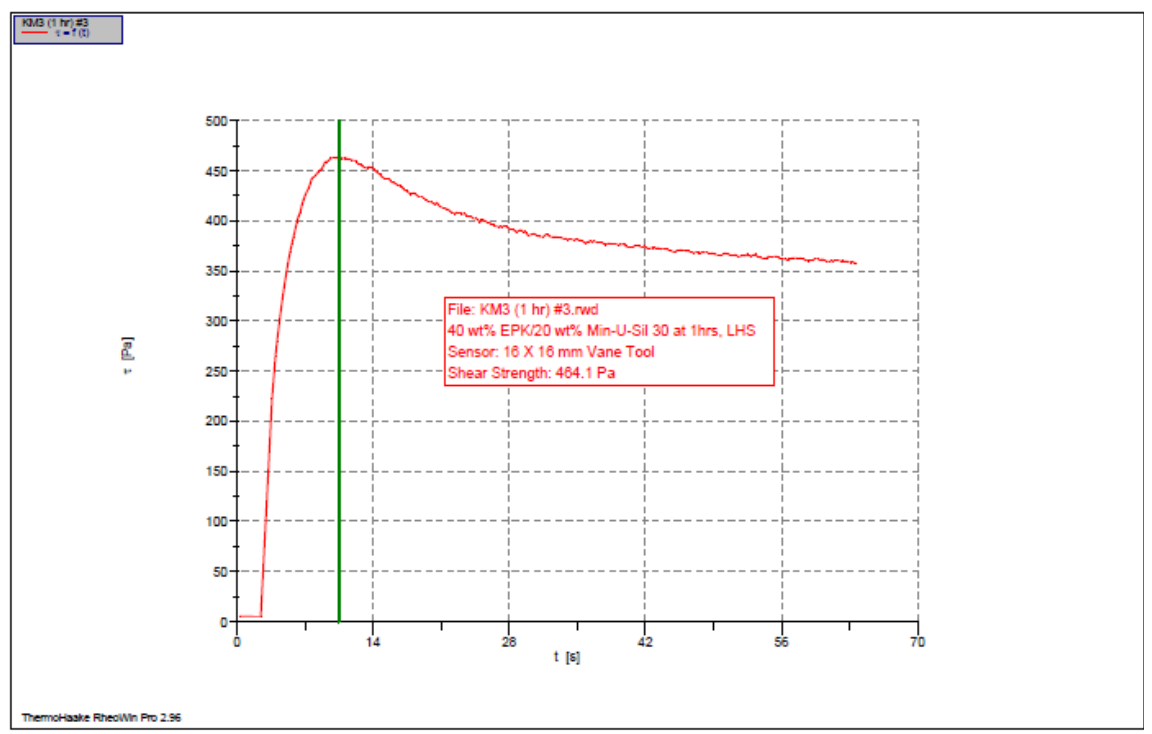

1: C:IK-Basin Rheol05272010KKM3 (1 hr) \#3.rwd Companv / Operator: PNNL / Jaehun Chun

Date / Time / Version: 27.05.2010 / 14:21:39 PM / RheoWin Pro 296

Substance / Sample no: KM3 (1 hr) \#3 / KM3 (1 hr) \#3

Curve discussion: Greatest value $\mathrm{t}[\mathrm{s}] 10.50 \tau[\mathrm{Pa}] 464.1$

Figure A.119. $40 \mathrm{wt} \%$ Kaolin Clay/20 wt\% Min-U-Sil 30, LHS Sampling Location (1 hr)

ThermoHaake RheoWin 7/30/2010/5:14 PM

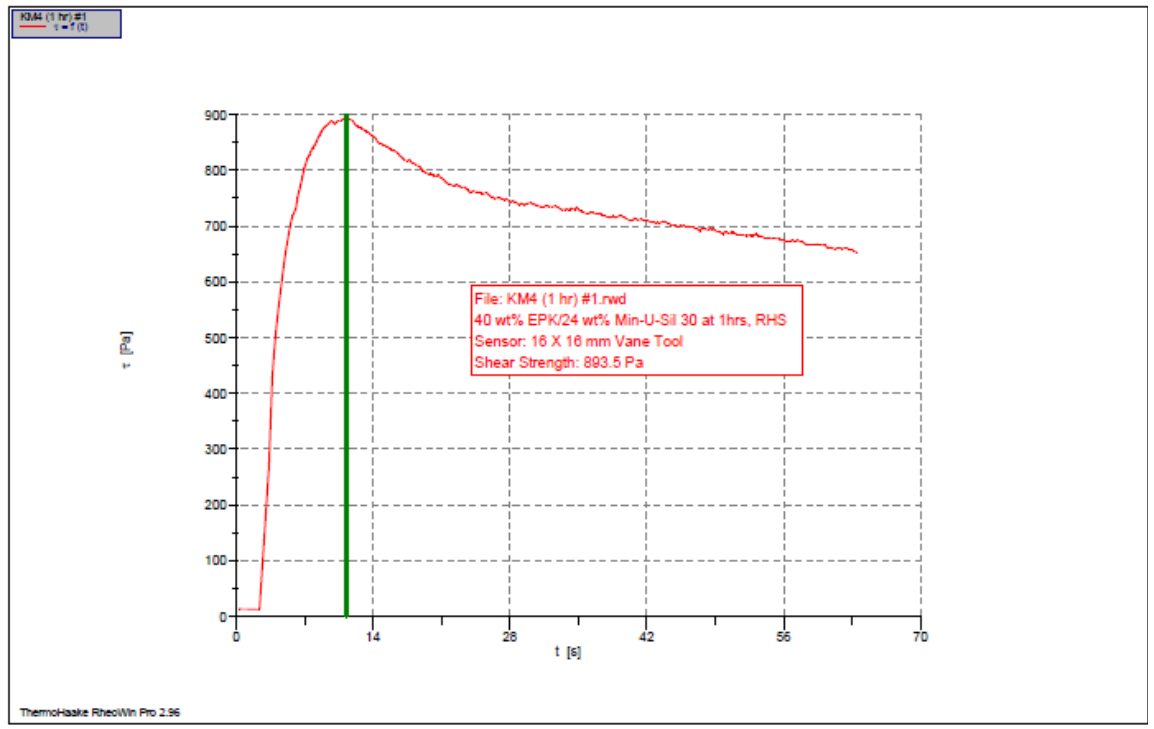

1: C:IK-Basin Rheol05282010KMM4 (1 hr) \#1.rwd Company / Operator: PNNL / Jaehun Chun

Date / Time / Version: 28.05.2010/ 10.58.07 AM / RheoWin Pro 296

Substance / Sample no: KM4 (1 hr) \#1 / KM4 (1 hr) \#1

Curve discussion: Greatest value $t[s] 11.26 \tau[\mathrm{Pa}] 893.5$

Figure A.120. $40 \mathrm{wt} \%$ Kaolin Clay/24 wt $\%$ Min-U-Sil 30, RHS Sampling Location (1 hr) 


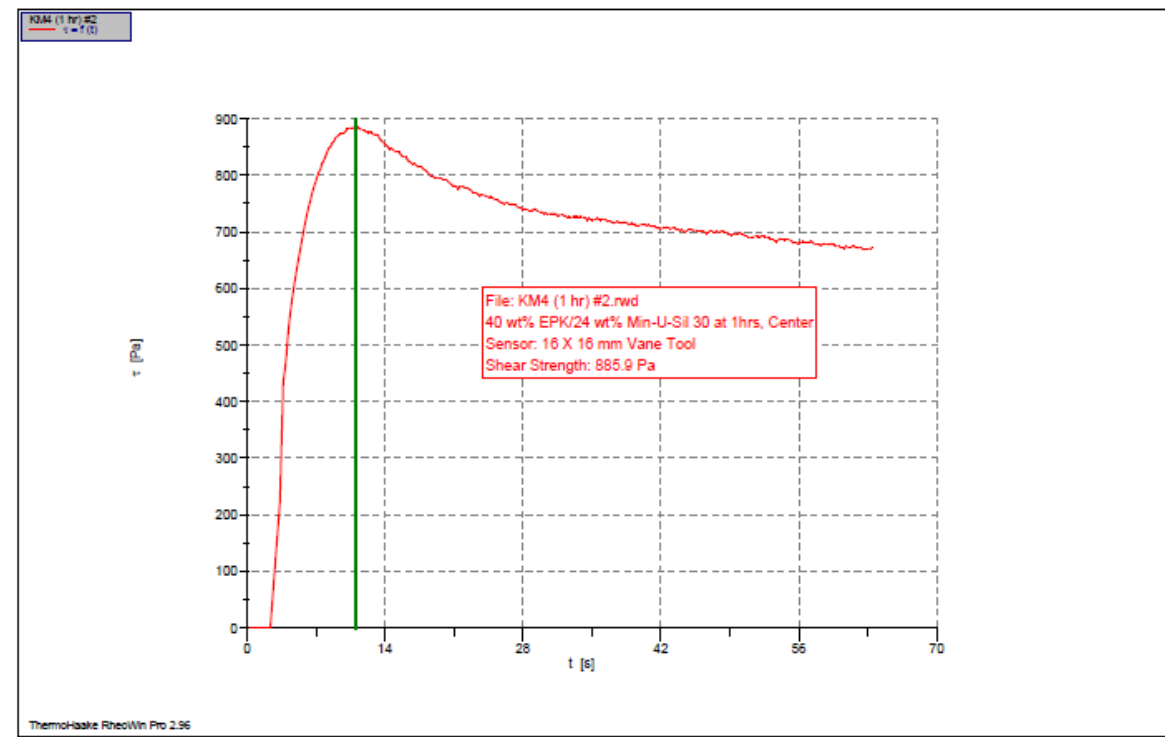

1: C:IK -Basin Rheol05282010 KMM4 (1 hr) \#2.rwd Companv / Operator: PNNL / Jaehun Chun

Date / Time / Version: 28.05.2010 / 11:01:21 AM / RheoWin Pro 296

Substance / Sample no: KM4 (1 hr) \#2 / KM4 (1 hr) \#2

Curve discussion: Greatest value $t[s] 11.03 \tau[\mathrm{Pa}] 885.9$

Figure A.121. 40 wt $\%$ Kaolin Clay/24 wt $\%$ Min-U-Sil 30, Center Sampling Location (1 hr)

ThermoHaake RheoWin 7/30/2010/5:17 PM

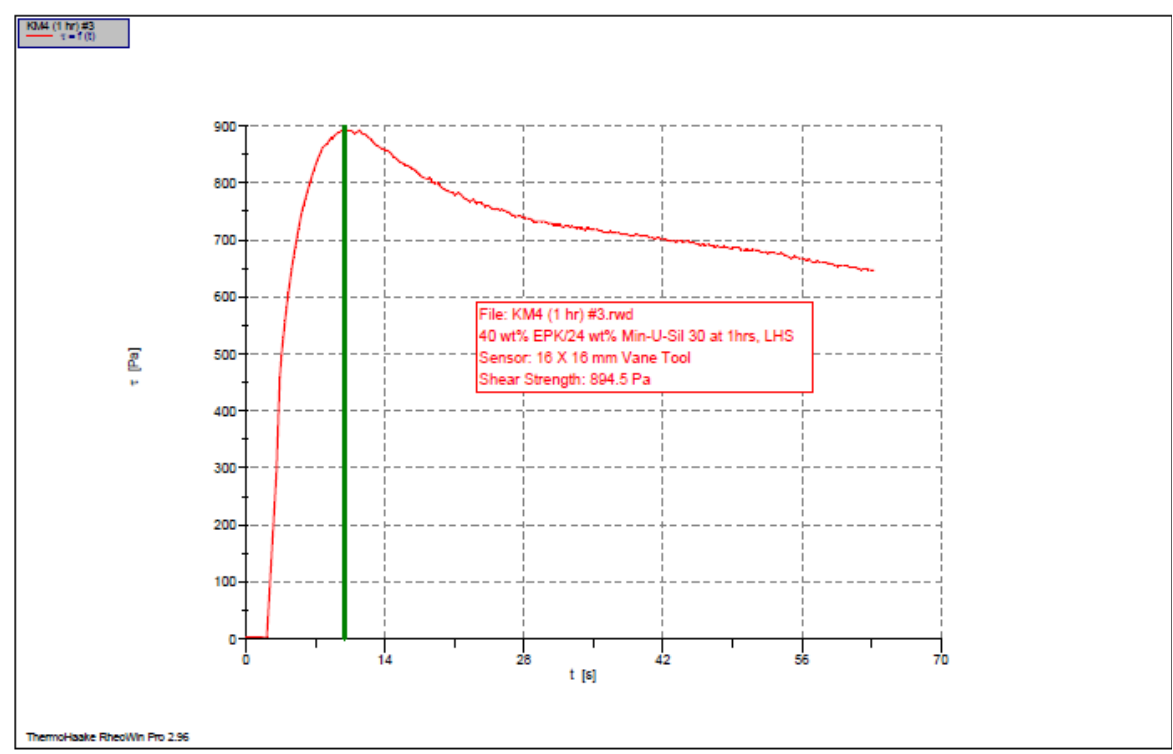

1: C:IK-Basin Rheol05282010KKM4 (1 hr) \#3.rwd

Companv/ Operator: PNNL / Jaehun Chun

Date / Time / Version: 28.05.2010 / 11:04:28 AM / RheoWin Pro 296

Substance / Sample no: KM4 (1 hr) \#3 / KM4 (1 hr) \#3

Curve discussion: Greatest value $\mathrm{t}[\mathrm{s}] 9.922 \tau[\mathrm{Pa}] 894.5$

Figure A.122. 40 wt $\%$ Kaolin Clay $/ 24$ wt\% Min-U-Sil 30, LHS Sampling Location (1 hr) 
ThermoHaake RheoWin 7/30/2010/6:02 PM

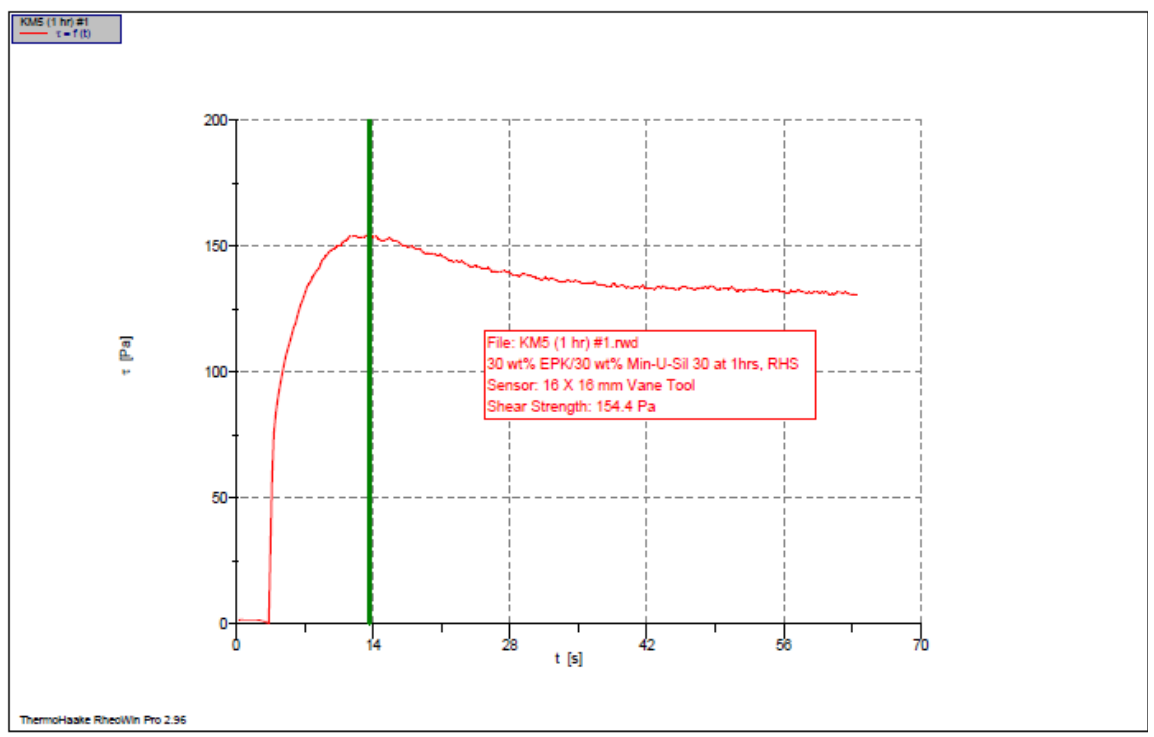

1: C:IK-Basin Rheol05272010UKM5 (1 hr) \#1.rwd

Companv / Operator: PNNL / Jaehun Chun

Date / Time / Version: 27.05.2010 / 15:44:11 PM / RheoWin Pro 296

Substance / Sample no: KM5 (1 hr) \#1 / KM5 (1 hr) \#1

Curve discussion: Greatest value $\mathrm{t}[\mathrm{s}] 13.63 \tau[\mathrm{Pa}] 154.4$

Figure A.123. 30 wt $\%$ Kaolin Clay/30 wt\% Min-U-Sil 30, RHS Sampling Location (1 hr)

ThermoHaake RheoWin 7/30/2010/6:03 PM

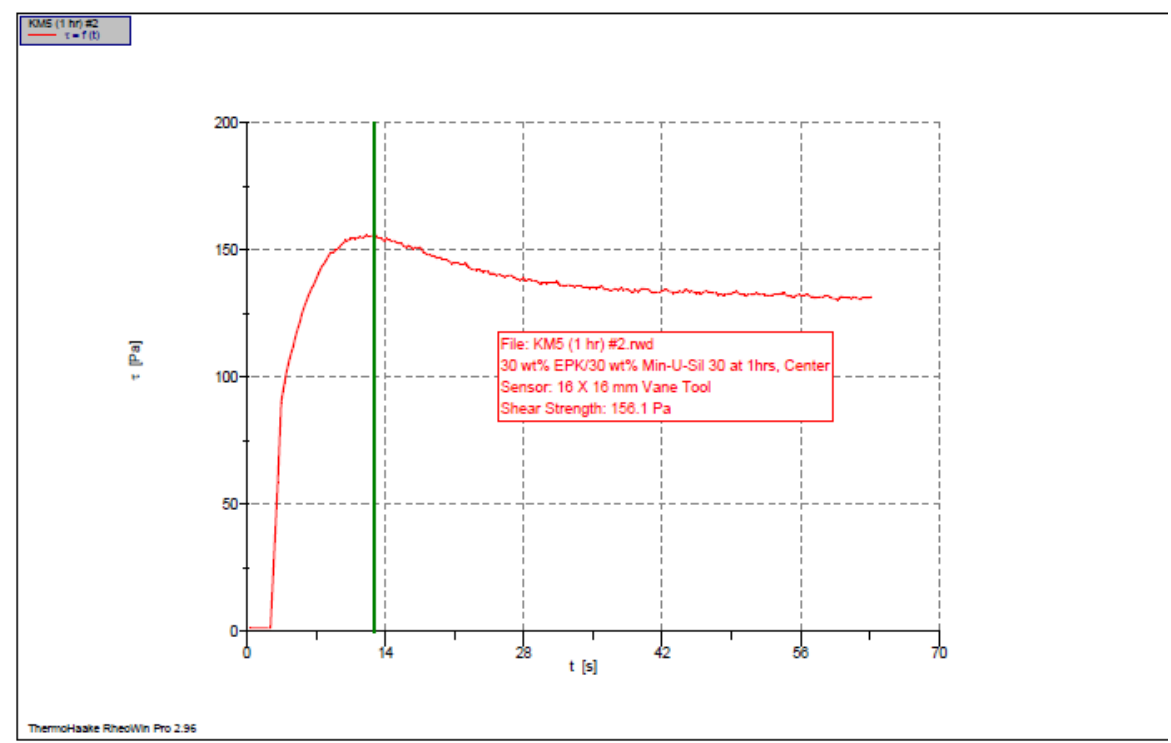

1: C:IK-Basin Rheol05272010KKM5 (1 hr) \#2.rwd

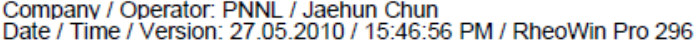

Substance / Sample no: KM5 (1 hr) \#2 / KM5 (1 hr) \#2

Curve discussion: Greatest value $t[s] 12.90 \tau[\mathrm{Pa}] 156.1$

Figure A.124. $30 \mathrm{wt} \%$ Kaolin Clay $/ 30 \mathrm{wt} \%$ Min-U-Sil 30, Center Sampling Location (1 hr) 
ThermoHaake RheoWin 7/30/2010/6:04 PM

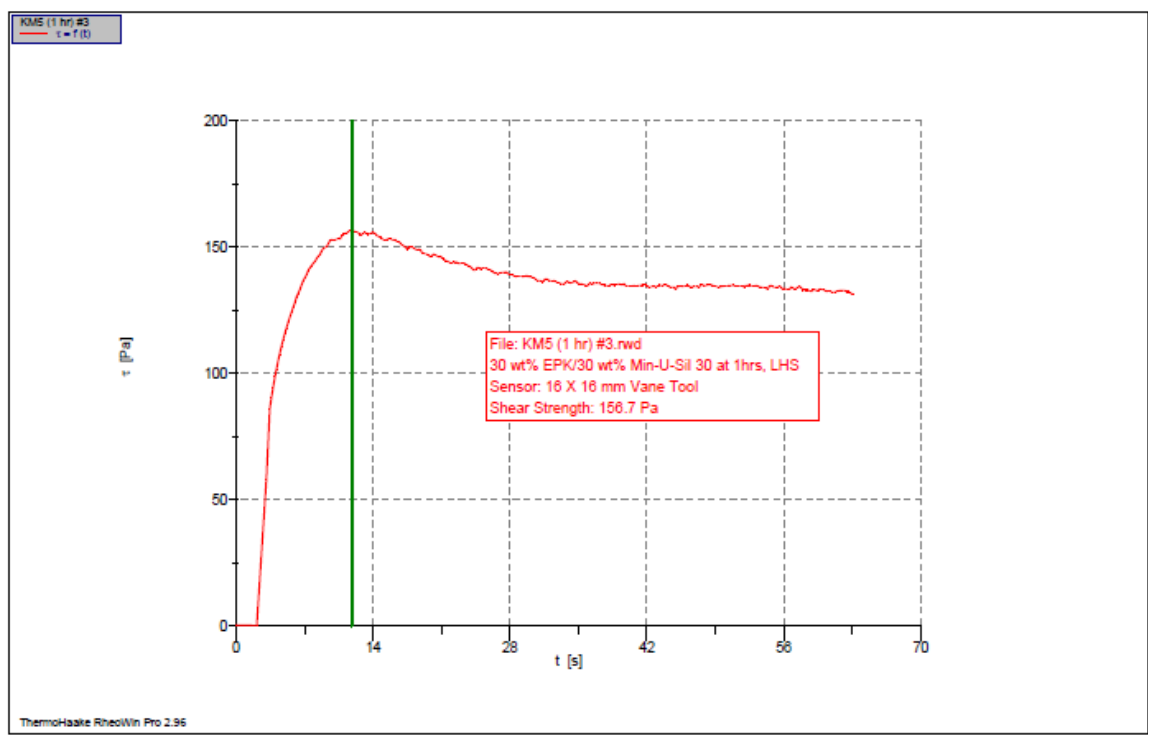

1: C:IK -Basin Rheol05272010खKM5 (1 hr) \#3.rwd

Companv / Operator: PNNL / Jaehun Chun

Date / Time / Version: 27.05.2010 / 15:49:40 PM / RheoWin Pro 296

Substance / Sample no: KM5 (1 hr) \#3 / KM5 (1 hr) \#3

Curve discussion: Greatest value $t[s] 11.84 \tau[\mathrm{Pa}] 156.7$

Figure A.125. $30 \mathrm{wt} \%$ Kaolin Clay/30 wt\% Min-U-Sil 30, LHS Sampling Location (1 hr)

ThermoHaake RheoWin 7/30/2010 / 5:18 PM

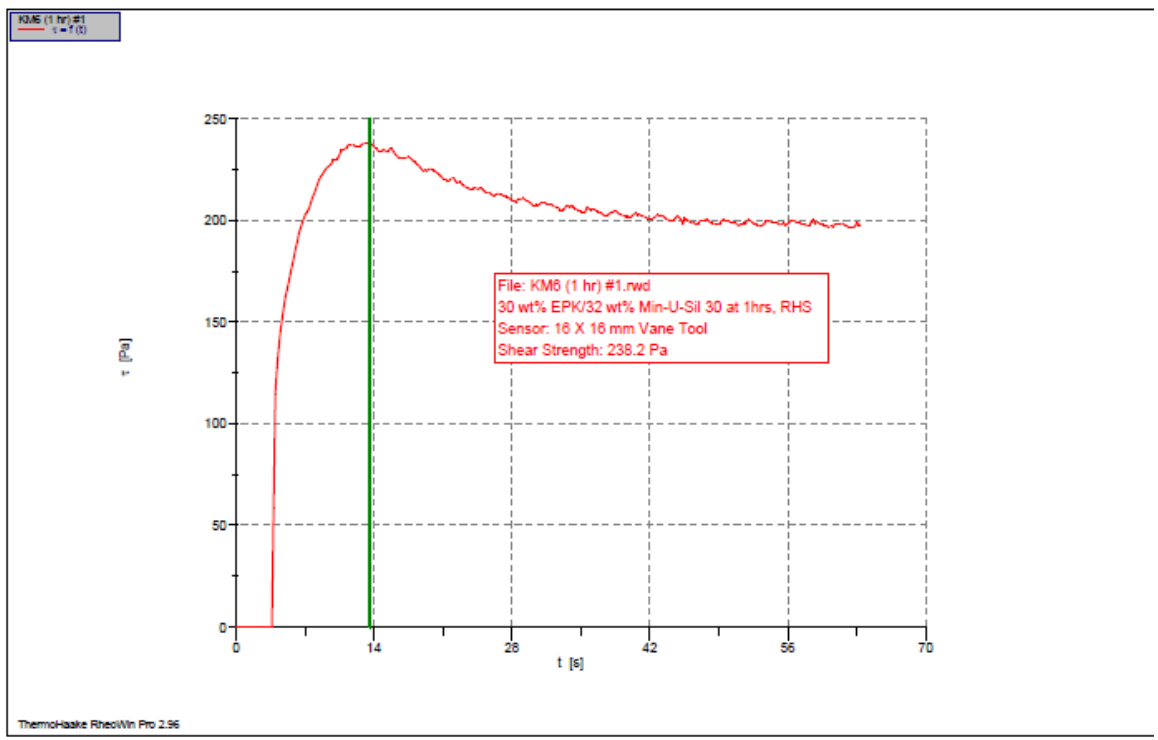

1: C:IK -Basin Rheol05282010KKM6 (1 hr) \#1.rwd

Company / Operator: PNNL / Jaehun Chum

Date / Time / Version: 28.05.2010 / 8:38:30 AM / RheoWin Pro 296

Substance / Sample no: KM6 (1 hr) \#1 / KM6 (1 hr) \#1

Curve discussion: Greatest value $\mathrm{t}[\mathrm{s}] 13.59 \tau[\mathrm{Pa}] 238.2$

Figure A.126. $30 \mathrm{wt} \%$ Kaolin Clay/32 wt $\%$ Min-U-Sil 30, RHS Sampling Location (1 hr) 
ThermoHaake RheoWin 7/30/2010/5:20 PM

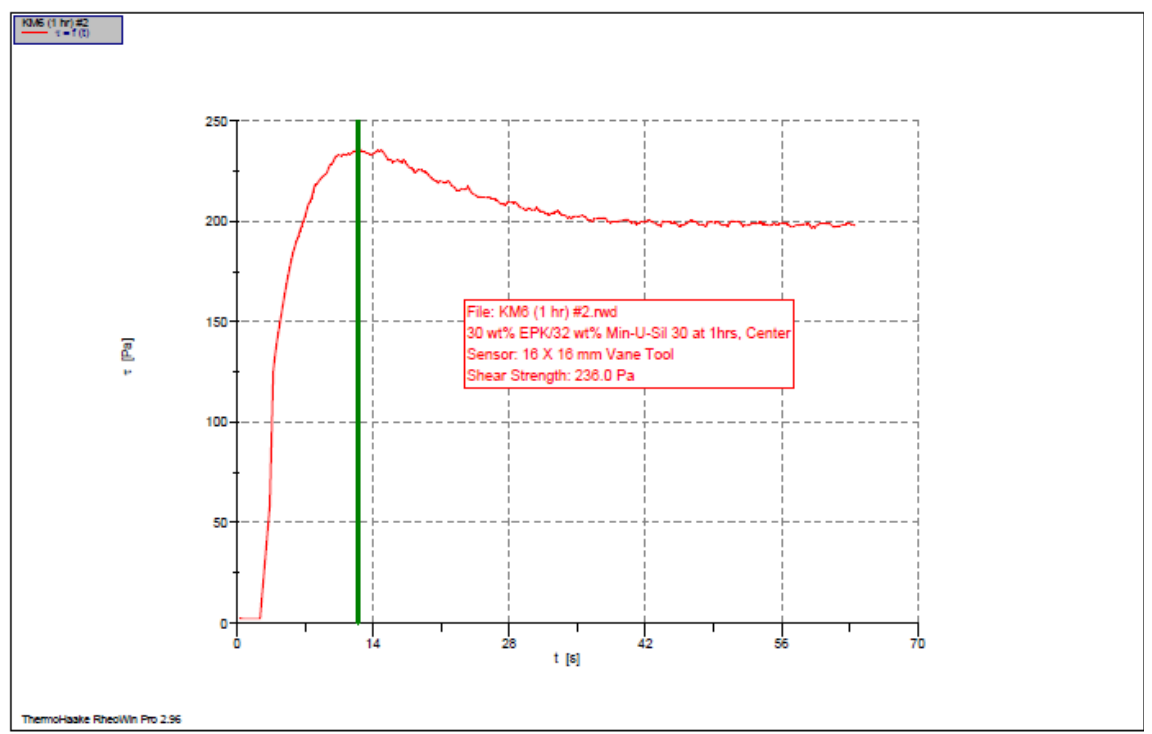

1: C:IK-Basin Rheol05282010 KM 6 (1 hr) \#2.rwd

Companv / Operator: PNNL / Jaehun Chun

Date / Time / Version: 28.05.2010 / 8:41:14 AM / RheoWin Pro 296

Substance / Sample no: KM6 (1 hr) \#2 / KM6 (1 hr) \#2

Curve discussion: Greatest value $\mathrm{t}[\mathrm{s}] 12.47 \tau[\mathrm{Pa}] 236.0$

Figure A.127. 30 wt\% Kaolin Clay/32 wt\% Min-U-Sil 30, Center Sampling Location (1 hr)

ThermoHaake RheoWin 7/30/2010/5:21 PM

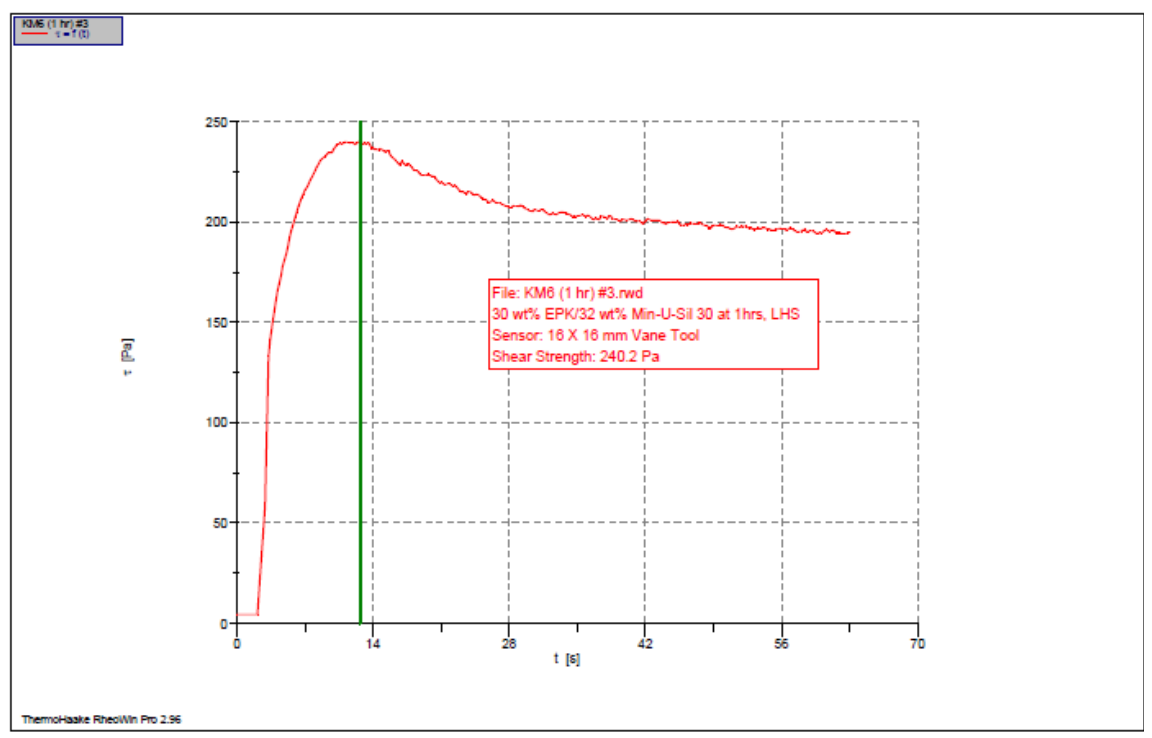

1: C:IK-Basin Rheol05282010VKM6 (1 hr) \#3.rwd

Companv / Operator: PNNL/Jaehun Chun

Date / Time/Version: 28.05.2010/8.43.55 AM / RheoWin Pro 296

Substance / Sample no: KM6 (1 hr) \#3 / KM6 (1 hr) \#3

Curve discussion: Greatest value $\mathrm{t}[\mathrm{s}] 12.67 \tau[\mathrm{Pa}] 240.2$

Figure A.128. $30 \mathrm{wt} \%$ Kaolin Clay $/ 32 \mathrm{wt} \%$ Min-U-Sil 30, LHS Sampling Location (1 hr) 


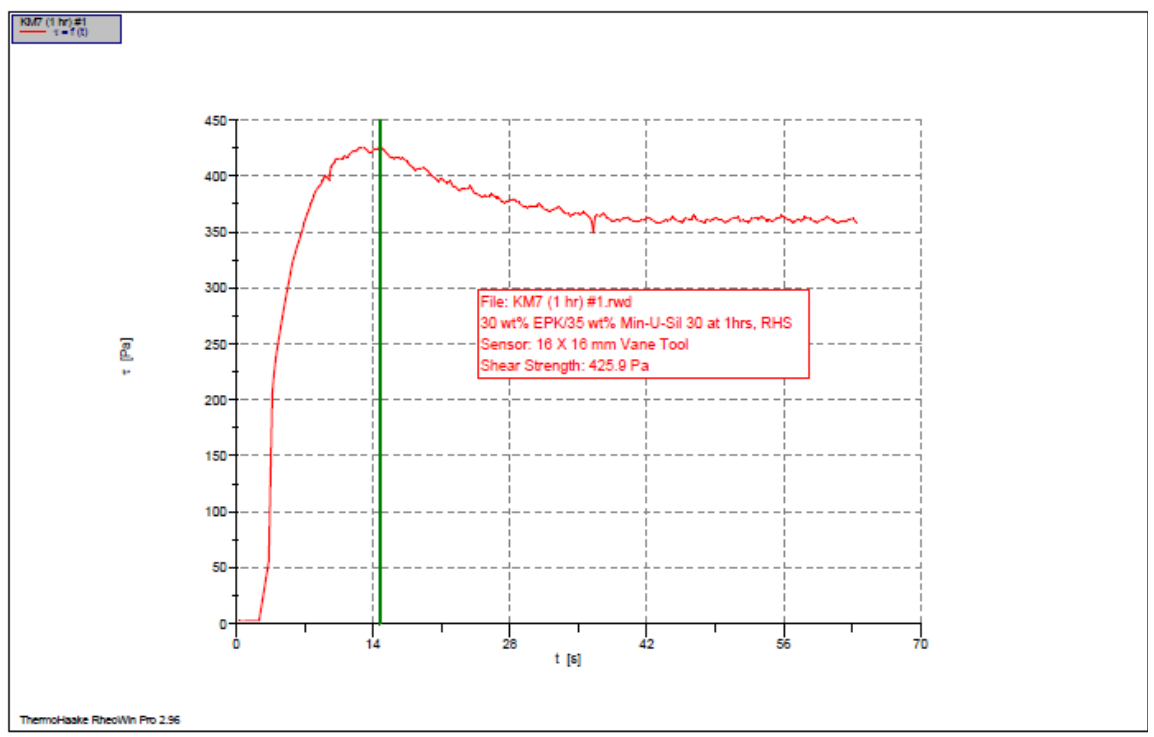

1: C:IK-Basin Rheol05282010ไKM7 (1 hr) \#1.rwd

Company / Operator: PNNL / Jaehun Chun

Date / Time / Version: 28.05.2010 / 9:00:25 AM / RheoWin Pro 296

Substance / Sample no: KM7 (1 hr) \#1 / KM7 (1 hr) \#1

Curve discussion: Greatest value $\mathrm{t}[\mathrm{s}] 14.69 \tau[\mathrm{Pa}] 425.9$

Figure A.129. 30 wt \% Kaolin Clay $/ 35$ wt $\%$ Min-U-Sil 30, RHS Sampling Location (1 hr)

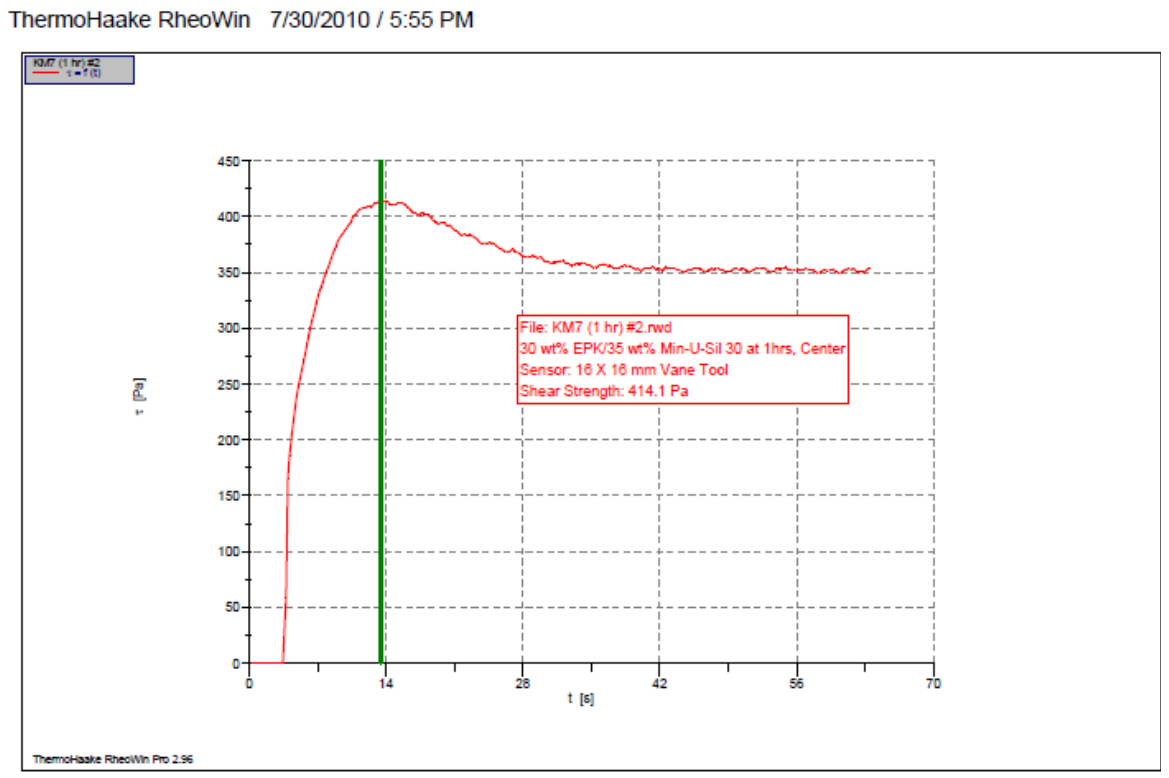

1: C:IK-Basin Rheol05282010KKM7 (1 hr) \#2.rwd

Companv / Operator: PNNL / Jaehun Chun

Date / Time/Version: 28.05.2010/9.03.51 AM / RheoWin Pro 296

Substance / Sample no: KM7 (1 hr) \#2 / KM7 (1 hr) \#2

Curve discussion: Greatest value $\mathrm{t}[\mathrm{s}] 13.51 \tau[\mathrm{Pa}] 414.1$

Figure A.130. 30 wt $\%$ Kaolin Clay $/ 35$ wt\% Min-U-Sil 30, Center Sampling Location (1 hr) 


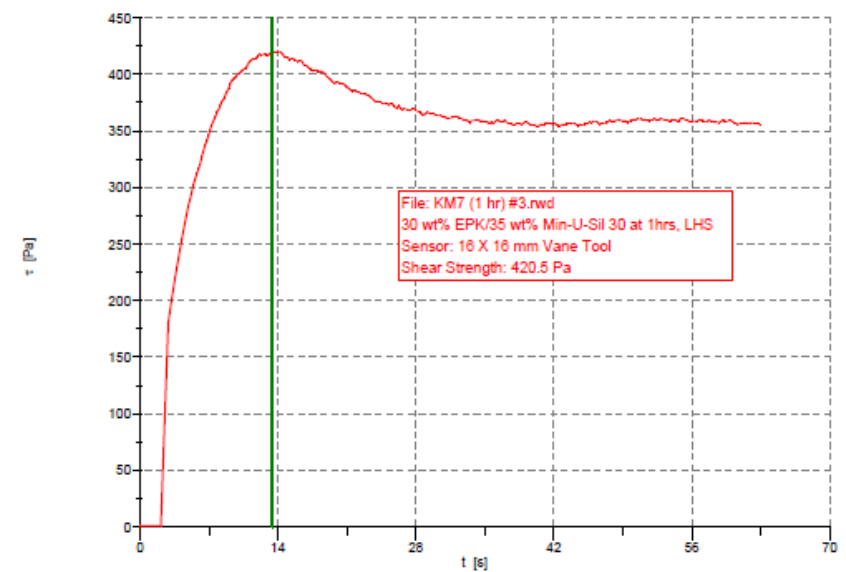

1: C:MK-Basin Rheol05282010KKM7 (1 hr) \#3.rwd Companv / Operator: PNNL / Jaehun Chun

Date / Time / Version: 28.05.2010 / 9.07.00 AM / RheoWin Pro 296

Substance/ Sample no: KM7 (1 hr) \#3 / KM7 (1 hr) \#3

Curve discussion: Greatest value $t[s] 13.40 \tau[\mathrm{Pa}] 420.5$

Figure A.131. $30 \mathrm{wt} \%$ Kaolin Clay/35 wt\% Min-U-Sil 30, LHS Sampling Location (1 hr)

ThermoHaake RheoWin 7/30/2010/5:57 PM

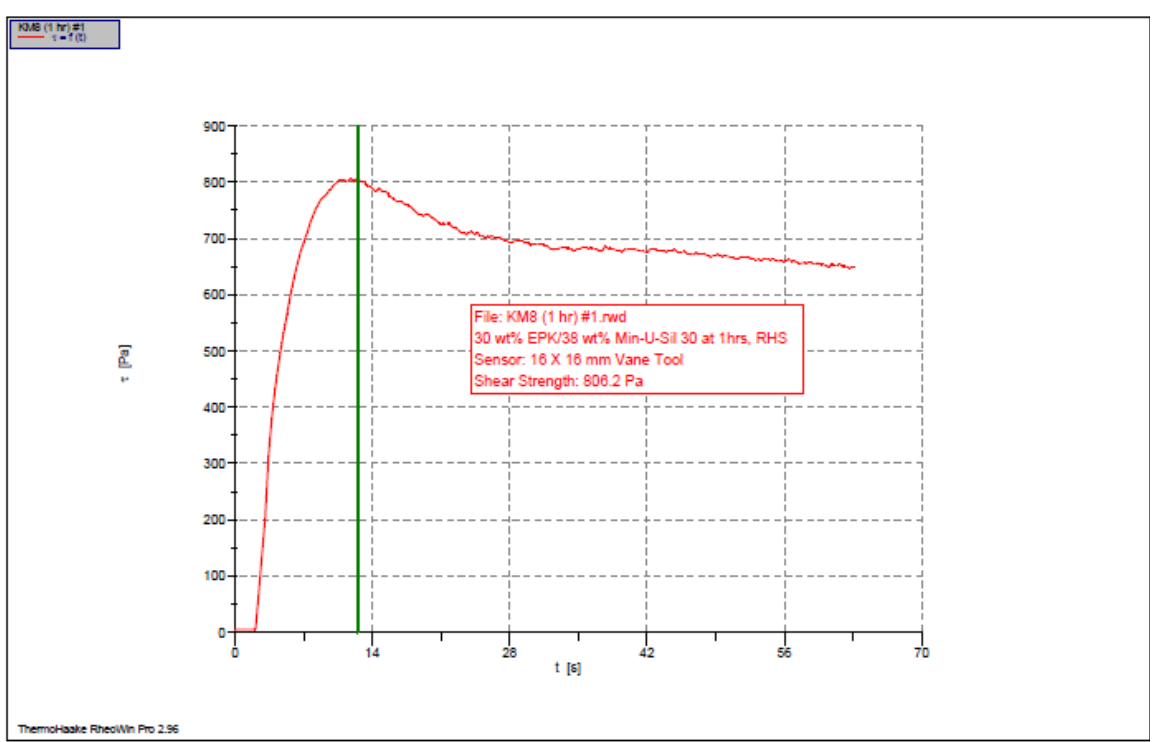

1: C:IK-Basin Rheol05282010KKM8 (1 hr) \#1.rwd

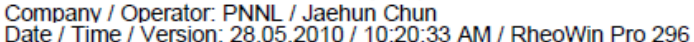

Substance / Sample no: KM8 (1 hr) \#1 / KM8 (1 hr) \#1

Curve discussion: Greatest value $\mathrm{t}[\mathrm{s}] 12.50 \tau[\mathrm{Pa}] 806.2$

Figure A.132. $30 \mathrm{wt} \%$ Kaolin Clay $/ 38 \mathrm{wt} \%$ Min-U-Sil 30, RHS Sampling Location $(1 \mathrm{hr})$ 


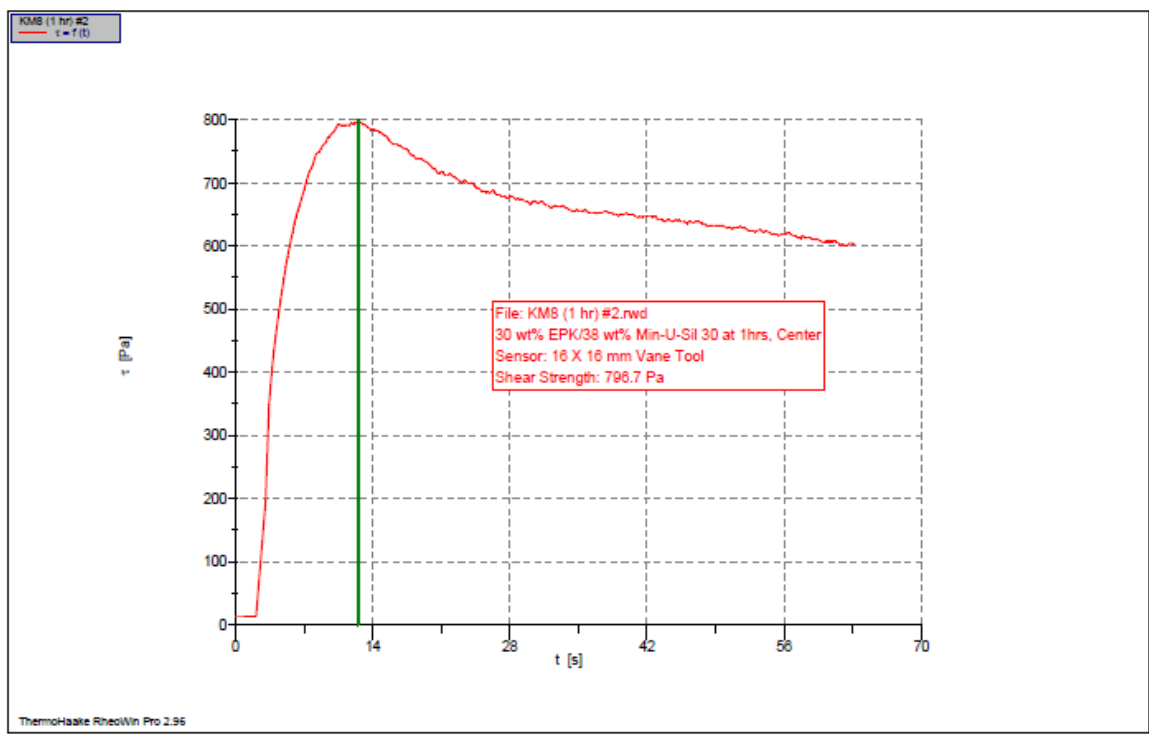

1: C:IK -Basin Rheol05282010 KM 8 (1 hr) \#2.rwd

Company / Operator: PNNL / Jaehun Chun

Date / Time / Version: 28.05.2010/10:23:37 AM / RheoWin Pro 296

Substance / Sample no: KM8 (1 hr) \#2/ KM8 (1 hr) \#2

Curve discussion: Greatest value $t[s] 12.50 \tau[\mathrm{Pa}] 796.7$

Figure A.133. 30 wt $\%$ Kaolin Clay/38 wt\% Min-U-Sil 30, Center Sampling Location (1 hr)

ThermoHaake RheoWin 7/30/2010 / 6:01 PM

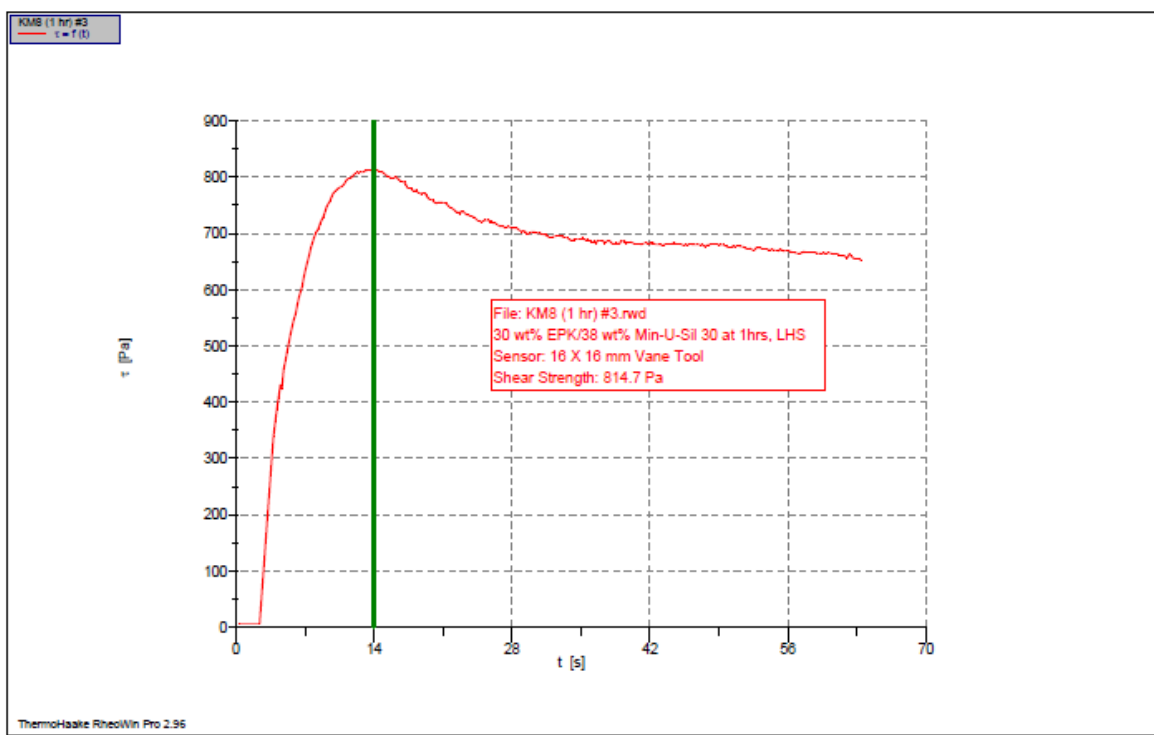

1: C:IK-Basin Rheol05282010IKM8 (1 hr) \#3.rwd

Companv / Operator: PNNL / Jaehun Chun

Date / Time / Version: 28.05.2010 / 10:27:09 AM / RheoWin Pro 296

Substance / Sample no: KM8 (1 hr) \#3 / KM8 (1 hr) \#3

Curve discussion: Greatest value $\mathrm{t}[\mathrm{s}] 14.02 \tau[\mathrm{Pa}] 814.7$

Figure A.134. 30 wt \% Kaolin Clay/38 wt\% Min-U-Sil 30, LHS Sampling Location (1 hr) 


\section{A.6.6 Kaolin/Min-U-Sil 30 Simulants Used in the 10-in.-Diameter Vessel}

ThermoHaake RheoWin 9/16/2010 / 8:49 AM

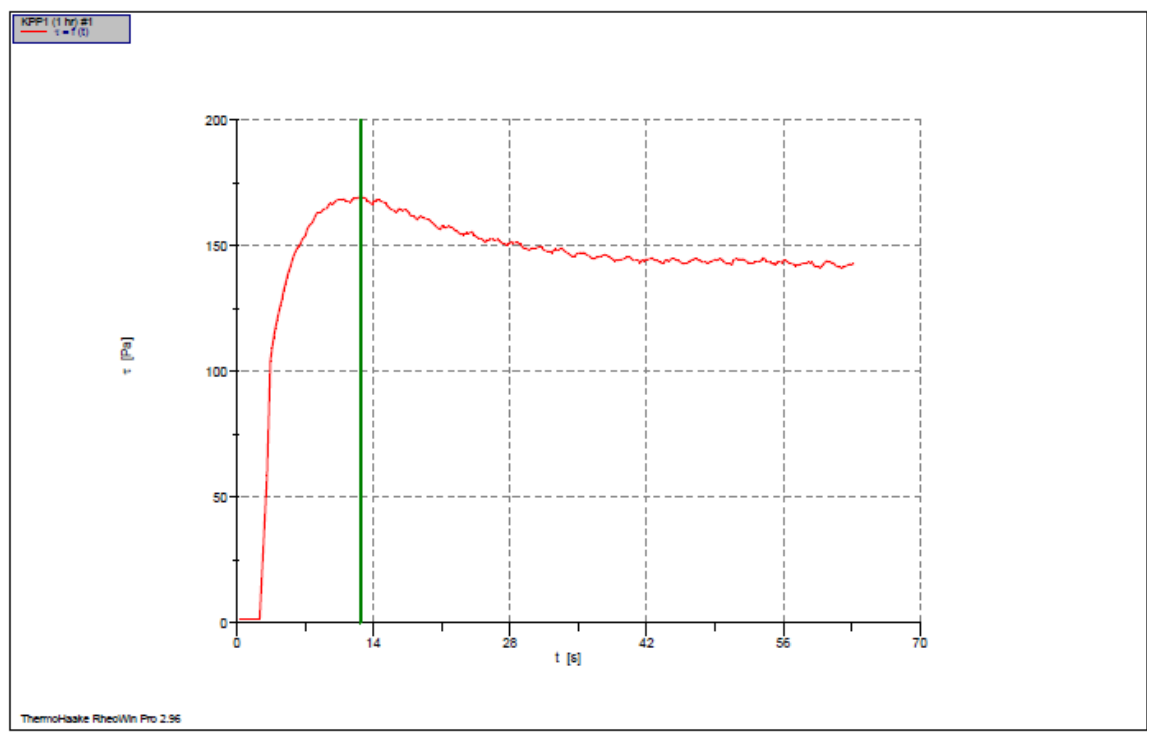

1: C:IK -Basin Rheol06022010KKPP1 (1 hr) \#1.rwd

Companv / Operator: PNNL / Jaehun Chun

Date / Time / Version: 02.06.2010/11:35:13 AM / RheoWin Pro 296

Substance / Sample no: KPP1 (1 hr ) \#1 / KPP1 (1 hr) \#1

Curve discussion: Greatest value $\mathrm{t}[\mathrm{s}] 12.69 \tau[\mathrm{Pa}] 169.6$

Figure A.135. $40-w t \%$ Kaolin/16 wt \% Min-U-Sil Clay, RHS Sampling Location

ThermoHaake RheoWin 9/16/2010 / 8:56 AM

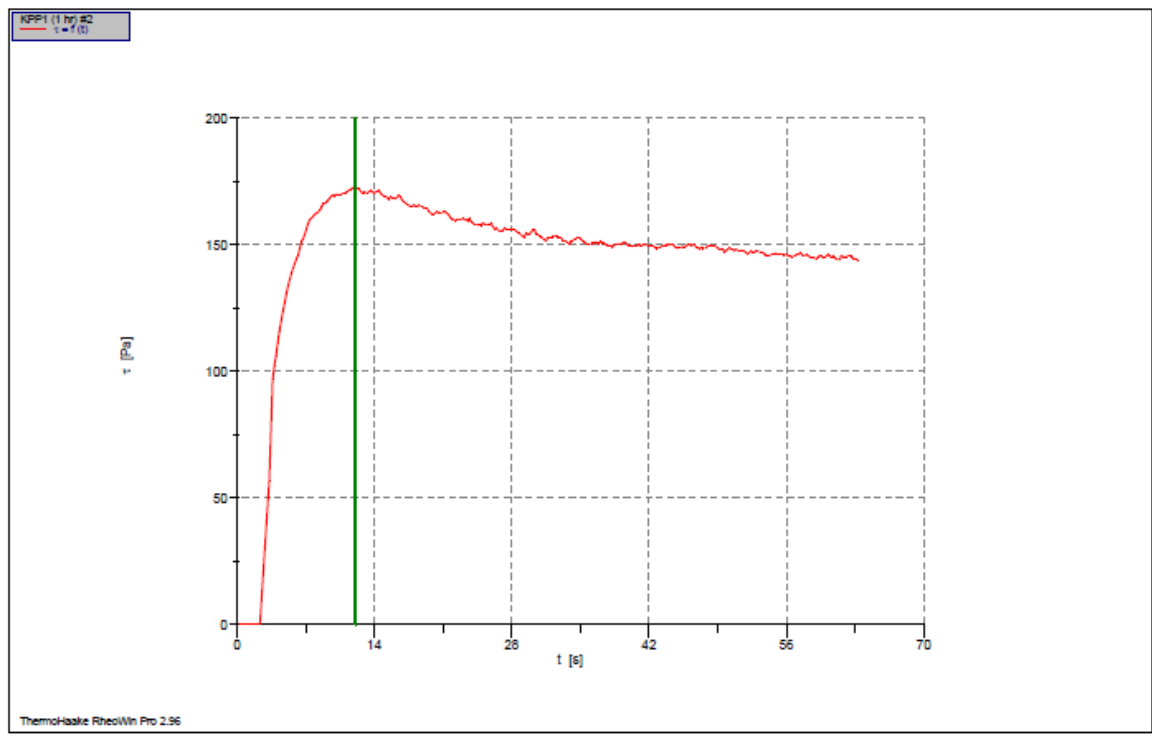

1: C:IK -Basin Rheol060220101KPP1 (1 hr) \#2.rwd

Company / Operator: PNNL / Jaehun Chun

Date / Time / Version: 02.06.2010 / 11:38:19 AM / RheoWin Pro 296

Substance / Sample no: KPP1 (1 hr ) \#2 / KPP1 (1 hr) \#2

Curve discussion: Greatest value $t[s] 12.06 \tau[\mathrm{Pa}] 172.6$

Figure A.136. $40-w t \%$ Kaolin/16 wt \% Min-U-Sil Clay, Center Sampling Location 
ThermoHaake RheoWin 9/16/2010 / 8:56 AM

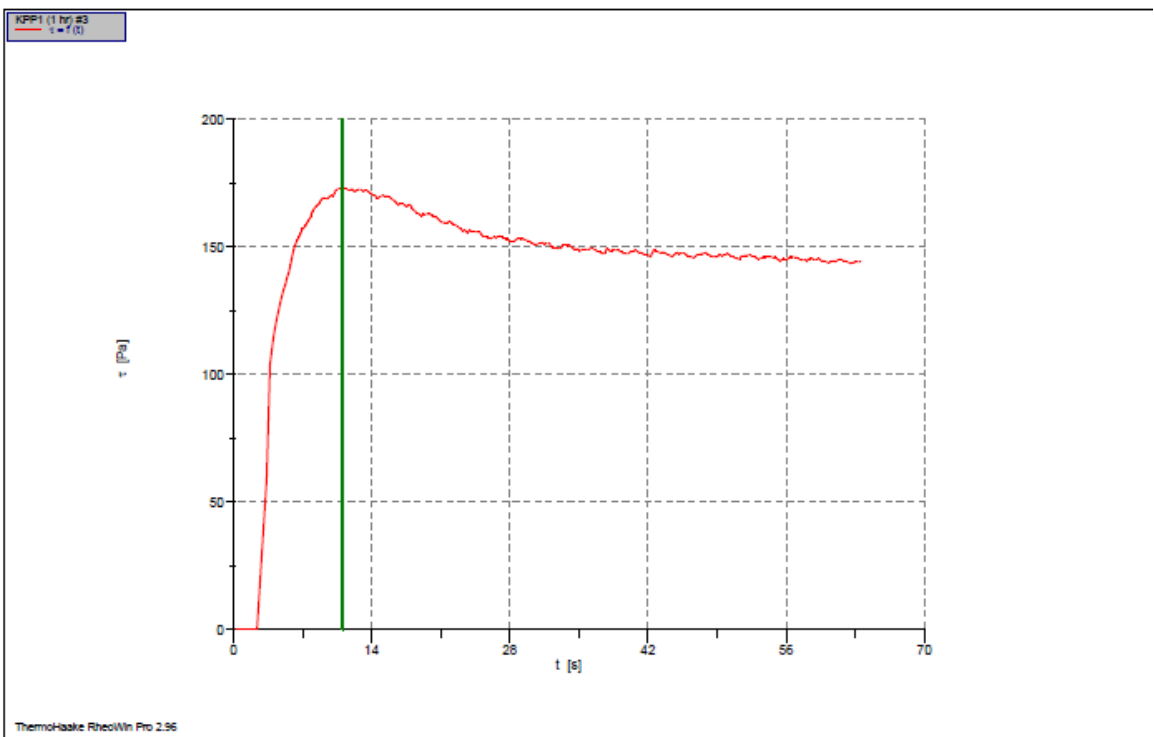

1: C:IK-Basin Rheol06022010KKPP1 (1 hr) \#3.rwd Companv / Operator: PNNL / Jaehun Chun

Date / Time / Version: 02.06.2010 / 11:41:53 AM / RheoWin Pro 296

Substance / Sample no: KPP1 (1 hr ) \#3 / KPP1 (1 hr) \#3

Curve discussion: Greatest value $t[s] 11.07 \tau[\mathrm{Pa}] 173.1$

Figure A.137. 40-wt \% Kaolin/16 wt \% Min-U-Sil Clay, LHS Sampling Location

ThermoHaake RheoWin 9/16/2010/8:57 AM

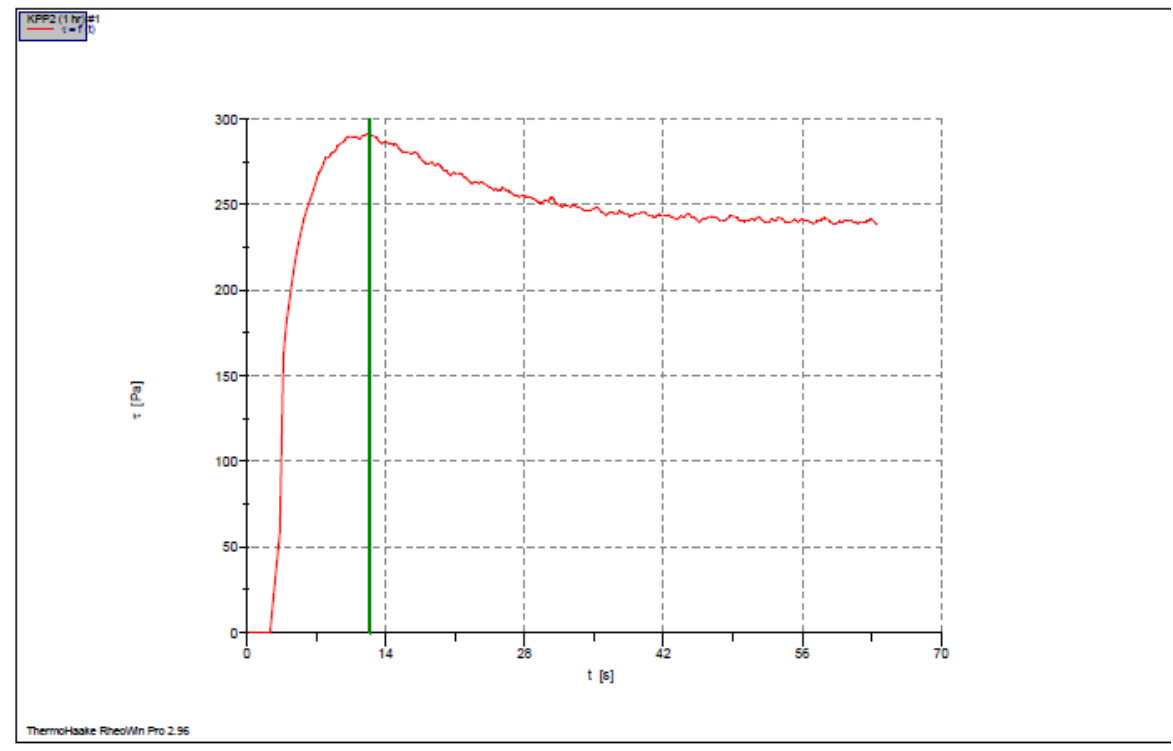

1: C:IK-Basin Rheol06022010KKPP2 (1 hr) \#1.rwd

Companv / Operator: PNNL / Jaehun Chun

Date / Time / Version: 02.06.2010 / 13:26:56 PM / RheoWin Pro 296

Substance / Sample no: KPP2 (1 hr ) \#1 / KPP2 (1 hr) \#1

Curve discussion: Greatest value $\mathrm{t}[\mathrm{s}] 12.42 \tau[\mathrm{Pa}] 291.4$

Figure A.138. $40-w t \%$ Kaolin/19 wt \% Min-U-Sil Clay, RHS Sampling Location 
ThermoHaake RheoWin 9/16/2010/8:57 AM

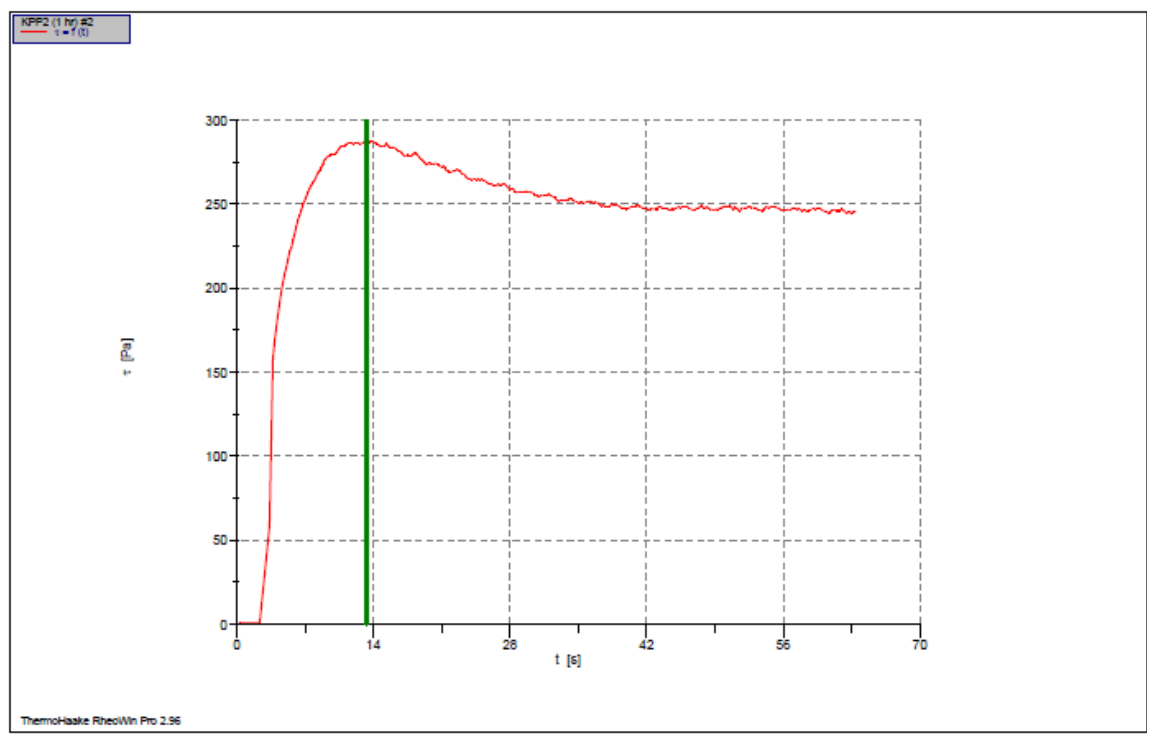

1: C:IK -Basin Rheol06022010KKPP2 (1 hr) \#2.rwd

Company / Operator: PNNL / Jaehun Chun

Date / Time / Version: 02.06.2010 / 13:29:49 PM / RheoWin Pro 296

Substance / Sample no: KPP2 (1 hr ) \#2 / KPP2 (1 hr) \#2

Curve discussion: Greatest value $\mathrm{t}[\mathrm{s}] 13.29 \tau[\mathrm{Pa}] 288.3$

Figure A.139. $40-w t \%$ Kaolin/19 wt \% Min-U-Sil Clay, Center Sampling Location

ThermoHaake RheoWin 9/16/2010/8:58 AM

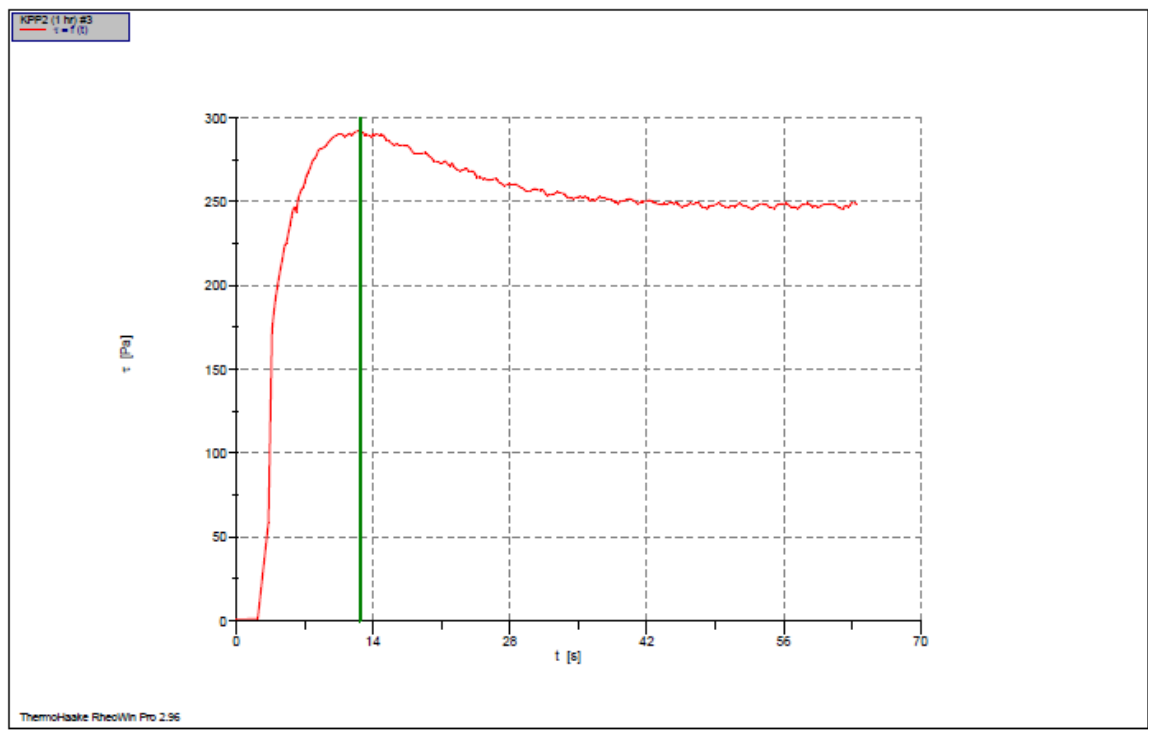

1: C:IK-Basin Rheol06022010UKPP2 (1 hr) \#3.rwd

Companv / Operator: PNNL / Jaehun Chun

Date/ Time/Version. 02.06.2010/13.32:44 PM / RheoWin Pro 296

Substance / Sample no: KPP2 (1 hr ) \#3 / KPP2 (1 hr) \#3

Curve discussion: Greatest value $\mathrm{t}[\mathrm{s}] 12.67 \tau[\mathrm{Pa}] 292.1$

Figure A.140. $40-w t \%$ Kaolin/19 wt \% Min-U-Sil Clay, LHS Sampling Location 


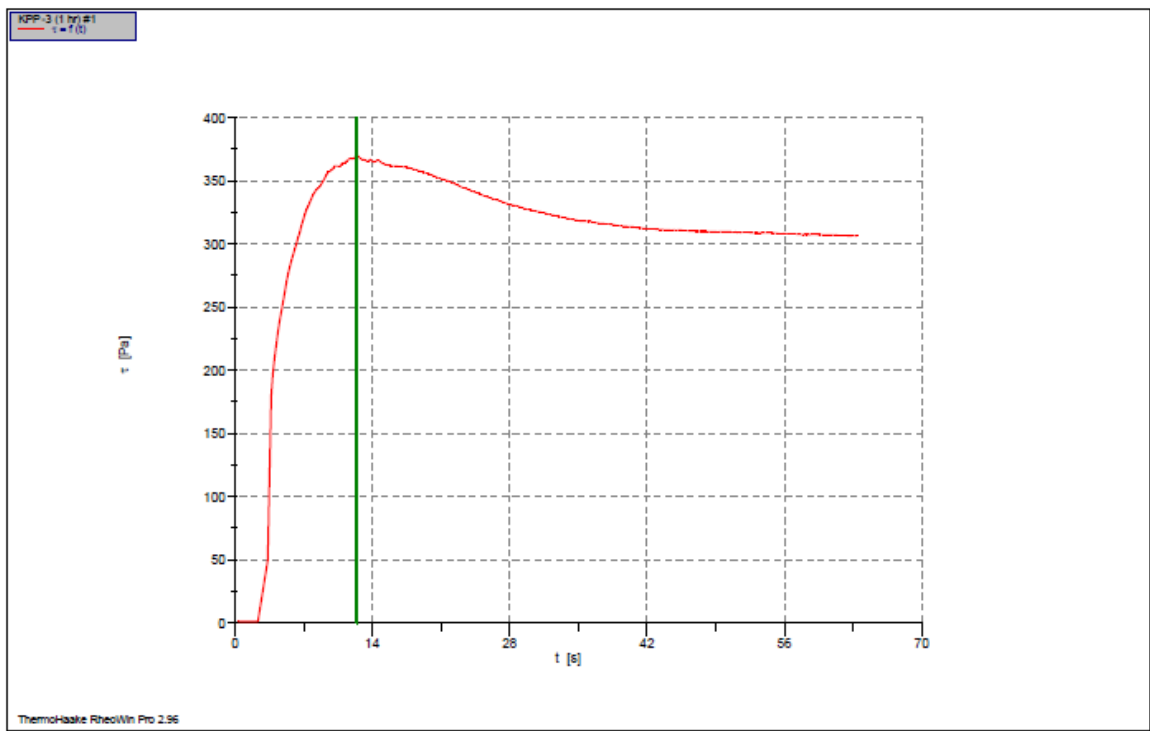

1: C:IK-Basin Rheol06092010KKPP -3 (1 hr) \#1.rwd

Companv / Operator: PNNL / Jaehun Chun

Date / Time / Version: 09.06.2010 / 12:35:40 PM / RheoWin Pro 296

Substance / Sample no: KPP -3 (1 hr) \#1/ KPP -3 (1 hr) \#1

Curve discussion: Greatest value $\mathrm{t}[\mathrm{s}] 12.41 \tau[\mathrm{Pa}] 370.1$

Figure A.141. $40-w t \%$ Kaolin/20.5 wt \% Min-U-Sil Clay, RHS Sampling Location

ThermoHaake RheoWin 9/16/2010/9:00 AM

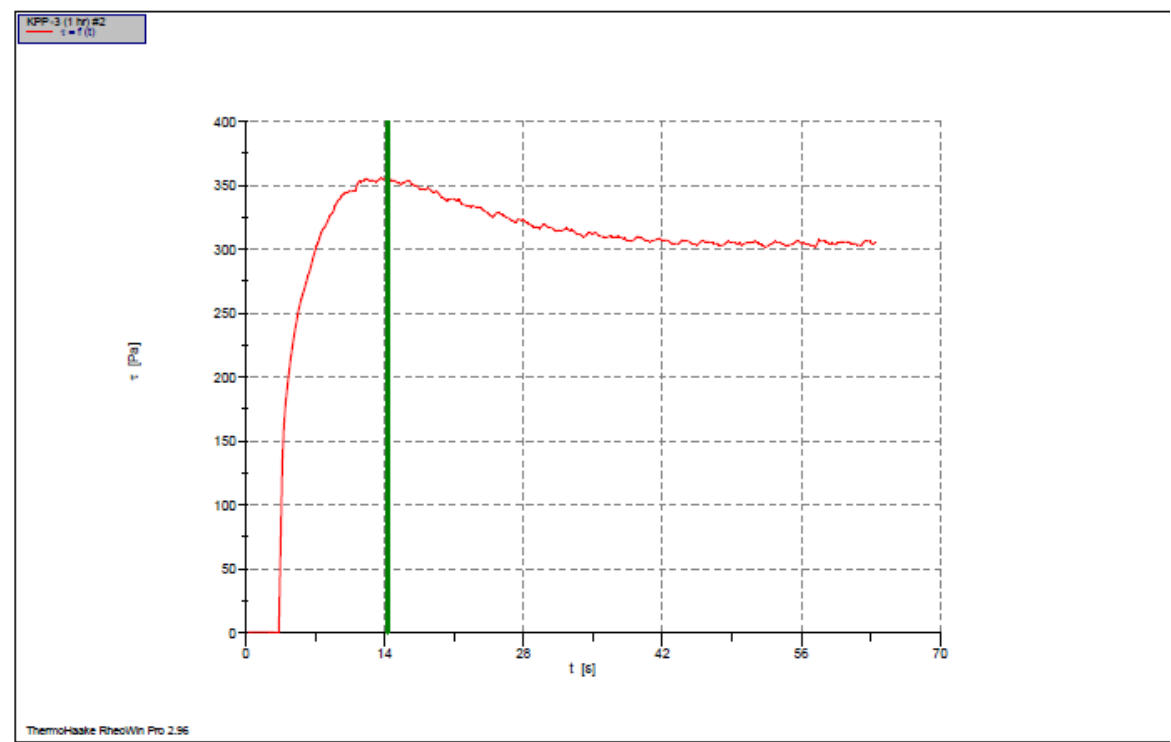

1: C:IK-Basin Rheol06092010 KKPP -3 (1 hr) \#2.rwd

Companv / Operator: PNNL / Jaehun Chun

Substance/ Semplo

Substance / Sample no: KPP -3 (1 hr) \#2 / KPP -3 (1 hr) \#2

Curve discussion: Greatest value $t[s] 14.31 \tau[\mathrm{Pa}] 356.1$

Figure A.142. 40-wt\% Kaolin/20.5 wt \% Min-U-Sil Clay, Center Sampling Location 
ThermoHaake RheoWin 9/16/2010 / 9:01 AM

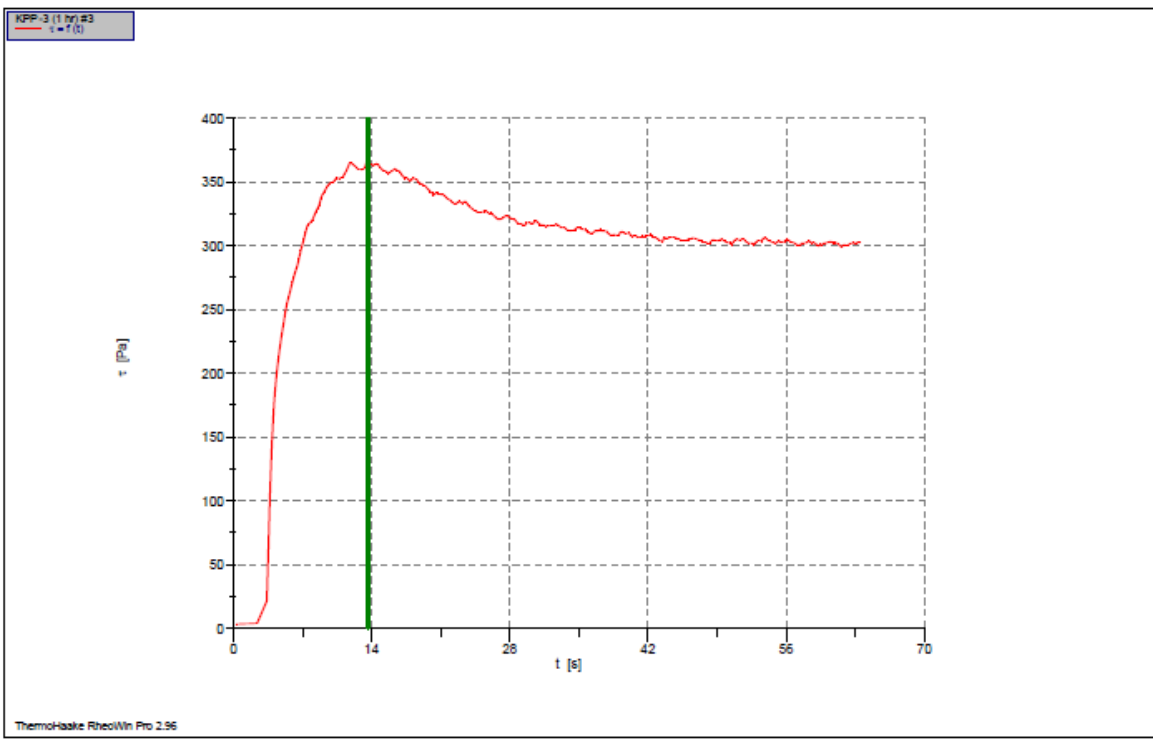

1: C:IK-Basin Rheol060920104KPP -3 (1 hr) \#3.rwd Companv / Operator: PNNL / Jaehun Chun

Date / Time / Version: 09.06.2010 / 12:42:14 PM / RheoWin Pro 296

Substance / Sample no: KPP -3 (1 hr) \#3 / KPP -3 (1 hr) \#3

Curve discussion: Greatest value $t[s] 13.65 \tau[\mathrm{Pa}] 365.1$

Figure A.143. $40-w t \%$ Kaolin/20.5 wt \% Min-U-Sil Clay, LHS Sampling Location

ThermoHaake RheoWin 8/5/2010/ 2:03 PM

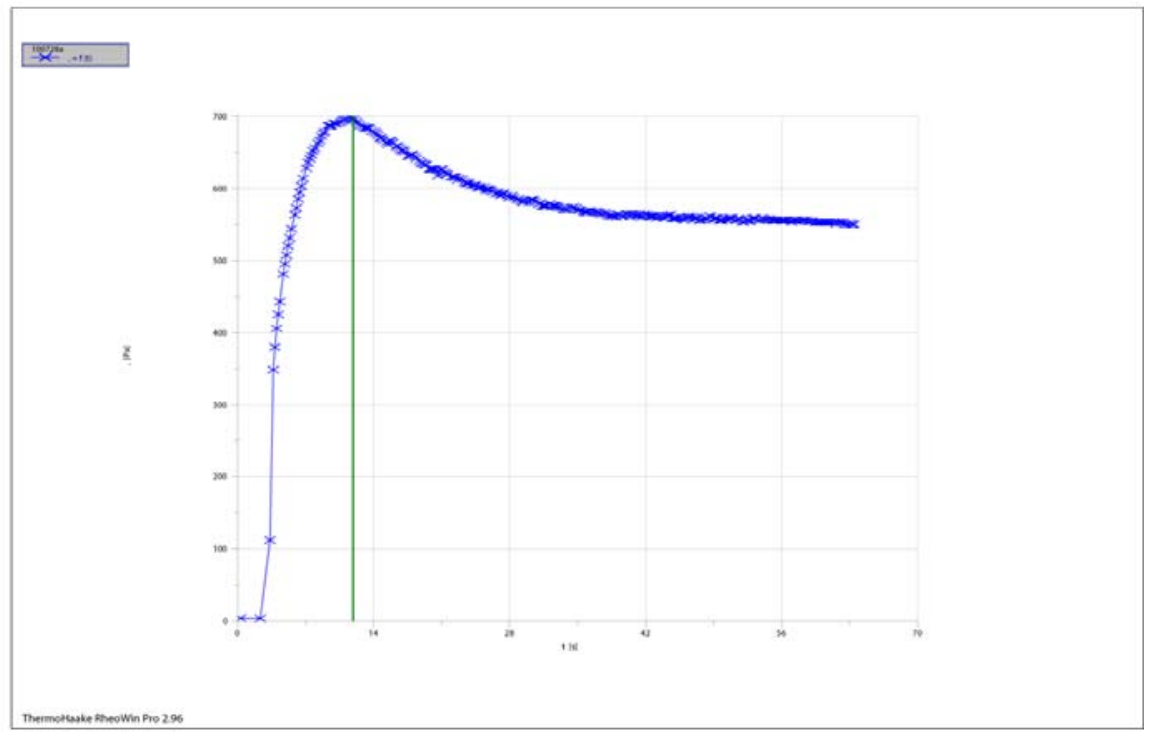

1: C:IProqram Files\RheoWin\Data\Bill\KBasin Rheo\100728a.rwd Company / Operator: PNNL / WC Buchmiller

Date / Time / Version: 28.07.2010 / 13:50:38 PM / RheoWin Pro 296

Substance / Sample no: KPP-4 / 100728a

Curve discussion: Greatest value $\mathrm{t}[\mathrm{s}] 11.89,[\mathrm{~Pa}] 697.9$

Figure A.144. 40-wt\% Kaolin/23 wt \% Min-U-Sil Clay, Center Sampling Location 


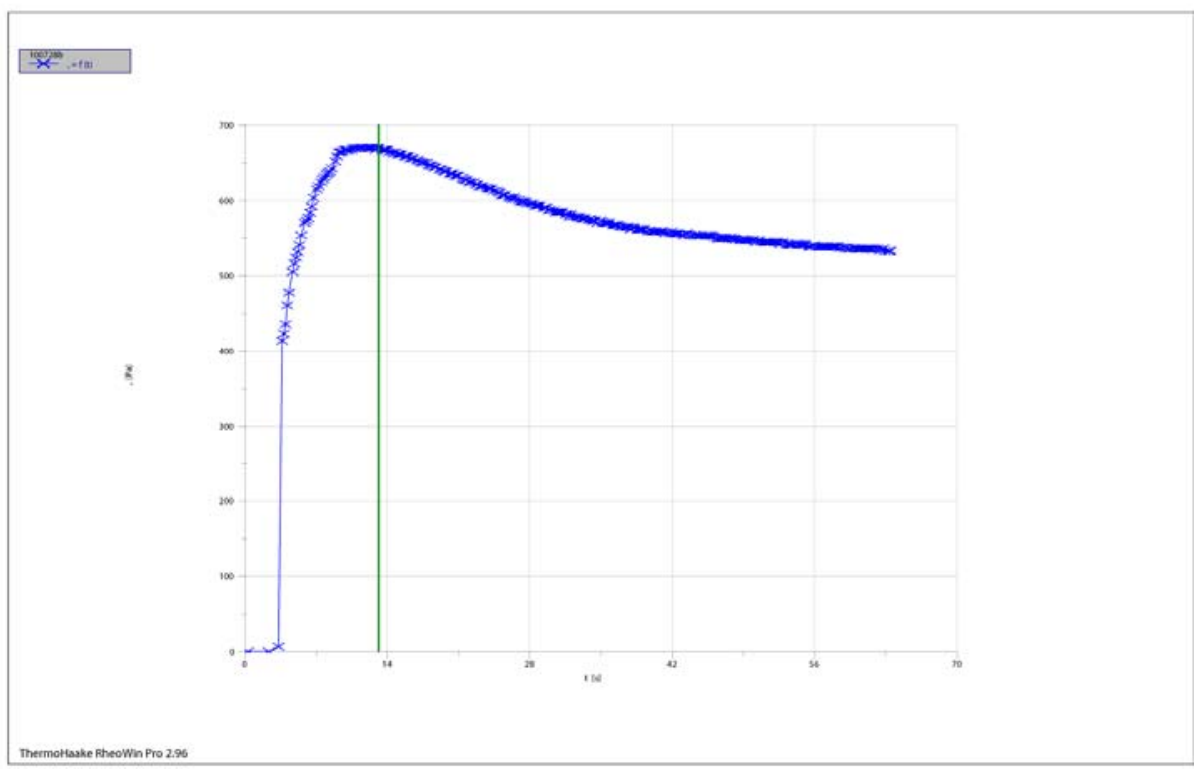

1: C:IProqram Files\RheoWin\Data\Bill\KBasin Rheo\100728b.rwd Company / Operator: PNNL / WC Buchmiller

Date / Time / Version: 28.07.2010 / 14:01:25 PM / RheoWin Pro 296

Substance / Sample no: KPP-4 / $100728 \mathrm{~b}$

Curve discussion: Greatest value $\mathrm{t}[\mathrm{s}] 13.16,[\mathrm{~Pa}] 669.4$

Figure A.145. $40-w t \%$ Kaolin/23 wt \% Min-U-Sil Clay, RHS Sampling Location ThermoHaake RheoWin 8/5/2010/2:06 PM

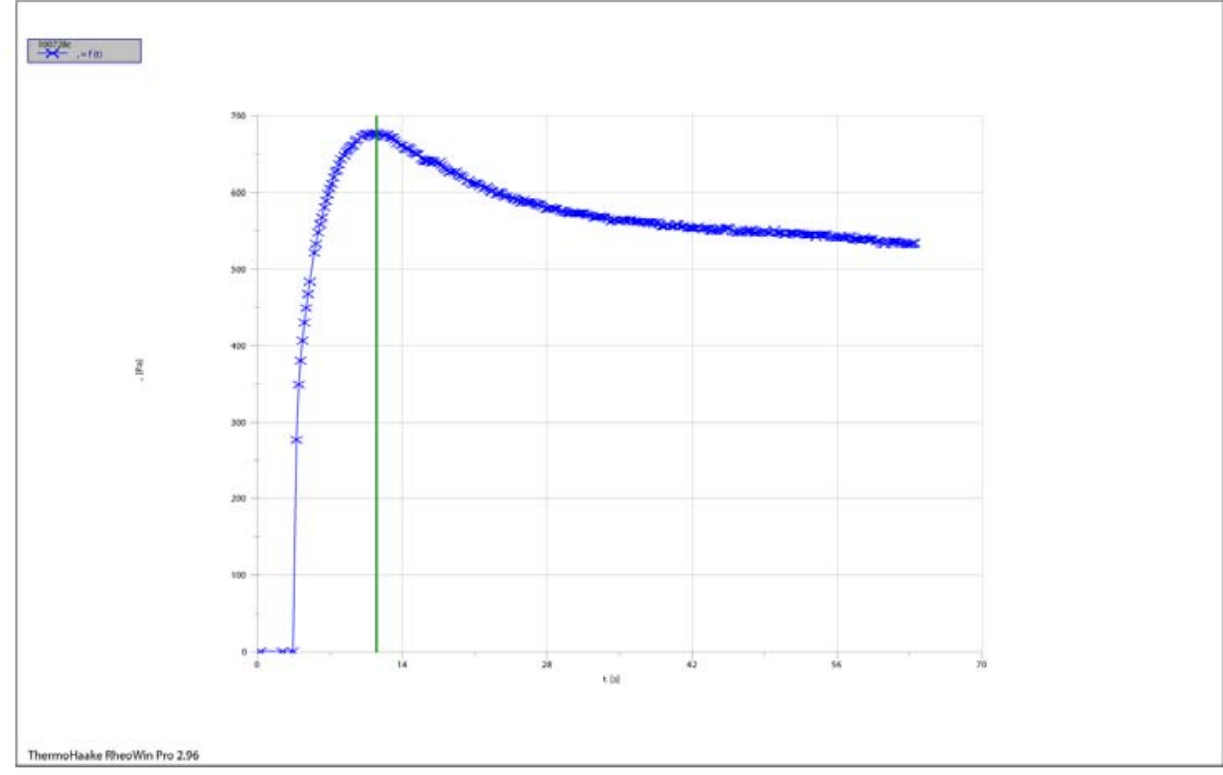

1: C:\Proqram Files\RheoWin\Data\Bill\KBasin Rheo\100728c.rwd Company / Operator: PNNL / WC Buchmiller

Date / Time / Version: 28.07.2010 / 14:08:47 PM / RheoWin Pro 296

Substance / Sample no: KPP-4 / 100728c

Curve discussion: Greatest value $\mathrm{t}[\mathrm{s}] 11.52$, $[\mathrm{Pa}] 677.0$

Figure A.146. $40-w t \%$ Kaolin/23 wt \% Min-U-Sil Clay, LHS Sampling Location 


\section{A.6.7 KW Container Simulant (Complete) (KW-A)}

ThermoHaake RheoWin 7/31/2010/10:46 PM

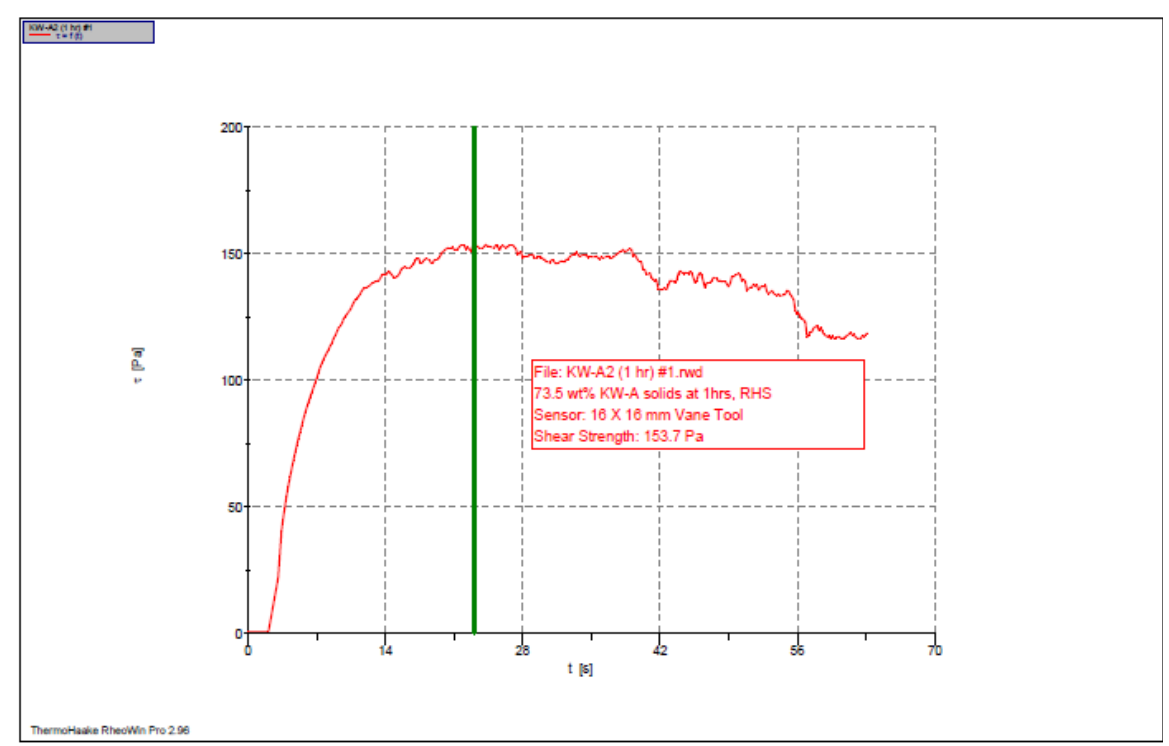

1: C:IK -Basin Rheol06032010KKW-A2 (1 hr) \#1.rwd

Companv / Operator: PNNL / Jaehun Chun

1.55 PM / RheoWin Pro 296

Substance / Sample no: KW -A2 (1 hr)\#1/ KW-A2 (1 hr) \#1

Curve discussion: Greatest value $\mathrm{t}[\mathrm{s}] 23.05 \tau[\mathrm{Pa}] 153.7$

Figure A.147. $73.5 \mathrm{wt} \% \mathrm{KW}$-A Solids, RHS Sampling Location (1 hr)

ThermoHaake RheoWin 7/31/2010/10:48 PM

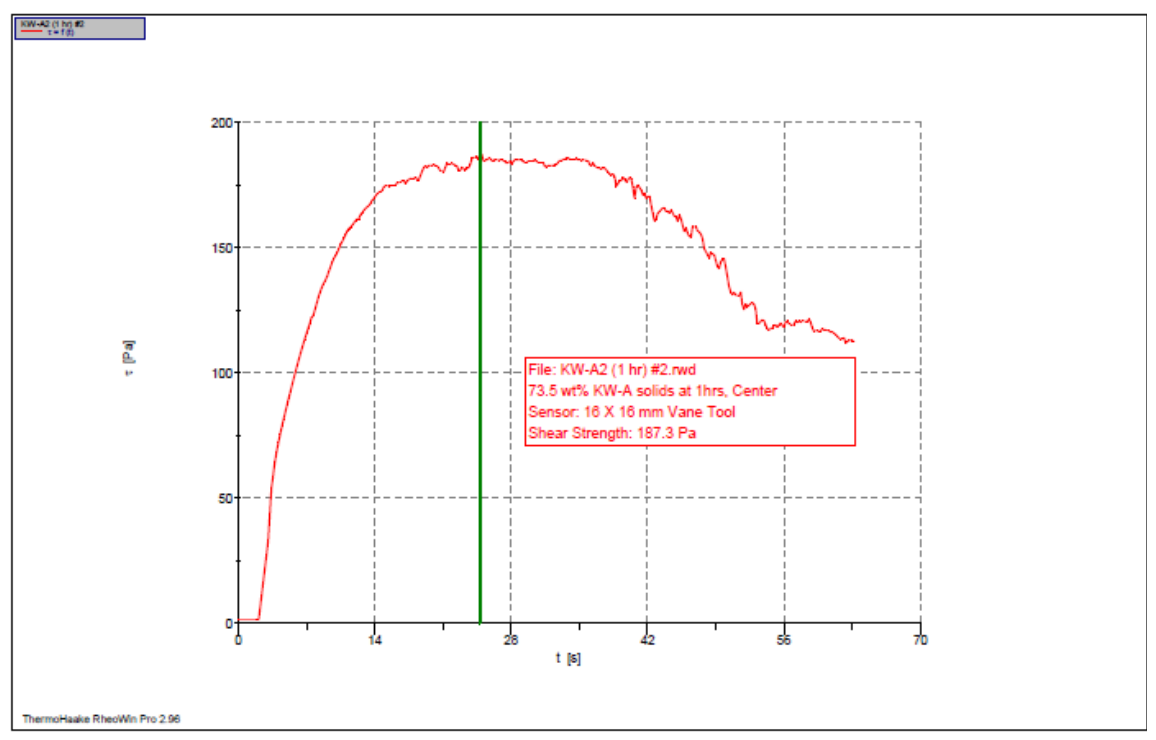

1: C:IK-Basin Rheol06032010 KKW-A2 (1 hr) \#2.rwd

Companv/ Operator: PNNL / Jaehun Chun

Date / Time / Version: 03.06.2010/13:36:34 PM / RheoWin Pro 296

Substance / Sample no: KW-A2 (1 hr) \#2 / KW-A2 (1 hr) \#2

Curve discussion: Greatest value $\mathrm{t}[\mathrm{s}] 24.82 \tau[\mathrm{Pa}] 187.3$

Figure A.148. 73.5 wt $\%$ KW-A Solids, Center Sampling Location (1 hr) 


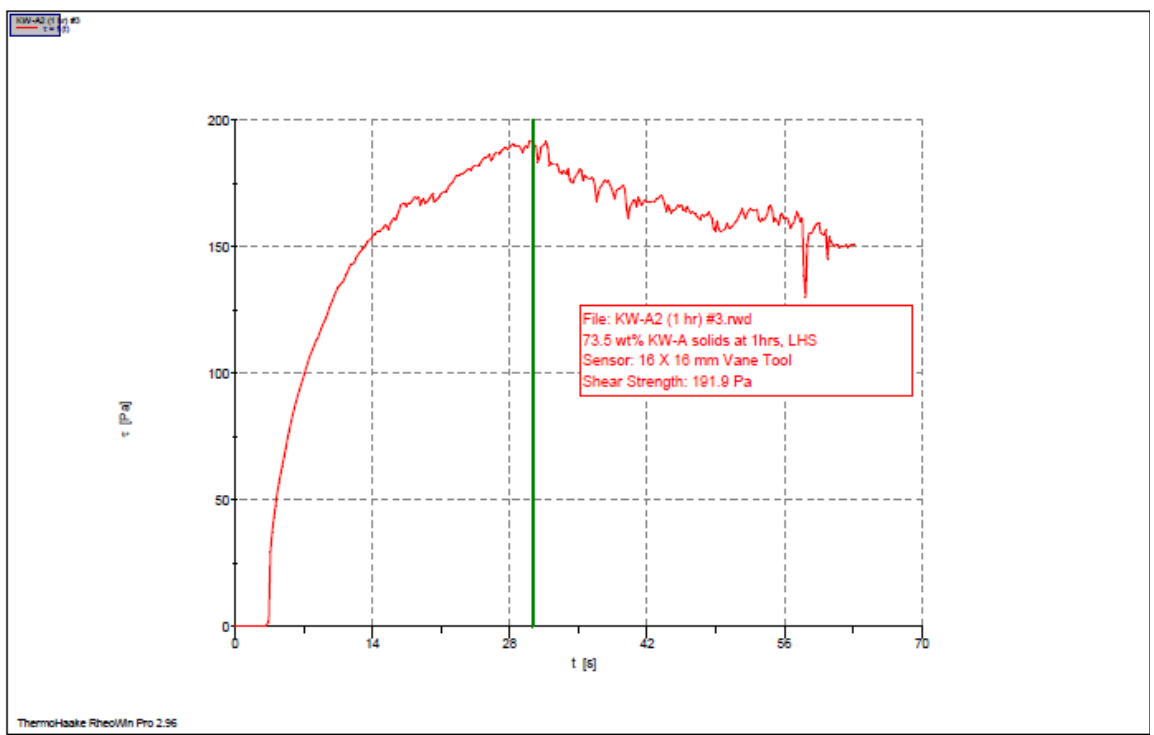

1: C:IK-Basin Rheol06032010 KKW -A2 (1 hr) \#3.rwd Companv / Operator: PNNL / Jaehun Chun

me / Version: 03.06.2010 / 13:39:42 PM / RheoWin Pro 296

Substance / Sample no: KW-A2 (1 hr) \#3 / KW -A2 (1 hr) \#3

Curve discussion: Greatest value $t[s] 30.36 \tau[\mathrm{Pa}] 191.9$

Figure A.149. $73.5 \mathrm{wt} \% \mathrm{KW}-\mathrm{A}$ Solids, LHS Sampling Location $(1 \mathrm{hr})$

ThermoHaake RheoWin 7/31/2010/ 10:35 PM

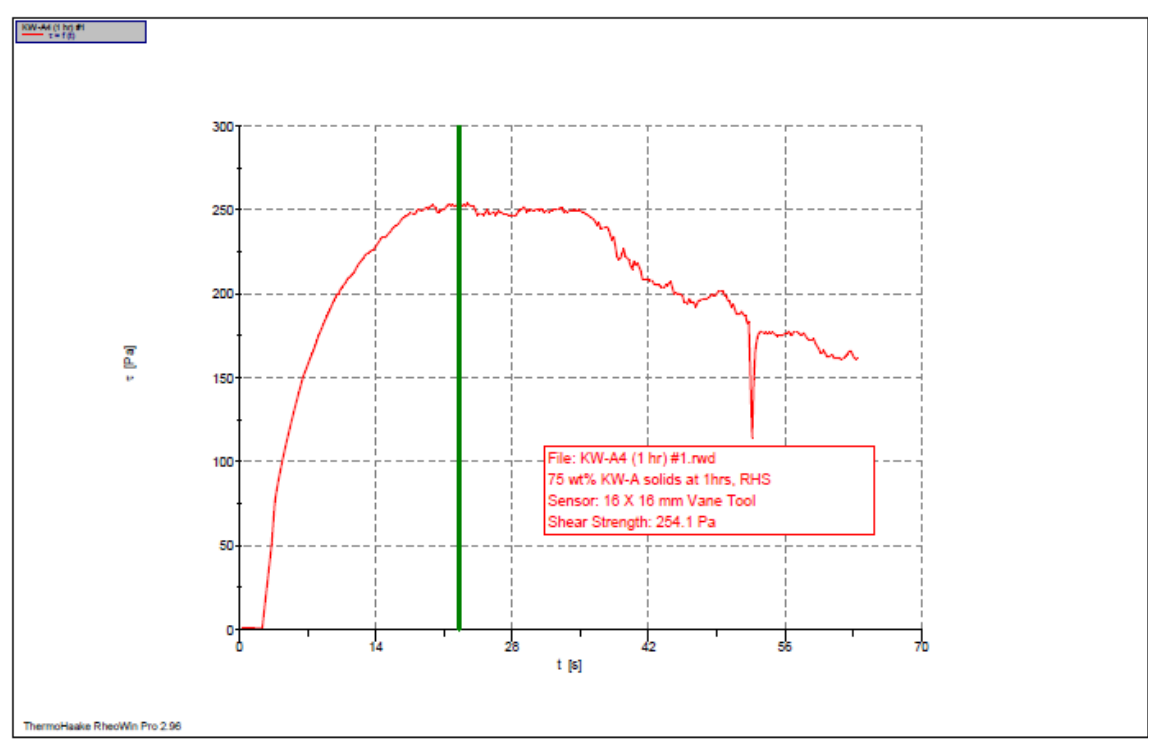

1: C:IK-Basin Rheol06022010VKW-A4 (1 hr) \#1.rwd

Company / Operator: PNNL / Jaehun Chun

Date / Time / Version: 02.06.2010 / 9:42:02 AM / RheoWin Pro 296

Substance / Sample no: KW-A4 (1 hr) \#1 / KW-A4 (1 hr) \#1

Curve discussion: Greatest value $t[s] 22.54 \tau[\mathrm{Pa}] 254.1$

Figure A.150. 75 wt $\%$ KW-A Solids, RHS Sampling Location (1 hr) 


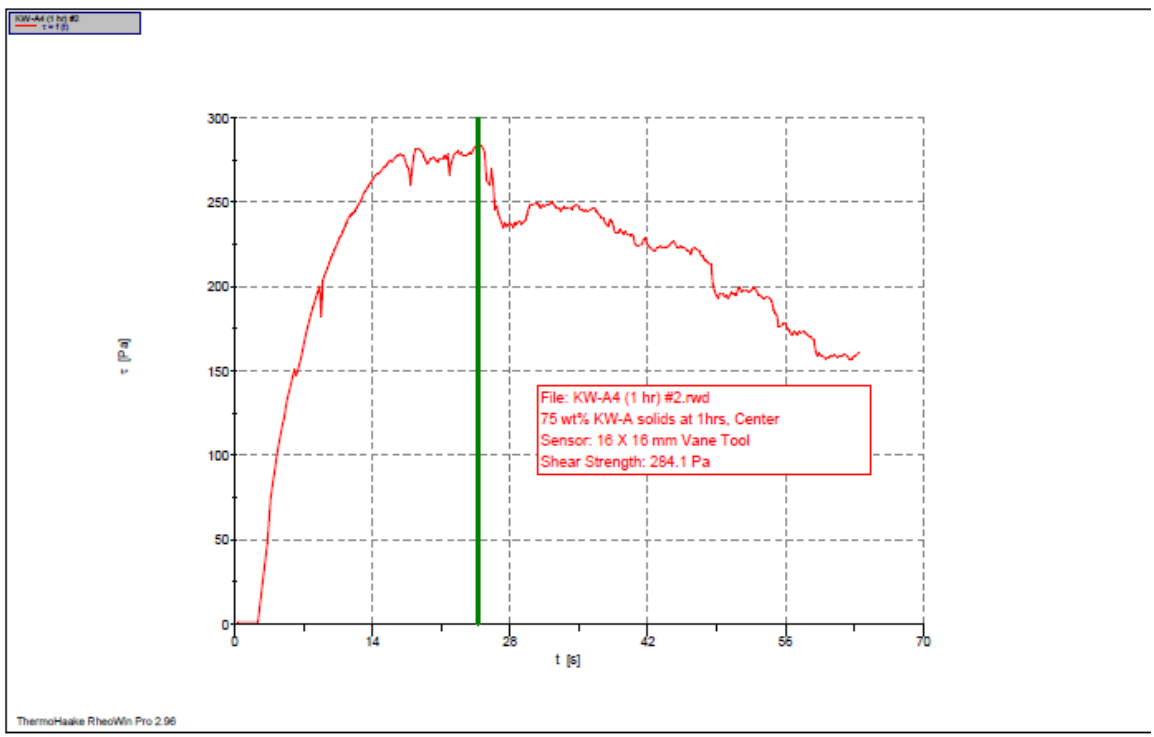

1: C:IK-Basin Rheol060220101KW -A4 (1 hr) \#2.rwd

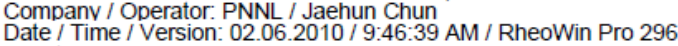

Substance / Sample no: KW-A4 (1 hr) \#2 / KW-A4 (1 hr) \#2

Curve discussion: Greatest value $\mathrm{t}[\mathrm{s}] 24.74 \tau[\mathrm{Pa}] 284.1$

Figure A.151. $75 \mathrm{wt} \% \mathrm{KW}$-A Solids, Center Sampling Location $(1 \mathrm{hr})$

ThermoHaake RheoWin 7/31/2010/10:38 PM

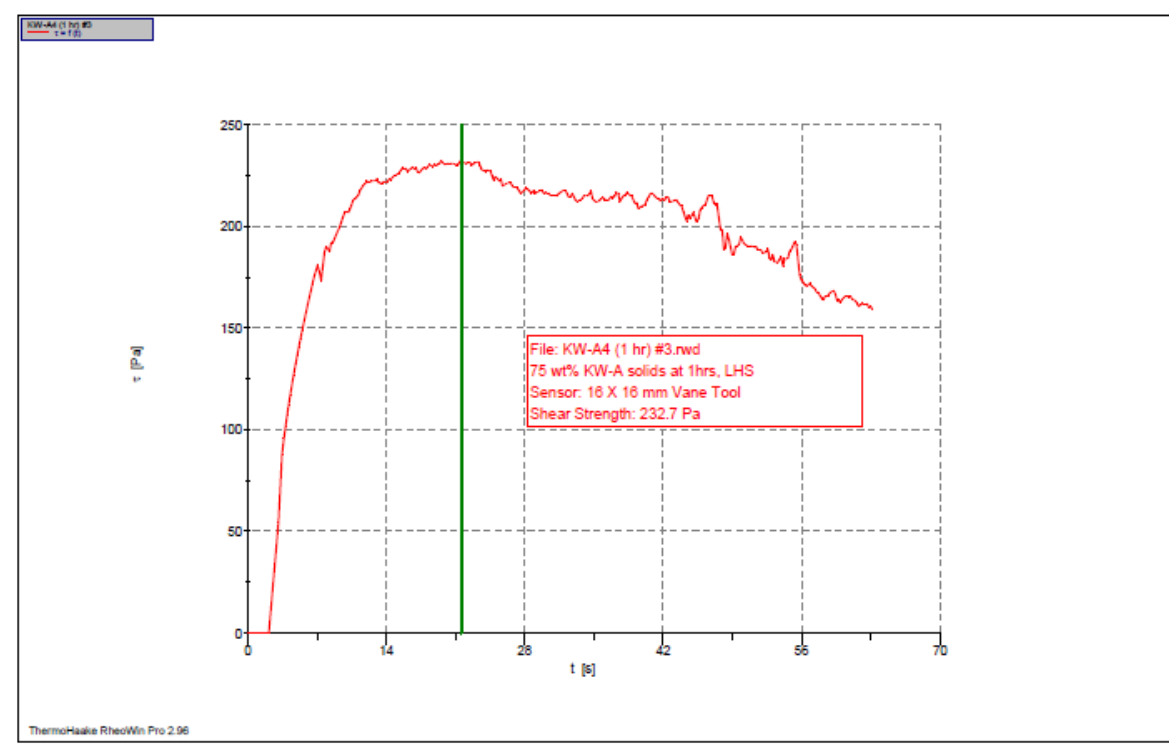

1: C:IK-Basin Rheol06022010KKW-A4 (1 hr) \#3.rwd

Companv / Operator: PNNL / Jaehun Chun

Substance / Sample no: KW-A4 (1 hr) \#3 / KW-A4 (1 hr) \#3

Curve discussion: Greatest value $\mathrm{t}[\mathrm{s}] 21.60 \tau[\mathrm{Pa}] 232.7$

Figure A.152. 75 wt $\%$ KW-A Solids, LHS Sampling Location (1 hr) 


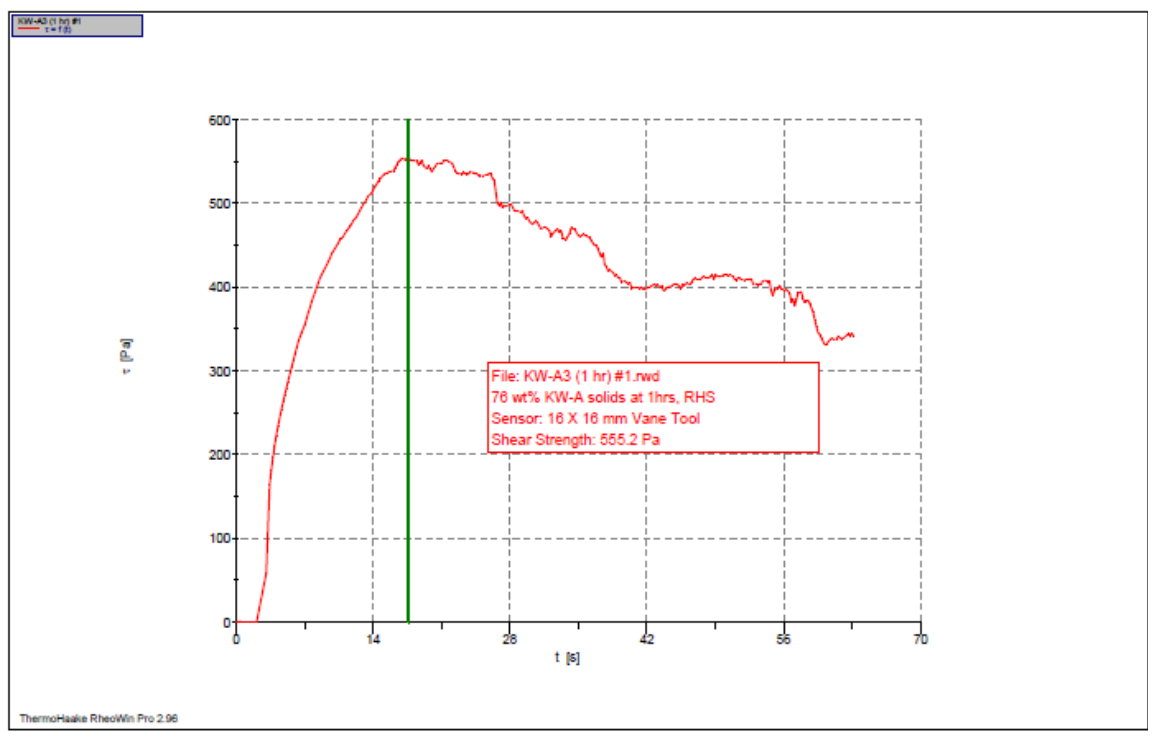

1: C:IK-Basin Rheol06032010 KWW-A3 (1 hr) \#1.rwd

Company / Operator: PNNL / Jaehun Chun

Date / Time / Version: 03.06.2010 / 12:25:09 PM / RheoWin Pro 296

Substance / Sample no: KW-A3 (1 hr) \#1 / KW-A3 (1 hr) \#1

Curve discussion: Greatest value $\mathrm{t}[\mathrm{s}] 17.62 \tau[\mathrm{Pa}] 555.2$

Figure A.153. 76 wt\% KW-A Solids, RHS Sampling Location (1 hr)

ThermoHaake RheoWin 7/31/2010/ 10:52 PM

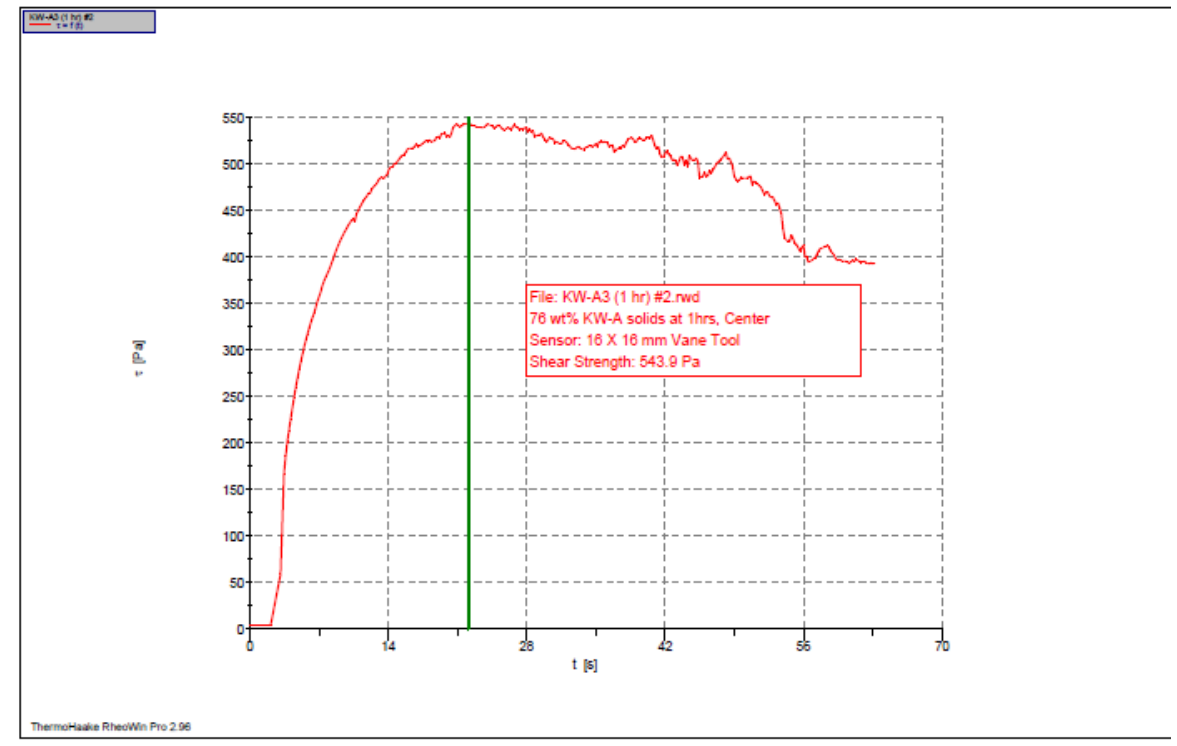

1: C:IK -Basin Rheol06032010tKW -A3 (1 hr) \#2.rwd

Companv / Operator: PNNL / Jaehun Chun

Substance / Sample no: KW-A3 (1 hr) \#2 / KW-A3 (1 hr) \#2

Curve discussion: Greatest value $\mathrm{t}[\mathrm{s}] 22.11 \tau[\mathrm{Pa}] 543.9$

Figure A.154. $76 \mathrm{wt} \% \mathrm{KW}$-A Solids, Center Sampling Location (1 hr) 


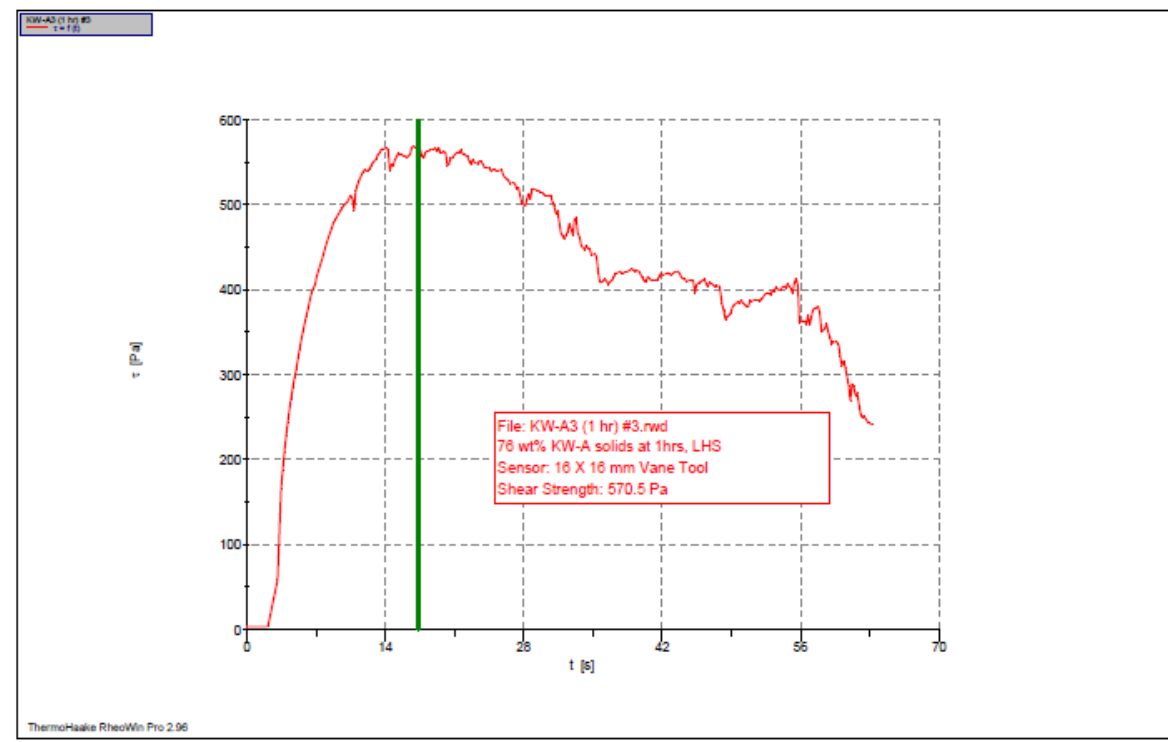

1: C:IK-Basin Rheol06032010 KW -A3 (1 hr) \#3.rwd Companv / Operator. PNNL / Jaehun Chun

Date / Time / Version: 03.06.2010 / 12:32:49 PM / RheoWin Pro 296

Substance / Sample no: KW-A3 (1 hr) \#3 / KW-A3 (1 hr) \#3

Curve discussion: Greatest value $\mathrm{t}[\mathrm{s}] 17.36 \tau[\mathrm{Pa}] 570.5$

Figure A.155. 76 wt\% KW-A Solids, LHS Sampling Location (1 hr)

ThermoHaake RheoWin 7/31/2010/10:42 PM

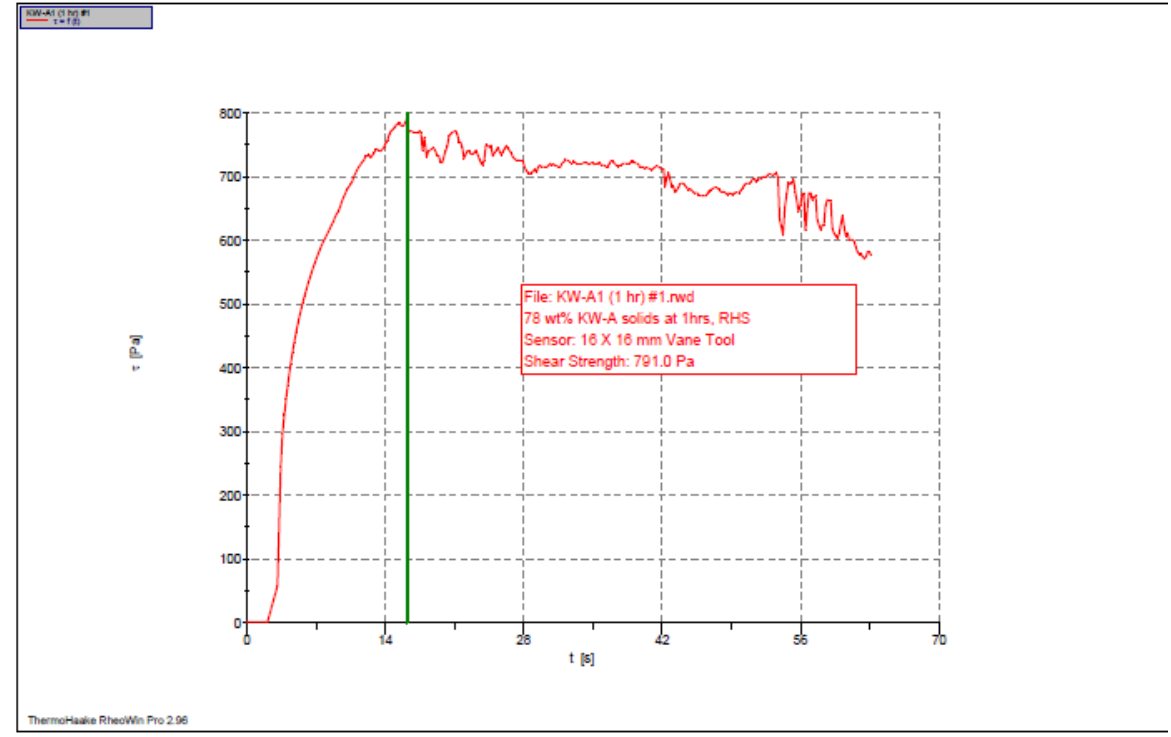

1: C:IK-Basin Rheol06032010 KW-A1 (1 hr) \#1.rwd

Companv / Operator: PNNL / Jaehun Chun

Date / Time / Version: 03.06.2010 / 9:35:23 AM / RheoWin Pro 296

Substance / Sample no: KW-A1 (1 hr) \#1 / KW-A1 (1 hr) \#1

Curve discussion: Greatest value $\mathrm{t}[\mathrm{s}] 16.20 \tau[\mathrm{Pa}] 791.0$

Figure A.156. 78 wt\% KW-A Solids, RHS Sampling Location (1 hr) 


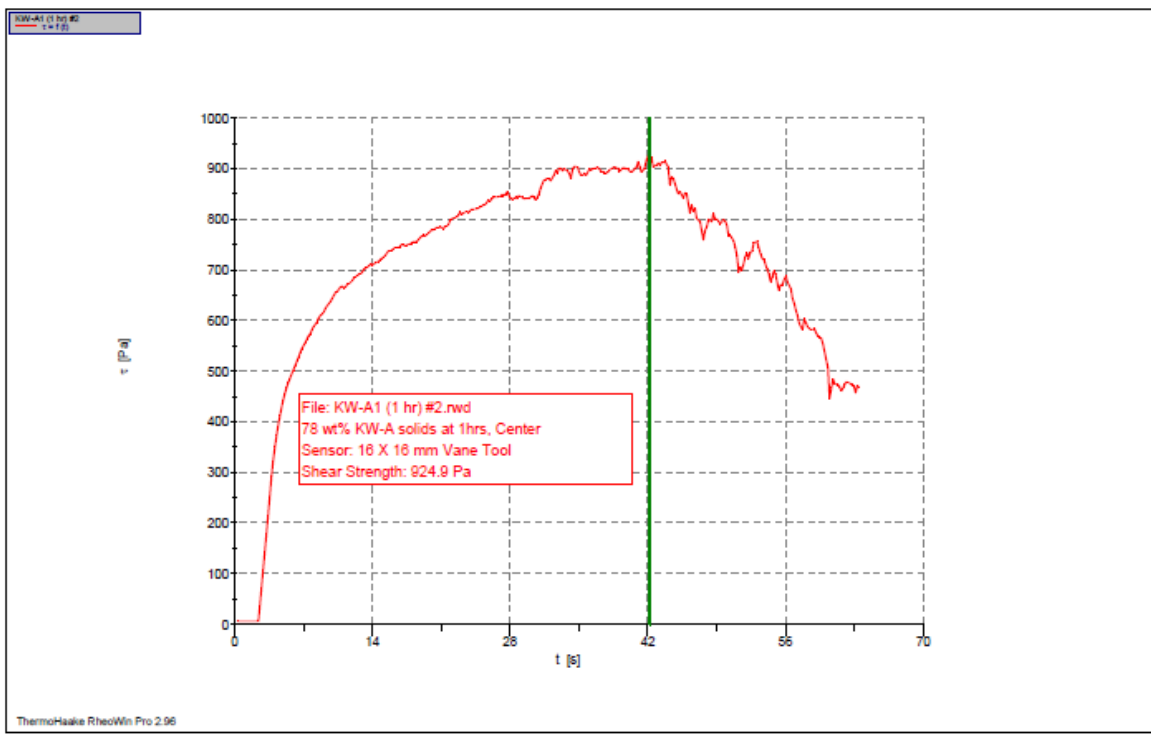

1: C:IK -Basin Rheol06032010/KW-A1 (1 hr) \#2.rwd Companv / Operator: PNNL / Jaehun Chun

/ / Tersion: 03.06.2010 / 9:38:58 AM / RheoWin Pro 296

Substance / Sample no: KW-A1 (1 hr) \#2 / KW-A1 (1 hr) \#2

Curve discussion: Greatest value $t[s] 42.21 \tau[\mathrm{Pa}] 924.9$

Figure A.157. $78 \mathrm{wt} \% \mathrm{KW}$-A Solids, Center Sampling Location (1 hr)

ThermoHaake RheoWin 7/31/2010 / 10:44 PM

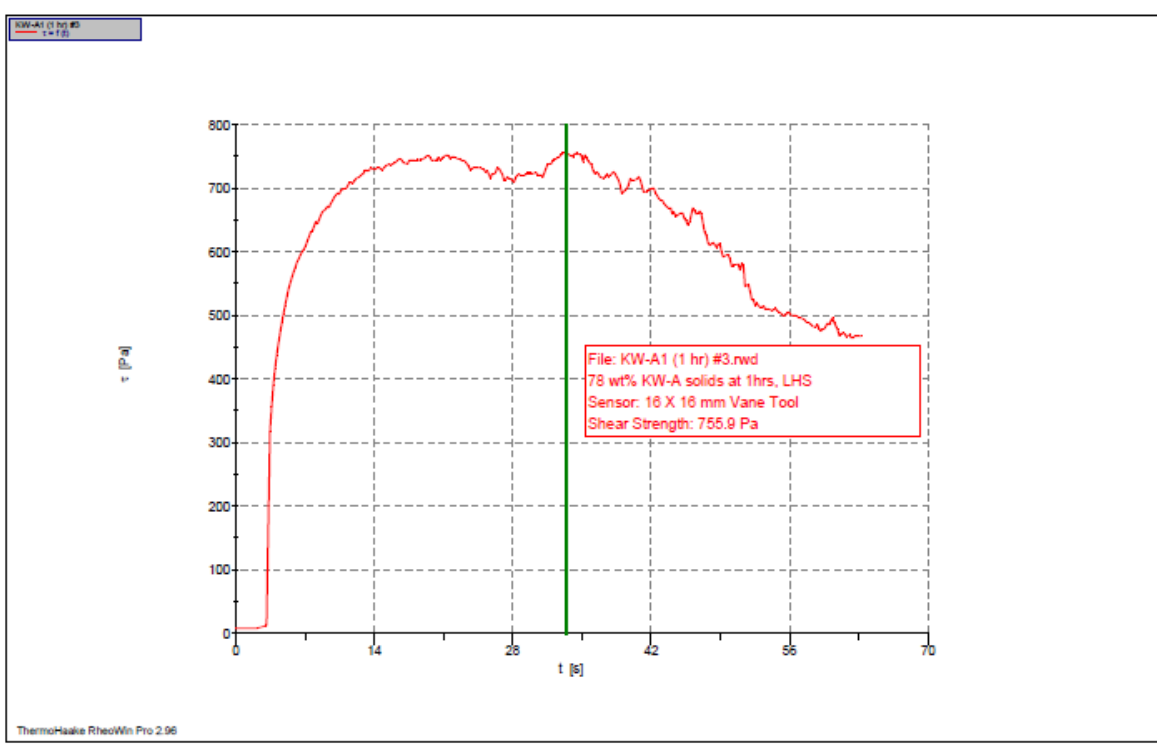

1: C:IK-Basin Rheol06032010/KW-A1 (1 hr) \#3.rwd

Companv / Operator: PNNL / Jaehun Chun

Date / Time / Version: 03.06.2010 / 9:43.06 AM / RheoWin Pro 296

Substance / Sample no: KW-A1 (1 hr) \#3 / KW-A1 (1 hr) \#3

Curve discussion: Greatest value $\mathrm{t}[\mathrm{s}] 33.41 \tau[\mathrm{Pa}] 755.9$

Figure A.158. $78 \mathrm{wt} \% \mathrm{KW}$-A Solids, LHS Sampling Location (1 hr) 


\section{A.6.8 Depth Profile of Shear-Strengths for KW Container Simulant (Complete) (KW-A)}

ThermoHaake RheoWin 8/1/2010/9:11 PM

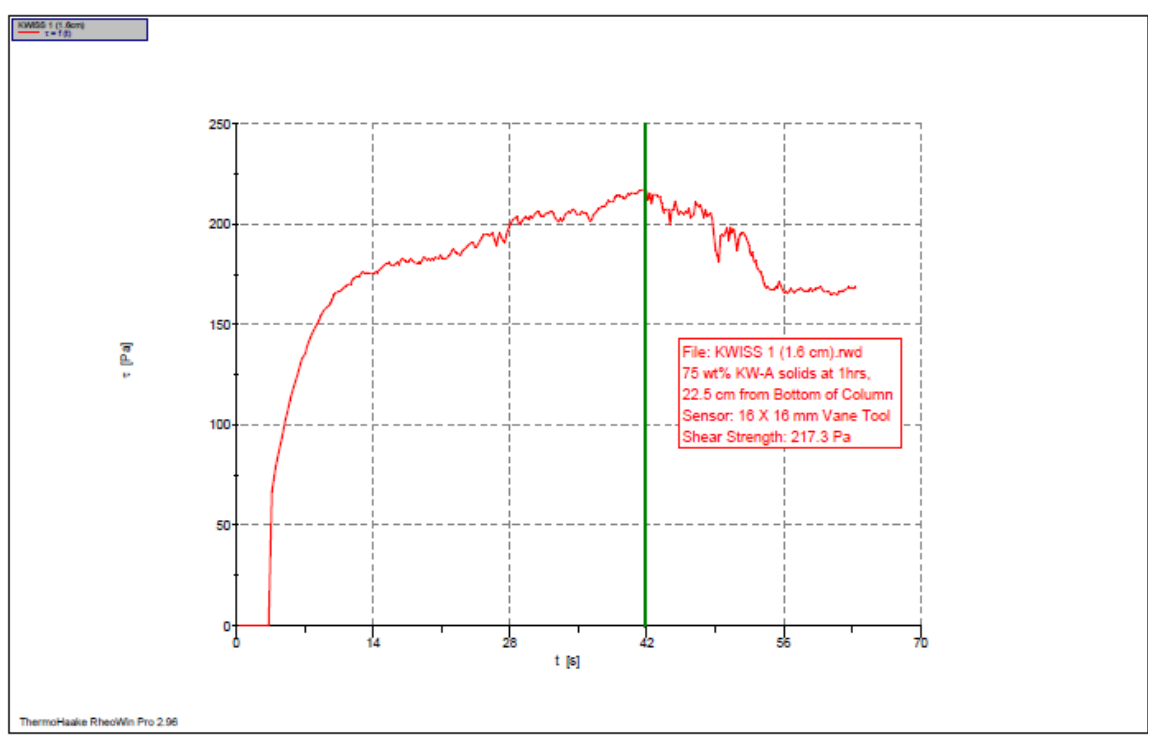

1: C:IK-Basin Rheol06112010KKWISS 1 (1.6cm).rwd

Company / Operator: PNNL / Jaehun Chun

Date / Time / Version: 11.06.2010 / 10:40:14 AM / RheoWin Pro 296

Substance / Sample no: KWISS $1(1.6 \mathrm{~cm}) / \mathrm{KWISS} 1(1.6 \mathrm{~cm})$

Curve discussion: Greatest value $\mathrm{t}[\mathrm{s}] \mathrm{41.82} \tau[\mathrm{Pa}] 217.3$

Figure A.159. $75 \mathrm{wt} \% \mathrm{KW}$-A Solids at $1 \mathrm{hr}, 22.5 \mathrm{~cm}$ from Bottom of Column

ThermoHaake RheoWin 8/1/2010/9:34 PM

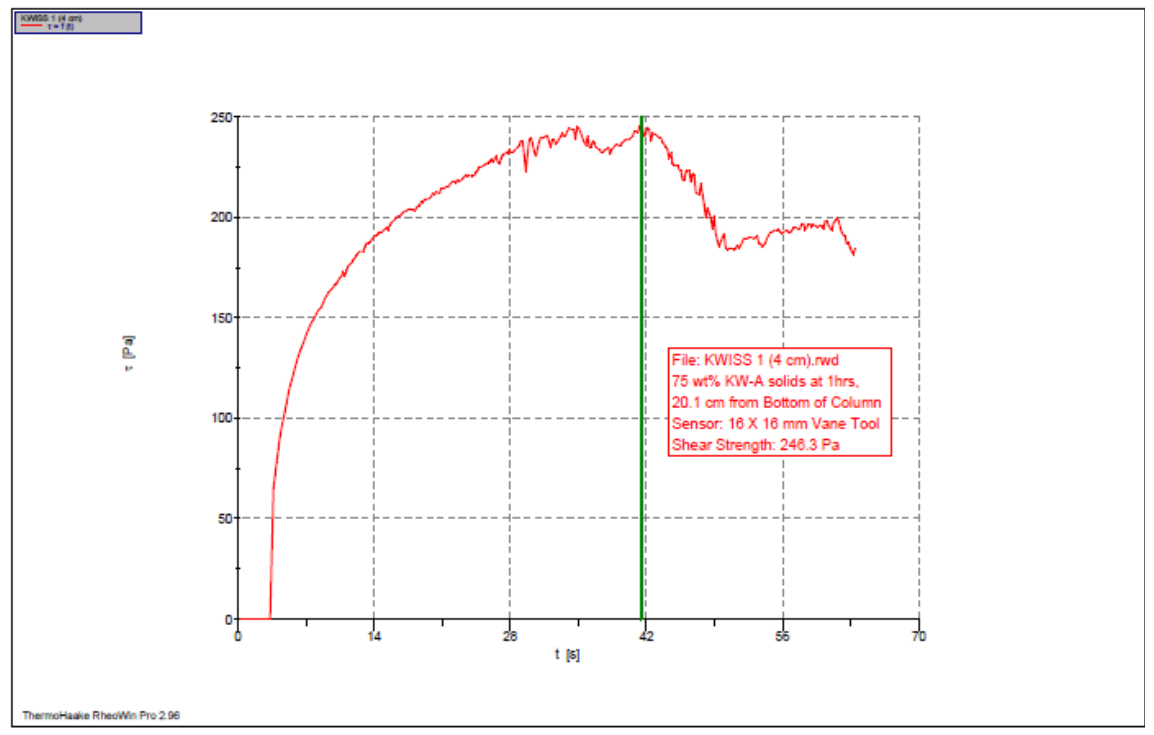

1: C:IK-Basin Rheol06112010WKWISS $1(4 \mathrm{~cm})$.rwd

Companv / Operator: PNNL / Jaehun Chun

Date/Time/Version: 11.06.2010/10.44.27 AM / RheoWin Pro 296

Substance / Sample no: KWISS $1(4 \mathrm{~cm}) /$ KWISS $1(4 \mathrm{~cm})$

Curve discussion: Greatest value $\mathrm{t}[\mathrm{s}] 41.46 \tau[\mathrm{Pa}] 246.3$

Figure A.160. $75 \mathrm{wt} \% \mathrm{KW}$-A Solids at $1 \mathrm{hr}, 20.1 \mathrm{~cm}$ from Bottom of Column 


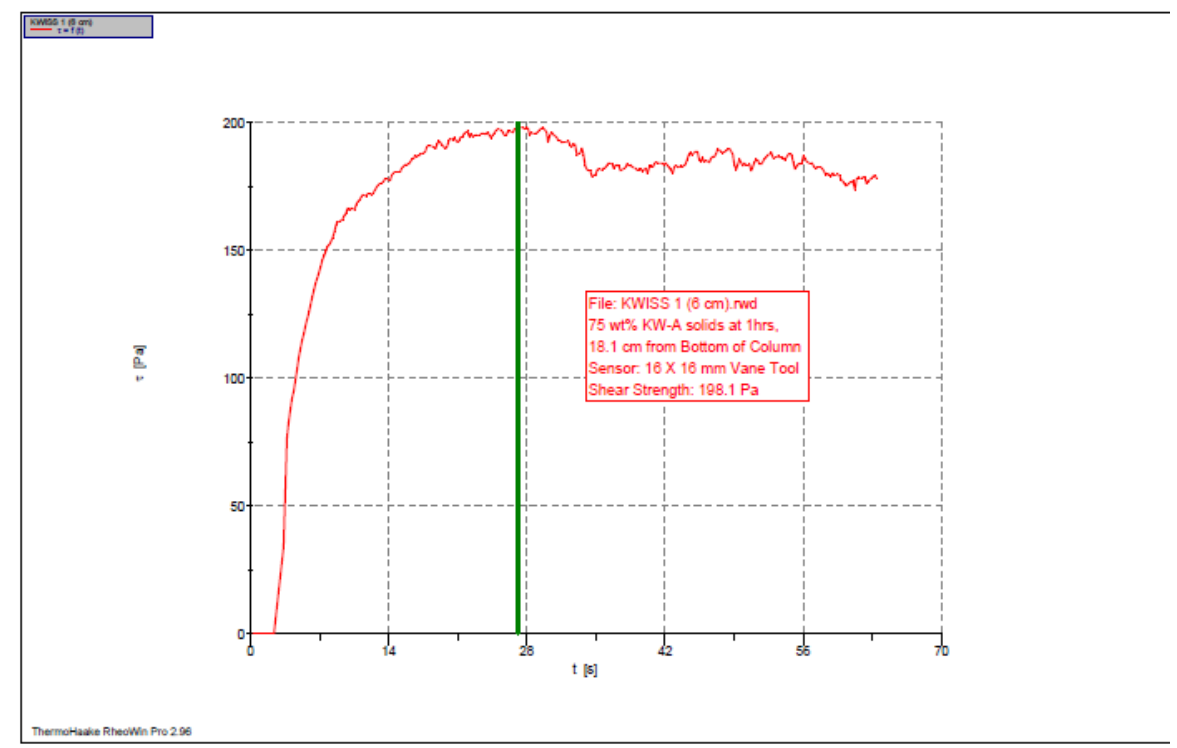

1: C:IK-Basin Rheol06112010KKWISS $1(6 \mathrm{~cm})$.rwd

Companv / Operator: PNNL / Jaehun Chun

Date / Time / Version: 11.06.2010 / 10:48:48 AM / RheoWin Pro 296

Substance / Sample no: KWISS 1 (6 cm) / KWISS $1(6 \mathrm{~cm})$

Curve discussion: Greatest value $\mathrm{t}[\mathrm{s}] 27.10 \tau[\mathrm{Pa}]$ 198.1

Figure A.161. $75 \mathrm{wt} \% \mathrm{KW}$-A Solids at $1 \mathrm{hr}, 18.1 \mathrm{~cm}$ from Bottom of Column

ThermoHaake RheoWin 8/1/2010/9:38 PM

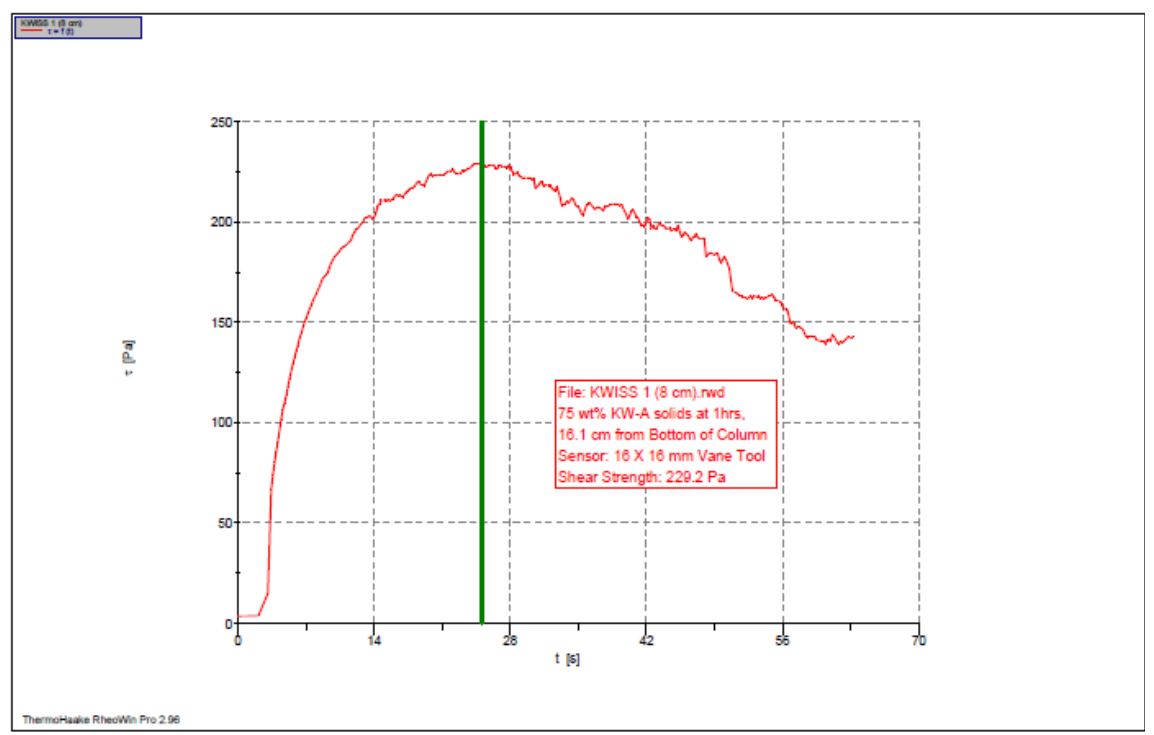

1: C:IK-Basin Rheol06112010KKWISS $1(8 \mathrm{~cm})$.rwd Companv/ Operator: PNNL/Jaehun Chun

Date / Time / Version: 11.06.2010 / 10:52:56 AM / RheoWin Pro 296

Substance / Sample no: KWISS $1(8 \mathrm{~cm}) / \mathrm{KWISS} 1(8 \mathrm{~cm})$

Curve discussion: Greatest value $\mathrm{t}[\mathrm{s}] 25.12 \tau[\mathrm{Pa}] 229.2$

Figure A.162. $75 \mathrm{wt} \% \mathrm{KW}$-A Solids at $1 \mathrm{hr}, 16.1 \mathrm{~cm}$ from Bottom of Column 


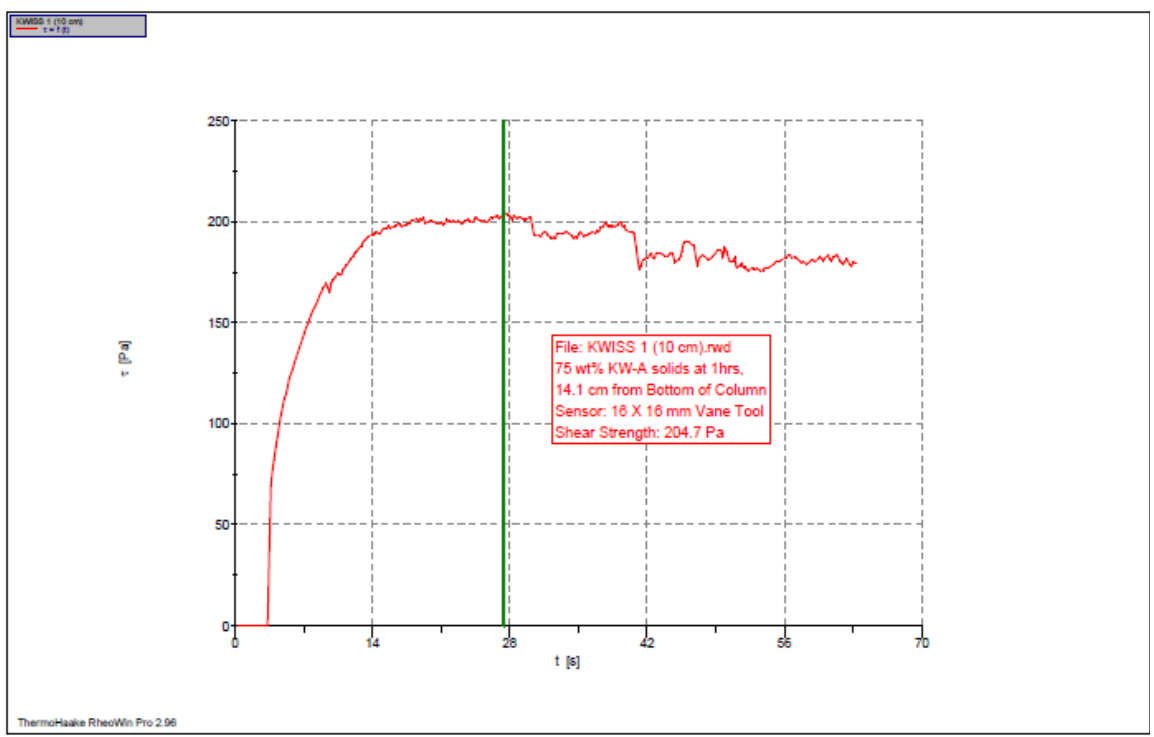

1: C:IK -Basin Rheol06112010KKWISS $1(10 \mathrm{~cm}) . r w d$

Company / Operator: PNNL / Jaehun Chun

Date / Time / Version: 11.06.2010 / 10:57:36 AM / RheoWin Pro 296

Substance / Sample no: KWISS $1(10 \mathrm{~cm}) / \mathrm{KWISS} 1(10 \mathrm{~cm})$

Curve discussion: Greatest value $\mathrm{t}[\mathrm{s}] 27.40 \tau[\mathrm{Pa}] 204.7$

Figure A.163. $75 \mathrm{wt} \% \mathrm{KW}$-A Solids at $1 \mathrm{hr}, 14.1 \mathrm{~cm}$ from Bottom of Column

ThermoHaake RheoWin 8/1/2010/9:41 PM

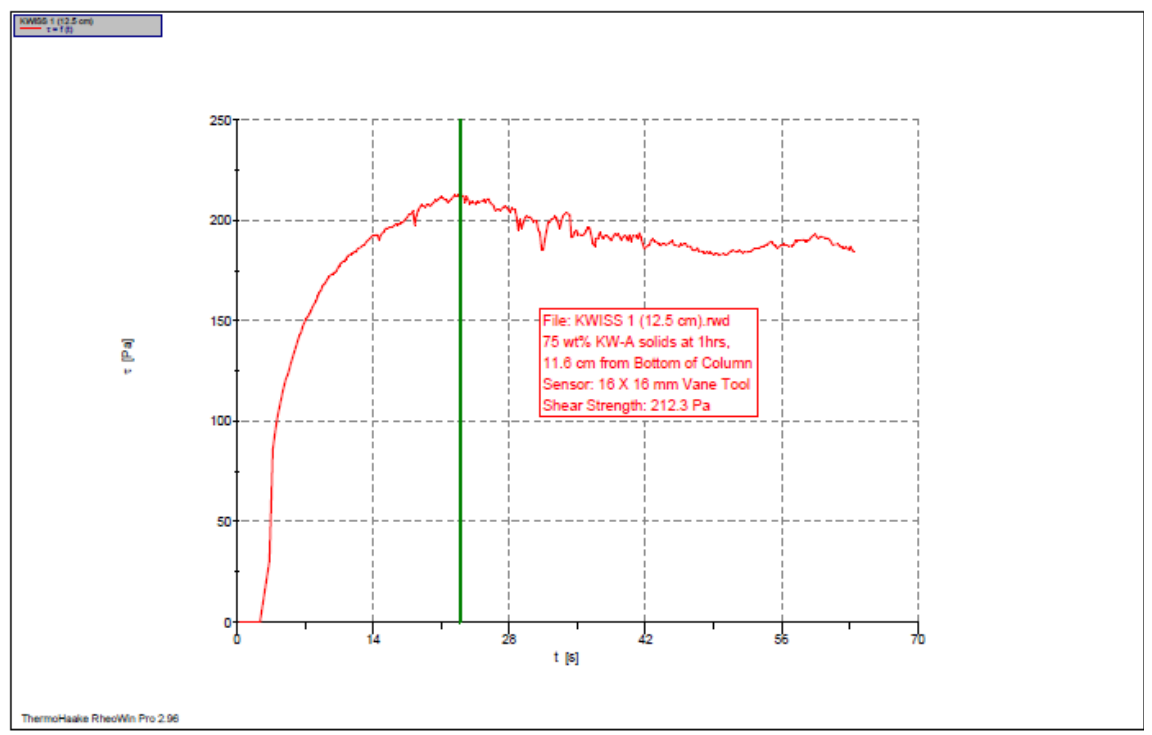

1: C:IK-Basin Rheol06112010VKWISS $1(12.5 \mathrm{~cm})$.rwd

Date / Time / Version: 11.06.2010 / 11:13:30 AM / RheoWin Pro 296

Substance / Sample no: KWISS $1(12.5 \mathrm{~cm}) / \mathrm{KWISS} 1(12.5 \mathrm{~cm})$

Curve discussion: Greatest value $\mathrm{t}[\mathrm{s}] 22.96 \tau[\mathrm{Pa}] 212.3$

Figure A.164. $75 \mathrm{wt} \% \mathrm{KW}$-A Solids at $1 \mathrm{hr}, 11.6 \mathrm{~cm}$ from Bottom of Column 


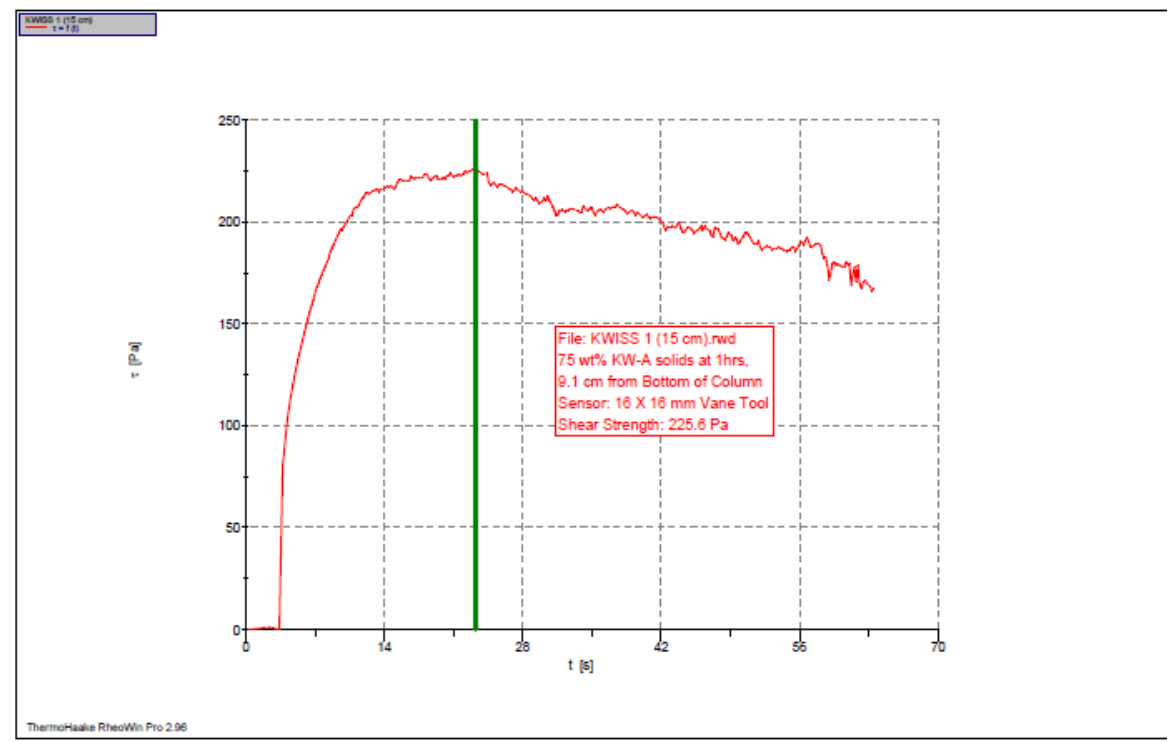

1: C-IK-Basin Rheol06112010KKWISS 1 (15 cm).rwd Companv / Operator: PNNL / Jaehun Chun

Date / Time / version. 11.06.2010/11:17:04 AM / RheoWin Pro 296

Substance / Sample no: KWISS $1(15 \mathrm{~cm}) /$ KWISS $1(15 \mathrm{~cm})$

Curve discussion: Greatest value $\mathrm{t}[\mathrm{s}] 23.21 \tau[\mathrm{Pa}] 225.6$

Figure A.165. $75 \mathrm{wt} \% \mathrm{KW}-\mathrm{A}$ Solids at $1 \mathrm{hr}, 9.1 \mathrm{~cm}$ from Bottom of Column

ThermoHaake RheoWin $8 / 1 / 2010 / 9: 52$ PM

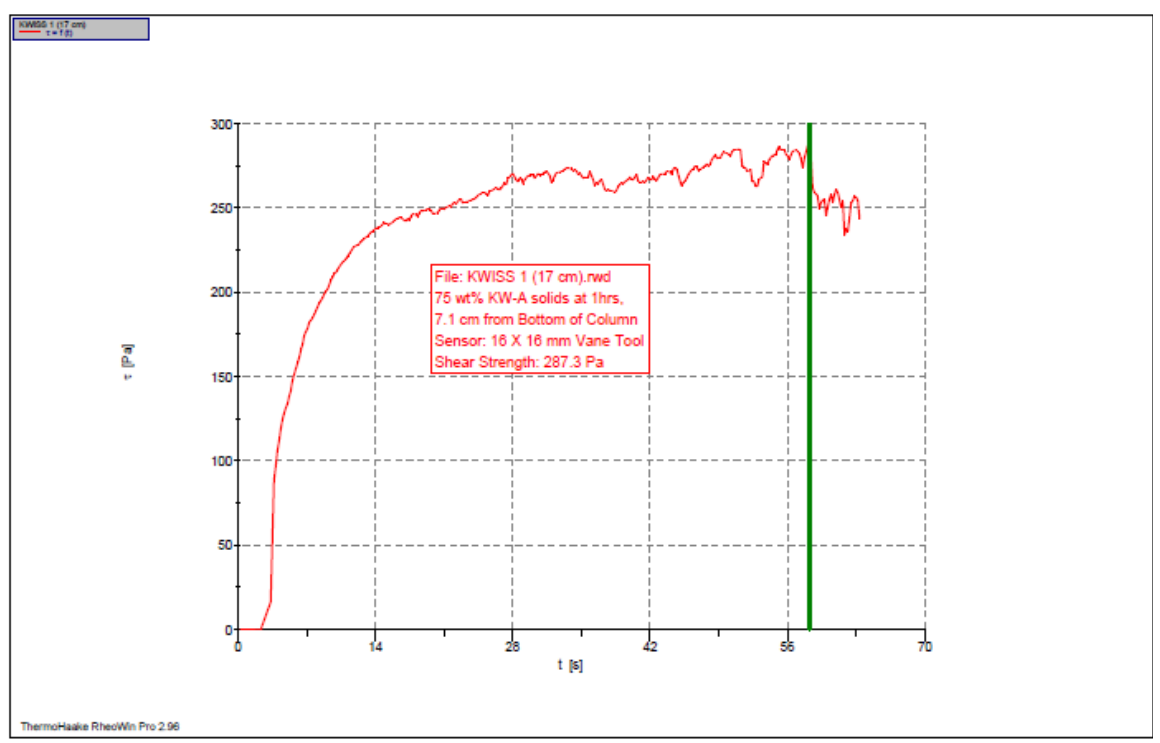

1: C:IK-Basin Rheol06112010WKWISS 1 (17 cm).rwd

Companv / Operator: PNNL / Jaehun Chun

11.21:21 AM / RheoWin Pro 296

Substance / Sample no: KWISS $1(17 \mathrm{~cm}) /$ KWISS $1(17 \mathrm{~cm})$

Curve discussion: Greatest value $\mathrm{t}[\mathrm{s}] 58.23 \tau[\mathrm{Pa}] 287.3$

Figure A.166. $75 \mathrm{wt} \% \mathrm{KW}$-A Solids at $1 \mathrm{hr}, 7.1 \mathrm{~cm}$ from Bottom of Column 


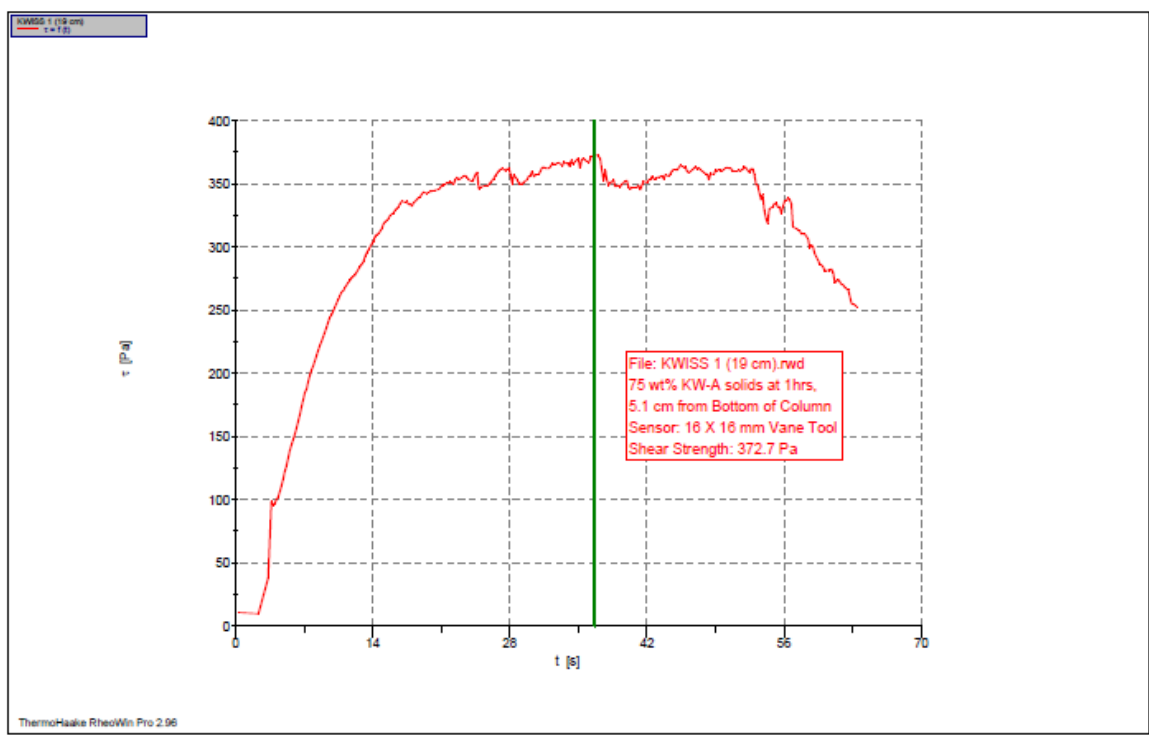

1: C:IK-Basin Rheol06112010KKWISS $1(19 \mathrm{~cm})$.rwd

Company / Operator: PNNL / Jaehun Chun

Date / Time / Version: 11.06.2010 / 11:25:17 AM / RheoWin Pro 296

Substance / Sample no: KWISS $1(19 \mathrm{~cm}) /$ KWISS $1(19 \mathrm{~cm})$

Curve discussion: Greatest value $\mathrm{t}[\mathrm{s}] 36.66 \tau[\mathrm{Pa}] 372.7$

Figure A.167. $75 \mathrm{wt} \% \mathrm{KW}$-A Solids at $1 \mathrm{hr}, 5.1 \mathrm{~cm}$ from Bottom of Column

ThermoHaake RheoWin 8/1/2010 / 10:11 PM

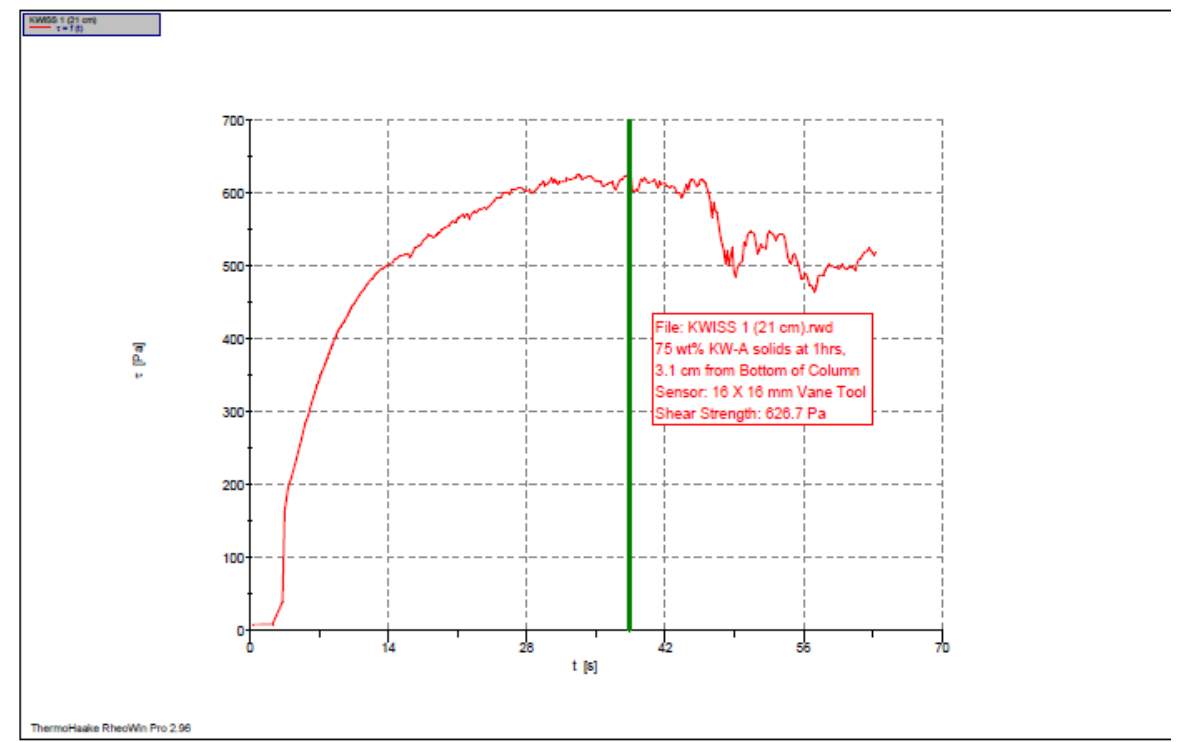

1: C:IK-Basin Rheol06112010KKWISS $1(21 \mathrm{~cm}) \cdot$.rwd

Company / Operator: PNNL / Jaehun Chun

Substance / Sample no: KWISS $1(21 \mathrm{~cm}) /$ KWISS $1(21 \mathrm{~cm})$

Curve discussion: Greatest value $\mathrm{t}[\mathrm{s}] 38.37 \tau[\mathrm{Pa}] 626.7$

Figure A.168. $75 \mathrm{wt} \% \mathrm{KW}$-A Solids at $1 \mathrm{hr}, 3.1 \mathrm{~cm}$ from Bottom of Column 


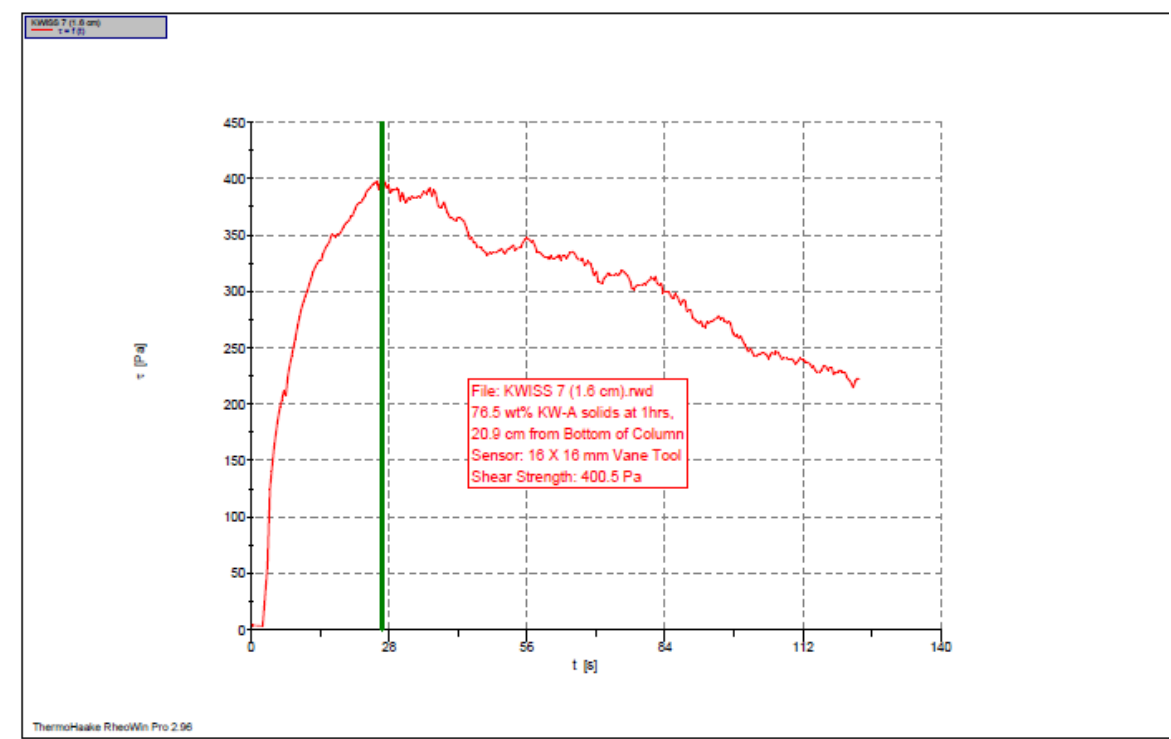

1: C:IK -Basin Rheol06252010XKWISS 7 (1.6 cm).rwd Companv / Operator: PNNL / Jaehun Chun

Date / Time / Version: 25.06.2010/13:20:16 PM / RheoWin Pro 296

Substance / Sample no: KWISS 7 (1.6 cm) / KWISS 7 (1.6 cm)

Curve discussion: Greatest value $\mathrm{t}[\mathrm{s}] 26.64 \tau[\mathrm{Pa}] 400.5$

Figure A.169. $76.5 \mathrm{wt} \% \mathrm{KW}$-A Solids at $1 \mathrm{hr}, 20.9 \mathrm{~cm}$ from Bottom of Column

ThermoHaake RheoWin 8/1/2010/10:40 PM

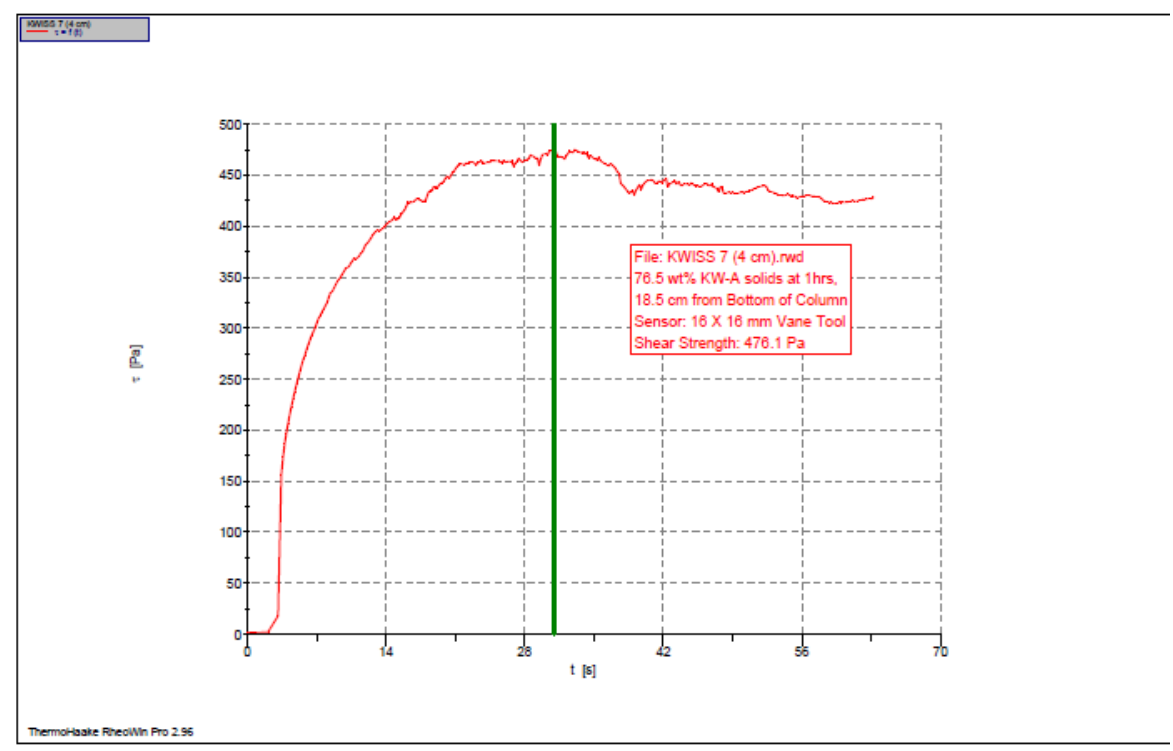

1: C:IK -Basin Rheol06252010UKWISS 7 (4 cm).rwd

Companv / Operator: PNNL / Jaehun Chun

Date/ Time/ / ReoWin Pro 296

Substance / Sample no: KWISS $7(4 \mathrm{~cm}) /$ KWISS $7(4 \mathrm{~cm})$

Curve discussion: Greatest value $\mathrm{t}[\mathrm{s}] 31.00 \tau[\mathrm{Pa}] 476.1$

Figure A.170. $76.5 \mathrm{wt} \% \mathrm{KW}$-A Solids at $1 \mathrm{hr}, 18.5 \mathrm{~cm}$ from Bottom of Column 


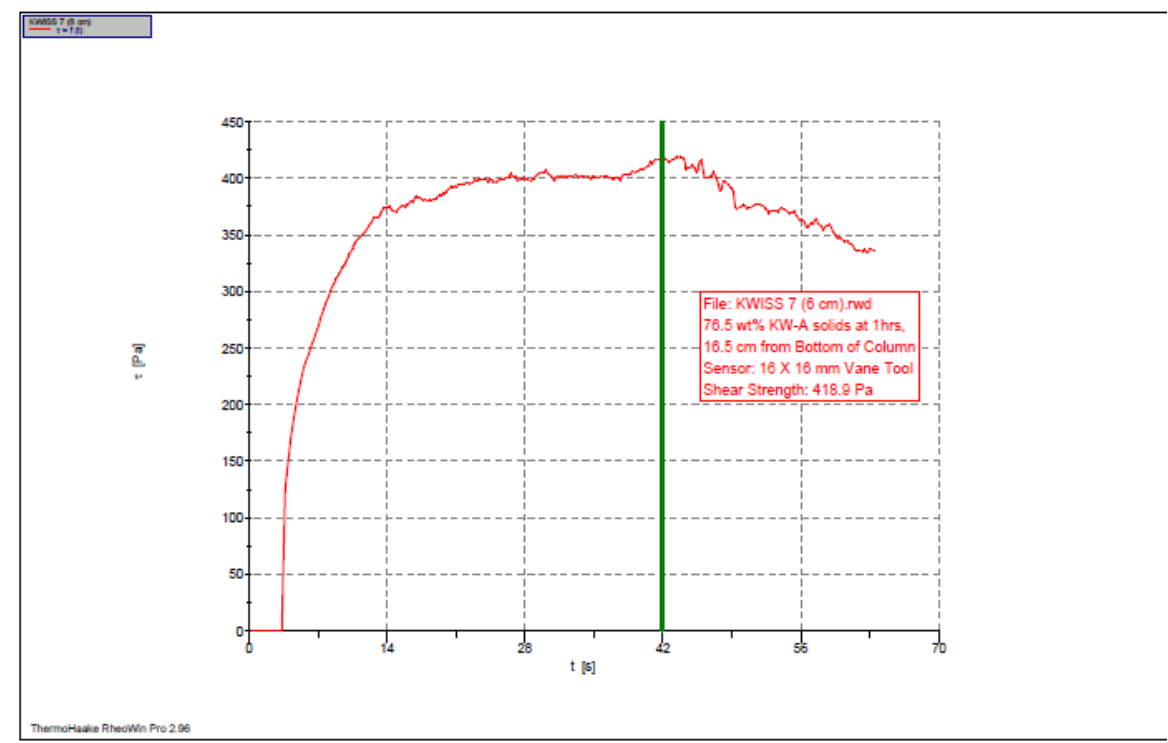

1: C:IK-Basin Rheol06252010UKWISS 7 (6 cm).rwd

Companv / Operator: PNNL / Jaehun Chun

Substance / Sample no: KWISS $7(6 \mathrm{~cm}) / \mathrm{KWISS} 7(6 \mathrm{~cm})$

Curve discussion: Greatest value $\mathrm{t}[\mathrm{s}] 41.95 \tau[\mathrm{Pa}] 418.9$

Figure A.171. $76.5 \mathrm{wt} \% \mathrm{KW}-\mathrm{A}$ Solids at $1 \mathrm{hr}, 16.5 \mathrm{~cm}$ from Bottom of Column

ThermoHaake RheoWin 8/1/2010/10:42 PM

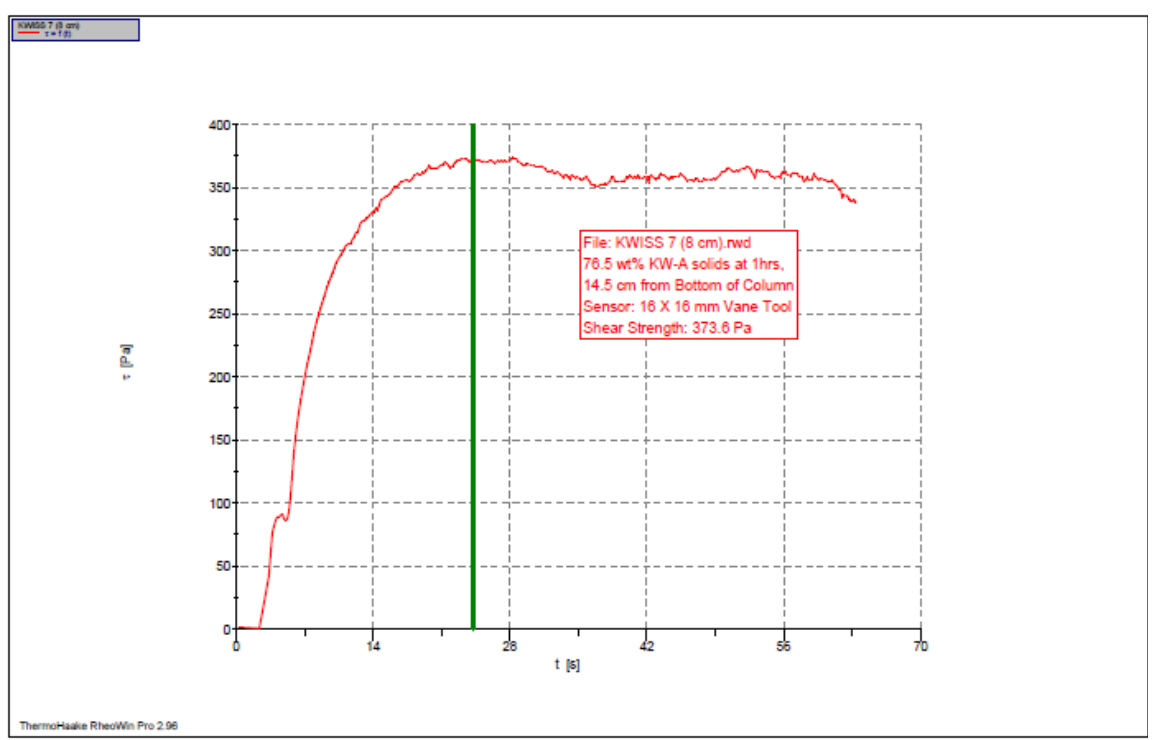

1: C:IK -Basin Rheol06252010UKWISS 7 (8 cm).rwd

Companv / Operator: PNNL / Jaehun Chun

Substance / Sample no: KWISS $7(8 \mathrm{~cm}) /$ KWISS $7(8 \mathrm{~cm})$

Curve discussion: Greatest value $\mathrm{t}[\mathrm{s}] 24.23 \tau[\mathrm{Pa}] 373.6$

Figure A.172. $76.5 \mathrm{wt} \% \mathrm{KW}-\mathrm{A}$ Solids at $1 \mathrm{hr}, 14.5 \mathrm{~cm}$ from Bottom of Column 


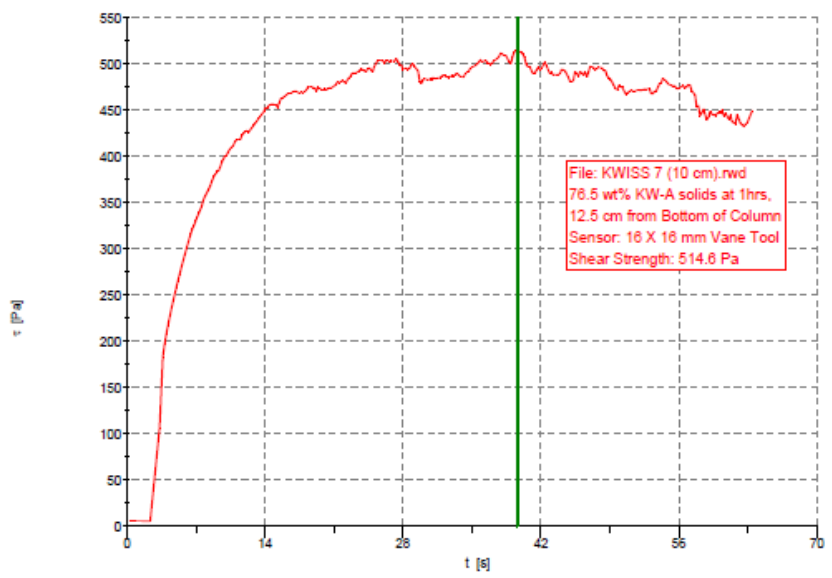

1: C:IK-Basin Rheol06252010VKWISS 7 (10 cm).rwd Company / Operator: PNNL / Jaehun Chun

Date / Time / Version: 25.06.2010/13:36:35 PM / RheoWin Pro 296

Substance / Sample no: KWISS $7(10 \mathrm{~cm}) /$ KWISS $7(10 \mathrm{~cm})$

Curve discussion: Greatest value $\mathrm{t}[\mathrm{s}] 39.65 \tau[\mathrm{Pa}] 514.6$

Figure A.173. $76.5 \mathrm{wt} \% \mathrm{KW}$-A Solids at $1 \mathrm{hr}, 12.5 \mathrm{~cm}$ from Bottom of Column

ThermoHaake RheoWin 8/1/2010/10:45 PM

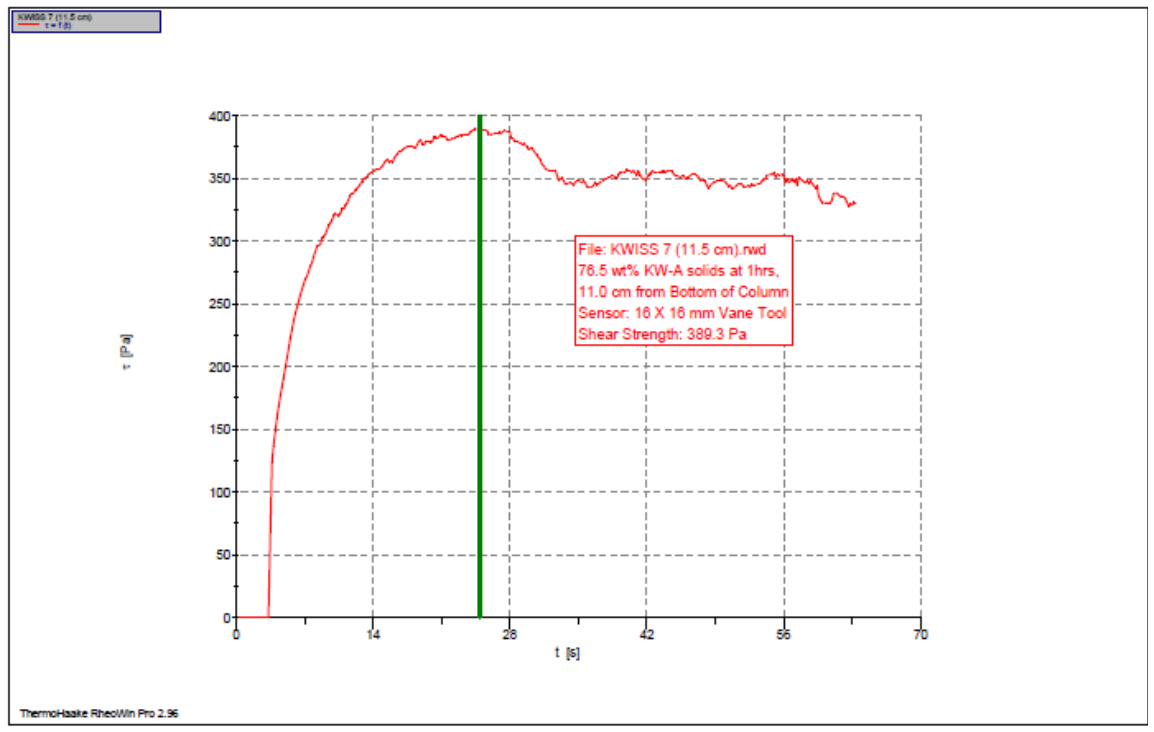

1: C:IK-Basin Rheol06252010XKWISS $7(11.5 \mathrm{~cm}) . r w d$

Date / Time / Version: 25.06.2010 / 13:50:43 PM / RheoWin Pro 296

Substance / Sample no: KWISS $7(11.5 \mathrm{~cm}) /$ KWISS $7(11.5 \mathrm{~cm})$

Curve discussion: Greatest value $t[s] 24.92 \tau[\mathrm{Pa}] 389.3$

Figure A.174. $76.5 \mathrm{wt} \% \mathrm{KW}$-A Solids at $1 \mathrm{hr}, 11.0 \mathrm{~cm}$ from Bottom of Column 


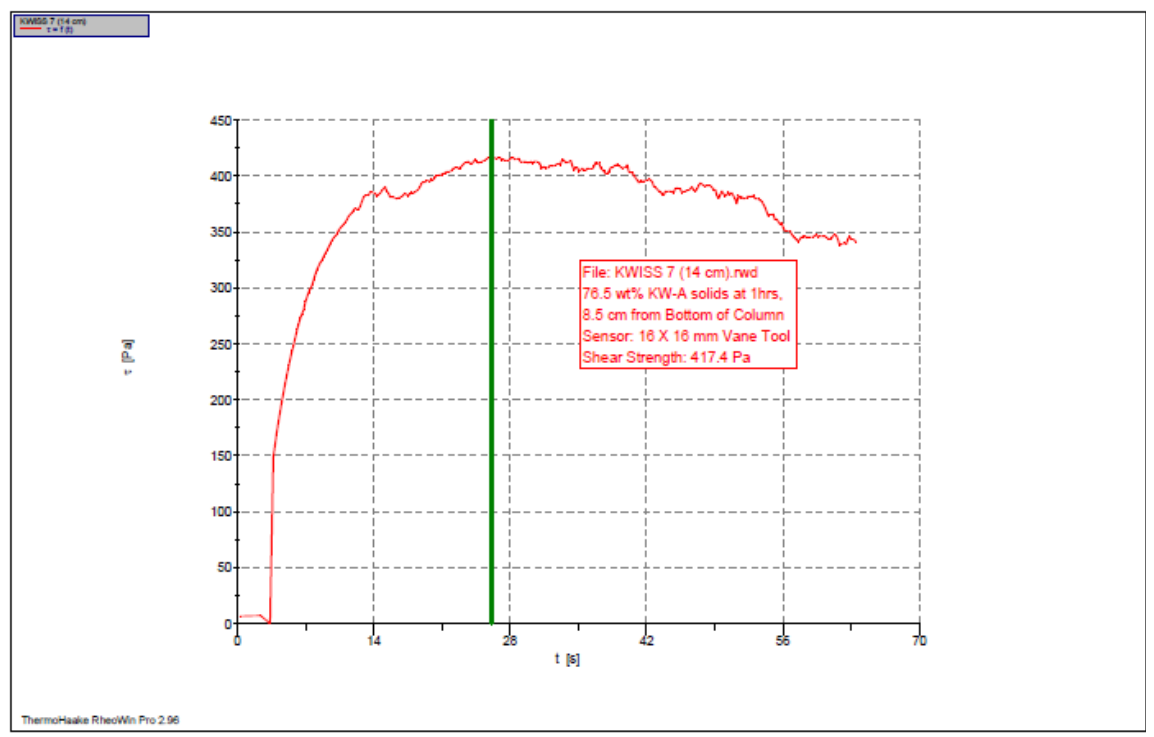

1: C:IK -Basin Rheol06252010UKWISS 7 (14 cm).rwd

Company / Operator: PNNL / Jaehun Chun

Date / Time / Version: 25.06.2010 / 13:53:54 PM / RheoWin Pro 296

Substance / Sample no: KWISS 7 (14 cm) / KWISS $7(14 \mathrm{~cm})$

Curve discussion: Greatest value $\mathrm{t}[\mathrm{s}] 26.08 \tau[\mathrm{Pa}] 417.4$

Figure A.175. $76.5 \mathrm{wt} \% \mathrm{KW}$-A Solids at $1 \mathrm{hr}, 8.5 \mathrm{~cm}$ from Bottom of Column

ThermoHaake RheoWin 8/1/2010/10:47 PM

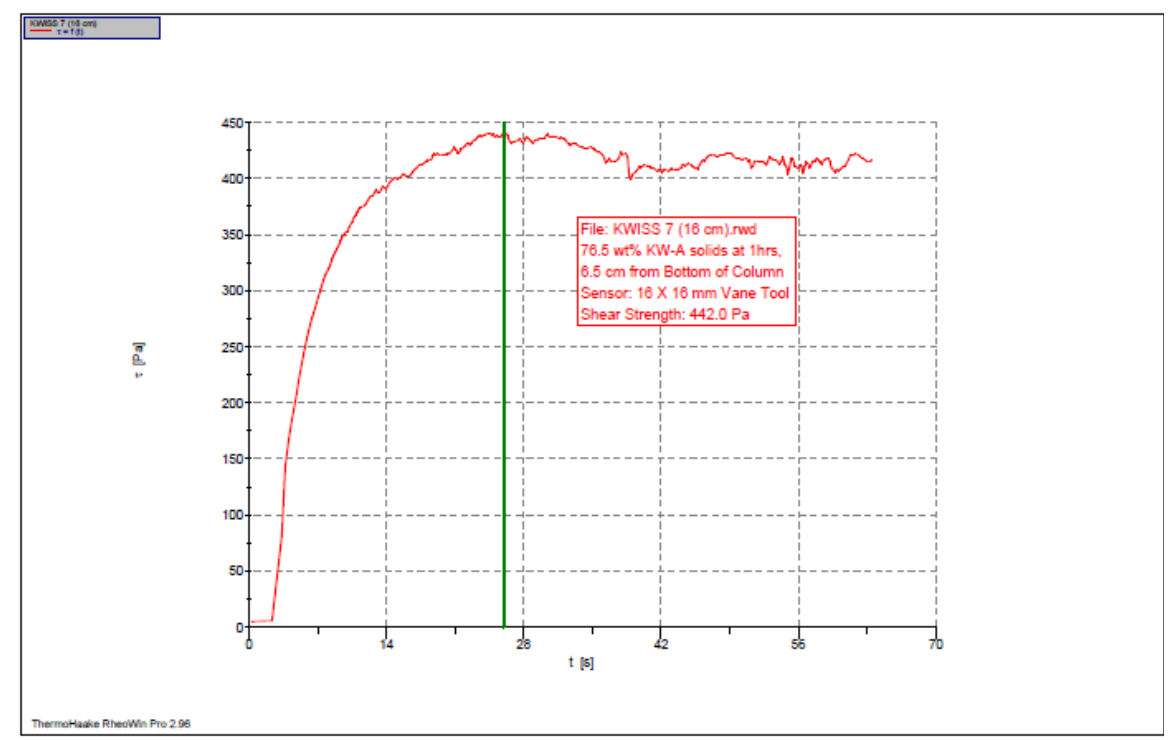

1: C:IK-Basin Rheol06252010UKWISS $7(16 \mathrm{~cm})$.rwd

Date / Time / Version: 25.06.2010/13:57:17 PM / RheoWin Pro 296

Substance / Sample no: KWISS 7 (16 cm)/ KWISS 7 (16 cm)

Curve discussion: Greatest value $\mathrm{t}[\mathrm{s}] 25.99 \tau[\mathrm{Pa}] 442.0$

Figure A.176. $76.5 \mathrm{wt} \% \mathrm{KW}$-A Solids at $1 \mathrm{hr}, 6.5 \mathrm{~cm}$ from Bottom of Column 


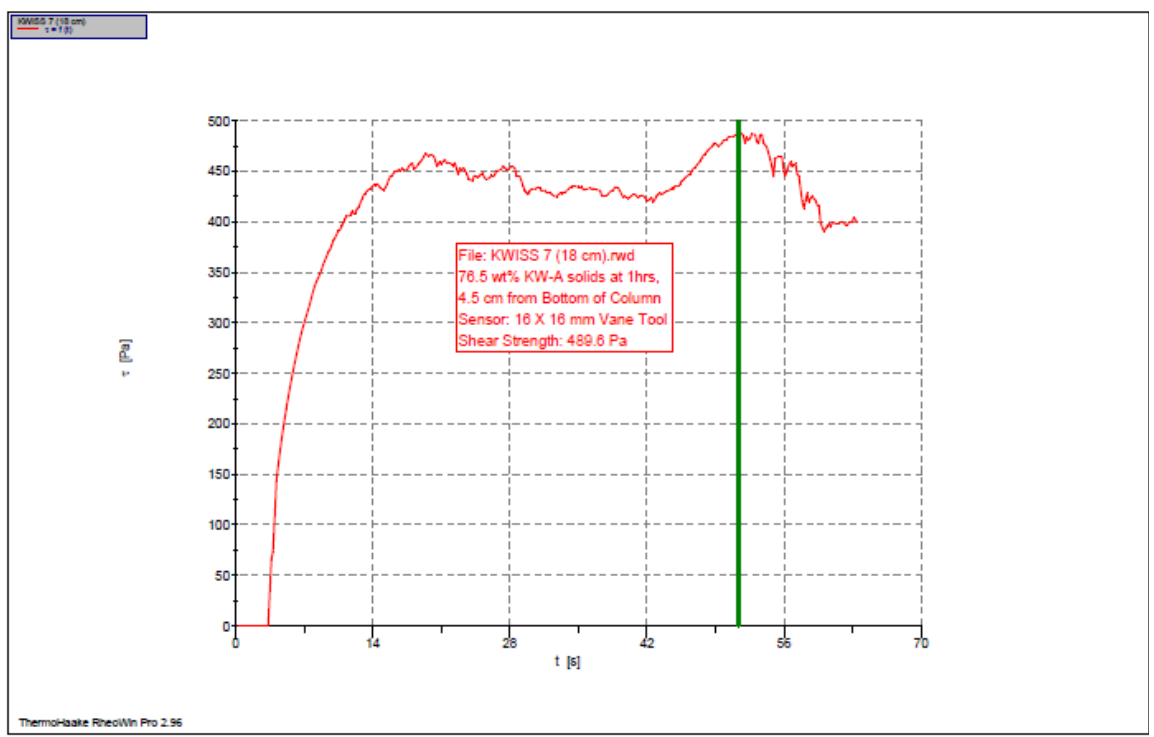

1: C:IK-Basin Rheol06252010WKWISS $7(18 \mathrm{~cm})$.rwd

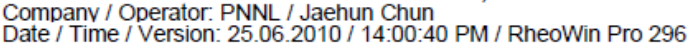

Substance / Sample no: KWISS $7(18 \mathrm{~cm}) / \mathrm{KWISS} 7(18 \mathrm{~cm})$

Curve discussion: Greatest value $\mathrm{t}[\mathrm{s}]$ 51.34 $\tau[\mathrm{Pa}] 489.6$

Figure A.177. $76.5 \mathrm{wt} \% \mathrm{KW}$-A Solids at $1 \mathrm{hr}, 4.5 \mathrm{~cm}$ from Bottom of Column

ThermoHaake RheoWin 8/1/2010/10:49 PM

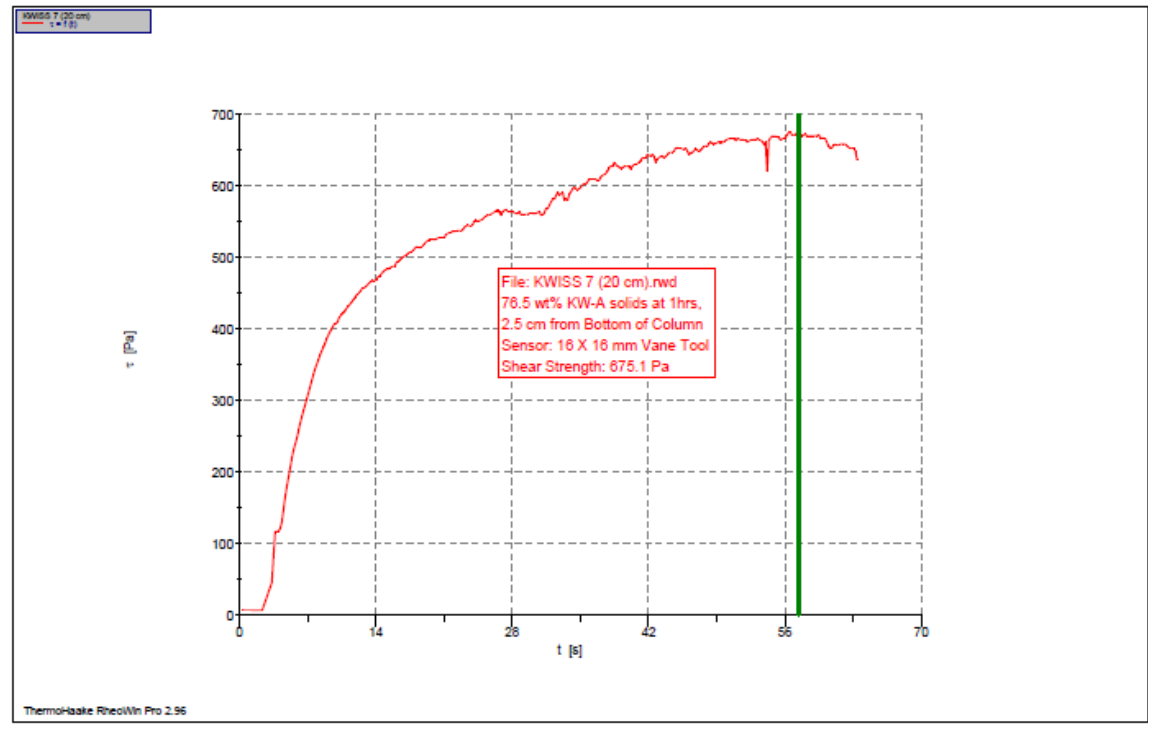

1: C:IK-Basin Rheol06252010UKWISS 7 (20 cm).rwd

Companv / Operator: PNNL / Jaehun Chun

Substance / Sample no: KWISS $7(20 \mathrm{~cm}) /$ KWISS $7(20 \mathrm{~cm})$

Curve discussion: Greatest value $\mathrm{t}[\mathrm{s}] 57.41 \tau[\mathrm{Pa}] 675.1$

Figure A.178. $76.5 \mathrm{wt} \% \mathrm{KW}$-A Solids at $1 \mathrm{hr}, 2.5 \mathrm{~cm}$ from Bottom of Column 
ThermoHaake RheoWin 8/2/2010 / 9:33 AM

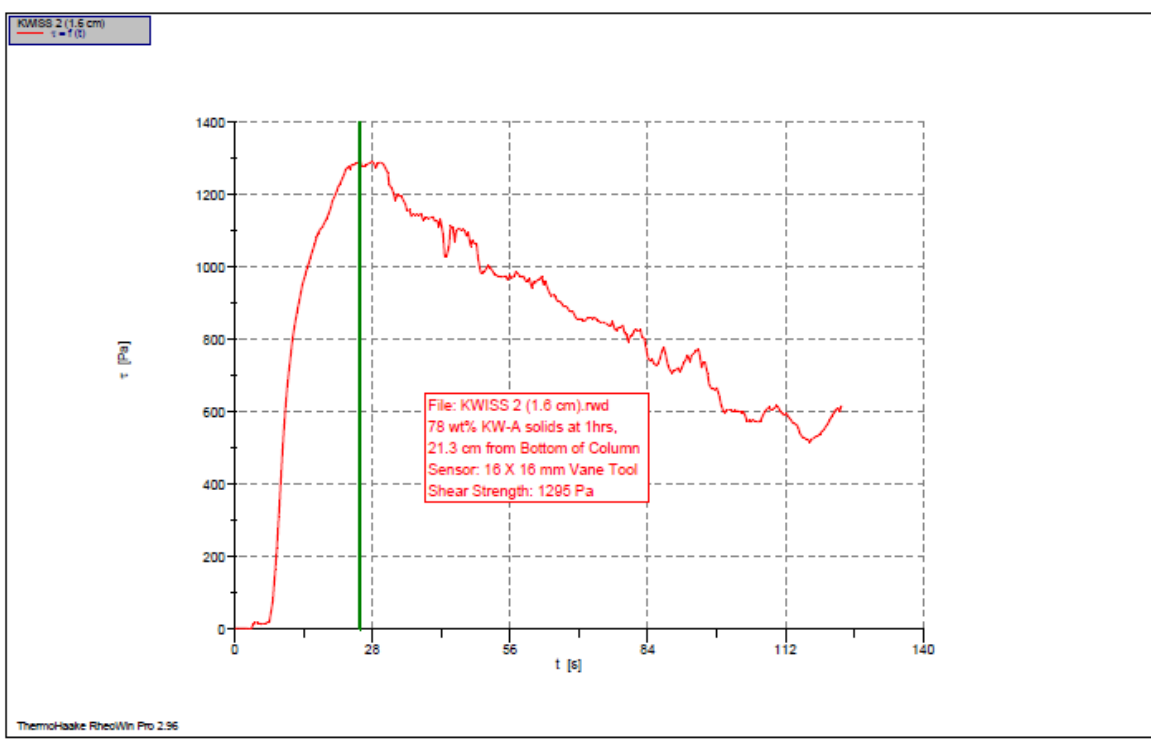

1: C:IK -Basin Rheol06162010UKWISS 2 (1.6 cm).rwd

Companv / Operator: PNNL / Jaehun Chun

Substance / Sample no: KWISS 2 $(1.6 \mathrm{~cm}) / \mathrm{KWISS} 2(1.6 \mathrm{~cm})$

Curve discussion: Greatest value $\mathrm{t}[\mathrm{s}] 25.51 \tau[\mathrm{Pa}] 1295$.

Figure A.179. $78 \mathrm{wt} \% \mathrm{KW}-\mathrm{A}$ Solids at $1 \mathrm{hr}, 21.3 \mathrm{~cm}$ from Bottom of Column

ThermoHaake RheoWin 8/2/2010/9:43 AM

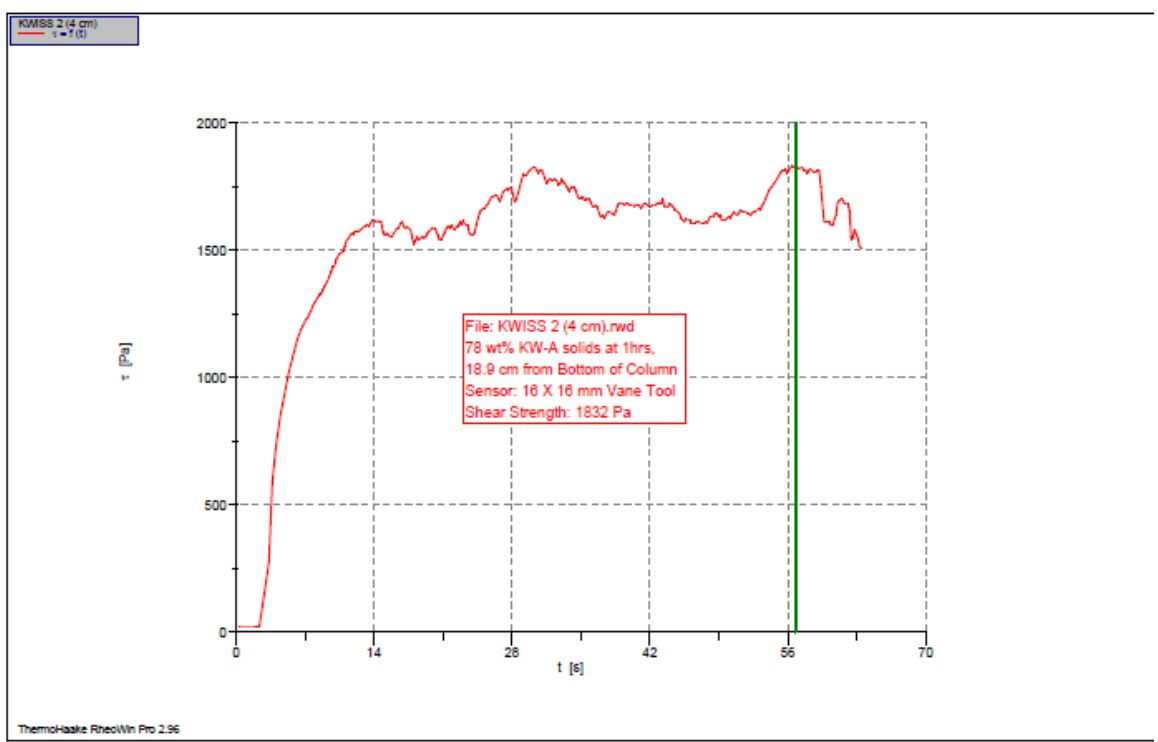

1: C:IK-Basin Rheol06162010XKWISS 2 (4 cm).rwd

Company / Operator: PNNL / Jaehun Chun

40:51 PM / RheoWin Pro 296

Substance / Sample no: KWISS $2(4 \mathrm{~cm}) / \mathrm{KWISS} 2(4 \mathrm{~cm})$

Curve discussion: Greatest value t [s] $56.79 \tau[\mathrm{Pa}] 1832$.

Figure A.180. $78 \mathrm{wt} \% \mathrm{KW}-\mathrm{A}$ Solids at $1 \mathrm{hr}, 18.9 \mathrm{~cm}$ from Bottom of Column 
ThermoHaake RheoWin 8/2/2010/9:44 AM

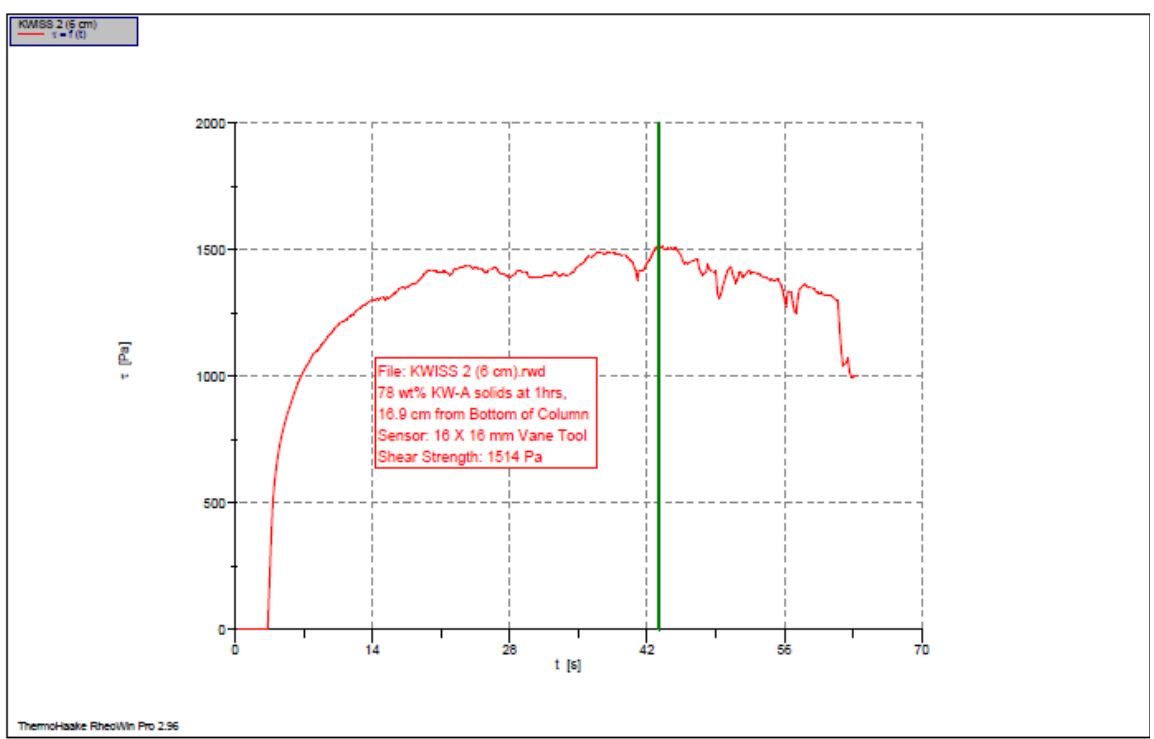

1: C:IK -Basin Rheol06162010UKWISS 2 (6 cm).rwd

Companv / Operator: PNNL / Jaehun Chun

Substance / Sample no: KWISS $2(6 \mathrm{~cm}) /$ KWISS $2(6 \mathrm{~cm})$

Curve discussion: Greatest value $\mathrm{t}[\mathrm{s}] 43.22 \tau[\mathrm{Pa}] 1514$.

Figure A.181. $78 \mathrm{wt} \% \mathrm{KW}-\mathrm{A}$ Solids at $1 \mathrm{hr}, 16.9 \mathrm{~cm}$ from Bottom of Column

ThermoHaake RheoWin $8 / 2 / 2010 / 9: 47$ AM

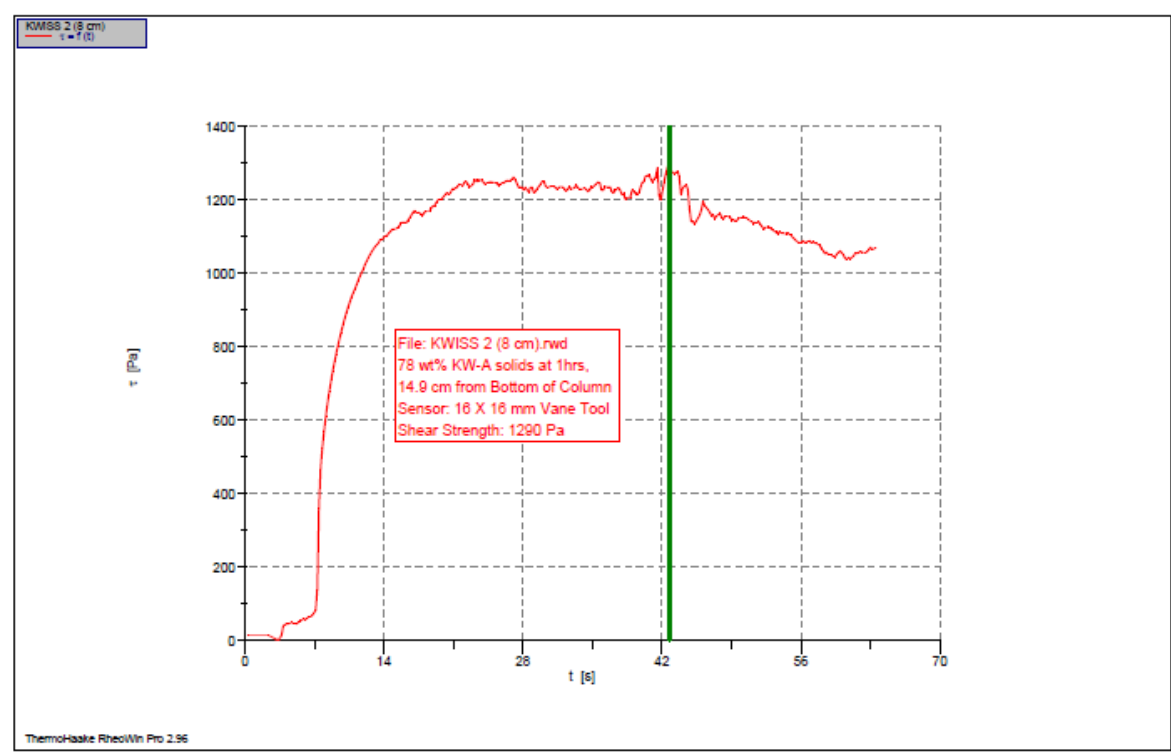

1: C:IK -Basin Rheol06162010UKWISS 2 (8 cm).rwd

Company / Operator: PNNL / Jaehun Chun

Date / Time / Version: 16.06.2010 / 14:50:38 PM / RheoWin Pro 296

Substance / Sample no: KWISS $2(8 \mathrm{~cm}) /$ KWISS $2(8 \mathrm{~cm})$

Curve discussion: Greatest value $\mathrm{t}[\mathrm{s}] 42.73 \tau[\mathrm{Pa}] 1290$.

Figure A.182. $78 \mathrm{wt} \% \mathrm{KW}-\mathrm{A}$ Solids at $1 \mathrm{hr}, 14.9 \mathrm{~cm}$ from Bottom of Column 
ThermoHaake RheoWin 8/2/2010/9:49 AM

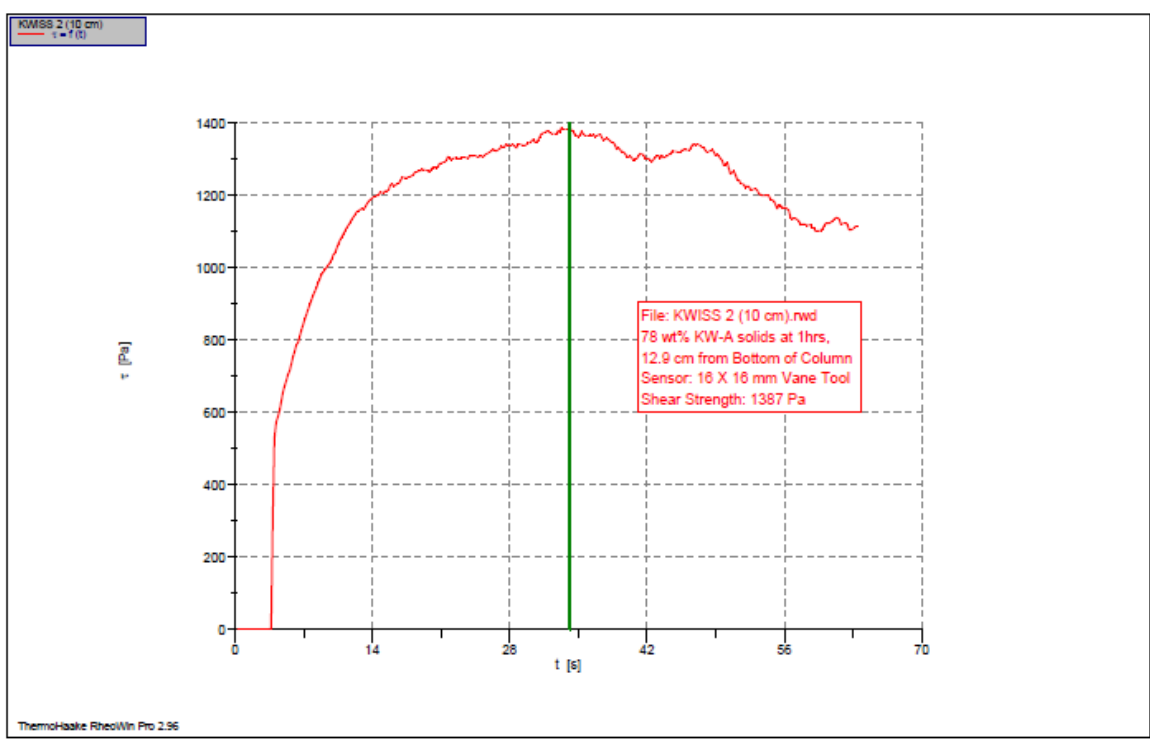

1: C:IK-Basin Rheol06162010XKWISS 2 (10 cm).rwd

Date / Time / Version: 16.06.2010 / 14:55:09 PM / RheoWin Pro 296

Substance / Sample no: KWISS $2(10 \mathrm{~cm}) / \mathrm{KWISS} 2(10 \mathrm{~cm})$

Curve discussion: Greatest value $\mathrm{t}[\mathrm{s}] 34.14 \tau[\mathrm{Pa}] 1387$.

Figure A.183. $78 \mathrm{wt} \% \mathrm{KW}-\mathrm{A}$ Solids at $1 \mathrm{hr}, 12.9 \mathrm{~cm}$ from Bottom of Column

ThermoHaake RheoWin 8/2/2010/9:50 AM

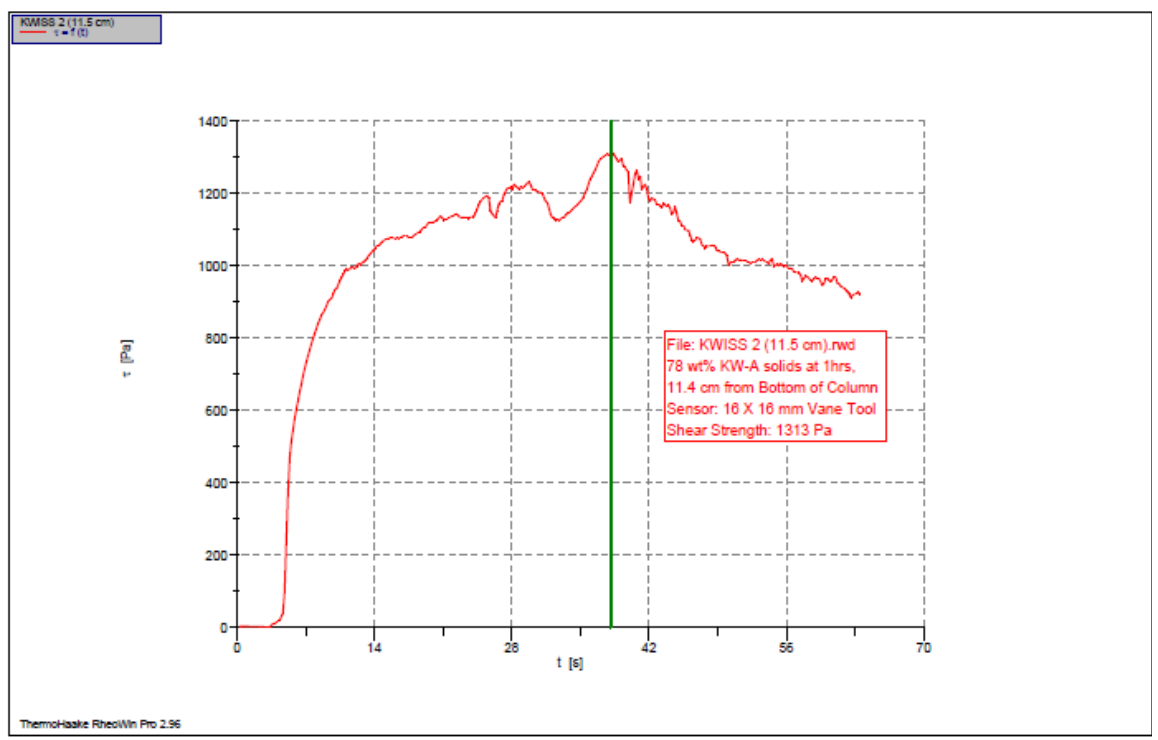

1: C:IK-Basin Rheol06162010XKWISS 2 (11.5 cm).rwd

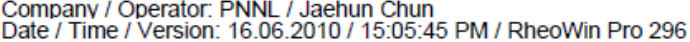

Substance / Sample no: KWISS $2(11.5 \mathrm{~cm}) /$ KWISS $2(11.5 \mathrm{~cm})$

Curve discussion: Greatest value $\mathrm{t}[\mathrm{s}] 38.13 \tau[\mathrm{Pa}] 1313$.

Figure A.184. $78 \mathrm{wt} \% \mathrm{KW}-\mathrm{A}$ Solids at $1 \mathrm{hr}, 11.4 \mathrm{~cm}$ from Bottom of Column 


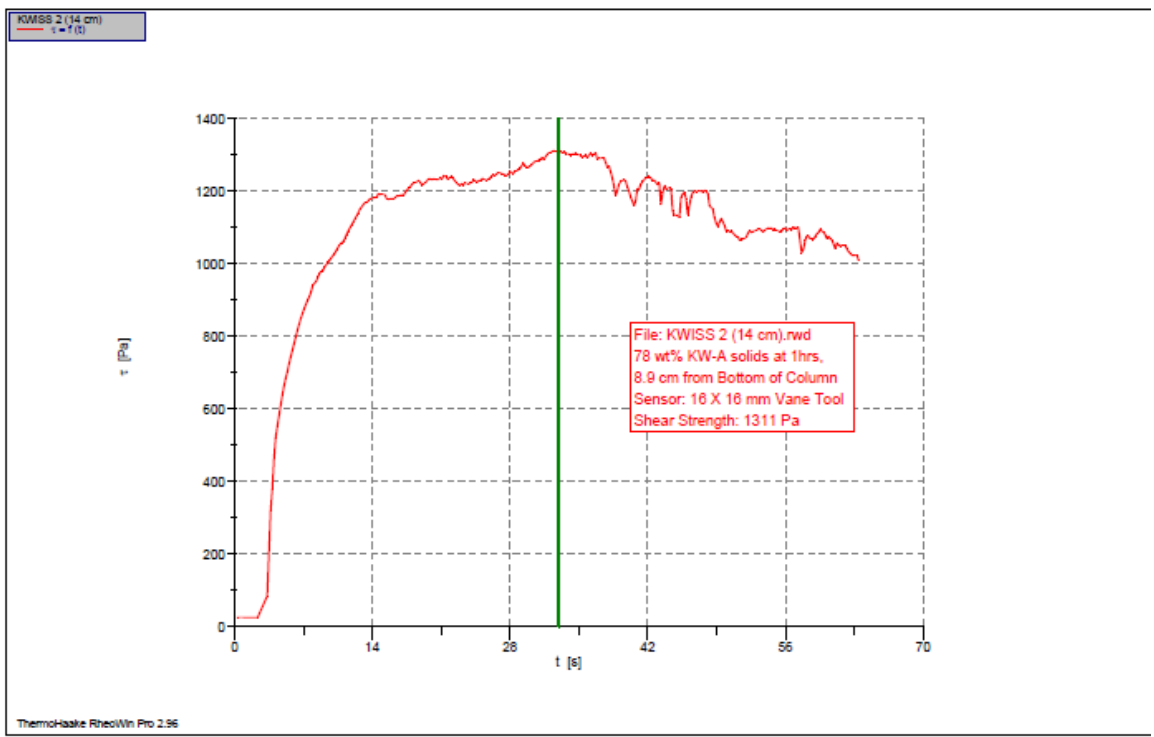

1: C:IK-Basin Rheol06162010XKWISS 2 (14 cm).rwd Companv / Operator: PNNL / Jaehun Chun

Ch:20 PM / RheoWin Pro 296

Substance / Sample no: KWISS 2 ( $14 \mathrm{~cm}$ ) / KWISS 2 (14 cm)

Curve discussion: Greatest value $\mathrm{t}[\mathrm{s}] 32.94 \tau[\mathrm{Pa}] 1311$.

Figure A.185. $78 \mathrm{wt} \% \mathrm{KW}$-A Solids at $1 \mathrm{hr}, 8.9 \mathrm{~cm}$ from Bottom of Column

ThermoHaake RheoWin 8/2/2010/9:54 AM

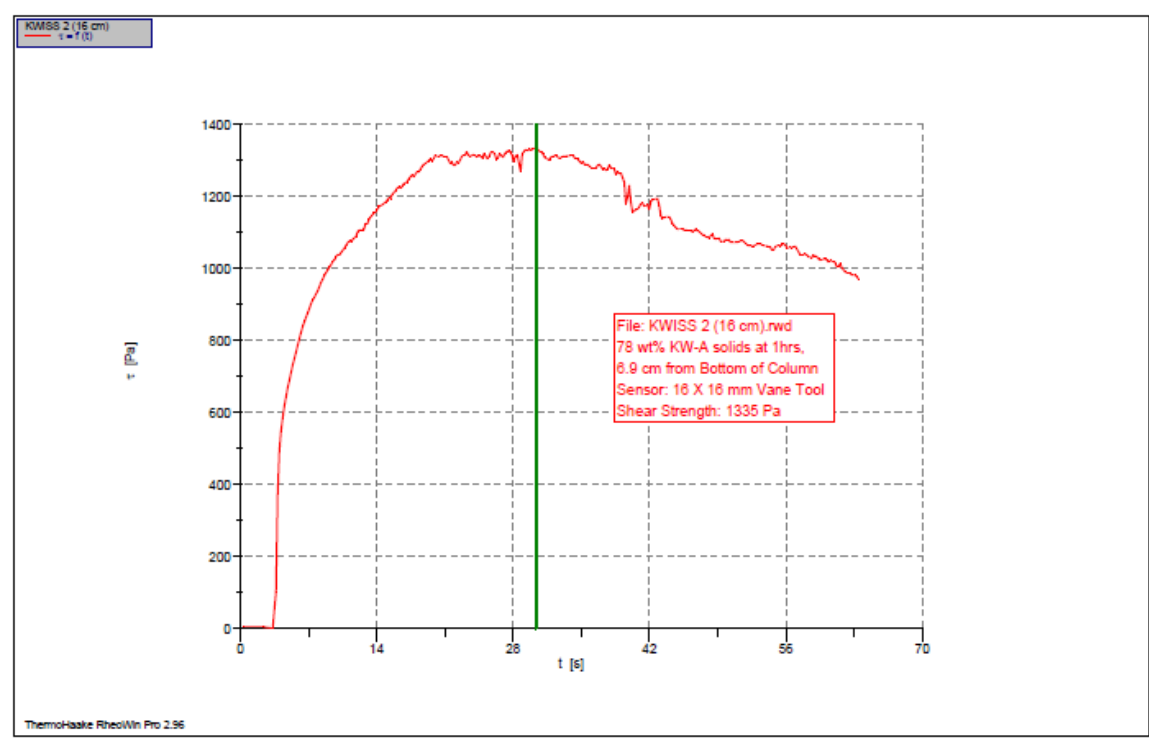

1: C:IK-Basin Rheol06162010UKWISS 2 (16 cm).rwd

Companv / Operator: PNNL / Jaehun Chun

Date / Time / Version: 16.06.2010 / 15:13:44 PM / RheoWin Pro 296

Substance / Sample no: KWISS 2 $(16 \mathrm{~cm}) /$ KWISS $2(16 \mathrm{~cm})$

Curve discussion: Greatest value $\mathrm{t}[\mathrm{s}] 30.37 \tau[\mathrm{Pa}] 1335$.

Figure A.186. $78 \mathrm{wt} \% \mathrm{KW}-\mathrm{A}$ Solids at $1 \mathrm{hr}, 6.9 \mathrm{~cm}$ from Bottom of Column 


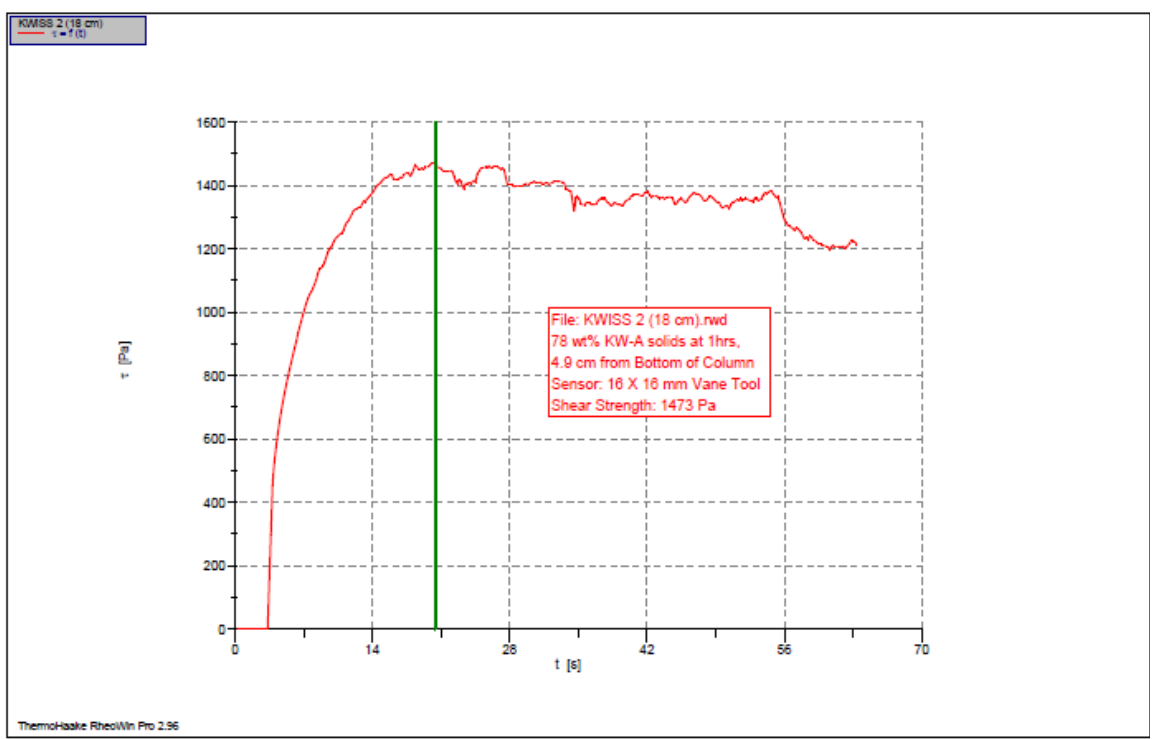

1: C:IK -Basin Rheol06162010UKWISS 2 (18 cm).rwd

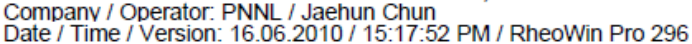

Substance / Sample no: KWISS $2(18 \mathrm{~cm}) /$ KWISS $2(18 \mathrm{~cm})$

Curve discussion: Greatest value $\mathrm{t}[\mathrm{s}] 20.43 \tau[\mathrm{Pa}] 1473$.

Figure A.187. $78 \mathrm{wt} \% \mathrm{KW}$-A Solids at $1 \mathrm{hr}, 4.9 \mathrm{~cm}$ from Bottom of Column

ThermoHaake RheoWin 8/2/2010/9:57 AM

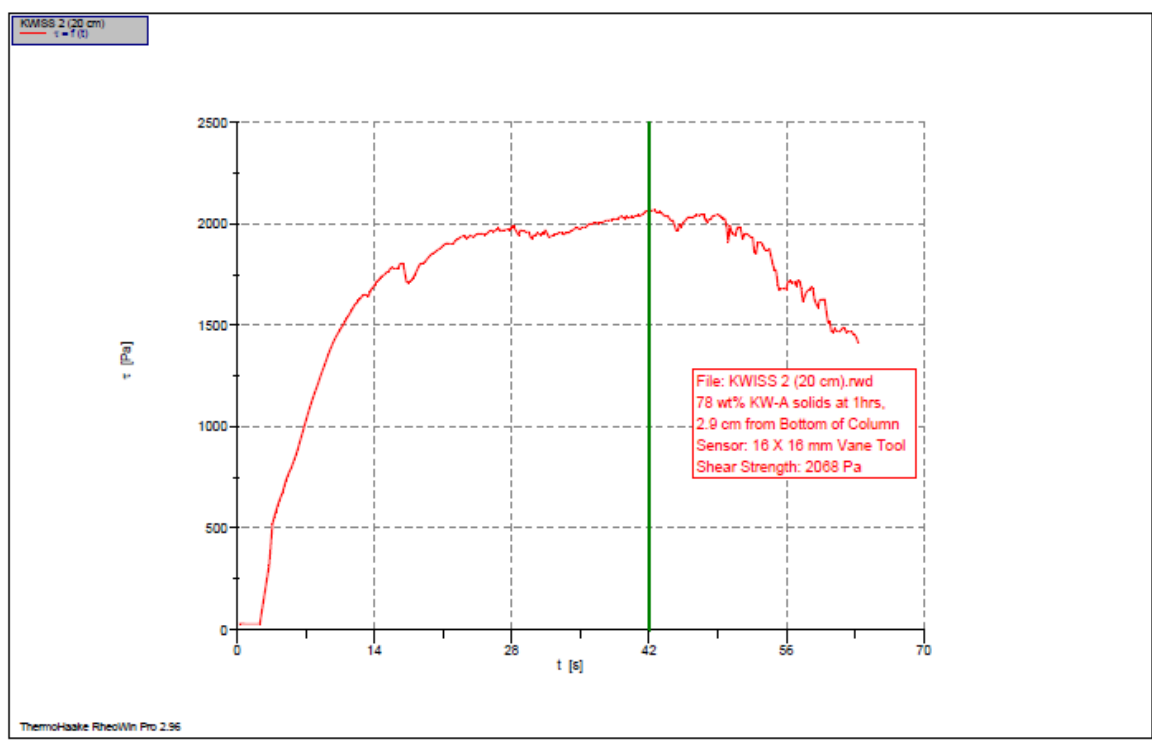

1: C:IK -Basin Rheol06162010UKWISS 2 (20 cm).rwd

Date / Time / Version: 16.06.2010 / 15:22:11 PM / RheoWin Pro 296

Substance / Sample no: KWISS $2(20 \mathrm{~cm}) /$ KWISS $2(20 \mathrm{~cm})$

Curve discussion: Greatest value $\mathrm{t}[\mathrm{s}] 42.05 \tau[\mathrm{Pa}] 2068$.

Figure A.188. $78 \mathrm{wt} \% \mathrm{KW}$-A Solids at $1 \mathrm{hr}, 2.9 \mathrm{~cm}$ from Bottom of Column 


\section{A.7 References}

Burns CA, PA Gauglitz, and RL Russell. 2010. Shear Strength Correlations for Kaolin/Water Slurries: A Comparison of Recent Measurements with Historical Data. PNNL-19094, Pacific Northwest National Laboratory, Richland, Washington.

Daniel RC. 2007. PNNL Technical Procedure, "Measurement of Physical and Rheological Properties of Solutions, Slurries and Sludges.” RPL-Colloid-02 Rev. 1, Pacific Northwest National Laboratory, Richland, Washington.

Kreyszig E. 1979. Advanced Engineering Mathematics. John Wiley \& Sons, New York.

Nguyen QD and DV Boger. 1985. "Direct Yield Stress Measurement with the Vane Method.” Journal of Rheology 29(3):335-347. 


\section{Appendix B}

KW Container Sludge Simulant (Complete) (KW-A) Provided to the Pacific Northwest National Laboratory 



\section{Appendix B: KW Container Sludge Simulant (Complete) (KW-A) Provided to the Pacific Northwest National Laboratory}

PNNL received dry batches of KW container sludge simulant (complete) from the CH2MHILL Plateau Remediation Company. Six small batches of about $2 \mathrm{~kg}$ and two large batches of about $20 \mathrm{~kg}$ were prepared and received. The specific masses of the individual components for each batch are given in the attached sheets in this appendix together with documentation of the receipt of the material.

Burbank (2009) provides a discussion of the individual components and the particle densities (see Table 7-5 of Burbank) for the material used in preparing the simulant batches. The individual particle densities and the calculated average from Burbank (2009) are given below in Table B.1 together with the weight fraction of the components. Burns et al. (2009) refer to this simulant as KW-A and provide additional characterization information.

Table B.1. Individual and Average Particle Density for KW Container Sludge Simulant (Complete) from Table 7-5 of Burbank et al. (2009) (KW-A)

\begin{tabular}{lcc}
\hline \multicolumn{1}{c}{ Component } & $\begin{array}{c}\text { Particle Density } \\
\left(\mathrm{kg} / \mathrm{m}^{3}\right)\end{array}$ & $\begin{array}{c}\text { Target wt\% } \\
(\%)\end{array}$ \\
\hline Cerium Oxide - $\mathrm{CeO}_{2}$ & 7130 & 30.9 \\
Steel Grit - $\mathrm{G} 120$ & 7860 & 4.2 \\
Gibbsite - $\mathrm{Al}(\mathrm{OH})_{3}(\mathrm{OC}-1000)$ & 2420 & 7.8 \\
Iron Oxide Hydroxide - Fe(OOH) & 2850 & 21.9 \\
Sand (Lane Mountain LM30) & 2600 & 14.7 \\
Aggregate (Gravel) & 2600 & 16.9 \\
Tungsten & 16900 & 3.6 \\
& & \\
\hline Average Particle Density & 3550 & \\
\hline
\end{tabular}

Burbank DA. 2009. Sludge Simulant Strategy and Design Basis. PRC-STP-00034 Rev. 0, CH2M Hill Plateau Remediation Company, Richland, Washington.

Burns CA, M Luna, and AJ Schmidt. 2009. Characterization of Settler Tank and KW Container Sludge Simulants. PNNL-18408, Pacific Northwest National Laboratory, Richland, Washington. 


\section{Buchmiller, William C}

From: Buchmiller, William C

Sent: Monday, May 03, 2010 3:50 PM

To: Gauglitz, Phillip A

Cc: Chun, Jaehun; Zumhoff, Mac R

Subject: FW: Simulants for Phil Gauglitz

Subject simulants received and placed in Chem storage. Please note that these are dry, batched chemicals .... not hydrated sludge. Where does this material go if it is deemed not appropriate for storage in APEL 117? How long will it be before it will be used for testing activities?

Thanks,

Bil

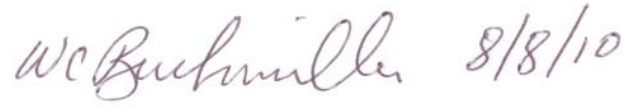

From: Lokken, Ryan O

Sent: Monday, May 03, 2010 1:45 PM

To: Buchmiller, William C

Subject: Simulants for Phil Gauglitz

Bill,

I have the simulants ready to deliver to APEL for Phil Gauglitz. Let me know when you would be available for receipt.

Thanks,

Ozyan 6 . Lokken

Principal Engineer

AEM Consulting, LLC

STP Testing

376-1011

460-1206 (cell) 


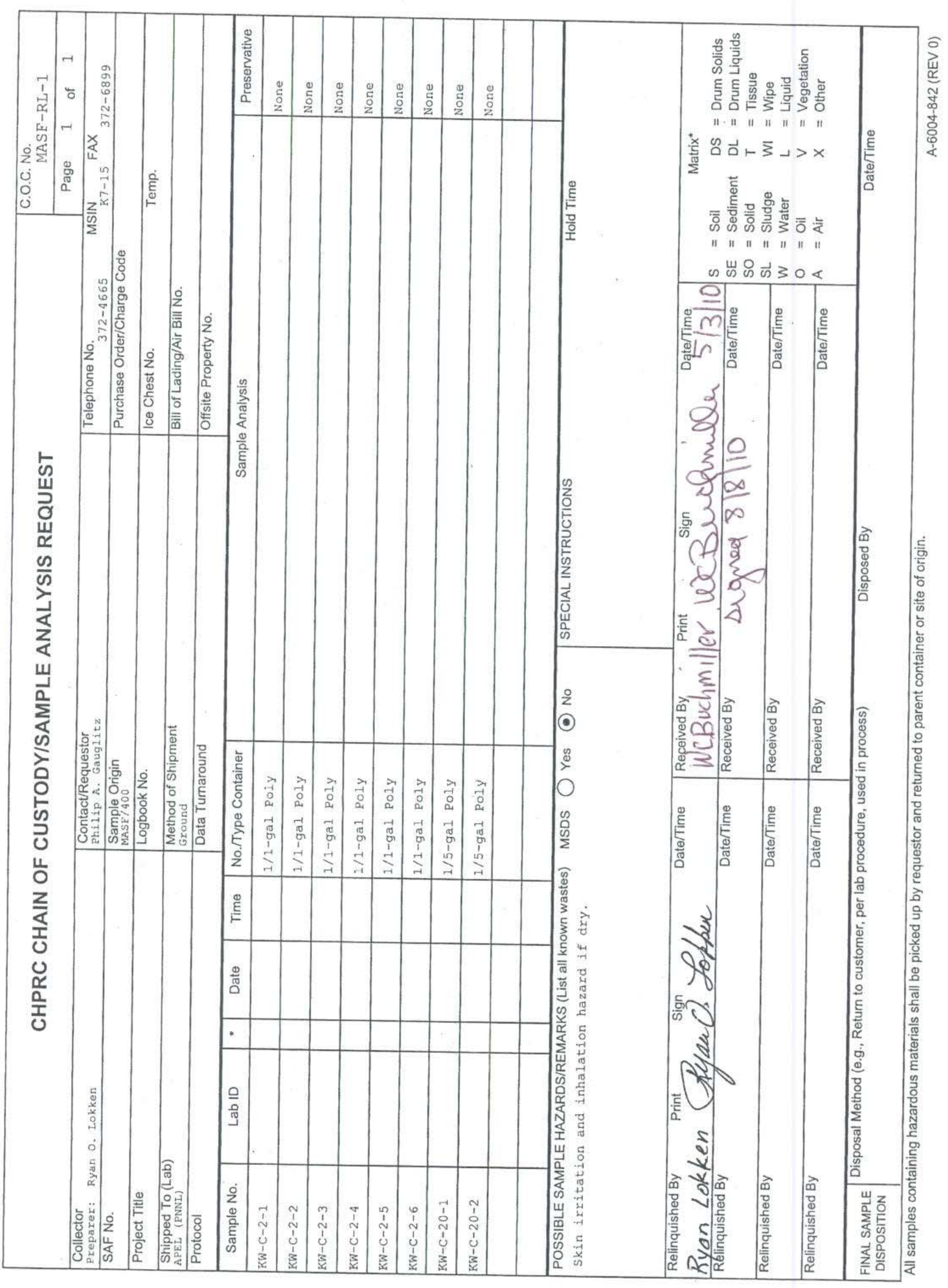




\section{KW Container Sludge Simulant (Complete)}

Batch No. 20 - 1

Target Dry Mass, kg

\begin{tabular}{|c|c|c|c|c|c|}
\hline \multirow[b]{2}{*}{ Component } & \multirow[b]{2}{*}{ Size Fraction } & \multicolumn{3}{|c|}{ (yargotMace } & (20.000 \\
\hline & & $\begin{array}{c}\text { Simulant size } \\
\text { distribution }\end{array}$ & Wt $\%$ of Total & $\begin{array}{c}\text { Target Mass } \\
(\mathrm{g})\end{array}$ & Measured Mass (g) \\
\hline Cerium Oxide $(\mathrm{CeO} 2)$ & $\mathrm{n} / \mathrm{a}$ & $100.00 \%$ & $30.90 \%$ & 6202 & 6203 \\
\hline Steel G120 & $\mathrm{n} / \mathrm{a}$ & $100.00 \%$ & $4.20 \%$ & 843 & 843 \\
\hline $\mathrm{Al}(\mathrm{OH}) 3-\mathrm{OC}-1000$ & $\mathrm{n} / \mathrm{a}$ & $100.00 \%$ & $7.80 \%$ & 1566 & 1565 \\
\hline $\mathrm{FeOOH}$ (Shepherd) & $\mathrm{n} / \mathrm{a}$ & $100.00 \%$ & $21.90 \%$ & 5053 & 5053 \\
\hline LM 30 Sand & $\mathrm{n} / \mathrm{a}$ & $100.00 \%$ & $14.70 \%$ & 2951 & 2950 \\
\hline \multirow{3}{*}{ Aggregate } & $-1 / 4+8$ & $35.00 \%$ & \multirow{3}{*}{$16.90 \%$} & 1186 & 1187 \\
\hline & $-8+12$ & $54.00 \%$ & & 1830 & 1830 \\
\hline & $-12+20$ & $11.00 \%$ & & 373 & 373 \\
\hline \multirow{14}{*}{ Tungsten } & $-12+20$ & $26.96 \%$ & \multirow{14}{*}{$3.60 \%$} & 194.8 & 195 \\
\hline & $-20+40$ & $16.55 \%$ & & 119.6 & 120 \\
\hline & $-40+60$ & $8.72 \%$ & & 63.0 & 63 \\
\hline & $4830 \mu \mathrm{m}$ Shot & $8.61 \%$ & & 62.2 & $62.34^{*}$ \\
\hline & $4570 \mu \mathrm{m}$ Shot & $5.02 \%$ & & 36.3 & 36.89 \\
\hline & $3810 \mu \mathrm{m}$ Shot & $5.90 \%$ & & 42.7 & 42.70 \\
\hline & $3560 \mu \mathrm{m}$ Shot & $3.94 \%$ & & 28.5 & 28.37 \\
\hline & $3300 \mu \mathrm{m}$ Shot & $4.79 \%$ & & 34.6 & 34.77 \\
\hline & $3050 \mu \mathrm{m}$ Shot & $4.36 \%$ & & 31.5 & 31.61 \\
\hline & $2790 \mu \mathrm{m}$ Shot & $4.36 \%$ & & 31.5 & 31.47 \\
\hline & $2540 \mu \mathrm{m}$ Shot & $3.51 \%$ & & 25.3 & 25.35 \\
\hline & $2290 \mu \mathrm{m}$ Shot & $2.99 \%$ & & 21.6 & 21.67 \\
\hline & $2160 \mu \mathrm{m}$ Shot & $2.22 \%$ & & 16.1 & 16.05 \\
\hline & $2030 \mu \mathrm{m}$ Shot & $2.06 \%$ & & 14.9 & 14.85 \\
\hline & & & $100.00 \%$ & 20725 & \\
\hline
\end{tabular}

M\&TE - Mettler PB4002-S-FACT (548-66-06-001) Expires 10/5/10

Mettler 32200 Gram Capacity (548-06-01-001) Expires 1/19/11

Tyoull topken $4 / 27 / 10 \quad$ Gross $22,150 \mathrm{~kg}$


KW Container Sludge Simulant (Complete)

Batch No. 20-2

Target Dry Mass, kg

\begin{tabular}{|c|c|c|c|c|c|}
\hline Component & Size Fraction & $\begin{array}{c}\text { Simulant size } \\
\text { distribution }\end{array}$ & $\mathrm{Wt} \%$ of Total & \begin{tabular}{|c|} 
Target Mass \\
$(\mathrm{g})$
\end{tabular} & Measured Mass (g) \\
\hline Cerium Oxide (CeO2) & $\mathrm{n} / \mathrm{a}$ & $100.00 \%$ & $30.90 \%$ & 6202 & 6202 \\
\hline Steel G120 & $\mathrm{n} / \mathrm{a}$ & $100.00 \%$ & $4.20 \%$ & 843 & 844 \\
\hline $\mathrm{Al}(\mathrm{OH}) 3-\mathrm{OC}-1000$ & $\mathrm{n} / \mathrm{a}$ & $100.00 \%$ & $7.80 \%$ & 1566 & 1566 \\
\hline FeOOH (Shepherd) & $\mathrm{n} / \mathrm{a}$ & $100.00 \%$ & $21.90 \%$ & 5053 & 5053 \\
\hline LM 30 Sand & $\mathrm{n} / \mathrm{a}$ & $100.00 \%$ & $14.70 \%$ & 2951 & 2951 \\
\hline \multirow{3}{*}{ Aggregate } & $-1 / 4+8$ & $35.00 \%$ & \multirow{3}{*}{$16.90 \%$} & 1186 & 1185 \\
\hline & $-8+12$ & $54.00 \%$ & & 1830 & 1830 \\
\hline & $-12+20$ & $11.00 \%$ & & 373 & 373 \\
\hline \multirow{14}{*}{ Tungsten } & $-12+20$ & $26.96 \%$ & \multirow{14}{*}{$3.60 \%$} & 194.8 & 195 \\
\hline & $-20+40$ & $16.55 \%$ & & 119.6 & 120 \\
\hline & $-40+60$ & $8.72 \%$ & & 63.0 & 63 \\
\hline & $4830 \mu \mathrm{m}$ Shot & $8.61 \%$ & & 62.2 & 61.91 \\
\hline & $4570 \mu \mathrm{m}$ Shot & $5.02 \%$ & & 36.3 & 36.64 \\
\hline & $3810 \mu \mathrm{m}$ Shot & $5.90 \%$ & & 42.7 & 42.59 \\
\hline & $3560 \mu \mathrm{m}$ Shot & $3.94 \%$ & & 28.5 & 28.57 \\
\hline & $3300 \mu \mathrm{m}$ Shot & $4.79 \%$ & & 34.6 & 34.56 \\
\hline & $3050 \mu \mathrm{m}$ Shot & $4.36 \%$ & & 31.5 & 31.86 \\
\hline & $2790 \mu \mathrm{m}$ Shot & $4.36 \%$ & & 31.5 & 31.64 \\
\hline & $2540 \mu \mathrm{m}$ Shot & $3.51 \%$ & & 25.3 & 25.32 \\
\hline & $2290 \mu \mathrm{m}$ Shot & $2.99 \%$ & & 21.6 & 21.73 \\
\hline & $2160 \mu \mathrm{m}$ Shot & $2.22 \%$ & & 16.1 & 16.10 \\
\hline & $2030 \mu \mathrm{m}$ Shot & $2.06 \%$ & & 14.9 & 14.82 \\
\hline & & & $100.00 \%$ & 20725 & \\
\hline
\end{tabular}

M\&TE - Mettler PB4002-S-FACT (548-66-06-001) Expires 10/5/10

Mettler 32200 Gram Capacity (548-06-01-001) Expires 1/19/11

Ffanc Lohken 4/27/10 Gross 22,15/ kg 


\section{KW Container Sludge Simulant (Complete)}

Batch No. 2-1

Target Dry Mass, $\mathrm{kg}$

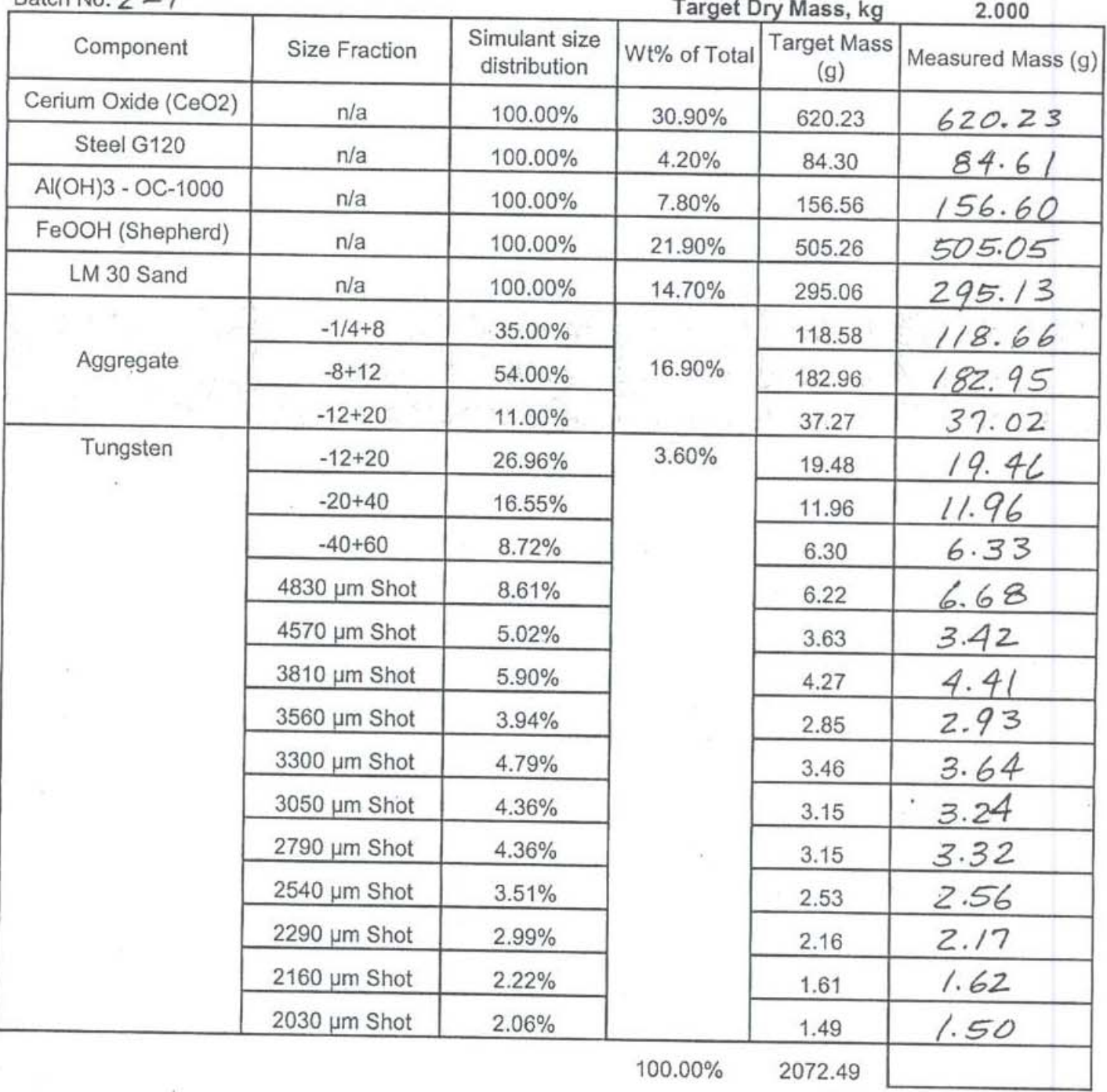

Gross Shipping Wt. $2357 \mathrm{~g}$

M\&TE - Mettler PB4002-S-FACT (548-66-06-001) Expires 10/5/10

Mettler 32200 Gram Capacity (548-06-01-001) Expires 1/19/11

Prepared by: Bufan Q Solken 4/27/10 
KW Container Sludge Simulant (Complete)

Batch No. $2-3$

Target Dry Mass, kg

2.000

\begin{tabular}{|c|c|c|c|c|c|}
\hline Component & Size Fraction & $\begin{array}{c}\text { Simulant size } \\
\text { distribution }\end{array}$ & Wt $\%$ of Total & \begin{tabular}{|c|}
$\begin{array}{c}\text { Target Mass } \\
(\mathrm{g})\end{array}$ \\
\end{tabular} & Measured Mass (g) \\
\hline Cerium Oxide (CeO2) & $\mathrm{n} / \mathrm{a}$ & $100.00 \%$ & $30.90 \%$ & 620.23 & 620.27 \\
\hline Steel G120 & $\mathrm{n} / \mathrm{a}$ & $100.00 \%$ & $4.20 \%$ & 84.30 & 84.37 \\
\hline $\mathrm{Al}(\mathrm{OH}) 3-\mathrm{OC}-1000$ & $\mathrm{n} / \mathrm{a}$ & $100.00 \%$ & $7.80 \%$ & 156.56 & 156.53 \\
\hline FeOOH (Shepherd) & $\mathrm{n} / \mathrm{a}$ & $100.00 \%$ & $21.90 \%$ & 505.26 & .505 .32 \\
\hline LM 30 Sand & $\mathrm{n} / \mathrm{a}$ & $100.00 \%$ & $14.70 \%$ & 295.06 & 295.35 \\
\hline \multirow{3}{*}{ Aggregate } & $-1 / 4+8$ & $35.00 \%$ & \multirow{3}{*}{$16.90 \%$} & 118.58 & 118.56 \\
\hline & $-8+12$ & $54.00 \%$ & & 182.96 & 183.00 \\
\hline & $-12+20$ & $11.00 \%$ & & 37.27 & 37.5 \\
\hline \multirow[t]{14}{*}{ Tungsten } & $-12+20$ & $26.96 \%$ & \multirow[t]{14}{*}{$3.60 \%$} & 19.48 & 19.42 \\
\hline & $-20+40$ & $16.55 \%$ & & 11.96 & 11.98 \\
\hline & $-40+60$ & $8.72 \%$ & & 6.30 & 6.34 \\
\hline & $4830 \mu \mathrm{m}$ Shot & $8.61 \%$ & & 6.22 & 6.49 \\
\hline & $4570 \mu \mathrm{m}$ Shot & $5.02 \%$ & & 3.63 & 3.66 \\
\hline & $3810 \mu \mathrm{m}$ Shot & $5.90 \%$ & & 4.27 & 4.41 \\
\hline & $3560 \mu \mathrm{m}$ Shot & $3.94 \%$ & & 2.85 & 2.91 \\
\hline & $3300 \mu \mathrm{m}$ Shot & $4.79 \%$ & & 3.46 & 3.54 \\
\hline & $3050 \mu \mathrm{m}$ Shot & $4.36 \%$ & & 3.15 & 3.24 \\
\hline & $2790 \mu \mathrm{m}$ Shot & $4.36 \%$ & & 3.15 & 3.11 \\
\hline & $2540 \mu \mathrm{m}$ Shot & $3.51 \%$ & & 2.53 & 2.53 \\
\hline & $2290 \mu \mathrm{m}$ Shot & $2.99 \%$ & & 2.16 & 2.15 \\
\hline & $2160 \mu \mathrm{m}$ Shot & $2.22 \%$ & & 1.61 & 1.61 \\
\hline & $2030 \mu \mathrm{m}$ Shot & $2.06 \%$ & & 1.49 & 1.48 \\
\hline & & & $100.00 \%$ & 2072.49 & \\
\hline
\end{tabular}

Gross Shipping Wt. $2368 \mathrm{~g}$

M\&TE - Mettler PB4002-S-FACT (548-66-06-001) Expires 10/5/10

Mettler 32200 Gram Capacity (548-06-01-001) Expires 1/19/11 (Not used)

Prepared by: Gyauc. Sorkw 4/22/10

B.7 


\section{KW Container Sludge Simulant (Complete)}

Batch No. 2 - 2

Target Dry Mass, kg

2.000

\begin{tabular}{|c|c|c|c|c|c|}
\hline Component & Size Fraction & $\begin{array}{c}\text { Simulant size } \\
\text { distribution }\end{array}$ & Wt $\%$ of Total & $\begin{array}{c}\text { Target Mass } \\
\text { (g) }\end{array}$ & Measured Mass $(\mathrm{g})$ \\
\hline Cerium Oxide $(\mathrm{CeO} 2)$ & $\mathrm{n} / \mathrm{a}$ & $100.00 \%$ & $30.90 \%$ & 620.23 & 620.25 \\
\hline Steel G120 & $\mathrm{n} / \mathrm{a}$ & $100.00 \%$ & $4.20 \%$ & 84.30 & 84.26 \\
\hline $\mathrm{Al}(\mathrm{OH}) 3-\mathrm{OC}-1000$ & $\mathrm{n} / \mathrm{a}$ & $100.00 \%$ & $7.80 \%$ & 156.56 & 156.51 \\
\hline FeOOH (Shepherd) & $\mathrm{n} / \mathrm{a}$ & $100.00 \%$ & $21.90 \%$ & 505.26 & 505.39 \\
\hline LM 30 Sand & $\mathrm{n} / \mathrm{a}$ & $100.00 \%$ & $14.70 \%$ & 295.06 & 295.24 \\
\hline \multirow{3}{*}{ Aggregate } & $-1 / 4+8$ & $35.00 \%$ & \multirow{3}{*}{$16.90 \%$} & 118.58 & 118.61 \\
\hline & $-8+12$ & $54.00 \%$ & & 182.96 & 183.00 \\
\hline & $-12+20$ & $11.00 \%$ & & 37.27 & 37.05 \\
\hline \multirow[t]{14}{*}{ Tungsten } & $-12+20$ & $26.96 \%$ & \multirow[t]{14}{*}{$3.60 \%$} & 19.48 & 19.51 \\
\hline & $-20+40$ & $16.55 \%$ & & 11.96 & 11.96 \\
\hline & $-40+60$ & $8.72 \%$ & & 6.30 & 6.40 \\
\hline & $4830 \mu \mathrm{m}$ Shot & $8.61 \%$ & & 6.22 & 6.33 \\
\hline & $4570 \mu \mathrm{m}$ Shot & $5.02 \%$ & & 3.63 & 3.27 \\
\hline & $3810 \mu \mathrm{m}$ Shot & $5.90 \%$ & & 4.27 & $4 \cdot 42$ \\
\hline & $3560 \mu \mathrm{m}$ Shot & $3.94 \%$ & & 2.85 & 2.84 \\
\hline & $3300 \mu \mathrm{m}$ Shot & $4.79 \%$ & & 3.46 & 3.54 \\
\hline & $3050 \mu \mathrm{m}$ Shot & $4.36 \%$ & & 3.15 & 3.22 \\
\hline & $2790 \mu \mathrm{m}$ Shot & $4.36 \%$ & & 3.15 & 3.32 \\
\hline & $2540 \mu \mathrm{m}$ Shot & $3.51 \%$ & & 2.53 & 2.53 \\
\hline & $2290 \mu \mathrm{m}$ Shot & $2.99 \%$ & & 2.16 & 2.15 \\
\hline & $2160 \mu \mathrm{m}$ Shot & $2.22 \%$ & & 1.61 & 1.61 \\
\hline & $2030 \mu \mathrm{m}$ Shot & $2.06 \%$ & & 1.49 & 1.45 \\
\hline
\end{tabular}

Gross Shipping Wt. $2354 \mathrm{~g}$

M\&TE - Mettler PB4002-S-FACT (548-66-06-001) Expires 10/5/10

Mettler 32200 Gram Capacity (548-06-01-001) Expires 1/19/11

Prepared by: Pyan (2) Sokpen 4/27/10 


\section{KW Container Sludge Simulant (Complete)}

Batch No. 2-3

Target Dry Mass, kg

2.000

\begin{tabular}{|c|c|c|c|c|c|}
\hline Component & Size Fraction & $\begin{array}{c}\text { Simulant size } \\
\text { distribution }\end{array}$ & $\mathrm{Wt} \%$ of Total & \begin{tabular}{|c|}
$\begin{array}{c}\text { Target Mass } \\
(\mathrm{g})\end{array}$ \\
\end{tabular} & Measured Mass $(\mathrm{g})$ \\
\hline Cerium Oxide (CeO2) & $\mathrm{n} / \mathrm{a}$ & $100.00 \%$ & $30.90 \%$ & 620.23 & 620.27 \\
\hline Steel G120 & $\mathrm{n} / \mathrm{a}$ & $100.00 \%$ & $4.20 \%$ & 84.30 & 84.37 \\
\hline $\mathrm{Al}(\mathrm{OH}) 3-\mathrm{OC}-1000$ & $n / a$ & $100.00 \%$ & $7.80 \%$ & 156.56 & 156.53 \\
\hline FeOOH (Shepherd) & $n / a$ & $100.00 \%$ & $21.90 \%$ & 505.26 & 505.32 \\
\hline LM 30 Sand & n/a & $100.00 \%$ & $14.70 \%$ & 295.06 & 295.35 \\
\hline \multirow{3}{*}{ Aggregate } & $-1 / 4+8$ & $35.00 \%$ & \multirow{3}{*}{$16.90 \%$} & 118.58 & 118.56 \\
\hline & $-8+12$ & $54.00 \%$ & & 182.96 & 183.00 \\
\hline & $-12+20$ & $11.00 \%$ & & 37.27 & 37.5 \\
\hline \multirow[t]{14}{*}{ Tungsten } & $-12+20$ & $26.96 \%$ & \multirow[t]{14}{*}{$3.60 \%$} & 19.48 & 19.42 \\
\hline & $-20+40$ & $16.55 \%$ & & 11.96 & 11.98 \\
\hline & $-40+60$ & $8.72 \%$ & & 6.30 & 6.34 \\
\hline & $4830 \mu \mathrm{m}$ Shot & $8.61 \%$ & & 6.22 & 6.49 \\
\hline & $4570 \mu \mathrm{m}$ Shot & $5.02 \%$ & & 3.63 & 3.66 \\
\hline & $3810 \mu \mathrm{m}$ Shot & $5.90 \%$ & & 4.27 & 4.41 \\
\hline & $3560 \mu \mathrm{m}$ Shot & $3.94 \%$ & & 2.85 & 2.91 \\
\hline & $3300 \mu \mathrm{m}$ Shot & $4.79 \%$ & & 3.46 & 3.54 \\
\hline & $3050 \mu \mathrm{m}$ Shot & $4.36 \%$ & & 3.15 & 3.24 \\
\hline & $2790 \mu \mathrm{m}$ Shot & $4.36 \%$ & & 3.15 & 3.11 \\
\hline & $2540 \mu \mathrm{m}$ Shot & $3.51 \%$ & & 2.53 & 2.53 \\
\hline & $2290 \mu \mathrm{m}$ Shot & $2.99 \%$ & & 2.16 & 2.15 \\
\hline & $2160 \mu \mathrm{m}$ Shot & $2.22 \%$ & & 1.61 & 1.61 \\
\hline & $2030 \mu \mathrm{m}$ Shot & $2.06 \%$ & & 1.49 & 1.48 \\
\hline
\end{tabular}

Gross Shipping Wt. $2368 \mathrm{~g}$

M\&TE - Mettler PB4002-S-FACT (548-66-06-001) Expires 10/5/10

Mettler 32200 Gram Capacity (548-06-01-001) Expires 1/19/11 (Not used)

Prepared by: ByanC. Folpur 4/27/10 


\section{KW Container Sludge Simulant (Complete)}

Batch No. $2-4$

Target Dry Mass, kg

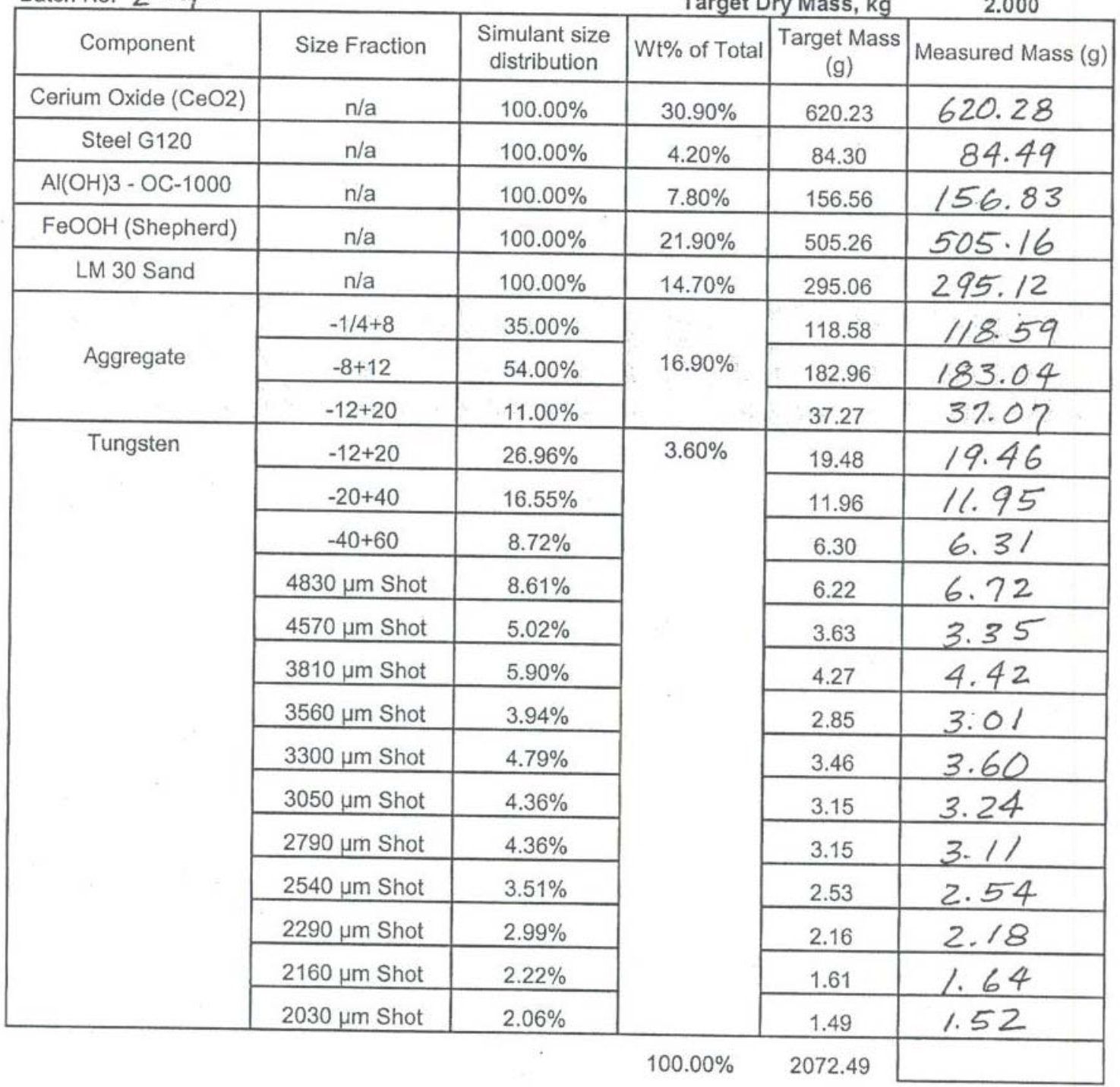

Gross Shipping Wt. $2375 \mathrm{~g}$

M\&TE - Mettler PB4002-S-FACT (548-66-06-001) Expires 10/5/10

Mettler 32200 Gram Capacity (548-06-01-001) Expires 1/19/11

Prepared by: PefanC. Lophen 4/27/10 
KW Container Sludge Simulant (Complete)

Batch No. 2-5

Target Dry Mass, kg

\begin{tabular}{|c|c|c|c|c|c|}
\hline \multicolumn{6}{|c|}{ and } \\
\hline Component & Size Fraction & $\begin{array}{c}\text { Simulant size } \\
\text { distribution }\end{array}$ & Wt $\%$ of Total & \begin{tabular}{|c|}
$\begin{array}{c}\text { Target Mass } \\
(\mathrm{g})\end{array}$ \\
\end{tabular} & Measured Mass (g) \\
\hline Cerium Oxide ( $\mathrm{CeO} 2)$ & $n / a$ & $100.00 \%$ & $30.90 \%$ & 620.23 & 620.32 \\
\hline Steel G120 & n/a & $100.00 \%$ & $4.20 \%$ & 84.30 & 84.31 \\
\hline $\mathrm{Al}(\mathrm{OH}) 3-\mathrm{OC}-1000$ & $\mathrm{n} / \mathrm{a}$ & $100.00 \%$ & $7.80 \%$ & 156.56 & 156.56 \\
\hline $\mathrm{FeOOH}$ (Shepherd) & $\mathrm{n} / \mathrm{a}$ & $100.00 \%$ & $21.90 \%$ & 505.26 & 505.22 \\
\hline LM 30 Sand & $\mathrm{n} / \mathrm{a}$ & $100.00 \%$ & $14.70 \%$ & 295.06 & 295.08 \\
\hline \multirow{3}{*}{ Aggregate } & $-1 / 4+8$ & $35.00 \%$ & \multirow{3}{*}{$16.90 \%$} & 118.58 & 118.55 \\
\hline & $-8+12$ & $54.00 \%$ & & 182.96 & 183.07 \\
\hline & $-12+20$ & $11.00 \%$ & & 37.27 & 37.05 \\
\hline \multirow[t]{14}{*}{ Tungsten } & $-12+20$ & $26.96 \%$ & \multirow[t]{14}{*}{$3.60 \%$} & 19.48 & 19.45 \\
\hline & $-20+40$ & $16.55 \%$ & & 11.96 & 12.02 \\
\hline & $-40+60$ & $8.72 \%$ & & 6.30 & 6.26 \\
\hline & $4830 \mu \mathrm{m}$ Shot & $8.61 \%$ & & 6.22 & 6.62 \\
\hline & $4570 \mu \mathrm{m}$ Shot & $5.02 \%$ & & 3.63 & 3.27 \\
\hline & $3810 \mu \mathrm{m}$ Shot & $5.90 \%$ & & 4.27 & 4.37 \\
\hline & $3560 \mu \mathrm{m}$ Shot & $3.94 \%$ & & 2.85 & 3.05 \\
\hline & $3300 \mu \mathrm{m}$ Shot & $4.79 \%$ & & 3.46 & 3.61 \\
\hline & $3050 \mu \mathrm{m}$ Shot & $4.36 \%$ & & 3.15 & 3.20 \\
\hline & $2790 \mu \mathrm{m}$ Shot & $4.36 \%$ & & 3.15 & 3.10 \\
\hline & $2540 \mu \mathrm{m}$ Shot & $3.51 \%$ & & 2.53 & 2.55 \\
\hline & $2290 \mu \mathrm{m}$ Shot & $2.99 \%$ & & 2.16 & 2.19 \\
\hline & $2160 \mu \mathrm{m}$ Shot & $2.22 \%$ & & 1.61 & 1.62 \\
\hline & $2030 \mu \mathrm{m}$ Shot & $2.06 \%$ & & 1.49 & 1.52 \\
\hline \multirow{2}{*}{\multicolumn{5}{|c|}{$\begin{array}{rr}100.00 \% & 2072.49 \\
\text { Gross Shipping Wt. } 23549\end{array}$}} & . \\
\hline & & & & & $2368 g^{234}$ \\
\hline
\end{tabular}

Mettler 32200 Gram Capacity (548-06-01-001) Expires 1/19/11

Prepared by: Gyan O. Lokkew 4/27/10 
KW Container Sludge Simulant (Complete)

Batch No. $2-6$

\begin{tabular}{|c|c|c|c|c|c|}
\hline & & & \multicolumn{2}{|c|}{ Target Dry Mass, kg } & 2.000 \\
\hline Component & Size Fraction & $\begin{array}{c}\text { Simulant size } \\
\text { distribution }\end{array}$ & Wt $\%$ of Total & \begin{tabular}{|c|}
$\begin{array}{c}\text { Target Mass } \\
(\mathrm{g})\end{array}$ \\
\end{tabular} & Measured Mass (g) \\
\hline Cerium Oxide $(\mathrm{CeO} 2)$ & $\mathrm{n} / \mathrm{a}$ & $100.00 \%$ & $30.90 \%$ & 620.23 & 620.41 \\
\hline Steel G120 & $n / a$ & $100.00 \%$ & $4.20 \%$ & 84.30 & 84.30 \\
\hline $\mathrm{Al}(\mathrm{OH}) 3-\mathrm{OC}-1000$ & n/a & $100.00 \%$ & $7.80 \%$ & 156.56 & 156.91 \\
\hline FeOOH (Shepherd) & $n / a$ & $100.00 \%$ & $21.90 \%$ & 505.26 & 505.25 \\
\hline LM 30 Sand & $\mathrm{n} / \mathrm{a}$ & $100.00 \%$ & $14.70 \%$ & 295.06 & 295.09 \\
\hline \multirow{3}{*}{ Aggregate } & $-1 / 4+8$ & $35.00 \%$ & \multirow{3}{*}{$16.90 \%$} & 118.58 & 118.73 \\
\hline & $-8+12$ & $54.00 \%$ & & 182.96 & 183.00 \\
\hline & $-12+20$ & $11.00 \%$ & & 37.27 & 37.00 \\
\hline \multirow[t]{14}{*}{ Tungsten } & $-12+20$ & $26.96 \%$ & \multirow[t]{14}{*}{$3.60 \%$} & 19.48 & 19.55 \\
\hline & $-20+40$ & $16.55 \%$ & & 11.96 & 11.92 \\
\hline & $-40+60$ & $8.72 \%$ & & 6.30 & 6.03 \\
\hline & $4830 \mu \mathrm{m}$ Shot & $8.61 \%$ & & 6.22 & 6.59 \\
\hline & $4570 \mu \mathrm{m}$ Shot & $5.02 \%$ & & 3.63 & 3.32 \\
\hline & $3810 \mu \mathrm{m}$ Shot & $5.90 \%$ & & 4.27 & 4.42 \\
\hline & $3560 \mu \mathrm{m}$ Shot & $3.94 \%$ & & 2.85 & 2.88 \\
\hline & $3300 \mu \mathrm{m}$ Shot & $4.79 \%$ & & 3.46 & 3.56 \\
\hline & $3050 \mu \mathrm{m}$ Shot & $4.36 \%$ & & 3.15 & 3.21 \\
\hline & $2790 \mu \mathrm{m}$ Shot & $4.36 \%$ & & 3.15 & 3.33 \\
\hline & $2540 \mu \mathrm{m}$ Shot & $3.51 \%$ & & 2.53 & 2.55 \\
\hline & $2290 \mu \mathrm{m}$ Shot & $2.99 \%$ & & 2.16 & 2.15 \\
\hline & $2160 \mu \mathrm{m}$ Shot & $2.22 \%$ & & 1.61 & 1.64 \\
\hline & $2030 \mu \mathrm{m}$ Shot & $2.06 \%$ & & 1.49 & 1.51 \\
\hline & & & $100.00 \%$ & 2072.49 & \\
\hline
\end{tabular}

Gross Shipping Wt.

M\&TE - Mettler PB4002-S-FACT (548-66-06-001) Expires 10/5/10

Mettler 32200 Gram Capacity (548-06-01-001) Expires 1/19/11 (Not used)

Prepared by: CyeneO. Fopken 4/27/10 


\section{Appendix C}

\section{Vessel-Spanning Bubble Test Conditions and Results}





\section{Appendix C: Vessel-Spanning Bubble Test Conditions and Results}

The following tables provide a listing of the individual tests, conditions, and results for the vesselspanning bubble and fin performance tests presented in Section 4. 
Table C.1. Test Results for Kaolin, 10-Inch, Flat-Bottom Vessel, 5-Degree/0.34-Inch Fin

\begin{tabular}{|c|c|c|c|c|c|c|c|c|c|c|c|}
\hline $\mathrm{TI}^{(\mathrm{a})}$ & Test \# & $\begin{array}{c}\text { wt } \% \\
\text { Kaolin } \\
\left(w_{t} \%\right)\end{array}$ & $\begin{array}{l}\text { Density } \\
\left(\mathrm{kg} / \mathrm{m}^{3}\right)\end{array}$ & $\begin{array}{l}\text { Measured } \\
\text { Shear } \\
\text { Strength } \\
(\mathrm{Pa})\end{array}$ & $\begin{array}{c}\text { Vessel } \\
\text { Diameter } \\
(\mathrm{m})\end{array}$ & $\mathrm{Y}_{\mathrm{G}}$ & $\begin{array}{l}\text { Layer } \\
\text { Depth } \\
\text { H/D }\end{array}$ & $\begin{array}{c}\text { Fin } \\
\text { Slope } \\
\text { (degrees) }\end{array}$ & $\begin{array}{l}\text { Fin } \\
\text { Width } \\
\text { (in.) }\end{array}$ & $\begin{array}{l}\text { Time at Release } \\
\text { (min.) }\end{array}$ & Stability \\
\hline 26 & $\mathrm{~K}-5$ & 49 & 1437 & 229 & 0.254 & 0.064 & 0.5125 & N/A & N/A & 11 & unstable \\
\hline 26 & $\mathrm{~K}-8$ & 50 & 1450 & 259 & 0.254 & 0.072 & 0.2875 & N/A & N/A & 15 & unstable \\
\hline 26 & K-9 & 50 & 1450 & 259 & 0.254 & 0.072 & 0.4875 & N/A & N/A & 27 & unstable \\
\hline 26 & $\mathrm{~K}-14$ & 52 & 1477 & 405 & 0.254 & 0.110 & 0.275 & $\mathrm{~N} / \mathrm{A}$ & N/A & 26 & unstable \\
\hline 26 & $\mathrm{~K}-22 \mathrm{~A}$ & 58 & 1563 & 1093 & 0.254 & 0.281 & 0.275 & N/A & N/A & 18 & unstable \\
\hline 23 & $14 \mathrm{D}$ & 48 & 1424 & 157 & 0.254 & 0.044 & 1.019 & N/A & N/A & 2 & unstable \\
\hline 23 & $14 \mathrm{E}$ & 48 & 1424 & 157 & 0.254 & 0.044 & 1.019 & N/A & N/A & 3 & unstable \\
\hline 23 & 14B & 49 & 1437 & 229 & 0.254 & 0.064 & 1.025 & N/A & N/A & 3 & unstable \\
\hline 23 & 18 & 49 & 1437 & 229 & 0.254 & 0.064 & 1.0 & 5 & 0.34 & 4 & unstable \\
\hline 23 & $13 \mathrm{C}$ & 52 & 1477 & 405 & 0.254 & 0.110 & 0.3 & 5 & 0.34 & 6 & Unstable w/fin \\
\hline 23 & $13 \mathrm{~B}$ & 52 & 1477 & 405 & 0.254 & 0.110 & 0.25 & 5 & 0.34 & 5 & Unstable w/fin \\
\hline 26 & K-16 & 55 & 1519 & 723 & 0.254 & 0.191 & 0.2625 & N/A & N/A & $62^{(\mathrm{b})}$ & stable \\
\hline 26 & $\mathrm{~K}-17$ & 55 & 1519 & 723 & 0.254 & 0.191 & 0.525 & N/A & N/A & $96^{(\mathrm{b})}$ & stable \\
\hline 26 & $\mathrm{~K}-22 \mathrm{~B}$ & 58 & 1563 & 1093 & 0.254 & 0.281 & 0.275 & N/A & N/A & $120^{(\mathrm{c})}$ & stable \\
\hline 23 & $14 \mathrm{C}$ & 49 & 1437 & 229 & 0.254 & 0.064 & 1.025 & N/A & N/A & $120^{(\mathrm{c})}$ & stable \\
\hline 23 & $14 \mathrm{~A}$ & 50 & 1450 & 259 & 0.254 & 0.072 & 1.025 & N/A & N/A & $120^{(\mathrm{c})}$ & stable \\
\hline 23 & 1 & 55 & 1519 & 723 & 0.254 & 0.191 & 1 & N/A & N/A & $84^{(\mathrm{c})}$ & stable \\
\hline 23 & 0 & 58 & 1563 & 1093 & 0.254 & 0.281 & 0.988 & N/A & $\mathrm{N} / \mathrm{A}$ & $84^{(\mathrm{c})}$ & stable \\
\hline 26 & K-6 & 49 & 1437 & 229 & 0.254 & 0.064 & 0.7625 & N/A & N/A & $120^{(\mathrm{c})}$ & stable \\
\hline 26 & $\mathrm{~K}-10$ & 50 & 1450 & 259 & 0.254 & 0.072 & 0.725 & N/A & N/A & $120^{(\mathrm{c})}$ & stable \\
\hline 26 & K-15 & 52 & 1477 & 405 & 0.254 & 0.110 & 0.5 & N/A & N/A & $120^{(\mathrm{c})}$ & stable \\
\hline 26 & $\mathrm{~K}-13$ & 50 & 1450 & 259 & 0.254 & 0.072 & 0.725 & 5 & 0.34 & $97^{(\mathrm{b})}$ & stable \\
\hline 23 & $18 \mathrm{~B}$ & 49 & 1437 & 229 & 0.254 & 0.064 & 1 & 5 & 0.34 & $121^{(\mathrm{b})}$ & stable \\
\hline 23 & 19 & 50 & 1450 & 259 & 0.254 & 0.072 & 1.025 & 5 & 0.34 & $101^{(b)}$ & stable \\
\hline 23 & $13 \mathrm{~A}$ & 52 & 1477 & 405 & 0.254 & 0.110 & 1.038 & 5 & 0.34 & $150^{(\mathrm{c})}$ & stable \\
\hline 26 & $\mathrm{~K}-7$ & 49 & 1437 & 229 & 0.254 & 0.064 & 0.7625 & 5 & 0.34 & 35 & disrupted \\
\hline 23 & $13 \mathrm{E}$ & 52 & 1477 & 405 & 0.254 & 0.110 & 0.75 & 5 & 0.34 & 14 & disrupted \\
\hline 23 & $13 \mathrm{~F}$ & 52 & 1477 & 405 & 0.254 & 0.110 & 0.75 & 5 & 0.34 & 8 & disrupted \\
\hline 23 & $13 \mathrm{D}$ & 52 & 1477 & 405 & 0.254 & 0.110 & 0.5 & 5 & 0.34 & 10 & disrupted \\
\hline 23 & 4 & 55 & 1519 & 723 & 0.254 & 0.191 & 1.013 & 5 & 0.34 & 2 & disrupted \\
\hline 23 & 6 & 55 & 1519 & 723 & 0.254 & 0.191 & 1.025 & 5 & 0.34 & 4 & disrupted \\
\hline 23 & 00 & 58 & 1563 & 1093 & 0.254 & 0.281 & 1 & 5 & 0.34 & 6 & disrupted \\
\hline
\end{tabular}

(b) Tests considered stable since gas release occurred after VSB reached a height over $\mathrm{H} / \mathrm{D}=0.15$ (criteria for considering a stable VSB in 10-inch vessel)

(c) VSB reached a height of 5 inches $(\mathrm{H} / \mathrm{D}=0.50)$ and test was terminated 
Table C.2. Test Results for Kaolin/Min-U-Sil 30, 10-Inch, Flat-Bottom Vessel, 5-Degree/0.34-Inch Fin

\begin{tabular}{|c|c|c|c|c|c|c|c|c|c|c|c|c|}
\hline $\mathrm{TI}^{(\mathrm{a})}$ & $\begin{array}{c}\text { Test } \\
\#\end{array}$ & $\begin{array}{c}\mathrm{wt} \% \\
\text { Kaolin } \\
(\mathrm{wt} \%)\end{array}$ & $\begin{array}{c}\text { wt } \% \\
\text { Min-U- } \\
\text { Sil 30 } \\
(w t \%)\end{array}$ & $\begin{array}{l}\text { Density } \\
\left(\mathrm{kg} / \mathrm{m}^{3}\right)\end{array}$ & $\begin{array}{l}\text { Measured } \\
\text { Shear } \\
\text { Strength } \\
\text { (Pa) }\end{array}$ & $\begin{array}{l}\text { Vessel } \\
\text { Diameter } \\
(\mathrm{m})\end{array}$ & $\mathrm{Y}_{\mathrm{G}}$ & $\begin{array}{c}\text { Layer } \\
\text { Depth } \\
\text { H/D }\end{array}$ & $\begin{array}{c}\text { Fin } \\
\text { Slope } \\
\text { (degrees) }\end{array}$ & $\begin{array}{l}\text { Fin } \\
\text { Width } \\
\text { (in.) }\end{array}$ & $\begin{array}{l}\text { Time at } \\
\text { Release } \\
\text { (min.) }\end{array}$ & Stability \\
\hline 26 & $\mathrm{P}-1 \mathrm{~A}$ & 40 & 16 & 1533 & 172 & 0.254 & 0.045 & 0.25 & $\mathrm{~N} / \mathrm{A}$ & $\mathrm{N} / \mathrm{A}$ & 9 & unstable \\
\hline 26 & P-1B & 40 & 16 & 1533 & 172 & 0.254 & 0.045 & 1 & N/A & N/A & 9 & unstable \\
\hline 26 & P-3A & 40 & 19 & 1579 & 291 & 0.254 & 0.074 & 0.25 & N/A & N/A & 3 & unstable \\
\hline 26 & P-5 & 40 & 20.5 & 1602 & 363 & 0.254 & 0.091 & 0.275 & N/A & N/A & 1 & unstable \\
\hline 26 & P-3B & 40 & 19 & 1579 & 291 & 0.254 & 0.074 & 0.5125 & N/A & N/A & $120^{(\mathrm{b})}$ & stable \\
\hline 26 & P-6 & 40 & 20.5 & 1602 & 363 & 0.254 & 0.091 & 0.5 & $\mathrm{~N} / \mathrm{A}$ & $\mathrm{N} / \mathrm{A}$ & $120^{(\mathrm{b})}$ & stable \\
\hline 26 & P-10 & 40 & 20.5 & 1602 & 363 & 0.254 & 0.091 & 1.0125 & 5 & 0.34 & $120^{(\mathrm{b})}$ & stable w/fin \\
\hline 26 & P-10B & 40 & 20.5 & 1602 & 363 & 0.254 & 0.091 & 1 & 5 & 0.34 & $118^{(\mathrm{b})}$ & stable w/fin \\
\hline 26 & P-4B & 40 & 19 & 1579 & 291 & 0.254 & 0.074 & 1.05 & 5 & 0.34 & 20 & disrupted \\
\hline 26 & P-4A & 40 & 19 & 1579 & 291 & 0.254 & 0.074 & 0.5125 & 5 & 0.34 & 19 & disrupted \\
\hline 26 & P-9 & 40 & 20.5 & 1602 & 363 & 0.254 & 0.091 & 0.5 & 5 & 0.34 & 5 & disrupted \\
\hline 26 & C-36B & 40 & 23 & 1643 & 681 & 0.254 & 0.166 & 0.5 & 5 & 0.34 & 8 & disrupted \\
\hline 26 & C-36A & 40 & 23 & 1643 & 681 & 0.254 & 0.166 & 1 & 5 & 0.34 & 7 & disrupted \\
\hline
\end{tabular}

(b) VSB reached a height of 5 inches $(\mathrm{H} / \mathrm{D}=0.50)$ and test was terminated 
Table C.3. Test Results for KW Container Sludge Simulant (Complete), 10-Inch, Flat-Bottom Vessel, 5-Degree/0.34-Inch Fin

\begin{tabular}{|c|c|c|c|c|c|c|c|c|c|c|c|}
\hline \multirow[b]{2}{*}{$\mathrm{TI}^{(\mathrm{a})}$} & \multicolumn{11}{|c|}{ Measured } \\
\hline & $\begin{array}{c}\text { Test } \\
\#\end{array}$ & $\begin{array}{c}\mathrm{wt} \% \\
\text { KWSS } \\
(\mathrm{wt} \%)\end{array}$ & $\begin{array}{l}\text { Density } \\
\left(\mathrm{kg} / \mathrm{m}^{3}\right)\end{array}$ & $\begin{array}{c}\text { Shear } \\
\text { Strength } \\
(\mathrm{Pa})\end{array}$ & $\begin{array}{c}\text { Vessel } \\
\text { Diameter } \\
(\mathrm{m})\end{array}$ & $\mathrm{Y}_{\mathrm{G}}$ & $\begin{array}{c}\text { Layer } \\
\text { Depth } \\
\text { H/D }\end{array}$ & $\begin{array}{c}\text { Fin } \\
\text { Slope } \\
\text { (degrees) }\end{array}$ & $\begin{array}{c}\text { Fin } \\
\text { Width } \\
\text { (in.) }\end{array}$ & $\begin{array}{c}\text { Time at } \\
\text { Release } \\
\text { (min.) }\end{array}$ & Stability \\
\hline 26 & KWSS1-1 & 75 & 2169 & 220 & 0.254 & 0.041 & 0.9625 & 5 & 0.34 & 1 & unstable \\
\hline 26 & KWSS1-2 & 75 & 2169 & 220 & 0.254 & 0.041 & 0.95 & N/A & $\mathrm{N} / \mathrm{A}$ & 1 & unstable \\
\hline 26 & KWSS2-2B & 78 & 2275 & 1350 & 0.254 & 0.238 & 0.9 & N/A & N/A & $61^{(\mathrm{b})}$ & stable \\
\hline 26 & KWSS7-2 & 76.5 & 2221 & 410 & 0.254 & 0.074 & 0.8875 & N/A & $\mathrm{N} / \mathrm{A}$ & $125^{(\mathrm{c})}$ & stable \\
\hline 26 & KWSS2-1 & 78 & 2275 & 1350 & 0.254 & 0.238 & 0.9 & 5 & 0.34 & 7 & disrupted \\
\hline 26 & KWSS7-1 & 76.5 & 2221 & 410 & 0.254 & 0.074 & 0.8875 & 5 & 0.34 & 9 & disrupted \\
\hline 26 & KWSS7-1B & 76.5 & 2221 & 410 & 0.254 & 0.074 & 0.8875 & 5 & 0.34 & 10 & disrupted \\
\hline
\end{tabular}

(b) Tests considered stable since gas release occurred after VSB reached a height over H/D $=0.15$ (criteria for considering a stable VSB in 10-inch vessel)

(c) VSB reached a height of 5 inches $(\mathrm{H} / \mathrm{D}=0.50)$ without release 
Table C.4. Test Results for Kaolin, 10-Inch, Flat-Bottom Vessel, All Alternative Fin Designs

\begin{tabular}{|c|c|c|c|c|c|c|c|c|c|c|c|}
\hline $\mathrm{TI}^{(\mathrm{a})}$ & $\begin{array}{c}\text { Test } \\
\#\end{array}$ & $\begin{array}{c}\text { wt } \% \\
\text { Kaolin } \\
\left(w_{t} \%\right)\end{array}$ & $\begin{array}{l}\text { Density } \\
\left(\mathrm{kg} / \mathrm{m}^{3}\right)\end{array}$ & $\begin{array}{l}\text { Measured } \\
\text { Shear } \\
\text { Strength } \\
\text { (Pa) }\end{array}$ & $\begin{array}{c}\text { Vessel } \\
\text { Diameter } \\
\text { (m) }\end{array}$ & $\mathrm{Y}_{\mathrm{G}}$ & $\begin{array}{c}\text { Layer } \\
\text { Depth } \\
\text { H/D }\end{array}$ & $\begin{array}{c}\text { Fin } \\
\text { Slope } \\
\text { (degrees) }\end{array}$ & $\begin{array}{c}\text { Fin } \\
\text { Width } \\
\text { (in.) }\end{array}$ & $\begin{array}{c}\text { Time at Release } \\
\text { (min.) }\end{array}$ & Stability \\
\hline 23 & $26 \mathrm{~A}$ & 49 & 1437 & 229 & 0.254 & 0.064 & 1.0125 & 5 & $0.69^{(\mathrm{c})}$ & 47 & stable \\
\hline 23 & 27 & 50 & 1450 & 259 & 0.254 & 0.072 & 1.05 & 5 & $0.69^{(\mathrm{c})}$ & 76 & stable \\
\hline 23 & $30^{(\mathrm{b})}$ & 49 & 1437 & 229 & 0.254 & 0.064 & 1.013 & 5,5 & $0.34,0.69^{(\mathrm{f})}$ & 90 & stable \\
\hline 23 & 2 & 55 & 1519 & 723 & 0.254 & 0.191 & 1.0375 & 5 & 0.086 & 5 & disrupted \\
\hline 23 & $2 \mathrm{~B}$ & 55 & 1519 & 723 & 0.254 & 0.191 & 1.0438 & 5 & 0.086 & 3 & disrupted \\
\hline 23 & 3 & 55 & 1519 & 723 & 0.254 & 0.191 & 1 & 5 & 0.17 & 3 & disrupted \\
\hline 23 & 5 & 55 & 1519 & 723 & 0.254 & 0.191 & 1.0125 & 5 & $0.69^{(\mathrm{d})}$ & 3 & disrupted \\
\hline 23 & 8 & 55 & 1519 & 723 & 0.254 & 0.191 & 1 & 2.5 & 0.086 & 4 & disrupted \\
\hline 23 & 9 & 55 & 1519 & 723 & 0.254 & 0.191 & 1 & 2.5 & 0.34 & 4 & disrupted \\
\hline 23 & 11 & 55 & 1519 & 723 & 0.254 & 0.191 & 1 & 10 & 0.34 & 2 & disrupted \\
\hline 23 & $22 \mathrm{~A}$ & 50 & 1450 & 259 & 0.254 & 0.072 & 1.025 & 10 & 0.34 & 27 & disrupted \\
\hline 23 & $26 \mathrm{~B}$ & 49 & 1437 & 229 & 0.254 & 0.064 & 1 & 5 & $0.69^{(\mathrm{c})}$ & 3 & disrupted \\
\hline 23 & 28 & 55 & 1519 & 723 & 0.254 & 0.191 & 1 & 5 & $0.69^{(\mathrm{c})}$ & 4 & disrupted \\
\hline 23 & 29 & 52 & 1477 & 405 & 0.254 & 0.110 & 1.025 & 5 & $0.69^{(\mathrm{c})}$ & 17 & disrupted \\
\hline 23 & $31^{(\mathrm{b})}$ & 50 & 1450 & 259 & 0.254 & 0.072 & 1 & 5,5 & $0.34,0.69^{(\mathrm{f})}$ & 15 & disrupted $^{(\mathrm{e})}$ \\
\hline 23 & $32^{(\mathrm{b})}$ & 52 & 1477 & 405 & 0.254 & 0.110 & 1 & 5,5 & $0.34,0.69^{(\mathrm{f})}$ & 45 & stable ${ }^{(\mathrm{e})}$ \\
\hline $\begin{array}{l}\text { (a) } \\
\text { (b) } \\
\text { (c) } \\
\text { (d) } \\
\text { (e) } \\
\text { (f) }\end{array}$ & $\begin{array}{l}\text { K-Basin } \\
\text { Test run } \\
\text { Face wic } \\
\text { Straight } \\
\text { Release } \\
\text { Width or }\end{array}$ & $\begin{array}{l}\text { roject Test } \\
\text { ith } 2 \text { fins i } \\
1 \text { of T-Fin } \\
n \text { width } \\
\text { curred at } \\
\text { traight fin, }\end{array}$ & $\begin{array}{l}\text { truction } 53 \\
\text { de vessel }\end{array}$ & $\overline{-T I 23, \operatorname{Rev} 0}$ & & & & & & & \\
\hline
\end{tabular}


Table C.5. Test Results for Kaolin, 10- Inch Elliptical 2:1 Vessel

\begin{tabular}{|c|c|c|c|c|c|c|c|c|c|c|c|}
\hline $\mathrm{TI}^{(\mathrm{a})}$ & Test \# & $\begin{array}{c}\mathrm{wt} \% \\
\text { Kaolin } \\
(\mathrm{wt} \%)\end{array}$ & $\begin{array}{l}\text { Density } \\
\left(\mathrm{kg} / \mathrm{m}^{3}\right)\end{array}$ & $\begin{array}{l}\text { Measured } \\
\text { Shear } \\
\text { Strength } \\
\text { (Pa) }\end{array}$ & $\begin{array}{c}\text { Vessel } \\
\text { Diameter } \\
(\mathrm{m})\end{array}$ & $\mathrm{Y}_{\mathrm{G}}$ & $\begin{array}{c}\text { Layer } \\
\text { Depth } \\
\text { H/D }\end{array}$ & $\begin{array}{c}\text { Fin } \\
\text { Slope } \\
\text { (degrees) }\end{array}$ & $\begin{array}{c}\text { Fin } \\
\text { Width } \\
\text { (in.) }\end{array}$ & $\begin{array}{c}\text { Time at Release } \\
\text { (min.) }\end{array}$ & Stability \\
\hline 23 & $23 \mathrm{~A}$ & 55 & 1519 & 723 & 0.254 & 0.191 & 1 & $\mathrm{~N} / \mathrm{A}$ & $\mathrm{N} / \mathrm{A}$ & 72 & stable \\
\hline 23 & $23 \mathrm{~B}$ & 58 & 1563 & 1093 & 0.254 & 0.281 & 1.0125 & N/A & N/A & 77 & stable \\
\hline 23 & $23 \mathrm{C}$ & 52 & 1477 & 405 & 0.254 & 0.110 & 1 & $\mathrm{~N} / \mathrm{A}$ & N/A & 52 & stable \\
\hline 23 & $23 \mathrm{D}$ & 50 & 1450 & 259 & 0.254 & 0.072 & 1.05 & $\mathrm{~N} / \mathrm{A}$ & N/A & 14 & unstable \\
\hline 23 & $23 \mathrm{E}$ & 50 & 1450 & 259 & 0.254 & 0.072 & 1.05 & N/A & N/A & 23 & unstable \\
\hline 23 & $23 \mathrm{~F}$ & 49 & 1437 & 229 & 0.254 & 0.064 & 1.0125 & $\mathrm{~N} / \mathrm{A}$ & $\mathrm{N} / \mathrm{A}$ & 4 & unstable \\
\hline 23 & $23 \mathrm{G}$ & 55 & 1519 & 723 & 0.254 & 0.191 & 1 & N/A & N/A & 35 & unstable \\
\hline 23 & $24 \mathrm{D}$ & 49 & 1437 & 229 & 0.254 & 0.064 & 1 & 5 & 0.34 & 3 & unstable \\
\hline 23 & $24 \mathrm{~F}$ & 55 & 1519 & 723 & 0.254 & 0.191 & 1.025 & 5 & 0.34 & 39 & unstable $^{(b)}$ \\
\hline 23 & 24 & 55 & 1519 & 723 & 0.254 & 0.191 & 1.05 & 5 & 0.34 & 28 & disrupted \\
\hline 23 & $24 B$ & 52 & 1477 & 405 & 0.254 & 0.110 & 1.019 & 5 & 0.34 & 15 & unstable \\
\hline 23 & $24 \mathrm{C}$ & 50 & 1450 & 259 & 0.254 & 0.072 & 1 & 5 & 0.34 & 9 & unstable \\
\hline 23 & $24 \mathrm{E}$ & 58 & 1563 & 1093 & 0.254 & 0.281 & 1 & 5 & 0.34 & 19 & disrupted \\
\hline
\end{tabular}

(b) This test could also be noted as stable because the exact criteria is $37 \mathrm{~min}$ of gas injection, 
Table C.6. Test Results for Kaolin/Min-U-Sil 30, 10-Inch Elliptical 2:1 Vessel

\begin{tabular}{|c|c|c|c|c|c|c|c|c|c|c|c|c|}
\hline $\mathrm{TI}^{(\mathrm{a})}$ & $\begin{array}{c}\text { Test } \\
\#\end{array}$ & $\begin{array}{c}\mathrm{wt} \% \\
\text { Kaolin } \\
(\mathrm{wt} \%)\end{array}$ & $\begin{array}{c}\text { wt } \% \\
\text { Min-U- } \\
\text { Sil } 30 \\
(w t \%)\end{array}$ & $\begin{array}{l}\text { Density } \\
\left(\mathrm{kg} / \mathrm{m}^{3}\right)\end{array}$ & $\begin{array}{l}\text { Measured } \\
\text { Shear } \\
\text { Strength } \\
(\mathrm{Pa})\end{array}$ & $\begin{array}{c}\text { Vessel } \\
\text { Diameter } \\
(\mathrm{m})\end{array}$ & $\mathrm{Y}_{\mathrm{G}}$ & $\begin{array}{c}\text { Layer } \\
\text { Depth } \\
\text { H/D }\end{array}$ & $\begin{array}{c}\text { Fin } \\
\text { Slope } \\
\text { (degrees) }\end{array}$ & $\begin{array}{c}\text { Fin } \\
\text { Width } \\
\text { (in.) }\end{array}$ & $\begin{array}{c}\text { Time at } \\
\text { Release } \\
\text { (min.) }\end{array}$ & Stability \\
\hline 26 & E-1 & 40 & 16 & 1533 & 172 & 0.254 & 0.045 & 1 & $\mathrm{~N} / \mathrm{A}$ & $\mathrm{N} / \mathrm{A}$ & 4 & unstable \\
\hline 26 & E-6 & 40 & 20.5 & 1602 & 363 & 0.254 & 0.091 & 1 & N/A & $\mathrm{N} / \mathrm{A}$ & 6 & unstable \\
\hline 26 & E-3 & 40 & 19 & 1579 & 291 & 0.254 & 0.074 & 1 & $\mathrm{~N} / \mathrm{A}$ & $\mathrm{N} / \mathrm{A}$ & 8 & unstable \\
\hline 26 & E-4 & 40 & 19 & 1579 & 291 & 0.254 & 0.074 & 1 & 5 & 0.34 & 8 & unstable \\
\hline 26 & E-2 & 40 & 16 & 1533 & 172 & 0.254 & 0.045 & 1 & 5 & 0.34 & 2 & unstable \\
\hline 26 & E-8 & 40 & 20.5 & 1602 & 363 & 0.254 & 0.091 & 0.9875 & 5 & 0.34 & 22 & unstable \\
\hline 26 & E-10 & 40 & 23 & 1643 & 681 & 0.254 & 0.166 & 0.975 & 5 & 0.34 & 8 & unstable \\
\hline 26 & E-9 & 40 & 23 & 1643 & 681 & 0.254 & 0.166 & 1 & N/A & N/A & 83 & stable \\
\hline
\end{tabular}


Table C.7. Test Results for Kaolin, 5-Inch, Flat-Bottom Vessel, 5-Degree/0.17-Inch Fin

\begin{tabular}{|c|c|c|c|c|c|c|c|c|c|c|c|}
\hline $\mathrm{TI}^{(\mathrm{a})}$ & Test \# & $\begin{array}{c}\text { wt\% } \\
\text { Kaolin } \\
\left(w^{0} \%\right)\end{array}$ & $\begin{array}{l}\text { Density } \\
\left(\mathrm{kg} / \mathrm{m}^{3}\right)\end{array}$ & $\begin{array}{l}\text { Measured } \\
\text { Shear } \\
\text { Strength } \\
(\mathrm{Pa})\end{array}$ & $\begin{array}{c}\text { Vessel } \\
\text { Diameter } \\
\text { (m) }\end{array}$ & $\mathrm{Y}_{\mathrm{G}}$ & $\begin{array}{c}\text { Layer } \\
\text { Depth } \\
\text { H/D }\end{array}$ & $\begin{array}{c}\text { Fin } \\
\text { Slope } \\
\text { (degrees) }\end{array}$ & $\begin{array}{c}\text { Fin } \\
\text { Width } \\
\text { (in.) }\end{array}$ & $\begin{array}{c}\text { Time at Release } \\
\text { (min.) }\end{array}$ & Stability \\
\hline 31 & C-19B & 47 & 1412 & 112 & 0.127 & 0.06 & 0.50 & $\mathrm{~N} / \mathrm{A}$ & $\mathrm{N} / \mathrm{A}$ & 20 & unstable \\
\hline 31 & C-20B & 47 & 1412 & 112 & 0.127 & 0.06 & 0.25 & N/A & N/A & 2 & unstable \\
\hline 31 & C-21B & 49 & 1437 & 176 & 0.127 & 0.10 & 0.50 & $\mathrm{~N} / \mathrm{A}$ & $\mathrm{N} / \mathrm{A}$ & 9 & unstable \\
\hline 31 & $\mathrm{C}-21 \mathrm{C}$ & 49 & 1437 & 176 & 0.127 & 0.10 & 0.25 & N/A & $\mathrm{N} / \mathrm{A}$ & 4 & unstable \\
\hline 31 & C-30C & 45 & 1387 & 62 & 0.127 & 0.04 & 0.25 & $\mathrm{~N} / \mathrm{A}$ & $\mathrm{N} / \mathrm{A}$ & 1 & unstable \\
\hline 31 & C-30B & 45 & 1387 & 62 & 0.127 & 0.04 & 0.50 & $\mathrm{~N} / \mathrm{A}$ & $\mathrm{N} / \mathrm{A}$ & 1 & unstable \\
\hline 31 & C-30A & 45 & 1387 & 62 & 0.127 & 0.04 & 1.00 & N/A & N/A & 2 & unstable \\
\hline 31 & C-31B & $50^{(\mathrm{b})}$ & 1450 & 259 & 0.127 & 0.14 & 0.50 & 5 & 0.17 & 8 & unstable w/fin \\
\hline 31 & C- $18 \mathrm{C}$ & 47 & 1412 & 112 & 0.127 & 0.06 & 1.03 & N/A & $\mathrm{N} / \mathrm{A}$ & $106^{(\mathrm{c})}$ & stable \\
\hline 31 & C-21A & 49 & 1437 & 176 & 0.127 & 0.10 & 1.00 & N/A & N/A & $100^{(\mathrm{c})}$ & stable \\
\hline 31 & C-38B & $50^{(\mathrm{b})}$ & 1450 & 259 & 0.127 & 0.14 & 0.5 & N/A & $\mathrm{N} / \mathrm{A}$ & $102^{(\mathrm{c})}$ & stable \\
\hline 31 & $\mathrm{C}-23$ & 49 & 1437 & 176 & 0.127 & 0.10 & 0.95 & 5 & 0.17 & 77 & stable w/fin \\
\hline 31 & C-31A & $50^{(\mathrm{b})}$ & 1450 & 259 & 0.127 & 0.14 & 1.00 & 5 & 0.17 & 64 & stable w/fin \\
\hline 31 & C-33A & 52 & 1477 & 346 & 0.127 & 0.19 & 1.00 & 5 & 0.17 & 57 & stable w/fin \\
\hline 31 & C-22 & 47 & 1412 & 112 & 0.127 & 0.06 & 1.00 & 5 & 0.17 & 12 & unstable w/fin \\
\hline 31 & C-33B & 52 & 1477 & 346 & 0.127 & 0.19 & 0.50 & 5 & 0.17 & 16 & disrupted \\
\hline 31 & C-34B & 55 & 1519 & 524 & 0.127 & 0.28 & 0.50 & 5 & 0.17 & 10 & disrupted \\
\hline 31 & C-34A & 55 & 1519 & 524 & 0.127 & 0.28 & 1.00 & 5 & 0.17 & 12 & disrupted \\
\hline
\end{tabular}

(a) K-Basin Project Test Instruction 53451-TI31, Rev 0

(b) Same clay sample used in 10 " vessel tests

(c) VSB reached a height of 2.5 inches $(\mathrm{H} / \mathrm{D}=0.50)$ without release 
Table C.8. Test Results for Kaolin, 23-Inch, Flat-Bottom Vessel

\begin{tabular}{|c|c|c|c|c|c|c|c|c|c|c|c|}
\hline $\mathrm{TI}^{(\mathrm{a})}$ & Test \# & $\begin{array}{c}\mathrm{wt} \% \\
\text { Kaolin } \\
(\mathrm{wt} \%)\end{array}$ & $\begin{array}{l}\text { Density } \\
\left(\mathrm{kg} / \mathrm{m}^{3}\right)\end{array}$ & $\begin{array}{l}\text { Measured } \\
\text { Shear } \\
\text { Strength } \\
(\mathrm{Pa})\end{array}$ & $\begin{array}{l}\text { Vessel } \\
\text { Diameter } \\
\text { (m) }\end{array}$ & $\mathrm{Y}_{\mathrm{G}}$ & $\begin{array}{c}\text { Layer } \\
\text { Depth } \\
\text { H/D }\end{array}$ & $\begin{array}{c}\text { Fin } \\
\text { Slope } \\
\text { (degrees) }\end{array}$ & $\begin{array}{l}\text { Fin } \\
\text { Width } \\
\text { (in.) }\end{array}$ & $\begin{array}{l}\text { Time at Release } \\
\text { (min.) }\end{array}$ & Stability \\
\hline 31 & $\mathrm{C}-8 \mathrm{~A}$ & 52 & 1477 & 346 & 0.5842 & 0.04 & 0.250 & $\mathrm{~N} / \mathrm{A}$ & $\mathrm{N} / \mathrm{A}$ & 6 & unstable \\
\hline 31 & $\mathrm{C}-8 \mathrm{C}$ & 52 & 1477 & 346 & 0.5842 & 0.04 & 0.500 & 5 & 0.79 & 3 & unstable \\
\hline 31 & $\mathrm{C}-11$ & 55 & 1519 & 524 & 0.5842 & 0.06 & 0.261 & N/A & N/A & 5 & unstable \\
\hline 31 & $\mathrm{C}-32 \mathrm{~A}$ & 49 & 1437 & 183 & 0.5842 & 0.02 & 0.543 & N/A & N/A & 6 & unstable \\
\hline 31 & $\mathrm{C}-32 \mathrm{~B}$ & 49 & 1437 & 183 & 0.5842 & 0.02 & 1.000 & N/A & N/A & 3 & unstable \\
\hline 31 & $\mathrm{C}-35 \mathrm{~A}$ & 58 & 1563 & 1234 & 0.5842 & 0.14 & 0.261 & N/A & N/A & 18 & unstable \\
\hline 31 & $\mathrm{C}-10$ & 55 & 1519 & 524 & 0.5842 & 0.06 & 0.495 & N/A & N/A & $126^{(\mathrm{b})}$ & stable \\
\hline 31 & $\mathrm{C}-8 \mathrm{~B}$ & 52 & 1477 & 346 & 0.5842 & 0.04 & 0.500 & $\mathrm{~N} / \mathrm{A}$ & N/A & $128^{(\mathrm{b})}$ & stable \\
\hline 31 & $\mathrm{C}-8 \mathrm{D}$ & 52 & 1477 & 346 & 0.5842 & 0.04 & 0.967 & 5 & 0.79 & 4 & disrupted \\
\hline 31 & C-13 & 55 & 1519 & 524 & 0.5842 & 0.06 & 0.978 & 5 & 0.79 & 3 & disrupted \\
\hline 31 & C-13B & 55 & 1519 & 524 & 0.5842 & 0.06 & 0.978 & 5 & 0.79 & 3 & disrupted \\
\hline 31 & C-29 & 55 & 1519 & 524 & 0.5842 & 0.06 & 0.495 & 5 & 0.79 & 3 & disrupted \\
\hline 31 & $C-35 B$ & 58 & 1563 & 1234 & 0.5842 & 0.14 & 0.500 & 5 & 0.79 & 4 & disrupted \\
\hline 31 & $\mathrm{C}-35 \mathrm{C}$ & 58 & 1563 & 1234 & 0.5842 & 0.14 & 0.957 & 5 & 0.79 & 6 & disrupted \\
\hline 31 & C-37 & 58 & 1563 & 1234 & 0.5842 & 0.14 & 0.957 & 5 & $1.59^{(\mathrm{c})}$ & 2 & disrupted \\
\hline
\end{tabular}

(b) VSB reached a height of 11.5 inches $(\mathrm{H} / \mathrm{D}=0.50)$ without release

(c) Face width of T-fin 
Table C.9. Test Results for Kaolin/Min-U-Sil 30, 23-Inch, Flat-Bottom Vessel

\begin{tabular}{|c|c|c|c|c|c|c|c|c|c|c|c|c|}
\hline $\mathrm{TI}^{(\mathrm{a})}$ & $\begin{array}{c}\text { Test } \\
\#\end{array}$ & $\begin{array}{c}\text { wt } \% \\
\text { Kaolin } \\
(w t \%)\end{array}$ & $\begin{array}{c}\text { wt } \% \\
\text { Min-U- } \\
\text { Sil } 30 \\
(w t \%)\end{array}$ & $\begin{array}{l}\text { Density } \\
\left(\mathrm{kg} / \mathrm{m}^{3}\right)\end{array}$ & $\begin{array}{l}\text { Measured } \\
\text { Shear } \\
\text { Strength } \\
(\mathrm{Pa})\end{array}$ & $\begin{array}{c}\text { Vessel } \\
\text { Diameter } \\
(\mathrm{m})\end{array}$ & $\mathrm{Y}_{\mathrm{G}}$ & $\begin{array}{c}\text { Layer } \\
\text { Depth } \\
\text { H/D }\end{array}$ & $\begin{array}{c}\text { Fin } \\
\text { Slope } \\
\text { (degrees) }\end{array}$ & $\begin{array}{c}\text { Fin } \\
\text { Width } \\
\text { (in.) } \\
\end{array}$ & $\begin{array}{c}\text { Time at Release } \\
\text { (min.) }\end{array}$ & Stability \\
\hline 31 & C-1A & 40 & 20.5 & 1602 & 512 & 0.5842 & 0.056 & 0.272 & $\mathrm{~N} / \mathrm{A}$ & $\mathrm{N} / \mathrm{A}$ & 2 & unstable \\
\hline 31 & $\mathrm{C}-2 \mathrm{~A}$ & 40 & 25 & 1678 & 1010 & 0.5842 & 0.105 & 0.272 & N/A & N/A & 3 & unstable \\
\hline 31 & C-1B & 40 & 20.5 & 1602 & 512 & 0.5842 & 0.056 & 0.533 & N/A & N/A & $128^{(\mathrm{b})}$ & stable \\
\hline 31 & $\mathrm{C}-2 \mathrm{~B}$ & 40 & 25 & 1678 & 1010 & 0.5842 & 0.105 & 0.527 & N/A & N/A & $126^{(\mathrm{b})}$ & stable \\
\hline 31 & $\mathrm{C}-1 \mathrm{C}$ & 40 & 20.5 & 1602 & 512 & 0.5842 & 0.056 & 0.533 & 5 & 0.79 & 3 & disrupted \\
\hline 31 & C-1D & 40 & 20.5 & 1602 & 512 & 0.5842 & 0.056 & 0.978 & 5 & 0.79 & 3 & disrupted \\
\hline 31 & C-3A & 40 & 25 & 1678 & 1010 & 0.5842 & 0.105 & 0.511 & 5 & 0.79 & 3 & disrupted \\
\hline 31 & $\mathrm{C}-3 \mathrm{~B}$ & 40 & 25 & 1678 & 1010 & 0.5842 & 0.105 & 0.967 & 5 & 0.79 & 2 & disrupted \\
\hline 31 & C-4 & 40 & 25 & 1678 & 1010 & 0.5842 & 0.105 & 0.957 & 5 & $1.59^{(\mathrm{c})}$ & 2 & disrupted \\
\hline
\end{tabular}

(b) VSB reached a height of 11.5 inches $(\mathrm{H} / \mathrm{D}=0.50)$ without release

$\stackrel{\Omega}{\Omega}$

(c) Face width of T-Fin 


\section{Distribution}

No. of

Copies

OFFSITE

$1 \quad$ M Epstein

Fauske and Associates, LLC 16W070 $83^{\text {rd }}$ Street

Burr Ridge, IL 60527
No. of

\section{Copies}

\section{Internal Distribution}

Pacific Northwest National Laboratory

WC Buchmiller

K6-24

CA Burns

$\mathrm{P} 7-25$

J Chun

K6-24

RC Daniel

P7-22

$\mathrm{CH}$ Delegard

$\mathrm{P} 7-25$

PA Gauglitz (10)

K7-15

JJ Jenks

K7-15

MM Mastor

K7-15

Y Onishi

$\mathrm{K} 7-15$

AJ Schmidt

P8-60

SD Rassat

K6-28

RL Russell

K6-24

BE Wells

$\mathrm{K} 7-15$

Project File

K3-52

Information Release (pdf)

11 CH2M HILL Plateau Remediation Company

RB Baker A3-06

DA Burbank A0-26

GR Franz A3-06

DW Hamilton

A3-06

JO Honeyman

A3-06

ME Johnson

A $0-26$

H Mashaw A $0-26$

RE Raymond A0-26

WW Rutherford

A3-06

JP Sloughter

A3-06

STP Project File (FE Wickstrand)

H6-08 


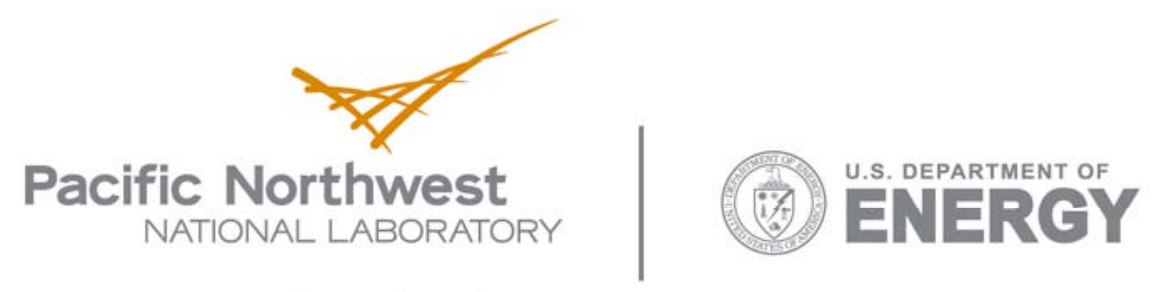

902 Battelle Boulevard

P.O. Box 999

Richland, WA 99352

1-888-375-PNNL (7665)

www.pnl.gov 